\title{
Oak Ridge K-25 Site Technology Logic Diagram
}

26 Feb 1993

Oak Ridge K-25 Site, TN (United States)

Reproduced and Distributed by:

U.S. DEPARTMENT OF ENERGY

Office of Scientific and Technical Information

P.O. Box 62

Oak Ridge, TN 37831 


\section{DISCLAIMER}

This report was prepared as an account of work sponsored by an agency of the United States Government. Neither the United States Government nor any agency thereof, nor any of their employees, make any warranty, express or implied, or assumes any legal liability or responsibility for the accuracy, completeness, or usefulness of any information, apparatus, product, or process disclosed, or represents that its use would not infringe privately owned rights. Reference herein to any specific commercial product, process, or service by trade name, trademark, manufacturer, or otherwise does not necessarily constitute or imply its endorsement, recommendation, or favoring by the United States Government or any agency thereof. The views and opinions of authors expressed herein do not necessarily state or reflect those of the United States Government or any agency thereof. 


\section{DISCLATMER}

Portions of this docoment misy be illegible in electronic inage products. Imsges are produced from the best arailable original docomentert 
$\mathrm{K}--2073-\mathrm{Vol} \cdot 1$

DE93 009485

\section{Oak Ridge K-25 Site Technology Logic Diagram}

\section{Volume 1 Technology Evaluation}

Prepared for the Office of Technology Development U.S. Department of Energy

Published: February 26, 1993 

ACKNOWLEDGMENTS $\ldots \ldots \ldots \ldots \ldots \ldots \ldots \ldots \ldots \ldots$ vii

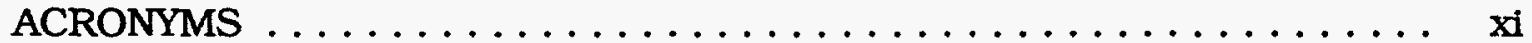

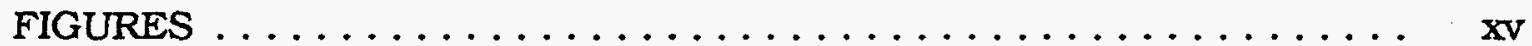

TABLES $\ldots \ldots \ldots \ldots \ldots \ldots \ldots \ldots \ldots \ldots \ldots \ldots \ldots \ldots \ldots \ldots \ldots \ldots$ xvii

FOREWORD $\ldots \ldots \ldots \ldots \ldots \ldots \ldots \ldots \ldots \ldots \ldots \ldots \ldots \ldots \ldots \ldots \ldots \ldots$

EXECUTIVE SUMMARY $\ldots \ldots \ldots \ldots \ldots \ldots \ldots \ldots \ldots \ldots$ xxiii

1. INTRODUCTION $\ldots \ldots \ldots \ldots \ldots \ldots \ldots \ldots \ldots \ldots \ldots \ldots \ldots \ldots \ldots, 1-3$

1.1 PURPOSE AND SCOPE $\ldots \ldots \ldots \ldots \ldots \ldots \ldots \ldots \ldots \ldots \ldots$

1.2 THE TECHNOLOGY LOGIC DIAGRAM $\ldots \ldots \ldots \ldots \ldots \ldots \ldots, 1-4$

1.3 THE K-25 SITE . . . . . . . . . . . . . . . . . . . . 1-7

1.4 OAK RIDGE K-25 SITE MISSION $\ldots \ldots \ldots \ldots \ldots \ldots \ldots \ldots, 1-13$

1.5 SITE PROBLEMS AND ISSUES $\ldots \ldots \ldots \ldots \ldots \ldots \ldots \ldots \ldots$ 1-14

1.5.1 Decommissioning ................... 1-14

1.5.2 Remedial Action ..................... 1-14

1.5.3 Waste Management $\ldots \ldots \ldots \ldots \ldots \ldots \ldots \ldots \ldots$ 1-19

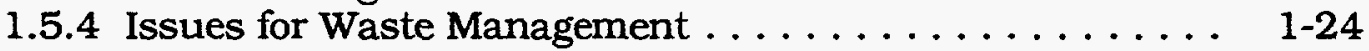

$1.6 \mathrm{~K}-25$ SITE ROADMAP $\ldots \ldots \ldots \ldots \ldots \ldots \ldots \ldots \ldots \ldots . \ldots \ldots$

2. DESCRIPTION OF THE TECHNOLOGY LOGIC DIAGRAM $\ldots \ldots \ldots, 2-3$

2.1 TECHNICAL APPROACH $\ldots \ldots \ldots \ldots \ldots \ldots \ldots \ldots \ldots \ldots, 2-3$

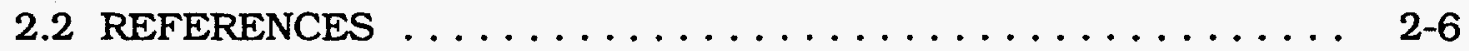

3. CHARACTERIZATION $\ldots \ldots \ldots \ldots \ldots \ldots \ldots \ldots \ldots \ldots \ldots \ldots \ldots$ 3-3

3.1 INTRODUCTION $\ldots \ldots \ldots \ldots \ldots \ldots \ldots \ldots \ldots \ldots \ldots \ldots \ldots \ldots, 3-3$

3.1.1 Approach ....................... 3-4

3.1 .2 Mechanics ..................... 3-7

3.2 TECHNOLOGY OPTIONS $\ldots \ldots \ldots \ldots \ldots \ldots \ldots \ldots \ldots, 3-9$

3.2 .1 Introduction $\ldots \ldots \ldots \ldots \ldots \ldots \ldots \ldots \ldots \ldots, 3-9$

3.2.2 Technology Summary $\ldots \ldots \ldots \ldots \ldots \ldots \ldots \ldots \ldots$ 3-9

3.2.3 Technology Evaluation ................. 3-11

3.3 SCIENCE AND TECHNOLOGY NEEDS $\ldots \ldots \ldots \ldots \ldots \ldots \ldots, 3-12$

3.4 IMPLEMENTATION NEEDS $\ldots \ldots \ldots \ldots \ldots \ldots \ldots \ldots \ldots, 3-14$

3.5 TECHNOLOGY RANKINGS FOR THE K-25 SITE $\ldots \ldots \ldots \ldots .3-15$

3.6 TECHNOLOGIES UNDER DEVELOPMENT BY DOE . . . . . . 3-27

4. DECONTAMINATION $\ldots \ldots \ldots \ldots \ldots \ldots \ldots \ldots \ldots \ldots \ldots$ 4-3

4.1 INTRODUCTION ...................... 4

4.2 TECHNOLOGY OPTIONS $\ldots \ldots \ldots \ldots \ldots \ldots \ldots \ldots, 4-5$

4.2.1 Introduction $\ldots \ldots \ldots \ldots \ldots \ldots \ldots \ldots \ldots \ldots, 4-5$

4.2.2 Summary of Decontamination Technologies ....... 4-5

4.3 SCIENCE AND TECHNOLOGY NEEDS $\ldots \ldots \ldots \ldots \ldots \ldots \ldots$ 4-14

4.3.1 Introduction $\ldots \ldots \ldots \ldots \ldots \ldots \ldots \ldots \ldots \ldots$ 4 4 .14

4.3.2 Summary of Science and Technology Needs ........ 4-14 
4.4 IMPLEMISNTATION NEEDS $\ldots \ldots \ldots \ldots \ldots \ldots \ldots \ldots \ldots \ldots$ 4-18

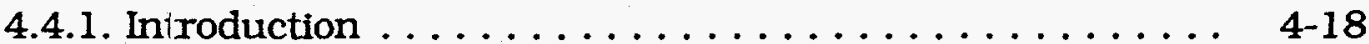

4.4.2 Summary of Implementation Needs ........... 4-18

4.5 TECHNOI OGY RANKINGS FOR THE K-25 SITE $\ldots \ldots \ldots \ldots \ldots$ 4-21

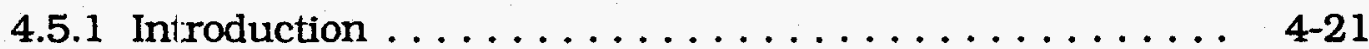

4.5.2 Ranking System $\ldots \ldots \ldots \ldots \ldots \ldots \ldots \ldots \ldots \ldots \ldots$ 4-22

4.5.3 Ranking Criteria . . . . . . . . . . . . . . . . . 4-22

4.5.4 Ranking Procedure $\ldots \ldots \ldots \ldots \ldots \ldots \ldots \ldots$ 4-24

4.5.5 Results of Overall Rankings . . . . . . . . . .

4.6 TECHNOLOGIES UNDER DEVELOPMENT BY DOE . . . . . 4 4-40

4.7 REFEREINCES . . . . . . . . . . . . . . .

5. DisMANTLEMENT $\ldots \ldots \ldots \ldots \ldots \ldots \ldots \ldots \ldots \ldots \ldots \ldots$ 5-3

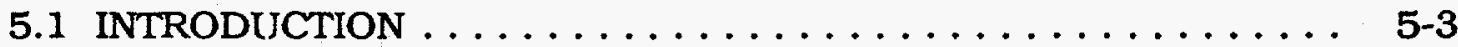

5.1 .1 Approach $\ldots \ldots \ldots \ldots \ldots \ldots \ldots \ldots \ldots \ldots \ldots$ 5-3

5.1 .2 Problem statement $\ldots \ldots \ldots \ldots \ldots \ldots \ldots \ldots \ldots$ 5-10

5.2 TECHNOLOGY OPTIONS $\ldots \ldots \ldots \ldots \ldots \ldots \ldots \ldots \ldots, 5-13$

5.2.1 Melssive Concrete $\ldots \ldots \ldots \ldots \ldots \ldots \ldots \ldots \ldots$ 5-13

5.2 .2 Structural Steel $\ldots \ldots \ldots \ldots \ldots \ldots \ldots \ldots \ldots \ldots \ldots$ 5-13

5.2 .3 Asbestos Materials . . . . . . . . . . . . . . 5-13

5.2.4 Major dismantlement $\ldots \ldots \ldots \ldots \ldots \ldots \ldots \ldots \ldots$ 5-13

5.2.5 Disassembly of major components $\ldots \ldots \ldots \ldots \ldots \ldots$ 5-16

5.2.6 Enabling Technologies . . . . . . . . . . . . . . 5-16

5.3 SCIENCE; AND TECHNOLOGY NEEDS $\ldots \ldots \ldots \ldots \ldots \ldots \ldots$ 5-18

5.3.1 Massive Concrete . . . . . . . . . . . . . 5-18

5.3 .2 Structural Steel $\ldots \ldots \ldots \ldots \ldots \ldots \ldots \ldots \ldots \ldots$ 5-18

5.3.3 Asbestos Removal ... . . . . . . . . . . . . . . . 5-18

5.3.4 Maijor Dismantlement ................. 5-18

5.3.5 Disassembly of Components ............. 5-18

5.3.6 Configuration Verification, Configuration Definition, and Dismantlement Support . . . . . . . . . . . . 5-19

5.4 IMPLEMENTATION NEEDS $\ldots \ldots \ldots \ldots \ldots \ldots \ldots \ldots \ldots$ 5-20

5.4.1 Massive Concrete $\ldots \ldots \ldots \ldots \ldots \ldots \ldots \ldots \ldots \ldots$ 5-20

5.4 .2 Stuctural Steel $\ldots \ldots \ldots \ldots \ldots \ldots \ldots \ldots \ldots \ldots \ldots$ 5-20

5.4 .3 As bestos Removal . . . . . . . . . . . . . . . . . 5 5-20

5.4.4 Maijor Dismantlement ................... 5-20

5.4.5 Disassembly of Components . . . . . . . . . . . . 5-20

5.4.6 Configuration Verification, Configuration Definition, and Dismantlement Support . . . . . . . . . . 5-21

5.5 TECHNOLOGY RANKINGS FOR THE K-25 SITE $\ldots \ldots \ldots \ldots \ldots$ 5-22

5.5 .1 Introduction . . . . . . . . . .

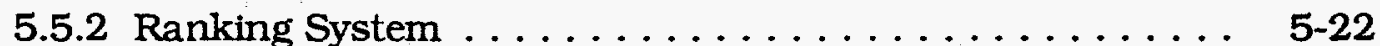

5.5.3 Ranking Criteria . . . . . . . . . . . . . . 5-22

5.5.4 Ranking Procedure . . . . . . . . . . . . . 5-28

5.5.5 Conclusions From Ranking Exercises $\ldots \ldots \ldots \ldots \ldots$ 5-28

5.5.6 Recommendations .................. 5-31

5.6 TECHNOLOGIES UNDER DEVELOPMENT BY DOE $\ldots \ldots \ldots \ldots \quad 5-33$ 
6. ROBOTICS AND AUTOMATION $\ldots \ldots \ldots \ldots \ldots \ldots \ldots \ldots \ldots$ 6-3

6.1 INTRODUCTION $\ldots \ldots \ldots \ldots \ldots \ldots \ldots \ldots \ldots \ldots \ldots, 6.3$

6.2 TECHNOLOGY OPTIONS $\ldots \ldots \ldots \ldots \ldots \ldots \ldots \ldots \ldots, 6-5$

6.3 SCIENCE AND TECHNOLOGY NEEDS $\ldots \ldots \ldots \ldots \ldots \ldots \ldots$ 6-7

6.4 IMPLEMENTATION NEEDS $\ldots \ldots \ldots \ldots \ldots \ldots \ldots \ldots \ldots, 6.9 .6$

6.5 TECHNOLOGY RANKINGS FOR THE K-25 SITE $\ldots \ldots \ldots \ldots .66-12$

6.6 TECHNOLOGIES UNDER DEVELOPMENT BY DOE . . . . . . 6 6-16

7. REMEDIAL ACTION $\ldots \ldots \ldots \ldots \ldots \ldots \ldots \ldots \ldots \ldots \ldots \ldots \ldots, 7-3$

7.1 INTRODUCTION $\ldots \ldots \ldots \ldots \ldots \ldots \ldots \ldots \ldots \ldots \ldots \ldots \ldots, 7-3$

7.1.1 Contaminated Media $\ldots \ldots \ldots \ldots \ldots \ldots \ldots \ldots$ 7-3

7.1 .2 Characterization .................. 7-4

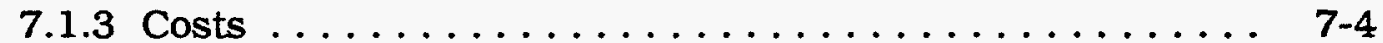

7.1.4 References ..................... 7-5

7.2 TECHNOLOGY OPTIONS-SOILS, GROUNDWATER, AND

SURFACE WATER $\ldots \ldots \ldots \ldots \ldots \ldots \ldots \ldots \ldots \ldots$ 7-6

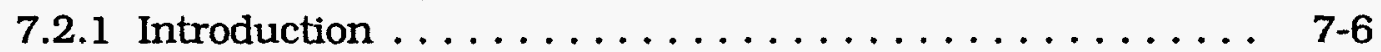

7.2.2 Waste and Contaminated Material Retrieval ...... 7-13

7.3 SCIENCE AND TECHNOLOGY NEEDS $\ldots \ldots \ldots \ldots \ldots \ldots, 7-15$

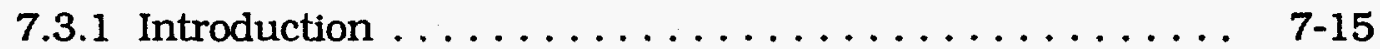

7.3.2 Characterization ................. 7-15

7.4 IMPLEMENTATION NEEDS $\ldots \ldots \ldots \ldots \ldots \ldots \ldots \ldots \ldots .7 . \ldots \ldots$

7.5 TECHNOLOGY RANKINGS FOR THE K-25 SITE $\ldots \ldots \ldots \ldots \ldots, 7-27$

7.6 TECHNOLOGIES UNDER DEVELOPMENT BY DOE $\ldots \ldots \ldots \ldots .7-39$

8. WASTE MANAGEMENT $\ldots \ldots \ldots \ldots \ldots \ldots \ldots \ldots \ldots$ 8-3

8.1 INTRODUCTION $\ldots \ldots \ldots \ldots \ldots \ldots \ldots \ldots \ldots \ldots \ldots, 8,3$

8.2 TECHNOLOGY OPTIONS $\ldots \ldots \ldots \ldots \ldots \ldots \ldots \ldots \ldots, 8-5$

8.2 .1 Introduction $\ldots \ldots \ldots \ldots \ldots \ldots \ldots \ldots \ldots \ldots$ 8-5

8.2.2 Conceptual Framework for Waste Management Planning .. 8-5

8.2.3 Description of Functional Areas Included in the WMTLD .. 8-9

8.3 SCIENCE AND TECHNOLOGY NEEDS $\ldots \ldots \ldots \ldots \ldots \ldots$ 8-18

8.3.1 Introduction $\ldots \ldots \ldots \ldots \ldots \ldots \ldots \ldots \ldots \ldots \ldots$ 8-18

8.3.2 Summary of Science and Technology Needs ........ 8-18

8.4 IMPLEMENTATION NEEDS $\ldots \ldots \ldots \ldots \ldots \ldots \ldots \ldots \ldots .8 .6 \ldots$

8.5 TECHNOLOGY RANKINGS FOR THE K-25 SITE $\ldots \ldots \ldots \ldots .8$ 8-21

8.5.1 Introduction $\ldots \ldots \ldots \ldots \ldots \ldots \ldots \ldots \ldots \ldots, 8$ 8-21

8.5.2 Prioritized Rankings of Technologies . . . . . . . . 8-21

8.5.3 Ranking System $\ldots \ldots \ldots \ldots \ldots \ldots \ldots \ldots \ldots \ldots \ldots, \quad 8-22$

8.5.4 Ranking Criteria ................... 8-22

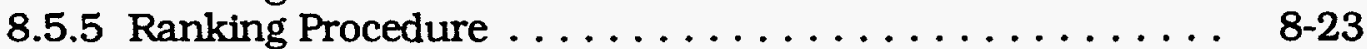

8.5.6 Conclusions from Rankings $\ldots \ldots \ldots \ldots \ldots \ldots \ldots$ 8-28

8.6 TECHNOLOGIES UNDER DEVELOPMENT BY DOE . . . . . . $8-29$ 
9. MATERIALS IIISPOSITION $\ldots \ldots \ldots \ldots \ldots \ldots \ldots \ldots \ldots \ldots \ldots$ 9-3

9.1 INTRODUCTION $\ldots \ldots \ldots \ldots \ldots \ldots \ldots \ldots \ldots \ldots \ldots, 9 \ldots \ldots$

9.2 TECHNOLOGY OPTIONS $\ldots \ldots \ldots \ldots \ldots \ldots \ldots \ldots \ldots \ldots$ 9-4

9.2.1 Criteria for Selecting Materials Disposition ......... 9-4

9.2.2 Economic and Other Usage Criteria $\ldots \ldots \ldots \ldots \ldots \ldots$ 9-6

9.2.3 Te:hnology Developments and Initiatives . . . . . . . . 9-8

9.2.4 Description of the K-25 Site Situation . . . . . . . . 9-9

9.3 REFEREINCES $\ldots \ldots \ldots \ldots \ldots \ldots \ldots \ldots \ldots \ldots \ldots$ 9-16

10. REGULATOFY COMPLIANCE $\ldots \ldots \ldots \ldots \ldots \ldots \ldots \ldots \ldots, 10-3$

10.1 INTRODUCTION . . . . . . . . . . . . . .

10.2 OVERTIEW OF ENVIRONMENTAL LAWS AFFECTING DECONTAMINATION AND DECOMMISSIONING

ACTIVTTIES . . . . . . . . . . . . . . . . . . . . . . . 10-11

10.3 CHEMICAL-SPECIFIC REGULATIONS $\ldots \ldots \ldots \ldots \ldots \ldots$ 10-15

10.3.1 Groundwater and Surface Water . . . . . . . . 10-15

10.3.2 Air . . . . . . . . . . . . . . . . . .

10.3.3 Soil . . . . . . . . . . . . . . . . . . . . 10-33

10.3.4 Nonregulatory Guidance . . . . . . . . . . . 10-33

10.4 RADIATION PROTECTION STANDARDS $\ldots \ldots \ldots \ldots \ldots \ldots$ 10-35

10.4.1 Generic Below-Regulatory-Concern Levels for

Radioactive Wastes . . . . . . . . . . . . . 10-36

10.4.2 EPA Regulations . . . . . . . . . . . . . 10-37

10.4.3 Department of Transportation Regulations . . . . . . 10-39

10.4.4 DOE Orders .................... 10-40

10.5 ACTION-SPECIFIC REGULATIONS $\ldots \ldots \ldots \ldots \ldots \ldots \ldots$ 10-48

10.5.1 Comprehensive Environmental Response,

Compensation, and Liability Act . . . . . . . 10-48

10.5.2 Resource Conservation and Recovery Act . . . . . . 10-48

10.5.3 Clean Air Act $\ldots \ldots \ldots \ldots \ldots \ldots \ldots \ldots \ldots . \ldots \ldots$ 10-53

10.5.4 Clean Water Act $\ldots \ldots \ldots \ldots \ldots \ldots \ldots \ldots \ldots$ 10-53

10.5.5 Safe Drinking Water Act $\ldots \ldots \ldots \ldots \ldots \ldots \ldots$ 10-55

10.5.6 Toxic Substances Control Act .......... 10-55

10.5.7 Federal Insecticide, Fungicide, and Rodenticide Act . 10-55

10.5.8 Occupational Safety and Health Administration .... 10-56

10.5.9 Federal and State Regulations . . . . . . . . . . . 10-56

10.6 LOCATION-SPECIFIC REGULATIONS $\ldots \ldots \ldots \ldots \ldots \ldots$ 10-94

10.6.1 Caves, Salt-Dome Formations, Salt-Bed Formations, and Underground Mines . . . . . . . . . . . . . 10-94

10.6.2 Faults . . . . . . . . . . . . . . . . . . . . 10-94

10.6.3 Wetlands and Floodplains . . . . . . . . . 10-102

10.6.4 Wilderness Areas, Wildlife Refuges, Wildlife Resources, and Scenic Rivers . . . . . . . . . . . . . 10-102

10.6.5 Rare, Threatened, or Endangered Species ...... 10-103

10.6.6 Historic Sites and Archaeological Findings . . . . . . 10-104

10.7 REFEFENCES . . . . . . . . . . . . . . . . . . 10-106

10.8 CHAPTER 10 ACRONYMS $\ldots \ldots \ldots \ldots \ldots \ldots \ldots \ldots \ldots$ 10-109 
The authors acknowledge the significant contributions made by the DOE Overview Team for the Technology Logic Diagram Review and Development: Robert Benedetti, Holmer Dugger, Mitchell Erickson, Ned Hutchins, William Schutte, and Randall Snipes.

\section{Project Manager}

R.K. Kibbe

D\&D IDC

\section{Deputy Project Manager, General Editor}

R.L. Fellows

K-25 Tech.

\section{Team Leaders \& Section Editors}
R.D. Bundy
L.C. Hensley
H.M. Henson
C.G. Jones
S.L. Schrock
S.P.N. Singh
J.S. Watson
J.R. Weir

\author{
Decontamination (K-25 Tech.) \\ Dismantlement (MMES Engr.) \\ Characterization (K-25 Tech.) \\ MMES Env. Compl. \\ Robotics/Automation (ORNL Robotics) \\ Waste Management (Chem. Tech.) \\ Remedial Action (Env. Restr.) \\ Materials Disposition (ORNL M\&C)
}

\section{Deputy Team Leaders \& Section Editors}

G.D. Del Cul

D.C. Haley

D.P. Hoffmann

B. Prince

A.L. Rivera

J.W. Smith

J.H. Wilson
Waste Management (K-25 Tech.)

Robotics/Automation (ORNL Robotics)

Characterization (K-25 Tech.)

Materials Disposition (K-25 D\&D Progam)

Waste Management (ORNL Chem. Tech.)

Dismantlement (Cent. Engr.)

Decontamination (ORNL Chem. Tech.)

\section{Senior Advisory Group}
E.J. Barber
J.T. Bradbury
R.K. Genung
J.M. Googin
A.L. Lotts
J.R. Merriman
J.O. Moore
J.H. Pashley

Enrich. Tech.

Co-chairman

ORNL Chem. Tech.

Y-12 Develop.

Consultant; Retired ORNL M\&C

Chairman (V.P. ERWM)

DOE-OR

Int. Tech. 
Planning/Oversi;sht/Coordination

L.D. Charles

R.L. Fellows

J.M. Kennerly'

R.K. Kibbe

R.L. Snipes

M.J. Stephenson

J.S. Watson
MMES Engr.

K-25 Tech.

MMES D\&D

D\&D IDC

HAZWRAP

MMES Waste Mgt.

MMES Env. Restr.

\section{Planning and Integration}

R.L. Fellows

D.W. Phifer, cIr.
K-25 Tech.

Publications Manager (K-25 Tech.)

\section{Publications}

J.M. Asher

S.N. Boone

B.Y. Brown

R.M. French

J.A. Getsi

G. Glandon

C.D. Gross

R.J. Harnett

D.Y. Johnsor

M.G. Jones

G.W. Llanos

L.J. McCracken

L.A. Palmer

D.W. Phifer, ,Jr.

G.E. Powell

N.C. Smith

C.J. Stanfill

R.N. Thurmer

R.H. Van Dylse

Y.W. Walton

A.L. Wampler

P.S. Wood

\section{Contributors}
R.B. Alderfer
K.A. Bane
T. Barnes
D.E. Beck
C.E. Benson
J.L. Bock
W.D. Bostick:
D.H. Bunch
M. Carroll

Technical Editor

Technical Editor

Secretary (K-25 Tech.)

Secretary (K-25 Tech.)

Technical Editor

Electronic Publisher

Electronic Publisher

Technical Editor

Electronic Publisher

Electronic Publisher

Electronic Publisher

Graphic Designer (Analysas Corp.)

Graphic Designer (Analysas Corp.)

Publications Manager (K-25 Tech.)

Technical Editor

Electronic Publisher

Technical Editor

Technical Editor

Technical Editor

Electronic Publisher

Electronic Publisher

Electronic Publisher

Decontamination (K-25 Tech.)

Dismantlement (K-25 Maint.)

Dismantlement (Mach. Kinetics Corp.)

Remedial Action, Decontamination (K-25 Tech.)

Decontamination (ORNL Chem. Tech.)

Characterization (K-25 Quality)

Waste Management, Materials Disposition (K-25 Tech.)

Decontamination (K-25 Tech.)

Dismantlement (Mach. Kinetics Corp.) 


\section{Contributors (continued)}

J.M. Chaing

P.E. Denny

J.G. Dorsey

C. Dudney

E.L. Etnier

R.L. Fellows

C.A. Foster

C.W. Francis

R.B. Gammage

W.L. Gardner

P.L. Goddard

C.D. Goins

M.R. Guerin

R.C. Hagenauer

J. Hannah

H.H. Haselton

W. Harwood

H.W. Hayden

W.H. Hermes

L.C. Hensley

J.N. Herndon

J.P. Hitch

L.M. Houlberg

K.A. Ingle

J.M. Kennerly

W.K. Key

C. Kimbrough

H.E. Knee

J.W. Koger

S.Y. Lee

D.K. Little

G. Mackin

M.E. Mitchell

E.B. Munday

L.L. Oakes

P. Paulauskas

J.J. Perona

K.E. Plummer

D.P. Schaeffer

S.L Schrock

B.H. Singletary

D.B. Smith

S.H. Stow

S.L. Tayloe

G. Taylor

C.C. Tsai

T.L. White

J. Zolyniak
Waste Management (MMES Engr.)

Dismantlement (Penn. State)

Characterization (Y-12 Analytical)

Characterization (ORNL Health \& Safety)

Regulatory Compliance (ORNL H\&SRD)

Decontamination (K-25 Tech.)

Decontamination (ORNL Fusion Energy)

Remedial Action (ORNL Env. Sci.)

Characterization (ORNL Health \& Safety)

Decontamination (ORNL Fusion Energy)

Remedial Action (K-25 Env. Restr.)

Regulatory Compliance (MMES Legal)

Characterization (ORNL Analytical)

Characterization (Int. Tech.)

Dismantlement (DOE France)

Decontamination (ORNL Fusion Energy)

Remedial Action (ORISE)

Materials Disposition (ORNL Env. Sci.)

Waste Management (MMES Engr.)

Characterization (MMES Engr.)

Robotics/Automation (ORNL Robotics)

Regulatory Compliance (ORNL H\&SRD)

Regulatory Compliance (ORNL H\&SRD)

Dismantlement (DSRD)

Decontamination, Dismantlement (MMES Cent. D\&D)

Dismantlement (ORNL Appl. Tech.)

Characterization (MMES Central)

Robotics/Automation (ORNL Engr., Phy., Math)

Dismantlement (Y-12 Develop.)

Characterization (ORNL Env. Sciences)

Waste Management ( $\mathrm{Y}-12 \mathrm{~W}$ Minimization)

Remedial Action (N.C. A\&T)

Regulatory Compliance (MMES Env. Compl.)

Decontamination (K-25 Tech.)

Dismantlement (HAZWRAP)

Dismantlement (ORNL Appl. Tech.)

Remedial Action (ORNL Chem. Tech.)

Waste Management (ORNL Fuel Recycle)

Waste Management (K-25 WM)

Dismantlement (ORNL Robotics)

Dismantlement, Robotics/Automation (MMES Engr.)

Decontamination (ORNL Appl. Tech.)

Materials Disposition (ORNL Env. Sci.)

Regulatory Compliance (ORNL H\&SRD)

Dismantlement $(\mathrm{Y}-12$ Develop.)

Decontamination (ORNL Fusion Energy)

Decontamination (ORNL Fusion Energy)

Characterization (K-25 Quality) 


\begin{tabular}{|c|c|}
\hline ACLs & Alternate concentration limits \\
\hline AEA & Atomic Energy Act \\
\hline ALARA & as low as reasonably achievable \\
\hline ANPRM & advance notice of proposed rulemaking \\
\hline APEG & ammonium polyethylene glycolate \\
\hline ARAR & applicable, relevant, and appropriate requirements \\
\hline BAT & best available technology \\
\hline BCBG & Bear Creek Burial Ground \\
\hline BDAT & Best Demonstrated Available Technology \\
\hline BMP & best management practice \\
\hline BRC & below-regulatory-concern \\
\hline CAA & Clean Air Act of 1970 \\
\hline CEP & catalytic extraction process \\
\hline CERCLA & $\begin{array}{l}\text { Comprehensive Environmental } \\
\text { Compensation, and Liability Act }\end{array}$ \\
\hline CNF & Central Neutralization Facility \\
\hline COE & U. S. Army Corps of Engineers \\
\hline CRADAs & cooperative research and development agreements \\
\hline CSFs & carcinogen slope factors \\
\hline CWA & Clean Water Act \\
\hline $\mathrm{D} \& \mathrm{D}$ & decontamination and decommissioning \\
\hline DCG & derived concentration guide \\
\hline DES & Division of Ecological Services \\
\hline DFs & Decontamination factors \\
\hline DNAPLS & Dense nonaqueous phase liquids \\
\hline DOE & Department of Energy \\
\hline DOE-OR & DOE Oak Ridge Field Office \\
\hline DOI & Department of the Interior \\
\hline DOT & Department of Transportation \\
\hline EBASCO & EBASCO Services \\
\hline EIS & Environmental Impact Statement \\
\hline EM & Environmental Management \\
\hline Energy Systems & Martin Marietta Energy Systems, Inc. \\
\hline $\mathrm{EO}$ & Executive Order \\
\hline EPA & Environmental Protection Agency \\
\hline ER & Environmental Restoration \\
\hline ERWM & Environmental Restoration and Waste Management \\
\hline ES\&H & environmental, safety, and health \\
\hline ESA & Endangered Species Act of 1973 \\
\hline FFAs & Federal Facility Agreements \\
\hline FFCA & Federal Facility Compliance Agreement \\
\hline FFCA of 1992 & Federal Facility Compliance Act of 1992 \\
\hline
\end{tabular}


FIFRA

FSs

FWCA

GDPs

GIS

HAs

HAZWRAP

HMTA

$\mathrm{HQ}$

HSWA

IAEA

IAGs

ICMS

IRIS

KPEG

Federal Insecticide, Fungicide, and Rodenticide Act of 1947

Feasibility Studies

Fish and Wildlife Coordination Act of 1958

gaseous diffusion plants

Geographic Information Systems

Health Advisories

Hazarclous Waste Remedial Actions Program

Hazarclous Materials Transportation Act of 1975

DOE H.eadquarters

Hazarclous and Solid Waste Amendments of 1984

International Atomic Energy Agency

Inter-A.gency Agreements

Interim Corrective Measures

Integrated Risk Information Systern

potassium polyethylene glycolate

LDR-FFCA/ORR Federal Facilities Compliance Agreement for mixed waste subject to land disposal restriction for the Oak Ridge Reservation

LDR

LLW

M\&O

MCLGs

MCLS

NAAQS

NARM

Land Disposal Restrictions

low-level waste

management and operating

maximum contaminant level goals

maximum contaminant levels

National Ambient Air Quality Standards

naturally occurring and accelerator-produced radioactive material

NAS

Natural Areas

NCP

NDE

NEPA

NERP

NESHAPS

NPDES

NPDWS

NPL

NPRM

NRC

NSDWS

NSPS

ODW

OECD/NEA

ORGDP

National Oil and Hazardous Substance Pollution Contirigency Plan nondestructive evaluation

National Environmental Policy Act

DOE National Environmental Research Park

Nation.al Emission Standards for Hazardous Air Pollutants

Natiorial Pollutant Discharge Elimination System

National Primary Drinking Water Standards

National Priorities List

Notice of Proposed Rulemaking

Nuclear Regulatory Commission

Natiorial Secondary Drinking Water Standards

New Source Performance Standards

Office of Drinking Water

Orgarization for Economic Cooperation and Development/Nuclear Energy Agency

Oak Ridge Gaseous Diffusion Plant

Page xii

February 26, 1993 


\begin{tabular}{|c|c|}
\hline ORNL & Oak Ridge National Laboratory \\
\hline ORR & Oak Ridge Reservation \\
\hline OSHA & Occupational Safety and Health Act \\
\hline OSWER & Office of Solid Waste and Emergency Response \\
\hline OTD & Office of Technology Development \\
\hline OUs & Operable Units \\
\hline PA & Preliminary Assessment \\
\hline PCBs & polychlorinated biphenyls \\
\hline PEG & Program Execution Guidance \\
\hline PELs & Permissible Exposure Limits \\
\hline POTW & Publicly owned treatment works \\
\hline PRDAs & Program Research and Development Announcements \\
\hline QA & quality assurance \\
\hline RA & Remedial Action \\
\hline RAD & radioactive contamination \\
\hline RAs & Reference Areas \\
\hline RCRA & Resource Conservation and Recovery Act \\
\hline RFCs & reference concentrations \\
\hline RFDs & reference doses \\
\hline RFI & RCRA Facility Investigation \\
\hline RI & Remedial Investigation \\
\hline RSAs & Research Areas \\
\hline $\mathrm{S} / \mathrm{T}$ & Science and Technology \\
\hline SARA & Superfund Amendments and Reauthorization Act \\
\hline SCS & Site Characterization Summary \\
\hline SDMP & Site Decommissioning Management Plan \\
\hline SDWA & Safe Drinking Water Act of 1974 \\
\hline SEG & Scientific Ecology Group, Inc. \\
\hline SEN & Secretary of Energy Notice \\
\hline SI & Site Inspection \\
\hline SMCLs & secondary maximum contaminant levels \\
\hline SNAs & State Natural Areas \\
\hline SNM & Special Nuclear Material \\
\hline SRS & Savannah River Site \\
\hline SWDA & Solid Waste Disposal Act \\
\hline SWMU & solid waste management units \\
\hline TCA & Tennessee Code Annotated \\
\hline TCE & trichloroethylene \\
\hline TCLP & Toxicity Characteristic Leaching Procedure \\
\hline TD & Technology Development \\
\hline TDEC & $\begin{array}{l}\text { Tennessee Department of Environment and } \\
\text { Conservation }\end{array}$ \\
\hline TEDS & Technology Evaluation Data Sheet \\
\hline TLD & Technology Logic Diagram \\
\hline TOA & Tennessee/DOE Monitoring and Oversight Agreement \\
\hline TRU & transuranic \\
\hline
\end{tabular}


TSCA

Toxic Siubstance Control Act

TSCA-FFCA PCB Federal Facilities Compliance Agreement Between the U.'S. DOE and the EPA, Washington, D.C. for the Uranium Enrichment Facilities

TSD

TSP treatment, storage, and disposal

TSS Total suspended particulates

UCC

UHPW

UIC

USC

USDW

UST

Treatability Studies

Union Carbide Corporation

ultra-righ pressure water

Underground injection control

United States Code

undergyround sources of drinking water

WM

Volatile organic compounds

WMTLD

Waste Management

WPH\&T

Waste Management Technology Logic Diagram

WQC

Waste Packaging, Handling, and Transportation

water quality criteria 
1.1. The K-25 Site Technology Logic Diagram team. . . . . . . . 1-5

1.2. Aerial view of the $\mathrm{K}-25$ Site. $\ldots \ldots \ldots \ldots \ldots \ldots \ldots \ldots, 1-8$

1.3. Typical U.S. gaseous diffusion stage arrangement. $\ldots \ldots \ldots \ldots$ 1-9

1.4. The largest axial flow type gas compressor used in

1.5. Diffusers containing nickel barrier in a typical K-33 cell configuration. . ................. 1-10

1.6. Stage equipment and piping, $\mathrm{K}-29$ Building $\ldots \ldots \ldots \ldots \ldots \ldots$ 1-11

1.7. Centrifugal stage equipment $\ldots \ldots \ldots \ldots \ldots \ldots \ldots \ldots \ldots, 1-11$

1.8. Cooling towers at the $\mathrm{K}-25$ Site. $\ldots \ldots \ldots \ldots \ldots \ldots \ldots \ldots, 1-12$

1.9. Map of the K-25 Site operable units. .............. 1-18

1.10. Toxic Substance Control Act Incinerator . . . . . . . . . . 1-20

1.11. Photograph of the Central Neutralization Facility $\ldots \ldots \ldots \ldots \ldots 1-20$

1.12. Photograph of the $\mathrm{K}-25$ Building. $\ldots \ldots \ldots \ldots \ldots \ldots \ldots \ldots, 1-22$

5.1. Decontamination and decommissioning sequence. $\ldots \ldots \ldots \ldots$ 5-4

5.2. One of the "withdrawal alleys" in the K-25 Site facility . . . . . . . . . . . . . .

5.3. Compressor and drive being installed during construction in $1944 \ldots \ldots \ldots \ldots \ldots \ldots \ldots \ldots \ldots \ldots . \ldots \ldots$

5.4. Typical concrete and steel construction in the older diffusion facilities. . . . . . . . $\ldots \ldots \ldots \ldots \ldots \ldots$ 5-11

5.5. Concept for automated dismantlement of older (1940s vintage) diffusion equipment. . . . . . . . . . . 5-14

5.6. Concept for dismantlement of newer (1950s vintage) diffusion plant equipment. . . . . . . . . . 5 5.15

5.7. Evaluation criteria summary for dismantlement. . . . . . . . . 5-23

5.8. Integrated diffusion facility dismantlement concept conceptual design for highly enriched uranium facility. . . . . 5 5-29

8.1. Conceptual framework for waste management and technology planning. .................. 8-6

8.2. Combination of technologies in the planning of waste management systems. . . . . . .

9.1. Schematic showing relationship between costs for materials decontamination and wastes disposal. ......... 

1.1. Preliminary K-25 Site Problem List $\ldots \ldots \ldots \ldots \ldots \ldots \ldots \ldots, 1-15$

1.2. Preliminary K-25 Site Problem List $\ldots \ldots \ldots \ldots \ldots \ldots \ldots \ldots, 1-16$

1.3. Current $\mathrm{K}-25$ Waste Capacity and Waste in Storage $\ldots \ldots \ldots \ldots$. . . . . .

1.4. Federal Facility Agreement for the

Oak Ridge Reservation . . . . . . . . . . . . . . . . . . . 1-28

1.5. Compliance Agreement between the U.S. Department of Energy and the Environmental Protection Agency, Washington, D.C. [Federal Facility Compliance Agreement (FFCA) Toxic Substances Control Act (TSCA)] . . . . . 1-30

1.6. Plan for the Management Waste Removed from K-1407-B and -C Ponds at the Oak Ridge K-25 Site . . . . . . . . . . . . . 1-30

3.1. Cascade systems . . . . . . . . . . . . . . . . . . 3-8

3.2. Characterization technologies $\ldots \ldots \ldots \ldots \ldots \ldots \ldots \ldots \ldots, 3-18$

3.3. DOE funded development $\ldots \ldots \ldots \ldots \ldots \ldots \ldots \ldots \ldots \ldots, 3-28$

4.1. Decontamination technologies $\ldots \ldots \ldots \ldots \ldots \ldots \ldots \ldots \ldots$ 4-6

4.2. Summary of implementation needs . . . . . . . . . . . . 4-19

4.3 Decontamination technology rankings vs criteria of group 1 (concrete) . . . . . . . . . . . . . . . . . . . 4-26

4.4 Decontamination technology rankings vs criteria of group 2 (exterior equipment surfaces) $\ldots \ldots \ldots \ldots \ldots \ldots \ldots$ 4-27

4.5 Decontamination technology rankings vs criteria of group 3 (interior equipment surfaces) . . . . . . . . . . . 4-29

4.6 Decontamination technology rankings vs criteria of group 4 (porous nickel) . . . . . . . . . . . . . . 4 4-31

4.7 Decontamination technology rankings vs criteria of group 5 (deposit removal) . . . . . . . . . . . . . . . . .

4.8 Decontamination technology rankings vs criteria of group 6 (other materials) $\ldots \ldots \ldots \ldots \ldots \ldots \ldots \ldots \ldots . \ldots \ldots$ 4-33

4.9. Overall ratings of decontamination technologies $\ldots \ldots \ldots \ldots \ldots$ 4-35

4.10. DOE funded decontamination development $\ldots \ldots \ldots \ldots \ldots \ldots, 4-41$

5.1. Acceptable exterior surface contamination levels according to DOE Order $5400.5 \ldots \ldots \ldots \ldots \ldots \ldots \ldots \ldots$. $5-5$

5.2. Radioactive scrap metal streams from decommissioning gaseous diffusion plants

5.3. Radioactive scrap metal currently in storage . . . . . . . . 5-6

5.4. Ranking of technologies $\ldots \ldots \ldots \ldots \ldots \ldots \ldots \ldots \ldots \ldots, 5-24$

5.5. DOE funded development $\ldots \ldots \ldots \ldots \ldots \ldots \ldots \ldots \ldots .5,54$

6.1. Ranking of robotics/automation technologies ........... 6-14

6.2. DOE funded development $\ldots \ldots \ldots \ldots \ldots \ldots \ldots \ldots, 6,6,17$

7.1. Considerations for prioritization $\ldots \ldots \ldots \ldots \ldots \ldots \ldots \ldots, 7-28$

7.2. Priorities for remedial action $\ldots \ldots \ldots \ldots \ldots \ldots \ldots \ldots \ldots, 7-29$

7.3 DOE funded development $\ldots \ldots \ldots \ldots \ldots \ldots \ldots \ldots \ldots .7-40$ 
8.1. Categories of waste management needs

for technology arplications $\ldots \ldots \ldots \ldots \ldots \ldots \ldots \ldots \ldots, 8$

8.2. Treatment processes for solid wastes $\ldots \ldots \ldots \ldots \ldots \ldots \ldots$ 8-11

8.3. Physical treatment processes for liquid wastes $\ldots \ldots \ldots \ldots \ldots$ 8-12

8.4. Chemical treatment processes for liquid wastes $\ldots \ldots \ldots \ldots \ldots$ 8-13

8.5. Thermal and biological treatment processes

for liquid wastes $\ldots \ldots \ldots \ldots \ldots \ldots \ldots \ldots \ldots \ldots . . \ldots$ 8-14

8.6. Treatment processes for gaseous wastes $\ldots \ldots \ldots \ldots \ldots \ldots \ldots$ 8-15

8.7. Generic waste stabilization technologies $\ldots \ldots \ldots \ldots \ldots \ldots \ldots$ 8-16

8.8. Rankings for treatment processes for solid wastes $\ldots \ldots \ldots \ldots$ 8-24

8.9. Rankings for phy'sical treatment processes

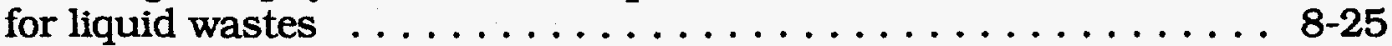

8.10. Rankings for chemical treatment processes

for liquid wastes $\ldots \ldots \ldots \ldots \ldots \ldots \ldots \ldots \ldots \ldots . \ldots .6 .26$

8.11. Rankings for thermal and biological treatment

processes for liquid wastes $\ldots \ldots \ldots \ldots \ldots \ldots \ldots \ldots \ldots \ldots$ 8-27

8.12. Rankings for treatment processes for gaseous wastes $\ldots \ldots \ldots$ 8-28

8.13. DOE funded development $\ldots \ldots \ldots \ldots \ldots \ldots \ldots \ldots \ldots . . .68$

9.1. Radioactive scrap metal streams arising from decommissioning gaseous diffusion plants $\ldots \ldots \ldots \ldots \ldots \ldots \ldots \ldots . \ldots .10$

9.2. Materials generated from the $\mathrm{K}-25$ Site

Decommissioning and Decontamination Program .......... 9-11

9.3. Radioactive scrap metal currently in storage

at selected DOE sites . . . . . . . . . . . . . . . . 9-13

9.4. Scrap metal prices (Iron Age, June 1992) . . . . . . . . . . 9-14

9.5. Primary metal pitices (Iron Age, June 1992) ... . . . . . . 9-14

10.1 Examples of major of committed milestones under signed and pending agreements for the Oak Ridge Reservation . . . . . . . 10-6

10.2 Chemical-specific federal regulations for protection of human health. . . . . . . . . . . . . . . . . 10-15

10.3 Federal and Tennessee secondary drinking water regulations . . . . . . . . . . . . . 10.22

10.4 Federal ambient water quality criteria for the protection of human healtr. . . . . . . . . . . . . . . . . . 10-24

10.5 Tennessee water quality criteria for designated water uses . . . . 10-27

10.6 Federal ambient water quality criteria for the protection of freshwater organisms . . . . . . . . . . . . . .

10.7 Radionuclide-specific standards under the SDWA for groundwater and surface water contamination at the Oak Ridge Reservation . 10-36

10.8 Radiation protection standards that may be applicable to Oak Ridge Reservation D\&]) activities . . . . . . . . . . . . . . 10-37

10.9 DOE Order 5401).5, "Radiation Protection of the Public and the Environment" ................... 10-40

10.10 DOE Order 5820.2A, "Radioactive Waste Management" ...... 10-45

10.11 RCRA Subtitle C - standards for the treatment, storage and disposal of hazardous waste $\ldots \ldots \ldots \ldots \ldots \ldots \ldots \ldots \ldots \ldots \ldots \ldots$ 
10.12 Federal RCRA land disposal regulations $\ldots \ldots \ldots \ldots \ldots \ldots$ 10-49

10.13 Rules of the TDEC Bureau of Environment Division of Air Pollution Control ...................... 10-53

10.14 Action-specific regulations applicable to decontamination and decommissioning activities at the Oak Ridge Reservation . . 10-56

10.15 Location-specific regulations applicable to decontamination and decommissioning activities at the Oak Ridge Reservation .... 10-96 

The Oak Ridge K-25 Technology Logic Diagram (TLD), a decision support tool for the K-25 Site, was developed to provide a planning document that relates environmental restoration and waste management problems at the Oak Ridge K-25 Site to potential technologies that can remediate these problems. The TLD uses information from the Strategic Road Map for the Oak Ridge Reservation and from a previous Hanford TLD.

The TLD technique identifies the research necessary to develop these technologies to a state that allows for technology transfer and application to waste management, remedial action, and decontamination and decommissioning activities. It is essential that follow-on engineering studies are conducted to build on the output of this project. These studies will begin by selecting the most promising technologies identified in the TLD and finding an optimum mix of technologies that will provide a socially acceptable balance between cost and risk.

The Oak Ridge K-25 Site TLD consists of four separate volumes-Vol. 1, Vol. 2, Vol. 3A, and Vol. 3B. Volume 1 provides introductory and overview information about the TLD. Volume 2 contains logic diagrams. Volume 3 has been divided into two separate volumes to facilitate handling and use.

This volume is divided into ten chapters. The first chapter is a brief introduction, and the second chapter details the technical approach of the TLD. Chapters 3 through 8 are organized into subelement categories. These categories are the work activities necessary for successful decontamination and decommissioning, waste management, and remedial action of the K-25 Site. The categories are characterization, decontamination, dismantlement, robotics and automation, remedial action, and waste management. Materials disposition is addressed in Chap. 9. The final chapter contains regulatory compliance information concerning waste management, remedial action, and decontamination and decommissioning.

The technology evaluations that are contained in these volumes are based on the best information available during the TLD compilation. New or more accurate information is solicited to improve the TLD data base. Please FAX comments $(615-576-8558)$ to $R$. $L$. Fellows, Editor, Oak Ridge K-25 Site Technology Logic Diagram, Martin Marietta Energy Systems, P.O. Box 2003, Oak Ridge, TN 37831-7274. 

During World War II, the Oak Ridge Gaseous Diffusion Plant (ORGDP) was built as a part of the Manhattan Project to supply enriched uranium for weapons production. ORGDP provided enriched uranium until 1985, when the enrichment operations ceased. In 1990, ORGDP was renamed the Oak Ridge K-25 Site, and subsequently, a new mission evolved that focused on environmental management (EM), specifically decontamination and decommissioning (D\&D), Remedial Actions (RA) on the soils, groundwater and surface water, and management of the waste being generated now and in the future.

The D\&D of the K-25 Site facilities is a massive operation. The most expedient plan would be to use existing state-of-the-art technologies. However, according to the Ebasco estimate, these technologies could cost as much as $\$ 8$ billion.

The K-25 Site effort includes information regarding the efficacy of various technologies, any obvious regulatory considerations, and rough estimates of the costs to develop and deploy each technology. However, because of the enormous estimated costs of $D \& D$ at this site, selecting the most cost-effective option is vital.

This is why the Oak Ridge Technology Logic Diagram (TLD) has been developed. The goal of the TLD is to provide a planning document that relates ER/Waste Management (WM) problems at the K-25 Site to the technologies that can be used to remediate these problems. To do this, it will be necessary to conduct follow-on engineering studies, which build on the output of this TLD. These studies will begin by selecting the most promising technologies identified in the TLD, examining these in much greater detail, especially concerning costs and efficacy, and finding an optimum mix of technologies that will provide a socially acceptable balance between cost and risk. In many cases, decisions regarding the acceptable end state of a facility (i.e., demolish and return to green field, restricted reuse, unrestricted reuse, etc.) will be guided by these systems studies. Without conducting these studies, the cost trade-offs and efficacy of the technology mixes are too complex for any person or group to be able to predict the end states most desirable to society.

The K-25 Site TLD builds on the methodology transferred by the U.S. Air Force to the EM organization within DOE, and from a recently completed diagram effort from the DOE Hanford Reservation. The final document from the K-25 Site includes contributions from the K-25 Site and Hanford. Other Oak Ridge sites and DOE-operating units from across the complex could be added to this diagram, as well as unique site-specific technology needs for DOE. This process will result in gaining information needed to begin selecting an optimum mix of available technologies and new technical innovations.

Because of its form, the TLD is often referred to as a "Wiring Diagram." It is a diagrammatic technique used to portray logical interrelationships that have been applied to relationships between the K-25 Site's EM problems and the suite of potential technologies needed to resolve these problems. The logical procession moves in the following manner: 
- Department of Energy (DOE) Goals

- Environmental Problems identified by DOE EM as areas with issues needing resolution.

- The K-25 Site Problems

- Problem Area arid Target Constituents are uniquely formulated for each the subelements (bilow).

- Reference Requirements are legal or binding commitments, schedules, "drivers" or corisiderations. In particular, site-, waste- and technologyspecific factors will determine the precise, applicable laws and regulatory requirements.

- Subelement identifies a strategy or classification for further logic analysis.

- Alternatives are typically generic technologies.

- Technology can be specifically applied to the K-25 Site problem.

- Status of the te:chnology is the stage the technology is in and when or under what impetus the technology might be brought to a mature level.

- Science and Technology Needs are used to bring the technology to maturity and eventual implementation at the K-25 Site.

- Implementation Needs are Identified for technology development and technology deployment activities. These subelement needs include:

- Resources (e.g., financial, personnel, demonstration procurement),

- Hardware requirements (e.g., equipment, computers).

- Software requirements (e.g., models, procedures),

- Facility requirements (e.g., labs, shops, buildings),

- Educational requirements (e.g., classes, graduates with defined majors), and

- Reference requirements (modifications necessary to deploy technology successfully).

The logical interrelationships between text groupings in the categories listed above are depicted on the diagram by interconnecting lines. The organization of the TLD is designed to cirient and guide the reader through the logical paths from DOE management goalis, through site problem definitions, to problem solutions.

In August 1991, a DOE D\&D workshop in Knoxville resulted in the development of the categorization strategy used for this document. In the workshop, which DOE representatives attended from across the DOE Complex, all basic D\&D activities were divided into six categories of work activities. However, the categories were extended in the K-25 Site TLD to all activities of D\&D, RA and WM. These categories are characterization, decontamination, dismantlement, remedial action, waste management, robotics and automation, and regulatory compliance. These are the categories that make up the organization of this document. 


\section{Introduction}




\section{INTRODUCTION}

\subsection{PURPOSE AND SCOPE}

The purpose of the TLD is to provide a planning document for DOE, DOE operating contractors, and private industry that relates the ER/WM problems at the Oak Ridge K-25 Site to the technologies that can be used to remediate these problems. In doing so, the status of each potential remediation technology is evaluated. This is a significant focus of the diagram preparation. Several important aspects impacting implementation of each technology are folded into the evaluation in a way that the appropriateness of each technology can be evaluated. These aspects are (1) potential efficacy of the technology. How successful will it be applied to the site problem? (2) level of maturity of the technology. When can it be applied to site problems? and (3) level of waste management required for the technology. What wastes are generated as a result of the use of the technology? The TLD addresses the enforceable compliance and cleanup agreements that have designated timetables for ameliorating the specific site problems. For potentially attractive but immature technologies or those that improvement paths (which make them faster, better, safer, and cheaper) are visualized, priorities can then be assigned to technology development activities.

Because of enforceable compliance agreements, DOE is bound by Executive Order 12088, which requires the Secretary of the Department of Energy to submit a plan and request sufficient funding each year to comply with federal pollution control standards. This document will aid in the annual planning and budget submittals.

This document will address all D\&D, RA, and WM problems that have been identified at the K-25 Site. The technology listings in the diagrams were judged to have some reasonable prospect for application at the K-25 Site, although in a few cases the prospect is limited. The Hanford Site Wiring Diagram has been used whenever possible. There are classified technologies which are well developed and applicable to the $D \& D, R A$, and WM problems. These technologies are not addressed in this document because they are unavailable for unclassified application. 


\subsection{THE TECHNOLOGY LOGIC DIAGRAM}

The formulation of the K-25 Site Technology Logic Diagram (TLD) was led by personnel from the K-25 Program Management Organization and the K-25 Technical Division, with participation from across Martin Marietta Energy Systems, Inc. Although a number of K-25 Site personnel were involved, approximately half of the team was selected from other Energy Systems organizations in Oak Ridge, such as the Y-12 Plant, Central Engineering, and Oak Ridge National Laboratory. The personnel from these organizations represent input from personnel associated with programs under the Department of Energy (DOE) Deputy Assistant Secretaries of Waste Management (EM-30), Environmental Restoration (EM-40) and Technology Development (EM-50). Figure 1.1 shows a staffing plan for the K-25 Site TLD Team.

Specialists worked as members of each team that was formed for each of the subelement categories. Fepresentatives from each team served on a coordinating committee, which functioned as a common communication forum for the TLD. More than 100 specialists were involved in this effort. The teams (1) compiled the site problems in terms that were applicable to each team; (2) identified and evaluated technologies that could be applied to remediate the problems; (3) furnished, through the technology evaluation, information on the opportunities that were evident for development and improvement in each technology, and (4) furnished the requirements for deployment of these developed and improved technologies.

Technology evaluation was a significant component of the TLD effort. Team members identified potential technologies, but it was not necessary for the technology evaluation experts to become familiar with the concepts of the TLD before their evaluations. The data sheets allowed the evaluations to be performed on a systematic basis. 'The data sheets (Vol. 3) are published with the diagram (Vol. 2), which provide; detailed information and the basis upon which the diagram was devised.

The TLD provides several benefits to the DOE community. The diagram identifies technologies that can be used for Environmental Management (EM) programs. It serves as a vehicle to identify the deficiencies in technologies that otherwise have potenticl to (1) foster faster remediation; (2) allow safer project activities; (3) result in better remediation efforts; and (4) allow these projects to be accomplished at lower cost to DOE and the United States. Improving existing technologies, demonstrating the applicability of promising technologies, developing immature technologies, and supporting fundamental technology investigations are options that DOE can pursue to deploy technologies necessary for successful EM of DOE facilities. The diagram will highlight areas for private industry and university involvement in EM.

The "filtering" aspects of elements of the diagram (the regulatory drivers, technology cost, and implementation needs) permit selection of technologies that will meet committed schedules, milestones, and planning for these and future budgets. For example, the remediation of polychlorinated biphenyls at the K-25 Site has a fixed schedule of remediation during the 1990s, which is detailed in a Federal Facility Compliance Agreement negotiated between DOE and the Environmental Protection Agency (EPA). Technologies that are chosen for remediation must be deployable to meet this schedule. Another example is that the 


\begin{tabular}{|c|c|}
\hline \multicolumn{2}{|c|}{$\begin{array}{l}\text { Senior Advis, Group } \\
\text { J.R. Merriman, Chairman (V.P. ERWM) } \\
\text { J.T. Bradbury, Co-Chairman }\end{array}$} \\
\hline $\begin{array}{l}\text { E.J. Barber (Enrich. Tech.) } \\
\text { R.K. Genung (ORNL Chem. Tech.) } \\
\text { I.M. Googin (Y-12 Develop.) } \\
\text { A.L. Lotts (Consultant, Retired ORNL M\&C }\end{array}$ & $\begin{array}{l}\text { 1.O. Moore (DOE-OR) } \\
\text { 1.H. Pastley (int. Tech.) } \\
\text { M.J. Stephen Ison (MMES Waste Mgmt.) }\end{array}$ \\
\hline
\end{tabular}

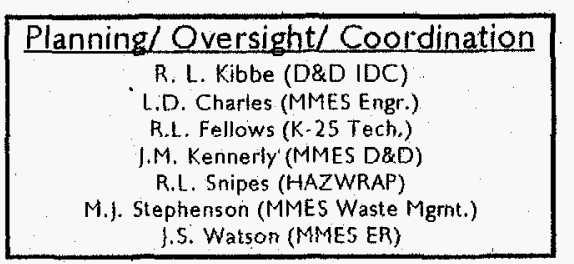

Planning \& Integration R.L. Fellows (K-25 Tech.)
D.W. Phifer (K-25 Tech.)

(Menson (MMES Waste Mgrnt)

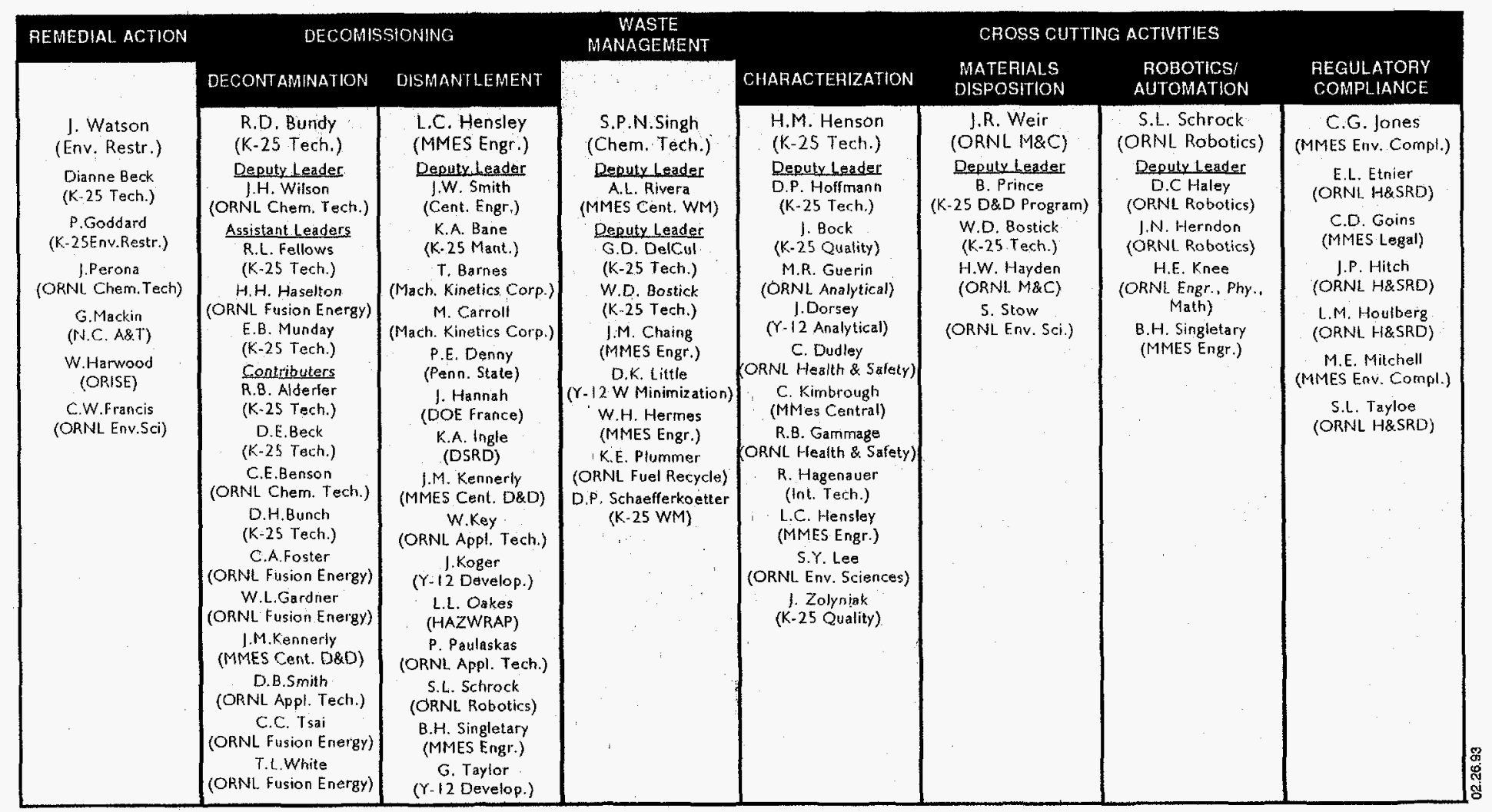

Fig. 1.1. The K-25 Site Technology Logic Dlagram team. 
decontamination and decommissioning (D\&D) costs for the K-25 Site facilities associated with the curtailed gaseous diffusion operations have been estimated at approximately $\$ 7.8$ billion dollars and $\$ 20$ billion for the entire uranium enrichment complex (the "EBASCO estimate"). This cost estimate offers opportunities for the development and improvement of technologies that promise to reduce decommissioning costs. The K-25 Site is one of the few sites in the DOE Complex that has estimated the decommissioning cost. 
The Oak Ridge Gaseous Diffusion Plant (ORGDP) was built as a part of the Manhattan Project during World War II to supply enriched uranium for nuclear weapons production. It was the oldest and largest gaseous diffusion uranium enrichment facility in the world. Construction of the plant started in 1943, and the $\mathrm{K}-25$ Building, the first diffusion facility for large-scale separation of ${ }^{235} \mathrm{U}$, was fully operable by August 1945. Additional buildings involved in the enrichment process, $\mathrm{K}-27, \mathrm{~K}-29, \mathrm{~K}-31$, and $\mathrm{K}-33$, were operable by 1956 . In response to the nation's postwar nuclear emphasis, plant operations were modified to include the production of enriched uranium with an enrichment that was appropriate for the fuel for nuclear reactors used to generate electric power. ORGDP continued to provide enriched uranium until 1985, when enrichment operations ceased. The plant was renamed the Oak Ridge K-25 Site in 1990, and its mission subsequently changed to focus on EM, including D\&D.

The magnitude of the enrichment facilities makes D\&D a monumental task. If pursued with existing state-of-the-art technologies for D\&D, the costs would be extremely large $-\$ 7.5$ billion according to the Ebasco estimate. There are five processing facilities with $\sim 120$ acres of roof area and several floors. Over 50 support facilities of various sizes are shut down. Figure 1.2 is an aerial view of the $\mathrm{K}-25$ Site, showing the scale of the facilities, where the largest building $(\mathrm{K}-25)$ is $\sim 1$ mile long around the U-shaped building. The five main processing buildings contain over 5000 stages of similar enrichment equipment. The largest items weigh $70,000 \mathrm{lb}$ (35 tons). Figure 1.3 illustrates a gaseous diffusion stage arrangement of the axial flow type, and Fig. 1.4 shows the largest axial flow type gas compressor used in the K-33 Building at the K-25 Site. There are 640 large axial flow compressors in the K-33 Building. Figure 1.5 shows diffusers containing nickel barrier in a cell configuration in the K-33 Building. Eight such combinations of compressors, diffusers, and associated piping make up a typical $\mathrm{K}-33$ cell. Components in the diffusion process are connected by large welded piping in diameters up to $40 \mathrm{in}$. Much of this equipment is coated with uranium deposits on the inside surfaces. The quantities of valuable material available for recycle are massive. At the K-25 Site, there are 22,000 tons of nickel metal, for example. The scale of the D\&D problem is illustrated by Fig. 1.6, which shows the maze of equipment and piping fitted into the 11-acre footprint of the K-29 Bullding, which was the pilot plant for the axial flow process. Figure 1.7 shows a cell housing the original, smaller scale centrifugal equipment comprising the K-25 and K-27 building process. The site stores about five thousand 14-ton cylinders containing depleted uranium, -1000 cylinders of natural uranium feed material (which will be shipped to the operating diffusion plants) and -100 cylinders of various capacities that contain small amounts (heels) of other product.

$\mathrm{RA}$ at the K-25 Site is dominated by facilities associated with the gaseous diffusion process and support of that process. Uranium, technetium, other radioactive materials, lead, asbestos, polychlorinated biphenyls (PCBs), lube oils, chlorofluorocarbon coolants, mercury, and fluorides all exist in large quantities at the K-25 Site. Several examples of sites for RA are groundwater and surface water contaminated from burial grounds; radioactive settling and holding ponds and their legacies; and potential soil and groundwater contamination from liquid transfer lines within the facilities. There are six large cooling towers (Fig. 1.8) that contain chromates and possible dioxins from water treatment, arsenic and barium from preserved lumber, and small amounts of uranium, meaning these facilities contain mixed wastes. 


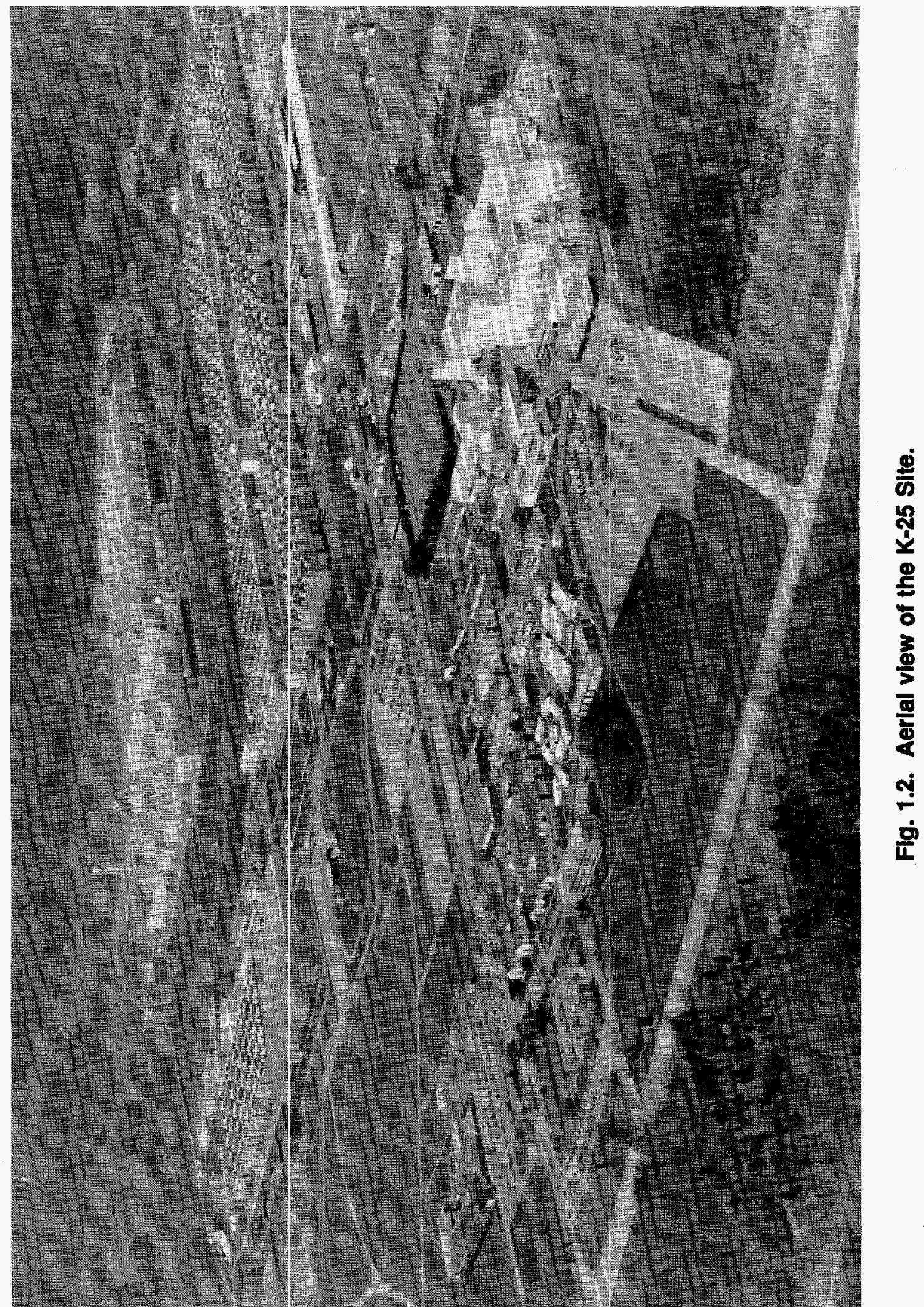




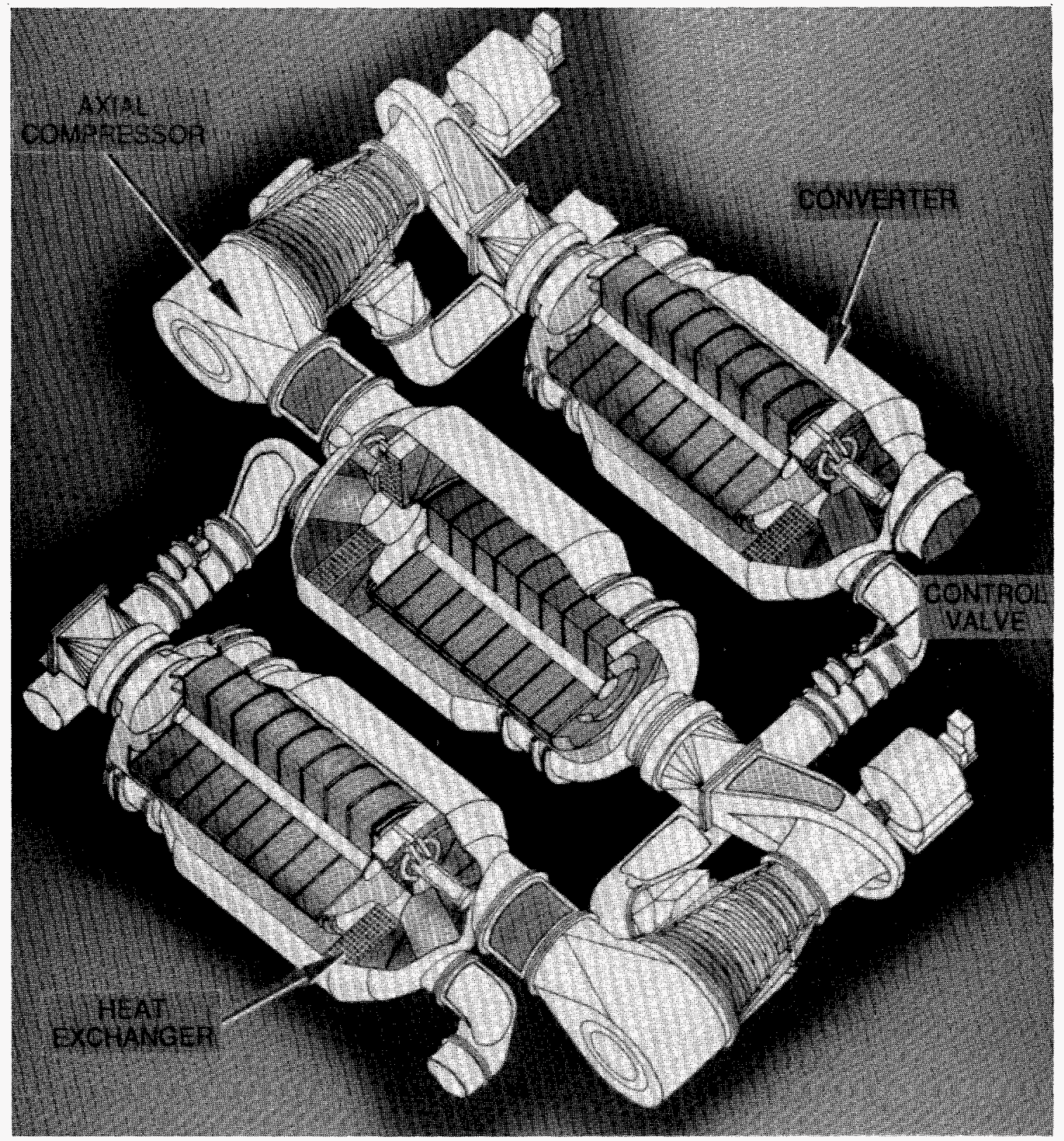

Fig. 1.3. Typical U.S. gaseous diffusion stage arrangement. 


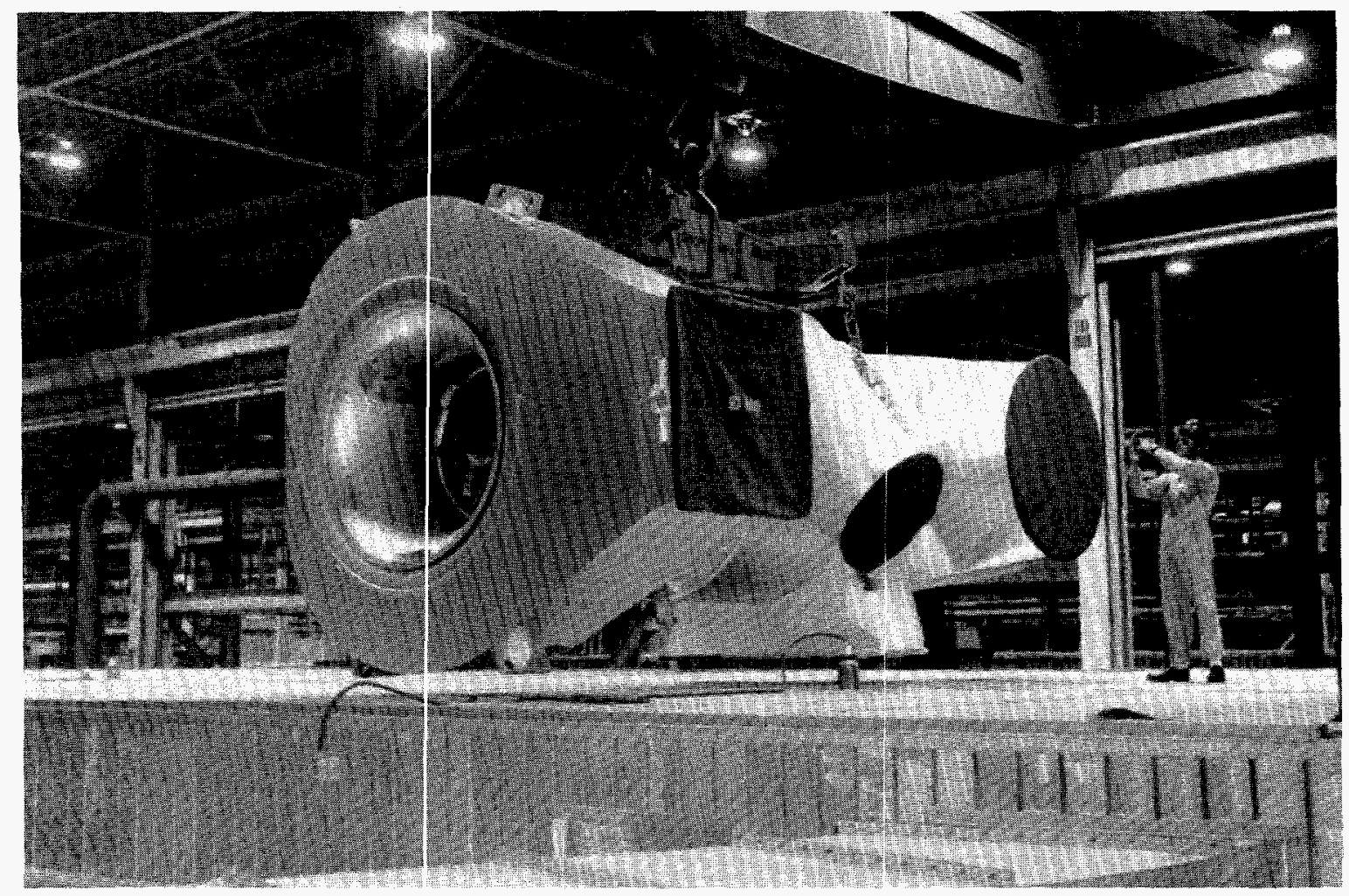

Fig. 1.4. The largest axial flow type gas compressor used in the K-33 Bullding at the K-25 Site.

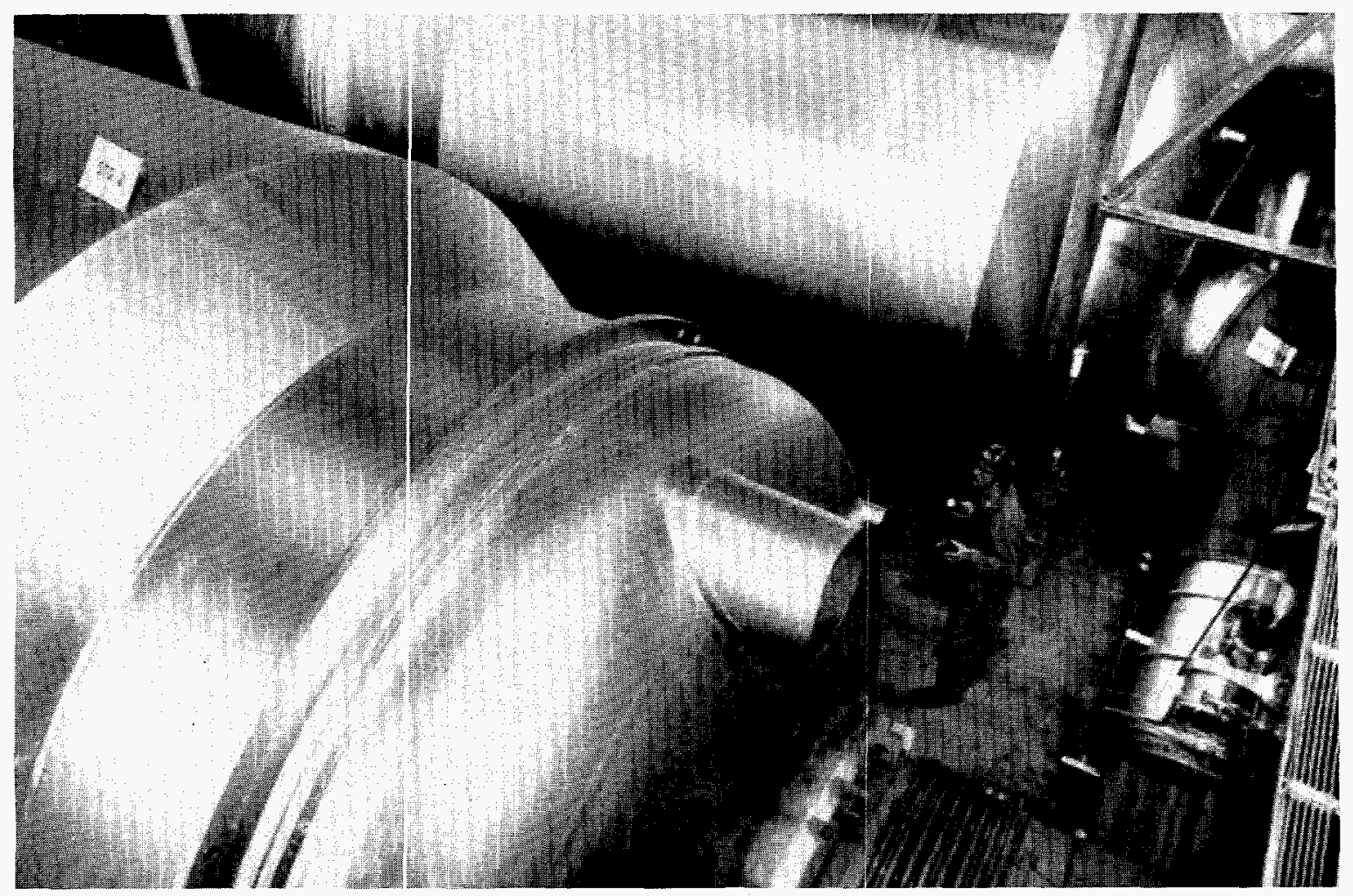

Fig. 1.5. Diffusers ciontaining nickel barrier in a typical K-33 cell configuration. 


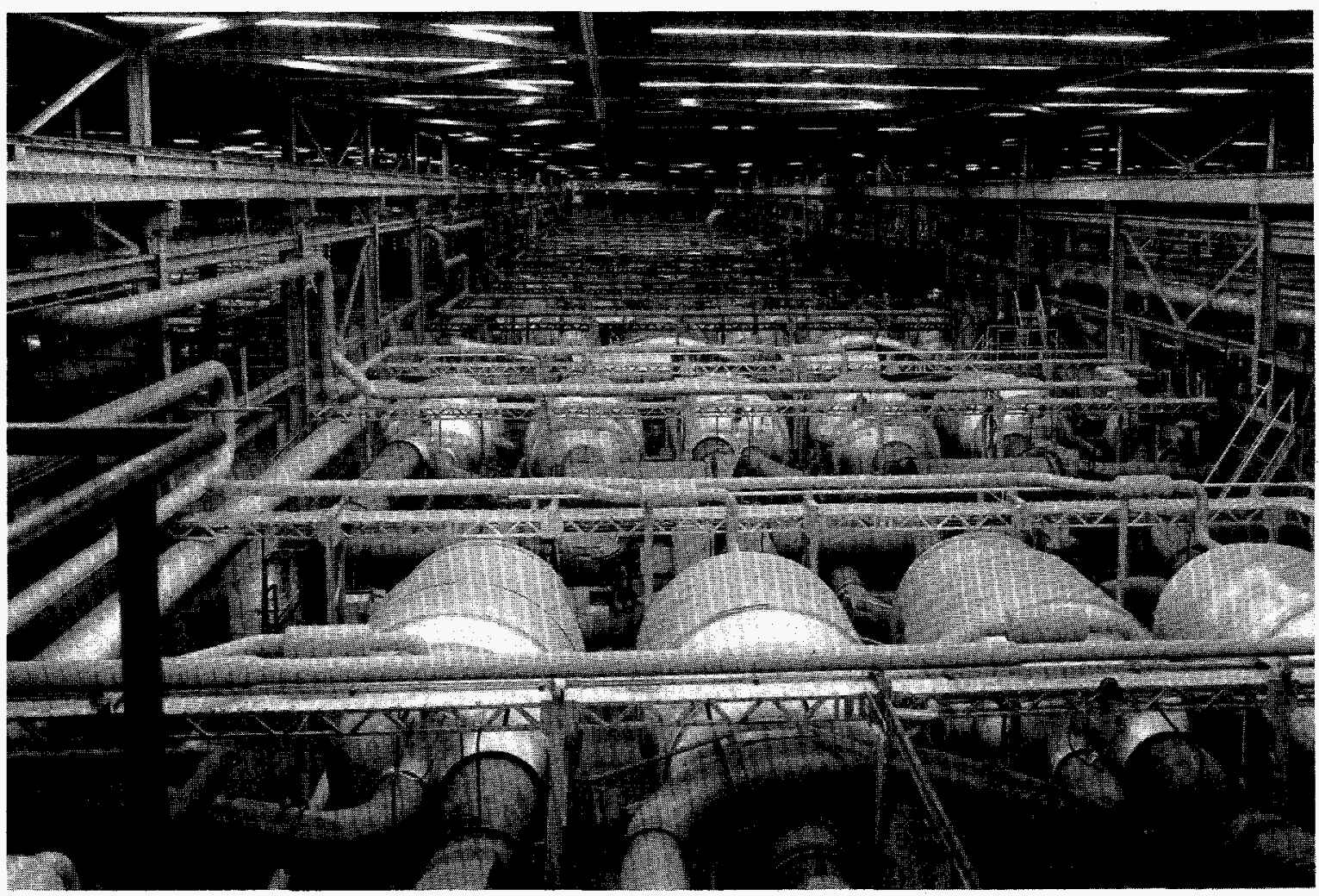

Fig. 1.6. Stage equipment and piping, K-29 Bullding.

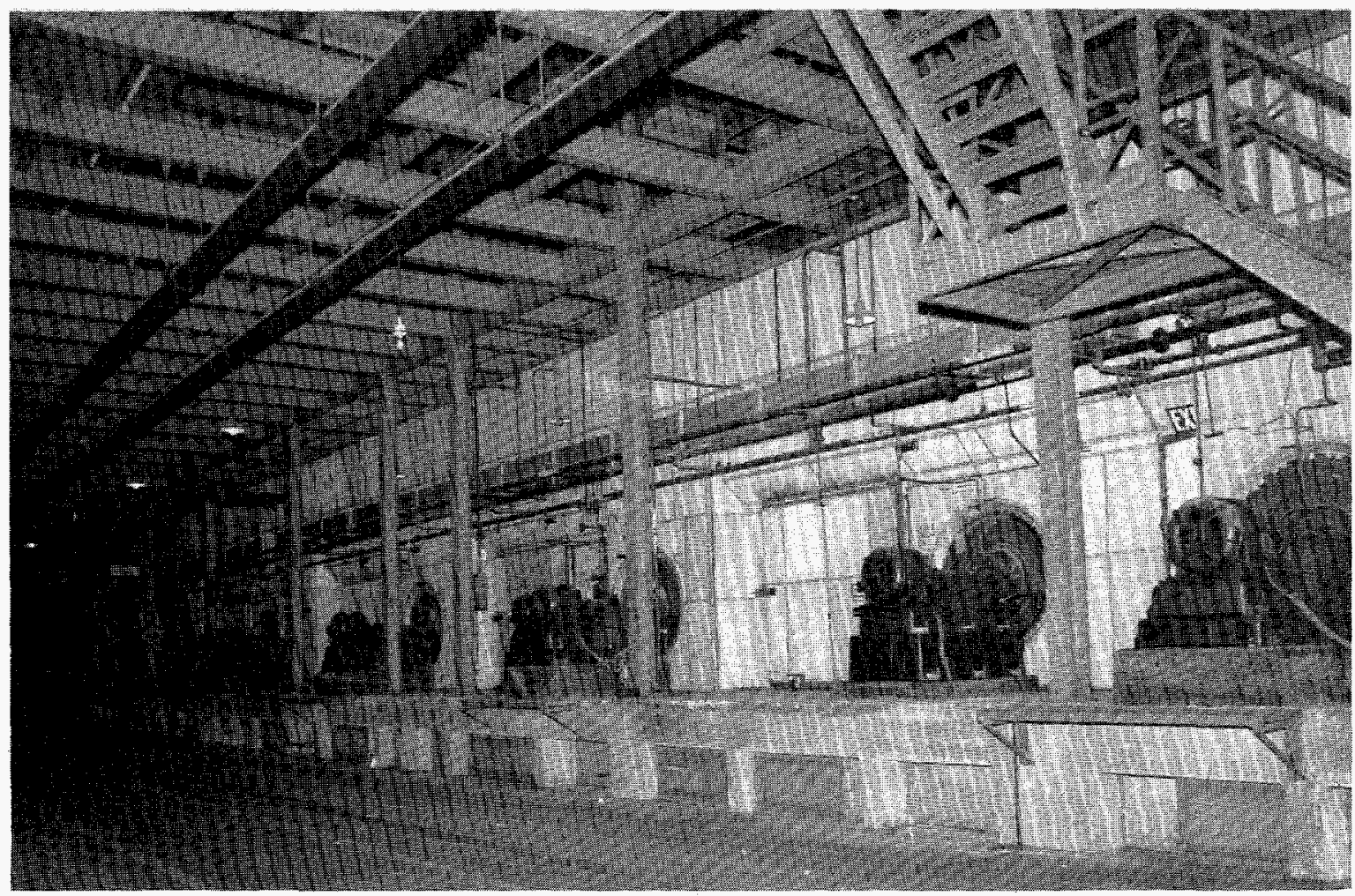

Fig. 1.7. Centrifugal stage equipment. 


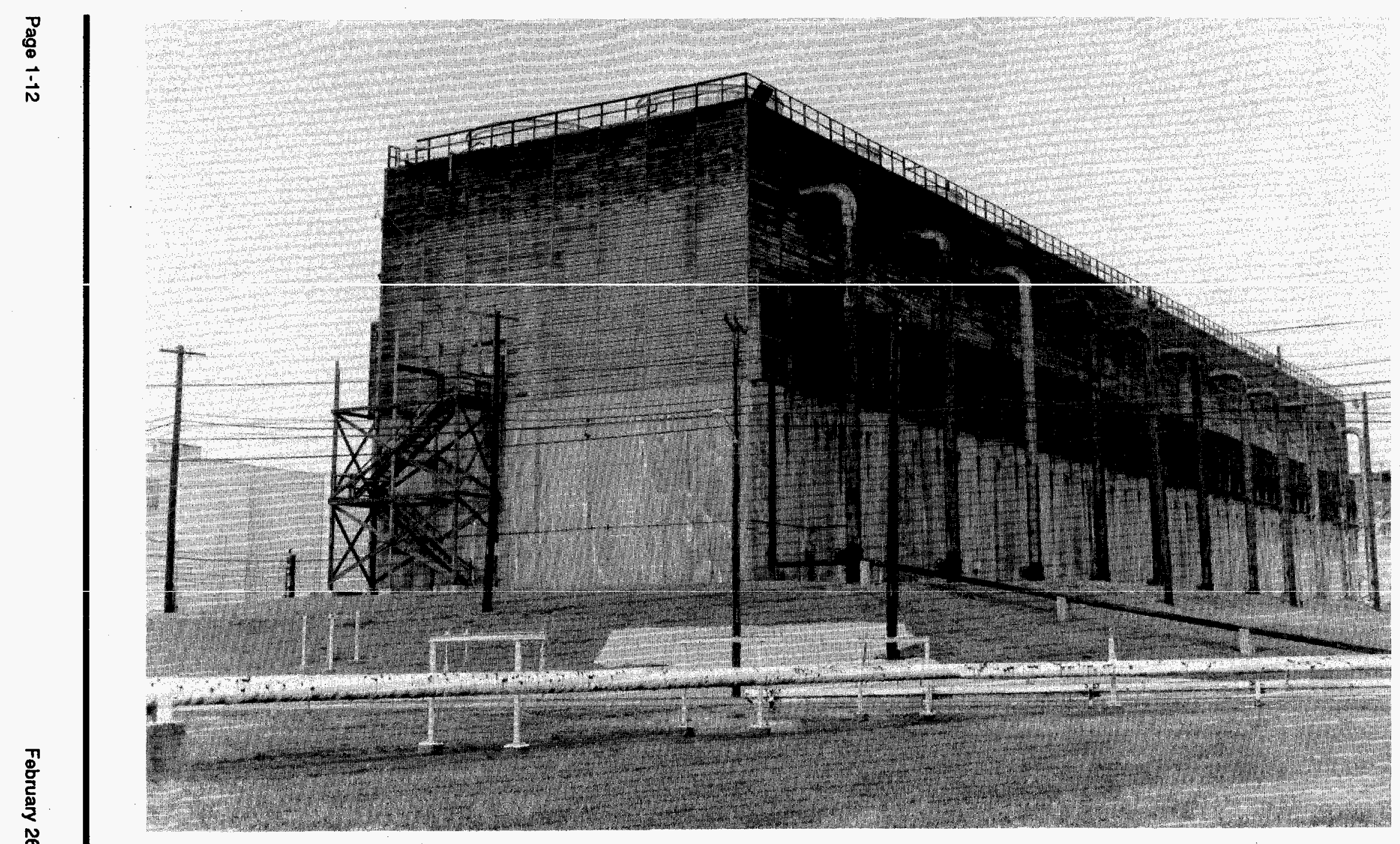

Fig. 1.8. Cooling towers at the K-25 Site. 


\subsection{OAK RIDGE K-25 SITE MISSION}

The mission of the Oak Ridge K-25 Site is to provide a base of operations for the Energy Systems Environmental Restoration and Waste Management (ERWM) Programs, thus serving as a "platform" for the restoration of the environment and management of DOE wastes through management of the Environmental Restoration (ER), Waste Management (WM), and Technology Development (TD) Programs in support of DOE; DOE sites operated by Martin Marietta Energy Systems, Inc. (Energy Systems); other elements of the federal government; and the public.

The Oak Ridge K-25 Site mission includes:

- Management of the Toxic Substance Control Act (TSCA) Incinerator, a unique mixed waste treatment facility.

- Support of risk-based cleanup programs for all contaminated facilities and natural resources with full involvement of regulators and the public, all Energy Systems sites and other sites as required by DOE, assuring that cleanup programs at these sites are models for these activities.

- Compliant and safe waste management at the K-25 Site, and support to these activities at all DOE Oak Ridge Field Office (DOE-OR) sites, including minimization, treatment, storage and disposal for all programs and activities.

- Operation of a national center for the demonstration of advanced environmental technologies. Two new centers were designated $2 / 93$ ).

- Research, development, and demonstration of innovative technologies for ER and WM, leading to the most technically-efficient and cost-effective programs.

- Support to the Hazardous Waste Remedial Actions Program (HAZWRAP) for DOE sites and other federal sites as requested by DOE.

- Provision of cost-effective support and services to all K-25 Site users and customers, including programs of the Unites States Uranium Enrichment Enterprise; the International Technology Program; Energy Systems Engineering, Computing, and Business Operations; and Data Systems Research and Development. 


\subsection{SITE PROBLEMS AND ISSUES}

\subsubsection{Decommissionirig}

The current list of facilities identified for $D \& D$ at the K-25 Site is shown in Table 1.1.

The size of enrichment facilities makes decommissioning a monumental task. The diffusion facilities are massive structures containing large numbers of similar components weighing as much as $70,000 \mathrm{lb}$. In the $\mathrm{K}-33$ Building, there are over 600 converters that weigh $60,000-70,000 \mathrm{lb}$. These converters are an assembly of nickel, aluminum, monel, and steel components that represent significant recycle opportunity. The components in the diffusion process are connected by large welded piping in diameters up to $42 \mathrm{in}$. in which deposits of uranium and other radioactive materials are contained. Estimates by EBASCO Services (EBASCO) indicate D\&D of the K-25 Site will cost $\$ 7.5$ billion (the three diffusion plants will cost $\$ 20$ billion) using current technologies. The technologies currently in use at the diffusion plants were designed to provide efficient maintenance on failed items and do not provide the production rates and low personnel exposure necessary to complete decommissior.ing in a timely or cost-effective manner.

Current ongoing DiBD projects such as the removal of the Special Nuclear Material (SNM) Facility at Mound Laboratory and D\&D of the Babcock and Wilcox Nuclear Facility at Apollo, Pennsylvania, have shown that costs of disposal of materials can vary by a factor of 5 depending upon the final method selected. Contaminated equipment that is removed, externally decontaminated, and "fixed" by painting or foaming interior contamination costs $-\$ 100 / \mathrm{ft}^{3}$ to ship and bury in approved locations. Sitructural components, steel, concrete rubble, siding, and soils cost $-\$ 20 / \mathrm{ft}^{3}$. Burial costs are increasing rapidly, and available disposal space is diminishing rapidly. Also, it is not clear that this method of "fixing" and burying contaminated materials is consistent with DOE objectives of cleaning up the legacy (of past operations), preventing future (environmental) insult, and developing environmental stewardship.

\subsubsection{Remedial Action}

Environmental coritamination at the K-25 Site can be divided into four categories of problems cr contaminated media: (1) soils, (2) groundwater, (3) burial grounds and other point and line sources of contamination, and (4) pond waste sludges, which include sediments and liquids. Several contaminated areas within the K-25 Site are included in each grouping. Although work has been done to identify contaminated sites and characterize the type and extent of contamination, exploration for contamination problems continues, suggesting that more contaminated sites might be found. Table 1.2 shows a list of areas needing remediation at the K-2.5 Site. Figure 1.9 shows a map of the K-25 Site, which is divided for administrative purposes into operable units to facilitate remedial action. 
Table 1.1. Preliminary K-25 Site Problem List

\section{Decontamination and Decommissioning List}

D-301-1 to K-312-3, K-25 Process

Building

K-25/K-27, Tielines, Outdoor Process

$\mathrm{K}-402-1$ to $\mathrm{K}-402-9$, Vaults $32-\mathrm{A}$ and

34-A, K-27 Process Building

K-27/K-131, Tielines, Outdoor Process

$\mathrm{K}-27 / \mathrm{K}-413$, Tielines, Outdoor Process

$\mathrm{K}-27 / \mathrm{K}-631$, Tielines, Outdoor Process

$\mathrm{K}-27 / \mathrm{K}-633$, Tielines, Outdoor Process

K-27/K-1131, Tielines, Outdoor Process

$\mathrm{K}-502-1$ to K-502-3, K-29 Process Building

$\mathrm{K}-602-1$ to $\mathrm{K}-602-6, \mathrm{~K}-31$ Process Building

$\mathrm{K}-31 / \mathrm{K}-631$, Tielines, Outdoor Process

$\mathrm{K}-902-1$ to K-902-8, K-33 Process Building

$\mathrm{K}-33 / \mathrm{K}-31$, Tielines, Outdoor Process

$\mathrm{K}-101$, Centrifuge Research Building

K-131, Feed Vaporization Building

K-413, Product Withdrawal Facility

K-631, Process Tails

K-633, K-1040, and K-633-D, Test Loop

Facility, Maintenance Shop, and

Storage

K-701, PH, Boiler House and Fabrication Shop

$\mathrm{K}-702, \mathrm{PH}$, Turbine Room and Discharge

K-703, PH, Fabrication Shop, Bio

Laboratory

K-705-B, PH, Crib House

K-706, PH, Pump House

K-707, PH, Auxiliary Switch House

K-708-E, PH, Scale House and Pit

K-709, K-25 Switchyard

$\mathrm{K}-724$, Storage Warehouse

$\mathrm{K}-735$ and K-735-A, Storage Buildings

$\mathrm{K}-762$, K-31 Switchyard and Valve Vaults 1 and 2

$\mathrm{K}-792, \mathrm{~K}-33$ Switchyard and Valve Vaults $1,2,3$, and 4

$\mathrm{K}-832$ and $\mathrm{K}-832-\mathrm{H}$, Recirculating Water Pump House and Cooling Tower

$\mathrm{K}-862, \mathrm{~K}-861$, and $\mathrm{K}-861-\mathrm{J}, \mathrm{K}-31$ Recirculating Water Pump House and Cooling Towers

$\mathrm{K}-892, \mathrm{~K}-892-\mathrm{G}, \mathrm{K}-892-\mathrm{H}, \mathrm{K}-892-\mathrm{J}$, K-896, K-896-A, and K-896-B, Pump House Area, Cooling Towers, Recycle Blowdown Facility, and Clarifier Tanks

K-1004-L and K-1004-N, Pilot Plant and Cooling Tower
$\mathrm{K}-1024, \mathrm{~K}-1024-\mathrm{B}, \mathrm{K}-1024-\mathrm{C}$, and $\mathrm{K}-1024-\mathrm{D}, \mathrm{D} \& \mathrm{D}$ Offices and Storage Areas

$\mathrm{K}-1031$, Power and Utilities Storage

$\mathrm{K}-1037$ and K-1037-C, Industrial Research

Facility and Smelter House

K-1066-B, Cylinder Storage Yard,

Northeast K-1423

K-1066-E, Cylinder Storage Yard, North $\mathrm{K}-832$

K-1066-J, Cylinder Storage Yard, North $\mathrm{K}-25$

$\mathrm{K}-1066-\mathrm{K}$, Cylinder Storage Yard, West $\mathrm{K}-33$

$\mathrm{K}-1131$, Feed and Tails Building

$\mathrm{K}-1132, \mathrm{~K}-1133, \mathrm{~K}-1134$, and $\mathrm{K}-1135, \mathrm{HF}$ Storage, Shed and Control Room

$\mathrm{K}-1231, \mathrm{~K}-1231-\mathrm{A}$, and K-1231-B, Process and Storage Facilities

K-1233 and K-1233-A, Collection Facility and Drum Cleaning

$\mathrm{K}-1251$, Barge Unloading Area

K-1300, Brick Stack

K-1301, Pump Storage

$\mathrm{K}-1302$, Fluorine Storage

K-1303, Research Comp. Building

K-1401-N, Converter Retubing Area

$\mathrm{K}-1410$, Plating Facility

$\mathrm{K}-1413$, Laboratory Engineering

K-797, K-1004-J, Electrical Switchgear Room

K-798, K-1023, Electrical Switchgear

Room

K-1004-J, Centrifuge, Lab-Special Development

K-1004-Q, Centrifuge Laboratory

$\mathrm{K}-1010$, Laboratory, Receiving and

Handling

K-1023, Laboratory

K-1045, Valve Shop

K-1052, Advanced Machine Development Laboratory

K-1200, Centrifuge, South Bay

$\mathrm{K}-1210$, Centrifuge Test Facility

$\mathrm{K}-1210-\mathrm{A}$, Advanced Engineering Test

Facility

$\mathrm{K}-1220$, CPDF-1 and CPDF-2

K-1600, Technology Test Facility 
Remedial Action List

Duct Island Road

Flannagan's Loop Road

K-25 Site Groundwater

K-27/-29 Recirculating Cooling Water Lines

K-31 Recirculating Cooling Water Lines

K-33 ANDCO Water Treatment Unit

K-33 Recirculating Cooling Water Lines

K-301-1 Vault 4 Hazardous Waste Storage Facility

K-303-5 Low-Level Waste S:orage

K-305 Vaults 19 and 19A Hazardous

Waste Storage Facility

K-306-1 PCB/Hazardous Waste Drum Storage

K-306-1 Vault 23A Hazardous Waste Storage Facility

$\mathrm{K}-310-1$ Vaults $2,2 \mathrm{~A}$, and $\mathrm{AB}$ Hazardous Waste Storage Facility

K-310-2 Low-Level Waste S:orage

K-310-3 Low-Level Waste S:orage

K-31 1-1 Radiogenic Lead Storage

K-631 Contaminated Soil

K-709 Switchyard

K-710 Sludge Beds and Imi ıff Tanks

K-711 Hazardous Waste Stcrage Facility

K-720 Fly Ash Pile

K-722 Property Sales Building

K-725 Beryllium Building

K-726 PCB Storage Facility

K-732 Switchyard

K-762 Switchyard

K-770 Contaminated Debris:

K-770 Scrap Metal Yard

K-792 Switchyard

K-801-H Cooling Tower Basin

$\mathrm{K}-802-\mathrm{H}$ Cooling Tower Basin

$\mathrm{K}-822$ Cooling Tower Basin

$\mathrm{K}-832-\mathrm{H}$ Cooling Tower Basin

K-861 Cooling Tower Basin

K-892-G Cooling Tower Basin

$\mathrm{K}-892-\mathrm{H}$ Cooling Tower Basin

$\mathrm{K}-892-\mathrm{J}$ Cooling Tower Basin

K-900 Bottle Smasher

K-901 Waste Disposal Area

K-901-A Holding Pond

K-901-A Sanitary Disposal Area

K-1001-B Waste Accumulation Area

K-1001-C Waste Accumulation Area
K-1001-D Waste Accumulation Area K-1003 Waste Accumulation Area

K-1004 Area Lab Drain

K-1004 Waste Accumulation Area

K-1004-J Vaults

K-1004-L Contaminated Scrap Metal Dumpster

K-1004-L Recirculating Cooling Water Lines

K-1004-L Underground Tank

K-1004-L Vaults

K-1004-N1 Recirculating Cooling

Water Lines

K-1006 Contaminated Scrap Metal Dumpster

K-1007 Gas Tank

K-1007 Waste Accumulation Area

$\mathrm{K}-1007-\mathrm{P} 1$ Holding Pond

K-1024 Dilution Pit

$\mathrm{K}-1025-\mathrm{C}$ Storage Building

K-1031 Waste Paint Accumulation Area.

K-1030 Building Contaminated Scrap Metal Dumpster

K-1030 Contaminated Scrap Metal Dumpster

K-1035 Acid Pits

K-1035-A Satellite Drum

Storage Area

K-1037 Recirculating Cooling Water Lines

K-1064 Drum Storage and Burn Area

K-1064-G Drum Deheading Facility

$\mathrm{K}$-1070-A Landfarm

$\mathrm{K}$-1070-A Old Contaminated Burial Ground

K-1070-B Old Classified Burial Ground

K-1070-C and -D Classified Burial Ground

$\mathrm{K}-1070-\mathrm{D} 1,-\mathrm{D} 2$, and -D3

Storage Dikes

K-1070-F Construction Spoil Area

K-1070-G Burial Ground

K-1085 Old Firehouse Burn Area

K-1095 Paint Shop

K-1095 Waste Accumulation Area

K-1099 Blair Quarry

K-1131 Neutralization Pile

$\mathrm{K}-1202$ Hazardous Waste Storage

Tanks

K-1203 Sewage Treatment Plant 
Table 1.2. (continued)

K-1210 Recirculating Cooling Water Lines

K-1225 Contaminated Scrap Metal

Dumpster

K-1232 Chemical Recovery Facility

K-1302 Gas Cylinder Storage Area

$\mathrm{K}-1303$ Mercury Distillation and

K-1401 Acid Line Recovery Unit

K-1401 Degreasers

K-1401-2W Contaminated Scrap Metal

Dumpster

K-1401-3E Contaminated Scrap Metal

Dumpster

K-1401-4W Contaminated Scrap Metal

Dumpster

K-1407-A Neutralization Pit

K-1407-B Holding Pond

K-1407-C Retention Basin

K-1407-C Soil

$\mathrm{K}-1407-\mathrm{E}$ Settling Pond

$\mathrm{K}-1407-\mathrm{F}$ Settling Pond

K-1407-H Central Neutralization Facility

K-1410 Neutralization Pit

K-1410 Plating Facility
K-1413 Process Lines

K-1413 Treatment Tank

$\mathrm{K}-1414$ Gas Tank

K-1417 Block Casting/Storage Area

$\mathrm{K}-1417$ Soil

K-1419 Sludge Fixation Plant

K-1420 Contaminated Drum Storage

K-1420 Contaminated Scrap Metal

Dumpster

K-1420 Mercury Recovery Room

K-1420 Oil Decontamination Facility

$\mathrm{K}-1420$ Oil Storage

K-1420 Process Lines

K-1420-A Flammable Waste Storage Tank

$\mathrm{K}-1421$ Incinerator

K-1425 Waste Oil/Hazardous Waste/PCB

Drum Storage

K-1435 Hazardous Waste/PCB

Incinerator

K-1503 Neutralization Pit

$\mathrm{K}-1515$ Lagoon

$\mathrm{K}-1515-\mathrm{F}$ Land Treatment

K-1654-A Waste Accumulation Tank

$\mathrm{K}-1700$ Stream

Characterization of identified sites continues, lending a better understanding of the nature and extent of the problems. The ER Program at the K-25 Site has identified seven classes of contaminants, which are addressed in this TLD study:

1. Petroleum Hydrocarbons,

2. Volatile Organic Compounds (often chlorinated),

3. Polynuclear Aromatic Hydrocarbons,

4. Toxic Metals,

5. Radioactivity (Uranium, Technetium),

6. Nonvolatile Organic Compounds (particularly PCBs), and

7. Asbestos.

These contaminants occur in groups of two or more at most sites. Occasionally they are present individually.

The principal radioactive contamination at the $\mathrm{K}-25$ Site is uranium and its decay products. Significant quantities of technetium and other radioisotopes contaminate selected parts of the facility where uranium recycled from reactors was introduced into the gaseous diffusion cascade. Most of the contamination under the aegis of Remedial Action (RA) is believed to reside principally in the burial grounds, although some radioactivity has migrated from the immediate vicinity of the burial grounds. Despite the attention often focused on radioactive contaminants, the nonradioactive contaminates often prove to be as difficult to handle and may eventually become critical ER problems. Solvents such as trichloroethylene (TCE) are found in several areas (K/ER-47). PCBs were used extensively as dielectrics during the operation of the gaseous diffusion cascades. 

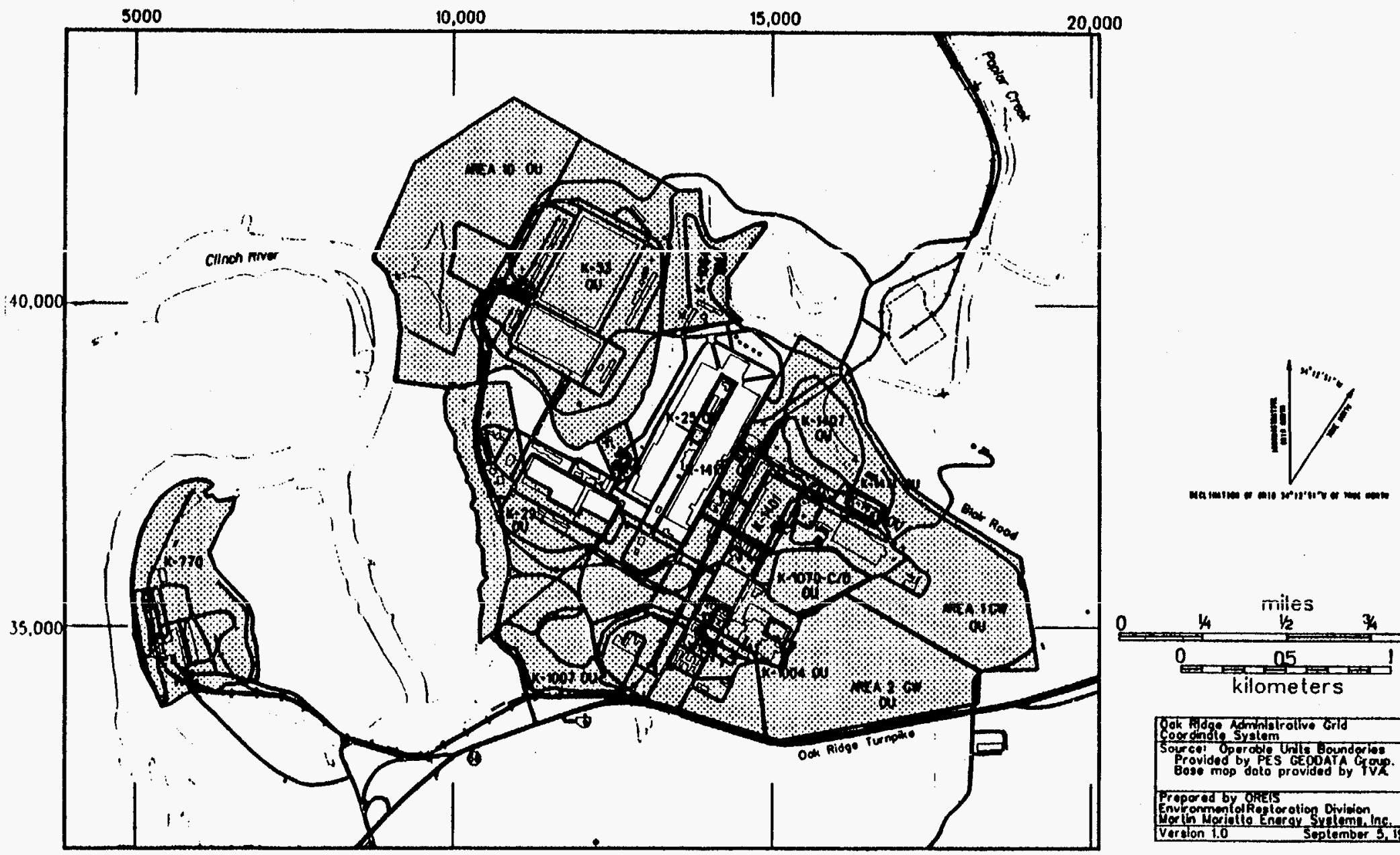

Fig. 1.9. Map of the K-25 Site operable units.

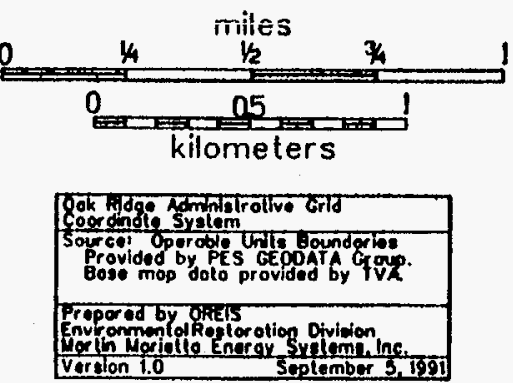


Significant quantities of these contaminated materials were buried and sometimes inadvertently spilled or leaked at sites within the plant. Several of more conventional contamination problems exist at the K-25 Site, such as fuels and other hydrocarbons that have leaked from underground storage tanks. Although these problems are much like those found at numerous industrial sites, the multiple presence of radioactivity jointly contaminating the $\mathrm{K}-25$ sites complicates remediation.

One example of a difficult and costly RA problem at the K-25 Site is metal hydroxide sludges that were excavated from neutralization ponds. These ponds were used until November 1988 for settling sludges generated from the neutralization of metal-laden solutions, sometimes including both solvents and low concentrations of radioactivity, uranium, and/or technetium. Some of the uranium may have been enriched in the 234 and 235 isotopes. Because of the presence of small quantities of both toxic and radioactive materials (i.e., mixed wastes), and in response to a negotiated State Environmental Milestone Agreement, the sludges were excavated from the ponds and stored both solidified within a concrete matrix and as raw materials in drums.

Although no DNAPLs have been found at the K-25 Site, the mechanism of some contamination (spills) suggests that the potential for DNAPL contamination is significant. Definite detection of DNAPLs is difficult, and successful detection of DNAPLs often depends upon "luck," drilling directly into a particular spot with the DNAPL. If DNAPLS are present, there are most likely to consist of VOCs. These are the most common DNAPL fluid detected in groundwater at the K-25 Site. Although all contamination levels seen in groundwater are well below saturation, that does not insure that the contamination did not come originally from a DNAPL region. There is a lesser potential for finding DNAPLs from PCB contaminated oils.

\subsubsection{Waste Management}

The K-25 Site was originally developed with the construction of the ORGDP for uranium enrichment through isotopic separation utilizing uranium hexafluoride $\left(\mathrm{UF}_{6}\right)$ and gaseous diffusion technology. This enrichment operation (until shut down in 1956) created facilities and sites containing hazardous and radioactive materials and wastes. The sites include burial grounds, storage facilities, underground storage tanks, surface impoundments, treatment facilities, process equipment and lines, accumulation areas, and other areas having the potential for releasing hazardous and radioactive constituents to the environment. A total of 156 solid waste management units (SWMU) have been identified at the K-25 Site. Current waste management operations at the K-25 Site consist predominantly of treatment, storage, and disposal of wastes stemming from activities associated with the enrichment operations at the K-25 Site and other DOE facilities. Wastes resulting from existing ER and D\&D programs are also being treated, stored, and disposed of at these sites.

The primary method of treatment at the K-25 Site is the mixed waste incinerator known as the TSCA Incinerator. Figure 1.10 is a photograph of the $\mathrm{K}$ 25 Site TSCA Incinerator. The TSCA Incinerator is designed to store and destroy up to 1 million gal/year of liquid PCB waste, hazardous waste las defined by the Resource Conservation and Recovery Act of 1976 (RCRA) as amended], and mixed waste, which consists of $\mathrm{PCB} /$ hazardous waste containing low-level radioactive materials. The facility consists of a rotary kiln incinerator, a secondary combustion 


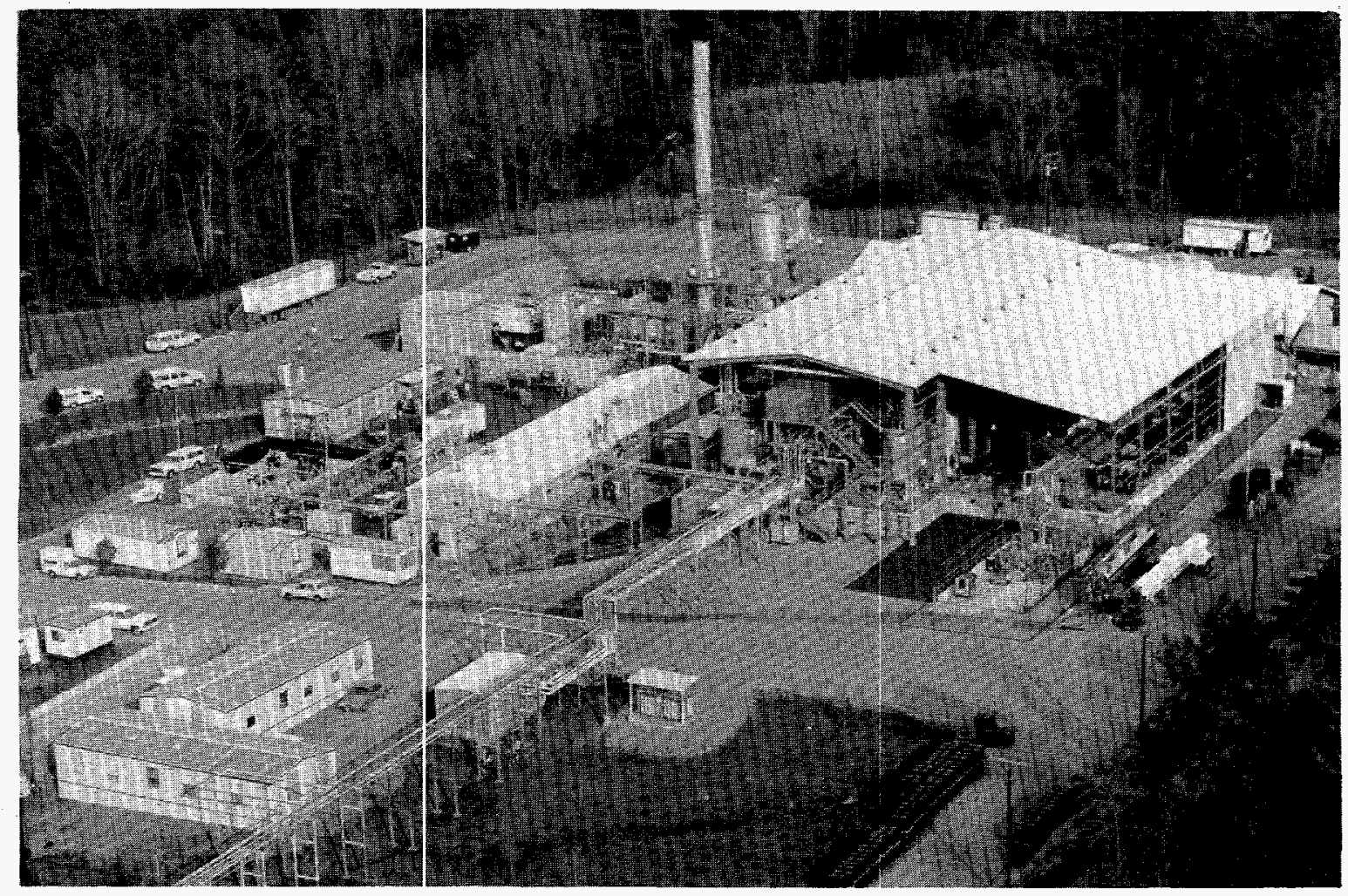

Fig. 1.10. Toxic Substance Control Act: Incinerator.

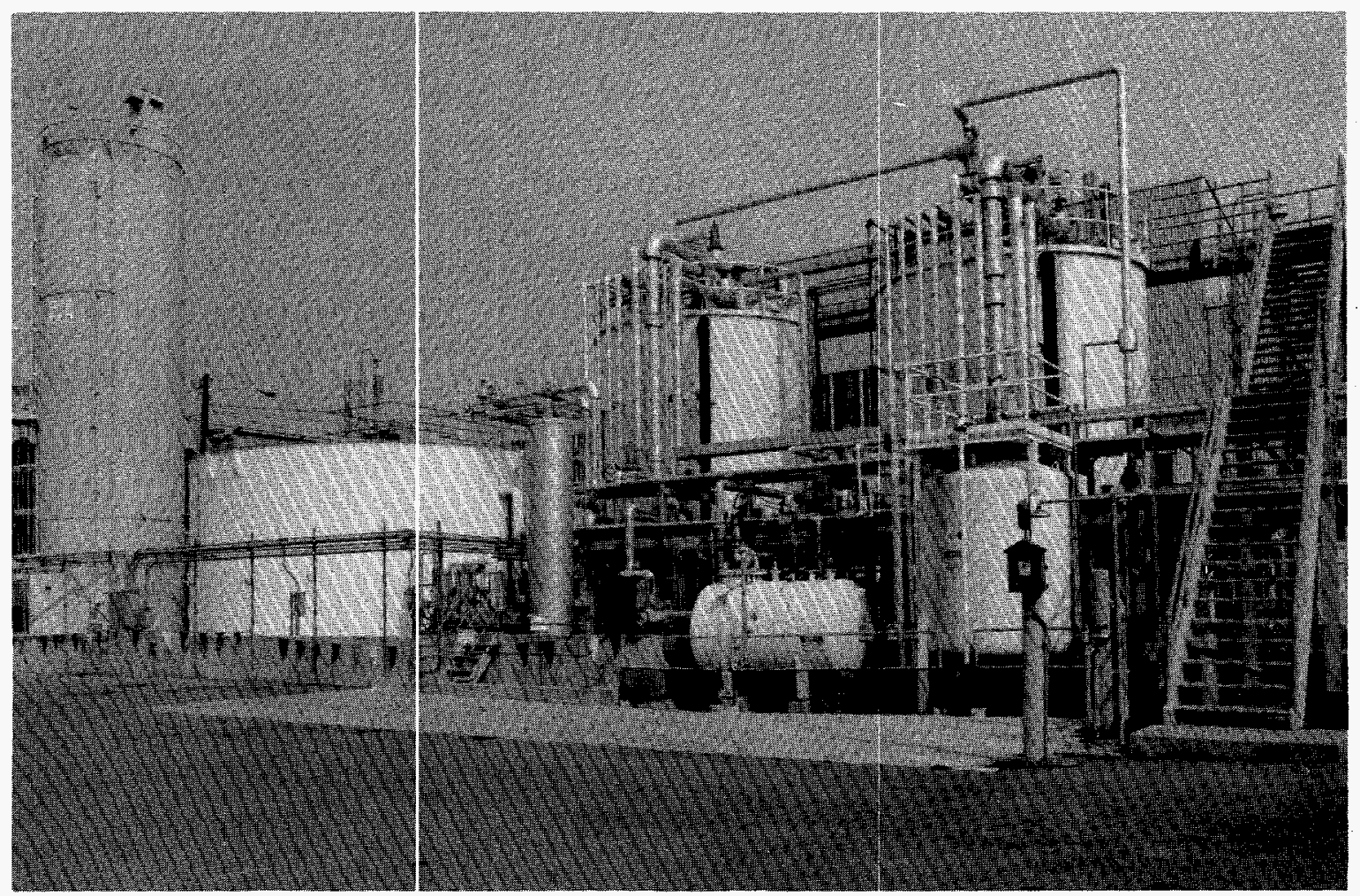

Flg. 1.11. Phciograph of the Central Neutrallzation Facillty. 
chamber, a recelving storage tank farm, a drummed waste storage area, liquid effluent holding and surge tanks, an off gas treatment system, flue gas monitoring equipment, and two carbon columns used for removing PCBs from the effluent on an as needed basis. Effluent and residuals from the incinerator are sent to the K-25 Site Central Neutralization Facility (CNF) for treatment before discharging through a National Pollutant Discharge Elimination System (NPDES) permitted outfall to Poplar Creek. In addition to processing wastes generated at the K-25 Site, the TSCA Incinerator also processes wastes generated at six other DOE sites [the Oak Ridge National Laboratory (ORNL), the Y-12 Plant, the Paducah Gaseous Diffusion Plant, the Portsmouth Gaseous Diffusion Plant, the Feed Material Production Center, and the RMI Extrusion Plantl. The TSCA Incinerator currently is not permitted by DOE to process solids waste streams.

Process wastewater at the K-25 Site is processed in the CNF. Figure 1.11 is a photograph of CNF. CNF was designed to treat specific industrial wastewater and for the removal of priority pollutants through neutralization and coprecipitation (with the addition of appropriate chemicals), clarification, and filtration. The facility includes mixing tanks, chemical addition equipment, pumps, piping, monitoring equipment, dewatering equipment, and settling basins. Waste streams received include aqueous wastes from the TSCA Incinerator, the K-25 steam plant, and various other sources at the site. Treatment at CNF is divided into hazardous and nonhazardous waste streams that discharge through a common NPDES permitted outfall. CNF processes $\sim 100,000$ gal/month of hazardous and nonhazardous aqueous wastes. CNF does not have the capability to process solid wastes.

In addition to waste processing and disposal at the TSCA Incinerator and CNF, current waste management operations at the K-25 Site include hazardous and mixed waste storage in compliance with appropriate regulatory guidelines and directives pending final disposition. These storage facilities (most of which are converted from use in association with gaseous diffusion operations) include several large and smaller buildings. The combined under-roof storage area is -265 acres. These facilities contain extensive amounts of asbestos insulation, potential RCRA-regulated oils and chemicals, PCBs, special nuclear materials, and residual radionuclides. Many of these buildings, specifically the $\mathrm{K}-25$ Building vaults, have been used for several years as a multisite facility for storage of wastes generated not only at the K-25 Site, but elsewhere on the Oak Ridge Reservation (ORR). Figure 1.12 is a photograph of the K-25 Building. Consequently, multisite storage planning for the ORR has focused on the K-25 Site, with lesser emphasis on sitespecific storage at other ORR sites. Because of a number of factors, including a moratorium on off-site shipment of hazardous waste, increased waste generation by the ER program, competition for available storage capacity with compliance driven programs, and closure of existing facilities, a shortage of adequate capacity for storage of low-level, hazardous, mixed, and TSCA wastes exists.

The Consolidated Storage Plan, as amended in October 1992, addressed significant factors and issues affecting storage capacities at the K-25 Site. A partial list of these issues include:

1. Off-Site Shipment Moratorium-The moratorium restricted shipment of hazardous waste potentially contaminated with radionuclides to off-site commercial treatment, storage, and disposal facilities, thus increasing storage requirements for the $\mathrm{K}-25$ Site. 


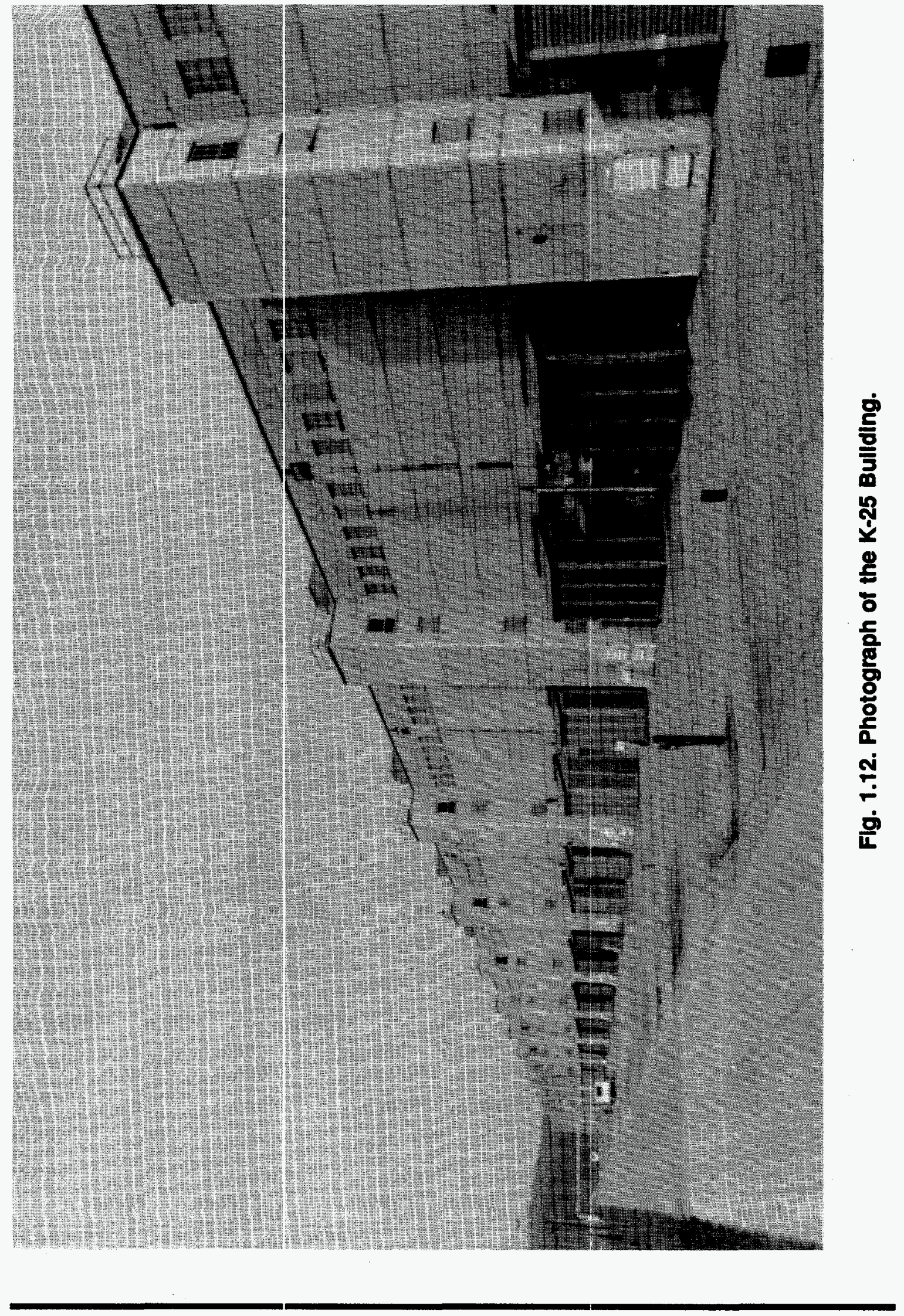


2. Existing use of the K-25 Building Vaults-Projected capacity of the K-25 Building vaults was significantly reduced by revised interpretations of regulatory requirements by the K-25 Site compliance personnel regarding aisle space and space required for adequate inspections. The revised space requirements impacted the number of containers that could be stored in additional vaults and generated requirements for additional vault space to hold the removed containers and satisfy revised space requirements.

3. TSCA-Federal Facilities Compliance Agreement (TSCA-FFCA)—The TSCA-FFCA placed restrictions on the use of storage buildings and required removal of PCB-contaminated duct work and equipment. The schedule and method for this work significantly impacted availability of waste storage space.

4. Closure of Bear Creek Burial Ground-The Y-12 Plant is the largest generator of low-level waste (LLW) on the ORR, and historically most of the Y-12 LLW has been disposed in shallow-land burial trenches located in the Bear Creek Burial Ground (BCBG). In June 1991, the burial ground was closed. Some of the waste previously disposed in BCBG is now stored at the K-25 Site.

5. Future Waste Generation Rates-Estimates of future waste generation rates have and will continue to change, making the storage planning activity more difficult. Recent changes in regulatory requirements, world events involving disarmament, and ER programs are expected to have significant impacts on waste generation rates and associated waste storage needs. As an example, in December 1991, the ER Program completed a reassessment of waste generation/storage estimates. Current estimates reveal that $\sim 9,100 \mathrm{ft}^{3} /$ year of LLW, RCRA, mixed, and TSCA wastes generated by the ER Program will require storage from FY 1993-1995. The volumes of wastes generated beyond 1995 could be larger with an average storage requirement of $16,500 \mathrm{ft}^{3} /$ year for LLW, RCRA, mixed, and TSCA wastes estimated for FY 1996-2000.

DOE has undertaken various programs and strategies to address requirements for permitted areas for storage of hazardous and mixed wastes. These programs include (1) permitting and upgrading existing facilities to meet the compliance requirements for the storage of hazardous and mixed wastes, (2) permitting and building new facilities to meet the compliance requirements for the storage of hazardous and mixed wastes, and (3) implementing activities directed toward reducing waste generation that requires storage in permitted facilities. These programs have been successful in addressing storage problems in the short term, however, because of the limited real estate available at the K-25 Site, continued waste generation from on going activities, and future remedial/decommissioning activities, there is a need for alternatives to long-term storage of hazardous and mixed waste.

Previous storage planning has been based on a combination of near-and longterm strategies, where the near-term strategy has been (1) one of maximum use of existing storage facilities, including upgrades to vaults in the K-25 and K-27 buildings, (2) maximum use of the TSCA Incinerator to minimize the amount of waste stored, (3) exterior storage of containerized LLW, and (4) completion and use of planned near-term storage projects. The long-term storage strategy focused on 
the completion of a large line item storage project to provide compliant storage for LLW and mixed waste. The number of potential uncertainties, including generation rates, funding availability, and use of existing facilities, have the potential to significantly impact the tuture direction of the storage program and have resulted in changes to the planned program. Regardless of the uncertainties, a need for onsite permitted storage will remain until applicable treatment and disposal options become available and the inventory of stored wastes can be disposed of.

\subsubsection{Issues for Waste Management}

Listed below are sorie of the potential issues facing WM:

1. The continued use of the shut-down diffusion plant facilities for waste storage (with an undefined destination for the inventory) will likely delay D\&D activities.

2. Capabilities for treating the wastes likely to be generated by the RA and D\&D activities are insufficient.

3. The capabilities for treatment and disposal of solid residues from current and projected waste management operations are undefined.

4. The current inventories of waste at $\mathrm{K}-25$ and the remaining storage capacity are listed in Table 1.3. 
Table 1.3. Current K-25 Waste Capacity and Waste in Storage

\begin{tabular}{|c|c|c|c|}
\hline Location & Waste Stream & $\begin{array}{c}\text { Total } \\
\text { Capacity } \\
\text { (ft' }\end{array}$ & $\begin{array}{l}\text { Present } \\
\text { Inventory }\end{array}$ \\
\hline Vault 3A & PCB wastes & 10,300 & 800 \\
\hline Vault 4A & Sludges and Incinerator ash & 21,500 & 21,500 \\
\hline Vault 5A & Mixed wastes & 12,000 & 12,000 \\
\hline Vault $15 \mathrm{~A}$ & $\mathrm{Y}-12 \mathrm{LLW}$ & 21,100 & 21,100 \\
\hline Vault 19A & Mixed wastes & 16,800 & 16,800 \\
\hline Vault 23A & Sludges & 15,100 & 14,100 \\
\hline Vaults $1 \mathrm{X}, 16 \mathrm{~A}, 31 \mathrm{X}$ & LLW & 15,600 & 15,600 \\
\hline $\mathrm{K}-33$ section -5 & PCB solids & 31,400 & 31,400 \\
\hline $\mathrm{K}-301-1$ & Acids, bases, organics & 15,200 & 9,800 \\
\hline $\mathrm{K}-301-2$ & $\begin{array}{l}\text { Photographic waste, sludges, } \\
\text { incinerator ash }\end{array}$ & 13,300 & 12,300 \\
\hline $\mathrm{K}-302-4$ & Mixed wastes & 17,800 & 17,800 \\
\hline $\mathrm{K}-302-5$ & Mixed wastes & 14,000 & 10,000 \\
\hline $\mathrm{K}-303-1$ & Mixed wastes & 14,000 & 0 \\
\hline $\mathrm{K}-303-2$ & Mixed wastes & 10,300 & 0 \\
\hline $\mathrm{K}-303-4$ & PCB-contaminated soil and zorbal & 10,300 & 10,300 \\
\hline K-303-5 & $\mathrm{K}-25 \mathrm{LLW}$ & 16,600 & 16,600 \\
\hline $\mathrm{K}-305-6$ & Sludges, and nitric acid waste & 9,300 & 9,300 \\
\hline $\mathrm{K}-306-1$ & PCB-contaminated capacitors/oil & 3,000 & 2,000 \\
\hline $\mathrm{K}-306-3$ & Mixed Wastes & 14,000 & 13,000 \\
\hline K-306-4 & Mixed Wastes & 10,300 & 6,300 \\
\hline $\mathrm{K}-306-7$ & Y-12 mercury contaminated soil & 12,100 & 12,100 \\
\hline K-309-2 & Y-12 LLW & 16,200 & 16,200 \\
\hline $\mathrm{K}-310-2,3$ & ORNL LLW & 57,400 & 57,400 \\
\hline $\mathrm{K}-311-1$ & Radiogenic lead and other solids & 16,100 & 1,100 \\
\hline $\mathrm{K}-711$ & $\begin{array}{l}\text { RCRA/PCB flammable liquids } \\
\text { and solids }\end{array}$ & 11,000 & 1,500 \\
\hline K-726 & PCB-contaminated dirt, etc & 3,300 & 3,300 \\
\hline $\mathrm{K}-1025 \mathrm{C}$ & Discarded chemicals & 300 & 300 \\
\hline $\mathrm{K}-1036 \mathrm{~A}$ & Mixed wastes & 4,700 & 4,700 \\
\hline K-1202 & $\begin{array}{l}\text { RCRA flammable and combustible } \\
\text { liquids }\end{array}$ & 3,800 & 0 \\
\hline K-1232 & Mixed wastes & 3,700 & 3,600 \\
\hline $\mathrm{K}-1302$ & Compressed gas cylinders & 100 & 100 \\
\hline $\begin{array}{l}\mathrm{K}-1417, \mathrm{~K}-31 \\
\mathrm{~K}-33, \mathrm{~K}-1065\end{array}$ & $\begin{array}{l}\text { Stabilized and nonstabilized } \\
\text { sludges }\end{array}$ & 886,000 & 886,000 \\
\hline $\mathrm{K}-1420 \mathrm{~A}$ & RCRA flammable liquids & 3,800 & 0 \\
\hline $\mathrm{K}-1435$ & RCRA/PCB liquids and solids & 18,300 & 18,300 \\
\hline Outside Storage $^{l}$ & Containerized LLW & 24,100 & 24,100 \\
\hline
\end{tabular}




\section{$1.6 \mathrm{~K}-25$ SITE ROADMAP}

The Roadmap is a generalized planning document that identifles broad categories of issues that keep the site outside full compliance with the law and other legally binding agreements. The Roadmap identifies possible generic paths to compliance and the szhedule for resolution of the issues. The role of the TLD is then to identify specific site issues (problems), identify specific technologies that can be brought to bear on the issues, and assess the current status and readiness of these technologies to be applied to remediation of the problem within the constraints of the schedule commitment.

Regulatory requirements and commitments contained in the roadmap are also included in the TLD as constraints to the application of immature technological solutions. Some otherwise attractive technological solutions may not be employed, for example, because these technologies may not be: deployable on the schedule enumerated in the regulatory agreements. Conversely, negotiators in the process of defining regulatory agreements may fruitfully take cognizance of the TLD assessments in order to schedule remediation milestones that allow cheaper, faster, better, or safer technologies to be used.

The Roadmap for the K-25 Site includes a list of 46 comprehensive logic diagrams for waste menagement of low-level, radioactive mixed, hazardous, sanitary and industrial, and transuranic waste. The following information is excerpted from that docc.ment. The roadmapping process gives comparisons of the installation as it exists now to the way the installation should exist under full compliance. The identification of the issues is the goal of roadmapping to allow accurate and timely activities to be formulated.

The roadmapping methodology is divided into nine steps and covers three phases-assessment, arialysis, and issue resolution.

The assessment phase identifies the current status and background of the installation. This phase is accomplished in four steps: (1) identifying installation assumptions that provide for the conduct of EM activities; (2) identifying regulatory requirements of federal, state, and local regulations and codes, DOE Orders, and other ag:eements that DOE is responsible to comply with; (3) describing those DOIE commitments, which include Inter-Agency Agreements (IAGs) and Federal Facility Agreements (FFAs); and (4) preparing a schedule that includes all commitments with all currently budgeted and forecast activities.

The analysis phase identifies key issues and actions needed for resolution. This phase is accomplished in four steps: (1) identification of issues that prevent the installation from accomplishing EM objectives; (2) analysis of issues to determine the root causes; (3) conversion of issues to needs for the resolution of issues and the identification of activities that satisfy these needs; and (4) preparing the schedule for the desired activities.

The issue resolution phase merges the issue resolution activities with ongoing and planned activities as the ninth and final step. Specific recommendations for modifications, additions, or deletions to current plans are formulated and captured in Activity Data Sheets or are forwarded to DOE Headquarters (HQ) for resolution.

The document entitled Oak Ridge Reservation Site Management Plan for the Environmental Restoration Program (DOE/OR-1001/RI), offers a general yet comprehensive description of the ER program and objectives for the K-25 Site. For 
a more detailed description of specific contaminated sites within the K-25 Site, refer to Site Descriptions of Environmental Restoration Units at Oak Ridge K-25 (K/ER-47).

\section{Summary of Major Committed Milestones}

Activities identified within signed and pending third-party agreements as well as agreements between DOE and the management and operating $(\mathrm{M} \& \mathrm{O})$ contractor were considered to be major committed milestones. All current, applicable, signed, and pending agreements have been included in this section.

Documents containing outstanding major committed milestones include:

- Federal Facility Agreement for the Oak Ridge Reservation. This FFA among DOE, the U.S. Environmental Protection Agency (EPA) Region IV, and the Tennessee Department of Environment and Conservation (TDEC) focuses on resolving compliance issues associated with ER of the ORR. The overall purpose of the agreement is to set up a procedural framework and schedule for developing, implementing, and monitoring response actions conducted in compliance with RCRA; Comprehensive Environmental Response, Compensation, and Liability Act (CERCLA); National Contingency Plan (NCP); National Environmental Policy Act (NEPA); appropriate guidance/policy; Tennessee laws/regulations; and other applicable, relevant, and appropriate requirements (ARAR). The FFA was designed to ensure that all necessary steps were taken to protect the public health and the environment during the investigation, evaluation, and remediation of all SWMUs or Operable Units (OUs). The FFA also specifies all reports to be prepared and states the deadlines for submittal to DOE and the regulators. In addition, the FFA specifies document review times to ensure that activities are undertaken in a timely manner. Committed milestones under this agreement are listed in Table 1.4. After preparation of the FFA, the investigations of environmental contamination follow a logical progression of events that include the following elements-the initial ones are included in the table:

- Preliminary Assessment (PA). This step includes investigation of existing, available records for a site, including photographs, drawings, and a compilation of information from workers who are either presently involved with the current operations of the unit or who have knowledge of the past operations of the unit, if the PA indicates that the unit may have treated, stored, or disposed-of hazardous waste in accordance with RCRA, may have contributed to environmental contamination in accordance with CERCLA, or the unit is placed on the SWMU list. If the PA indicates conclusively that no environmental contamination may have resulted from this unit, then no further action is recommended. This is indicated by the entry "no RFI" on the SWMU list.

- Site Inspection (SI). This step includes a collection of field samples to determine whether environmental contamination might have resulted from this unit. Analyses of the samples are compared with background and/or health-based guideline values to reach this determination. If the SI indicates that environmental contamination has resulted from operations 
Table 1.4. Federall Facility Agreement for the Oak Ridge Reservation

Major Committed Milestones--Environmental Restoration (K-25 Site) Remedial Actions (RA)

1. K-770. A 30-acre site containing $\sim 40,000$ tons of scrap and low-level rad-contaminated metal and debris

- Phase I Site Characterization Summary (SCS) . . . . . . . . . . . March 31, 1992

- Resource Conservation and Recovery Act (RCRA)

Facility Investigation (RFI) Report . . . . . . . . . . . . . . June 30, 1991

2. K-901-A. A 5-acre pond containing $\mathrm{Cr}$ and $\mathrm{U}$ in the sludge, and eight additional acres of buried waste contaminated with radioactive materials and RCRA waste.

- RFI Plan . . . . . . . . . . . . . . . . . . . . . . . . . September 28, 1991

- Operable Unit Remedial Investigation Work Plan $\ldots \ldots \ldots \ldots \ldots \ldots$ August 31, 1992

3. K-1035 Acid Pit. A small collection of pits that handled RCRA metals, acids, and solvents that were often rad contaminated. Estimated effluent $\sim 200$ gal/week for several decades.

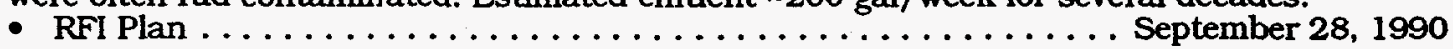

4. K-1070-A Burial Ground. A 1-acre site containing oil and metals such as thorium, uranium, lead, and scrap contaminated with radioactive materials. A possible source of groundwater contamination.

- Phase I Scs . . . . . . . . . . . . . . . . . . . . . . . . . . March 30, 1990

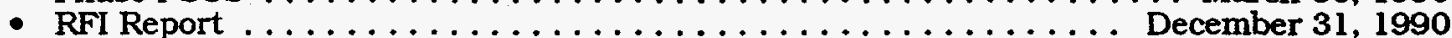

- Phase II SCS ............................... June 30, 1992

- Phase II RFI Report . . . . . . . . . . . . . . .

5. K-1070-C/D Burial Ground. A 22-acre site for burial of classified, rad-contaminated equipment. oils, chemicals, solvents. glass, and scrap metal, including lead and uranium. A known source of surface and groundwater contamination.

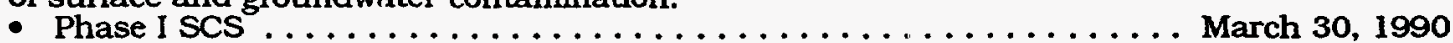

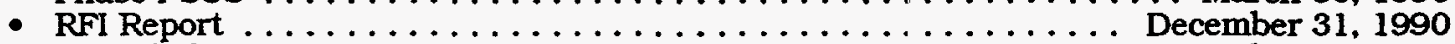

- Remedial Investigaticn Work Plan . . . . . . . . . . . . . December 31, 1991

- Leachate Stream Inte rim Proposed Plan $\ldots \ldots \ldots \ldots \ldots \ldots \ldots \ldots \ldots \ldots$. . . . . . . $19 . \ldots . \ldots$

- Phase II SCS . . . . . . . . . . . . . . . . . . . . . . . . . . June 30. 1992

- Leachate Stream Inte rim Record of Decision .............. September 18, 1992

- Phase II RFI Report. . . . . . . . . . . . . . . . . . . September 30, 1992

6. K-1407-B. A 1.3-acre, 1-million gal capacity holding pond, which operated for 40 years. The holding pond was a settling basin for neutralized effluent whose sludges contained radioactive materials, mercury, chrome, plating bath residues. Sludge was removed in 1988.

- Phase I SCS . . . . . . . . . . . . . . . . . . . . . . . December 31, 1990

- Phase I RFI Report . . . . . . . . . . . . . . . . . . . . . . . . September 30, 1991

- Remedial Investigation/Feasibility Study Report . . . . . . . . . . . April 8, 1992

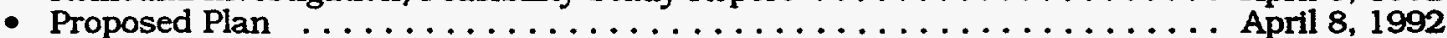

- Phase II SCS . . . . . . . . . . . . . . . . . . . . . . . June 30, 1992

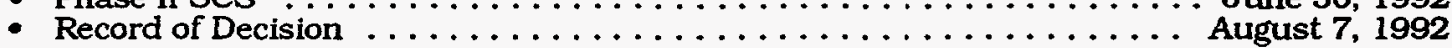

7. K-1407-C. A 2.5-million gal retention basin for sludge from $\mathrm{K}-1407-\mathrm{B}$ pond. Contains corrosive metal hydroxide sludges and radioactive contaminants.

- Phase I SCS .................................... September 28, 1990

- Phase I RFI Report .............................. June 28, 1991

- Remedial Investigation $/$ Feasibility study Report $\ldots \ldots \ldots \ldots \ldots \ldots \ldots \ldots$ April 8,1992

- Phase II SCS ................................. June 30, 1992

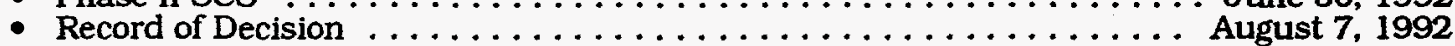

8. K-1420. Decontamination building, which contained mercury recovery operations, oil decontamination and storage operations, gaseous diffusion process equipment decontamination facilities, and uranium recovery operations. Building and (leaking) transfer lines contain RCRA material and organic and PCB waste. An associated incinerator (K-1421) operated for 20 years to burn low-level contarninated waste.

- Phase I SCS . . . . . . . . . . . . . . . . . . . . . . . . . June 30, 1992

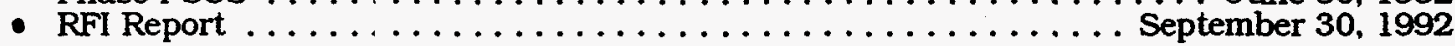


at this unit or that the resulting contamination is above health-based guideline values and consequently poses a risk to human health or the environment, then a recommendation of further action may be made.

- Remedial Investigation (RI). This step is necessary if the PA/SI phases have indicated that the unit has, or is very likely to have, contributed to environmental contamination. The RI phase can include more than one round of sample collection, analysis, and evaluation. When the nature and extent of contamination in all relevant media have been determined, an RI report is prepared, which will include a baseline risk assessment. The baseline risk assessment evaluates the risk posed to human health and the environment based on health-based guideline values and background contamination.

- Subsequent possible steps or phases of remediation include: Interim Corrective Measures (ICMs), Feasibility Studies (FSs), Treatability Studies (TSs), and RAs. These phases were not included in the current FFA agreement.

- Tennessee/Department of Energy Monitoring and Oversight Agreement. The Tennessee Oversight Agreement (TOA) details the obligations and agreements between DOE and TDEC with respect to the DOE provision for technical and financial support of state environmental activities. These activities include participation in the FFA, covering ER of the ORR, oversight, monitoring, access, and emergency response initiatives. Such activities are designed to ensure compliance with DOE Orders and applicable federal, state, and local laws and regulations concerning the ORR and its environs. This agreement seeks to (1) ensure compliance with applicable federal, state, and local environmental laws and (2) assure the citizens of Tennessee that their health, safety, and environment are being protected through a program of independent monitoring and oversight by the state.

- Program Execution Guidance (FY 1991). Program Execution Guidance (PEG) milestones are those actions identified annually by the operating contractor and determined to be Key Accountable milestones by DOE. PEG is used to establish FY 1991 technical baselines, funding allocations, and schedules for the Waste Operations Program under the DOE Office of Waste Operations (EM-30).

- Compliance Agreement Between the U.S. Department of Energy and the Environmental Protection Agency, Washington, D.C. (TSCA-FFCA). This TSCA-FFCA between DOE and EPA focuses on resolving compliance issues related to the regulation of PCBs (TSCA and 40 CFR 761) at DOE uranium enrichment plants such as the K-25 Site and at their support facilities. Committed milestones under this agreement are listed in Table 1.5. 
Table 1.5. Compliance Agreement between the U.S. Department of Energy and the Environmental Frotection Agency, Washington, D.C. [Federal Facility Compliance Agreement (FFCA) Toxic Substances Control Act (TSCA)]

Major Committed Milestones-Environmental Restoration (K-25 Site) Remedial Activities

1. Gaseous Diffusion F'acilities

- Dispose of PCB-Contaminated Mineral Oil ........ March 31, 1992

- Complete Disposition of PCB Electrical Equipment September 30, 1994

- Complete PCB V'entilation Gasket Removal from K-29,

$\mathrm{K}-31$, and K-33 enrichment process buildings .. September 30, 2001

- Complete Disposal of All Waste PCBs ......... December 31, 2015

2. Centrifuge Facilities

- None

- Action Plan for the Management of K-1407-B and-C Ponds Waste at the Oak Ridge K-25 Site (K/PW-6, 8/16/91). This Energy Systems plan (approval pending) proposes milestones to address issues originating from various audits and appraisals (Table 1.6). Major issues identified in these reviews are addressed in other agreements or planning documents.

Table 1.6. Plan for the Management Waste Removed from K-1407-B and -C Ponds at the Oak Ridge K-25 Site

Major Committed Milestones-Environmental Restoration (K-25 Site)

1. Remedial Activities 1 K-1407-B and -C Pond Waste Interim Remediation (also called K-1417 Drum Storage Interim Remediation)

- Part B Permit Application on K-1065 Storage Facilities February 2, 1992

- Begin Overpack and Transfer of Stabilized Waste from $\mathrm{K}-1417$. . . . . . . . . . . . . . . . March 30, 1992

- Part A Revision on K-31/K-33 Storage Sites . . . . . . . A April 30, 1992

- Part B Application on K-31/K-33 Storage Sites . . . . . . May 30, 1992

- Begin Volume Reduction of Raw Sludge ... . . . . . J July 30, 1992

- Complete Transier of Stabilized Waste . . . . . . . . October 30, 1992

- Complete Volurie Reduction and Transfer of Material to Compliant Strorage . . . . . . . . . . . . February 28, 1993

2. Waste Management (K-25 Site) EPA

- National Capaciy Exemption granted by EPA to DOE for RCRA - LDR "Third Third" wastes covers the period to . . . . . . . . May 1994

- In addition, a National Capacity Exemption was granted by EPA to DOE for RCRA-Land Disposal Restrictions of 1984 (LDR) "Thirds" waste covering the period to May 1994. 
Compliance Agreement Between the U. S. Department of Energy - Oak Ridge Reservation and the Environmental Protection Agency, Region IV (LDR-FFCA/ORR). This LDR-FFCA/ORR was signed June 12, 1992 in order to bring mixed waste generation and storage facilities at ORR into compliance with the RCRA land disposal restrictions for mixed waste. U. S. DOE applied for a one-year case-bycase extension under 40 CFR 268.5 of the May 8, 1992, effective date of the land disposal restrictions applicable to Third Third mixed wastes generated and stored at K-25, as well as 30 other sites (57 FR 22024, May 26, 1992). 

2. Description of the Technology Logic Diagram 


\section{DESCRIPTION OF THE TECHNOLOGY LOGIC DIAGRAM}

\subsection{TECHNICAL APPROACH}

This section describes the overall layout and development of the TLD. The logical progression flows from (DOE) EM Goals $\rightarrow$ EM Problems $\rightarrow$ the K-25 Site Problems $\rightarrow$ Problem Area (Target Constituents) $\rightarrow$ Reference Requirements $\rightarrow$ Subelements $\rightarrow$ Alternatives (Generic Technology) $\rightarrow$ Technologies $\rightarrow$ Technology Status $\rightarrow$ Science/Technology Needs $\rightarrow$ Implementation Needs.

Three different levels of information are provided. First, the most visually comprehensive but least detailed is produced as a set of single sheets, each containing a complete logic diagram. These will be located in the pocket pages in Chap. 8 when this document is completed in FY 1993. Second, more detailed diagrams are provided in Vol. 2. Although each large sheet contains the entire logic path, several sheets are necessary to describe each evaluation area. Finally, each single logic path is published as a technology data sheet. These sheets are the most detailed source of information about each technology.

The information found under each logic element is described below.

EM Goals has three components: Clean Up Legacy, Prevent Future Insult, and Develop Environmental Stewardship. These problems are shared by all elements of the DOE complex to varying extents.

EM Problem contains problem areas agreed upon by EM/DOE: Decommissioning; Soils, Groundwater, and Surface Water; Waste Retrieval; Waste Processing; Waste Stabilization; and Waste Minimization. Disposal and transportation are not addressed. These EM problems are used to organize the diagrams and will be discussed in succeeding sections.

The K-25 Site Problem describes the problem areas identified at the K-25 Site. These problem areas have been defined by $D \& D, E R$, and WM staff. The magnitudes of the site problems will be indicated in terms of floor areas, estimated metal tonnages, etc., in the final document.

Problem Area/Constituent addresses a team-specific list of problems, all of which are traceable directly to the K-25 Site problems. For example, the diagram for decontamination defines the problems/constituents in terms of (hazardous) contaminants and the substrate on which the contaminants reside. In contrast, the dismantlement diagram defines the problems/constituents in terms of massive concrete, structural steel, metal equipment, etc. In both examples, the problem/constituent is the dominating factor in selection of technologies to remediate the problem.

Reference Requirements refers the reader to Chap. 10 of Vol. 1. Requirements can only be determined after consideration of detailed site-, waste-, and technology-specific characteristics.

Subelements specifies the different components that must be addressed to solve the problem. All D\&D activities have been categorized into the following subelement groups: characterization, decontamination, dismantlement, disassembly materials disposition, robotics/automation, and regulatory compliance. ${ }^{1}$ The comparable subelements for RA are characterization, treatment, retrieval, materials disposition, robotics/automation, and regulatory compliance. The subelements for WM are waste retrieval, characterization, processing, stabilization, minimization, packaging handling and transportation (PH\&T), and 
disposal. For the purposes of this report, characterization, material disposition, robotics/automation, and regulatory compliance will contain contributions from RA, D\&D, and the waste categories.

Alternatives define the general technology approaches that may be applied to the problem.

Technology identifies specific technologies that may be applied to remediate the problem.

Status provides information on the status of the technologies identified in the previous column using the standard categories.

Some accepted technologies are fully developed or commercially available and if so are noted as such. These terms are used to denote slightly different meanings. Fully developed means that both the basis of the technology and the methods for designing remediation equipment or operations using the method are well known and covered in public literature. Commercially available means that the technology is offerecl by one or more commercial firms, but there may be data, design methods, or experience needed to assess the technology that are not fully available to the public. The only difference in these two categories is that the public's ability to assess the performance and reliability of the technology is restricted for commercial technology. It suggests an unknown degree of risk in the commercially available technologies that cannot be fully evaluated with generally available information (even though the amount of risk may be negligible).

1. Accepted: Accepted by industry and/or the regulators and the demonstrated technology exists for use at the K-25 Site.

2. Demonstration: Technology is available but is not demonstrated and/or accepted for the problem at the K-25 Site.

3. Predemonstration: Technology is under laboratory-, bench-, or pilot-scale testing.

4. Evolving Techizology: Technology status is at a conceptual or preconceptual stage.

- Conceptuat-A scientific or knowledge basis for the technology exists.

- Preconceptual-Only a partial scientific or knowledge basis of the technology exists.

These classifications should provide indirect relevant information on the present view of the near-term or longer term availability of technology.

Several different areas are specifically addressed to further clarify the status designations chosen above.

- Efficacy-The effectiveness of the technology in remediating the problem is addressed. Normally, quantitative measures are given for the technology's performance in standard practice such as: decontamination, estimating the final $\mathrm{dpm} / \mathrm{cm}^{2}$ of surface contamination; dismantlement, the time to cut a 24-in. pipe; and characterization, the analysis time and lower detection limit. 
- Output from the technology-Describes the nature and volume of both the waste and the potentially useful materials.

Science and Technology (S/T) Needs are perceived needs in S/T where support should be applied to develop an accepted or "immature" technology. Science needs are related to the fundamental understanding of the scientific phenomena that forms the basis for the technology. These needs are typically for laboratory or bench-scale experiments and, when possible, experiments addressing specific areas of uncertainty are suggested. TD needs relate to improvements that make a current technology more economical to apply, safer, and more effective or efficient. The demonstration of a technology on a site-specific problem is classified as a technology improvement need.

If scientific needs are specified, it should be understood that the needs of scientific technology development or improvement are necessary to implement newly developed scientific understanding. Likewise, testing a TD opportunity implies that technology improvements are also likely to be needed.

DOE funding for a project that addresses the technology deficits is indicated by a TTP number, ADS number, or other reference number. Other work related to the technology area may also be referenced.

Most new technologies that are not in common use will require a large-scale test or demonstration to show that they are capable of achieving expected results on the site-specific problem. These tests demonstrate that a suitable and workable process or facility can be designed, built, and operated successfully. They show that no unknown condition prevents the process or facility from functioning as it was designed and that the equipment can last an acceptable lifetime. Demonstrations are intended to provide final tests of all aspects of a technology. If, however, particular questions remain about the technology, these are specifically mentioned on the diagram.

Implementation Needs or specialized needs were evaluated for both development of a technology and deployment of a mature technology. These needs were evaluated in the areas of: (1) resources such as financial or personnel; (2) hardware such as process equipment, development equipment, and computers; (3) software such as models, procedures, computer programs; (4) facilities such as labs, shops, and buildings, and (5) education such as training classes or degreed personnel. An estimate of the cost of the process and any potential cost payback are also given. Only extraordinary needs are highlighted, (i.e., those needs that would require long lead time or unusual procurements such as line items for facility construction).

The cost of applying the technology and the payback cost potential has been estimated. There are many reasons for payback such as reducing the waste volume compared to a reference process, the sale of useable products, and the reduction of labor compared to a reference technology.

When standard laboratory facilities are sufficient, facility needs are not identified. Since the facilities on the ORR are relatively extensive, including the K-25 Site, the ORNL and the Y-12 Plant, the diagram does not address needs for standard facilities but focuses on unique facility needs.

However, additional conventional facilities may be needed to meet the technology needs for remedial actions at the K-25 Site because the available facilities may not provide adequate capacity for testing the various technologies. To assess the availability of standard facilities for these programs, it will be necessary to know (1) the rate at which TD in Oak Ridge will proceed and (2) the extent at which other programs will compete for the facilities. 


\subsection{REFERENCES}

1. Decontamination arıd Decommissioning Workshop Knoxville, 1991. 


\section{Characterization}




\section{CHARACTERIZATION}

\subsection{INTRODUCTION}

Characterization to support ER and WM activities at DOE sites must provide information needed to make current and future facility utilization decisions as well as to support compliant site activities. Characterization should be used effectively beyond these baseline requirements to optimize choices and minimize future problems. As such, it is often targeted for a specific need-to-know, budgeted and utilized accordingly. The purpose of the Characterization portion of this TLD is to review the provision of analytical information provided to both meet baseline requirements and to support operational needs at the K-25 Site, with a focus on cleanup activities, then to identify areas where characterization needs could be either more fully and/or more economically met. The charter is a broad one, with an emphasis on cost-effectiveness.

Characterization studies can and do provide information concerning how much of a material is present, in what form that material exists, how the material is distributed within a particular matrix (spatial and depth distribution), how it interacts with its local environment (matrix interactions, transport mechanisms), and how it is dispersed. Regulatory issues primarily address the "how much" question. Risk assessment, cost and feasibility studies, as well as technology selection and deployment decisions, are better made as more information is supplied.

However, characterization is in itself a significant part of cleanup-activity cost. Payback potential must be evaluated, including improvements in reduced risk and improved public acceptance, as well as potential cost savings such as:

- identification of the extent of contamination,

- reduction in the total area to be decontaminated (no need to decontaminate clean areas) and waste produced,

- reduction in the total waste produced,

- identification of waste streams,

- optimization of decontamination technologies, and

- optimization of personnel protection and monitoring.

For example, in the D\&D of large areas (hundreds of acres of process buildings, thousands of components of large equipment) the cost savings of statistically assisted, detailed characterization can be enormous ${ }^{1}$. Although the costs associated with this characterization can be enormous, the potential for savings by either improving characterization quality or reducing characterization cost is very high. The challenge to the characterization team was to identify and concentrate on problem areas particular to the K-25 Site where improvements in

\footnotetext{
${ }^{1}$ For example the baseline EBASCO cost estimate for environmental restoration of the cascade buildings assumed that all structural surfaces were contaminated and that very little characterization would be required. However, this assumption resulted in a very large $(\$ 160 \mathrm{M})$ cost estimate for structural decontamination. Sufficient characterization to reduce the structural surfaces considered contaminated would significantly reduce anticipated decontamination costs.
} 
characterization would offer potential overall enhancement of DOE Operations; in other words, to look at sur specific problems from a generic point of view in a logical manner.

Similar TLD characterization activity at other sites would result in differing problem area definitions, but an overlapping set of technology development and implementation needs. For example, decontamination and dismantlement of the large enrichment procesis buildings at the K-25 Site make improvements in data handling very attractive; improved data handling capability would be equally attractive in the dismanilement of large hot cells at other DOE facilities.

It was noted that there exists a considerable body of applicable, developed technology which remains restricted in its availability for unclassified applications; so it is not addressed in this diagram.

\subsubsection{Approach}

Characterization of istructures and components for remedial action such as D\&D may be logically divided into at least four distinct stages: (1) Site, (2) Pretreatment, (3) Process support, and (4) Posttreatment characterization. The last three are convenieritly treated with the standard technology logic diagram format, and can be described as:

Pretreatment: Characterization is used to determine the extent and distribution of the target: constituent prior to cleanup activities. Characterization needs at this stage are likely to be driven by regulatory, risk [environmental, safety, and health (ES\&LH)] assessment, feasibility, and cost considerations in support of cleanup plons. The effectiveness (technology choice) and cost of potential decontamination scenarios depend on the chemical and physical form of the target constituent, its interaction with its host matrix, and its distribution over the area to be decontaminated. Examples of information that might be supplied by pre-treatment characterization include:

- how much of a contaminant is present but also the depth of penetration (uranium, PCBs, oil in a diffusion cascade building),

- percent and loc:ation (map) of contaminant coverage over large areas (floors, walls, ceilings) and,

- typical contamination profiles (qualitative, spatial distribution) for repetitive equiprnent/structures (i.e., converters, compressors, instrument stairwells).

Statistically valid sampling is an essential basis for pretreatment characterization; data quality objectives are likely to be defined specifically for individual situations. Improvements in pretreatment characterization reduces the necessity for overly conservative assumptions for decontamination and waste disposal; double savings (in both decontamination extent and waste minimization) can be potentially realized.

Process support (for decontamination, dismantlement): This includes personnel protection considerations as well as evaluation of treatment effectiveness and measurement of secondary waste stream parameters. Dispersion 
characteristics of dismantlement techniques and measurement of decontamination progress and effectiveness are important preliminary measurements; they are likely to influence the choice of processes employed. Health and safety of cleanup workers may be enhanced, and simultaneously costs reduced, by improvements in techniques for efficiently screening incoming laundry items for contamination. For example, unforeseen problem areas may be detected sooner if efforts are made to determine the work location from which contaminated personal protective items are consistently found; clearly these work sites become candidates for improved engineering controls to reduce worker exposure.

Improved characterization support during this treatment phase may have regulatory and economic impact; however, potential improvements in real-time and remote sensing to monitor and reduce personnel exposure are fertile areas for technology development and implementation.

Examples of information to be supplied during this stage include:

- toxins that exist in the working environment;

- level of worker exposure;

- $\quad$ projected and actual effectiveness of decontamination;

- waste-stream composition and composition range; and

- unexpected secondary products.

In addition to environmental, safety, and health, (ES\&H) characterization and monitoring, real-time, on-line monitoring of decontamination could serve to optimize efficiency. Similar technology could be used to ensure that the barriers and safeguards used during the dismantlement process are sufficient for controlling the spread of contamination.

When characterization is needed to support treatment activities, it may be more convenient to list the special characterization methods along with the particular treatment activities needing that characterization. However, in this document, in order to keep the organization of the TLD as simple as possible, characterization is treated together under a single heading, and the association of a characterization method or need with a retrieval or treatment method is done through notes on the diagram.

Posttreatment characterization: This characterization, in general, has strong regulatory drivers. Varying release limits will have major effects on characterization costs, as well as on disposal options. Most analytical data will address "how much" contamination is present. However, information concerning the nature of any residual contamination will allow a better understanding of the decontamination technology that had been employed, and the posttreatment contaminated surface serves as the source for subsequent pathways analysis. A better description of the stability of the treated system can lead to improved pathways analysis and a reduction in the costs associated with unnecessary conservatism. It is particularly important in post-treatment characterization that the techniques employed provide data that will be accepted by regulatory agencies. 


\section{A Special Note-Initial Site Characterization}

The characterization team's efforts centered on technology development and implementation to support the preceding three areas-pretreatment, process support, and post-treatment characterization. The TLD format works best to address specific site problems. Identifying these problems, the initial site characterization, is an additional issue, as well as one where a similar logical approach could prove beneficial.

The initial identification of contaminants of significance is important information for decision :naking regarding the ultimate use and/or disposal of the facility. These utilization decisions, in turn, determine selected options during the cleanup process. The accuracy of the total initial assessment (including both contamination expected present and contamination not expected) determines the effectiveness of up-front planning, as well as the number of expensive surprises likely during clean-up.

This initial assessneent traditionally depends a great deal on historical knowledge of processes and incidents, and this is certainly useful information. For example, it is evident that depleted and enriched uranium, uranium decay products, and some reactor products will be internal contaminants of process equipment in the diffusion cascades. Historical cascade gradient data is well known, and can in gerieral describe enrichment within the process systems. However configuration control of former operations was generally not tight enough to result in adequate site characterization through historical process knowledge alone.

It is necessary to determine how well (with what risk) knowledge from all sources describes the site. The full utilization of historical data to minimize expensive additional characterization, with the addition of a minimum program of statistical sampling and analyses to supplement this data as necessary to generate a "facility model"-which could then be developed and checked-is well within the capabilities of computerized data handling and statistical technologies. In addition, currently available computer-based imaging could add visual ready retrieval capability to the mass of data likely to be generated. Developing and verifying better identification of facility contamination patterns and deviations using, but not depending on histcrical process knowledge is an area ripe for technology utilization and improvement. This development, if done for the relatively simple K-25 Site, could prove even more useful for more complex DOE facilities.

Statistically adequate confidence in the model will require sampling for both contaminants assumed present and those postulated to be absent. The "smart cart," an automated wagon with extensive sensor instrumentation, represents a potentially invaluable tool in initial characterization and verification work. Computerization of characterization data as a visual image of the facility would serve as a data management system and operator guide during clean-up activities, as well as a useful communications tool.

The provision of this initial site characterization should be done as early as possible. The ideal time to initiate generation of the model and the collection of historical data is actually during site construction. It could, therefore, serve as a basis for configuration control during the useful lifetime of the site.

The Characterization diagram does not formally address initial site characterization for identification of problems. 


\subsubsection{Mechanics}

Characterization is divided into several subtasks, covered under the "Alternatives" column of the diagram. These consisted of:

- Statistics and Data Collection,

- Sampling (including Sample Preparation),

- In Situ Physical Characterization,

- Laboratory Physical Characterization,

- In Situ Chemical Characterization,

- Laboratory Chemical Characterization, and

- Data Assessment and Modeling.

Each of these was discussed under the specific headings of radioactive contamination (RAD), inorganic and organic contamination, after a more general section to discuss technology of overall applicability. PCBs were included under organic contamination; technologies with specific PCB application were identified within the diagram.

The K-25 Site problem areas were grouped to reflect common characteristics in terms of size, complexity, accessibility, and expected contaminants. Process building structures include structural features such as concrete, cinder blocks, galvanized sheet metal, structural steel, built-up roofs, transite siding, and general problems encountered on D\&D the structures. Process systems include the enriching cascade and auxiliary systems such as seal exhaust, scrubber, coolant, recirculating water, lube oil, electrical, and ventilation. These are described in Table 3.1. Other buildings included those at the K-25 Site not directly involved in the enrichment cascades; these consisted of research and development (R\&D) and analytical laboratories, cooling towers, and both specialized and incidental facilities. Characterization needs particular to environmental restoration activities were covered under "Soils and Groundwater," "Buried Waste," and "Pond Waste" headings.

Characteristic of the K-25 Site problems are their size. That is, massive amounts of material to be checked for either re-utilization or disposal, and the potential for massive cost impact through relatively minor alterations in the characterization process. Accordingly, the potential for high payback exists in many areas where characterization technology can be improved; and a resulting feature of the TLD is the large number of technologies discussed under the heading "General," where improvements in the development and implementation of site-specific applications, procedures, and protocols could significantly reduce risk, or result in large cost savings.

All technologies included in the TLD were judged useful to address K-25 Site problems. Technologies were evaluated on an individual basis, and assigned priority rankings of high through low based on evaluation of their potential for cost-effective implementation in the K-25 Site cleanup effort. Both TD and implementation needs were reflected in this evaluation. High $(\mathrm{H})$ rated technologies were judged to have major impact in one, or significant impact in several, K-25 Site areas or cleanup activities. These technologies are immediate candidates for "core" technology status within the DOE complex. Medium (M) rated technologies required more development, or were not unanimously judged to be as widely applicable at the time this report was written. Development of low (L) rated technologies did not seem as urgent, based on specific K-25 Site needs. The TLD arrows associated with the technologies reflected this rough assessment of utility, with bolder lines indicating higher priority. 
Table 3.1. Cascade systems

\begin{tabular}{|c|c|c|}
\hline $\begin{array}{l}\text { Enrichment Cascade (K-25, K-27, } \\
\text { K-29, K-31, and K-33) } \\
\text { Compressors } \\
\text { Converters } \\
\text { Valves } \\
\text { Bellows } \\
\text { Expansion joints } \\
\text { Piping } \\
\text { Instrument lines } \\
\text { Instruments } \\
\text { Chemical traps } \\
\text { Auxiliary Process Systems (All } \\
\text { Buildings) } \\
\text { Seal exhaust systems } \\
\text { Chemical traps } \\
\text { Vacuum pumps } \\
\text { Oil reservoirs } \\
\text { Scrubber Systems (K-27) } \\
\text { Pumps } \\
\text { Piping } \\
\text { Scrubber vessel } \\
\text { Chemical traps } \\
\text { Coolant Systems (All Buildings) } \\
\text { Pumps } \\
\text { Coolant cooler }\end{array}$ & $\begin{array}{l}\text { Coolant systems (All buildings) } \\
\text { (continued) } \\
\text { Piping } \\
\text { Filters } \\
\text { Valves } \\
\text { Recirculating water system (All } \\
\text { buildings) } \\
\text { Conlant conlers } \\
\text { Piping } \\
\text { Cooling towers } \\
\text { Lube oil systems (All Buildings) } \\
\text { Oil cooler } \\
\text { Drain drums } \\
\text { Pumps } \\
\text { Oil coolers } \\
\text { Cuno oll filters } \\
\text { Valves } \\
\text { Electrical Systems (All Buildings) } \\
\text { Motors } \\
\text { Wiring } \\
\text { Instruments } \\
\text { Switches } \\
\text { Plugs } \\
\text { Jacks } \\
\text { Transformers }\end{array}$ & $\begin{array}{l}\text { Electrical systems (All buildings) } \\
\text { (continued) } \\
\text { Breakers } \\
\text { Heaters } \\
\text { Cathodic protection rectifiers } \\
\text { Capacitors } \\
\text { Condensers } \\
\text { Lights } \\
\text { Auxillary generator } \\
\text { Ventilation systems (All buildings) } \\
\text { Blowers } \\
\text { Electrical motors } \\
\\
\text { Louvers } \\
\text { Ducts } \\
\text { Buildings (All) } \\
\text { Steel structure } \\
\text { Concrete } \\
\text { Siding (transite) } \\
\text { Roof } \\
\text { Cinder blocks } \\
\text { Doors } \\
\text { Cell enclosures } \\
\text { Pipe enclosures }\end{array}$ \\
\hline
\end{tabular}




\subsection{TECHNOLOGY OPTIONS}

\subsubsection{Introduction}

Technology options identified in the characterization area include both commonly used and accepted technologies as well as those needing technical development and adaptation. Effort placed here, for the reasons discussed in Chap. 2, (i.e., high impact on cleanup options and high cost), will prove fruitful in a number of areas. Technologies were grouped in the categories described in the previous section, and identified in the TLD as "alternatives." These general headings are discussed below.

A listing of the individual technologies, with development and implementation need identified, and their associated priority ranking is included in Table 3.2.

\subsubsection{Technology Summary}

\section{Statistics and Data Collection}

The most immediate cost reduction measure is decreasing characterization required to provide necessary information. Integration of sampling design to reflect both statistical reality and process knowledge considerations is a major area of technology development. In this work, it is possible to draw heavily from both the petroleum and mining industries. Geostatistics is an emerging area of statistics that provides tools for analyzing spatially correlated data that can be utilized to produce maps of contamination contours or some associated risk. Successful application of geostatistics in the past has been in $2 \mathrm{D}$; development to $3 \mathrm{D}$ is recommended.

Data handling has been identified as another productive area. Considerable process knowledge is available, and the large process buildings at the K-25 Site have been characterized in a limited manner for several projects and programs. This data need to be gathered in a retrievable manner for configuration control during cleanup. The same data set, if developed and maintained as a quality assurance database, may serve as evidence for regulatory release. Visualization of this data would be a major step forward to both cleanup personnel and regulatory agencies. Technologies needed for this data handling and visualization have been identified. They are being developed in both the private and public sector. This visualization capability could come from a union of data management systems, Geographic Information Systems (GIS), computer aided design systems, and scientific visualization technologies. Developments in neural networking and artificial intelligence would be extremely cost-effective if regulatory acceptance of proceduralized data gathering and handling using such a visualized database could be obtained. Current K-25 Site computing capability is inadequate for the demands of such a system and would need to be increased. Work is ongoing at Los Alamos National Laboratory and in Oak Ridge.

\section{Sampling and Sample Preparation}

Sampling and sample preparation improvements will have major effects on the data taken and in the interpretation of the data. Process support for cleanup activities and determining source terms for pathways analyses will be extremely beneficial. In areas of regulatory compliance the advantages of simplicity and 
consistency should be weighed against improvernents in technical characterization.

Technologies identified in this area include those that will provide depth distribution information, such as directional drilling and metallographic sample preparation. Included also are technologies for efficient extraction for in situ characterization and for more reproducible or sensitive laboratory analysis.

\section{In Situ and Laboratory Physical Characterization}

These technologies are expected to be useful in assessing the structural integrity of process equipment before and during decontamination and after systems dismantlement. Leak detection techniques for checking process gas handling systems, for example, will be employed before any gas-phase decontamination work. 'Technologies for measuring damage during $D \& D$ will be needed if structures ancl equipment are to be reused.

\section{In Situ Chemical Characterization}

In situ characterization has an immediate and far-reaching potential advantage for sites that, like the $\mathrm{K}-25$ Site, are likely to need extensive sampling and analysis or monitoring functions. The current emphasis on development of sensor technology for field use was confirmed in this work; in situ sensing eliminates sample handling and transport issues, as well as eliminating elaborate laboratory quality assurance (QA) procedures and practices designed to simulate field conditions (such as holding time and chain-of-custody requirements).

Technologies with potential in situ application to the K-25 Site needs were identified in the in situ section of the TLD. Many of these technologies are in common laboratory use as well. The provision of field laboratories also offers some of the advantages of true in situ measurements, and considerable effort is ongoing in Oak Ridge to implement this capability. Development work needed in this area to make the instrumentation field portable was generally covered under in situ development needs. The provision of a new analytical facility in the process area of the K-25 Site is currently under consideration (ADS 4701).

\section{Laboratory Chemical Characterization}

Laboratory analyses is expected to remain a mainstay support function for all phases of the cleanup process. Improvements in data handling, statistical design, and in situ analysis coild reduce the necessity for the provision of traditional laboratory functions. However, there will still be many samples.

Laboratory techniques have been developed and are accepted by regulatory agencies. Efforts need to be placed on the identification and implementation of streamlining the labora:ory analysis process. These efforts are ongoing and are likely to be cost-effective. A bottleneck at this time is laboratory capacity. Automated sample hanilling along with adding temporary capacity through the private sector would be effective in reducing this overload. Both are currently ongoing in Oak Ridge-a.utomation of laboratory methods and a computerized QA and data handling study is being pursued by the EM-50 Robotics Program (aimed primarily at regulatory agency-approved methods for water and soil), and outside laboratory support to increase capacity is being utilized. 
As noted in the previous section, laboratory technologies with identified potential for in situ application were discussed under the heading "In Situ Chemical Characterization."

\section{Data Assessment and Modeling}

Modeling and pathways analysis was not addressed by the characterization team, although this characterization step is vital to estimating the impact of legacy contamination on the environment.

\subsubsection{Technology Evaluation}

All technologies included in the TLD were judged useful to address the K-25 Site problems." Technologies were evaluated on an individual basis and assigned priority rankings of high (H), medium (M), and low (L) based on the evaluation of their potential cost-effective implementation in the K-25 Site cleanup effort. Both technology development and implementation needs were reflected in this evaluation.

$\mathrm{H}$ ranking technologies were judged to have major impact in one, or significant impact in several K-25 Site areas or cleanup activities: These technologies are immediate candidates for "core" technology status within the DOE complex. $M$ ranking technologies required more development, or were not unanimously judged to be as widely applicable at the time this report was written. Development of $L$ ranking technologies did not seem as urgent, based on specific K-25 Site needs.

"Examples of potential cost savings in one characterization area are as follows.

The analysis of large areas can be performed using a variety of sampling designs. Regardless of which sampling design is used the number of samples can quickly build up to place a real strain on existing analytical capabilities. This is an area where robotic-assisted field characterization can provide large cost savings. Using the process floors at the K-25 Site for example, one can determine that if $50 \%$ of the 325 acres is readily accessible to a robotic platform and a $100 \mathrm{ft}^{2}$ sampling grid is used that 78.650 sampling locations would be identified. If sampling and analysis were manually performed for PCBs, radiological, and metals of interest (U, Tc, $\mathrm{Hg}, \mathrm{Pb}, \mathrm{Cr})$, the total cost would be over \$40M (@ \$25 for all three sampling and analysis costs).

- Integration of process knowledge with statistical sampling could, with regulatory approval, reduce the number of samples taken up to a factor of 10 , with associated savings of $\$ 36 \mathrm{M}$.

- If three robotic units (@ $\$ 500 \mathrm{~K}$ each) were used and supported by 1.5 Full-Time-Equivalents (@ $\$ 300 \mathrm{~K}$ per FTE) then a similar characterization could be performed within the same time frame for approximately $\$ 2 \mathrm{M}$. The automated systems also produces less waste, increases data handling ease, and reduces the administrative burdens for monitoring and controlling a large scale manual characterization effort. Thus the overall cost savings is greater than that estimated by straight comparison of sampling and analysis costs.

- If sampling and laboratory analysis costs could be reduced $5 \%$ through efficiency improvements, the overall cost savings would be $\$ 2 \mathrm{M}$. 


\subsection{SCIENCE AND TECHNOLOGY NEEDS}

Specific research, development and improvement needs for each technology listed in the TLD are described in the individual data sheets included in Vol. 3 of this document. They are grouped in the list below.

Perhaps the most important and potentially gratifying result of the characterization team work was the identification of a great amount of technology, developed for other industrial applications, that is applicable for D\&D activities at the K-25 and other DOE sites with relatively modest (but present) adaptation cost. In many areas components are commercially available; they may need to be combined to optimize site-specific characterization, downsized, compared to more conventional characterization technologies under controlled conditions, and standard methods may rieed to be developed and documented for their use. While areas of basic research and development were indeed found to be valuable, however these were minimal in comparison to the need for an integrated effort for the adaptation of existing characterization technology.

There have been a number of review articles detailing the advances in various characterization technologies as applied to environmental monitoring. One particularly powerful literature tool is the Application Reviews, (Vol. 12, 1991) and the Fundamental Reviervs (Vol. 12, 1992) which is published in the Journal of Analytical Chemistry. These reviews clearly show the importance and everimproving drive for characterization technology.

\section{Areas of Basic Researish and Development}

This work is ongoing for other applications but it needs expanding to meet characterization needs:

- Surface-contaminant interaction studies (to support sensor development and improved sampling techniques),

- Pathways analysis for risk assessment,

- Mathematical modeling (to support risk assessment, statistics),

- Small power sources; (to support field characterization activities),

- Waste stream complexation and compatibility,

- Waste-containment interactions/compatibility studies, and

- Nonintrusive evaluation of waste sites.

\section{Areas of Development and Adaptation of Existing Technology}

Basic R\&D of these technologies has been completed; development, adaptation, and technology improvements would be cost-effective for our specific applications. In many of these areas work is currently underway, and the K-25 Site can benefit from these efforts (see Chap. 5). Where funding would be necessary to bring these technologies to the implementation stage, or to demonstrate their efficary for DOE needs, development costs are indicated within the TLD. Cooperative work with industry is an attractive possibility in many cases. From the K-25 Site viewpoint, opportunities for cost-effective development exist in the following areas: 
- Computer modeling (including artificial intelligence),

- Statistics,

- Sample preparation and characterization methods to determine 3-dimensional spatial distribution,

- Rapid response and remote surface sensing,

- Methods of monitoring protective clothing,

- Real-time monitoring of both air and water,

- Rapid field analysis,

- In situ characterization and sensing,

- Rapid surface screening techniques,

- Development of optimized and standard methods for both field and laboratory characterization in the areas of using commercially available instrumentation:

- Statistics and Data Collection,

- Sampling (including Sample Preparation),

- In situ Physical Characterization,

- Laboratory Physical Characterization,

- In situ Chemical Characterization,

- Laboratory Chemical Characterization, and

- Data Assessment and Modeling.

- Leak testing techniques,

- Enrichment determinations for small amounts of uranium (low levels, small particles),

- Methods for classification assessment,

- Data analysis (multi-variate, chemometrics, data bases),

- Nonintrusive techniques for geological mapping, and

- Biocompatibility studies for post-treatment areas.

".."see also Dismantlement Section 4.2.6.

-While technology development to address classification issues is expected to be significant in reducing costs associated with $D \& D$, it is not addressed fully in this document. 


\subsection{IMPLEMENTATION NEEDS}

More efficient utilization of existing resources is needed to meet our applications needs. Additional resources will be needed as well. Regulatory acceptance continues to be identified as an important issue, it is an area where integrated DOE-wide efforts may be very cost-effective. Specific resource requirements, including; development costs, are indicated in the TLD (Vol. 2). General areas are discussed below.

1. More efficient utilization of available resources capability is needed: communication and coordination of laboratory capacity within the DOE Complex should be improved; systematic sharing of technology development activities and results would help in the implementation of technology improvements. Cooperative R\&D activities with both university and industry partners will ensure that DOE needs are being addressed by the wider technical community. Cooperative R\&D agreements within the regulatory research framework will ensure that our technical expertise is integrated into the overall environm.ental effort. These efficiency improvements may be listed:

- Determination of data quality objectives,

- Communication and coordination of laboratory capacity and capability within the DOE Complex,

- Cooperative R\& J with industry and universities, and

- Cooperative R\&J with regulatory agencies.

2. New resources are needed as well: funding for development and adaptation of existing technologies should be clearly identified outside the scope of individual project operations. The $\mathrm{K}-25 \mathrm{Site}$ is specifically requesting funding for both analytical and development laboratory facilities. Cooperative work with universities and other educational institutions will encourage the development of technical personnel with experience in areas where DOE has significant programmatic needs. These needs may be summarized as:

- Funding for adclptation of existing and commercial technology (see also cooperative agreements),

- Cooperative R\&D with universities (and other educational institutions),

- Development arid analytical laboratory capacity and capability to handle hazardous, contaminated, and classified material samples. The K-25 Site is specifically requesting funding for laboratory facilities located within the process areas ( $A D S$ 4701). 


\section{K-25 Site Characteristics}

The TD and implementation needs identified and recommended previously were based on the specific K-25 Site characteristics listed below.

\section{The facilities are large.}

a. D\&D will be labor intensive. Automated robotics, real-time sensing, techniques for better characterization of radiological zones, improved monitoring to reduce protective clothing and equipment needs are likely to reduce the hazards associated with D\&D activities and result in improved operational efficiency.

b. Large amounts of data for individual units (such as process buildings) will need to be generated and handled. Statistics, computer modeling, improvements (rapid, better, cheaper) in data generation and utilization will result in a more cost-effective characterization effort. The overall characterization effort will be large; considerable cost savings can result from even minor improvements in these areas.

c. Large amounts of waste will be generated during cleanup. Detailed determination of both surface and depth distribution will reduce the amount of waste that must be treated as hazardous, or determine areas where criticality concerns exist in addition to contamination concerns.

2. Radiological and other risks are generally low but present. Most areas of the K-25 Site process buildings are accessible to personnel. Isolated "hot spots" need to be identified, and some hazardous materials (PCBs, $\mathrm{Hg}$ ) are present. Again, statistical and rapid screening techniques are likely to be costeffective. Automated robotics, real-time sensing, techniques for better characterization of radiological zones, improved monitoring to reduce protective clothing and equipment needs are likely to reduce the hazards associated with D\&D activities, and result in improved operational efficiency.

3. Many systems and areas are not readily accessible. Miniaturization of existing technology, qualitative remote sensing, and the application of nondestructive evaluation (NDE) techniques will be necessary. Cost-effective TD areas have been identified to meet these needs.

4. Some of the $\mathbf{K}-25$ Site materials are classified. Techniques associated with this issue are not discussed in the TLD. 


\section{Prioritization}

Approximately 100 :echnologies were identified with application to specific K-25 Site problems. S/T and implementation needs were identified and the characterization technologies were compared to these K-25 Site needs and ranked according to:

a. Environmental, Safety, and Health (ES\&H) Impact. This factor assesses the ES\&H impact of the process. If the analysis uses hazardous/toxic reactants or produces hazardous/toxic products, then the analysis is given a low ratir.g; if not, then it is given an appropriate higher rating. If the technology is expected to enhance worker safety and environmental management, then it is given a high ranking; if it is dangerous the ranking is low.

b. Payback Potential. This factor examines the ability of the process (e.g., a developmental process) to save money in the future as compared to its present $R D \& D$ costs. The future savings could result from for example, lower treatment and disposal costs by using the technology for treating the waste stream. If the payback potential is high, then the process is given a high rating; if not, then it is given an appropriate lower rating. It should be noted that the payback potential for developed technologies will likewise be high because of minimal RD\&D costs.

Factors used in determining these include:

- Characterization Performance: (sensitivity, reliability or efficiency). This factor evaluates the usefulness of the technique in determining contaminant levels.

- RD\&D Costs. This factor evaluates the RD\&D costs likely to be incurred in developing the process to the deployable state. If these costs are high, the process is given a low rating; if, not then it is given an appropriately higher rating.

- Deployment Costs. This factor captures both the capital and the operating cost for the technology; if the cost is high, then the process is given a low rating. If the cost is expected to be low, then it is given a high rating.

- Technical Maturity. This factor evaluates the development status of the technology. If the technology is expected to be ready for deployment during the next five years, then it is given a high rating; if not, then it is given an appropriate lower rating.

- Reliability. This factor evaluated the expected reliability of the technology to produce dependable data, with minimum need for extensive development of specific standards. 
- Versatility. This factor measures the robustness of the technology. This is, if the process can effectively measure contaminants with a wide range of characteristics (e.g., the number and varying concentrations of the contaminants, varying physical conditions of the waste streams, etc.), then the process is given a high rating. If, on the other hand, the process requires that the wastes processed be within specific narrow characteristics, then it is given an appropriately lower rating.

- Complexity. This factor evaluates the complexity of the process. If the process is highly complex involving, for example, many stages or complex reaction conditions, then the process is given a lower rating; if not, then it is given an appropriate higher rating.

- Waste Minimization Potential. This factor evaluates the production of secondary characterization wastes. If the process produces few, or no hazardous wastes, the technology is given a high rating; if not, then it is given an appropriate lower rating.

The first category of technologies were judged to have major impact in one, or significant impact in several K-25 Site areas or cleanup activities. These technologies are immediate candidates for "core" technology status within the DOE complex. Second category technologies required more development, or were not unanimously judged to be as widely applicable at the time this report was written. Development and implementation of the third category of technologies did not seem as urgent, based on specific K-25 Site needs. A listing of the individual technologies, with development and implementation needs identified, and their associated priority ranking is included in Table 3.2.

\section{Science and Technology Needs}

Perhaps the most important and gratifying result of the characterization teamwork is the identification of a vast amount of technology developed for other industrial applications that is applicable for D\&D activities at the K-25 Site and other DOE sites with modest adaptation cost. In many areas components are commercially available. They may need to be combined to optimize site-specific characterization, downsized, compared to more conventional characterization technologies under controlled conditions, and developed and documented for their use. While areas of basic R\&D were indeed found to be valuable, these were minimal in comparison to the need for an integrated effort for the adaptation of existing characterization technology.

\section{Areas of Basic Research and Development}

Basic R\&D is ongoing for other areas and it needs expanding to meet our applications.

- Surface-contaminant interaction studies (to support sensor development and improved sampling techniques),

- Pathways analysis for risk assessment, 
Table: 3.2. Characterization technologies

\begin{tabular}{|c|c|c|c|c|c|}
\hline Alternatives & Technologies & Reference ID & $\begin{array}{c}\text { Basic } \\
\text { R\&D } \\
\text { needed }\end{array}$ & $\begin{array}{l}\text { Devel. } \\
\text { and } \\
\text { Adapt. } \\
\text { needed }\end{array}$ & Rank $^{b}$ \\
\hline \multicolumn{6}{|c|}{ Genercally useful throughout the K-25 site problems } \\
\hline \multirow[t]{6}{*}{ Statistics/Data } & $\begin{array}{l}\text { Optimization of } \\
\text { Sampling } \\
\text { Designs }\end{array}$ & CHAR-71 & $\mathbf{x}$ & $\mathrm{x}$ & $\mathbf{H}$ \\
\hline & $\begin{array}{l}\text { Hadamard Masking for } \\
\text { Spatial Resolution }\end{array}$ & CHAR-28 & & $\mathbf{x}$ & $\mathrm{L}$ \\
\hline & $\begin{array}{l}\text { Database Mgmt. for } \\
\text { Large Data Collections }\end{array}$ & CHAR-72 & & $\mathbf{x}$ & $\mathbf{H}$ \\
\hline & $\begin{array}{l}\text { Visual Display of } \\
\text { Statistic.al Information }\end{array}$ & CHAR-73 & & $\mathrm{x}$ & $\mathbf{H}$ \\
\hline & $\begin{array}{l}\text { Statistical Methods for } \\
\text { Spatially' Correlated } \\
\text { Data }\end{array}$ & CHAR-75 & & $\mathrm{X}$ & $\mathbf{M}$ \\
\hline & $\begin{array}{l}\text { Artificial Intelligence/ } \\
\text { Neutral :Network }\end{array}$ & CHAR-22 & & $x$ & $\mathbf{M}$ \\
\hline \multirow[t]{11}{*}{ Sampling/prep } & $\begin{array}{l}\text { Membrane Technology } \\
\text { for Sample Collection } \\
\text { and Concentration }\end{array}$ & CHAR-55 & & $\mathrm{x}$ & $\mathbf{H}$ \\
\hline & $\begin{array}{l}\text { Continuous Air } \\
\text { Monitoring }\end{array}$ & CHAR-59 & & $\mathrm{x}$ & $\mathbf{H}$ \\
\hline & $\begin{array}{l}\text { Sensor Delivery } \\
\text { Systems }\end{array}$ & CHAR-120 & & $\mathrm{x}$ & $\mathbf{H}$ \\
\hline & $\begin{array}{l}\text { Multiangle Drilling for } \\
\text { Depth Profiling }\end{array}$ & CHAR-64 & & $\mathrm{x}$ & $\mathbf{M}$ \\
\hline & $\begin{array}{l}\text { Metallographic Sample } \\
\text { Preparalion }\end{array}$ & CHAR-67 & & $\mathbf{x}$ & $\mathrm{H}$ \\
\hline & Ultrasoric Extraction & CHAR-20 & $\mathrm{x}$ & $\mathbf{x}$ & $\mathbf{M}$ \\
\hline & Laser Alylation & CHAR-86 & & $\mathrm{x}$ & $\mathbf{H}$ \\
\hline & $\begin{array}{l}\text { Correlation of Matrix } \\
\text { Porosity with } \\
\text { Collection } \\
\text { Efficiency: Standard } \\
\text { Methodcilogy }\end{array}$ & CHAR-61 & $\mathbf{x}$ & $\mathrm{x}$ & $\mathbf{M}$ \\
\hline & $\begin{array}{l}\text { Laser/F.ashlamp } \\
\text { Heating }\end{array}$ & CHAR-87 & $\mathrm{x}$ & $\mathbf{x}$ & $\mathbf{H}$ \\
\hline & $\begin{array}{l}\text { Vacuum Assisted, } \\
\text { Reverse Flow Solvent } \\
\text { Extraction } \\
\text { Methods; }\end{array}$ & CHAR-62 & $\mathrm{x}$ & $\mathrm{x}$ & $\mathbf{M}$ \\
\hline & ' & & & & \\
\hline
\end{tabular}


Table 3.2. (continued)

\begin{tabular}{|c|c|c|c|c|c|}
\hline Alternatives & Technologies & Reference ID & $\begin{array}{c}\text { Basic } \\
\text { R\&D } \\
\text { needed }\end{array}$ & $\begin{array}{l}\text { Devel. } \\
\text { and } \\
\text { Adapt. } \\
\text { needed }\end{array}$ & $\operatorname{Rank}^{b}$ \\
\hline & $\begin{array}{l}\text { Sampling and Mixing } \\
\text { Methods }\end{array}$ & CHAR-81 & $\mathbf{x}$ & $\mathrm{X}$ & $\mathbf{H}$ \\
\hline & Microwave Digestion & CHAR-19 & & $\mathrm{x}$ & $\mathbf{H}$ \\
\hline \multirow{3}{*}{$\begin{array}{l}\text { Data } \\
\text { Assessment }\end{array}$} & Chemometrics & CHAR-21 & & $x$ & $\mathbf{M}$ \\
\hline & $\begin{array}{l}\text { Auto-Correlation Auto- } \\
\text { Convolution Optimized } \\
\text { Multivariant-Data } \\
\text { Analysis }\end{array}$ & CHAR-29 & & $\mathbf{x}$ & $\mathbf{M}$ \\
\hline & $\begin{array}{l}\text { Statistical Methods for } \\
\text { Multivariant Data }\end{array}$ & CHAR-74 & $\mathrm{x}$ & $\mathrm{X}$ & $\mathrm{H}$ \\
\hline \multirow[t]{4}{*}{ Physical in situ } & Computer Tomography & $\begin{array}{l}\text { CHAR-41 } \\
\text { CHAR-60 }\end{array}$ & & $\mathrm{X}$ & $\mathbf{M}$ \\
\hline & Holographic Imaging & CHAR-46 & $\mathbf{x}$ & $x$ & L \\
\hline & Particle Size Analysis & CHAR-26 & & $x$ & $\mathbf{H}$ \\
\hline & $\begin{array}{l}\text { Annular Denuder } \\
\text { Technology }\end{array}$ & CHAR-16 & & $\mathrm{X}$ & $\mathbf{H}$ \\
\hline \multirow[t]{3}{*}{ Physical lab } & $\begin{array}{l}\text { Transmission Electron } \\
\text { Microscopy }\end{array}$ & CHAR-34 & & $\mathrm{x}$ & $\mathrm{H}$ \\
\hline & $\begin{array}{l}\text { Scanning Electron } \\
\text { Microscopy }\end{array}$ & CHAR-33 & & $x$ & $\mathbf{H}$ \\
\hline & $\begin{array}{l}\text { Computerized Image } \\
\text { Analysis }^{c}\end{array}$ & CHAR-119 & & $x$ & $\mathbf{H}$ \\
\hline \multirow[t]{5}{*}{$\begin{array}{l}\text { Chemical in } \\
\text { situ }\end{array}$} & $\begin{array}{l}\text { Laser Photo Acoustic } \\
\text { Spectroscopy }\end{array}$ & CHAR-15 & & $\mathbf{x}$ & L \\
\hline & $\begin{array}{l}\text { Laser Raman } \\
\text { Scattering }\end{array}$ & CHAR-84 & $\mathrm{X}$ & $x$ & $\mathbf{M}$ \\
\hline & $\begin{array}{l}\text { Fiber Optic Chemical } \\
\text { Sensors }\end{array}$ & CHAR-25 & $x$ & $\mathrm{x}$ & $\mathbf{H}$ \\
\hline & Optical Microscopy & CHAR-32 & & $\mathrm{x}$ & $\mathbf{H}$ \\
\hline & Fluorescence & $\begin{array}{r}\text { CHAR-1 } 10 \\
\text { CHAR-92 }\end{array}$ & & $\mathbf{x}$ & $\mathrm{H}$ \\
\hline Chemical lab & $\begin{array}{l}\text { Electron Spectroscopy } \\
\text { for Chemical Analysis }\end{array}$ & CHAR-1 & & $\mathbf{x}$ & $\mathbf{H}$ \\
\hline
\end{tabular}


Table 3.2. (continued)

\begin{tabular}{|c|c|c|c|c|c|}
\hline Alternatives & Technologies & Reference ID & $\begin{array}{c}\text { Basic } \\
\text { R\&D } \\
\text { needed }\end{array}$ & $\begin{array}{l}\text { Devel. } \\
\text { and } \\
\text { Adapt. } \\
\text { needed }\end{array}$ & $\operatorname{Rank}^{b}$ \\
\hline & $\begin{array}{l}\text { Auger Ele:tron } \\
\text { Spectroscispyc }\end{array}$ & CHAR-2 & & $\mathrm{x}$ & $\mathbf{H}$ \\
\hline & $\begin{array}{l}\text { Secondary ion Mass } \\
\text { Spectrometry }\end{array}$ & CHAR-3 & & $\mathbf{x}$ & $\mathbf{M}$ \\
\hline & $\begin{array}{l}\text { Laser Ionization Mass } \\
\text { Spectrom:try }\end{array}$ & $\begin{array}{l}\text { CHAR-4 } \\
\text { CHAR-93 }\end{array}$ & & $\mathrm{x}$ & $\mathbf{H}$ \\
\hline & $\begin{array}{l}\text { Secondary Neutral } \\
\text { Mass Spei:trometry }\end{array}$ & CHAR-7 & $\mathrm{X}$ & $\mathrm{x}$ & $\mathbf{M}$ \\
\hline & $\begin{array}{l}\text { Chemical Leaching } \\
\text { Tests }\end{array}$ & CHAR-113 & & $\mathrm{x}$ & $\mathbf{H}$ \\
\hline & $\begin{array}{l}\text { Nuclear Magnetic } \\
\text { Resonance }\end{array}$ & $\begin{array}{l}\text { CHAR-11 } \\
\text { CHAR-58 }\end{array}$ & & $\mathbf{x}$ & $\mathbf{L}$ \\
\hline & $X$-ray Diffraction ${ }^{c}$ & CHAR-31 & & $\mathbf{x}$ & $\mathbf{H}$ \\
\hline & Electron I)iffraction & CHAR-37 & & $x$ & $\mathbf{H}$ \\
\hline & $\begin{array}{l}\text { Isotopic Dilution Mass } \\
\text { Spectrosc Jpy }\end{array}$ & CHAR-48 & & $x$ & $\mathbf{M}$ \\
\hline & $\begin{array}{l}\text { Electrochemical } \\
\text { Methods }\end{array}$ & CHAR-10 & & $\mathrm{X}$ & $\mathbf{M}$ \\
\hline & Ion Chromatography & CHAR-50 & & $\mathrm{x}$ & $\mathbf{H}$ \\
\hline \multicolumn{6}{|c|}{ Technologies targeted specifically to radioactive contamination } \\
\hline \multirow[t]{5}{*}{ In situ } & $\begin{array}{l}\text { Measurement of } \\
\text { Natural Gamma } \\
\text { Emitters }\end{array}$ & CHAR-51 & & $\mathbf{X}$ & $\mathbf{M}$ \\
\hline & $\begin{array}{l}\text { Passive Neutron } \\
\text { (Requires F) }\end{array}$ & CHAR-104 & & $\mathbf{x}$ & $\mathbf{H}$ \\
\hline & $\begin{array}{l}\text { Thermoluminescence } \\
\text { Dosimetry Array for a } \\
\text { Spatial } \\
\text { Characterization of } \\
\text { Surface Alpha } \\
\text { Contamination }\end{array}$ & CHAR-103 & & $\mathbf{x}$ & $\mathbf{M}$ \\
\hline & $\begin{array}{l}\text { NaI Gamrna } \\
\text { Spectroscopy }\end{array}$ & $\begin{array}{l}\text { CHAR-106 } \\
\text { CHAR-1 } 12\end{array}$ & & $x$ & $\mathbf{H}$ \\
\hline & Proportional Counting & CHAR-108 & . & $\mathbf{x}$ & $\mathbf{H}$ \\
\hline
\end{tabular}


Table 3.2. (continued)

\begin{tabular}{|c|c|c|c|c|c|}
\hline Alternatives & Technologies & Reference ID & $\begin{array}{c}\text { Basic } \\
\text { R\&D } \\
\text { needed }\end{array}$ & $\begin{array}{l}\text { Devel. } \\
\text { and } \\
\text { Adapt. } \\
\text { needed }\end{array}$ & $\operatorname{Rank}^{b}$ \\
\hline & $\begin{array}{l}\text { Small Long-Range } \\
\text { Alpha Detection }\end{array}$ & CHAR-65 & & $\mathrm{x}$ & $\mathbf{H}$ \\
\hline & $\begin{array}{l}\text { "Electret" Passive } \\
\text { Surface Alpha } \\
\text { Detection }\end{array}$ & CHAR-95 & & $\mathrm{x}$ & $\mathbf{H}$ \\
\hline & $\begin{array}{l}\text { In Situ Passive } \\
\text { Monitors for Surface } \\
\text { Contamination by } \\
\text { Weak Beta } \\
\text { Radionuclides }\end{array}$ & CHAR-102 & & $\mathbf{x}$ & $\mathbf{H}$ \\
\hline & $\begin{array}{l}\text { Alpha Track Etch } \\
\text { Detection }\end{array}$ & CHAR-105 & & $\mathrm{x}$ & $\mathbf{H}$ \\
\hline \multirow[t]{5}{*}{ Rad Laboratory } & $\begin{array}{l}\text { Waste Curie } \\
\text { Monitoring (Semi-Lab) }\end{array}$ & CHAR-109 & & $\mathrm{X}$ & $\mathbf{M}$ \\
\hline & $\begin{array}{l}\text { Select alpha } \\
\text { Radionuclide Analysis } \\
\text { by PERALS }{ }^{d} \text { (Semilab) }\end{array}$ & CHAR-97 & $\mathrm{X}$ & $\mathbf{x}$ & $\mathbf{M}$ \\
\hline & Neutron Activation & CHAR-107 & & $\mathbf{x}$ & $\mathbf{H}$ \\
\hline & $\begin{array}{l}\text { Liquid Scintillation } \\
\text { Counting }\end{array}$ & CHAR-129 & & $\mathrm{x}$ & $\mathbf{H}$ \\
\hline & \multicolumn{5}{|c|}{ Techniques targeted to inorganic contaminants (metals, etc.) } \\
\hline $\begin{array}{l}\text { Chemical in } \\
\text { situ }\end{array}$ & X-Ray Fluorescence & $\begin{array}{l}\text { CHAR-6 } \\
\text { CHAR-98 }\end{array}$ & & $\mathrm{X}$ & $\mathbf{H}$ \\
\hline & $\begin{array}{l}\text { Ultraviolet/Visible } \\
\text { Spectroscopy }\end{array}$ & CHAR-9 & & $\mathrm{x}$ & $\mathbf{M}$ \\
\hline & $\begin{array}{l}\text { Laser-Ablation } \\
\text { Inductively Coupled } \\
\text { Plasma Atomic } \\
\text { Emission Spectroscopy }\end{array}$ & CHAR-111 & & $x$ & $\mathbf{H}$ \\
\hline \multirow[t]{4}{*}{ Chemical lab } & $\begin{array}{l}\text { Atomic Absorbtion } \\
\text { Spectroscopy }\end{array}$ & CHAR-76 & & $\mathbf{x}$ & $\mathbf{H}$ \\
\hline & $\begin{array}{l}\text { Inductively-Coupled } \\
\text { Plasma Spectroscopy }\end{array}$ & CHAR-77 & & $\mathrm{x}$ & $\mathbf{H}$ \\
\hline & $\begin{array}{l}\text { Inductively-Coupled } \\
\text { Plasma Mass } \\
\text { Spectrometry }\end{array}$ & CHAR-78 & & $\mathbf{x}$ & $\mathbf{H}$ \\
\hline & $\begin{array}{l}\text { Particle-Induced X-ray } \\
\text { Emission }\end{array}$ & CHAR-17 & & $\mathrm{x}$ & L \\
\hline
\end{tabular}


Table 3.2. (continued)

\begin{tabular}{|c|c|c|c|c|c|}
\hline Alternatives & Technologies & Reference ID & $\begin{array}{c}\text { Basic } \\
R \& D^{a} \\
\text { needed }\end{array}$ & $\begin{array}{c}\text { Devel. } \\
\text { and } \\
\text { Adapt. } \\
\text { needed }\end{array}$ & Rank $^{b}$ \\
\hline & Cold Vapcr (Mercury) & CHAR-24 & & $\mathbf{x}$ & $\mathbf{H}$ \\
\hline & $\begin{array}{l}\text { Extended X-ray } \\
\text { Absorption Fine } \\
\text { Structure }\end{array}$ & CHAR-30 & $\mathbf{X}$ & $\mathbf{x}$ & L \\
\hline & $\begin{array}{l}\text { Energy-Dispersive } \\
\text { X-ray Spectroscopy } \\
\text { (EDS, ED:X, EDAX) }^{b}\end{array}$ & CHAR-35 & 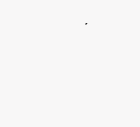 & $\mathbf{x}$ & $\mathbf{H}$ \\
\hline & $\begin{array}{l}\text { Wavelength Dispersive } \\
\text { X-ray Spectroscopy } \\
\text { Electron Microprobe) }^{c}\end{array}$ & CHAR-36 & & $x$ & $\mathrm{H}$ \\
\hline & $\begin{array}{l}\text { Mossbauer } \\
\text { Spectroscopy }\end{array}$ & CHAR-47 & & $\mathbf{x}$ & $\mathbf{L}$ \\
\hline \multicolumn{6}{|c|}{ Techniques: targeted to organic contaminants, including PCBs } \\
\hline Sampling & $\begin{array}{l}\text { Solid Sorkent } \\
\text { Sampling }\end{array}$ & CHAR-91 & & $\mathbf{x}$ & $\mathbf{M}$ \\
\hline \multirow[t]{8}{*}{$\begin{array}{l}\text { Chemical In } \\
\text { situ }\end{array}$} & $\begin{array}{l}\text { Organic Vapor } \\
\text { Monitoring }\end{array}$ & CHAR-5 & & $\mathbf{x}$ & $\mathbf{H}$ \\
\hline & Gas Chromatography & $\begin{array}{l}\text { CHAR-94 } \\
\text { CHAR-100 }\end{array}$ & $\mathbf{X}$ & $\begin{array}{l}\mathbf{x} \\
\mathbf{x}\end{array}$ & $\begin{array}{l}\mathbf{H} \\
\mathbf{H}\end{array}$ \\
\hline & $\begin{array}{l}\text { Differential } \\
\text { Ultraviolet Absorbtion } \\
\text { Spectroscopy }\end{array}$ & CHAR-130 & $\mathrm{X}$ & $x$ & $\mathbf{H}$ \\
\hline & $\begin{array}{l}\text { Fourier T.ansform } \\
\text { Infrared Sipectroscopy } \\
\text { (FTIR) }\end{array}$ & $\begin{array}{l}\text { CHAR-8 } \\
\text { CHAR-85 }\end{array}$ & & $\mathrm{X}$ & $\mathbf{M}$ \\
\hline & Long-Path FTIR & CHAR-18 & & $x$ & $\mathbf{M}$ \\
\hline & $\begin{array}{l}\text { Direct Sampling Ion } \\
\text { Trap Mass } \\
\text { Spectrometry }\end{array}$ & CHAR-90 & $\mathrm{x}$ & $\mathrm{X}$ & $\mathbf{H}$ \\
\hline & $\begin{array}{l}\text { Surface A.coustic Wave } \\
\text { Sensors }\end{array}$ & CHAR-14 & $\mathrm{x}$ & $x$ & $\mathrm{H}$ \\
\hline & Immunoessay & $\begin{array}{l}\text { CHAR-23 } \\
\text { CHAR-99 }\end{array}$ & & $\mathrm{X}$ & $\mathbf{H}$ \\
\hline \multirow[t]{3}{*}{ Chem Lab } & $\begin{array}{l}\text { Synchrorous } \\
\text { Fluorescence }\end{array}$ & CHAR-101 & & $x$ & $\mathbf{H}$ \\
\hline & $\begin{array}{l}\text { Gas Chrcimatography- } \\
\text { Mass Spe:ctroscopy }\end{array}$ & CHAR-88 & & $\mathbf{x}$ & $\mathbf{H}$ \\
\hline & $\begin{array}{l}\text { Gas Chromatography- } \\
\text { FTIR }\end{array}$ & CHAR-66 & & $\mathrm{x}$ & $\mathbf{M}$ \\
\hline
\end{tabular}


Table 3.2. (continued)

\begin{tabular}{|c|c|c|c|c|c|}
\hline Alternatives & Technologies & Reference ID & $\begin{array}{l}\text { Basic } \\
\text { R\&D } \\
\text { needed }\end{array}$ & $\begin{array}{l}\text { Devel. } \\
\text { and } \\
\text { Adapt. } \\
\text { needed }\end{array}$ & Rank $^{b}$ \\
\hline & $\begin{array}{l}\text { Liquid } \\
\text { Chromatography - } \\
\text { Mass Spectrometry }\end{array}$ & CHAR-89 & & $\mathbf{x}$ & $\mathbf{H}$ \\
\hline & $\begin{array}{l}\text { Glow Discharge } \\
\text { Ionization Mass } \\
\text { Spec }\end{array}$ & CHAR-56 & & $\mathbf{x}$ & $\mathbf{H}$ \\
\hline & $\begin{array}{l}\text { Differential Optical } \\
\text { Absorbtion } \\
\text { Spectroscopy }\end{array}$ & CHAR-27 & & $\mathrm{x}$ & $\mathbf{M}$ \\
\hline \multirow[t]{2}{*}{$\begin{array}{l}\text { Data } \\
\text { assessment }\end{array}$} & $\begin{array}{l}\text { Migration of } \operatorname{VOCS}^{e} \text { in } \\
\text { Porous Materials }\end{array}$ & CHAR-53 & $\mathrm{X}$ & $\mathrm{x}$ & $\mathbf{L}$ \\
\hline & $\begin{array}{l}\text { Environmental } \\
\text { Dynamics of } \\
\text { Organic Compounds }\end{array}$ & CHAR-57 & $\mathrm{x}$ & $\mathrm{x}$ & $\mathbf{L}$ \\
\hline $\begin{array}{l}\text { Process } \\
\text { Structures }\end{array}$ & General & & & & \\
\hline Physical in situ & $\mathrm{NDT}^{f}$ for Concrete & CHAR-38 & & $\mathbf{X}$ & $\mathbf{M}$ \\
\hline $\begin{array}{l}\text { Data } \\
\text { Assessment }\end{array}$ & $\begin{array}{l}\text { Inorganic Matrix- } \\
\text { Contaminant } \\
\text { Composite Modeling }\end{array}$ & CHAR-39 & $\mathrm{x}$ & $\mathbf{x}$ & $\mathbf{M}$ \\
\hline \multicolumn{6}{|c|}{ Technologies targeted specifically to radioactive contamination } \\
\hline In situ & NaI Floor Scanner & CHAR-105 & & $\mathbf{x}$ & $\mathrm{H}$ \\
\hline $\begin{array}{l}\text { Process } \\
\text { Systems }\end{array}$ & General & $"$ & & & \\
\hline \multirow[t]{4}{*}{ Physical in situ } & Radiographic Imaging & CHAR-40 & & $\mathbf{x}$ & $\mathbf{H}$ \\
\hline & $\begin{array}{l}\text { Conventional Leak } \\
\text { Detection Methods }\end{array}$ & CHAR-68 & & $\mathbf{x}$ & $\mathbf{M}$ \\
\hline & Acoustic Emission & CHAR-69 & & $\mathbf{X}$ & $\mathrm{H}$ \\
\hline & $\begin{array}{l}\text { Ultrasonic Leak } \\
\text { Detection }\end{array}$ & CHAR-70 & & $x$ & $\mathbf{H}$ \\
\hline $\begin{array}{l}\text { Data } \\
\text { Assessment }\end{array}$ & Criticality Indices & CHAR-44 & & $\mathrm{x}$ & $\mathrm{H}$ \\
\hline
\end{tabular}


Table 3.2. (continued)

\begin{tabular}{|c|c|c|c|c|c|}
\hline Alternatives & Technologies & Reference ID & $\begin{array}{c}\text { Basic } \\
R \& D^{a} \\
\text { needed }\end{array}$ & $\begin{array}{l}\text { Devel. } \\
\text { and } \\
\text { Adapt. } \\
\text { needed }\end{array}$ & $\operatorname{Rank}^{b}$ \\
\hline $\begin{array}{l}\text { Soils and } \\
\text { Groundwater }\end{array}$ & Gunetal & & & & \\
\hline $\begin{array}{l}\text { Statistics, Data } \\
\text { Collection and } \\
\text { Data System }\end{array}$ & Ultrasonic: Ranging & CHAR-123 & & $\mathbf{x}$ & $\mathrm{H}$ \\
\hline \multirow[t]{5}{*}{ Sampling } & Punch Cores & CHAR-82 & & $\mathbf{x}$ & $\mathbf{H}$ \\
\hline & Wells \& Punch Sources & CHAR-83 & & $\mathbf{x}$ & $\mathrm{H}$ \\
\hline & & CHAR-45 & $\mathrm{x}$ & & $\mathbf{L}$ \\
\hline & $\begin{array}{l}\text { Tc Geochemical } \\
\text { Behaviorall Modeling }\end{array}$ & CHAR-49 & $\mathbf{x}$ & $\mathbf{x}$ & $\mathbf{L}$ \\
\hline & $\begin{array}{l}\text { Biocompatibility } \\
\text { Studies }\end{array}$ & CHAR-114 & & & \\
\hline \multirow[t]{5}{*}{$\begin{array}{l}\text { Physical } \\
\text { in situ }\end{array}$} & $\begin{array}{l}\text { Ground-Fenetrating } \\
\text { Radar }\end{array}$ & CHAR-124 & $\mathrm{x}$ & $x$ & $\mathbf{M}$ \\
\hline & $\begin{array}{l}\text { Electrical and } \\
\text { Electromagnetic (EM) } \\
\text { Methods }\end{array}$ & CHAR-125 & $\mathbf{x}$ & $\mathrm{x}$ & $\mathbf{H}$ \\
\hline & $\begin{array}{l}\text { Seismic Methods } \\
\text { (Refraction, Profiling, } \\
\text { Reflectior.) }\end{array}$ & CHAR-126 & & $\mathbf{x}$ & $\mathbf{M}$ \\
\hline & Microgravity Methods & CHAR-127 & $\mathbf{x}$ & $\mathbf{x}$ & $\mathbf{M}$ \\
\hline & Magnetic; & CHAR-128 & & $\mathbf{x}$ & $\mathbf{H}$ \\
\hline
\end{tabular}

$a_{R} \& D=$ research and derelopment.

Letters are ratings: $H=$ high; $M=$ medium; and $L=$ low.

This grouping of technologies, individually considered, would not in themselves deserve a top priority rating. However, as a group of microstructural and surface characterization technologies, they can provide invaluable information to Site cleanup efforts. They are commonly used together.

dPhoton-electron rejecting alpha liquid scintillation.

Volatile Organic Compoinds.

Nondestructive testing.

- Mathematical modeling (to support risk assessment, statistics),

- Small power sources (to support field characterization activities),

- Waste-stream comflexation and compatibility, and

- Waste-containment interactions and compatibility studies.

\section{Areas of Development: and Adaptation of Existing Technology}

Basic R\&D of these technologies has been completed and development, adaptation, and technology improvements would be cost-effective for our specific 
applications. In many of these areas work is currently underway, and the K-25 Site can benefit from these efforts. Funding would be necessary to implement these technologies and demonstrate their efficacy for DOE needs. Development costs are indicated within the TLD. Cooperative work with industry is an attractive possibility in many cases. Work in the following areas is recommended from the K-25 Site:

- Computer modeling (including artificial intelligence),

- Statistics,

- Sample preparation and characterization methods to determine 3-dimensional spatial distribution,

- Rapid response and remote surface sensing,

- Methods of monitoring protective clothing,

- Real-time monitoring of air and water,

- Rapid field analysis,

- In situ characterization and sensing,

- Rapid surface screening techniques,

- Development of optimized and standard methods for both field and laboratory characterization using commercially available instrumentation:

- Statistics and Data Collection,

- Sampling (including Sample Preparation),

- In situ Physical Characterization,

- Laboratory Physical Characterization,

- In situ Chemical Characterization,

- Laboratory Chemical Characterization, and

- Data Assessment and Modeling.

- Leak testing techniques,

- Enrichment determinations for small amounts of uranium (low levels, small particles),

- Screening methods for classified materials,

- Data analysis (multivariate, chemometrics, data bases), and

- Biocompatibility studies for post-treatment areas.

\section{Implementation Needs}

More efficient utilization of available resources is needed, as well as additional resources to meet the application needs. Communication and coordination of laboratory capacity within the DOE complex should be improved. Systematic sharing of TD activities and results would help in the implementation of technology improvements. Cooperative $R \& D$ activities with both university and industry partners will ensure that DOE needs are being addressed by the wider technical community. Cooperative $R \& D$ agreements within the regulatory research framework will ensure that our technical expertise is integrated into the overall environmental effort.

New resources are needed also. Funding for developing and adapting existing technologies should be clearly identified outside the scope of individual project operations. The K-25 Site is specifically requesting funding for both analytical and development laboratory facilities. Cooperative work with universities and other educational institutions will encourage the development of technical personnel with experience in areas where DOE has significant programmatic needs. 


\section{Future Characterization Technology Logic Diagram Development}

Currently, additional implementation and development requirements need to be identified, and integration of the technologies listed with ongoing work is not complete. Risk analysis $a n d$ modeling (for data assessment) should be included in future TLD work.

There are many ide:atified technologies to avoid repetition in the diagram. Technologies associated with specific site needs are not always clear and future TLD development shoulcl address this issue in terms of user-friendliness. 
DOE is currently developing technologies through the EM-30, EM-40, and EM50 program which have the potential for making effective contributions to solving environmental and waste recycling problems at the different DOE sites. Some of these projects may have relevant and beneficial elements with respect to the technologies identified in the K-25 Site TLD. A search of available information on programs funded in FY 1992 was performed to identify the possible matches between technologies in the K-25 TLD and TTPs (or ADSs). A listing of the DOE EM-50 Program Guide for FY 1992 and abstracts for funded EM-50 projects were the principal sources for determining matches and relevancy between TEDS and TTPs. Relevant ADS activities were identified through staff personal knowledge.

In Table 3.3, those projects described in TTP or ADS and determined to be potentially relevant and beneficial are listed by TTP (or ADS) number along with the corresponding relevant Technology Evaluation Data Sheet (TEDS) identifier. Along with the matched TEDS is a succinct statement of the technology approach or problem being addressed in both documents. 
Table 3.3. DOE funded development

\begin{tabular}{|c|c|c|c|c|c|c|}
\hline \multicolumn{2}{|c|}{ Technology Diagram } & \multicolumn{2}{|c|}{ DOE TTP } & \multirow{2}{*}{$\begin{array}{l}\text { DOE FY-92 } \\
\text { Program Guidance } \\
\text { (page) }\end{array}$} & \multirow{2}{*}{ Comments } & \multirow{2}{*}{ Relevance } \\
\hline Subelement & TEDS Identifier & Title & TTP No. & & & \\
\hline \multirow[t]{10}{*}{ Characterization } & \multicolumn{3}{|c|}{ Characterization } & & & \\
\hline & CHAR-1 10 & & OR121201 & B1-28 & Fluorescence & $\mathrm{H}$ \\
\hline & CHAR-92 & & OR121201 & $\mathrm{B} 1-28$ & Fluorescence & $\mathrm{H}$ \\
\hline & CHAR-6 & & $\begin{array}{l}\text { RL321113 } \\
\text { RI 3211114 }\end{array}$ & $\begin{array}{l}\text { A9-25 } \\
\text { A9-2.6 }\end{array}$ & $\begin{array}{l}\text { X-ray fluorescence } \\
\text { X-ray flunrescence }\end{array}$ & $\begin{array}{l}\mathrm{H} \\
\mathrm{H}\end{array}$ \\
\hline & CHAR-98 & & $\begin{array}{l}\text { RL321113 } \\
\text { RL321 } 114\end{array}$ & $\begin{array}{l}\text { A9-25 } \\
\text { A9-26 }\end{array}$ & $\begin{array}{l}X \text {-ray fluorescence } \\
\mathrm{X} \text {-ray fluorescence }\end{array}$ & $\begin{array}{l}\mathrm{L} \\
\mathrm{L}\end{array}$ \\
\hline & CHAR-84 & & RLA01206 & $\mathrm{B} 2-21$ & $\begin{array}{l}\text { Raman } \\
\text { spectroscopy }\end{array}$ & $\mathrm{H}$ \\
\hline & CHAR-14 & & $\begin{array}{l}\text { AL221102 } \\
\text { AL221 } 104\end{array}$ & $\begin{array}{l}\text { A1-5 } \\
\text { A4-1 }\end{array}$ & $\begin{array}{l}\text { Acoustic wave } \\
\text { Acoustic wave }\end{array}$ & $\begin{array}{l}\mathrm{H} \\
\mathrm{H}\end{array}$ \\
\hline & CHAR-25 & & $\begin{array}{l}\text { SF211203 } \\
\text { SF221104 }\end{array}$ & $\begin{array}{l}\mathrm{B} 2-33 \\
\mathrm{~A} 4-17\end{array}$ & $\begin{array}{l}\text { FO sensors } \\
\text { FO sensors }\end{array}$ & $\begin{array}{l}\mathrm{H} \\
\mathrm{H}\end{array}$ \\
\hline & CHAR-8 & & RLA21206 & B2-27 & FTIR spectroscopy & $\mathrm{H}$ \\
\hline & CHAR-64 & & RL421103 & A4-11 & Drilling & L. \\
\hline
\end{tabular}




\section{Decontamination}




\section{DECONTAMINATION}

\subsection{INTRODUCTION}

In general, decontamination is accomplished by removal of contaminants from surfaces with little damage to the surface being decontaminated or by intentionally removing a layer of the contaminated surface along with the embedded contaminant. The energy needed to remove the surface layer may be either mechanical, chemical, or thermal. Bulk decontamination requires entirely different techniques such as incineration, smelting, or leaching. Removal of contaminants from surfaces is based upon cleaning techniques that have been used for decades. Many procedures and reagents used in decontaminating equipment and facilities in the nuclear industry were first developed and used for cleaning conventional nonnuclear plants. ${ }^{1}$ Decontamination procedures were developed to provide high decontamination efficiencies and moderate corrosion attack on the surface. Additional criteria to be met were prompt availability of equipment, simple operation and control, acceptable time requirements, satisfactory safety aspects, acceptable costs of application, planned future use of facility, and minimal amounts of wastes. The choice of a decontamination procedure for a particular application will depend upon the importance and priorities assigned to the various criteria, on the characteristics of the system to be decontaminated, and on the specific capabilities at the facility.

To develop the decontamination section of the TLD, the first step was to list the decontamination technologies that are known to be in use, under development, or proposed. For the Problem Area/Constituent logic element of the diagram, as discussed in Sect. 2.2, another step involved development of a list of problems specific to decontamination and traceable directly to the $\mathrm{K}-25$ Site problems. This list consisted of the various contaminated substrates (e.g., concrete, equipment, structural steel, etc.) and the particular hazardous contaminants that can be found residing on or throughout each substrate (i.e., surface or bulk contamination). For each problem (e.g., concrete contaminated with uranium and oil, or sheet metal contaminated with PCBs and oil), technologies were identified that could potentially be used for decontamination.

In most cases, the goal of the decontamination would be to remove the contamination from the substrate sufficiently so that the substrate material could pass an applicable release criterion. This level of decontamination would generally require removal of virtually all of the contamination. However, for the problem of deposit removal, only enough of the contamination (deposit) must be removed to alleviate the problem being caused by the deposit. In this case, removal of $80 \%$ or $90 \%$ of the deposit would be quite sufficient. In spite of these differences, for the purposes of this wiring diagram, deposit removal is considered a decontamination operation.

Because of the large number of problems (almost one hundred combinations of substrates and contaminants) that had been listed, some simplification was necessary to limit the size of the decontamination logic diagram. This was done by 
dividing the problems into ten different groups. The criterion for assigning a problem to a particular group was that all problems in that group could, in general, be treated by the same decontamination technologies. Finally, having identified the technologies applicable to each group of problems and with the detailed information for each technology as provided in the Technology Data Sheets, the decontamination section of the TLD was developed as outlined in Sect. 2.2. 


\subsection{TECHNOLOGY OPTIONS}

\subsubsection{Introduction}

The scope of this activity is to decontaminate DOE surplus facilities (systems or components), in particular the Oak Ridge K-25 Site. Reasons or requirements for decontamination include: ${ }^{2}$

- to permit unrestricted reuse/recycle,

- to permit reuse of the item in the DOE complex,

- to reduce worker radiation exposure,

- to avoid potential criticality accidents,

- to permit or enhance disposal, and

- to separate the hazardous from the radioactive constituents during decontamination.

This section summarizes the decontamination technologies that have been demonstrated or that have the potential to fulfill these requirements. Some of these decontamination technologies are also applicable to the problem of deposit removal.

\subsubsection{Summary of Decontamination Technologies}

Decontamination technologies have been grouped into six generic technologies as follows:

- Mechanical Surface Removal Methods,

- Thermal Surface Removal Methods,

- Surface Cleaning Methods,

- Metal Refining Methods,

- Chemical Surface Cleaning Methods, and

- Bulk Decontamination Methods.

As suggested by the name, surface removal methods take off the surface layer of the substrate (e.g., metal, concrete, etc.) itself and, at the same time, any fixed or loose (i.e., transferrable) contamination that is present on the surface. The surface cleaning methods remove the fixed or loose contamination without disturbing the surface of the substrate. The metal refining and the bulk decontamination methods remove contamination that is distributed throughout the substrate.

The decontamination technologies that have been identified are grouped according to generic technology in Table 4.1. The technologies listed are at various levels of development, including (1) available and accepted by industry, (2) in the demonstration phase, (3) under study at the laboratory. scale, and (4) at the conceptual stage. A brief description of the technologies is provided in the following. 
Takile 4.1. Decontamination technologies

Mechanical Surface Rimoval Methods

1. Ultra high-pressure water

2. Shot blasting

3. Scabblers/scarifiers

4. Grit blasting

5. Centrifugal cryogenic $\mathrm{CO}_{2}$ blasting

6. Ice blasting

7. Supercritical $\mathrm{CO}_{2}$ blasting

8. Plastic pellet blasting

9. Hand grinding, honing, scraping

10. Automated grinding;

11. Metal milling

12. Concrete milling

13. Explosive

\section{Thermal Surface Removal Methods}

1. Microwave scabbling,

2. Plasma torch

3. Laser heating

4. Laser etching and alslating

5. Plasma surface cleaning

6. Plasma etching/fluorination

7. Flashlamp cleaning

\section{Surface Cleaning Metlods}

1. Compressed air crycigenic $\mathrm{CO}_{2}$ blasting

2. High-pressure water

3. Superheated water

4. Hot water

5. Steam

6. Hand brushing

7. Automated brushing;

8. Sponge blasting

9. Hot air

10. Dry heat (roasting)
11. Solvent washing to remove radiological contamination

12. Solvent washing to remove organics

13. Strippable coatings

14. Vacuum

15. Ultrasonic cleaning

Metal Refining Methods

1. Smelt purification

2. Electrorefining

3. Mond (nickel carbonyl) process

4. Leach/electro-winning

\section{Chemical Surface Cleaning} Methods

1. Chemical foams

2. Chemical gels

3. Organic acid treatment

4. Fluoboric acid treatment

5. Inorganic acid treatment

6. Caustic treatment

7. REDOX treatment

8. Electropolishing

9. Gas phase

10. Biological

11. Laser-activated chemistry

12. UV/ozone (UV light activation)

13. Electromigration

\section{Bulk Decontamination Methods}

1. Solvent extraction

2. Incineration

3. Biological

4. Dry heat

5. Chemical leaching

6. Catalytic extraction process

7. Vacuum (low pressure) 
1. Mechanical Surface Removal Methods. Most of the technologies in this generic group involve impacting or blasting a surface with a high velocity stream of fluid or solid particles. These technologies include ultra-high pressure water (UHPW), shot blasting, grit blasting, centrifugal cryogenic $\mathrm{CO}_{2}$ blasting, ice blasting, supercritical $\mathrm{CO}_{2}$ blasting, and plastic pellet blasting. The supercritical $\mathrm{CO}_{2}$ blasting is under development by industry. ${ }^{3}$ The centrifugal $\mathrm{CO}_{2}$ blasting technology is being developed using the DOE Fusion Energy Program's centrifuge pellet acceleration method. The others are accepted and used by industry for decontamination work. The grit and shot blasting technologies will remove the surface layer of most substrates. The other blasting methods will remove concrete surface layers. For purposes of cost reduction and waste minimization, separation of the removed contamination and recycle of the working fluid or solid particles might be desired. For technologies using $\mathrm{CO}_{2}$, separation is facilitated as the solid or supercritical $\mathrm{CO}_{2}$ converts to the gaseous phase during impact with the surface being decontaminated. But, containment and collection of the contaminated dust could be a problem depending upon the configuration of the surface being blasted. For UHPW, effective methods for water recycle are needed. For shot and grit blasters, increased recycle of materials is dependent upon the development of more durable and easily cleaned shot and grit.

Mechanical scarifiers and scabblers are available for removing a surface layer of contaminated concrete. Scarifier heads usually have several carbide tips; multiple-head machines are used for large-surface floor or wall applications. Scabblers use moving chains, saws, and steel bars or rollers. The method is effective, but is slow and can generate airborne contaminants.

Manual methods such as scraping tend to be labor-intensive and slow, and might result in excessive worker exposure to radiation or contamination. Radiation exposure, however, is not likely in most of the expected K-25 Site operations. Grinding, honing, and milling machines are commercially available for decontaminating surfaces. These machines would be more suitable for regular surfaces. The explosive technique involves the selective detonation of small explosive charges in the surface of concrete to shatter the surface layer.

Since the technologies in this generic group remove the surface layer of the substrate, essentially $100 \%$ decontamination should result (if the depth of penetration of the contamination is less than the depth of surface removal, and if back-contamination can be prevented). For blasting technologies, the waste generated will consist of the particular blasting medium and the contaminated layer of substrate that is removed. If the blasting medium can be separated, the waste generated by the technologies in this generic group will consist primarily of the detached substrate layer. These techniques will also produce a small volume of contaminated filters. Recycle systems for UHPW will probably produce small volumes of contaminated ion exchange media and other components such as filter cakes or sludges.

2. Thermal Surface Removal Methods. For surface removal of concrete, the microwave scabbling, plasma torch, and flashlamp methods flash the hydration water in the concrete to steam. The resulting volume expansion 
fractures the concrete surface. Removal of the debris captures most of the contamination.

The plasma torch, flashlamp, and laser methods remove the surface layer of other substrates by supplying enough heat to the surface to cause vaporization. The vaporized materials and contaminants may then be captured by vacuum removal with a cover gas stream, thus effecting decontamination. The plasma torch method will produce a significantly higher gas-flow rate than the laser method. Because of the unidirectional nature of these technologies, application to complex geometries might be a problem. Burn-through could also occur when treating walls.

In plasma cleaning, glow discharges may be used either to clean the inside surfaces of vessels or, in reactive plasma cleaning, to produce chemically reactive species that clean contaminated surfaces by the processes of chemisorption, reaction, and desorption or gasification. For example, with an oxygen plasma, oxygen atoms, ozone, and UV photons convert hydrocarbons to $\mathrm{CO}_{2}$ and water vapor, and a fluorine plasma may provide for separation and recovery of valuable uranium by converting it to $\mathrm{UF}_{6}$. For the latter, the low volatility of $\mathrm{UF}_{6}$ wo dld need to be taken into account in the system design. Because of the relatively low melting point of metal fluorides, "burn through" with fluorine "hard" plasmas would have to be prevented. This could be done by monitoring the p:oduction of $\mathrm{UF}_{6}$ and other off-gases and by controlling the plasma discharge parameters. The $\mathrm{UF}_{6}$ gas can be recovered and the excess fluorine reused. Plasma cleaning is routinely used to clean the inside of fusion devices before the main plasma is lighted. A pollution control methodology for the effluent gas from the plasma treatment step would be needed.

For the technologies; in this generic group that remove the surface layer of the substrate, essentially $100 \%$ decontamination should result if a sufficient depth of surface is removed. Thus, control of the depth of surface removal is a critical factor. The waste generated will consist primarily of the detached substrate layer.

The thermal surface removal technologies produce smokes, which have smaller particle siyes than the dusts resulting from mechanical surface removal. The smokes from thermal surface removal will be harder to remove by filtration than thie dusts from mechanical surface removal. ${ }^{4}$

3. Surface Cleaning Methods. Surface cleaning methods remove the fixed and/or loose contamination without disturbing the surface of the substrate. They should be particularly effective for loose contamination. Several technologies that are described in the mechanical surface removal methods group may also be listed in this group in their less-aggressive modes. These include scraping, UHPW, shot blasting, grit blasting, centrifugal cryogenic $\mathrm{CO}_{2}$ blasting, ice blastirig, supercritical $\mathrm{CO}_{2}$ blasting, and plastic pellet blasting. Depending upon the operating conditions or the particular substrate being treated, these techrologies can achieve decontamination without affecting the substrate surface. 
Other blasting technologies in this generic group are compressed air cryogenic $\mathrm{CO}_{2}$ blasting, sponge blasting, high pressure water, superheated water, hot water, and steam. In this $\mathrm{CO}_{2}$ blasting method, the cryogenic pellets are accelerated by compressed air rather than by centrifugal force. The sponge blasting technology decontaminates by blasting surfaces with various grades of patented, water-based urethane foam particles using 110 psig air as the propellant. The foam is absorptive and can be used either dry or wet to treat a variety of surface contaminants such as oils, greases, lead compounds, chemicals, and radionuclides. A nonaggressive grade of foam is used for surface cleaning on sensitive or otherwise critical surfaces. Aggressive grades, which are impregnated with abrasives, are capable of removing tightlyadherent materials such as paints, protective coatings, and rust, and can roughen concrete and metallic surfaces if desired. High pressure (500-1000 psi) water sprays are used extensively in the nuclear industry for smearable contamination. Decontamination factors (DFs) of 1.5 to 10 are typically obtained, depending upon the amount of fixed contamination. Superheated water $\left(300-400^{\circ} \mathrm{F}\right.$ and several hundred psi) machines are commercially available. Their use is usually limited to floors. Commercial equipment using steam and hot water jets for decontamination is also available. Again, for technologies using water, effective methods are needed for treating the contaminated wastewater and recycling clean water to the blasting machine.

Manual decontamination methods of brushing and scrubbing will remove loose contamination but usually will be ineffective for fixed contamination. Also, they have the same undesirable features of the manual methods in the first generic group.

Solvent washing is typically used for organic contamination such as oils and PCBs. Loose or smearable contamination may also be removed. To minimize waste, solvent recovery is needed. All low-boiling organic solvents are RCRA hazardous by the rules and increase the cost of operation.

The strippable coating technology involves "painting" a surface with, for example, a water-based organic polymer. When dry the coating can be removed, along with the contaminants captured by the coating, mechanically, chemically, or, in the case of "auto-release" coatings, by vacuuming. DFs are reported to range from 3-5 up to several hundred, depending upon how tightly the contaminants are bound to the surface.

The technology of dry heat (e.g., roasting) would be used to remove volatiles such as mercury, oils, and PCBs.

The use of vacuum cleaners and their filters is accepted and widely used for removing and collecting loose contamination at gaseous diffusion plants. It is often used to clean up during and after grinding, honing, scraping, and other surface removal methods. Vacuuming might be effective for removing loose contamination that has settled on girders, cell housings, other nonvertical surfaces, cracks, etc. 
Ultrasonic cleaning; has been used for many years for removing surface contamination from. relatively small metal parts. Use of this technology on a large scale would likely require separation of the contaminants from the cleaning fluid so that the fluid could be recycled.

4. Metal Refining Methods. Smelt purification involves adding oxidizing fluxes to scrap metal that react with impurities when the metal is heated. The contaminants are removed in the slag that forms and floats to the top of the molten metal. Lab-scale and large-scale studies of smelt purification of radioactive metals have been made. Good results were obtained with the easily oxidized elements like uranium, but the more noble technetium reportedly is not removed by this technology. Estimates of capital and operating costs for smelting 90,000 toris of DOE scrap metal have been developed.

Electrorefining is a well established, commercial technology but is much less established for decontaminating radioactive metal. Electrorefining uses an electrolysis cell that: contains an anode made from contaminated metal and deposits a cathode of pure metal. A voltage applied between the cathode and anode causes metal to ionize from the anode and to plate out on the cathode. Lab-scale tests with. electrorefining of contaminated nickel resulted in plateout of technetium with the nickel on the cathode. The electrolytic waste solutions from this process will be characterized as mixed wastes. Decontamination and recycle of the electrolytic solutions will be needed. Studies to deterrnine the electropotentials, current densities, and concentrations to use might make this method successful. At the thermodynamic limit, this process can separate all elements adequately. ${ }^{4}$

In the leach/electro-winning process, impure metal is dissolved, the solution is passed through a purification step, and purified metal is then plated out on a cathode in an electrolytic cell. This process is a well-established, commercial method for producing nickel from ore but is not used commercially to refine contaminated nickel metal. As in the case of electrorefining, decontamination and recycle of the electrolytic solutions will be needed. Technetium can be removed by ion exchange with the impure metal solution.

The Mond process involves reaction of $\mathrm{CO}$ at high temperature and pressure with nickel to form nickel carbonyl. Under the proper conditions, only the nickel reacts to form a carbonyl. The nickel carbonyl separates from the contaminants and is removed in the gas phase. Subsequent decomposition of the nickel carbonyl at high temperature and at reduced pressure produces purified nickel. The Mond process has been used for decades to refine nickel for certain end uses.

5. Chemical Surface Cleaning Methods. Technologies comprising chemical foams, chemical gels, acid treatments, caustic treatments, and redox treatments involve reaction with the contaminant to form a species that is dissolved in the cleaning solution and thereby removed from the substrate. Depending upon the strength of the chemical solution, physical degradation of the surface can also occur. Foams and gels are used to enhance the performance of the chemicals and to reduce subsequent waste volumes by 
better holding the decontamination chemical in contact with the contaminated surface. These methods of application can be used for in situ decontamination of exterior surfaces. The other solutions may be applied in dipping baths, loop systems, or by spraying. Recovery would be a problem in the use of the spraying technique for decontamination of exterior surfaces unless decontamination is done in a spray booth with suitable critically-safe drains. Spray booths similar to car washes are used at gaseous diffusion plants to decontaminate the interior and exterior of disassembled equipment. For waste volume reduction, regeneration and recycle of the chemical is necessary. Depending upon the strength or reactivity of the chemical, DFs range from 5-10 to several hundred. British Nuclear Fuels, Ltd., uses several different chemical technologies to decontaminate equipment from the Capenhurst Diffusion Plant to below British below-regulatory-concern (BRC) limits.

Electropolishing selectively removes contaminant metal ions from a metal surface. This method, using an electrolyte and electricity, has usually been applied on small areas. For waste volume reduction, separation of the contaminant from the electrolyte and recycle of the electrolyte would be needed.

Gas phase decontamination uses a strong fluorinating gas to convert uranium fluoride and oxyfluoride deposits in the inside of gas-tight equipment to uranium hexafluoride gas, which could then be recovered with chemical or cold traps. (The fluorides of nickel and other materials used to construct the gaseous diffusion cascades are not volatile.) The excess fluorinating gas could be reused. Lab studies have shown that over $99.9 \%$ uranium removal can be obtained by reaction at room temperature. ${ }^{5}$ However, thorium and protactinium fluorides and most of the fluorides of elements formed in the decay chains of ${ }^{235} \mathrm{U}$ and ${ }^{238} \mathrm{U}$ are not volatile. In most cases, the levels of these contaminants are expected to be low enough that surface release criteria can be met. Further studies are needed to determine ultimate DFs. Treatment of the off-gasses will generate wastes from liquid scrubbers and dry chemical traps when using current technology. Technetium added to the cascades in the feed may also be removed by this method. ${ }^{4}$

Plasma etching and fluorination technologies may be used to enhance performance of gas phase decontamination. The plasmas of fluorinating gas can be created to promote room temperature chemical reactions converting uranium fluoride and oxyfluoride deposits into uranium hexafluoride gas. A research project would be needed to perform a feasibility test in the gas phase facility.

The biological, laser-activated chemistry, and UV/ozone technologies are in the evolving technology stage. Research projects would be needed to investigate the feasibility of using these technologies for surface decontamination. A pilot-scale UV/ozone decontamination system, which is available from a private company, could be used for such a study. 
Biological treatment is envisioned as applying a layer of microbes to a surface, supplying needed nutrients, and eventually removing the microbe layer from the decontaminated surface. Laser-activated chemistry is a proven technique for accelerating chenical reaction rates at surfaces and for selecting reaction paths and chemical stoichiometries.

In the use of UV/ozone to remove oils, greases, and solvents, UV light produces ozone from oxygen and also excites and/or dissociates contaminant molecules. These reactive species then produce $\mathrm{CO}_{2}$ and water vapor (and $\mathrm{HCl}$ in the case of chlorinated solvents).

Electromigration uses an electric potential to cause migration of metal ions from a surface into an electrolyte. The technology may be applied in a localized area or as a "factory style" process in batch fashion to contaminated areas. For waste volume reduction, separation of the contaminant from the electrolyte and recyile of the electrolyte would be needed.

6. Bulk Decontamination Methods. Solvent extraction removes organics from bulk materials simply by dissolution. The technology could be applied as a "factory style" process in either a batch or continuous fashion. For waste volume reduction, separation of the contaminants from the solvent and recycle of the solvent woulcl be needed. Also, the solvent would have to be removed from the decontaminated material by a method such as heating or vacuum. The chemical leaching technology would be applied in a manner similar to that of solvent extraction. The chemical leaching and biological technologies are essentially as described under chemical surface cleaning. Solvent extraction and chemical leaching are well established technologies in current use.

Incineration of varicius materials is accepted by the EPA. The incineration of contaminated combustible building materials is common in the nuclear industry. The waste generated will depend upon the design of the incinerator and the ash conterit of the material being burned. The flyash and smoke particles have to be contained with particular care. ${ }^{4}$

As in the surface cleaning methods, the technology of dry heat, (e.g., calcination), would be used to remove volatiles such as oils and PCBs. Treatment of off-ge.ses to remove the volatilized contaminants would be necessary. Bench scale studies would be needed to determine the applicability of the technology to the identified problem areas (as shown on the TLD).

The catalytic extraction process (CEP) is similar to smelt purification in that a furnace is used in both to form a molten metal bath. In the CEP, the bath is used not only to furify metal, but at the high operating temperatures, also more effectively destroys hazardous organic materials such as aromatic hydrocarbons and P'CBs. Also, mixing is better in the CEP process because material is introduced from the bottom of the process; control of the oxidation potential is better vith the CEP process because oxygen, rather than air is injected into the furnace. The process has not been used commercially to treat scrap contaminated with radionuclides. Experiments at the Oak Ridge Y-12 Plant with different : metals showed good results in reducing uranium levels in 
steel, nickel, copper, and monel. Aluminum was more difficult to purify, and technetium reportedly was not removed. Waste generated could include radioactive slag and wet scrubber solutions.

Very limited use of vacuum (i.e., low pressure to remove volatile compounds) has been made for bulk decontamination. Some information has been obtained on a proprietary vacuum-based process for removing water soluble $\mathrm{Cr}^{+6}$ from transite sheeting surfaces. Vacuum can also be used to remove contamination from porous materials by boiling solvents out of the material if the solvent foams out and the solvent is collected. ${ }^{4}$ Because of their low vapor pressures, the technique would probably be rather ineffective for most oils and PCBs. 


\subsection{SCIENCE AND TE.CHNOLOGY NEEDS}

\subsubsection{Introduction}

This section summarizes the science and technology needs of the decontamination technologies that were described in Sect. 4.2.2. The science (i.e., basic research) needs usually apply to technologies that are in the evolving or predemonstration phasie. Technology development needs are related to those technologies in the predemonstration or demonstration phase, whereas technology improvement needs pertain to technologies that have been demonstrated or accepted.

\subsubsection{Summary of Science and Technology Needs}

\section{Mechanical surface removal methods}

For waste minimization, a water treatment and recycle system needs to be developed for the UHPTV and ice blasting technologies. Also, improved vacuum systems are needed to recover the water, and thus prevent the spread of contamination, when cleaning equipment and structures with complex geometries. For the abrasive blastings technologies-shot, grit, and plastic pellet-more durable materials that resist deformation and abrasion and can be recycled through the process more times are ineeded for waste minimization. Higher velocity and harder cryogenic $\mathrm{CO}_{2}$ pellets are needed to increase the aggressiveness of this technology and extend its usefulness to more difficult decontamination applications. Again, better containment methods are needed to avoid the spread of contamination.

The supercritical $\mathrm{CO}_{2}$ technology, which appears promising because of its similarity to UHPW, requires development work to establish it as an accepted technology. The explosive technology for concrete needs improved methods for containing dust, applying the explosive, and obtaining greater uniformity of destruction. Better containment methods for the dust that is generated is also needed for the grinding and milling technologies.

Development of capabilities for remote operation is needed for the mechanical surface removal technologies for use in areas of high levels of radiation or contamination, improving the operable efficiency of the equipment, or increasing the decontamination efficiency. High-radiation areas are not expected at the K-25 Site.

\section{Thermal surface removal methods}

For microwave scabbling, development and testing of a mobile concrete removal prototype should be completed. Mathematical modelling is recommended for optimization of concrete removal rates and efficiencies. Remote operation requires the development of remote-controlled robotic arms for the microwave applicator and the vacuum collection system. Development of real-time monitoring sensors to monitor the progress of decontamination would help to minimize wastes. 
Commercially available flashlamp systems should be evaluated on a bench scale for possible use on decontamination problems at the K-25 Site. If these tests are successful, larger scale demonstrations should be initiated.

The plasma torch heating technology requires laboratory-scale testing on various substrates with different contaminants to determine efficiencies and problem areas for elevation to the predemonstration stage. The laser heating technology also needs similar evaluation for use on decontamination problem areas.

Plasma discharge cleaning could be an effective decontamination technique for the inside of equipment. The main reasons that plasma discharge and plasma etching/ fluorination technologies were not ranked higher were the uncertainty concerning the effectiveness of these technologies and the extensive development and demonstration programs that would be required to prove their effectiveness.

The needs of the plasma discharge cleaning technology include a (1) demonstration that glow-discharge plasmas can be ignited in vessels with complex shapes similar to those of interest and that the plasma will reach into all of the crevices and corners within these complex vessels, (2) demonstration of the gasification of uranium deposits using fluorine discharges, (3) construction and operation of prototypical equipment for generating reactive plasmas to remove hydrocarbon contaminants, to decompose PCBs, and to gasify uranium, and (4) determination of the applicability of plasma cleaning to equipment internals with large surface areas. Computer modelling could help provide improvements in removal rate and efficiencies of plasma discharge methods.

\section{Surface cleaning methods}

Cryogenic $\mathrm{CO}_{2}$ pellet blasting is commercially available and is certain to successfully decontaminate some items at the K-25 Site. However, evaluation of this technology on a number of typically contaminated items would elucidate how broadly applicable this technology would be. Brushing and vacuuming are accepted technologies. Hand brushing has no identified science or technology needs. Vacuuming would benefit from the development of cleanable, reusable prefilters and high efficiency recyclable particulate absolute filters to minimize waste generation. The same is true of several other decontamination technologies that require vacuum collection systems. The surface cleaning technologies that use either liquid water or steam have the same needs for development of water recycle systems and improved vacuum systems as listed for UHPW and ice blasting under the mechanical surface removal technologies.

In the removal of oils and PCBs, the hot air stripping and dry heat technologies will generate off-gases. Specific needs will depend upon the effluent treatment requirements. However, these technologies probably will not be used at the K-25 Site.

The solvent washing and ultrasonic cleaning technologies need solvents that are more environmentally acceptable to be identified and demonstrated. Water is the standard for these techniques.

\section{Metal refining methods}

For the Mond (nickel carbonyl) process, bench scale tests are needed to verify that nickel is separated from technetium and other radioactive materials 
indigenous to diffusior. plant operations. Technetium forms several carbonyl compounds. Those whose volatility has been determined $\left[\mathrm{Tc}^{2}(\mathrm{CO})_{10}\right.$ and $\left.\mathrm{HTc}(\mathrm{CO})_{6}\right]$ are reported to be poorly volatile. ${ }^{6}$ These results suggest that technetium may be left behind when volatile nickel carbonyl is formed. At a lower priority, for the smelt purification technology to be a viable option, a fluxing agent capable of removing technetium needs to be identified, and the poor results in smelting aluminum should be further investigated. (Basic thermodynamics suggest that technetium removal by fluxing may not be possible. ${ }^{4}$ ) For the electrorefining technology, a method of removing technetium is also needed, and a recycle system for the electrolyte solution needs to be developed.

\section{Chemical surface cleaning methods}

The fluoboric acid technology generates a metal waste as a result of surface removal. The optimum material for solidification of this waste needs to be determined.

To advance the gas phase technology, laboratory studies should be continued to determine the feasibility of the process and, if results are favorable, a demonstration of a mobile system for in situ decontamination should be conducted. ${ }^{7}$ If recovery of unreacted fluorinating agent is to be a part of the process, research to determine the best method will be needed. This method will then need to be demonstrated. Separation of reaction by-products could be a problem.

Several aspects of electromigration require fundamental evaluation. Selection of the best characteristics for an electrolyte to cause migration of all contaminants to the surface is needed. Concrete imbibing studies are needed to evaluate the flow or migration mechanisrn. Parametric studies are needed to optimize operating conditions. Electrolyte gels must be developed for nonhorizontal surfaces. Systems that will recycle electrolytes must be designed and demonstrated.

For the nitric acid-type cleaning technologies, adaptation of the Portsmouth process modifications ie.g., scrubbers, filters, and nitrate and heavy metal treatment) by the $\mathrm{K}-25$ Site is needed to meet regulatory requirements. Also, development of $\mathrm{HNO}_{3} / \mathrm{HF}$ cleaning with or without ultrasonic agitation should be considered. For the organic acid technology, pilot plant studies of waste treatment (ion exchange) are net:ded to meet regulatory requirements. Research and development on alkaline dissolution of surface oxide films is recommended for the caustic treatment technology. Determination of the usefulness of the REDOX technologies for decontamination of gaseous diffusion facilities would require extensive R\&D.

The biological, laser activated chemistry, and UV/ozone technologies are also in the evolving technology stage, and lower-priority $R \& D$ projects would be needed to determine the feasibility of surface decontamination by these treatments. The costs of such R\&D projects may not be justified by the expected benefits from these technologies. 


\section{Bulk decontamination methods}

The needs of the solvent extraction, biological, dry heat, chemical leaching, and vacuum technologies are the same as those described above for analogous technologies. For the CEP technology, a method for removing technetium is needed; its effectiveness should also be demonstrated for the materials and contaminants of interest at the K-25 Site. 


\subsubsection{Introduction}

This section summarizes the implementation needs of the decontamination technologies that were described in Sect. 4.2.2. Implementation needs include (1) technology developnent/improvement and (2) prerequisites to successful technology deployment after demonstration or acceptance.

\subsubsection{Summary of Implementation Needs}

The specific implementation needs of each technology are detailed in the data sheets. In this section, cnly those needs that are considered significant, primarily in terms of resources, are cited. Table 4.2 shows three such implementation needs and the specific technologies that have these needs. In Table 4.2, the relation of a need to a particular technology is indicated either by an " $\mathrm{X}$ " or, whenever available, by the estimated cost of providing that need.

The three implementation needs listed in Table 4.2 are R\&D/DEMO, WASTE, and ROBOTICS. The first need pertains to those technologies, which have not advanced to the accepted status level and which need $R \& D$ and/or demonstration programs to bring the basic decontamination technology to that level. The second need is usually associated with accepted technologies for which the development of systems for waste collection, waste treatment, waste minimization, or material recycle is recommendecl. The last need is related to those technologies that are adaptable to remote-controlled operation. Reasons for implementing remotecontrolled operation include (1) necessity (e.g., due to high radiation levels), (2) improvement of the operability of the equipment, and (3) increase of the decontamination efficiency. High radiation levels will not be encountered at the K-25 Site.

One implementation need worthy of note is for the incineration technology. Installation of a new incinerator similar to the K-1435 incinerator might require as much as 8-10 years for writing an environmental impact statement, holding public hearings, and obtaining the necessary permits-TSCA, RCRA, NESHAP, and Clean Air Act. ${ }^{7.8}$ Streamlining of this process would be needed if implementation of this technology is required within a shorter time period and for less money. 
Table 4.2. Summary of implementation needs

\begin{tabular}{|c|c|c|c|}
\hline \multirow{2}{*}{ Technology } & \multicolumn{3}{|c|}{ Implementation need } \\
\hline & $\mathrm{R} \& \mathrm{D} / \mathrm{Demo}^{\alpha}$ & Waste & Robotics \\
\hline \multicolumn{4}{|l|}{ Mechanical Surface Removal } \\
\hline Ultrahigh-pressure water & 1.3 & $\mathbf{X}$ & $\mathrm{X}$ \\
\hline Shot Blasting & 1.5 & $\mathbf{X}$ & $\mathrm{X}$ \\
\hline Scabblers/Scarifiers & & & $\mathbf{X}$ \\
\hline Grit Blasting & $4-10$ & $x$ & $X$ \\
\hline $\begin{array}{l}\text { Centrifugal Cryogenic } \mathrm{CO}_{2} \\
\text { Blasting }\end{array}$ & 3.4 & & $\mathrm{X}$ \\
\hline Ice Blasting & 1.2 & $\mathrm{X}$ & $\mathbf{X}$ \\
\hline Supercritical $\mathrm{CO}_{2}$ Blasting & $.25-4$ & & $\mathrm{X}$ \\
\hline Plastic Pellet Blasting & $5.5+$ & $\mathrm{X}$ & $\mathrm{X}$ \\
\hline Hand Grinding, Honing, Scraping & & $X$ & \\
\hline Automated Grinding & $1-4$ & & $\mathbf{x}$ \\
\hline \multicolumn{4}{|l|}{ Milling - Metal } \\
\hline Milling - Concrete & & & $\mathbf{X}$ \\
\hline Explosive & $1-4$ & $\mathrm{x}$ & \\
\hline \multicolumn{4}{|l|}{ Thermal Surface Removal } \\
\hline Microwave Scabbling & 2.5 & & $\mathrm{X}$ \\
\hline Plasma Torch & -3 & & $\mathbf{x}$ \\
\hline Laser Heating & $2+$ & & $\mathrm{X}$ \\
\hline Laser Etching \& Ablating & $2-3$ & & \\
\hline Plasma Surface Cleaning & 4 & & \\
\hline Plasma Etching/Fluorination & 7 & & \\
\hline Flashlamp Cleaning & $\mathrm{X}$ & & \\
\hline \multicolumn{4}{|l|}{ Surface Cleaning } \\
\hline \multicolumn{4}{|l|}{$\begin{array}{l}\text { Compressed Air Cryogenic } \mathrm{CO}_{2} \\
\text { blasting }\end{array}$} \\
\hline High-Pressure Water & -1.2 & $\mathrm{X}$ & $\mathrm{X}$ \\
\hline Superheated Water & -1.2 & $\mathrm{x}$ & $\mathrm{x}$ \\
\hline Hot Water & -1.2 & $\mathrm{X}$ & $\mathrm{X}$ \\
\hline Steam & -1.2 & $\mathrm{x}$ & $\mathbf{X}$ \\
\hline \multicolumn{4}{|l|}{ Hand Brushing } \\
\hline Automated Brushing & $\mathrm{X}$ & & \\
\hline Sponge Blasting & -1.2 & $x$ & \\
\hline Hot Air & $1-5$ & & \\
\hline Dry Heat (Roasting) & $0.2-1$ & & \\
\hline $\begin{array}{l}\text { Solvent Washing (Rad } \\
\text { Contamination) }\end{array}$ & $1-5$ & $\mathrm{X}$ & \\
\hline
\end{tabular}


Table 4.2 (continued)

\begin{tabular}{|c|c|c|c|}
\hline \multirow{2}{*}{ Technology } & \multicolumn{3}{|c|}{ Implementation need } \\
\hline & $\mathrm{R} \& \mathrm{D} / \mathrm{Demo}^{\alpha}$ & Waste & Robotics \\
\hline \multicolumn{4}{|l|}{$\begin{array}{l}\text { Solvent Washing (Organic } \\
\text { Contamination) }\end{array}$} \\
\hline Strippable Coatiņs & 0.5 & $\mathbf{x}$ & \\
\hline \multicolumn{4}{|l|}{ Vacuum } \\
\hline Ultrasonic Cleaning & 1 & $\mathbf{X}$ & \\
\hline \multicolumn{4}{|l|}{ Metal Refining } \\
\hline Smelt Purification. & $3-5$ & $\mathrm{X}$ & \\
\hline Electrorefining & $3-4$ & $\mathrm{X}$ & \\
\hline Mond Process & $0.75-3$ & & \\
\hline Leach/Electro-Winning & $3-4$ & $\mathrm{x}$ & \\
\hline \multicolumn{4}{|l|}{ Chemical Surface Cleaning } \\
\hline Chemical Foams & $1-4$ & $\mathrm{X}$ & \\
\hline Chemical Gels & $1-4$ & $\mathrm{x}$ & \\
\hline Organic Acid Tree.tments & $x$ & $\mathrm{x}$ & \\
\hline Fluoboric Acid Treatment & & $\mathrm{x}$ & \\
\hline Inorganic Acid Treatment & & $\mathrm{x}$ & \\
\hline Caustic Treatments & & $\mathbf{x}$ & \\
\hline REDOX Treatmer.ts & $2.5-5$ & $\mathrm{X}$ & \\
\hline Electropolishing & $0.4-1$ & & \\
\hline Gas Phase & 5 & & \\
\hline Biological & $0.3-110$ & $\mathrm{x}$ & \\
\hline Laser Activated Chemistry & $2+$ & & \\
\hline UV/Ozone (UV Lişht Activation) & 3 & & \\
\hline Electromigration & 1.7 & & \\
\hline \multicolumn{4}{|l|}{ Bulk Decontamination } \\
\hline Solvent Extraction & & $x$ & \\
\hline Incineration & & $\mathbf{x}$ & \\
\hline Biological & $0.3-10$ & $\mathbf{X}$ & \\
\hline \multicolumn{4}{|l|}{ Dry Heat } \\
\hline Chemical Leachirig & $1.2-5$ & $\mathrm{X}$ & \\
\hline Catalytic Extraction Process & $3-5$ & $\mathrm{x}$ & \\
\hline Vacuum (low pressure) & $1-3$ & - & \\
\hline
\end{tabular}

${ }^{a}$ Numbers in table are costs in millions of dollars 


\subsection{TECHNOLOGY RANKINGS FOR THE K-25 SITE}

\subsubsection{Introduction}

The technologies that have been identified as being potentially applicable to the K-25 Site have been discussed in this chapter and are listed in each TLD (see Vol. 2). These technologies have been ranked or prioritized for each subelement category to indicate the degree of probability that each technology can make significant contributions to the D\&D efforts at the K-25 Site. Three categories are designated-high, medium, and low. Even those ranked low should not be dismissed as viable technologies because the first criterion for inclusion in the diagrams is that a technology can be reasonably applied to K-25 problems. Rather, a low ranked technology may be so specialized or be applicable to such a limited problem set as to have only limited application or to be dependent on discoveries that are more difficult to predict. Technology rankings will not split evenly between these three categories because each was ranked on its own perceived merits.

The relative rankings have been visualized on the diagrams by using different line widths to the technologies. The widest lines represent the high ranking technologies with decreasing widths for the lower rankings. A description of the rankings for each subelement follows.

The application of a particular decontamination technology will depend upon the assessment of several factors. Among these factors are:

- the contaminants present and their physical and chemical states;

- the surface and substrate material upon which the contamination is present;

- the size, configuration, location, and relationship to other surfaces of the contaminated surface;

- accessibility of the contaminated area;

- desired degree of decontamination to be achieved;

- expected efficacy of the candidate technology;

- equipment and materials available for use in decontamination;

- worker safety and radiation dose minimization;

- environmental regulations;

- security and criticality requirements;

- development, capital, and operating costs; and

- quantity and nature of the waste that will be generated.

Because of the varieties of substrates (type and configuration) and contaminants, no single decontamination technology can be chosen as the most preferred for all problems. In order to make some general evaluation of the decontamination technologies, the K-25 Site problems were divided into six generic groups. These groups are (1) contaminated concrete surfaces; (2) contaminated exterior metal surfaces such as structural steel, sheet metal, and the exterior of metal equipment; (3) contaminated interior equipment surfaces composed mainly of nickel-lined steel but also including steel, monel, copper, depleted uranium, and aluminum; (4) contaminated porous nickel barrier and porous aluminum components; (5) removal of selected large deposits that cause specific problems; and (6) other contaminated materials. The last category includes such items as contaminated instruments, insulated copper wiring, transite, asbestos pipe 
insulation, Munter's Fill (plastic in cooling towers), freon, tile, wood, gasket material, plastic, and composite roofing. Contaminated steel and aluminum pipe and steel $\mathrm{UF}_{6}$ storage cylinders can be considered part of the third category.

For each of the six seneric problem groups, the applicable decontamination technologies were then lanked to indicate their relative potential for treating the problems of the particular group. In the ranking process, the technologies were first ranked by decontamination team members using certain criteria. These rankings were then combined to produce the final rankings for the technologies. The details and the resu ts of the ranking procedure are discussed in the following subsections.

The rankings that are presented herein are considered to be qualitative in nature. In the actual process of technology selection for a particular decontamination application, more detailed analyses could produce different rankings. For example, a technology that was ranked highly by the procedure used here might be eliminated from consideration because it could not meet a requirement on decontrimination efficiency. Also, based on evaluation of total system cost, the relative: rankings of technologies could change depending upon the magnitude of the decontamination application (e.g., total square feet of surface to be cleaned). Nonetheless, the information provided in this document should provide guidance for pctential funding for technology development and will be valuable input to the detailed analyses of future technology selection activities.

\subsubsection{Ranking System}

The ranking system used in this exercise consisted of ranking each technology that was considered to be applicable to a particular problem group as being of high, medium, or low ir.terest (designated by $\mathrm{H}, \mathrm{M}$, and $\mathrm{L}$, respectively) for that group. High interest (or value) means that the characteristics of that technology are favorable for use in the indicated application. Low interest means that the characteristics of the technology do not lend themselves to this decontamination application as well as do the characteristics of the technologies that are ranked higher. A medium ranking indicates an intermediate interest in that technology.

\subsubsection{Ranking Criteria}

The decontamination technologies were ranked according to the following criteria:

\section{Development cost}

This is the cost of cleveloping the technology from its present status to the status that it could be usied for the indicated task. Technologies with development costs of less than $\$ 1 \mathrm{M}$ were ranked high in this category. Accepted technologies that require no development also received high rankings. Technologies with development costs between one and four million dollars were ranked medium. Those with development costs over $\$ 4 \mathrm{M}$ were ranked low for this criterion. 


\section{Capital cost}

This is the cost of all facilities and equipment that are directly required to use the technology. Technologies with capital costs greater than $\$ 10 \mathrm{M}$ were ranked low and those with costs less than $\$ 0.5 \mathrm{M}$ were ranked high. Technologies with intermediate costs were given a medium ranking. The cost of support facilities, such as utilities, are not included in these capital costs.

\section{Operating cost}

This represents direct costs associated with operating the decontamination equipment. These costs do not include waste disposal costs or costs for industrial hygiene, safety, or radiation protection. Operating costs were generally dominated by labor costs. Thus, technologies that decontaminated more rapidly tended to have lower operating costs. The general guidelines were that technologies with estimated operating costs greater than one dollar $/ \mathrm{ft}^{2}$ of surface cleaned would have low interest and those with costs less than 0.1 dollar $/ \mathrm{ft}^{2}$ would have high interest. Technologies with intermediate costs were given a medium ranking. The cost estimates are more valuable in comparative ranking than as absolute figures.

\section{Development schedule}

This criterion is the length of time required to develop the technology from its present status to the status that it could be used for the indicated task. Technologies with short development times, as well as accepted technologies that require no development, receive the highest ranking for this criterion. Technologies with long development schedules receive low rankings. Generally, the length of the development schedule was roughly proportional to the development cost.

\section{Deployment schedule}

This criterion is the length of time required to implement the technology in the field. Factors that could affect deployment schedule include ability to construct and operate the technology, monitoring requirements, coordination with other agencies, availability of services and materials, etc. As for the development schedule, technologies with short deployment schedules receive high rankings and those with long schedules get low rankings.

\section{Waste}

This evaluation criterion addresses the preference for decontamination technologies that minimize the toxicity and quantity of the wastes produced in the treatment process. Higher rankings are given to those technologies that effect greater waste minimization. 


\section{Environmental, Safety and Health}

This criterion assesses whether the decontamination technology provides adequate protection of human health and safety and the environment. This relates to the operating conditions for the technology, the use of hazardous materials in the operation, and the production of hazardous wastes. Higher rankings are given to those technologies that provide greater protection.

\section{Expected efficacy}

This criterion evaluates the effectiveness of a technology in removing the problem contaminants from the particular substrate. The higher rankings are given to those technologies that are expected to accomplish higher degrees of contaminant removal.

\section{Development probability}

This criterion estime.tes the probability that a decontamination technology will be developed successfully to the stage that it can be implemented in the field. The development probability is related to factors such as the maturity and complexity of the technology. The more mature and simpler technologies would receive higher rankings. Obviously, the highest ranking would be given to a technology that is commercially available. A complex technology that is in the conceptual stage would likely get the lowest ranking.

\subsubsection{Ranking Procedure}

As discussed previously, the technologies were first ranked by individual decontamination team rnember using the criteria defined above. These rankings were then combined to produce the final rankings for the technologies for each generic problem group. The method used to accomplish this ranking involved conversion between letter and number rankings and the use of weighing factors.

The steps in the ranking procedure are described in the following steps. These steps were applied to each technology in each generic problem group.

1. For the individual rankings by the decontamination team members, the high $(\mathrm{H})$, medium $(\mathrm{M})$, and, low $(\mathrm{L})$ rankings were assigned numeric values of 1,2 , and 3 , respectively.

2. Using these numeric values, the team members ranked the technologies according to the nine criteria listed above (e.g., the shot blasting technology as applied to concrete decontamination would have a set of nine numeric velues assigned by each team. member).

3. Composite rankings for each of the criteria were then obtained by averaging the rankings of the team members. 
4. For each technology, the overall ranking was obtained by (a) multiplying the composite ranking for each of the criteria by a weighing factor, (b) summing these nine weighted rankings, and (c) dividing this sum by the sum of the weighing factors.

5. Finally, the numeric rankings were converted back to the $H / M / L$ ranking format.

The results of the rankings for the six problem groups are presented in Tables 4.3 through 4.8. These tables show the composite rankings for each of the criteria for all technologies in each generic problem group as well as the overall rankings for each technology. The weighing factors used for each of the evaluation criteria are included in the tables. The values used for these weighing factors were based on the judgement of the team members as to the importance of each of the evaluation criteria in decontamination technology selection. For example, the experience at the K-25 Site has been that waste disposal costs are often greater than the cost of decontamination. Thus, minimum waste generation would be a primary consideration in the ranking and, consequently, receive a high weighing factor. The same weighting factors were used for each decontamination problem area except for deposit removal. Because of the relatively small amount of material in this program, the same weighting factor was assigned to development, capital, and operating costs. The weighting factor for schedule was increased because this project is to begin in the near future. The weighting factor for health physics, criticality, safeguards, and safety was made very high because concerns in these areas are the drivers for this program and because these problems are particularly severe in this program. The weighting factors for waste, expected effectiveness, and probability of successful development remained unchanged (and high).

For conversion of the overall rankings from numeric to alphabetic format, the following guidelines were used:

$$
\begin{aligned}
& \text { H-highest }(<\text { or }=1.5 \text { or } 1.6 \text { ) } \\
& \text { L-lowest }(>\text { or }=2.0 \text { or } 1.9 \text { ) }
\end{aligned}
$$

In order to preserve the inputs of the experts these guidelines were based on continued judgement calls rather than on a mathematical derivation. Otherwise, little or no discrimination between the technologies would have resulted. For example, if the conversion from numeric to alphabetic rankings had been based on three equal intervals from 1 to 3 (which may seem to be a logical approach), no decontamination technology would have received a ranking of $L$. This would have been contrary to the opinion of the team members. 
Table 4.3. Decontamination technology rankings vs criterla of group 1 (concrete)

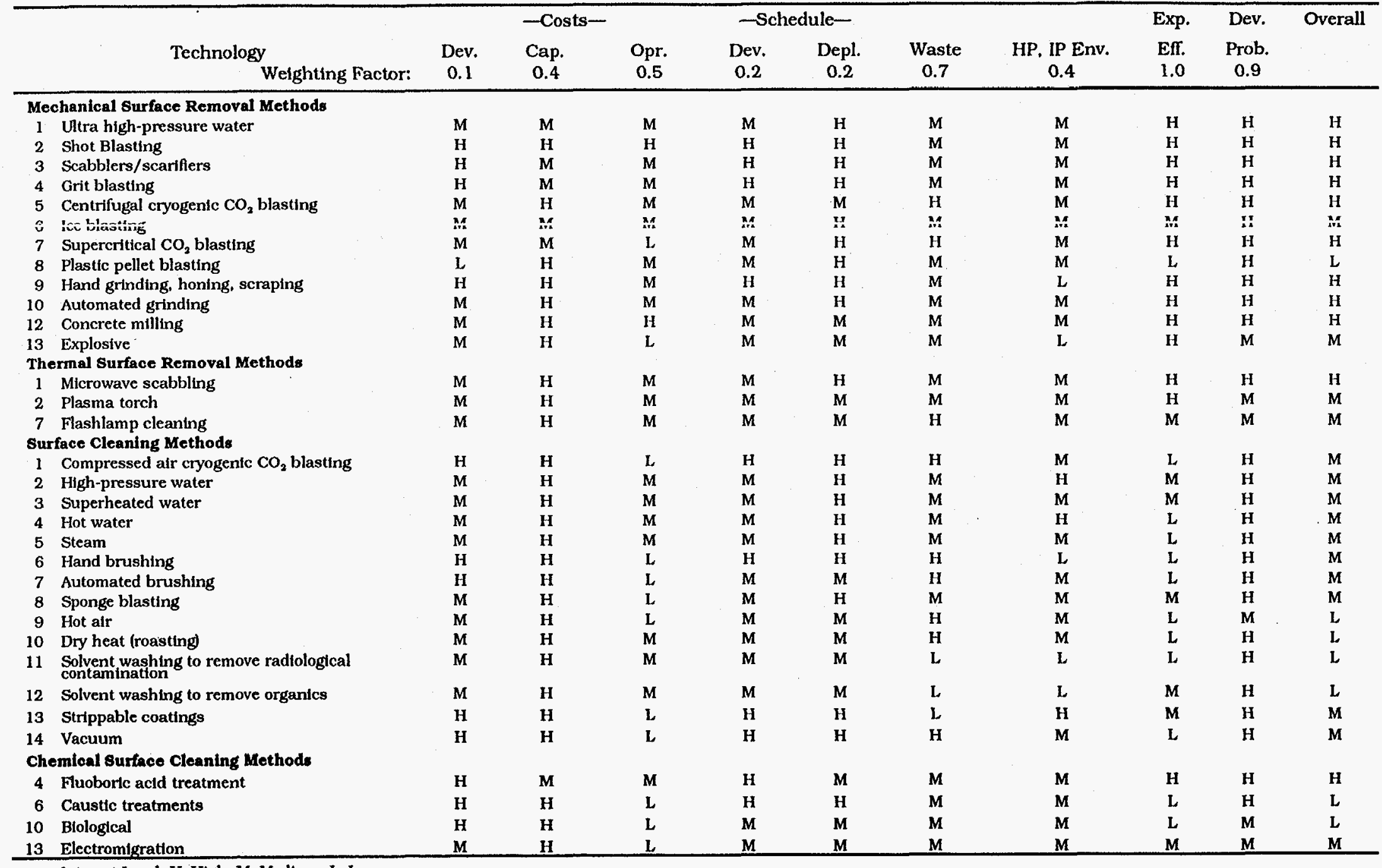

Interest Level: $\mathrm{H}=\mathrm{High}$; M=Medium; L=Low 
Table 4.4. Decontamination technology rankings vs criterla of group 2 (exterlor equlpment surfaces)

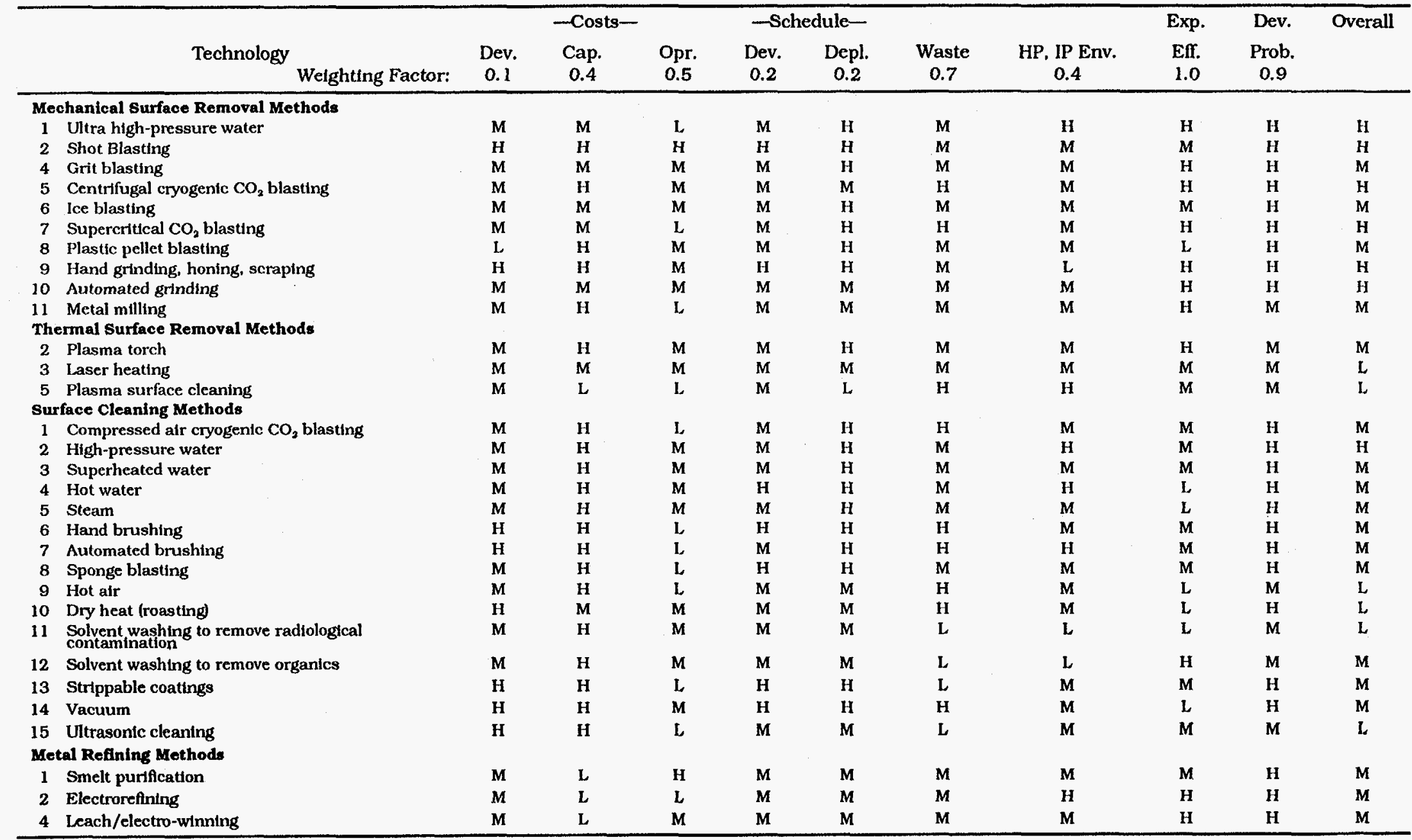

Interest Level: $\mathrm{H}=\mathrm{High} ; \mathrm{M}=$ Medium; $\mathrm{L}=$ Low 


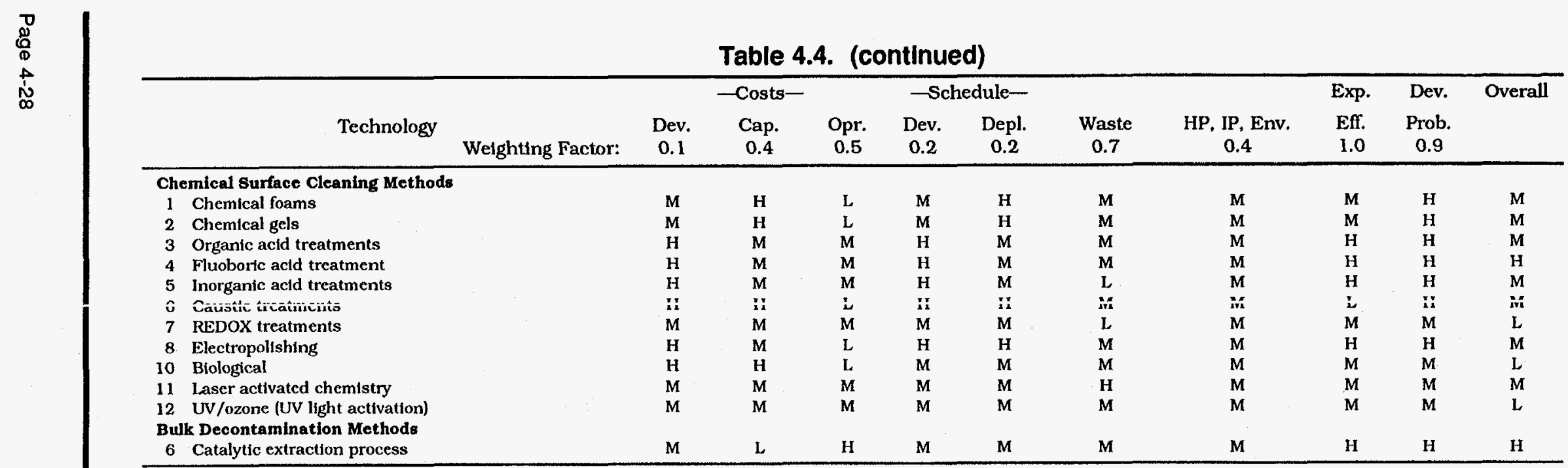

Interest Level: H=High; M=Medium; L=Low 


\begin{tabular}{|c|c|c|c|c|c|c|c|c|c|c|}
\hline \multirow[b]{2}{*}{$\begin{array}{l}\text { Technology } \\
\text { Weighting Factor: }\end{array}$} & \multirow[b]{2}{*}{$\begin{array}{c}\text { Dev. } \\
0.1\end{array}$} & \multicolumn{2}{|c|}{- Costs- } & \multicolumn{2}{|c|}{ Schedule- } & \multirow[b]{2}{*}{$\begin{array}{l}\text { Waste } \\
0.7\end{array}$} & \multirow[b]{2}{*}{$\begin{array}{l}\text { HP. IP. Env. } \\
0.4\end{array}$} & \multirow{2}{*}{$\begin{array}{l}\text { Exp. } \\
\text { Eff. } \\
1.0\end{array}$} & \multirow{2}{*}{$\begin{array}{c}\text { Dev. } \\
\text { Prob. } \\
0.9\end{array}$} & \multirow[t]{2}{*}{ Overall } \\
\hline & & $\begin{array}{c}\text { Cap. } \\
0.4\end{array}$ & $\begin{array}{l}\text { Opr. } \\
0.5\end{array}$ & $\begin{array}{l}\text { Dev. } \\
0.2\end{array}$ & $\begin{array}{c}\text { Depl. } \\
0.2\end{array}$ & & & & & \\
\hline \multicolumn{11}{|l|}{ Mechanical Surface Removal Methods } \\
\hline Ultra high-pressure water & M & $\mathbf{M}$ & L & $\mathbf{M}$ & $\mathbf{H}$ & $\mathbf{M}$ & $\mathbf{H}$ & $\mathrm{H}$ & H & $\mathbf{M}$ \\
\hline Shot Blasting & $\mathbf{H}$ & $H$ & $\mathbf{H}$ & $\mathbf{H}$ & $\mathbf{H}$ & $\mathbf{M}$ & $\mathbf{M}$ & $\mathbf{M}$ & $\mathbf{H}$ & $\mathrm{H}$ \\
\hline Grit blasting & $\mathbf{M}$ & $\mathbf{M}$ & $\mathrm{L}$ & $\mathbf{M}$ & $\mathbf{M}$ & $\mathbf{M}$ & $\mathbf{M}$ & $\mathbf{H}$ & $\mathbf{H}$ & $\mathbf{M}$ \\
\hline Centrifugal cryogenic $\mathrm{CO}_{2}$ blasting & $\mathbf{M}$ & $\mathbf{H}$ & $\mathbf{M}$ & M & $\mathbf{M}$ & H & $\mathbf{M}$ & $\mathrm{H}$ & $\mathbf{H}$ & $\mathrm{H}$ \\
\hline Ice blasting & M & $\mathbf{M}$ & $\mathbf{M}$ & $\mathbf{M}$ & $\mathbf{M}$ & $\mathbf{M}$ & $\mathbf{M}$ & $\mathbf{M}$ & $\mathbf{H}$ & $\mathbf{M}$ \\
\hline Supercritical $\mathrm{CO}_{2}$ blasting & M & $\mathbf{M}$ & $\mathbf{L}$ & $\mathbf{M}$ & $\mathbf{M}$ & $\mathbf{H}$ & $\mathbf{M}$ & $\mathbf{H}$ & $\mathbf{H}$ & $\mathrm{H}$ \\
\hline Plastic pellet blasting & $\mathbf{M}$ & H & L & $\mathbf{H}$ & $\mathbf{M}$ & $\mathbf{M}$ & $\mathrm{H}$ & $\mathbf{L}$ & $\mathbf{H}$ & $\mathbf{L}$ \\
\hline Hand grinding, honing, scraping & $\mathbf{H}$ & $\mathbf{H}$ & $\mathbf{M}$ & $\mathbf{H}$ & $\mathbf{H}$ & M & $\mathbf{L}$ & $\mathrm{H}$ & $\mathbf{H}$ & $\mathrm{H}$ \\
\hline Automated grinding & M & $\mathbf{M}$ & M & $M$ & $\mathbf{M}$ & M & $\mathbf{M}$ & $\mathrm{H}$ & $\mathrm{H}$ & $\mathbf{M}$ \\
\hline Metal milling & $\mathbf{H}$ & $\mathbf{H}$ & $\mathrm{L}$ & $\mathbf{H}$ & $\mathbf{M}$ & $\mathbf{M}$ & $\mathbf{M}$ & $\mathbf{H}$ & $\mathbf{H}$ & $\mathrm{H}$ \\
\hline \multicolumn{11}{|l|}{ Thermal Surface Removal Methods } \\
\hline Plasma torch & M & $\mathbf{H}$ & $\mathbf{M}$ & $\mathbf{M}$ & $\mathbf{M}$ & $\mathbf{M}$ & $\mathbf{M}$ & H & M & M \\
\hline Laser heating & $\mathbf{M}$ & $\mathbf{M}$ & L & $\mathbf{M}$ & $\mathbf{M}$ & $\mathbf{H}$ & $\mathbf{M}$ & $\mathbf{M}$ & $\mathrm{H}$ & $\mathbf{M}$ \\
\hline Laser etching and ablating & $\mathbf{M}$ & $\mathbf{M}$ & L & $\mathbf{M}$ & $\mathbf{M}$ & $\mathbf{H}$ & $\mathbf{M}$ & $\mathbf{H}$ & $\mathbf{H}$ & $\mathbf{M}$ \\
\hline Plasma surface cleaning & $\mathbf{M}$ & $\mathbf{M}$ & L & $\mathbf{M}$ & $\mathbf{M}$ & $\mathbf{H}$ & $\mathbf{M}$ & $\mathbf{M}$ & $\mathbf{M}$ & $\mathbf{M}$ \\
\hline Plasma etching/fluorination & $\mathbf{M}$ & $\mathbf{M}$ & $\mathbf{M}$ & $\mathbf{M}$ & $\mathbf{M}$ & $\mathbf{H}$ & $\mathbf{M}$ & $\mathbf{H}$ & $\mathbf{M}$ & $\mathbf{M}$ \\
\hline Flashlamp cleaning & $\mathbf{M}$ & $\mathbf{M}$ & $\mathbf{M}$ & $\mathbf{M}$ & $\mathbf{M}$ & $\mathbf{H}$ & $\mathbf{H}$ & $\mathrm{H}$ & $\mathbf{M}$ & $\mathbf{M}$ \\
\hline \multicolumn{11}{|l|}{ Surface Cleaning Methods } \\
\hline Compressed air cryogente $\mathrm{CO}_{2}$ blasting & $\mathbf{M}$ & $\mathbf{H}$ & $\mathrm{L}$ & $\mathbf{M}$ & $\mathbf{H}$ & $\mathbf{H}$ & $\mathbf{M}$ & $\mathbf{L}$ & $\mathbf{H}$ & $\mathbf{M}$ \\
\hline High-pressure water & $\mathbf{M}$ & $\mathbf{H}$ & $\mathbf{M}$ & $\mathbf{M}$ & $\mathbf{H}$ & $\mathbf{M}$ & $\mathbf{M}$ & $\mathbf{M}$ & $\mathrm{H}$ & $\mathbf{M}$ \\
\hline Superheated water & $\mathbf{M}$ & $\mathrm{H}$ & M & $\mathbf{M}$ & H & $\mathbf{M}$ & $\mathbf{M}$ & $\mathbf{M}$ & H & $\mathbf{M}$ \\
\hline Hot water & $\mathbf{M}$ & $\mathbf{H}$ & $\mathbf{M}$ & $\mathbf{M}$ & $\mathbf{H}$ & M & $\mathbf{M}$ & L & $\mathbf{H}$ & $\mathbf{M}$ \\
\hline Steam & M & $\mathbf{H}$ & $\mathbf{M}$ & $\mathbf{M}$ & $\mathbf{H}$ & $\mathbf{M}$ & $\mathbf{M}$ & $\mathbf{L}$ & $\mathbf{H}$ & $\mathbf{M}$ \\
\hline Hand brushing & $\mathrm{H}$ & H & $\mathrm{L}$ & H & $\mathrm{H}$ & H & $\mathrm{L}$ & $\mathbf{M}$ & $\mathbf{H}$ & $\mathbf{M}$ \\
\hline Automated brushing & $\mathbf{H}$ & $\mathrm{H}$ & $\mathbf{L}$ & $\mathbf{M}$ & $\mathbf{M}$ & $\mathbf{H}$ & $\mathbf{H}$ & $\mathbf{M}$ & $\mathbf{H}$ & $\mathbf{M}$ \\
\hline Sponge blasting & $\mathbf{M}$ & $\mathbf{H}$ & $L$ & $\mathbf{M}$ & $\mathbf{M}$ & $\mathbf{M}$ & $\mathbf{M}$ & $\mathbf{M}$ & H & $\mathbf{M}$ \\
\hline Hot alr & $M$ & $\mathrm{H}$ & $L$ & $M$ & $H$ & $\mathbf{H}$ & $\mathbf{M}$ & $\mathbf{L}$ & $\mathbf{M}$ & $\mathbf{L}$ \\
\hline Dry heat (roasting) & H & $\mathbf{M}$ & $\mathbf{M}$ & $\mathbf{M}$ & $\mathbf{M}$ & $\mathbf{H}$ & $\mathbf{M}$ & L & $\mathbf{H}$ & $\mathbf{M}$ \\
\hline $\begin{array}{l}\text { Solvent washing to remove radiological } \\
\text { contamination }\end{array}$ & $\mathbf{M}$ & $\mathbf{H}$ & M & $\mathbf{M}$ & $\mathbf{M}$ & L. & $\mathbf{L}$ & $\mathbf{L}$ & $\mathbf{M}$ & L \\
\hline Strippable coatings & $\mathbf{H}$ & $\mathrm{H}$ & $L$ & $\mathbf{H}$ & $\mathbf{H}$ & $L$ & $\mathbf{M}$ & $\mathbf{M}$ & $\mathbf{H}$ & $\mathbf{M}$ \\
\hline Ultrasonic cleaning & $\mathbf{H}$ & $\mathbf{H}$ & L & $\mathbf{M}$ & $\mathbf{H}$ & $\mathbf{L}$ & $\mathbf{M}$ & $\mathbf{M}$ & $\mathbf{M}$ & $\mathbf{L}$ \\
\hline \multicolumn{11}{|c|}{ Metal Refining Methods } \\
\hline Smelt puriflcation & $\mathbf{M}$ & $\mathbf{L}$ & $\mathbf{H}$ & $\mathbf{M}$ & $\mathbf{M}$ & $\mathbf{L}$ & $\mathbf{M}$ & $\mathbf{M}$ & $\mathbf{M}$ & $\mathbf{M}$ \\
\hline Electrorefining & $\mathbf{M}$ & $\mathbf{L}$ & $\mathbf{L}$ & $\mathbf{M}$ & $\mathbf{M}$ & $\mathbf{M}$ & $\mathbf{H}$ & H & $\mathbf{M}$ & $\mathbf{M}$ \\
\hline Leach/electro-winning & $\mathbf{M}$ & $\mathbf{L}$ & $\mathbf{M}$ & $\mathbf{M}$ & $\mathbf{M}$ & $\mathbf{M}$ & $\mathbf{M}$ & $\mathbf{H}$ & $\mathbf{M}$ & $\mathbf{M}$ \\
\hline
\end{tabular}

Interest Level: $\mathrm{H}=\mathrm{High}$; $\mathrm{M}=$ Medium; L=Low 


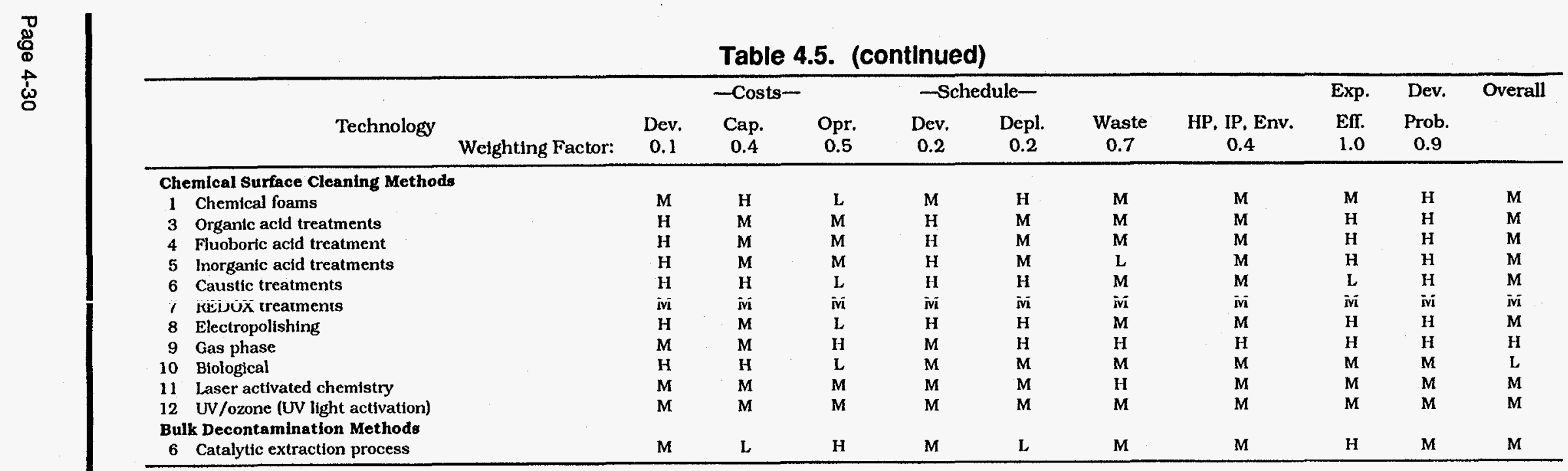

\footnotetext{
Interest Level: H=High; M=Medium; L=Low
} 
Table 4.6. Decontamination technology rankings vs criteria of group 4 (porous nickel)

\begin{tabular}{|c|c|c|c|c|c|c|c|c|c|c|c|}
\hline \multirow{2}{*}{\multicolumn{2}{|c|}{$\begin{array}{l}\text { Technology } \\
\text { Welghting Factor: }\end{array}$}} & \multirow[b]{2}{*}{$\begin{array}{l}\text { Dev. } \\
0.1\end{array}$} & \multicolumn{2}{|c|}{- Costs- } & \multicolumn{2}{|c|}{-Schedule- } & \multirow[b]{2}{*}{$\begin{array}{c}\text { Waste } \\
0.7\end{array}$} & \multirow[b]{2}{*}{$\begin{array}{l}\text { HP, IP, Env. } \\
0.4\end{array}$} & \multirow{2}{*}{$\begin{array}{l}\text { Exp. } \\
\text { Eff. } \\
1.0\end{array}$} & \multirow{2}{*}{$\begin{array}{c}\text { Dev. } \\
\text { Prob. } \\
0.9\end{array}$} & \multirow[t]{2}{*}{ Overall } \\
\hline & & & $\begin{array}{l}\text { Cap. } \\
0.4\end{array}$ & $\begin{array}{c}\text { Opr. } \\
0.5\end{array}$ & $\begin{array}{l}\text { Dev. } \\
0.2\end{array}$ & $\begin{array}{c}\text { Depl. } \\
0.2\end{array}$ & & & & & \\
\hline \multicolumn{12}{|c|}{ Metal Refining Methods } \\
\hline 1 & Smelt purffication & $\mathbf{M}$ & $\mathbf{M}$ & $\mathbf{H}$ & $\mathbf{M}$ & $\mathbf{M}$ & $\mathbf{M}$ & $\mathbf{M}$ & $\mathbf{M}$ & $\mathbf{M}$ & $\mathbf{M}$ \\
\hline 2 & Elcctrorefining & $\mathbf{M}$ & $\mathbf{L}$ & $\mathbf{L}$ & $\mathbf{M}$ & $\mathbf{M}$ & $\mathbf{M}$ & $\mathbf{H}$ & $\mathbf{H}$ & $\mathbf{M}$ & $\mathbf{M}$ \\
\hline 3 & Mond Pracess & $\mathbf{M}$ & $\mathrm{L}$ & $\mathbf{M}$ & $\mathbf{M}$ & $\mathbf{M}$ & $\mathbf{H}$ & $\mathbf{M}$ & $\mathbf{H}$ & $\mathbf{H}$ & $\mathbf{H}$ \\
\hline 4 & Leach/electro-winning & M & L & $\mathbf{M}$ & $\mathbf{M}$ & $\mathbf{M}$ & $\mathbf{M}$ & $\mathbf{H}$ & $\mathbf{H}$ & $\mathbf{M}$ & $\mathbf{M}$ \\
\hline \multicolumn{12}{|c|}{ Chemical Surface Cleaning Methods } \\
\hline $\mathbf{5}$ & Inorganic acid treatments & H & $M$ & $\mathbf{M}$ & $\mathbf{H}$ & $\mathbf{M}$ & $\mathbf{M}$ & $\mathbf{M}$ & $\mathbf{M}$ & $\mathbf{H}$ & $\mathbf{M}$ \\
\hline 9 & Gas phase & $\mathbf{M}$ & $\mathbf{M}$ & $\mathrm{H}$ & $\mathbf{M}$ & $\mathbf{M}$ & $\mathbf{H}$ & $\mathbf{H}$ & $\mathbf{H}$ & $\mathbf{H}$ & $\mathbf{H}$ \\
\hline \multicolumn{12}{|c|}{ Bulk Decontamination Methods } \\
\hline & Catalytic extraction process & $\mathbf{M}$ & $\mathbf{L}$ & $\mathbf{H}$ & M & $\mathbf{M}$ & $\mathbf{M}$ & M & $\mathbf{M}$ & $\mathbf{M}$ & M \\
\hline
\end{tabular}

Interest Level: $\mathrm{H}=\mathrm{High}$; $=$ Medium; L=low 
Table 4.7. Decontamination technology rankings vs criterla of group 5 (deposit removal)

\begin{tabular}{|c|c|c|c|c|c|c|c|c|c|c|c|}
\hline \multirow{2}{*}{\multicolumn{2}{|c|}{$\begin{array}{l}\text { Technology } \\
\text { Welghting Factor: }\end{array}$}} & \multirow[b]{2}{*}{$\begin{array}{c}\text { Dev. } \\
0.3\end{array}$} & \multicolumn{2}{|c|}{ - Costs- } & \multicolumn{2}{|c|}{-Schedule- } & \multirow[b]{2}{*}{$\begin{array}{c}\text { Waste } \\
0.7\end{array}$} & \multirow[b]{2}{*}{$\begin{array}{l}\text { HP. IP, Env. } \\
1.0\end{array}$} & \multirow{2}{*}{$\begin{array}{l}\text { Exp. } \\
\text { Eff. } \\
1.0\end{array}$} & \multirow{2}{*}{$\begin{array}{c}\text { Dev. } \\
\text { Prob. } \\
0.9\end{array}$} & \multirow[t]{2}{*}{ Overall } \\
\hline & & & $\begin{array}{c}\text { Cap. } \\
0.3\end{array}$ & $\begin{array}{c}\text { Opr. } \\
0.3\end{array}$ & $\begin{array}{c}\text { Dev. } \\
0.3\end{array}$ & $\begin{array}{c}\text { Depl. } \\
0.3\end{array}$ & & & & & \\
\hline \multicolumn{12}{|c|}{ Mechanical Surface Removal Methods } \\
\hline 2 & Shot Blasting & $H$ & $H$ & H & $\mathbf{H}$ & $H$ & $\mathbf{M}$ & $\mathbf{M}$ & $\mathbf{H}$ & $\mathbf{H}$ & $M$ \\
\hline 3 & Scabblers/scarificrs & $\mathbf{H}$ & $\mathbf{M}$ & $\mathbf{M}$ & $\mathbf{H}$ & H & M & $\mathbf{M}$ & $\mathbf{H}$ & $\mathbf{H}$ & $\mathbf{M}$ \\
\hline 4 & Grit blasting & $\mathbf{M}$ & $\mathbf{M}$ & $\mathbf{L}$ & $\mathbf{H}$ & $\mathrm{H}$ & $\mathbf{M}$ & $\mathbf{M}$ & $\mathbf{H}$ & $\mathbf{H}$ & $M$ \\
\hline 5 & Centrifugal cryogenic $\mathrm{CO}_{2}$ blasting & $\mathbf{M}$ & $\mathbf{H}$ & $\mathbf{M}$ & $\mathbf{M}$ & M & $\mathbf{H}$ & $\mathbf{M}$ & $\mathbf{H}$ & $\mathbf{H}$ & $\mathrm{H}$ \\
\hline 7 & Supercriticai $\bar{C}_{2}$ biasting & $\overline{m i}$ & $\overline{\mathbf{M}} \overline{\mathbf{I}}$ & $i$ & $\overline{\mathbf{m}}$ & $\overline{\mathbf{H}}$ & $\overline{\mathbf{i i}}$ & $\overline{\mathbf{y}} \mathbf{i}$ & $\mathrm{H}$ & Hi & $\overline{\mathbf{H}}$ \\
\hline 8 & Plastic pellet blasting & $\mathbf{M}$ & $\mathrm{H}$ & $\mathbf{L}$ & H & $\mathbf{H}$ & $\mathbf{M}$ & $\mathbf{M}$ & $\mathbf{L}$ & $\mathbf{H}$ & $\mathbf{L}$ \\
\hline 9 & Hand grinding, honing, scraping & $\mathbf{H}$ & $\mathrm{H}$ & $\mathbf{M}$ & $\mathbf{H}$ & H & $\mathbf{M}$ & $\mathbf{L}$ & $\mathbf{H}$ & $\mathbf{H}$ & $\mathbf{H}$ \\
\hline \multicolumn{12}{|c|}{ Thermal Surface Removal Methods } \\
\hline 2 & Plasma torch & $\mathbf{M}$ & $\mathrm{H}$ & $\mathbf{M}$ & $\mathbf{M}$ & $\mathbf{M}$ & $\mathbf{M}$ & L & $\mathbf{M}$ & $\mathbf{M}$ & $\mathbf{L}$ \\
\hline 3 & Laser heating & M & $\mathbf{M}$ & $\mathbf{L}$ & $\mathbf{M}$ & $\mathbf{M}$ & $\mathbf{M}$ & $\mathbf{M}$ & $\mathbf{M}$ & $M$ & $\mathbf{L}$ \\
\hline 4 & Laser etching and ablating & $M$ & $\mathbf{M}$ & $\mathbf{L}$ & $\mathbf{M}$ & $\mathbf{M}$ & $\mathrm{H}$ & $M$ & $\mathrm{H}$ & $\mathrm{H}$ & $\mathbf{M}$ \\
\hline 5 & Plasma surface cleaning & $\mathbf{M}$ & $\mathbf{M}$ & $\mathrm{L}$ & $M$ & M & $\mathbf{H}$ & $\mathbf{M}$ & M & $\mathbf{M}$ & $\mathbf{M}$ \\
\hline 6 & Plasma etching/fluortnation & M & $\mathbf{M}$ & M & $\mathbf{M}$ & $\mathbf{M}$ & M & $\mathbf{M}$ & $\mathbf{H}$ & $\mathbf{M}$ & $M$ \\
\hline 7 & Flashlamp cleaning & $\mathbf{M}$ & $\mathbf{M}$ & $\mathbf{L}$ & M & $\mathbf{M}$ & $\mathrm{H}$ & $\mathbf{H}$ & $\mathbf{H}$ & $\mathbf{M}$ & $\mathbf{M}$ \\
\hline \multicolumn{12}{|c|}{ Surface Cleaning Methods } \\
\hline 1 & Compressed air cryogenic $\mathrm{CO}_{2}$ blasting & $\mathbf{M}$ & $\mathbf{H}$ & $\mathbf{L}$ & $\mathbf{M}$ & M & $\mathbf{H}$ & $\mathbf{M}$ & $\mathbf{L}$ & $\mathrm{H}$ & $\mathbf{L}$ \\
\hline 6 & Hand brushing & $\mathbf{H}$ & $\mathbf{H}$ & $\mathrm{L}$ & $\mathrm{H}$ & $\mathbf{H}$ & $\mathbf{M}$ & $\mathbf{L}$ & $\mathbf{H}$ & $\mathbf{H}$ & $\mathbf{M}$ \\
\hline 8 & Sponge blasting & $\mathbf{M}$ & $\mathbf{H}$ & $\mathbf{L}$ & $\mathbf{M}$ & $\mathbf{H}$ & $\mathbf{M}$ & $\mathbf{M}$ & $\mathbf{M}$ & $\mathbf{H}$ & $\mathbf{M}$ \\
\hline 14 & Vacuum & $\mathbf{n i}$ & in & $\mathbf{L}$ & II & iì & ì & in & $\mathbf{i}$ & $\mathbf{H}$ & $\mathrm{M}$ \\
\hline \multicolumn{12}{|c|}{ Chemical Surface Cleaning Methods } \\
\hline 9 & Gas phase & $\mathbf{M}$ & M & $\mathbf{M}$ & $\mathbf{M}$ & $\mathbf{M}$ & $\mathbf{H}$ & $\mathbf{H}$ & $\mathbf{H}$ & $\mathbf{H}$ & $\mathbf{H}$ \\
\hline 11 & Laser activated chemistry & $\mathbf{M}$ & $\mathbf{M}$ & $\mathbf{H}$ & $\mathbf{M}$ & $\mathbf{M}$ & $\mathbf{M}$ & $\mathbf{M}$ & $\mathbf{M}$ & $\mathbf{M}$ & $\mathbf{L}$ \\
\hline
\end{tabular}

Interest Level: $\mathrm{H}=\mathrm{High} ; \mathrm{M}=$ Medium; L=Low 


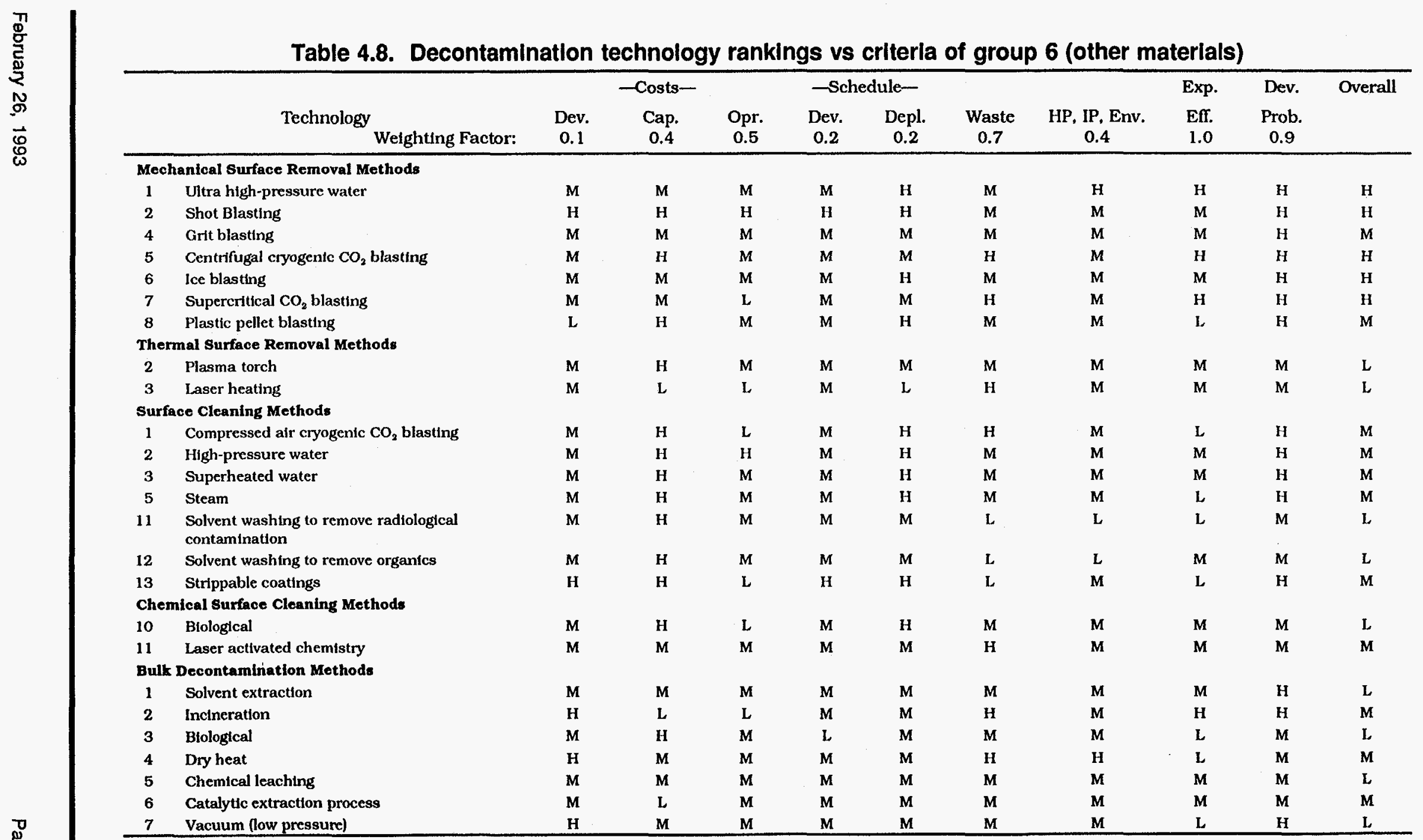

Interest Level: H=High; M=Medium; LaLow 


\subsubsection{Results of Overall Rankings}

The results of the overall rankings for the decontamination technologies are summarized in Table 4.9. The technologies with the highest rankings are discussed briefly in the following subsections. To minimize repetition, technologies with high rankings in more than one generic problem group are not necessarily discussed more than once. Although not specifically mentioned in the following discussion, appropriate containment collection systems and/or effluent treatment would be required for all technologies.

\section{Contaminated Concrete Surfaces}

Mechanical scabblers are available and have been used extensively for decontaminating concrete surfaces. No secondary waste streams other than the removed concrete surface layer are produced. Mechanical scabblers have problems with uniform application on irregular and/or nonhorizontal surfaces. However, this problem is typical of other technologies for concrete decontamination and is one of the areas for development.

Shot blasters and grit blasters are also available and have been used extensively for decontarinating concrete surfaces. The volume of waste shot is a reasonably small fraction of the waste comprised of the removed concrete surface layer.

Ultra High-Pressure: Water (UHPW) blasting is also available and accepted for concrete decontamination. The depth of the concrete surface that is removed can be controlled by varying the water pressure and unit speed. A water recycle system may be available for some environments, but will generally have to be developed and demonstrated for each specific application.

Microwave scabbling is being developed. The secondary waste is the removed concrete surface layer. Operating and capital costs have yet to be demonstrated. Microwave scabbling may result in the removal of a deeper concrete layer than is desired with attendant generation of more secondary waste than is necessary.

Supercritical $\mathrm{CO}_{2}$ blasting, which is under development commercially, should act very much like UHPW except that no water will remain that must be treated. Abrasive high-speed pel.lets from a centrifugal cryogenic $\mathrm{CO}_{2}$ pellet blasting system under development should also be effective in removing contaminants along with a thin layer of concrete

Fluoboric (or fluosilicic) acid is effective in decontaminating cement and brickwork by surface removal up to a few millimeters in depth. The acid can be electrolytically regenesated and recycled. Other treatment options are neutralization and precipitation with solidification in cement or treatment by ion exchange with solidification of the ion exchange resin or mineral in cement.

The technologies involving hand and automated grinding and milling received high rankings due to their low capital costs, expected high decontamination efficiencies, and high development probabilities. Remote operation capabilities and efficient vacuum systems should be developed for these technologies. 
Table 4.9. Overall ratings of decontamination technologies

\begin{tabular}{|c|c|c|c|c|c|c|}
\hline \multirow{2}{*}{ Technologies } & \multicolumn{6}{|c|}{ Group number ${ }^{a, b}$} \\
\hline & 1 & 2 & 3 & 4 & 5 & 6 \\
\hline \multicolumn{7}{|l|}{ Mechanical surface removal } \\
\hline Ultra high-pressure water & $\mathrm{H}$ & $\mathbf{H}$ & $\mathbf{M}$ & & & $\mathbf{H}$ \\
\hline Shot blasting & $\mathrm{H}$ & $\mathrm{H}$ & $\mathrm{H}$ & & $\mathbf{M}$ & $\mathrm{H}$ \\
\hline Scabblers/scarifiers & $\mathrm{H}$ & & & & $\mathbf{M}$ & \\
\hline Grit blasting & $\mathrm{H}$ & $\mathbf{M}$ & $\mathbf{M}$ & & $\mathbf{M}$ & $\mathbf{M}$ \\
\hline Centrifugal cryogenic $\mathrm{CO}_{2}$ blasting & $\mathrm{H}$ & $\mathrm{H}$ & $\mathrm{H}$ & & $\mathbf{H}$ & $\mathbf{H}$ \\
\hline Ice blasting & $\mathbf{M}$ & $\mathbf{M}$ & $\mathbf{M}$ & & & $\mathbf{H}$ \\
\hline Supercritical $\mathrm{CO}_{2}$ blasting & $\mathrm{H}$ & $\mathrm{H}$ & $\mathrm{H}$ & & $\mathrm{H}$ & $\mathbf{H}$ \\
\hline Plastic pellet blasting & $\mathrm{L}$ & $\mathbf{M}$ & $\mathrm{L}$ & & $L$ & $\mathbf{M}$ \\
\hline Hand grinding, honing, scraping & $\mathrm{H}$ & $\mathrm{H}$ & $\mathbf{H}$ & & $\mathrm{H}$ & \\
\hline Automated grinding & $\mathrm{H}$ & $\mathrm{H}$ & $\mathbf{M}$ & & & \\
\hline Milling-metal & & $\mathbf{M}$ & $\mathrm{H}$ & & & \\
\hline Milling-concrete & $\mathrm{H}$ & & & & & \\
\hline Explosive & $\mathbf{M}$ & & & & & \\
\hline \multicolumn{7}{|l|}{ Thermal surface removal } \\
\hline Microwave scabbling & $\mathrm{H}$ & & & & & \\
\hline Plasma torch & $\mathbf{M}$ & $\mathbf{M}$ & $\mathbf{M}$ & & L & $\mathrm{L}$ \\
\hline Laser heating & & $\mathrm{L}$ & $\mathbf{M}$ & & L & L \\
\hline Laser etching and ablating & & & $\mathbf{M}$ & & $\mathbf{M}$ & \\
\hline Plasma surface cleaning & & $\mathrm{L}$ & $\mathbf{M}$ & & $\mathbf{M}$ & \\
\hline Plasma etching/fluorination & & & $\mathbf{M}$ & & $\mathbf{M}$ & \\
\hline Flashlamp cleaning & M & & $\mathbf{M}$ & & $\mathbf{M}$ & \\
\hline \multicolumn{7}{|l|}{ Surface cleaning } \\
\hline$\underset{\text { Clasting }}{\text { Compressed air cryogenic } \mathrm{CO}_{2}}$ & $\mathbf{M}$ & $\mathbf{M}$ & $\mathbf{M}$ & & $L$ & $\mathbf{M}$ \\
\hline High-pressure water & $\mathbf{M}$ & $\mathrm{H}$ & $\mathbf{M}$ & & & $\mathbf{M}$ \\
\hline Superheated water & $\mathbf{M}$ & $\mathbf{M}$ & $\mathbf{M}$ & & & $\mathbf{M}$ \\
\hline Hot water & $\mathbf{M}$ & $\mathbf{M}$ & $\mathbf{M}$ & & & \\
\hline Steam & $\mathbf{M}$ & $\mathbf{M}$ & $\mathbf{M}$ & & & $\mathbf{M}$ \\
\hline Hand brushing & $\mathbf{M}$ & $\mathbf{M}$ & $\mathbf{M}$ & & $\mathbf{M}$ & \\
\hline Automated brushing & M & $\mathbf{M}$ & $\mathbf{M}$ & & & \\
\hline Sponge blasting & $\mathbf{M}$ & $\mathbf{M}$ & $\mathbf{M}$ & & $\mathbf{M}$ & \\
\hline Hot air & $\mathrm{L}$ & $\mathrm{L}$ & $\mathrm{L}$ & & & \\
\hline
\end{tabular}


Table 4.9. (continued)

\begin{tabular}{|c|c|c|c|c|c|c|}
\hline \multirow{2}{*}{ Technologies } & \multicolumn{6}{|c|}{ Group number ${ }^{a, b}$} \\
\hline & 1 & 2 & 3 & 4 & 5 & 6 \\
\hline Dry heat (roasting) & $\mathbf{L}$ & $\mathrm{L}$ & $\mathbf{M}$ & & & \\
\hline Solvent washing (rad contamination) & $\mathrm{L}$ & $\mathrm{L}$ & L & & & $\mathbf{L}$ \\
\hline Solvent washing (olganic contamination) & L & M & & & & $\mathbf{L}$ \\
\hline Strippable coatings & M & M & $\mathbf{M}$ & & & $\mathbf{M}$ \\
\hline Vacuum & $\mathbf{M}$ & $\mathbf{M}$ & & & $\mathbf{M}$ & \\
\hline Ultrasonic cleaning & & $L$ & $L$ & & & \\
\hline \multicolumn{7}{|l|}{ Metal refining } \\
\hline Smelt purification & & $\mathbf{M}$ & $\mathbf{M}$ & $\mathbf{M}$ & & \\
\hline Electrorefining & & $\mathbf{M}$ & $\mathbf{M}$ & $\mathbf{M}$ & & \\
\hline Mond (nickel carbonyl) process & & & & $\mathrm{H}$ & & \\
\hline Leach/electro-winning & & $\mathbf{M}$ & $\mathbf{M}$ & $\mathbf{M}$ & & \\
\hline \multicolumn{7}{|l|}{ Chemical surface cleaning } \\
\hline Chemical foams & & M & $\mathbf{M}$ & & & \\
\hline Chemical gels & & $\mathbf{M}$ & & & & \\
\hline Organic acid treatment & & $\mathbf{M}$ & $\mathbf{M}$ & & & \\
\hline Fluoboric acid trealment & $\mathrm{H}$ & $\mathrm{H}$ & $\mathbf{M}$ & & & \\
\hline Inorganic acid trealment & & M & M & $\mathbf{M}$ & & \\
\hline Caustic treatment & $\mathrm{L}$ & $\mathbf{M}$ & $\mathbf{M}$ & & & \\
\hline REDOX treatment & & $L$ & $\mathbf{M}$ & & & \\
\hline Electropolishing & & $\mathbf{M}$ & $\mathbf{M}$ & & & \\
\hline Gas phase & & & $\mathrm{H}$ & $\mathrm{H}$ & $\mathbf{H}$ & \\
\hline Biological & $\mathbf{L}$ & $L$ & $\mathbf{L}$ & & & $\mathbf{L}$ \\
\hline Laser activated chemistry & & $\mathbf{M}$ & $\mathbf{M}$ & & $\mathbf{L}$ & $\mathbf{M}$ \\
\hline UV/ozone (UV light activation) & & $\mathrm{L}$ & $\mathbf{M}$ & & & \\
\hline Electromigration & $\mathbf{M}$ & & & & & \\
\hline
\end{tabular}


Table 4.9. (continued)

\begin{tabular}{|c|c|c|c|c|c|c|}
\hline \multirow{2}{*}{ Technologies } & \multicolumn{6}{|c|}{ Group number ${ }^{a b b}$} \\
\hline & 1 & 2 & 3 & 4 & 5 & 6 \\
\hline \multicolumn{7}{|l|}{ Bulk decontamination } \\
\hline Solvent extraction & & & & & & $\mathbf{L}$ \\
\hline Incineration & & & & & & $\mathbf{M}$ \\
\hline Biological & & & & & & $\mathrm{L}$ \\
\hline Dry heat & & & & & & $\mathbf{M}$ \\
\hline Chemical leaching & & & & & & $\mathbf{L}$ \\
\hline Catalytic extraction process & & $\mathrm{H}$ & $\mathbf{M}$ & $\mathbf{M}$ & & $\mathbf{M}$ \\
\hline Vacuum (low pressure) & & & & & & $\mathbf{L}$ \\
\hline
\end{tabular}

${ }^{a} 1=\infty$ ncrete, $2=$ exterior equipment surfaces, 3 =interior equipment surfaces, $4=$ porous nickel,

$5=$ deposit removal, and $6=0$ ther.

Letters are ratings: $\mathrm{H}=$ high. $\mathrm{M}=$ medium, and $\mathrm{L}=\mathrm{low}$.

\section{Exterior Metal Surfaces}

UHPW is available and has been used to decontaminate metal surfaces with a treatment system to permit recycle of the water. A different recycle system will have to be developed and demonstrated for the specific contaminants at the K-25 Site.

Commercial cryogenic $\mathrm{CO}_{2}$ pellet blasting has been used to decontaminate tools at nuclear power plants. More abrasive, higher speed pellets from a centrifugal cryogenic $\mathrm{CO}_{2}$ pellet blasting system now being developed may be required to remove some of the contaminants at the $\mathrm{K}-25$ Site. The cryogenic $\mathrm{CO}_{2}$, and supercritical $\mathrm{CO}_{2}$ technologies are attractive options for this problem group because they produce minimal quantities of secondary waste.

Shot blasting and hand grinding, honing, and scraping have all been used successfully to decontaminate metal objects. The grinding operation could be partially automated, which would be advantageous for many operations. High pressure water should also be good for removing smearable and soluble contamination. The Catalytic Extraction Process (CEP) is attractive as a means for decontaminating metal surfaces while converting the metal to ingots. Demonstration of technetium removal is needed for this process.

\section{Internal Surfaces of Equipment Contaminated with Radionuclides}

In situ gas phase decontamination with a strong fluorinating agent would be attractive for uranium removal if high percentage removal of contaminants can be consistently obtained. This technology would minimize criticality concerns and worker exposure to radioactive and hazardous materials during dismantling, reduce dismantling costs, produce little secondary waste, and return the uranium contaminants to operating gaseous diffusion plants as $\mathrm{UF}_{6}$. British Nuclear Fuels, Ltd., used this as one of their chemical surface decontamination technologies for decommissioning the Capenhurst Diffusion Plant. 
Although commercial cryogenic $\mathrm{CO}_{2}$ pellet blasting may not be sufficiently aggressive to clean contamination from the inside of disassembled process equipment at the K-25 Site, the higher velocity pellets from centrifugal cryogenic $\mathrm{CO}_{2}$ pellet blasting are expected to provide effective decontamination. The only secondary waste would be the removed contamination and metal from a very thin layer of substrate metal that would also be removed.

British Nuclear Fuels, Ltd., successfully uses a combination of chemical surface cleaning technologies in their Capenhurst Diffusion Plant decommissioning activities. Implementable waste treatment technologies in the United States are different than in Great Britain but in most ways their controls were equally demanding. ${ }^{4}$ Chelating agents often provide good decontamination, but generate liquid wastes that are hard to treat acceptably for disposal.

If the equipment were disassembled, shot blasting, supercritical $\mathrm{CO}_{2}$ blasting, hand grinding and scraping and metal milling would be viable alternatives.

\section{Porous Nickel}

For contaminated rickel barrier, the well established Mond (nickel carbonyl) process would appear to be the leading contender. Confining the very hazardous gases used in this prociss will be a safety issue but this has been accomplished safely in the past and is used on a large industrial scale. Gas phase decontamination may ke partially successful for this purpose and needs further evaluation for this application. Among other processes, smelt refining has the advantage over electrorefining of not having to deal with spent electrolytic solution. Advanced Catalytic Extraction Process (CEP) is similar to smelt purification when applied to metal refining. Smelt refining is also attractive for decontamination of porous aluminum. If the safety issues associated with the Mond process are judged to be too severe, smelt refining would be an attractive backup process for nickel as well. However, the problem with poor removal of technetium needs to be solved by demonstrating either a smelting slag that will remove technetium or a method for oxidizing the technetium to a higher valence state so that the technetium oxyfluorides are volatile so the technetium can be captured by an improved off-gas syster... The leach electrowinning process can remove technetium by ion exchange with the dissolved metal solution. Basic thermodynamics indicates that a flux that will remove technetium is not possible. ${ }^{4}$ An off-gas treatment system woulcl be needed to remove the volatile technetium oxyfluorides.

\section{Deposit Removal}

In situ gas phase decontamination appears to be an attractive technology for the removal of many uranium (and possibly technetium) ${ }^{4}$ deposits, particularly those in items of equipment that would be difficult to dismantle and move safely while the deposits remain in the equipment. Any decontamination technology that would introduce a moderator, such as water, would be inappropriate for this application. For those items of equipment for which gas phase decontamination is not used, disassembly of the equipment with removal of the deposits by hand grinding, honing, or scraping is appropriate. Centrifugal cryogenic $\mathrm{CO}_{2}$ blasting and supercritical $\mathrm{CO}_{2}$ blasting also have desirable characteristics for this application. 


\section{Other Materials}

Except for incineration, all of the technologies that received high rankings for this problem group were mechanical surface removal methods. To facilitate this ranking exercise, this group was formed by combining three of the problems groups that were defined for the decontamination TLD as discussed in Sect. 4.1. As can be seen from Table 4.9, the highly ranked technologies for this group will not be appropriate to some of the substrates. For a particular substrate of interest, the decontamination TLD should be examined to verify the applicability of a technology. 


\subsection{TECHNOLOGIES UUNDER DEVELOPMENT BY DOE}

DOE is currently dereloping technologies through the EM-30, EM-40, and EM50 program which have the potential for making effective contributions to solving environmental and waste recycling problems at the different DOE sites. Some of these projects may have relevant and beneficial elements with respect to the technologies identified in the K-25 Site TLD. A search of available information on programs funded in FY! 1992 was performed to identify the possible matches between technologies ir the K-25 TLD and TTPs (or ADSs). A listing of the DOE EM-50 Program Guide for FY 1992 and abstracts for funded EM-50 projects were the principal sources for determining matches and relevancy between TEDS and TTPs. Relevant ADS activities were identified through staff personal knowledge.

In Table 4.10, those projects described in TTP or ADS and determined to be potentially relevant and beneficial are listed by TTP (or ADS) number along with the corresponding relevant Technology Evaluation Data Sheet (TEDS) identifier. Along with the matched TEDS is a succinct statement of the technology approach or problem being addressed in both documents. 


\begin{tabular}{|c|c|c|c|c|c|c|}
\hline \multicolumn{2}{|c|}{ Technology Diagram } & \multicolumn{2}{|c|}{ DOE TTP } & \multirow{2}{*}{$\begin{array}{c}\text { DOE FY-92 } \\
\text { Program Guddance } \\
\text { (page) }\end{array}$} & \multirow{2}{*}{ Comments } & \multirow{2}{*}{ Relevance } \\
\hline Subelement & TEDS Identifler & Title & TTP No. & & & \\
\hline & DCON-71 & & $\begin{array}{l}\text { OR101112 } \\
\text { OR101107 }\end{array}$ & $\begin{array}{l}\text { B7-2 } \\
\text { B7-2 }\end{array}$ & $\begin{array}{l}\text { Microwave } \\
\text { scabbling }\end{array}$ & $\mathbf{H}$ \\
\hline & DCON-73 & & CH101102 & B7-1 & Laser ${ }^{a}$ & $\mathrm{H}$ \\
\hline & DCON-74 & & $\mathrm{CH} 101102$ & B7-1 & Laser $^{\mathbf{a}}$ & $\mathrm{H}$ \\
\hline & DCON-16 & & $\operatorname{ADS} 416$ & N/A & Gas phase & $\mathrm{H}$ \\
\hline & DCON-17 & & $\begin{array}{l}\text { ID121103 } \\
\text { RF101205 }\end{array}$ & $\begin{array}{l}\text { A3-6 } \\
\text { B8-12 }\end{array}$ & $\begin{array}{l}\text { Biological } \\
\text { Biological }^{\mathrm{b}}\end{array}$ & $\begin{array}{l}\text { Unknown } \\
\text { Unknown }\end{array}$ \\
\hline & DCON-20 & & $\begin{array}{l}\text { ADS416 } \\
\text { AL121104 }\end{array}$ & $\begin{array}{l}\text { N/A } \\
\text { A3-1 }\end{array}$ & $\begin{array}{l}\text { Electromigration }{ }^{\mathrm{a}} \\
\text { Electromigration }^{\mathrm{a}}\end{array}$ & $\begin{array}{l}\mathrm{H} \\
\mathrm{H}\end{array}$ \\
\hline & DCON-10 & & OR111102 & B7-3 & Liquid phase $^{\mathrm{a}}$ & H \\
\hline & DCON-13 & & OR111102 & B7-3 & Liquid phase $^{a}$ & $\mathbf{H}$ \\
\hline & DCON-14 & & OR111102 & B7-3 & Liquid phase $^{a}$ & $\mathrm{H}$ \\
\hline & DCON-18 & & RF101205 & B8-12 & $U^{b}$ & Unknown \\
\hline & DCON-19 & & RF101205 & B8-12 & $U V^{b}$ & Unknown \\
\hline
\end{tabular}

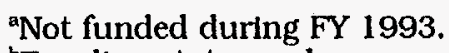

${ }^{\mathrm{b}}$ Funding status unknown. 


\subsection{REFERENCES}

1. "Decontamination of Nuclear Facilities to Permit Operation, Inspection, Maintenance, Modification, or Plant Decommissioning" Technical Reports Series No. 249, International Atomic Energy Agency, Vienna, 1985.

2. "Decontamination and Decommissioning Integrated Demonstration Strategy," prepared for Office of Technology Development, Environmental Restoration and Waste Managenent, U.S. Department of Energy; a product of Department of Energy Environmental Management Decontamination and Decommissioning Workshop held Aug, 12-16, 1991, Knoxville, TN; draft for review, Nov., 1991.

3. Private communication with C.E. Benson, Oak Ridge National Laboratory, Oak Ridge, TN.

4. Private communication from J. M. Googin (Some Notes on the Technology Logic Diagram Project), Oak Ridge Y-12 Plant, Oak Ridge, TN, February 3, 1993.

5. E. B. Munday and I). W. Simmons, Feasibility of Gas-Phase Decontamination of Gaseous Diffusion Equipment, K-TCD-1048, Martin Marietta Energy Systems, Inc. Oak Ridge, Tennessee, February, 1993.

6. E. J. Barber, persorial communication with R. D. Bundy, February 12, 1993.

7. E. B. Munday, Adıanced Gas-Phase Decontamination Technology, TTP No. OR1-4-20-08, subrnitted to DOE Office of Technology Development, Oak Ridge, Tennessee, February 13, 1993.

8. L. V. Gibson, Jr., telephone conversation with D. H. Bunch, June 16, 1992. 
5. Dismantlement 


\section{DISMANTLEMENT}

\subsection{INTRODUCTION}

The dismantlement of the diffusion plants has been divided into two major activities: (1) the removal and disassembly of equipment contaminated with enriched uranium, PCBs, asbestos, and radionuclides and (2) the "deconstruction" of very large buildings contaminated with similar materials. Figure 5.1 shows the basic D\&D sequence.

In proceeding with the dismantlement technology assessment some very basic assumptions are required. It has been assumed before dismantlement that:

- The equipment will have been decontaminated to an exterior surface level defined in DOE Order 5400.5, Chap. IV, per NRC Regulatory Guide 1.86. Levels permitted by this order are listed in Table 5.1.

- Remaining contamination, before dismantlement, will have been located and characterized so that proper safety procedures are in place before dismantlement.

- The product of dismantlement will be sorted materials in a form addressed by the disposition technologies.

- The remaining empty building will have been carefully zoned and kept as clean as practical during equipment removal and will have been decontaminated so that the resulting structural materials and rubble can be handled as Class I LLW for either disposal or recycle, or the decontaminated building can be reused.

The size of the enrichment facilities make $D \& D$, regardless of the contaminants or the technologies available, expensive. The dismantlement of the diffusion plants will face the same site problems as the decommissioning of the diffusion plants (Sect. 1.2).

The following list gives the approximate magnitude of the quantities of materials involved:

- Concrete

- Structural Steel

- Asbestos Materials

- Contaminated equipment (Tables 5.2 and 5.3 give this information)

With the quantities of structural materials in mind, it will be advantageous and cost effective to avoid any increased contamination of building interiors during dismantlement of the more highly contaminated equipment.

\subsubsection{Approach}

The dismantlement section of the TLD addresses site-specific problems and needed technologies, which appear to offer the most promise to remediate these problems within the framework of the DOE objectives of cleaning up this legacy, 


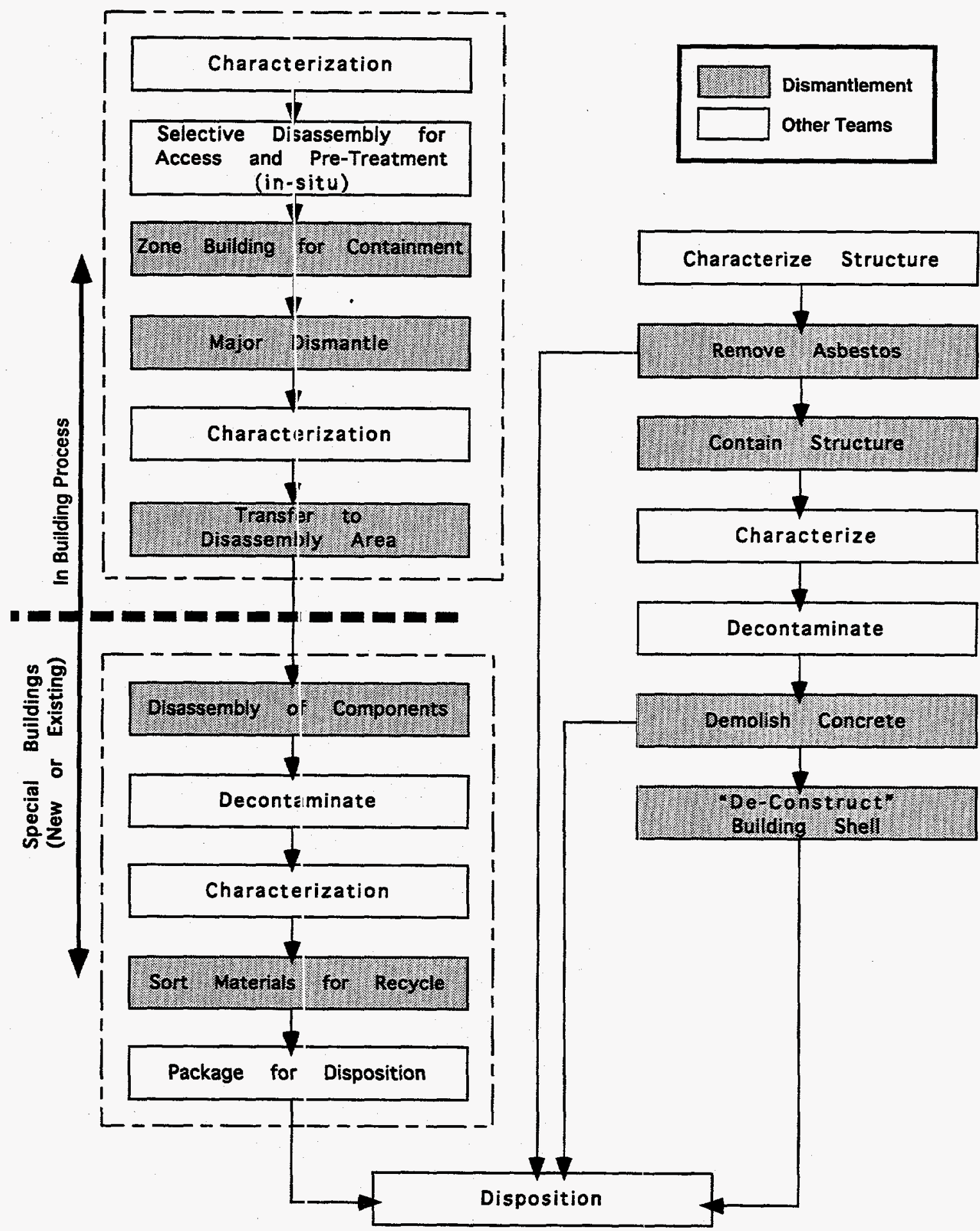

Fig. 5.1. Decontamination and decommissioning sequence. 
Table 5.1. Acceptable exterior surface contamination levels according to DOE Order 5400.5

\begin{tabular}{|c|c|c|c|}
\hline Nuclides $^{a}$ & Averages $^{b, a, f}$ & Maximum $^{b, d} f$ & Removable $^{b, e, f}$ \\
\hline $\begin{array}{l}\mathrm{U} \text {-nat., }{ }^{235} \mathrm{U},{ }^{238} \mathrm{U} \text {, and } \\
\text { associated decay } \\
\text { products }\end{array}$ & $\begin{array}{l}5000 \mathrm{dpm} \\
\mathrm{a} / 100 \mathrm{~cm}^{2}\end{array}$ & $\begin{array}{l}15,000 \mathrm{dpm} \\
\mathrm{a} / 100 \mathrm{~cm}^{2}\end{array}$ & $\begin{array}{l}1000 \mathrm{dpm} \\
\text { a/ } 100 \mathrm{~cm}^{2}\end{array}$ \\
\hline $\begin{array}{l}\text { Transuranics, }{ }^{226} \mathrm{Ra} \text {, } \\
{ }^{228} \mathrm{Ra},{ }^{228} \mathrm{Th},{ }^{230} \mathrm{Th}, \\
{ }^{231} \mathrm{PA},{ }^{227} \mathrm{Ac},{ }^{125} \mathrm{I}, \\
{ }^{229} \mathrm{ITransuranics},{ }^{226} \mathrm{Ra} \text {, } \\
{ }^{228} \mathrm{Ra},{ }^{228} \mathrm{Th} \text {, }\end{array}$ & $100 \mathrm{dpm} / 100 \mathrm{~cm}^{2}$ & $300 \mathrm{dpm} / 100 \mathrm{~cm}^{2}$ & $20 \mathrm{dpm} / 100 \mathrm{~cm}^{2}$ \\
\hline $\begin{array}{l}\text { Th-nat,, }{ }^{232} \mathrm{Th},{ }^{90} \mathrm{Sr} \\
{ }^{223} \mathrm{Ra},{ }^{224} \mathrm{Ra},{ }^{232} \mathrm{U},{ }^{126} \mathrm{I}, \\
{ }^{131} \mathrm{I},{ }^{133} \mathrm{I}\end{array}$ & $1000 \mathrm{dpm} / 100 \mathrm{~cm}^{2}$ & $3000 \mathrm{dpm} / 100 \mathrm{~cm}^{2}$ & $200 \mathrm{dpm} / 100 \mathrm{~cm}^{2}$ \\
\hline $\begin{array}{l}\text { Beta-gamma emitters } \\
\text { (nuclides with decay } \\
\text { modes other than } \\
\text { alpha emission or } \\
\text { spontaneous fission) } \\
\text { except }{ }^{90} \text { Sr and others } \\
\text { noted above }\end{array}$ & $\begin{array}{l}5000 \mathrm{dpm} \\
\mathrm{B}_{\mathrm{y}} / 100 \mathrm{~cm}^{2}\end{array}$ & $\begin{array}{l}15,000 \mathrm{dpm} \\
\mathrm{B}_{\mathrm{y}} / 100 \mathrm{~cm}^{2}\end{array}$ & $\begin{array}{l}1000 \mathrm{dpm} \\
\mathrm{B}_{\mathrm{y}} / 100 \mathrm{~cm}^{2}\end{array}$ \\
\hline
\end{tabular}

कWere surface contamination by both alpha-and beta-gamma-emitting nuclides exists, the limits established for alpha- and beta-gamma-emitting nuclides should apply independently.

${ }^{b}$ As used in this table, dpm (disintegrations per minute) means the rate of emission by radioactive material as determined by correcting the counts per minute observed by an appropriate detector for background, efficiency, and geometric factors associated with the instrumentation.

Measurements of average contaminant should not be averaged over more than $1 \mathrm{~m}^{2}$. For objects of less surface area, the average should be derived for each such object.

${ }^{d}$ The maximum contamination level applies to an area of not more than $100 \mathrm{~cm}^{2}$.

The amount of removable radioactive material per $100 \mathrm{~cm}^{2}$ of surface area should be determined by wiping that area with dry filter or soft absorbent paper, applying moderate pressure, and assessing the amount of radioactive material on the wipe with an appropriate instrument of known efficiency. When removable contamination on objects of less surface area is determined, the pertinent levels should be reduced proportionally and the entire surface should be wiped.

The average and maximum radiation levels associated with surface contamination resulting form beta-gamma emitters should not exceed $0.2 \mathrm{mrad} / \mathrm{h}$ at $1 \mathrm{~cm}$ and 1.0 $\mathrm{mrad} / \mathrm{h}$ at $1 \mathrm{~cm}$, respectively, measured through not more than $7 \mathrm{mg}$ per square centimeter of total absorber.

preventing future environmental insult, and developing environmental stewardship. The science and implementation needs necessary to the successful development and deployment of the proposed technologies are identified. As recommended in the Decontamination and Decommissioning Integrated Demonstration Strategy prepared for the DOE Office of Technology Development, the following benefits were noted as having a potentially high value to dismantlement: 
Table 5.2. Radioactive scrap metal streams from decommissioning gaseous diffuslon plants"

\begin{tabular}{lccccc}
\hline \multicolumn{1}{c}{ Category } & $\begin{array}{c}\text { K-25 Site } \\
\text { (KT) }\end{array}$ & $\begin{array}{c}\text { PGDP } \\
\text { (IKT) }\end{array}$ & $\begin{array}{c}\text { PORTS } \\
\text { (KT) }\end{array}$ & $\begin{array}{c}\text { Totals } \\
\text { (KT) }\end{array}$ & $\begin{array}{c}\text { Est. Value } \\
\left(\$ \times 10^{\circ}\right)\end{array}$ \\
\hline Miscellaneous ferrous & 74.2 & 52.9 & 64.9 & 192.0 & $15.0(1)^{b}$ \\
Large pipe and valves & 29.5 & 21.1 & 26.5 & 77.1 & $6.0(1)$ \\
Aluminum/copper & 8.5 & 6.1 & 7.6 & 22.2 & $16.7(2)$ \\
& & & & & $18.4(2)$ \\
Copper wire, tubing, and valves & 9.7 & 6.5 & 8.3 & 24.5 & $26.4(3)$ \\
Monel pipe/valves & 1.7 & 1.2 & 1.5 & 4.4 & $>400$ \\
Nickel & 22.1 & 15.9 & 19.8 & 57.8 & $>400$ \\
\hline
\end{tabular}

${ }^{a}$ Stream quantities from analysis by Ebasco Services, Inc., 1991.

${ }^{b}$ Assumed decontamination scrap values: (1) $\$ 78 /$ ton, (2) $\$ 750 /$ ton, based on annual average prices for iron/steel and copper

scrap metal, 1984-87.

Table 5.3. Radloactive scrap metal currently in storage

\begin{tabular}{|c|c|c|c|c|c|c|}
\hline Category & $\begin{array}{c}\text { Oak Ridge } \\
\text { (KI) }\end{array}$ & $\begin{array}{l}\text { Paducah } \\
\text { (KT) }\end{array}$ & $\begin{array}{l}\text { Portsmouth } \\
\text { (KT) }\end{array}$ & $\begin{array}{c}\text { Fernald } \\
\text { (KT) }\end{array}$ & $\begin{array}{c}\text { Totals } \\
\text { (KI) }\end{array}$ & $\begin{array}{c}\text { Est. value } \\
\left(\$ \times 10^{6}\right)\end{array}$ \\
\hline Ferrous metal/steel & 43.1 & 14.6 & 21.7 & 11.1 & 90.5 & 7.1 \\
\hline Aluminum & 5.4 & 3.9 & 2.5 & - & 11.8 & 5.0 \\
\hline Nickel, monel & $<.1$ & - & - & - & $<0.1$ & - \\
\hline Nickel, ingots & - & $>10$ & - & - & $>10$ & $>80$. \\
\hline Copper, ingots/wire & $<.1$ & - & $<.25$ & 10.4 & 10.6 & 8.0 \\
\hline Other & $<.5$ & 3.5 & $<.4$ & 1.6 & 5.8 & - \\
\hline
\end{tabular}

\footnotetext{
'Source: Material quantities from Radioactive Scrap Metal Recycling: A DOE Assessment, US DOE report, October 1991.
} 
- Increase recycle,

- Reduce cost through improved technology,

- Reduce storage and maintenance cost, and

- Reduce waste volumes.

Dismantlement activities, for the purpose for the TLD are highlighted in Fig. 5.1 and described below. The D\&D sequence shown is based on study of ongoing D\&D activities at other sites, both DOE and others, but is only one of many possible scenarios.

1. Zone building for containment,

2. Major dismantlement,

3. Transfer to disassembly,

4. Disassembly of components,

5. Sorting of materials for recycle,

6. Removal of asbestos materials,

7. Containment and zoning of structure,

8. Removal of massive concrete, and

9. Deconstruction of building shell.

Zone building for containment: Since the cost of $D \& D$ is sensitive to the eventual disposal cost of the resulting waste it is essential that spread of contamination during dismantlement be minimized to avoid increasing the contamination level of the general building areas. Zoning is the efforts made to isolate areas of the facility in which major dismantlement activities are taking place.

The large diffusion process facilities lend themselves well to zoning. The older K-25 and K-27 facilities are divided by large "withdrawal alleys" and "escape alleys" where temporary walls and enclosures could be constructed to isolate the ongoing dismantlement. The large and newer facilities have crane bays where the major dismantlement will take place. Each crane bay could be treated as an individual dismantlement area. In the K-33 Buildings there are 10 full-length crane bays with a 40-ton crane in each bay. In activity areas during dismantlement, there would need to be smaller areas isolated to further contain possible spread of contamination. The alleys are parallel and the process equipment are in housings between each pair of alleys.

Figure 5.2 shows a typical "withdrawal alley" in the K-25 Site facility, one of many in that building.

The dismantlement of the major equipment would progress from one alley or bay to the next until all contaminated equipment will have been removed. If zoning and containment is properly done the remaining structure will have a minimum of additional contamination and could be characterized and decontaminated selectively before building deconstruction or decontamination for re-use.

Major dismantlement: Major dismantlement, for the purposes of this discussion, includes activities associated with removal of major pieces of process equipment from its current location. The equipment would then be transferred to a disassembly/decontamination area. Included in this equipment are converters, compressors, valves, instrument cabinets, transformers, capacitor banks, and large sections of piping and any enclosures to be removed to gain access to these. 


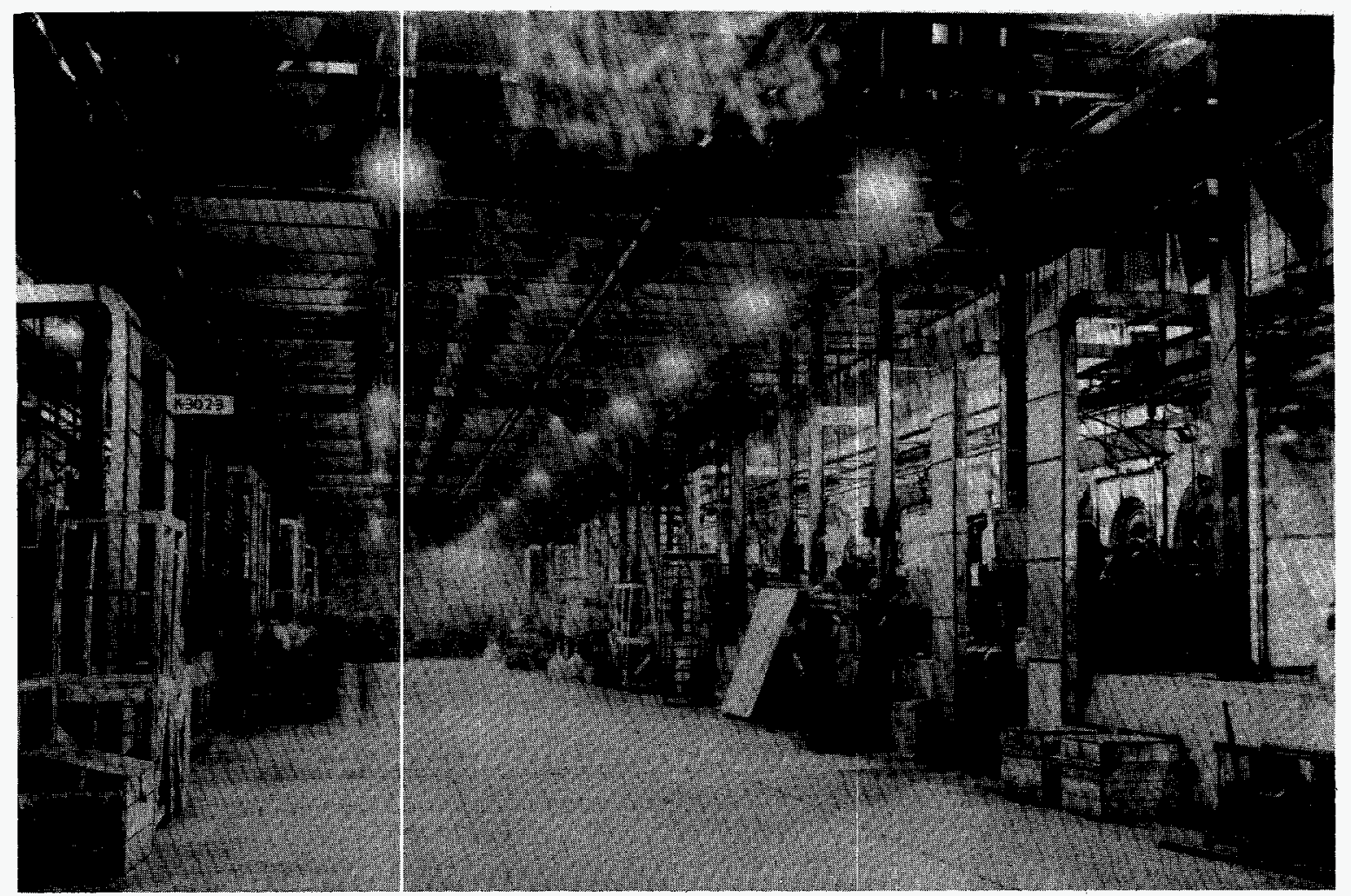

Fig. 5.2. One of the "withdrawal alleys" In the K-25 Site facllity.

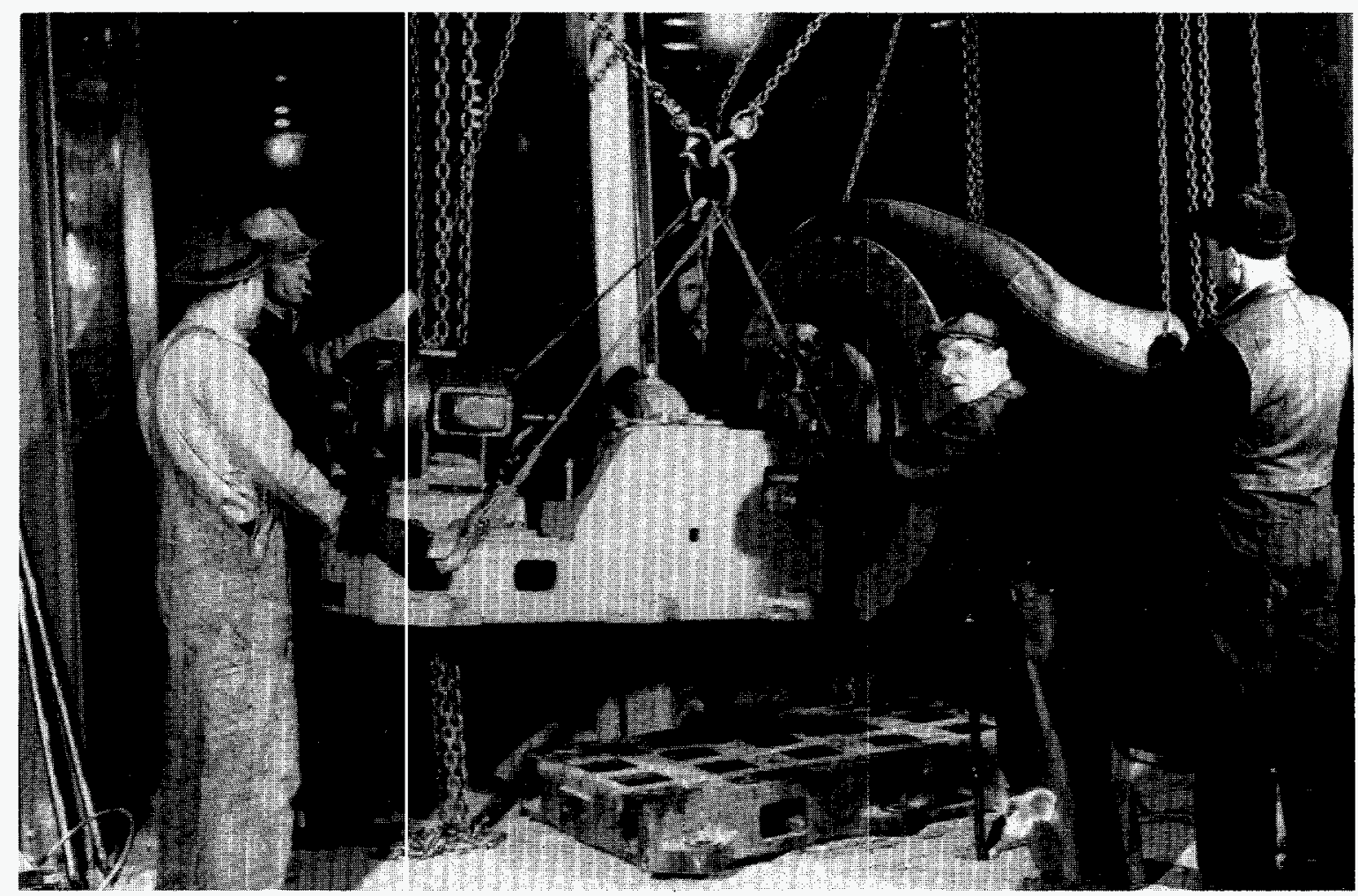

Fig. 5.3. Compressor and drive being Installed during construction in 1944. 
When the major equipment items were installed they were preassembled elsewhere and moved with special transfer fixtures to the process locations. No assembly of components was done in place. Figure 5.3 shows a compressor and drive being installed during construction in 1944. Figure 1.4 shows a large axial flow compressor ready for installation in the $\mathrm{K}-33$ building. Dismantlement of the facilities would be done essentially in reverse, whereby equipment would be removed in units and disassembled elsewhere. The major dismantlement task would then concentrate on removal of components and transfer, with special fixtures, to the disassembly/decontamination area.

Disassembly of components: This phase of dismantlement will involve the disassembly of the major components into a sorted inventory of the basic materials of construction. Emphasis has been placed on disassembly of components to make recovery of the sorted raw materials for recycle more achievable. The diffusion plant facilities included a converter shop, compressor shop, motor shop, piping shop, just to name a few. These component assembly facilities remain in various stages of maintenance. Refurbishment of these facilities or, as a minimum, duplication of the existing designs for the disassembly tooling may prove practical. Automation of these activities appears to be very beneficial.

Sorting of materials for recycle: The product of dismantlement is assumed to be sorted raw materials that are ready for decontamination/recycle by the disposition processes chosen.

Removal of asbestos materials: The first step in "deconstruction" of the building will be removal of asbestos-containing materials. If the zoning and decontamination is successful the building shell will have a minimum amount of increased surface contamination. The removal of asbestos will proceed in two phases:

1. Remove internal components including pipe insulation, remaining transite in cell housings, tile floors, and other items.

2. Remove transite siding on building and replace with metal siding. This step is required to avoid radioactive contamination of asbestos materials and mixing of wastes. The metal siding will provide containment of any dust generated during removal of concrete and nonstructural steel components that remain within the building shell. It may be possible to avoid the step of installing new siding if contamination of the internal surfaces of the building shell can be prevented or removed by other means.

Containment and zoning of structure: The empty building shell will require zoning to assure that encountered contamination is not spread within the structure. The zoning of the shell will not be as extensive as the zoning required for dismantlement but may be constructed at the same points and may use the existing materials from the previous zoning activity. 
Removal of massive concrete: Concrete will be removed within the enclosed shell and would result in an empty shell with a gravel/soil floor. The resulting materials from this step would be rubbled concrete.

Deconstruction of kuilding shell: This step involves the removal of the shell which includes siding and structural steel. The product of this step is large quantity of structural steel suitable for handling by the disposition processes.

Figure 5.4 shows typical concrete and steel construction in the older diffusion facilities. The photo is taken from the basement looking up at steel that now supports the major diffusion equipment.

\subsubsection{Problem statement}

The diffusion facilitits, as described earlier, are expansive and massive with multilevel construction. In all cases significant contamination is within the closed process equipment. Cortamination exists external to the equipment from small accidental releases during past operation and maintenance activities but can be characterized, isolated and removed before opening any process lines.

Diffusion support facilities, such as the plant decontamination facility $(\mathrm{K}-1420)$, is generally contaminated and will need to be extensively decontaminated before dismantlement.

All facilities at the difusion plant site have the following features in common:

1. Massive concrete stuctures: The K-25 Building itself has $200,000 \mathrm{yd}^{3}$ of concrete in the original construction design. There are $650,000 \mathrm{yd}^{3}$ of concrete in the total site.

2. Structural steel: The K-25 Building has 58,000 tons of structural steel within the original designed buildings. There are 180,000 tons of structural steel in the total site.

3. Asbestos materials: The diffusion facility has several forms of asbestos materials.

Transite siding

Transite in equipment enclosures

Piping insulation

Roofing flashing

Floor tile
1.3 million $\mathrm{ft}^{2}$

1.2 million $\mathrm{ft}^{2}$

$300,000 \mathrm{ft}^{3}$

$100,000 \mathrm{ft}^{2}$

$15,000 \mathrm{ft}^{2}$

4. Major dismantlement is required for contaminated process equipment. The equipment in the diffusion cascade is welded into the process lines. This is both a benefit, since virtually all significant uranium materials are well contained and a hindrance since all major items will require removal by some form of cutting. The cutting of the process lines will allow potential spread of contamination unless a well engineered effort is undertaken to provide additional containment during equipment removal.

"See problem area on dismantlement diagram. 


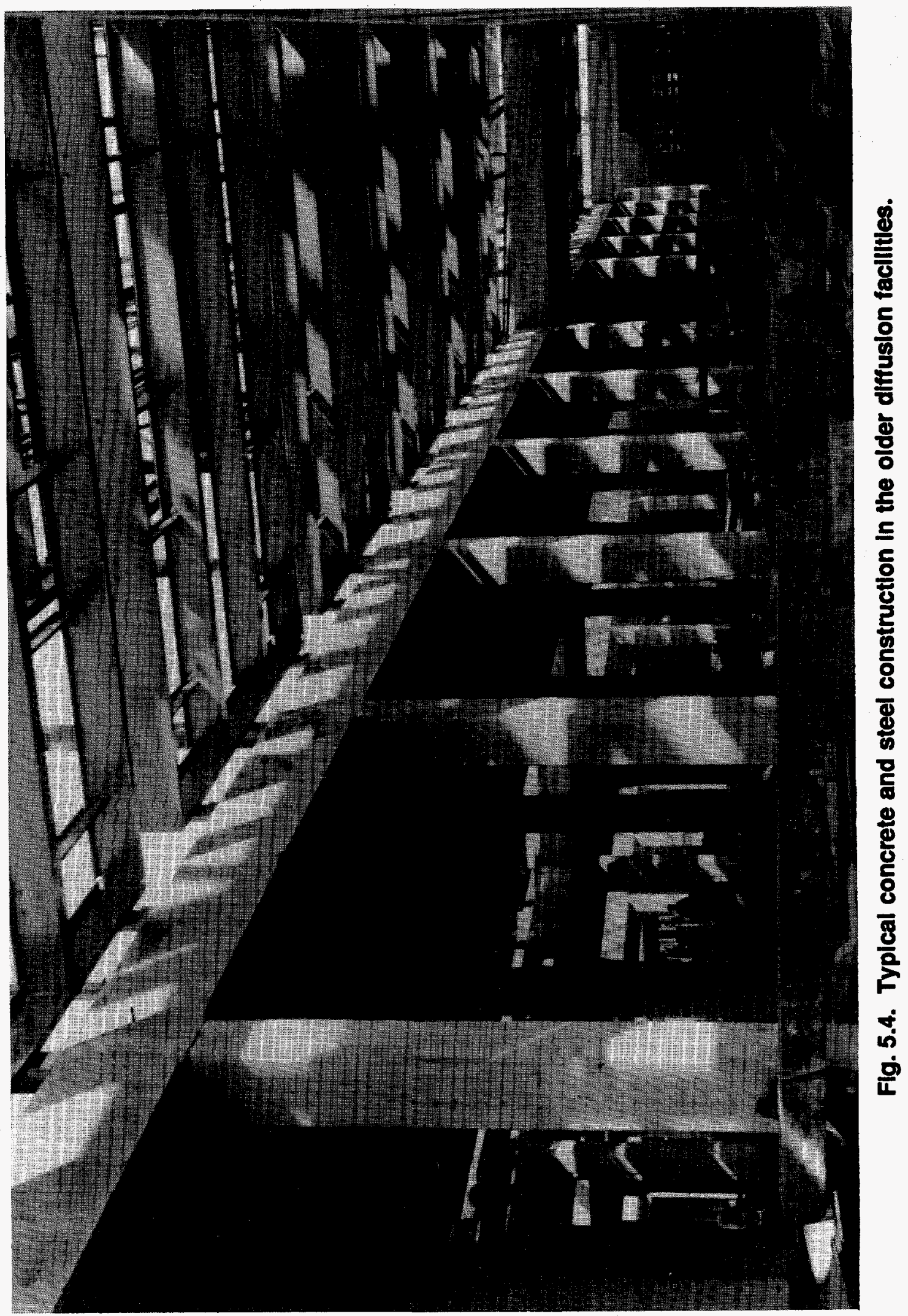

February 26, 1993

Page 5-11 
5. Disassembly of components will be required to allow sorting of the materials before final decontamination and/or sorting of the materials to be recycled. The large diffusion converters, for example, weigh nearly 35 tons and are an assembly of nickel plated steel, monel, porous nickel, and aluminum within a welded shell. The large: compressors, for example, weigh approximately 17 tons and are constructed of the same materials as the converters.

6. Enabling technologies are needed that will allow the development of advanced integrated systems. Configuration verification and configuration definition must be provided to define the existing equipment and structures and is essential to the engineering efforts required to both plan the detailed dismantlement effort as well as allow precise location of automated equipment needed. Configuration management is needed for similar reasons for characterization, decontamination, and robotics. If the configurations of the facilities can be accurately defined, the technologies such as advanced bar coding of equipment locations within the facilities could be used to locate and verify location of mobile robotic tool transporters and robotic dismantlement equipment.

Dismantlement support technologies are needed to permit use of the new tooling more efficiently. These would include new control technologies and better worker protection.

All problems that must be solved to permit dismantlement of the diffusion facilities can be grouped and listed under the above six generic problem headings. The dismantlement techrology options are described in Sect. 5.2. 


\subsection{TECHNOLOGY OPTIONS}

Dismantlement problems can be included in the six categories described under the problem statement (Sect. 5.1.2). Therefore, the TLD addresses each problem and the technologies identified to solve the problem.

\subsubsection{Massive Concrete}

Six technologies were identified that show promise for the removal of massive concrete in gaseous diffusion facilities. These technologies will permit the on-site burial of uncontaminated waste, or the technologies will use on-site burial as fill material for future road construction or foundation fill.

\subsubsection{Structural Steel}

Thirteen technologies were identified for the removal of structural steel. The generic categories are disassembly (breaking the original joints), cutting, and demolition. Massive shearing is the most visible and obvious method used in current ongoing projects. A portable shear on an earth moving machine is used to "bite down" large sections of structural steel framing. The structural steel problem can be dealt with by using available technologies. The major task will be to minimize the contamination of the steel structure before dismantlement so that the resulting material can be disposed of or recycled at minimum cost.

\subsubsection{Asbestos Materials}

Five technologies were identified for the removal of asbestos materials. The generic categories are either to cut the asbestos loose or strip it away. Both scenarios will require packaging of loose asbestos materials and reduction and/or collection of airborne asbestos. The focus of the overall dismantlement activities related to asbestos must keep the asbestos from becoming more contaminated so that the resulting materials can be disposed of at minimum cost. Also, containment of any contaminated asbestos or matrix materials dust must be achieved during removal.

\subsubsection{Major dismantlement}

Eight technologies were identified for removing equipment from diffusion facilities. Five technologies involve some form of cutting, since the equipment is welded into place. One technology that was identified can greatly enhance the automated location of equipment. All of the technologies are commercially available. The major task in applying these systems will be to cut the contaminated piping while containing the contamination within the process piping. One of the challenges of conducting these dismantlement tasks is maintaining the proper engineering of the containment systems to provide safety for workers. A combination of dismantlement and robotics will remove the worker from the actual cutting site and automation of the repetitive tasks will provide maximum benefits.

Figures 5.5 and 5.6 depict concepts that were considered during the technology identification stage. Figure 5.5 illustrates the older (1940s) process equipment and Fig. 5.6 illustrates the later (1950s) process equipment. 


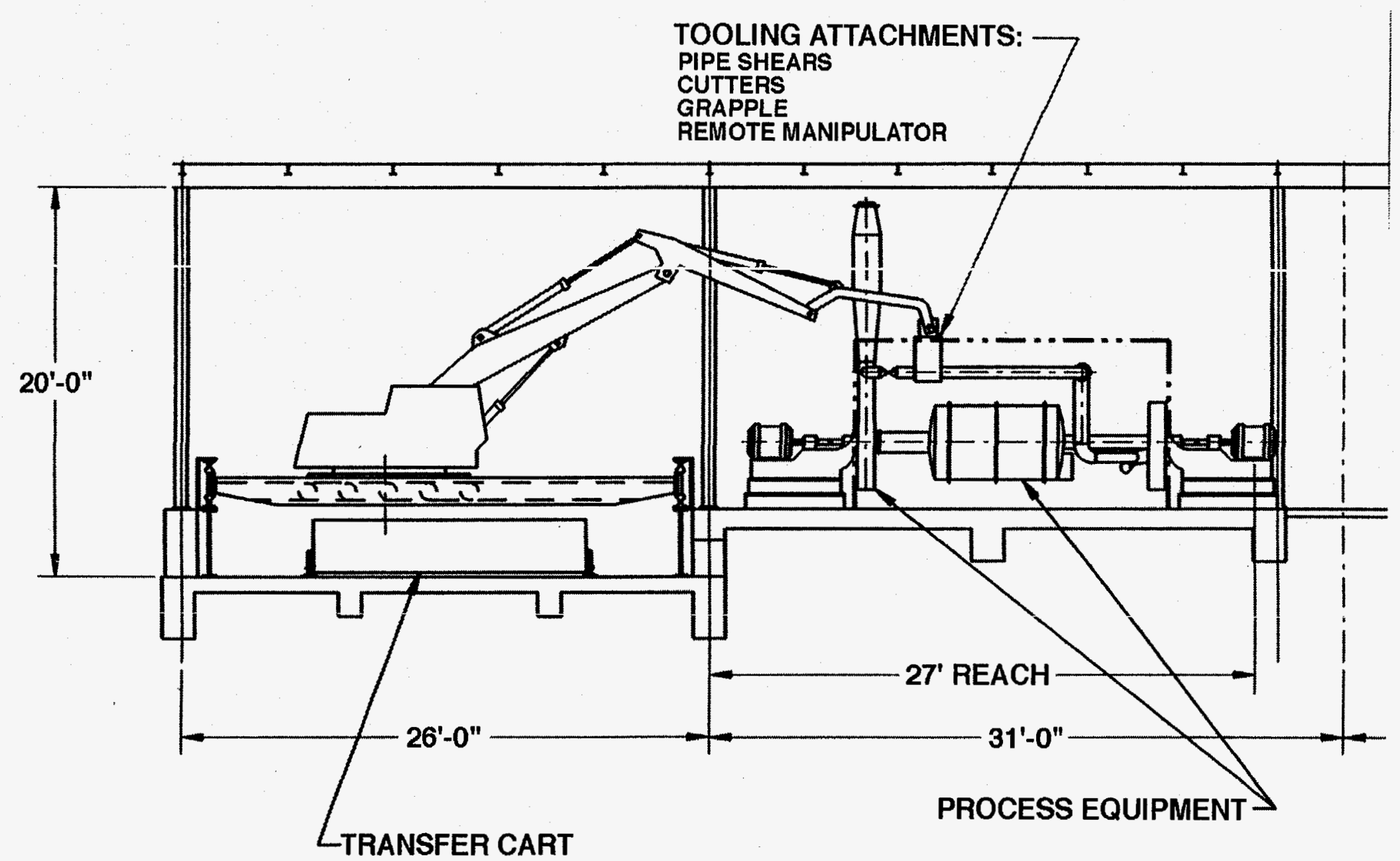

Fig. 5.5. Concept for automated dismantlement of older (1940s vintage) diffusion equipment. 


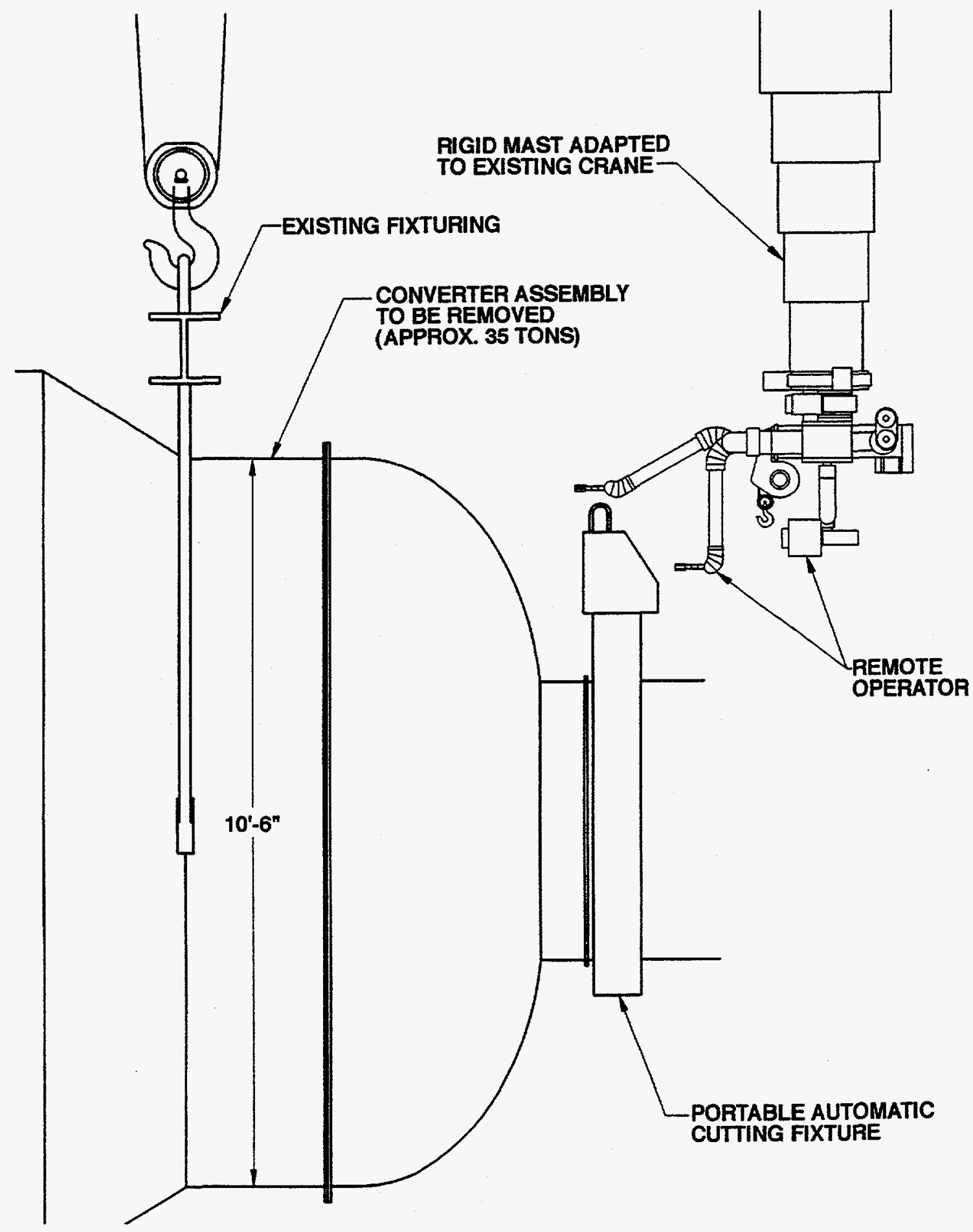

Fig. 5.6. Concept for dismantlement of newer (1950s vintage) diffusion plant equipment. 


\subsubsection{Disassembly of major components}

Eleven technologies were identified for possible use in the disassembly of components in an arec. separate from the process areas. Several of these technologies are similar or identical to those used in major dismantlement. The primary cost to implement these technologies will be the design and procurement of fixturing to hold the component and deliver the tooling to the work point. A combination of dismantlement and containment techniques will benefit the workers by separating them from the actual cutting site. Currently at the Y-12 Plant, uranium is machined without loss from the cutting site with relatively simple hooding and shrouding techniques. Even the burning of uranium metal chips produces easily controlled dust. The background experience that Oak Ridge has in operating diffusior plants and the current Y-12 Plant operation support the conclusion that cutting metal contaminated with uranium compounds is a simple problem to overcome.

\subsubsection{Enabling Technologies}

Thirteen technologies were identified in these areas. These technologies will, if properly engineered into the overall $D \& D$ of diffusion plants, provide benefits to dismantlement as well as; other tasks. Current as-built information is deficient in detail suitable for the accurate description of what is in the contaminated facilities. Diffusion equipment has been removed, modifications have been made, and items have been stored in the facilities without accurately updating of engineering information.

Examples of benefits from enabling technologies within configuration verification and configuration definition alternatives include:

1. updated engineering drawings for the facilities to be dismantled,

2. accurate 3-dimensional inventories of uranium and other materials,

3. reasonably accurate location of equipment to permit positioning of automatic dismantlement tooling,

4. dismantlement tooling utilization planning to aid the scheduling of equipment and manpower,

5. real-time status feedback to deconstruction schedules and progress reports,

6. continual waste and recycle materials tracking,

7. query capability for investigation of alternative approaches and processes,

8. accessible data for establishing a common mission and goals plan, and

9. conceptual 3-dimensional modeling capability for studying other technologies without actual procurement of equipment.

All of the technologies identified in the configuration verification, and configuration definition are intended to enhance or improve the available engineering data bases. Computer-based data bases that would provide accurate 3-dimensional data can be generated. This data could be used to record characterization, decontamination data, equipment locations, and related technologies by specific location in the facilities. Then this data could be used to guide automated tooling and/or robotics during the dismantlement process while providing a real-time automatic updated data base. 
There is no indication that the straightforward $D \& D$ of a diffusion plant justifies the technologies in this category that are beyond the state-of-the-art at this time; however, assuming that experience data from the diffusion plant D\&D effort will be utilized in facilities where the site problems are more severe (Hanford, Fernald, Savannah River, and ORNL) any demonstration of state-of-the-art configuration verification and configuration definition techniques would provide guidance in the future on these D\&D efforts. In fact, the K-25 Site facilities could be viewed as potential candidates for Integrated Demonstrations and/or test beds to serve as surrogates for facilities at other sites where remote equipment and tooling are essential. Therefore, the study group recommends including these technologies into any future $D \& D$ development effort or demonstration.

Two enabling technologies were identified under the alternative of Dismantlement Support. These are an automation technique for directing cutting called "point and direct" and "updated designs for protective clothing." Discussion is required to emphasize the need for updated protective clothing.

Although two different types of radiation worker protection can be considered, radiation shielding and radioactive material ingestion protection, the ingestion protection is most important. Historically, diffusion plant workers have received lower external radiation doses than other nuclear industry workers. During the diffusion plant Cascade Improvement Project in the 1970s, for example, annual doses on the order of 125 mrem were recorded for those workers who had direct contact with contaminated diffusion cascade equipment. Direct ingestion of radioactive contaminants is of greater concern. The principle ingestion route is breathing contamination-laden air. Improved protective clothing and equipment designs are important in minimizing worker internal doses due to this mechanism.

The studies to the time of this document have put emphasis on the use of currently demonstrated technologies. Among the high cost items included in this analysis is their dependency on labor intensive techniques and the necessary protective clothing. Experience indicates that 30-50\% of the cost can be attributed to reduced crew efficiency due to protective clothing and equipment required. This cost can be offset by automated dismantlement tooling and sophisticated delivery systems thereby reducing manual labor and to improving protection to D\&D workers.

Some manner of manual work will always be required regardless of the degree of automation used in the dismantlement tasks. To this degree the development of improved (cheaper, recyclable, lighter, more convenient to use, etc.) protective equipment is certainly justified.

New more efficient versions of clothing and protective equipment have the potential of saving vast sums of money and labor. Respirators, face mask, air packs, cloth suits, air-tight suits, gloves, shoe covers, laboratory coats, airconditioned and filtered equipment cabs, etc., need improved designs to reduce cost in a massive dismantlement project such as a diffusion plant and its' support facilities. 


\subsection{SCIENCE AND TEC:HNOLOGY NEEDS}

\subsubsection{Massive Concret!}

Massive concrete is currently being removed from several nuclear facilities in the United States. All technologies will need refinement for application to a diffusion facility. Primarily we need to develop integrated support systems including off-gas contairument and scale up. No significant science deficiencies were identified.

\subsubsection{Structural Steel}

Structural steel, like :nassive concrete, is being removed from several nuclear facilities in the United States. With the exception of conventional disassembly, all technologies identified are some type of cutting. Lasers appear very promising for application to nuclear facilities. The most significant need is to develop fiber optics delivery systems capable of carrying the power levels needed. Fiber optics delivery would prevent contamination of the laser source equipment. The laser generator could be located remotely and the expensive maintenance required for contaminated equipmerit could be avoided. At PennState Applied Research Laboratory related development and demonstration is proceeding for U.S. Navy programs. Through visits; to other D\&D sites it is apparent that massive shearing using large hydraulic sliears to remove sections of the steel structure is also favored. Chip generating; saws can be used if adequately contained as has been proven with uranium metal.

\subsubsection{Asbestos Removal}

Containment of asbestos dust continues to be challenging. Lasers have been used at PennState to cut asbestos pipe insulation with no release of airborne materials. Development and a large scale demonstration of this technique for diffusion plant application could be a very significant achievement.

\subsubsection{Major Dismantleınent}

Removal of diffusion equipment involves large: and repetitive equipment. Integration of cutting tooling with robotics and containment systems is essential. One technology identified is Bar-Code/Laser Tool Location, which could greatly enhance tool positioning and needs to be demonstrated in a program for diffusion facilities. Also, as in asbestos and structural steel dismantlement, lasers hold great promise but need to be demonstrated for diffusion plant application. An integrated demonstration of laser cutting and laser tool platform location would be significant.

\subsubsection{Disassembly of Components}

No significant science needs were identified. Many small scale integration demonstrations of autornation, tooling, and robotics are needed. 


\subsubsection{Configuration Verification, Configuration Definition, and Dismantlement Support}

In these three areas are the greatest science needs for dismantlement. All science needs in this problem area are related to development of faster computers with better data entry methods and man-machine interfaces. Robotic platforms delivering Automated Tooling to 3-Dimensional Mapped facilities using Bar-Code positioning requires development and demonstration. This cannot be achieved in today's computer environment at the desired rates without undue risk of uncontrolled cost and risk of failure. A large Integrated Demonstration with a phased development approach could result in major cost savings. Sect. 5.2 discusses the implementation needs for dismantlement.

The need to develop these configuration management technologies is not necessary for the straightforward D\&D of a diffusion facility; however, there are many facets of dismantlement as well as all other tasks that would benefit from advances in computer technologies. Computer technology is moving forward at such a pace that "timely borrowing" may prove adequate for D\&D purposes that is "borrowing" of the best commercial technology available at the appropriate time. Since this field is moving at such a pace, only the mention of a need to the appropriate computer applications firm would most likely result in eventual beneficial developments. For these reasons computer technologies must always be included in technology needs assessments and the eventual integrated demonstrations of those selected technologies. 


\subsection{IMPLEMENTATION NEEDS}

Significant engineering effort will be required in all dismantlement problem areas to develop specifications for equipment to do dismantlement tasks. After development of methods indicated in $S / T$ Needs it will require a significant engineering effort to specify the dismantlement tasks to assure that these new technologies are specifically used in the field. "Technology Transfer" from the Development Firm to the "Deconstruction" Contractor will require careful engineering monitoring and follow-up.

A method called "Front-End Engineering" has been successfully used in Oak Ridge to conceptually lay out the major details of a task -2 years before contracting to construction contractors. Implementation needs for dismantlement would enhance the ability to prepare a detailed Front-End Engineering Package.

\subsubsection{Massive Concreti}

Several significant implementation needs were identified for massive concrete removal. Many items were noted that can be called detailed design needs: interfacing with robotics, recovery of abrasives, multiple heads on tooling, more experience with technolcigy, and demonstration on a larger scale were listed. All of these issues would be resolved in an adequate integrated design and demonstration at a diffusion facility.

\subsubsection{Structural Steel}

As in massive concrete several significant implementation needs were found to permit inclusion of the technologies in an integrated demonstration.

\subsubsection{Asbestos Removal}

An Integrated Demonstration is needed to test the more promising technologies. Laser cutting is especially promising if a demonstration verifies that cuts are self "cauterizing,."

\subsubsection{Major Dismantleınent}

An integrated demonstration of selected technologies is needed to determine extent of contamination release during cutting of diffusion systems. Other topics to address are shrouding;, optimized tooling, lessons learned from other sites, and efficiency of robotics delivery systems.

\subsubsection{Disassembly of Components}

No significant technology implementation needs over those stated for Major Dismantlement are neecled. Integration of Robotics and Automation into tooling designs must be addressed in a significant demonstration. 


\subsubsection{Configuration Verification, Configuration Definition, and Dismantlement Support}

Implementation of these technologies will require a significant cooperative effort between suppliers and on-site contractors to develop the needed technology to the point of production application. A significant Integrated demonstration of these technologies is needed to verify function and reliability of equipment. Deconstruction contractors must use available on-site expertise and engineering to use data from integrated demonstrations to avoid duplication of ongoing programs. 


\subsection{TECHNOLOGY RAINKINGS FOR THE K-25 SITE}

\subsubsection{Introduction}

Selection of technologies for future development and use in the $D \& D$ of the diffusion plants is a difficult task because of the multidimensional trade-offs that must be made including significant uncertainty relative to availability, complexity, and cost of technologies that appear applicable but have not been demonstrated and/or accepted at the diffusion plant sites. This section of the report attempts to evaluate all technologies in a systematic way and recommend those showing the most potential for future: development. This development should occur through inclusion in future dernonstrations or in ongoing development activities at appropriate installations. The data show that directed $R \& D$ of the recommended candidate technologies will significantly reduce the cost of $D \& D$ of a diffusion plant. Also, benefits can be further magnified if candidate systems result in spinoff benefits to other DOE sites through the sharing of engineering documentation or actual hardware transfer.

\subsubsection{Ranking System}

Criteria was generated for evaluating technologies by listing those concerns that will be most prominent in the mind of engineers and program operators when it is time to select applice.ble technologies for inclusion in the systems required for dismantling the various diffusion plant facilities. Figure 5.7 lists these criteria under four major categories:

1. Safety/Environment and Public Health

2. Effectiveness

3. Implementability

4. Payback Potential

Each of these major categories were broken down into subcategories reflecting detailed concerns that evolved during the generation of the TLD and supporting data sheets. The detailed ranking criteria are listed under the major categories in Fig. 5.7.

\subsubsection{Ranking Criteria}

The technologies were ranked for each of the criteria individually. These rankings are given in Table 5.4. The ranking criteria is listed in summary across the top of Table 5.4 and all dismantlement technologies identified in the TLD are listed on the left side, creating the ranking matrix. A letter representing the relationship between criteria and technology was determined and inserted in the corresponding slot in the matrix as follows:

- $\mathrm{H}=$ Highly desirable-the technology is projected to strongly satisfy this criteria.

- $M=$ Moderately desirable - the technology will be acceptable but others are better. 


\section{Safety/Environment/Public Health}

- Significant improvement in worker safety over conventional dismantlement.

- Confidence level that the technology can be used in a manner that ensures a safe environment.

\section{Effectiveness}

- Minimization of secondary waste streams

- Improvement in worker efficiency (Reduction in labor required vs base case)

- Demonstrated success in on-going D\&D sites visited

- Reliability/Maintainability of resultant equipment (Will the equipment operate without large downtime penalties or undue maintenance shut-downs and calibrations?

- Potential to enhance recycle of materials (Does the technology produce recyclable materials)

- Applicability to other teams needs (Can the technology be applied to characterization, decontamination, etc.?)

- Minimization of overall waste quantities (The ability of a technology to reduce total waste volumes)

\section{Implementability}

- Time and cost to demonstrate (Can the technology be demonstrated before need in 2007 without excessive cost?)

- Automation potential (Can the technology be automated to the level needed for the scale of a diffusion plant?)

- Technical Risk (Confidence the technology will work at the scale needed)

- Complexity of the application (Can the technology be applied without excessive set-up labor and/or training requirements?)

\section{Payback Potential}

- The total cost to utilize the technology vs. the current baseline

Fig. 5.7. Evaluation criteria summary for dismantlement. 


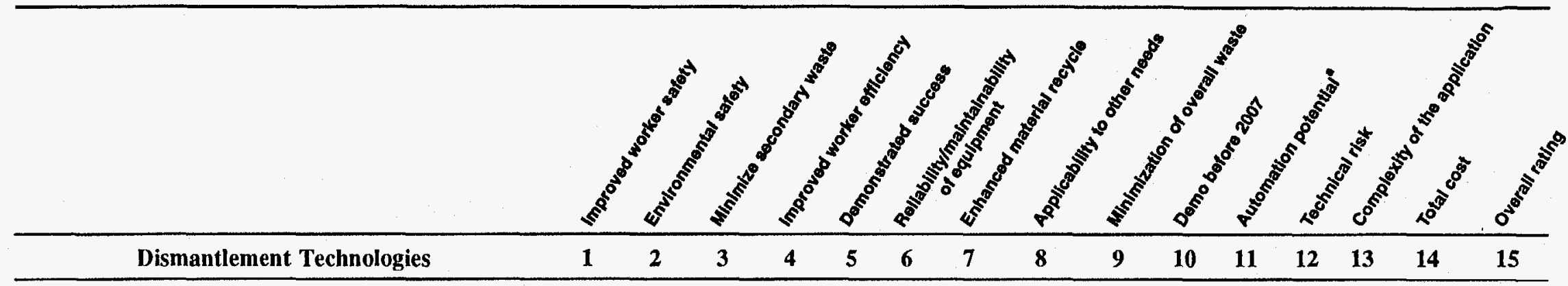

Massive Concrete

Abrasive Jet (High Pressure)

Diamond Wire Cutting

Conventional (Jackhammer, Headache Ball, etc.)

Blasting

Demolition Compounds (Expansive Grout)

Microwave Scabbling

Structural Steel

Qualitative IR Thermography (Crack Detection)

Conventional Disassembly (Cutting, Sawing, Wrench, etc.)

Nd: YAG or $\mathrm{CO}_{2}^{\prime}$ Laser Cutting

Abrasive Water Jet

Plasma Arc Cutting

Arc Saw Cutting

Oxygen Cutting

Plasma Arc Saw

$\begin{array}{ccccccccccccccc}\text { M } & \text { M } & \text { M } & \text { H } & \text { M } & \text { H } & \text { M } & \text { L } & \text { M } & \text { H } & \text { M } & \text { M } & \text { H } & \text { H } & \text { M+ } \\ \text { H } & \text { H } & \text { M } & \text { H } & \text { H } & \text { H } & \text { M } & \text { L } & \text { M } & \text { H } & \text { M } & \text { H } & \text { H } & \text { H } & \text { H- } \\ \text { N/A } & \text { M } & \text { H } & \text { N/A } & \text { H b } & \text { H } & \text { M } & \text { L } & \text { M } & \text { H } & \text { L } & \text { M } & \text { M } & \text { N/A } & \text { H } \\ \text { M } & \text { M } & \text { M } & \text { M } & \text { M } & \text { H } & \text { M } & \text { L } & \text { M } & \text { H } & \text { M } & \text { M } & \text { H } & \text { M } & \text { M } \\ \text { M } & \text { H } & \text { M } & \text { L } & \text { M } & \text { M } & \text { M } & \text { L } & \text { M } & \text { M } & \text { L } & \text { L } & \text { M } & \text { L } & \text { M- } \\ \text { H } & \text { M } & \text { M } & \text { L } & \text { L } & \text { M } & \text { M } & \text { H } & \text { M } & \text { M } & \text { M } & \text { L } & \text { M } & \text { M } & \text { M- }\end{array}$

$\begin{array}{llllllllllllllll}\text { M } & \text { H } & \text { M } & \text { L } & \text { L } & \text { L } & \text { L } & \text { H } & \text { M } & \text { L } & \text { L } & \text { L } & \text { L } & \text { M } & \text { L+ }\end{array}$

$\begin{array}{llllllllllllllll}\text { N/A } & M & \text { M } & \text { N/A } & \text { M } & \text { H } & \text { M } & \text { L } & \text { M } & \text { H } & \text { L } & \text { H } & \text { L } & \text { L } & \text { L+ }\end{array}$

$\begin{array}{lllllllllllllllll}\text { H } & \text { H } & \text { H } & \text { H } & \text { L } & \text { M } & \text { M } & \text { M } & \text { H } & \text { L } & \text { M } & \text { M } & \text { L } & \text { H } & \text { M+ }\end{array}$

$\begin{array}{llllllllllllllll}\text { M } & \text { M } & \text { M } & \text { M } & \text { M } & \text { H } & \text { M } & \text { L } & \text { M } & \text { M } & \text { M } & \text { H } & \text { M } & \text { M } & & \text { M }\end{array}$

$\begin{array}{llllllllllllllll}\text { M } & \text { H } & \text { H } & \text { M } & \text { H } & \text { H } & \text { M } & \text { L } & \text { M } & \text { H } & \text { H } & \text { H } & \text { H } & \text { M } & \text { H- }\end{array}$

$\begin{array}{llllllllllllllll}\text { M } & \text { M } & \text { L } & \text { L } & \text { L } & \text { L } & \text { M } & \text { L } & \text { M } & \text { M } & \text { M } & \text { L } & \text { M } & \text { M } & \text { M- }\end{array}$

$\begin{array}{lllllllllllllll}\text { N/A } & M & \text { M } & \text { N/A } & \text { M } & \text { H } & \text { L } & \text { L } & \text { L } & \text { H } & \text { L } & \text { H } & \text { H } & \text { H } & \text { M- }\end{array}$

$\begin{array}{lllllllllllllll}\text { M } & \text { L } & \text { M } & \text { M } & \text { L } & \text { L } & \text { M } & \text { L } & \text { M } & \text { H } & \text { M } & \text { L } & \text { L } & \text { M } & \text { L+ }\end{array}$ 


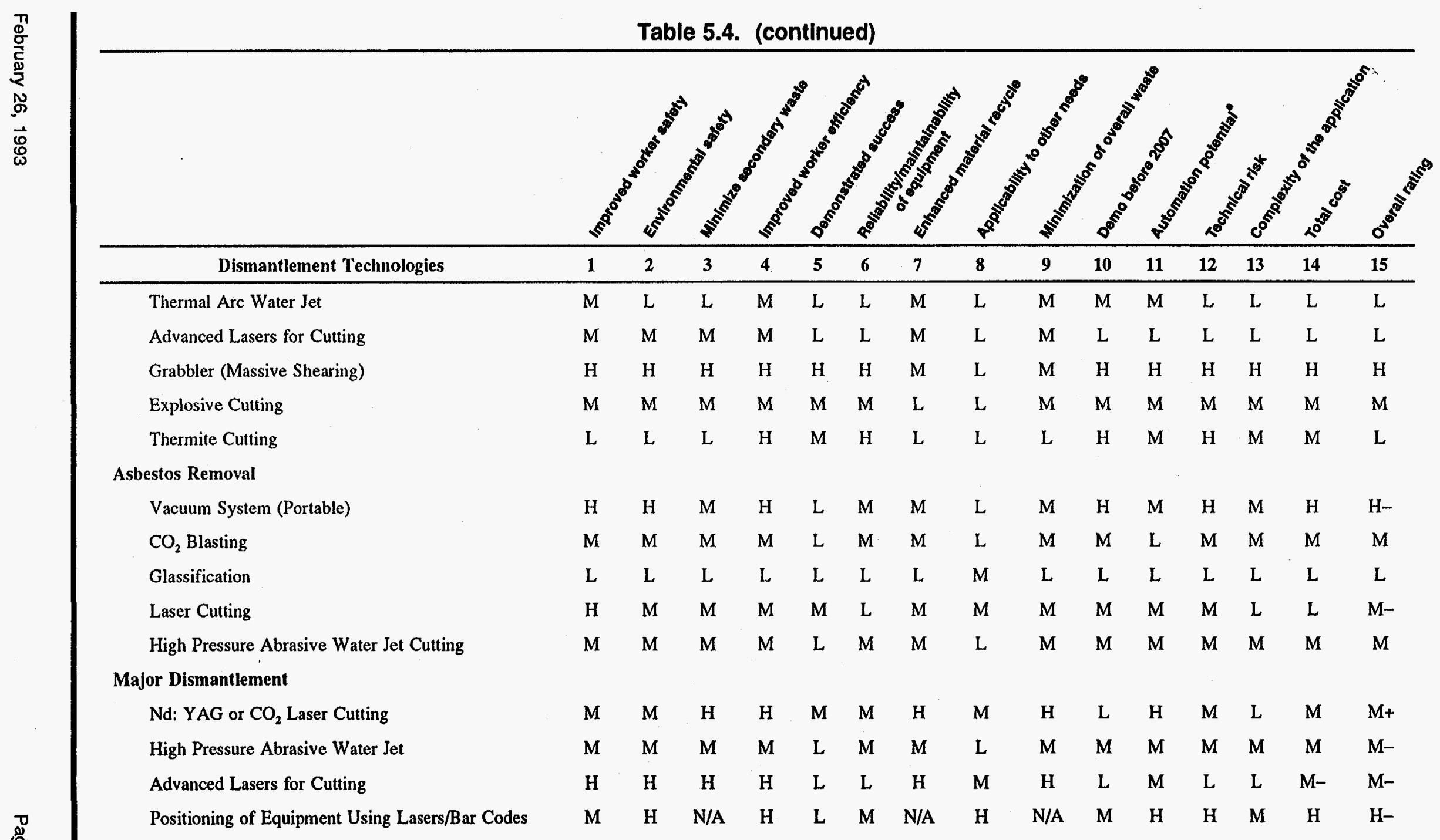




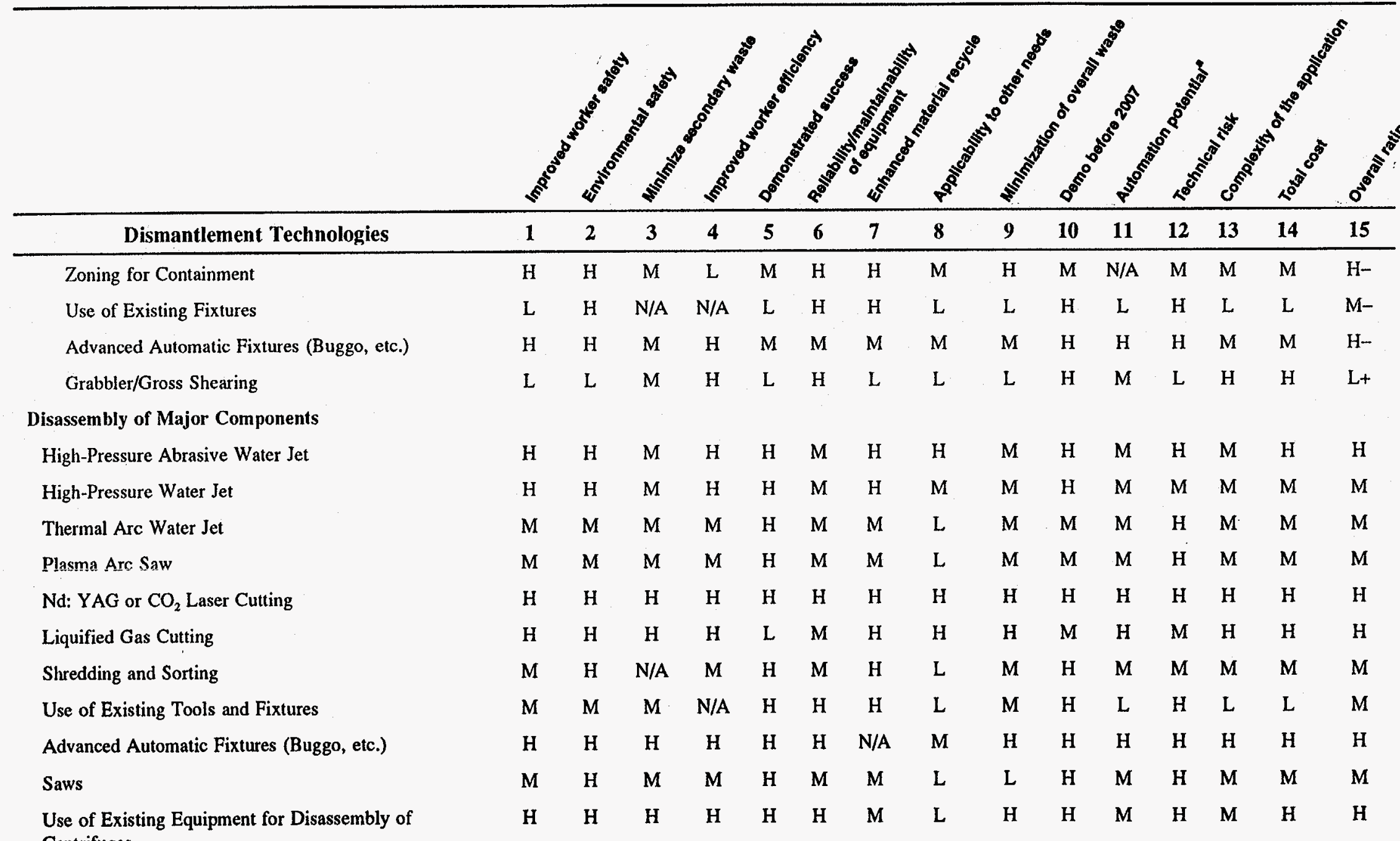

Use of Existing Equipment for Disassembly of
Centrifuges 
Table 5.4. (contlnued)

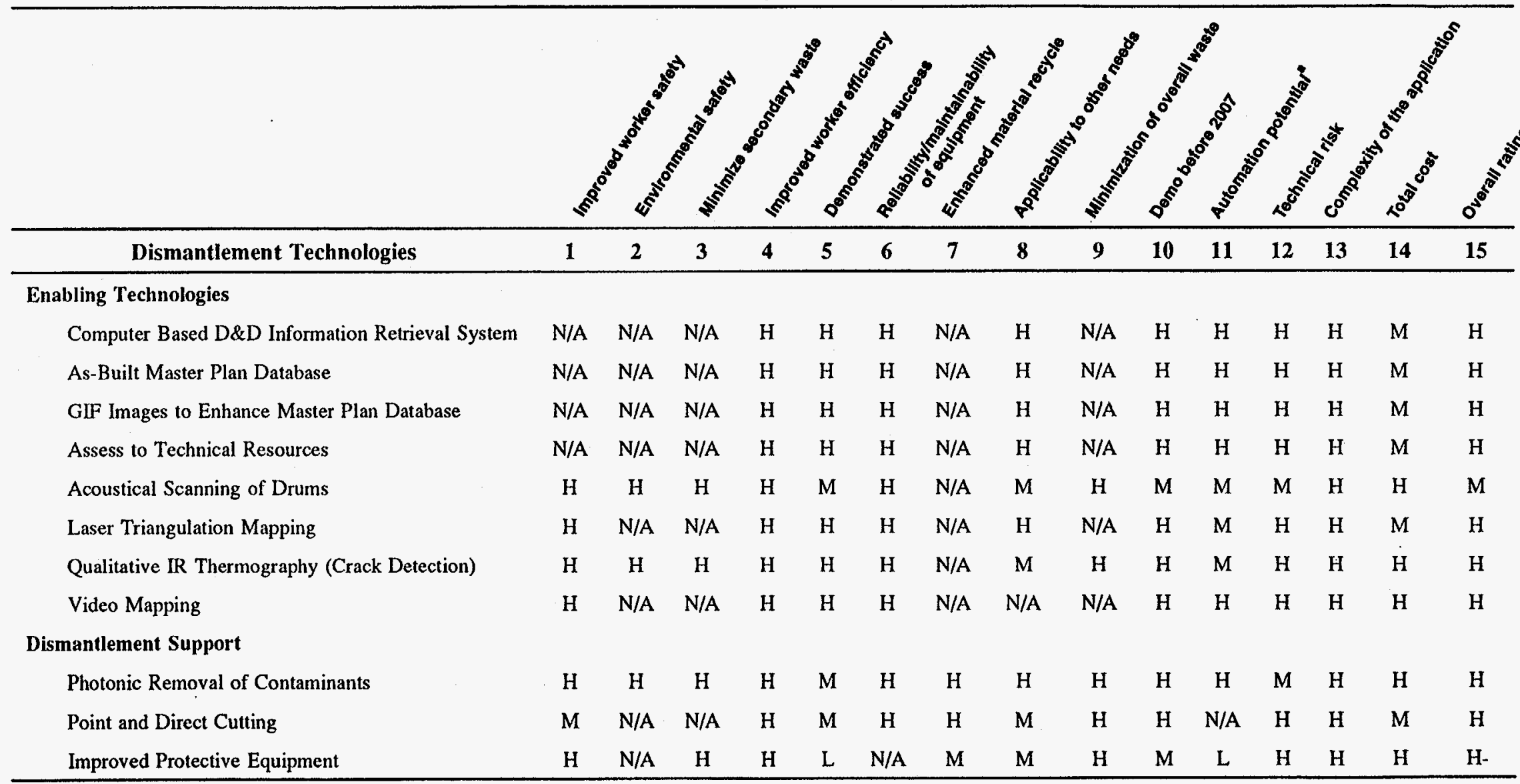

${ }^{a}$ When integrated with Robotics. 
- $\mathrm{L}=$ Low desirability - the technology is marginally acceptable.

- $\mathrm{X}=$ Adverse results expected-the technology violates the criteria.

- $\mathrm{N} / \mathrm{A}=$ Not Applicable-the criteria does not apply to the technology.

\subsubsection{Ranking Procedure}

Each technology criteria relationship was evaluated based on data collected during the generation of the individual data sheets in Vol. 3. This data resulted from trips to ongoing I \&D sites, vendor contracts, video tapes provided by vendors, visits to university research centers, interviews with experienced diffusion experts, and engineered systems concepts generated during the study. The final rating placed in each slot required integration of all pertinent data using the professional judgement of the authors of the Dismantlement section of this document.

\subsubsection{Conclusions From Ranking Exercises}

Technologies exist that if developed to the "accepted level" can reduce the D\&D cost of a diffusion facility. The most advantageous application of any dismantlement technology requires its incorporation into a dismantlement system. When designed, these systems would include not only dismantlement technologies, but possibly all of the teams needs merged into one or more systems. An example of this approach is shown in Fig. 5.8. In this figure four technologies are identified and incorfiorated into the concept. Furthermore, decontamination and characterization teclunologies may use the same "delivery system," magnifying the potential benefits.

The most promising technologies are listed below. All of the technologies will require a timely and adequate demonstration in an integrated demonstration, and proper specifications must be prepared by Engineering based on data available after completion of integrated demonstrations.

Dismantlement technologies are grouped by the K-25 Site Problem for Dismantlement. The ranking of the technologies is based on perceived benefits assuming that they are a.dequately addressed in an integrated demonstration and that proper specificatior.s are prepared by Engineering based upon development and engineering data available after completion of integrated demonstrations.

Massive Concrete. .he most promising technologies are:

- Diamond Wire Cutting,

- High Pressure Abrasive Jet, and

- Conventional/Robotic Integration.

Potentially promisinģ if development and engineering proves favorable:

- Expansive Grout,

- Microwave Scabbing, and

- Controlled Blasting. 


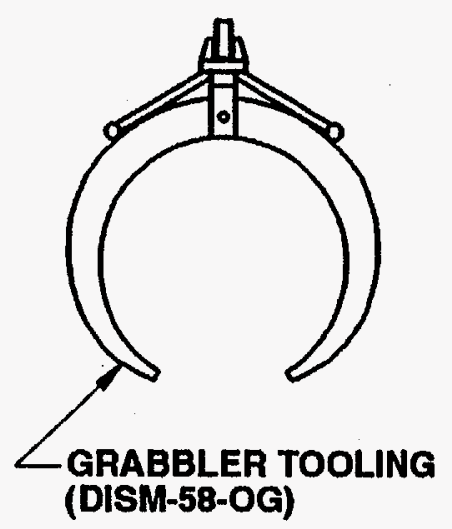

(DISM-58-OG)

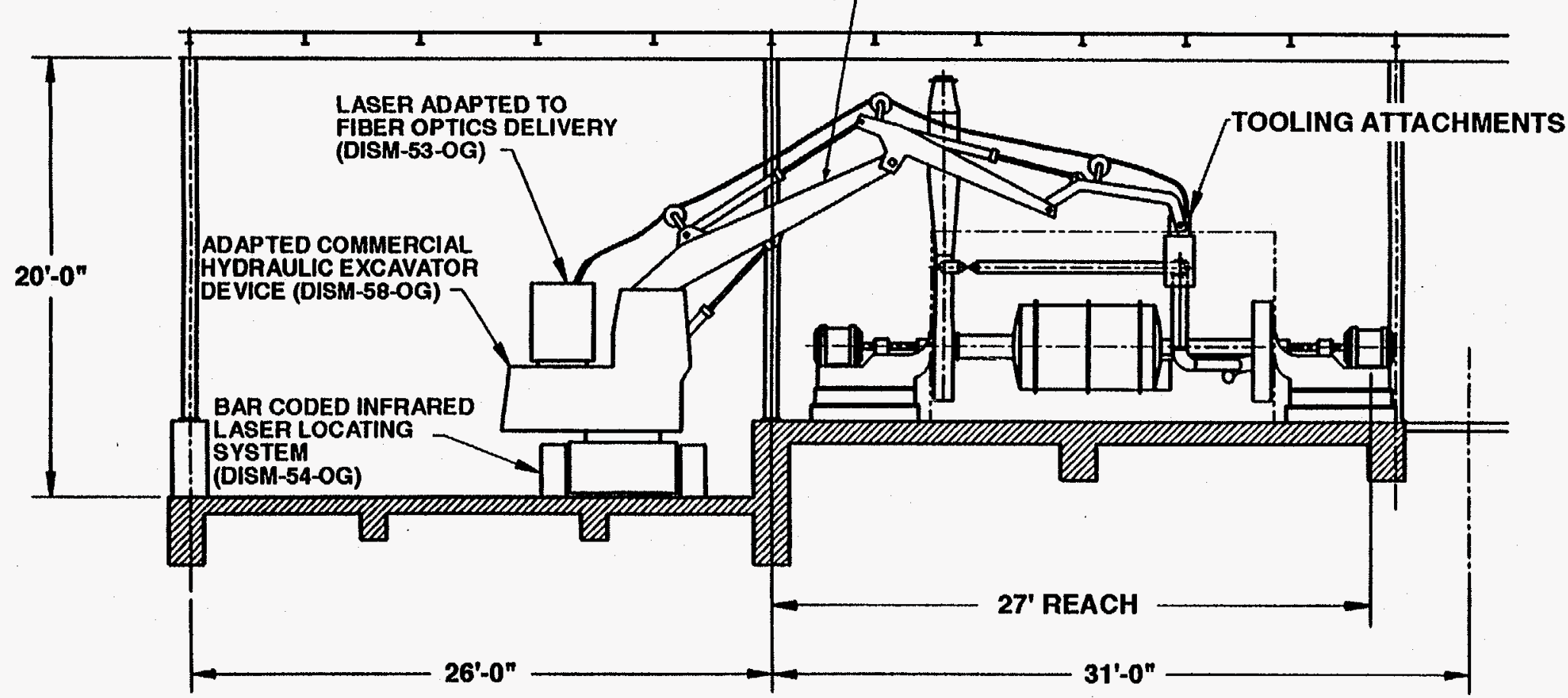

Fig. 5.8. Integrated diffusion facility dismantlement concept conceptual design for highly enriched uranlum facility. 
Structural Steel. The most promising technologies are:

- Massive Shearing,

- Nd:YAG or $\mathrm{CO}_{2}$ Laser Cutting, and

- Plasma Arc Cutting.

Potentially promising if development and engineering proves favorable:

- Explosive Cutting,

- Plasma Arc Saw, and

- Abrasive Water Jet.

Asbestos Removal. The most promising technologies are:

- Conventional removal. (with portable high power vacuum system), and

- Laser Cutting.

Potentially promising if development and engineering proves favorable:

- Abrasive Jet,

- $\mathrm{CO}_{2}$ Blasting, and

- Glassification.

Major Dismantlement. The most promising technologies are:

- Advanced Automatic Fixtures,

- Laser/Bar Code Positioning of Equipment,

- Zoning for Containment, and

- Nd:YAG or $\mathrm{CO}_{2}$ Laser Cutting.

Potentially promising if development and engineering proves favorable:

- Abrasive Jet (High Pressure),

- Advanced Lasers, and

- Use of Existing Fixtures.

Disassembly of Major Components. The most promising technologies are:

- Nd:YAG or $\mathrm{CO}_{2}$ Laser Cutting,

- High Pressure Abrasive Water Jet,

- Advanced Automatic Fixtures,

- Use of Existing Equipiment For Centrifuge Disassembly, and

- High Pressure Water Jet.

Potentially promising if development and engineering proves favorable:

- Shredding and Sortir.g, and

- Liquified Gas Cutting. 
Enabling Technologies. The most promising technologies are:

- As Built Master Plan Data Base,

- Laser Triangulation Mapping of Facilities,

- Video Mapping,

- Gif Images to Enhance As-Built Information,

- Computer D\&D Information Retrieval System, and

- Technical Resources Data Base.

Potentially promising if development and engineering proves favorable:

- Improved Protective Clothing and Equipment,

- Photonic Removal of Contaminants,

- Point and Direct Cutting, and

- Acoustical Scanning of Drums.

\subsubsection{Recommendations}

All of the technologies listed in Sect. 5.5.5 are applicable to the dismantlement of a diffusion facility. Each technology has an area where it would be of unique benefit if applied. An integrated demonstration of dismantlement technologies is needed and therefore recommended to allow proper conceptual engineering information to be generated and evaluated. From this information, well conceived specifications could be prepared for the eventual large-scale dismantlement equipment. This would avoid the need for conservative selection of currently proven processes. In this dismantlement study, technologies have been investigated individually. Integration of multiple new technologies would magnify the potential benefits. Significant cost and safety benefits would most likely result from the cascading effect in an integrated demonstration.

The integrated demonstration needed would require selection of two areas within the K-25 Site to be dismantled under very controlled conditions. One area is $\mathrm{K}-33$, which would develop techniques and tooling for the larger (1950s vintage) equipment. The other, possibly in $\mathrm{K}-27$, would develop techniques and tooling for the smaller (1940s vintage) equipment. In these areas of the buildings, each of the 20-30 technologies would be applied under controlled conditions and evaluated for efficiency of operation. The technologies could then be integrated either through computer modeling techniques or actual demonstrations. Performing such an Integrated Demonstration at the K-25 Site would have several immediate advantages, including:

- partial, but well cataloged, on-site engineering data bases for as-built condition,

- existing designs for conventional dismantlement tooling (for past maintenance and uprating task),

- on-site engineering personnel and other technical personnel as part of a skilled three-plant organization having extensive experience in many areas, including

- Technology Development

- remote handling,

- glove box design and operation, 
- special tooling design,

- weapons dismantlement,

- gaseous diffusion facility operations and maintenance (conventional disassembly),

- Remedial Action, and

- Waste Management

- project management expertise in all of the above.

Also available and specific to the $\mathrm{K}-25$ Site are:

- radiation hazard-experienced personnel,

- development facilities for laboratory testing,

- integrated staff of health physics, maintenance, and other support groups,

- immediate access to Y-12 and X-10 personnel with readily available related skills,

- minimum hazards to the public because of the isolated location of the facilities, and

- experience in dealing, with uranium contamination (detectable but relatively safe compared to other nuclear hazards). 


\subsection{TECHNOLOGIES UNDER DEVELOPMENT BY DOE}

DOE is currently developing technologies through the EM-30, EM-40, and EM50 program which have the potential for making effective contributions to solving environmental and waste recycling problems at the different DOE sites. Some of these projects may have relevant and beneficial elements with respect to the technologies identified in the K-25 Site TLD. A search of available information on programs funded in FY 1992 was performed to identify the possible matches between technologies in the K-25 TLD and TTPS (or ADSs). A listing of the DOE EM-50 Program Guide for FY 1992 and abstracts for funded EM-50 projects were the principal sources for determining matches and relevancy between TEDS and TTPs. Relevant ADS activities were identified through staff personal knowledge.

In Table 5.5, those projects described in TTP or ADS and determined to be potentially relevant and beneficial are listed by TTP (or ADS) number along with the corresponding relevant Technology Evaluation Data Sheet (TEDS) identifier. Along with the matched TEDS is a succinct statement of the technology approach or problem being addressed in both documents. 


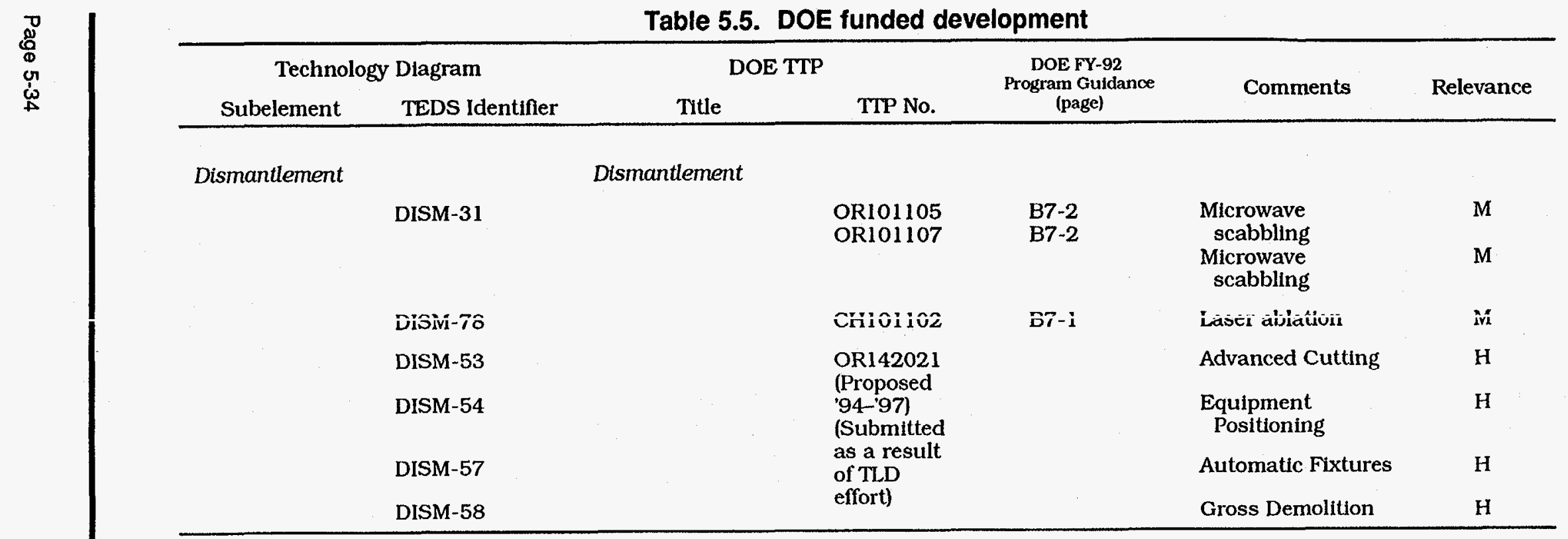


6. Robotics and Automation 


\section{ROBOTICS AND AUTOMATION}

\subsection{INTRODUCTION}

In identifying and assessing the robotic/automation technologies that would be useful for the decommissioning of the K-25 diffusion plant facilities, it was first necessary to understand the deployment needs of the characterization, decontamination, dismantlement, waste management, and remedial action activities. Further, after these needs were defined, it was then necessary to envision the robotic systems that could provide those needs, taking into consideration the type of environment in which the robotic system would be required to operate (e.g., cluttered versus open areas; floors, walls, ceiling, or ducts, etc.). This approach led to the following categorization of technologies identified in the TLD as "alternatives."

1. Mechanical
a. Mobility
b. Manipulation
c. End-effectors
d. Automated Separation Technologies for Material Recovery

2. Controls
a. Algorithms
b. Man-Machine Interface
c. Signal Transmission

\section{Sensors}
a. Perception
b. Control

A total of 45 technologies were identified and grouped into these categories. Also shown on the diagrams is an assessment of the status of each technology, its efficacy, and the S/T and implementation needs required to effectively utilize the technology for decommissioning activities. In the preparation of these diagrams, as well as in the supporting data sheets, several assumptions were made. These are as follows:

- Tools to perform the decontamination and dismantlement tasks will be provided to the robotic device. The responsibility of the robotic activity is to provide the means of deploying these tools. Similarly, the sensors for in situ characterization are the responsibility of characterization personnel and are not a part of the robotics activity.

- In buildings where functional overhead bridge cranes are available, these cranes will be used, when applicable, as a method of deploying robotic devices or characterization, decontamination, or dismantlement tools/sensors. 
As shown in the diagram, many of the robotics/automation technologies that have been identified ar'e considered either to be generally accepted, with few technology or implementation needs to be effectively utilized, or are at a point of maturity where only a demonstration of the technology is required to verify its acceptability. In this respect, the use of robotics/automation for decommissioning of diffusion plant facilities, will find more applications and will require less development than in cther remediation applications (e.g., buried waste and underground storage tanks) where each task requires unique solutions. Also, in these other remediation activities, less detailed information is usually available on the waste form and the :ype of waste, the level of hazards to remediation workers is normally higher, and the wastes are relatively inaccessible. 


\subsection{TECHNOLOGY OPTIONS}

Versatile robotics and automation technologies can significantly enhance the efficiency and effectiveness of decommissioning activities at the K-25 Site facilities. These technologies will be particularly useful for in situ characterization and laboratory analyses but will also find many applications in the decontamination, waste management, remedial action, and dismantlement of facilities and equipment.

Specific uses of robotics/automation for decommissioning depend upon the needs and requirements of the characterization, decontamination, and dismantlement activities. Robotics has the capabilities to deploy the tools and sensors required to perform the decommissioning functions.

Decommissioning tasks could be performed by personnel wearing protective clothing at the K-25 Site. Therefore, the justification for using robotics or automation is generally not based on the need to remove hands-on workers from an excessively hazardous environment, but is based on the following considerations:

- Many tasks can be performed faster and more economically using robotic methods of deploying tools and/or sensors. This is particularly true because suited personnel are significantly less efficient than unsuited, hands-on workers.

- The repetitive design and layout of diffusion plant facilities and equipment will permit programmed motions/movements to be developed and utilized cost effectively. The alternatives to programmed motions/movements range from teleoperation where an operator continuously monitors and controls the robotic device, to total autonomy, which requires sophisticated sensors and a high level of intelligence in the control system. Pure teleoperation requires one operator per robotic device and may not always be cost effective. Total autonomy requires an investment in both time and money to bring the technology to a level where autonomous devices could be deployed with sufficient confidence that they will perform the required tasks reliably and without causing damage to themselves or to other equipment. Much of the robotics technology under development now provides for enhanced teleoperation and semiautonomous operation. These improvements increase the efficiency and economic viability of robotic and automation systems.

- Robotic devices, because they do not require protective clothing, minimize the generation of secondary waste streams. It is estimated that workers wearing protective clothing would require a minimum of four sets of protective clothing per 8-hour shift to allow for lunch and rest breaks. Disposal costs for solid low-level wastes are currently $\$ 50-\$ 75$ per $\mathrm{ft}^{3}$. Further, even though some of the protective clothing could be laundered and reused, the cost estimated for this activity is $-\$ 100$ per worker per day. These savings would have to be compared to those from the use of improved protective clothing. 
- Robotic devices would generate more reliable data with less probability of error. Many clean-up tasks are both repetitive and boring and may be performed in areas that are not heated or air conditioned. Personnel wearing protective clothing and working under these conditions are not particularly accurate or reliable. There is a need for $R \& D$ for better protective clothing with improved characteristics to go along with the possible use of robotics.

- Large quantities of recoverable and semivaluable metals are contained in many equipment items in the diffusion plant facilities. Automated methods of dismantling and segregating the valuable metals from less valuable materials has the potential to substantially lower their recovery costs. 


\subsection{SCIENCE AND TECHNOLOGY NEEDS}

The TLD contains short statements describing science and/or technology needs for each of the robotics/automation technologies. These needs are described in more detail on the data sheets. It should be noted that, in many cases, the needs identified for one technology show up, from a somewhat different viewpoint, as a need for other technologies. This apparent duplication is normally caused by the need to utilize a number of robotic technologies to provide a "system" that can perform a particular activity. For example, the development of a semiautonomous, mobile platform, requiring only supervisory control, would in turn, require improvements in control systems, sensors, and man-machine interfaces.

The purpose of this section is to summarize $S / T$ needs and to prioritize them according to their anticipated impact on either the cost or the effectiveness of the decommissioning activities.

An attempt has also been made to prioritize the specific technologies shown on the data sheets to identify those that have the greatest potential to reduce or minimize decommissioning costs. In this evaluation, consideration was given to both the efficacy (i.e., is the technology likely to work and how useful would it be for decommissioning tasks required for gaseous diffusion plants?) and to the estimated cost of development and deployment. Several technology development needs have been identified. These include:

- Technology improvements are required to permit a single operator functioning in a supervisory capacity, to monitor and control multiple robotic platforms. This will require improvements in control systems, in the man-machine interface, and in the on-board robotic sensors.

- To permit preprogrammed movement of robotic devices through the facilities, reasonably accurate as-built and as-modified drawings of the facilities will be required or alternatively, robotic mapping capability will be required.

- Field-hardening will be required for many presently available robotic devices to improve their reliability/availability and to permit them to be decontaminated at the completion of a task.

- A major problem with robot vehicles is cable management when umbilical cords are used to supply power and to transmit data signals. Although power could be supplied by internal combustion engines, there is then the potential for sample contamination for characterization tasks. There are also safety issues to be considered in the use of fossil fuel powered vehicles in enclosed spaces. Alternatives to umbilical cords can be identified for signal transmission. However, for power there is a developmental need for high capacity batteries or fuel cells that can be rapidly re-energized or replaced to give an acceptably high duty cycle availability.

- Scientific improvements are required in automated physical separation technologies to permit the rapid and efficient segregation of valuable metals from a mixture of materials with similar physical properties. 
- A regulatory need for implementation of robotics in automated analytical laboratories is acceptance by the EPA of automated analytical protocols.

The needs described above are considered to be the most immediate and important improvements; to enhance the cost effectiveness of robotics/automation as a decommissioning tool. Other needs, as described on the data sheets, although important, would have at less significant impact on costs. 


\subsection{IMPLEMENTATION NEEDS}

The TLD summarizes some of the implementation needs for the robotics/automation technologies. Further details of these needs are then provided on the data sheets.

A common implementation need that has prevented the large scale use of robotic devices in the past is the lack of a well-defined, large-scale mission. Currently robots are being used in the nuclear industry for short-term, limited tasks, primarily replacing humans in excessively hazardous environments. The data sheets reflect this need with terms such as "integration and test" showing up on many of the sheets as technological or implementation needs. It should also be noted that some of the implementation needs are being addressed by the Office of Technology Development (OTD) in the ERWM Robotics Technology Development Program through demonstration projects. Generally these activities are also noted on the data sheets.

\section{Cost/Benefit Assessment for Robotics/Automation Technologies}

Additional implementation needs are sufficient levels of funding to develop and deploy robotic systems for decommissioning tasks and, as described below, an attempt has been made to estimate and bracket these funding requirements for various types of robotic systems and for different types of tasks. This assessment is not totally rigorous, nor does it encompass all of the requirements. It was conducted to identify those tasks that, with the necessary development, can use robotics cost effectively and conversely. Also, from a cost standpoint, robotics may not be applicable if the tasks could be performed by skilled workers wearing protective clothing or skilled workers without protective clothing. The protective clothing of the future is expected to be improved and the project will have an effort to adapt these improvements into the operation of the processes used.

This cost assessment illustrates many of the factors involved in robotic system cost analysis. It was necessary to make certain assumptions in performing this cost analysis. One of the major areas of interest in robotic development is to perform evaluations to establish the critical performance factors such as those relating the time to perform tasks using teleoperated systems versus manual performance. The assumptions are as follows.

- An FTE would cost $-\$ 170,000$ per year. This includes an allowance for the cost of processing the waste generated by the worker.

- A worker wearing protective clothing is only $40 \%$ as efficient as a worker without protective clothing. This includes an allowance for the time it takes for donning and doffing protective clothing 4 times a day per worker. New protective clothing of the future which could come from outside and inside the project would be expected to greatly lower this penalty. 
- The availability of the robotic device is 0.9 and it has a useful life of 5 years.

- Teleoperated equipnent used for dexterous manipulation tasks, for example, disassembly of large: equipment items, take $\sim 10$ times as long to perform the work as skilled workers without protective clothing.

- Teleoperated equipnent used for nondexterous tasks such as swipes, cutting, etc., take -4 times as long to perform the work as skilled workers without protective clothing.

- Teleoperated equipnent used for noncontact, nondexterous tasks (e.g. sensor sweeps), takes 2 tim.es as long to perform the work as an unprotected, skilled worker.

- Since it was assumed that suited workers are only $40 \%$ as efficient as workers without protective c.othing, for time comparisons the numbers above (i.e., 10, 4 , and 2,) must be multiplied by $40 \%$ and become $4,1.6$, and 0.8 . Much more favorable results are expected with protective clothing specifically designed for these functions.

- For different control modes, the relative times that it takes to perform a task, the number of robotic systems that can be monitored/controlled by an operator, and the relative system costs are based on the following estimates.

$\begin{array}{lccc}\text { Control Mode } & \begin{array}{c}\text { Relative } \\ \text { task times }\end{array} & \begin{array}{c}\text { Systems } \\ \text { per } \\ \text { operator }\end{array} & \begin{array}{c}\text { Relative } \\ \text { system } \\ \text { cost }\end{array} \\ \begin{array}{l}\text { Teleoperation } \\ \text { Enhance }\end{array} & 1.0 & 1 & 1.0 \\ \text { Teleoperation } & 0.75 & 1 & 1.25 \\ \text { Semiautonomiy } & 0.50 & 3 & 1.50 \\ \text { Autonomous } & 0.33 & 5 & 2.0 \\ \text { Preprogrammed } & 0.25 & 10 & 1.25\end{array}$

With these various assumptions, a number of combinations of tasks, equipment, and control modes were input to a simplified, cost-benefit assessment. An example of the output (for a teleoperated system that costs $\$ 500 \mathrm{~K}$ ), which illustrates the necessary points that need to be made, is as follows. 
Control mode

Teleoperation

Enhanced teleoperation

Semiautonomy

Autonomous

Preprogrammed

$$
\begin{gathered}
\text { Number } \\
\text { of } \\
\text { operators }
\end{gathered}
$$

$$
1
$$$$
1
$$

1

1

1

1

$$
\begin{gathered}
\text { Systems } \\
\text { per } \\
\text { operator }
\end{gathered}
$$

1

1

3

5

10
Cost

for 5

years

(\$K)

1350

1475

3100

5850

7100
Person-years work-5 years

2.81

3.75

16.88

42.61

112.50
Cost per

personyear work

(\$K)

480

393

184

137

63

It should be remembered that the basis for comparison of these costs is an unsuited worker at $-\$ 170 \mathrm{~K}$ per year.

This rather simple analysis quantifies the cost effectiveness of developing systems that can be used with preprogrammed motions to give a single operator, in a supervisory capacity, the capability to control multiple robotic systems. It would also indicate that a teleoperated device, even with enhanced capabilities, which requires a dedicated operator for each system, should be considered only if the environmental hazards are sufficient to preclude access by suited personnel or due to size and weight of objects, the number of workers a single machine can replace is increased and the factors in the analysis change in favor of robotics or automation.

GDPs represent structured, known, and repetitive environments that lend themselves to pre-programmed motions for many of the decommissioning activities, particularly characterization and decontamination. Further, these plants include large expanses of relatively uncluttered floors, walls, and ceilings which also makes the use of autonomous or semiautonomous robotics/automation attractive.

The implementation needs, shown on the TLDs, identify the estimated costs to develop and deploy a specific robotics/ automation technology. The assessment described above provides the basis for the deployment costs. Development costs are estimates based on the experience of the personnel inputting information to the TLD. 


\subsection{TECHNOLOGY RA.NKINGS FOR THE K-25 SITE}

The quantitative rankings of the technologies for robotics/automation are given below. These rankings reflect the recommendations of the robotics/automation team on the technological improvements that are required to most effectively utilize robotics/automation in the decommissioning of diffusion plant facilities. These recommendations are based on a number of observations and conclusions reached by the team over a period of several months while gathering the information necessary to construct the TLDs and data sheets. These conclusions can be summarized as follows:

- Decommissioning of gaseous diffusion plants represents a somewhat different but unique opportunity to utilize robotics/automation in ER tasks. As noted elsewhere in this document, the size and number of facilities to be characterized, decontaminated, and dismantled are quite large. To lower the cost of decommissioning to an acceptable level will require the innovative use of a variety of technologies including those identified for robotics/automation.

- Although the physical sizes of the facilities are quite large, the levels of contamination are generally relatively low compared to other restoration projects. As a result., the hazard level to clean-up personnel is also quite low and most of the tasks could be performed by suited workers. The dominant justification, therefore, for using robotics must be based on improved efficiency of operations and not on workplace hazards.

- The use of robotics in other restoration projects has generally been where the hazard level is sufficiently high to preclude direct human involvement. These projects have utilized what is normally called "teleoperated" equipment. This type of approach requires a human operator to be in, more-or-less, direct control of the robctic device at all times (i.e., a one operator per device system). For a vasit majority of the decommissioning tasks for gaseous diffusion facilities for which robotics would be considered, this type of approach cannot be economically justified. If robotics are to be used for the decommissioning of these facilities, then systems must be developed which will permit one operator to control or monitor, perhaps in a supervisory capacity, the operation of multiple robotic platforms.

- Again by comparison to other restoration projects, the diffusion plants represent an environment that is physically well defined. Reasonably accurate drawings exist for most of the facilities and can be utilized to effectively plan decommissioning tasks. Furthermore, many of facilities in the diffusion plants contain repetitive equipment layouts leading to substantial opportunities to use robotics in a p:eprogrammed mode to perform many of the tasks. This approach would be the preferred method of meeting the requirement that robotic systems mu.st be developed to allow one operator to control multiple robotic platforms. 
- It was concluded that many of the robotic technologies required to support decommissioning are available on commercially procured equipment. What is missing, however, is the integration of these technologies into systems that can be operated in a cost effective manner. For example, to permit a single operator to control multiple robotic platforms would require, amongst other things:

- improved methods of inputting preprogrammed motions into the control systems based on existing facility drawings.

- integration of sensors on each of the platforms to monitor for unexpected obstacles including the presence of other robotic platforms.

- improved human-machine interfaces to permit the operation of multiple platforms by one operator without overloading that operator with unnecessary information.

- integration of wireless signal transmission techniques or the development of methods to handle multiple umbilical cords.

- Additional technological improvements that are required and reflected in the rankings below are field-hardening of commercial devices, transportability of the control systems/human-machine interfaces, and improved reliability, a consideration that is based primarily on the magnitude of the decommissioning tasks.

In summary, it is recommended for applications of robotics for decommissioning of diffusion plant facilities, that maximum use be made of existing commercial devices and that the emphasis of further technological developments or improvements be oriented towards integrating these technologies into systems that can be deployed efficiently by a minimum number of personnel.

In one technological area, which falls more in the category of "automation," one notable deficiency was identified. There does not appear to be a suitable, costeffective, method presently available to automatically and efficiently separate metallic materials which have similar physical properties (e.g., nickel alloys from ferritic alloys). One separation method that could possibly be developed are magnetic separators based on slight differences in the magnetic properties of the various materials or alloys. It is recommended that this alternative be pursued at least to the point of verifying the feasibility of the approach.

In the table below, the technologies are prioritized or ranked within each of the main technological fields corresponding to the "Alternatives" column on the TLD. A ranking of " $\mathrm{H}$ " indicates the highest priority, " $\mathrm{M}$ " is a medium priority, and a ranking of " $L$ " the lowest priority. Again, as indicated in the discussions above, the need to develop a robotic system that incorporates numerous robotic technologies is reflected in the rankings in Table 6.1. 
Table 6.1. Ranking of robotics/automation technologies

\begin{tabular}{lll}
\hline Alternative & Technology & Ranking \\
\hline
\end{tabular}

1. MECHANICAL

1A. Mobility

Whee ed/Tracked Vehicle (ROBA-1)

$\mathrm{H}$

Pipe/Duct Crawler (ROBA-2) (ROBA-3)

$\mathrm{H}$

Bridgi--Mounted Robotic Platform (ROBA-4)

Power Sources for Mobile Platforms (ROBA-5)

Failure Recovery (ROBA-6)

L

M

L

1B. Manipulation

Long-Reach Arms (ROBA-7) (ROBA-8) (ROBA-9)

M

Arms with $>6$ Degrees of Freedom ((ROBA-10)

$\mathrm{H}$

Comfact, High-Capacity, Arms (ROBA-11)

1C. End-Effectors Multi ( $>2$ ) Fingered (ROBA-12)

Remotely/Automated Interchangeable

End-Effectors (ROBA-23)

Tool-A trm Interface (ROBA-24)

Force Limiter (ROBA-25)

$\mathbf{H}$

$\mathbf{H}$

M

1D. Automated Separa.tion Technologies for Material Recovery

Magnetic Separators (ROBA-26)

H

2. CONTROLS

2A. Algorithms

Multiple, Concurrent, Mobile Platform Control (ROBA-27)

H

Combined Mobility/manipulation/End-Effector Control (ROBA-28)

Preprogrammed Obstacle Avoidance (ROBA-29)

Programmed Motions (Per EPA Protocols) (ROBA-30)

Sample Management (ROBA-31)

$\mathbf{M}$

$\mathrm{H}$

L

2B. Man-Machine Interface

Single Human-Multiple Vehicle Control Station

(ROBA-32)

Data Fusion (ROBA-33)

Teach/Playback (ROBA-34)

Voice Control (ROBA-35)

Man-Robot Symbiosis (ROBA-46)

Fuzzy Control (ROBA-47)

Tranisportable Control Stations (ROBA-48)

$\mathbf{H}$

M

L

L

L

L

$\mathrm{H}$

2.C. Signal Transmission

Hard-Wire (Umbilical) (ROBA-49)

Microwave (ROBA-50)

$\mathrm{H}$

Radio (RF) (ROBA-5l)

$\mathrm{H}$

Laser- (ROBA-52)

M

L 
Table 6.1. (continued)

\begin{tabular}{llc}
\hline Alternative & \multicolumn{1}{c}{ Technology } & Ranking \\
\hline 3. SENSORS & & \\
3A. Perception & & H \\
& Vision (ROBA-53) (ROBA-54) & $\mathrm{L}$ \\
& Audio (Directional) (ROBA-65) & $\mathrm{L}$ \\
& Force (ROBA-66) & $\mathrm{H}$ \\
& Imaging and Image Processing (ROBA-67) & $\mathrm{M}$ \\
& Wall Thickness (ROBA-68) & \\
3B. Control & & $\mathrm{H}$ \\
& & $\mathrm{M}$ \\
& Proximity (ROBA-69) & $\mathrm{M}$ \\
& Positioning (ROBA-70) & $\mathrm{M}$ \\
& Laser Range Finders (ROBA-71) & $\mathrm{L}$ \\
& Force Control (ROBA-72) & $\mathrm{L}$ \\
& Liquid/Liquid Interface Detection for Phase Separation & \\
& (ROBA-73) & $\mathrm{L}$ \\
& Flow/Mass/Volume (ROBA-74) & \\
& Position Sensors for Manipulators and End-Effectors & \\
& (ROBA-75) & \\
\hline
\end{tabular}




\subsection{TECHNOLOGIES UNDER DEVELOPMENT BY DOE}

DOE is currently developing technologies through the EM-30, EM-40, and EM-50 program which have the potential for making effective contributions to solving environmental and waste recycling problems at the different DOE sites. Some of these projects may have relevant and beneficial elements with respect to the technologies identified in the K-25 Site TLD. A search of available information on programs funded in FY 1992 was performed to identify the possible matches between technologies in the K-25 TLD and TTPS (or ADSs). A listing of the DOE EM-50 Program Guide for FY 1992 and abstracts for funded EM-50 projects were the principal sources for determining matches and relevancy between TEDS and TTPs. Relevant ADS activities were identified through staff personal knowledge.

In Table 6.2, those projects described in TTP or ADS and determined to be potentially relevant and beneficial ar: listed by TTP (or ADS) number along with the corresponding relevant Technology Evaluation Data Sheet (TEDS) identifier. Along with the matched TEDS is a succinct statement of the technology approach or problem being addressed in both documents. 
Table 6.2. DOE funded development

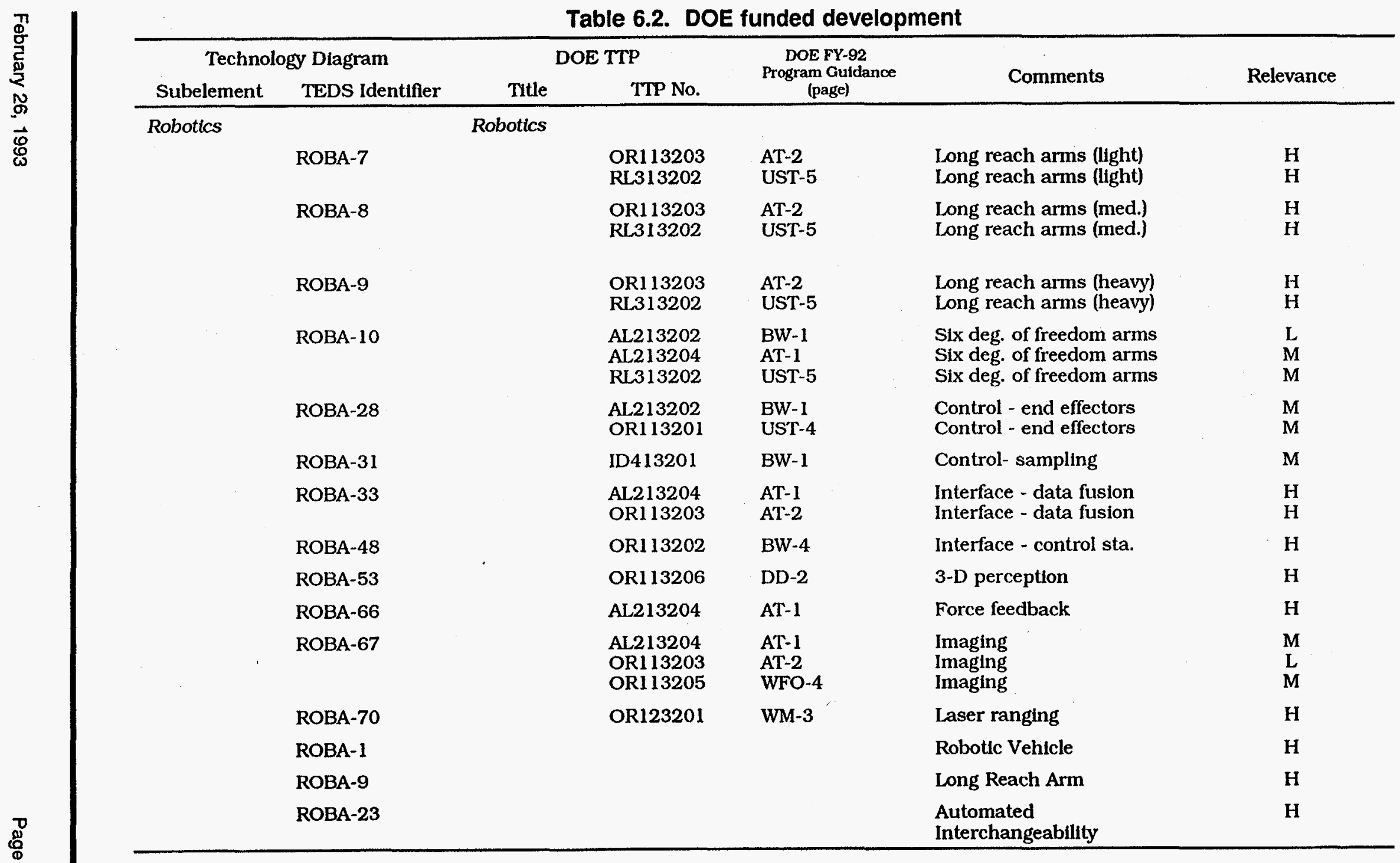





\section{REMEDIAL ACTION}

\subsection{INTRODUCTION}

In Chap. 1 , seven classes of contaminants have been identified at the $\mathrm{K}-25$ Site. These are:

- Petroleum Hydrocarbons,

- Volatile Organic Compounds (often chlorinated),

- Polynuclear Aromatic Hydrocarbons,

- Toxic Metals,

- Radioactivity (Uranium, Technetium TRVs),

- Nonvolatile Organic Compounds (particularly PCBs), and

- Asbestos.

For the purpose of the TLD, classes of contaminants were revised slightly to separate them into groups that are likely to be treated similarly. For instance, the chemistry of uranium and technetium are so different that they were handled as separate items since the removal methods for the two materials may be different. The organic materials were grouped into volatile and nonvolatile chlorinated compounds because the volatility greatly affects the treatment methods. The groupings are not perfect because within the nonvolatile compound group, different methods are used for highly chlorinated compounds like PCBs than for heavy petroleum hydrocarbons. The highly volatile compounds are more likely to be treated similarly if their volatility is the basis for the treatment. Dense nonaqueous phase liquids (DNAPLs) are not known to exist on the K-25 Site, the site has not been characterized extensively to identify the presence of DNAPLs. There are dense pollutants at the K-25 Site (like PCBs and TCE), dissolved in groundwater, but pockets of DNAPLs have not yet been found; only dissolved materials have been reported. However, since there remains a possibility that DNAPLs will be found at the K-25 Site, a brief discussion of DNAPLs is included in this study.

Most of the toxic metals at the K-25 Site are mercury, lead, and chromium. Again, the chemistry of these are different, and within this class some treatments for these contaminants are discussed separately when appropriate.

\subsubsection{Contaminated Media}

The kinds of materials contaminated were grouped as soils, groundwater, burial grounds, and sludges (pond waste). Currently, there are no plans or regulatory orders to excavate material from the burial grounds. Furthermore, there are no apparent requirements for new retrieval technologies needed for the burial grounds or soils from anywhere at the K-25 Site. This situation is different from the situations at ORNL or Hanford, where gamma radiation hinders or prohibits personnel from handling wastes. The requirements at the K-25 Site are not expected to be different from those at most hazardous burial grounds or waste sites. Extensive protective clothing will be required. Remote and even automated excavation may be desirable, but the modest size and the heterogeneity of the K-25 
Site's buried waste makies it less likely that robotics or automation will be as important as it was in cther operations and at other sites. Thus, burial ground treatment is handled in 1his TLD under the title "Retrieval." Here, the problems of the excavation of wastes is discussed, but no new technologies are given for priority for inclusion in the TLD. Separation and repackaging of components removed from burial grounds (if any are removed) is covered in Waste Disposal. An alternative to retrieving buried wastes is to "fix" them in place. This option is covered in the TLD also.

\subsubsection{Characterization}

Characterization is an important aspect of remedial action for essentially any contaminant and any coutaminated media, but characterization is also important in D\&D. To minimize dixplication, characterization was separated into its own topic and treated independently.

\subsubsection{Costs}

Costs for technologies are usually given in terms most appropriate for the media. Technology costs for soils is usually dollars per ton (approximate dollars per $\mathrm{yd}^{3}$ or $\mathrm{m}^{3}$ ) and for groundwater, dollars per $1000 \mathrm{gal}$ is the most common unit. When reasonable costs were found in references, these costs were mentioned; when no costs were found estimates were made. The only purpose of the estimates was to place the costs into a general grouping. In many cases the selection of a range for costs was little more than an educated guess. New methods for remedial action are being developed at Oak Ridge, at other DOE sites, in industry, and in universities. For some predevelopment technologies or for technologies where serious questions remain to be answered, it was premature to even guess the range for costs.

Since quantitative estimates of costs for several technologies was outside the scope of these efforts, the: estimates were only given as low, medium, and high. For soil treatment, costs significantly greater than 100 to a few hundred dollars/ton were considered high; costs in this range were considered medium; and costs significantly lower than this range were considered low. For groundwater treatment, costs of a few dollars per 1000 gal were considered medium, and costs above or below this range were considered high or low.

Although many of the costs are not much more than simple guesses, one should realize that they can also be made on different bases. For instance, costs quoted by different references could include different assumptions, but detailed resolution of costs for the numerous technologies was outside the goal of this study. Furthermore, it is important to realize that many costs are higher within the DOE facilities becaluse of such factors as additional safety, regulatory documentation, etc., required when there is the potential for even traces of radioactivity being prese: $t$. These costs can apply to field testing as well as actual implementation of a technology. To keep the costs as uniform as possible, some of the additional costs which are often also difficult to estimate are not included in the crude estimates given. This means that the cost estimates given for both development and implementation of technologies should be viewed more as relative costs and less as absolute costs. 


\subsubsection{References}

The major effort was devoted to assessing the mainline technologies; or those that find uses in remediating the K-25 Site, and every idea for remedial action may not be covered in this assessment. At least one reference was sought for each technology. References that can be obtained from any DOE site or technical library were preferred. The references should be available at most sites, at least through interlibrary loan; widely available journal articles were used when available. The references, while not complete, should give the reader a chance to start reading further about the technologies and draw his/her own conclusions. 


\subsection{TECHNOLOGY OPTIONS-SOILS, GROUNDWATER, AND SURFACE WATER}

\subsubsection{Introduction}

Contamination of soils and groundwater has usually resulted from burial of contaminated material, spills, or leaks of contaminants. Remediation can involve destroying the contaminant (organic compounds), removing the contaminant, or fixing the contaminant to prevent the spread of the contaminant and contact with the public or any sensitive portion of the environment. Treatment to destroy or remove the contaminant from soils can be carried out in situ (without removing the soils from the ground) or ex situ (in process equipment). Contaminated groundwater can be treated by direct removal of the contaminant, the source of the contaminant can be removed from the soil, or the groundwater flow can be diverted and prevented from coming in contact with contaminated soils or other materials. All of these approaches are represented somewhere in the technologies described in the TLD.

\section{Uranium in Soils}

Uranium contaminated soils can be treated to remove the uranium or to fix the uranium so it can not leach and spread the contamination or affect human health. Technologies have been suggested that follow both approaches, and some approaches can be used in situ or ex situ.

\section{Removal of uranium from soils}

The most promising approach for removing uranium from soils involve leaching with an acid or alkaline carbonate solution. Leaching operations can be made more compact if they are associated with physical separations, which separate the soil components that have the highest concentration of uranium. If the uranium is concentrated only in a small fraction of the soil, it may even be practical to package the physically separated concentrate for disposal. Separating soil fractions according to size is usually called "soil washing," but separations can be also made on the basis; of particle density or surface properties (floatation). Because soil washing involves treating the soils with water, leaching and "washing" can sometimes be combined.

Soil washing must be: done ex situ, and soil leaching is likely to be ex situ. An in situ method, "electrokinetic" removal of uranium from soils, is receiving significant attention. In that approach, electric fields are imposed by electrodes placed in the soil, which force the electromigration of uranium ions and electroosmotic flow of the water (solutions) through the soil. The uranium migrates toward electrodes where it is removed.

\section{Fixing uranium in nonleachable forms}

The alternative to the removal of uranium is "fixing" uranium in the soil so it will not leach out of the soil. This prevents contact with the public and spread to the environment. Three approaches to fixation assessed: (1) cement grouting, 
(2) polymer grouting, and (3) vitrification. Both cement and polymer grouting are more likely to be done ex situ. There are methods for adding grouting reagents and mixing them with the soil in situ, even to significant depths. However, the addition of reagents usually involves significant volume expansion, and some materials will be "above ground" where they are likely to be treated ex situ.

Cement grouting is commonly considered for fixing several metals in soils, including uranium. The fixation process results in a solid, which leaches more slowly than unconsolidated soils. Retention of metals by cement grouting is accomplished by controlling the $\mathrm{pH}$ of the grout-soil matrix to reduce the uranium solubility. The insoluble uranium-bearing particles are also entrapped in the cement matrix.

Polymer grouting is less commonly used and relies upon physical entrapment of metal ions by replacing water and/or air in the soil with the polymer. The permeability of polymer grout to water, which could leach uranium, is reduced toward zero.

Vitrification involves melting the soil to form a nonleachable glass. Additives can be used to form a more easily vitrified melt. Vitrification can be done either in situ or ex situ. Usually there is no expansion of the soil with vitrification unless significant additives are required. In fact, there is likely to be a volume reduction because void spaces within the soil are largely eliminated. Ex situ treatment is favored when it is necessary to add significant vitrifying agents to the soil. In situ vitrification is favored when there are hazards in removing and handling the soil.

\section{Uranium in Groundwater}

The best way to control groundwater contamination is to remove the source of the contamination, which is often impractical or impossible. At the K-25 Site it will be impractical to remove the large quantities of material that have been placed into burial grounds. A portion of the buried materials are classified. When it is necessary to leave buried materials in place, removing uranium from groundwater may involve adsorbing (or ion exchange) or concentrating the uranium by reverse osmosis or evaporation. Each of these processes could result in removing the uranium from the solution and creating a solid or liquid uranium concentrate. The concentrated material could be packaged for disposal, or the uranium could be recovered for further concentration or reuse.

\section{Ion exchange/adsorption}

The choice between materials for adsorbing uranium would be based on concentration requirements for the project and the associated costs, with cost being the determining factor. To control costs effectively, the uranium must be separated from other materials in the water, especially other metals such as calcium, sodium, etc., that are present in all groundwater. Commercial ion exchangers obviously have potential for recovering uranium, and cation exchangers may be chosen because of the low concentrations expected in contaminated groundwater at the K-25 Site. Most commercial exchangers will have only moderate selectivity for uranium over the other metals, but attempts have been made to develop selective ion exchange materials for recovering uranium. The Japanese developed a resin for removing low concentrations of uranium from 
seawater. However, custom resins usually prove to be more costly to manufacture or purchase than converitional ion exchange materials.

Less expensive adsorbent/ion exchangers may be produced from biological materials. Many organisins adsorb uranium in various parts of their cells, often in the cell wall. Some organisms appear to have good selectivities for uranium over other common metals. For high removal efficiencies, it is necessary to incorporate the organisms into a solid (usually a gel) or onto solid surfaces so that they can operate like any other acisorption or ion exchange system.

\section{Precipitation and coagulation}

Another option may be to precipitate and coagulate the uranium like conventional water treatrnent. After digesting the uranium, it could be precipitated or adsorbed on the coagulant. The concentration of uranium in the groundwater at the K-25 Site is believed to be so low that precipitation of the uranium alone would not be practical. Although coagulants are usually inexpensive, coagulation by itself may not result in the lowest potential waste volume. This option would have to be considered because of the cost for the disposal of uraniumcontaminated solids.

\section{Reverse osmosis}

This is the membrane process by which pressure forces water through a membrane that rejects (retains) the electrolytes, including uranium. There will generally be little separation of uranium from other dissolved mineral matter. Therefore, it would be advantageous to separate the uranium from the other salts stream. A number of recovery options such as solvent extraction could be explored for this highly concentrated solution. Other reagents can be used to aid the separation. In high sulfate or chloride solutions, uranium can be separated from most other metals by anion exchange. In chloride solutions, ferric iron will also follow uranium in ion exchange separations.

\section{Evaporation}

Evaporation could be used to concentrate the salts to dryness and packaging for disposal. Evaporation can be used for moderate size streams, and natural evaporation in surface waters will be significant.

\section{Volatile Organic Compisunds in Soil}

Volatile organic compounds (VOCs) can be removed from the soil, destroyed, or fixed within the soil sc that they cannot leach or otherwise escape to harm the environment. There are several approaches to any of these goals discussed in this assessment. As noted earlier, the most serious VOCs at the K-25 Site are chlorinated compounds, and this discussion is focused on those materials.

Because of their volatility, VOCs located above the water table (in the vadose zone) can be removed from the soils by "venting." This can be done in situ by drilling wells into the contaminated region and pumping air from the well. Air is pulled into the soil from the surface and then sweeps through the contaminated 
region. If the contamination is deep or if there is insufficient air flow for other reasons, separation injection wells can be used to introduce air. In one interesting arrangement being studied at the Savannah River Site (SRS), horizontal drilling can be used to introduce air below (or even above) the contaminated zone to produce vertical air flow. The air can approach saturation with the volatile compounds and carry the VOCs from the soil. Suitable off-gas treatment is often required to prevent release of the VOCs. This is likely to involve adsorbing the VOCs on activated carbon beds, but other methods could be considered.

If the rate needs to be increased, the soil could be heated by injecting steam or possibly by microwave heating of the soil. In other cases, the soil may not be sufficiently permeable to permit sufficient air to pass through it, and the resulting rates could be unacceptably low. Deep-soil mixing has been shown to permit more rapid release of VOCs in such cases.

Ex situ removal of VOCs from soil usually involves heating soil and flushing air through it : in process equipment. Under these conditions, higher temperatures can also be used, and the less volatile compounds can be removed. Although higher temperatures may not be required for all of the compounds present, they may be needed for less volatile contaminants. In that situation, all of the more volatile compounds are likely to be removed.

Destruction of the VOCs can be accomplished by biodegradation or incineration. Biodegradation can be carried out in situ or ex situ in specially designed bioreactors. Although in situ biodegradation may be preferred if it cost less, ex situ treatment permits more careful control of reaction conditions and may be better for destroying more of the refractory compounds. Incineration is usually carried out in a furnace or kiln and probably volatilizes the VOCs before actual combustion. Although there may be little incentive for using high temperatures (incineration) to get rid of volatile compounds, the high temperatures may be needed for less volatile contaminants, and the VOCs will be destroyed as well. In situ oxidation has been carried out with oxidants such as hydrogen peroxide or ozone added to soil.

Fixation of VOCs can involve using cement or polymer grouts. Although organic compounds are not normally incorporated within concrete directly, additives can be used with the concrete that hold the VOCs. Activated carbon is one suitable additive. Fixation can be done in situ or ex situ, but if the volume of additive is substantial, the volume of the soil-additive mixture will expand and some of that excess volume may have to be handled separately.

\section{Volatile Organic Compounds in Groundwater}

VOCs can be removed from ground water or destroyed. Removal usually involves stripping the materials with air or adsorbing them, probably on activated carbon. Stripping requires off-gas treatment, which also could involve use of carbon beds. Because some nonvolatile compounds like PCBs are not easily removed from carbon beds, it may be beneficial to remove the VOCs separately even if carbon beds are necessary for other contaminants to maximize the operating life of the carbon beds being used for the less volatile materials.

Destruction of VOCs in groundwater can involve biodegradation or chemical oxidation. Biodegradation can be in situ, but ex situ reactors are likely to be needed if the insurance of suitable degradation or special conditions are required. Oxidation can involve addition of oxygen, hydrogen peroxide or ozone. Catalysts 
such as iron can help with the oxidation of some chlorinated compounds. Ultraviolet radiation is useful with many compounds.

Recent reports have indicated that chlorinated hydrocarbons in water, including TCE, which is of most importance to the K-25 Site, can be chemically dechlorinated by reacting with iron particles. The results are preliminary, and the mechanism is not yet understood. It is assumed that the mechanism involves the participation of Fe(II) and Fe(III) in a solution within the bed of iron particles, but this is not confirmed. The preliminary data indicate that different types of iron are important in the rate of dechlorination. Several other metals can also dechlorinate TCE, but iron appears to be the best of the common metals tested. Although the preliminary data need to be considered with caution, the use of iron offers a relatively inexpensive method for destroying chlorinated compounds. Complete dechlorination of TCE would produce a nonhazardous product without the questions of emissions control raised by incineration. Even partial dechlorination of PCBs would produce compounds that are easily degraded by microorganisms. Furthermore, it has been suggested that iron particles could be introduced into trenches to stop plumes of TCE. This could be an attractive method for handling large volumes of water such as those in groundwater plumes.

\section{PCBs in Soil}

The methods for removing PCBs from soils can be classified as incineration processes, low tempereture thermal removal, biodegradation, and chemical dechlorination. Most of these methods are probably better suited for ex situ treatment. Biodegradation can be a potential in situ option, but even these processes have been studied more extensively for ex situ operations and may be limited to ex situ application. Incineration processes are costly and likely to leave the soil unsuitable for other uses. Low temperature volatilization removes the PCBs, but they must be collected and destroyed in separate operations. With the TSCA Incinerator available at the $\mathrm{K}-25$ Site for handling toxic liquids, there is more merit for considering removal methods than at other sites. Any incinerator would be able to handle more PCBs if it were not required to handle all of the soil.

The best approach tc biodegradation depends on the degree of chlorination in PCBs. Lightly chlorinated PCBs can be degraded aerobicly at reasonable rates, but highly chlorinated PCBs will not respond to aerobic treatment. The PCBs can first be dechlorinated with an aerobic organisms, and then the resulting less chlorinated compounds can be treated aerobicly for final destruction. Two step operations like this may need to be ca:ried out in ex situ bioreactors, and the entire process should not be considered developed or ready for application.

The best approach to the treatment of PCBs in soil may be chemical dechlorination by stron $\xi$ alkali. The potassium polyethylene glycolate (KPEG) or ammonium polyethylene: glycolate (APEG) approach developed and tested by the EPA look promising. They offer high degrees of dechlorination and operate at moderate temperatures. The resulting soil could lose a lot of its original organic material but may event xally become useful. Another alternative dechlorination approach that has been suggested involves using alkali metals dissolved in liquid ammonia, a strong reducing agent. 


\section{PCBs in Groundwater}

The most common approach to the removal of PCBs from groundwater is by adsorption on activated carbon. This is an effective method, but the resulting PCB loaded carbon beds become solid waste that is difficult to handle. Commercial firms will regenerate carbons with most contaminants, but they usually will not regenerate PCB-loaded beds. Adsorption on carbon is more likely to be attractive as a polishing step to remove the last traces of PCBs. Biodegradation is a possible answer to the removal of PCBs from groundwater, but as noted in the discussion of biodegradation of PCBs in soils, highly chlorinated PCBs are not easily degradable. Chemical oxidation, perhaps UV-catalyzed oxidation, is an attractive near-term approach, especially if carbon beds can remove traces of incompletely reacted materials.

A recently reported chemical dechlorination method (discussed earlier for VOCs) can be used ex situ and possibly in situ. Beds of fine particles of iron have dechlorinated organic compounds, PCBs, and chlorinated alkanes and alkenes. The mechanisms and limitations of this approach have not been established, but at this point, it looks interesting. The resulting dechlorinated compounds should be easily degraded biologically.

\section{Toxic Metals in Soils}

Since metals cannot be destroyed, treatment of soil contaminated with toxic metals involve removal or fixation of the metals into a nonleachable form. Removing of the metals may involve leaching also. This may be the preferred method when a suitable and economical leach solution is available that is specific to the metal(s) of interest. However, when concentrated acids are required, they may remove a lot of the soils metal content leaving the soil unusable while producing a complex leach liquor from which it may be difficult to concentrate the toxic components.

Fixing of the metals into a nonleachable form by incorporating the soil in a grout of concrete is only moderately expensive. It also produces a soil that cannot be used. It may be possible to develop highly specific adsorbents (perhaps zeolites) for holding (fixing) some toxic metals. Fixation also prevents the eventual recovery and use of the toxic metals. There could be some objection to permanently removing too many relatively scarce metals from the economy.

\section{Toxic Metals in Groundwater}

The most obvious method for removing metals from groundwater is with ion exchange resins. The problem is getting high capacities, good selectivity (over other metals), regenerating or recovering metals in a concentrated form, and using acceptable cost resins and regeneration solutions. Ion exchange resins may be the most appropriate approach for most metals. Reduction followed by adsorption has been reported to be selective for the more easily reduced metals such as $\mathrm{Hg}$ or $\mathrm{Pb}$. Reduction of $\mathrm{Cr}(\mathrm{VI})$ to $\mathrm{Cr}$ (III) has also been reported as an option for making the groundwater less toxic, but its acceptability as a permanent remediation method is questioned because the $\mathrm{Cr}$ is still present in the soil. If it were oxidized in the future, it would again become mobile and toxic. Coprecipitation methods are often 
well developed, but they can generate large volumes of solid wastes, which may be difficult and expensive to handle, especially if they are "mixed wastes."

\section{Hydrocarbons from Soil}

Removal of hydrocarbons, principally fuels, from soil can be accomplished by most of the methods indicated for VOC and PCBs, but there are some differences. The hydrocarbons from fiels are often not as toxic as chlorinated compounds, and they are usually more easily degraded by microorganisms than chlorinated compounds. Incineration of highly contaminated soils or recovered fuel components is also far more acceptable than combustion of chlorinated compounds that can forr highly toxic, immediate products and require expensive scrubbing systems. Biodegradation is clearly an attractive procedure for treating many contaminated soils where it is practical to get oxygen and essential nutrients to the contaminated regions.

\section{Hydrocarbons from Groundwater}

Most technologies mentioned for removing VOCs from groundwater are also effective for fuel based hydrocarbons. The reduction processes (dechlorination) are notable exceptions. However, adsorption and biological treatments can be more effective for fuel based hydrocarbons than for chlorinated compounds. Regeneration of carbon beds involves fewer problems, and biodegradation is usually rapid, especially for aerobic processes. However, if greater than normal concentrations of radioastivity is present in the groundwater and adsorbs on the beds, regeneration may be especially important to minimize waste handling problems.

\section{Technetium in Soils}

Leaching to remove Tc or attempting to stabilize Tc in soil appear to be the best options for treating $\mathrm{Tc}$ contaminated soils. However, both approaches involve some difficulties. Tc has proven to be difficult to remove and contain completely. Leaching is likely to invclve oxidation of Tc to its highest valance state, technate. Fixation methods or not fully developed. Innovative methods or methods that incorporate different forces to retain Tc are needed. For instance, cement grout with high concentrations or iron particles may be able to keep the Tc reduced and adsorbed on the iron su face until the iron is oxidized.

\section{Technetium in Groundwater}

A few sorbents are capable of removing Tc from water. The most promising new approach involves precipitation and adsorption of Tc on iron particles. Tc is probably attached to iron as $\mathrm{TcO}_{2}$ solid. Several other metals can also reduce technate to Tc(IV) and retain the product, but iron appears to be very effective and inexpensive as long as it: lasts. 


\section{Asbestos in Soils}

The hazards of asbestos in soil appears to be small because the asbestos is not mobile and will not migrate from the burial trench. However, it is possible that the asbestos may be exposed in the process of removing other materials from burial trenches. If asbestos is removed, it can be stabilized in cement grouts. Asbestosimpregnated concretes have been used for years, even for domestic drinking waters. It is likely that asbestos could be incorporated into concrete for disposal. With the asbestos incorporated within concrete, there will be protection for anyone who accidently penetrates the burial ground from spreading the asbestos contamination.

\subsubsection{Waste and Contaminated Material Retrieval}

Wastes and soils may have to be removed from the K-25 Site for treatment in the future, but at the presently no plans for removing buried wastes at the K-25 Site exist. Contaminated soils may have to be removed from around spill sites, containment ponds, and buried transfer piping. The contaminated wastes and soils at the K-25 Site are generally hazardous if inhaled or ingested, but they involve no significant gamma radiation that would require the use of remote handling exists. Standard evacuation procedures and techniques should to be adequate. Existing equipment should be adequate also. Thus, no specific technology needs are specified for retrieval of wastes directly. Equipment operators will have to dress in appropriate protective suits and wear respirators, which is standard clothing for sites contaminated with toxic materials. Protective clothing will lower worker productivity. Robotics will eliminate the time required for "suiting" workers. However, the K-25 burial sites are small and nonrepetitive enough that there might be little to gain from automation.

Field characterization technology could be important in defining the regions that need to be excavated. It should be beneficial to accurately know the boundaries of buried wastes and contamination. Excavation of additional soil will simply add to the waste volume. Failure to remove the contaminated soil could result in the further spread of contamination and the need to retreat the site.

The special conditions for excavation at the K-25 Site may include the need for covering the excavation site to reduce the emissions of dust or conceal the exposure of "classified" materials. However, there are no indications that classified or highly toxic materials will have to be excavated at the K-25 Site.

\section{Dense Nonaqueous Phase Liquids}

If DNAPLs are located above the water table, relatively conventional methods such as vacuum extraction (perhaps augmented with soil heating methods) can remove the DNAPLs. However, if the DNAPLs are located below the water table, the low solubilities in groundwater make removal more difficult, usually slower. Since DNAPLs have not been conclusively found at the K-25 Site, the location of the DNAPLs (if they exist) are even more conjectural than their existence. However, it is reasonable to assume that if they exist, much of the DNAPL will be below the water table. This, for this discussion, the $\mathrm{S} / \mathrm{T}$ needs will be based on DNAPLs under the water table. 
With DNAPLs so difficult to detect, it is obvious that detection or characterization will be a major S/T need. Although characterization needs are generally discussed separately in this document, for this problem, it is worthwhile stressing the need for better ways to detect the presence of DNAPLs. There should also be methods for loce.ting DNAPLs (of even locating regions without DNAPLs, which would define the region of DNAPL contamination). 


\subsubsection{Introduction}

More than 80 technologies were reviewed for solving remedial action problems, but no claim can be made that every possible technology was considered. It is only hoped that the major, or most promising, technologies were included. To keep the list of technologies from becoming too long and repetitive, there was only limited descriptions of the same technology for different problems such as VOCs, hydrocarbons, and PCBs. Some of the most important technologies were listed under all of the problems, especially when there are believed to be important differences in the applications of those technologies to different problems (bioremediation is a good example). Some of the more speculative technologies may be listed under only a single problem, usually the one for which it is being developed. However, the informed reader usually will be able to tell that the technology could be tested for one or more similar problems.

\subsubsection{Characterization}

Suitable methods for detecting and chemically analyzing pollutants are generally available. The time and cost for completing the analyses are problem areas. Response times from approved laboratories are often long, and in some cases holding times have been pushed to or beyond the accepted limits. The situation could be improved by setting up and approving additional laboratories without additional R \& D. However, the time required for analyses would still be longer than acceptable because of the transportation time and the time required to perform the analyses. The period of time between sampling and receiving results can delay decisions on remediation, thus, the time for remediation itself. The delays can cause nonoptimal use of equipment and personnel. These factors can mean more cost for remediation and high costs for analyses.

The preferred solution would be to have more approved analyses performed in the field. This would provide rapid access to results and faster decisions and actions on remediation. The analyses could be less expensive because transportation and chain-of-custody procedures and costs would be reduced or eliminated. Even greater cost reductions may be possible in remediation because the results are available more quickly. It could even become practical to have more analyses at comparable costs with shorter times. That could result in a better understanding of the problem when remediation begins.

Many of the analytical instruments that, until recently, were available only for use in relatively sophisticated laboratories can now be obtained for use in the field. In some cases, the instruments are only slightly reduced in size so that they can be mounted in mobile laboratories. In other cases, however, the instruments have been reduced sufficiently in size and improved in ruggedness so that they can be carried by technicians (or perhaps later by robots) directly into the field. When portable sensors are coupled with innovative sampling techniques, a technician can survey a site quickly and inexpensively. Although mounting more compact analytical instruments into mobile laboratories is beneficial, the best way to reduce cost, and improve performance, the use of portable instruments with comparable accuracy and reliability is preferred. 
With further develofment, other methods may be adapted for use in the field with sufficient accuracy and reliability. New sensors also have been proposed, which may be better suited for use in the field than the methods that are currently standard for laboratories. Validation procedures need to be adapted for checking field instruments, methods, and personnel so findings from field results will be as reliable as results from current laboratory procedures. In most cases, reliability may be a more serious question than precision or accuracy. Many of the methods that have been developed for use in the field have sufficient sensitivity for most problems. The concern will focus on the reliability of the results; can they be trusted to the same clegree as current laboratory results? When the field instrument is contained within a mobile laboratory, the validation procedures may need to be altered only silightly from those currently used in central laboratories, but new procedures may be needed for portable field instruments and instruments with new types of sensors.

Characterization methods appear to be inadequate for detecting and characterizing of NAPLs in soils and underground formations. Although there are no apparent NAPL sites at the K-25 Site, without reliable methods for finding such problems, there is no guarantee that these problems do not exist.

There is also a need for better remote sensing of contamination and contaminant plumes. With the exception of improved radiation detectors used to locate uranium, most techniques seem to be well developed or of little use at the K-25 Site. One major problem is the high clay and water content in the K-25 Site soil. This reduces the: absorption of ground-penetrating radar and other electromagnetic signals. Another problem is the highly fractured nature of the $\mathrm{K}-25$ Site geology, which creates many signals when sonic methods are used. The K-25 Site geology needs attention but until new ideas become available that increase the chance for significant improvements, this area will be given lower priority. The present alternative requires many wells and many core samples from each well.

\section{Uranium in Soils}

A major topic for an. important DOE Integrated Demonstrations at Fernald, Ohio, is the removal of uranium from soils. That program is likely to provide most of the research and development needed to cleanup soils at the K-25 Site. Some demonstration or testing, may be required to insure that the technology developed and tested at Fernald will perform comparably at the K-25 Site. Applying the technology at the K-25 site will necessitate caution as well.

Selecting priorities to develop technologies for removing uranium from soils is a function of the Uranium in Soils Integrated Demonstration, and more time and manpower are available for setting priorities in the integrated demonstration than were available for this stixdy. Thus, the reader is encouraged to follow the priorities set by the integrated clemonstration as well as those suggested here. Major differences in the priorilies set by the two studies are not expected.

Effective removal of: uranium from excavated soil may involve the same techniques used in the uranium ore industry. The major difference will be the lower uranium concentrations usually found in slightly contaminated soils. Soils and rocks in the Oak Riclge area contain low concentrations of uranium naturally, especially in some of the shales. Efforts to remove uranium from soil at the K-25 Site are expected to be: limited to those that were most contaminated by the 
operation of the gaseous diffusion plant and pose a risk to people or the environment. The soil may be significantly different from the rock that usually contain uranium ores, but the methods for extracting uranium in the ore industry are so aggressive that the differences in soil and rock may not be of major importance. Carbonate- and possibly acid-leaching with oxidants may prove to be the most effective approach, and development efforts should first test those methods. Other approaches may be cheaper, if not more effective. However, the longer development time and decreased likelihood of success lowers their priority. Of course, difficulties with adapting the more standard procedures for soil would raise the priority for alternatives. Natural uranium in soils at the K-25 Site has always produced enough radon to make calibration of radiation instruments difficult.

Physical separations are expected to be useful in reducing the volume of soil to be treated by more aggressive chemical methods. The uranium is not likely to be concentrated in one small fraction of the soil, but if physical separations produce a concentrate contaminated product with a small volume, it could make disposal less expensive. It is likely that important and significant volumes of soils can be removed that have acceptably low levels of contamination. Large rocks and pebbles, for instance, may have little uranium. Magnetic separation is another method that has been suggested for separating contaminated and uncontaminated fractions of soils. Only testing will demonstrate what each of these separation techniques can do, but size separation should be considered first.

Different equipment types have been suggested for soil leaching and physical separations. In some cases, the physical separations and leaching can occur in the same device (i.e., in a soil washing system). The separation and leaching could be done in separate devices. The initial $R \& D$ does not need to address the specific devices used. First, establish the leaching requirements and the merits of different size (and possibly other physical) separations (i.e., if larger particles contain little uranium, determine at what size the rejection should be set). Then the particular equipment can be selected, perhaps with less extensive large-scale testing of different equipment. The equipment could consist of small, high throughput soil washing equipment with leaching, large leach tanks, or even controlled heap leaching.

There has been some interest in situ processes for removal of uranium. Most of these methods are speculative and should not rank high in priority. Electrokinetic transport of uranium is one such technique, but few aspects of the method are understood. There are questions such as the role of different uranium forms that lower the expectations for this method.

\section{Uranium in Groundwater}

If uranium must be removed from groundwater at the K-25 Site, the concentrations are expected to be so low that an adsorbent or ion exchange material may be used. The priority for development should be aimed in that direction. Decisions to treat groundwater or surface waters at the K-25 Site for uranium removal should be based on the potential risk of human exposure, and that depends on the water flow path as well as the uranium concentration in the water. Anion exchangers, which remove uranyl complexes are very specific for uranium and are likely to remove only a few other metals such as iron. However, they would require adding ligands to complex the uranium and additions would 
be undesirable, especially for large streams. Cation exchangers can be expected to remove essentially all soluble uranium, but their selectivity would be limited. That means that large fractions of the other cations in the stream would also be removed, often including, more $\mathrm{Ca}, \mathrm{Na}$, etc., than uranium. When the uranium is removed for disposal, ei her by disposing the resin or eluting the uranium and disposing salts of the eluted cations. These additional salts will add to the waste volume.

Existing ion exchangse materials can remove uranium effectively, but new methods could reduce the cost. There are two approaches to these improvements, and both should be given high priority. The first improvement would involve testing better quality and more selective ion exchange materials. The Japanese have developed highly selective materials for removing uranium from sea water. These materials may cost more than conventional ion exchangers, but the better selection should allow recovery of the uranium from lower concentrations in the waste and at higher concentrations for reuse or less costly disposal.

The second approainh with essentially the same priority would involve development of less costly adsorption/ion exchange materials. Biological substances can be grown and incorporated into gel particles or other solid structures suitable for use in packed beds. Living microorganisms are capable of concentrating uranium, perhaps even precipitating the uranium in or near the cell wall. There is significant selectivity for uranium in some of these processes, but the selectivity is not likely to ever become as high as that achieved by the materials designed specifically for uranium selectivity. However, the principal advantage of such materials may be their potential low cost and the possibility of incinerating the low-cost: material for concentrating the uranium further.

Adsorption and ion exchange materials, which require major changes in the groundwater or surface water, such as lowering the $\mathrm{pH}$ or addition of significant ligand concentration, should be given a lower priority. The materials should not be investigated extensively unless other options begin to appear less promising.

\section{Chlorinated VOCs in Soils}

VOCs are volatile (by definition) and easily removed if enough air flow can be forced through the soils. The problems probably result from not being able to get sufficient air flow to the contaminated region. Operations like deep soil mixing can help increase the permeability of soils and improve the air flow. The principal S/T needs are improvements in getting air flow to and through the contaminated region. There can be more difficult problems with contamination located below the water table. Vacuum exiraction will not bring air through the groundwater. Air can, however, be introcluced to the groundwater and removed from properly designed extraction wells and linings. Note that some extraction of VOCs from the vadose zone occurs naturally from changes in barometric pressure and variations in the water table.

Recovery of VOCs after extraction should be optimized, especially when high concentrations and large: quantities of chlorinated VOCs are involved. Adsorption on carbon is a common practice that is effective, involves small capital costs, and is particularly good as a backup or polishing step. Development of better regeneration and VOC recovery methods should be sought. The goals should be to reduce adsorbent and regeneration costs and produce higher concentrations of the recovered VOCs for destruction, disposal, or reuse. 


\section{Chlorinated VOCs in Groundwater}

Ex situ gas stripping is currently the most promising technology. The greatest improvement in gas stripping can be made in the VOC recovery system, adsorption, and adsorbent regeneration. Catalyzed UV-peroxide oxidation is an attractive technology that appears to be well developed and demonstrated. Chemical dechlorination with iron particles is a new and attractive technology for this problem. This technology has the potential for being used in situ to block groundwater plumes. Metallic iron has been suggested to reduce chlorinated hydrocarbons for removal of chlorine atoms. The resulting dechlorinated compounds generally would be nontoxic and easily degraded by microorganisms. This may be the most interesting approach to develop, but little is understood about the process. Therefore, it must be viewed as speculative, but it should be a high priority for testing (confirmation).

\section{Hydrocarbons in Soils}

There has been considerable research on the removal of fuel components from soils. Biodegradation is probably the most promising approach to develop. S/T should stress better and more reliable in situ processes. A major goal should be to improve the performance with the more refractory (usually the heavier) components and improvements in the reliability (predictability) of the processes.

\section{Hydrocarbons in Groundwater}

Hydrocarbons that are found in groundwater are another common problem that has been studied extensively. Biodegradation appears to be the most promising low-cost approach, but it must be developed sufficiently to give reliable and predictable results. Chemical oxidation is a more rapid approach. Peroxide or other oxidants have been tested with $\mathrm{UV}$ and/or catalysts (such as metals, $\mathrm{TiO}_{2}$ or $\mathrm{Fe}$ (II)/Fe(III), and the technology is available commercially.

\section{Toxic Metals in Soils}

Most of the research work on toxic metals in soils appear to have been devoted to solidification (stabilization). Cement grouting could be improved by making the treatment more reliable. That could mean a better understanding of which grout mixture to use and/or the sensitivity of the grout performance compared to the composition and formation conditions.

More information should be known about using the leaching process to remove metals from soils. This is the alternative treatment and it offers the advantage of leaving the soil and the site more useful for future economic activities. R\&D on leaching must include studies of ways to concentrate and recover the metals for disposal or reuse.

\section{Toxic Metals in Groundwater}

Removal of toxic metals from aqueous solutions is more likely to involve adsorption or ion exchange methods. Solvent extraction methods are options, but 
the question of the toxicity of a residual solvent that is soluble or entrained in a water product must be raised. Reverse osmosis is well developed and can be effective, but it could be: more costly and produce a less concentrated product (waste). The principal need is for adsorbents or ion exchange materials that are specific for toxic metals; of interest. The objective is to concentrate the toxic materials, which generally makes the waste disposal problems less difficult and costly. If there are cases where it should be worth recovering the material, the high concentrations would also be helpful. To achieve high concentrations of the removed materials, more selective adsorbents (or ion exchange materials) are needed. That is, the adscirbent should remove enough of the toxic material and as little other materials as possible. The selectivities are needed with respect to the contaminants that are present in the soil. In the K-25 area, the important (major) cations are likely to be $\mathrm{Ca}, \mathrm{Mg}$, and $\mathrm{Na}$. If the toxic metals are to be removed from the adsorbent (ion exchange material), it is necessary to have an efficient regeneration method that produces a concentrated product. High adsorbent capacities are also helpful in controlling the cost of removal systems.

\section{Technetium in Soils}

Solidification into nonleachable forms or removal of Tc are two options for treating soils with $\mathrm{Tc}$ contamination. It may be possible to maintain $\mathrm{Tc}$ in cement based grouts, but serious consideration is also expected to be given to the removal of Tc from soils. This is most likely to involve leaching. There seems to be little work on leaching of Tc from soils, and an investigation of leaching methods is needed. Before considering a Tc removal process, tests are necessary for the actual soils of interest.

\section{Technetium in Groundwater}

Tc can be removed from groundwater by a number of adsorbents and ion exchange materials. Transition metals are particularly interesting for Tc removal because they offer high-removal efficiencies, high-bed capacities, and relatively low costs; iron is a prime example. However, the mechanism and the parameters affect adsorption of Tc. The "adsorption" may involve reducing technate to insoluble $\mathrm{TcO}_{2}$, which coats the iron metal. It is unclear how long iron particles can be used and how much Tc they can hold before the adsorption rate declines to unacceptable levels. The performance of iron from different sources may to be different, and the cause s of these differences is not understood.

\section{Asbestos in Soils}

It is not certain how much asbestos will have to be removed from burial sites at the K-25 Site and what treatment, if any, would be required to return them to the soil. The principal problem with removing asbestos is associated with handling the materials, not with the actual treatment. Burying asbestos-containing materials or incorporating asbestos into grouts may not have any major science/technology needs. Separating asbestos from structural components with which it was buried may be the most serious problem. The methods used for D\&D of asbestos containing inaterials may be effective, but the presence of clays and 
other soil materials could be a complication. Most large quantities of asbestos in retrieved buried materials may be identified from the components in which they are incorporated, but detection of smaller quantities of asbestos that may have become dispersed in soils could be difficult.

\section{Dense Nonaqueous Phase Liquids}

No technology is considered developed and reliable removing DNAPLs from saturated soils. The technique that is probably the best understood is surfactant flooding. If one includes all non-aqueous phase liquids (NAPLs), this technique is widely used since it is common practice in the petroleum industry for secondary recovery of oil. However, there are major differences in partially depleted oil wells and TCE or PCB contamination cleanup, especially in the degree of NAPL removal that must be achieved. Surfactant flooding removes the DNAPL be increasing the apparent solubility of the DNAPL so it can be removed more rapidly by more contentional methods such as ex situ air stripping. This apparent solubility increase results from formation of micelles or even small droplets of DNAPL surrounding with surfactant. The "dissolved" DNAPL will be in such small particles that it will follow the water flow and be removed in extraction wells. However, surfactants also lower the surface tension (DNPAL-water interfacial tension), and this could allow the DNAPL to "settle" through smaller openings in the soil and reach greater depths int he soils where it would be more difficult to detect and/or remove. Thus selection of surfactants must include consideration of surfactant effects, and an understanding of the soil structure in which the DNAPL is contained can be important. If the DNAPL have descended to bed rock, further movement downward would require fractures in the bed rock or sufficient slope in the rock for the DNAPL to move lower. Unfortunately, the rock structures at the K-25 Site are highly fractured; so continuous and stable rock is not likely to be found.

Selection of DNAPL needs to be made on the basis of their effects on DNAPL mobility as well as "solubilities." This may require measurements of interfacial tension under the range of conditions expected. The presence of other solutes in the soil (including surfactants produced by natural organisms may have to be considered.) 


\subsection{IMPLEMENTATION NEEDS}

The selection and implementation of a technology for a remedial action at the K-25 Site would require establishing a level of cleanup and testing for problems that could interfere with the use of that technology. In many cases, especially in the cleanup of soils, the removal standard has not been fully established. If the K-25 Site remediation is to be covered by CERCLA, the cleanup standards are expected to be set by risk analyses, and the appropriate analyses would have to be made before initiating, the remediation.

RA requires treatment of soils and/or groundwater that can never be fully characterized. Technolog;ies that have been used extensively at other sites will need some treatability testing to ensure that there are no unexpected properties of the K-25 Site soils and groundwaters that prohibit the use of that technology. Even treatability studies have limitations because of the heterogeneity of all soils, especially the soils in eastern Tennessee. It is usually far easier to characterize groundwater than soils since heterogeneity is not as serious a problem with groundwaters as with soils. Nevertheless, the presence of unknown inhibiting components should be assessed, and treatability studies are still recommended.

\section{Uranium in Soils}

The level of uranium removal has not been established. It is important to note that natural undisturbed and uncontaminated soils in the K-25 Site area contain small concentrations of uranium. Concentrations in shales can even be relatively high by some standards. If the treatment limit is set too close to zero, uranium could be found throughout the site and off-site as well. Thus, it is important that the treatment limit be set to include only the uranium that was added to the soils by operations at the K-25 Site facilities and that the limit reflect a reduction of a significant risk of human exposure. Other sites in the DOE system have similar problems in establishing suitable limits, and a consensus for the limits should be established before remediation of the K-25 Site soil begins.

With incomplete characterization, treatability studies are essential to minimize the risk that problems will develop in applying a technology, even a well tested technology. To insure that all of the problem is treated and to avoid unnecessary costs by treating more soil than necessary, the extent of contamination needs to be established accurately. Both characterization and treatment are costly, and optimal use must be made of both. Further characterization work must be justified on the basis of its probability of reducing treatment costs (as risks) sufficiently to cover the costs of additional characterization.

\section{Uranium in Groundwater}

Because groundwaters are less heterogeneous than soils, suitable treatability studies are more likely to eliminate technical uncertainties in the performance of a technology. The need for suitable treatment objectives or limits remains, but there are better bases for risk analyses and guidance from related regulation such as the Clean Water Act. 


\section{Chlorinated Volatile Organic Compounds in Soils}

The extent of contamination and treatment levels need to be established for each site or problem. As noted earlier, several treatment options are available; the choice depends on the soil conditions and the presence of other contaminants. The lower cost and nonintrusive nature of soil venting and in situ biodegradation are often likely to be preferable, but both the effectiveness of biodegradation and the presence of other contaminants need to be considered. If biologically refractive and nonvolatile contaminants are also present, more aggressive thermal treatments may be required. The potential for finding traces of radioactivity or other nonvolatile contamination in the soil and even the time and expense of testing the soil for these contaminants before it can be returned to the ground makes in situ treatment methods easier to implement than many ex situ methods. The only current or planned treatment for chlorinated VOCs are for groundwater that could originate from buried waste and the surrounding soils.

\section{Chlorinated Volatile Organic Compounds in Groundwater}

The principal problems are determining the treatment level and selecting the most cost-effective method for treating the groundwater. Again, the presence of other contaminants can affect the choice of a treatment method so it is necessary to have a good characterization of the water. Air stripping and biodegradation are likely candidates to handle compounds most easily removed if more refractive (less volatile or more difficult to degrade biologically) compounds must be treated with technologies that cost more.

\section{PCBs in Soils}

More information should be available about $\mathrm{PCB}$ contamination at the $\mathrm{K}-25$ Site before treatment can begin. Besides knowing the extent of PCB contamination, the level of treatment that is required needs to be determined. The acceptable concentration or fraction to be removed needs to be established. The other contaminants in the soils may also play an important part in selecting and designing treatment systems. Although in situ biodegradation methods are being considered, the most promising near-term solutions require excavation and ex situ treatment. If the treated soil can be returned to the ground after PCBs are removed, an aggressive chemical treatment such as chemical dechlorination is a likely choice. The same treatment may still be advantageous if it converts the soil from a mixed waste to a LLW. However, if the residue will have to be grouted or stored because of other toxic materials like metals, solidification of the entire soil may be considered. The potential presence of radioactivity in the soil can make the solidified material a mixed waste, which is difficult to handle under current regulations. 


\section{PCBs in Groundwater}

Although it is uncertain if PCBs from groundwaters at the K-25 Site need to be removed, the implementation requirements for such operations will be discussed. PCBs are often removed from groundwater by activated carbon beds. The removal is efficient and relatively inexpensive. However, lack of regeneration methods makes waste disposal problems difficult and costly. The problem is compounded if uranium or other radioactivity is adsorbed so the carbon becomes a mixed waste. Although most carbon beds can be regenerated by vendors, PCBloaded beds are often not accepted by vendors. Beds with potential radioactivity and PCBs are unacceptable by vendors for regeneration. Permits for regeneration "on-site" would free the carbon for reuse and reduce the solid waste generation considerably. The TSCA Incinerator at the K-25 Site may be able to accept small volumes of liquids produced by regeneration of the beds. Both thermal and solvent regenerants may be possible.

\section{Hydrocarbons in Soils}

Although traces of uranium (from natural sources as well as possible contamination) can be found in the $\mathrm{K}-25$ area, no waters are known to require treatment at this time. Flydrocarbon contamination in soils at K-25 come largely from a leaking fuel tank. The tank has been removed, but some contamination remains. As noted earlier, there have been many studies of hydrocarbon removal from soils that showed significant success. The difficulties in using those technologies at the K-25 Site involve the establishment of a suitable treatment level, verifying the treatment level, and the effects of treatment on other issues. The likelihood that any' soil removed from the K-25 Site will be considered radioactive and not be allowed to return to the ground often favors the use of in situ processes. However, the complex soil structure makes it difficult to insure that treatment does not alter underground water flow in unacceptable ways. It is also difficult to ensure that the treatment does not deliver its fluids (air for soil venting or air and nutrients for biodegradation) to the contaminated area. Better understanding of grourdwater flow is needed for implementing most in situ technologies.

\section{Hydrocarbons in Groundwater}

Several technologies iave been mentioned that can remove hydrocarbons from water, and there have been several successful applications of these technologies at other sites contaminated with fuel components. A serious implementation problem at the K-25 Site is assurance that contaminants (hydrocarbons, PCBs, chlorinated VOCs, etc.) have been removed adequately from the water to permit them to be discharged. Significant groundwater flows make it impractical to store treated water for significant periods of time, which may be required to complete verified analyses that the product meets discharge requirements. This is a potential problem for ariy groundwater treatment, but it is most evident when there are few other technical questions about the technologies used. 


\section{Metals in Soils}

The need for removing metals from soils at the K-25 Site has not presently been established as a priority. Traces of toxic metals have been found in surface water and groundwater. This suggests some level of contamination in surrounding soils, though probably at low contamination levels. If it becomes necessary, the implementation difficulties are likely to be the determination of the required treatment level and the return of the soil to the ground. The most likely removal methods require leaching. The treatment levels generally are not established, and the presence of other components that could affect disposal is unknown. The final state of the soil and the relative merits of removing trace metals at the expense of soil productivity may have to be established.

Solidification (in situ) is the only approach that could eliminate the problems encountered from returning the soil to the ground. However, solidified soil is not likely to have any future use, and the benefits of removing large volumes of soil and land may have to be weighed against the risk of the trace metal components. Such a balance of risk vs land (soil) loss may establish the amount of soil that is appropriately treated with this technology.

\section{Metals in Groundwater}

Presently there are no apparent groundwaters that are contaminated with toxic metals at a level that requires treatment. Implementation questions may concern analysis and discharge of the treated water and minimization of the solid waste produced. Only the second question can be answered using technology. The treatment methods discussed above will need to be assessed as part of a complete treatment system, including concentrating the metals removed and producing a suitable waste form or recyclable material.

\section{Technetium in Soils}

Treatment levels are not established, and the necessity of removing $\mathrm{Tc}$ from soils at the K-25 Site is not established. Removal methods are likely to involve excavation. Also, the possibility of returning treated soil to the ground needs to be determined. Solidification of Tc in cement based grouts needs to be evaluated for long-term stability.

\section{Technetium in Groundwater}

The methods for removal of Tc from the K-25 Site groundwater are uncertain. Some removal methods look promising but have not been demonstrated at a significant scale or used for a suitable length of time. (It is important to perform validated analysis and discharge water quickly to avoid long treated water holding time.) 


\section{Asbestos in Soils}

The need for removal of asbestos-containing materials from the K-25 Site soils is uncertain. The requirements for returning materials to the ground are also uncertain. Because grouting technologies are expected to be suitable lother simpler packaging and burial methods may be acceptable), the principal difficulties may involve safety concerns in retrieving and mechanically separating asbestos from other materials. These could even be native asbestos in the soil.

\section{Dense Nonaqueous Phase Liquids}

Use of surfactant flushing to remove DNAPLs will require relatively good assurance that the treatment will not result in less desirable redistribution of the DNAPL in the soil, 11sually to deeper regions. This implies that site characterization, especially in terms of underground structure, is better understood than is usually required for other remediation approaches. Since the contaminants will be mobilized by the surfactant, it becomes important that recovery wells be well designed and placed. This requirement is probably more severe than in other contaminant treatment schemes where the treatment inherently reduces spread of the contamination. Recovery of the TCE from surfactant flush liquid is likely to involve conventional technology, usually air stripping. For non-volatile DNAPLs such as PCBs, more innovative recovery methods may be desired. Activated carbon probably will remove the "dissolved" PCBs, but the hydrophilic surfaces of the micelles may affect the adsorption of PCBs on carbon. 


\subsection{TECHNOLOGY RANKINGS FOR THE K-25 SITE}

Prioritization of TD for RA involved significant factors like the probability of success in the development, the cost of development, etc. The bases for the prioritization are given in Table 7.1. There are obvious subjective considerations in the selection of priorities. It was generally recognized that some time is required for new development efforts to have a major impact on RA. The current plans (Roadmap) call for important RA activities to begin by or near the end of this decade. This allows time for better characterization of the problems, but it also makes development of significant new technologies possible. There are two time scales used for prioritization. One priority is for technologies that are expected to be available during the next 5 to 10 years and the other priorities are for technologies that could be developed 10 to 20 years from now. A list of the priorities is given in Table 7.2. All technologies included in the TLD were judged useful to address the K-25 Site problems. Technologies were evaluated on an individual basis and assigned priority rankings of high (H), medium (M), and low (L) based on the evaluation of their potential cost-effective implementation in the K-25 Site cleanup effort. Both technology development and implementation needs were reflected in this evaluation.

With important technologies being developed in industries and in well established programs such as the DOE/EM Integrated Demonstrations and Integrated Programs, the prioritization stressed the need for new or additional efforts. A review of the Integrated Demonstrations and Integrated Programs indicated that those programs are well directed and will help meet many of the needs for the K-25 Site. In most of the prominent cases, this is acknowledged either on the diagram or in the associated text, but in-depth evaluation of the Integrated Demonstrations and Integrated Programs for their relations to the K-25 Site was not part of this effort. A similar situation exists for development of

Examples of potential cost savings in one characterization area are as follows.

The analysis of large areas can be performed using a variety of sampling designs. Regardless of which sampling design is used the number of samples can quickly build up to place a real strain on existing analytical capabilities. This is an area where robotic-assisted field characterization can provide large cost savings. Using the process floors at the K-25 Site for example, one can determine that if $50 \%$ of the 325 acres is readily accessible to a robotic platform and a $100 \mathrm{ft}^{2}$ sampling grid is used that 78,650 sampling locations would be identified. If sampling and analysis were manually performed for PCBs, radiological, and metals of interest (U, Tc, $\mathrm{Hg}, \mathrm{Pb}, \mathrm{Cr})$, the total cost would be over $\$ 40 \mathrm{M}$ (@ \$525 for all three sampling and analysis costs).

- Integration of process knowledge with statistical sampling could, with regulatory approval, reduce the number of samples taken up to a factor of 10 , with associated savings of $\$ 36 \mathrm{M}$. If three robotic units (@ $\$ 500 \mathrm{~K}$ each) were used and supported by 1.5 Full-Time-Equivalents ( $\$ 300 \mathrm{~K}$ per FTE) then a similar characterization could be performed within the same time frame for approximately $\$ 2 \mathrm{M}$. The automated systems also produces less waste, increases data handling ease, and reduces the administrative burdens for monitoring and controlling a large scale manual characterization effort. Thus the overall cost savings is greater than that estimated by straight comparison of sampling and analysis costs.

- If sampling and laboratory analysis costs could be reduced $5 \%$ through efficiency improvements, the overall cost savings would be $\$ 2 \mathrm{M}$. 
Table 7'.1. Considerations for prioritization

Limits on performance of the technology

Probability of successful development of the technology

Application to an important problem at the K-25 Site

Timeliness of the technology

Cost of using the technology

Cost of developing and demonstrating the technology

Wastes generation (or waste minimization)

Anticipated reliability of the technology under expected variation in field conditions

Level of current development efforts

Flexibility of the technology to meet new and unanticipated needs at the K-25 Site and similar problems at other DOE sites

technology in industry. The use of many technologies can be controlled by patents or propriety information and developed effectively by commercial firms. The capabilities and the adequacy of a technological industrial development are substantial, but details are usually unavailable concerning industrial R\&D until the results are demonstrated and offered commercially. Trade literature can either conceal the ongoing development of new ideas or overstate the status of a technology for commercial purposes. Therefore, the requirements for additional development efforts are uncertain for those technologies that are being handled by industry. The government can have less direct influence on the expenditures for technological development by industrial firms, but of course, the government could influence the development by insuring a market for the technology.

As more technologies become available, priorities should shift toward other ideas that can make greater improvements in RA performance. New data may show that some technologies that are now considered speculative have become promising and that some new data may show ideas that were acceptable in the past have serious faults. Changing regulations on treatment levels and schedules for treatment may also alter the priorities. Any exercise like this will need to be reassessed periodically to insure that the results are meaningful. 
Table 7.2. Priorities for remedial action

\begin{tabular}{lcc}
\hline Priority & $\begin{array}{c}\text { Ranking } \\
\text { Short Term }\end{array}$ & $\begin{array}{c}\text { Ranking } \\
\text { Long Term }\end{array}$ \\
\hline Solids separation & Uranium in soils & \\
Soil washing & $\mathrm{M}$ & $\mathrm{M}$ \\
Mobile wash/leach unit & $\mathrm{H}$ & $\mathrm{H}$ \\
Acid leaching & $\mathrm{M}$ & $\mathrm{M}$ \\
Alkaline leaching & $\mathrm{M}$ & $\mathrm{M}$ \\
Electrokinetic removal & $\mathrm{H}$ & $\mathrm{H}$ \\
In situ vitrification & $\mathrm{L}$ & $\mathrm{M}$ \\
Ex situ vitrification & $\mathrm{L}$ & $\mathrm{L}$ \\
Cement grouting & $\mathrm{L}$ & $\mathrm{L}$ \\
Polymer grouting & $\mathrm{M}$ & $\mathrm{L}$ \\
& $\mathrm{L}$ & $\mathrm{L}$
\end{tabular}

Uranium in groundwater

Coagulation

Ion exchange

Biosorption

Adsorption on inorganic material

Adsorption on carbon

Reverse osmosis

L L

$\mathrm{H} \quad \mathrm{M}$

$\mathrm{H} \quad \mathrm{H}$

M M

L L

M L

VOCs in soils

Vacuum extraction

Steam extraction

Vapor extraction with RF

Ground freezing

In situ biodegradation

Ex situ biodegradation

Chemical dechlorination

VOCs in groundwater

Air stripping

Adsorption on carbon

Peroxide-UV oxidation

Membrane separation

Lime-softening coagulation

PCBs in soil

In situ bioremediation

$\mathrm{H} \quad \mathrm{H}$

$\mathrm{H} \quad \mathrm{M}$

M M

L L

$\mathrm{H} \quad \mathrm{H}$

$\mathrm{H} \quad \mathrm{H}$

$\mathrm{H} \quad \mathrm{H}$

Land farming

In situ grouting

Incorporating into asphalt

$\mathrm{H} \quad \mathbf{M}$

$\mathrm{H} \quad \mathrm{M}$

$\mathrm{H} \quad \mathrm{H}$

M M

L L

$\mathrm{H} \quad \mathrm{H}$

L L

M L

L L 
Table 7.2. (continued)

\begin{tabular}{|c|c|c|}
\hline Priority & $\begin{array}{l}\text { Ranking }^{a} \\
\text { Short Term }\end{array}$ & $\begin{array}{l}\text { Ranking } \\
\text { Long Term }\end{array}$ \\
\hline \multicolumn{3}{|c|}{$P C B$ s in soil (continued) } \\
\hline Incineration & M & M \\
\hline Destruction in cement kiln & $\mathbf{M}$ & $\mathbf{M}$ \\
\hline Ex situ biodegradation & $\mathrm{H}$ & $\mathbf{H}$ \\
\hline APEG/KPEG & $\mathrm{H}$ & $\mathrm{H}$ \\
\hline Photocatalysis & $\mathbf{M}$ & $\mathbf{M}$ \\
\hline Low temperature thermal treatment & $\mathbf{M}$ & $\mathbf{M}$ \\
\hline Solvent extractior. & M & $\mathbf{M}$ \\
\hline Ex situ grouting & $\mathbf{M}$ & $\mathbf{L}$ \\
\hline \multicolumn{3}{|c|}{ Hydrocarbons in soils } \\
\hline In situ biodegradattion & $\mathrm{H}$ & $\mathrm{H}$ \\
\hline In situ grouting & $\mathbf{M}$ & $\mathbf{L}$ \\
\hline Incorporating intc asphalt & $\mathbf{M}$ & L \\
\hline Incineration & $\mathbf{M}$ & $\mathbf{M}$ \\
\hline Destruction in cement kiln & $\mathbf{M}$ & L \\
\hline Ex situ biodegradation & $\mathrm{H}$ & $\mathrm{H}$ \\
\hline Low temperature thermal treatment & $\mathbf{M}$ & L \\
\hline Soil venting & $\mathrm{H}$ & $\mathbf{M}$ \\
\hline Ex situ chemical degradation & $\mathbf{M}$ & $\mathbf{M}$ \\
\hline \multicolumn{3}{|c|}{ Heavy metals in soils } \\
\hline In situ vitrificatio:? & $\mathbf{M}$ & $\mathbf{M}$ \\
\hline In situ grouting & $\mathbf{M}$ & $\mathbf{L}$ \\
\hline Electrokinetic separations & $\mathrm{L}$ & $\mathbf{M}$ \\
\hline Leaching & $\mathrm{H}$ & $\mathbf{H}$ \\
\hline \multicolumn{3}{|c|}{ Technetium in soils } \\
\hline In situ grouting & $\mathbf{M}$ & $\mathbf{M}$ \\
\hline In situ vitrification & $\mathbf{M}$ & $\mathbf{M}$ \\
\hline Ex situ grouting & M & $\mathbf{M}$ \\
\hline Leaching & $\mathrm{H}$ & $\mathbf{H}$ \\
\hline
\end{tabular}


Table 7.2. (continued)

\begin{tabular}{lcc}
\hline & $\begin{array}{c}\text { Ranking } \\
\text { Priority }\end{array}$ & $\begin{array}{c}\text { Ranking } \\
\text { Short Term }\end{array}$ \\
Long Term
\end{tabular}

¿etter rankings: $\mathrm{H}=$ high, $\mathrm{M}=$ medium, and $\mathrm{L}=$ low.

*Unknown because the presence of DNAPLs at the K-25 Site is not established.

\section{Uranium in Soils}

Establishing the utility of standard ore leach methods is a priority technology requirement for removing uranium from soils. Because of the high carbonate rock in the region, acid methods will not work (use carbonate leaching) or uranium containing soil fraction will have to be separated before leaching. Physical separations have the potential for reducing the quantity of soil to be processed. This potential should be explored. Other treatment methods should be explored on a limited scale unless the promising and conventional approaches are inadequate.

Uranium contaminated soils should be separated into size fractions to determine if the uranium is principally in one or more fractions. For physical separations to be as useful, the remaining fraction must be uncontaminated or contain insufficient contamination to require separate treatment. (There is also the potential for separating different soil fractions because the treatment on each 
fraction should be diffe:ent.) The form of the uranium in each contaminated fraction should be determined. The information could include the valence and whether the uranium is aldsorbed or incorporated as a separate phase. It could be important if the uranium is in more than one form. If the uranium is distributed among most size fractions, separation by density or surface properties (floatation) should be considered.

Leach tests should kie made with each contaminated soil fraction. If most of the soil fractions are contaminated, it may be beneficial to perform leach tests on the entire composite soil. The leach tests should include the standard carbonate leach solutions used to recover uranium from ores. The leach time, the effects of solids concentration, arid the proper leach solution should be explored. It is important that the treated soil be free of uranium so it can be returned to the ground. The soil should be suitable for growing vegetation or resuming the use it had before treatment. It is essential that the soil is sufficiently decontaminated. The treated soil should be characterized to determine the fate of other toxic contaminants.

If other contaminants are present in the soil, the behavior of those contaminants in the soil treatment will have to be determined. Treatments to remove uranium should not hinder treatments to remove other contaminants. Some contaminants mayr be removed by the treatment for uranium.

Uranium must be resovered and concentrated from leach solutions. Although standard techniques are available from the ore industry, these techniques should be checked to insure that the concentrations and other contaminants in soils will not hinder the use of standard extraction techniques. Maximum recycle capacity of leach solution and minimization of wastes will be important considerations in selecting treatment methods.

Electrokinetic removal of uranium is not considered a mature technology. The work on electrokinetic removal should proceed at the bench scale with field implementation at controlled sites until implementation concerns about this method are resolved.

\section{Uranium in Groundwater}

Adsorption and/or ion exchange processes are expected to be the most attractive methods for removing uranium from dilute groundwater and surface waters. The S/T needs focus on those methods. Precipitation (and coagulation) methods are not recommended because the waste volume could be too high. However, if coagulation methods are necessary to remove other pollutants, the behavior of uranium in such systems should be apparent, and efforts should be made to use this method to remove both contaminants.

The key information. needed for evaluating ion exchange systems are (1) the equilibrium properties, (2) the rates of exchange, (3) the cost of the material, (4) the potential for regeneration to minimize waste volume and reduce resin cost, and (5) the cost of the ion exchange resin. Engineering design (or scale up) of ion exchange systems is not: simple, but it can be reliable. The equilibrium relations should be known for all of the ions in the groundwater, at least in the concentration range of interest. The maximum uranium loadings that can be expected is the most ir.nportant parameter (this is the loading on the resin in equilibrium with fresh groundwater) along with the related separation from other cations in the groundwater. Any cation exchange material will remove the cations 
from any groundwater. It is inadequate to do a "treatability test" to see if a resin can reduce the uranium concentration to a desired level. The treatability test only determines if there are other nonionized forms of uranium that cannot be removed by ion exchange. Such tests tell little about the merits of the material in a practical process. It is beneficial to get as much uranium and as little other cations as possible on the resin. If the resin is sent directly to disposal, the waste volume should be as low as possible and the uranium concentration should be as high as possible. If the resin can be regenerated, it may be possible to concentrate the uranium even further and reuse the resin. Of course, if other metal cations are in the regeneration solution, extra metals may accompany the uranium sent to disposal and increase the waste volume. Further separations of uranium from other metals can be made if the additional step is justified. Fractionation of metal mixtures can be accomplished by using ion exchange with more complicated equipment if necessary.

It is not always obvious if a material is an ion exchange material or an adsorber. In a few cases, a material such as a biological organism may act in both manners. Adsorption materials and ion exchange resins have similar needs. Capacity, selectivity, and exchange or adsorption rates are the key parameters.

Two directions are suggested for exploring and developing better ion exchange and/or adsorption processes. In one direction, there should be a search for better ion exchange resins or adsorbents. Synthetic ion exchange resins may provide the greatest range of options to explore. In the other direction, there should be a search for less costly materials that can be combusted to leave little ash to add to the waste volume when the uranium is concentrated for disposal. These adsorbents are more likely to be biological material, perhaps even microorganisms. It is attractive when organisms can concentrate uranium in their cell wall or other regions of the cell. If these materials can only be used once, it is important that they be low-cost and preferable that they be easily burned or degraded. In all of these cases, the capacity, selectivity, and rates must be assessed.

Although other methods are not considered to be as effective or as costeffective as adsorption or ion exchange, they could be important if they are needed to remove other contaminants. Using coagulation to remove other contaminants was mentioned earlier. Reverse osmosis is another method that could be selected to remove pollutants and would also remove uranium. Although these methods are not currently viewed as the best option for removing uranium, they may become the preferred method where multiple pollutants are involved. The generation of insoluble uranium materials found in nature should be investigated (the carnotites perhaps). Specific mineral exchangers from the zeolite series should be investigated.

\section{Chlorinated Volatile Organic Compounds in Soils}

Soil venting, air stripping, and biodegradation may be the most popular method for removing VOCs from soils. Both of these methods are as economical as any of the alternatives. A major portion of the R\&D on VOCs from soils should address problems that improve these techniques or extend their applications. Grouting and incineration are both likely to remain more expensive and create a greater disturbance in the soil properties. Soil venting and air stripping can be improved by improved understanding and characterization of soils and air flow through the soils. Improved drilling techniques such as the horizontal drilling 
technique developed at the Savannah River Site may be able to extend the applications of soil ventir.g and air stripping. Methods for improving permeabilities of deep soils would extend these techniques to more applications. The recent demonstration at Portsmiouth showed how deep soil mixing makes gas stripping effective even with normally "tight" soils with little permeability. That demonstration was able to explore only a few techniques using deep soil mixing with air stripping.

Applications of soil venting and air stripping could be improved by advances in the supporting operations. There can also be improvements in gas handling operations. Improvements in recovering organic compounds need to be addressed. Carbon beds are effective in removing organics, but they can be costly if regeneration is not allowed. In some cases, regeneration costs could be reduced if the regeneration could be done on-site rather than shipping the spent beds to a vendor. It would be helpful to minimize or avoid the disposal of carbon. This means that concentration or even incineration of the VOCs could reduce waste volumes, thus costs. The effects of regeneration/disposal costs on the overall operation costs depends on the amount of organic compounds in the soil. The amount of carbon needied depends upon the amount of contaminant present. When there is only trace $V O C$ contamination, the amount of carbon needed should be small.

Interest in biodegradation seems to be growing, especially for in situ biodegradation. It is attractive because it requires minimal disturbance to the site. Unfortunately, biodegradation is viewed as a "simple" operation because there is less equipment involved. However, biodegradation is very complex. The reliability of biodegradation needs to be improved. This usually means that the processes are not fully understood and all of the parameters are not identified or controlled. Complex organic compounds may be degraded in several steps and involve several organisms. Complex organic compounds need to be understood if improvements are to be made on a rational basis. Biodegradation is less effective for some compounds than others, and it would be helpful if biodegradation could be extended to handle miore of these refractory compounds. Because some biodegradation occurs naturally, contaminants at old spill sites are more likely to contain higher fractions of these refractory compounds. The chlorinated compounds like TCE are particularly refractory to aerobic organisms. Methods for handling these compounds need to be improved. In situ operations is preferred.

When we think of biodegradation research, we think principally of selecting the proper organisms, conditions, temperature, nutrients, etc. However, in situ biodegradation operations have two other serious problems that need to be researched. First, the problem (detection of contaminants and extent of the contamination) and resilts should be assessed. With any in situ method, it is difficult to be sure that sufficient contaminant has been removed. This is a problem with soil ventirig and air stripping also, but with these operations, the concentration of contaminants in the gas stream leaving the soil can be followed using the decline in concentration as a guide. Similar indicators are needed for biodegradation. Periodic soil sampling is costly and based on the extent of contamination. (One advantage of biodegradation is that the process continues even after normal suppcirt of the operations have ended, though at a lower rate.) This means that there is a chance that residual contamination will eventually be degraded, even if it is not detected in the final assessment. Perhaps the 
identification of organisms and degradation products (carbon dioxide, etc) can be used to follow the progress of the degradation process.

In situ biodegradation also needs better methods for creating conditions conducive to effective biodegradation. In most cases, this means the delivery of oxygen and nutrients to the region of interest. In other cases, it may mean introducing foreign organisms to the contaminated region or altering the $\mathrm{pH}$ or redox conditions in the region. Introducing oxygen and nutrients are common problems that need attention. The deeper or the more remote the contamination, the more serious these problems will become. Using cone penetrometers, which is an easier method than drilling, to reach remote locations may be part of the solution. However, ensuring that the nutrients reach all of the contamination is a more difficult problem.

Most organisms that have been used so far in biodegradation have been "native" organisms that are normally found at contaminated sites. Old contaminated sites are examined for the presence of organisms that could be useful in degrading pollutants. There has been, however, interest in finding or even "engineering" organisms with specific abilities to degrade selected contaminants. This may be a promising approach to the more difficult problems, but one that is likely to be useful in ex situ biodegradation where the conditions can be controlled more carefully. Native organisms may be more hardy than new organisms in situ, but in ex situ operations native organisms could even be killed (sterilized) before the new organisms are introduced.

Studies of grouting, incineration, and low temperature thermal treatment should be limited to those problems where economical processes cannot be used or where secondary problems occur. For instance grouting may be necessary because of the presence of toxic metals and VOCs. If grouting is used, the retention of VOCs is necessary. Also, very high concentrations of toxic metals could affect the performance of biodegradation processes. The long term treatment with air, a trace of ammonia, and a little vapor of a volatile phosphate, like trimethyl phosphate, may be the best plan to remove solvents and encourage biodegradation.

\section{Volatile Organic Compounds in Groundwater}

Gas stripping and adsorption on carbon beds are expected to remain ideal approaches, but several aspects of these treatments need to be explored. An R\&D focus is suggested. Acceptable methods are needed for the regeneration of carbon beds that generate less waste. The formation of solids in gas strippers is a concern, and equipment capable of operating effectively with such solids and/or easily cleaned equipment should be explored.

Catalyzed UV-peroxide oxidation is proving to be effective, even for many chlorinated compounds and commercial systems using this technology are being offered. The potential formation of solids is especially important in this technology because the solids can accumulate on the lamp surfaces or on the titania catalyst. Commercial firms claim to have developed equipment that can handle considerable quantities of solids.

Because groundwater can be removed easily from the ground, most operations appear to be ex situ. However, there is a growing interest in placing carbon beds or other devices in situ. The recent dechlorination approach using beds of iron particles could be used in situ. Clever designs like this should be encouraged, but 
systems based on underground adsorption should consider if the adsorbent will eventually have to be removed.

\section{PCBs in Soils}

For the short term, shemical dechlorination of PCBs appears to be the best approach for removing FCBs from soils. This approach is under development by the EPA and is capable of making major reductions in PCB levels. This is an ideal approach for producing suitable treatment methods that can be used in the near term. Further development of this approach should be encouraged. This method has an advantage-incounplete dechlorination does not produce more hazardous materials than the original contaminant. Other reductive chemical methods and even oxidative methods may show potential, but oxidation methods will need to show that fewer toxic products are formed.

There are disadvantages to chemical dechlorination that could make other approaches more promising for the long-term use. The disadvantages include (1) the need for excavation, (2) the use of moderately high temperatures, (3) the probably limiting of future uses of the soil, and (4) moderately high cost. The approaches that appeiar to have the best chance for overcoming these disadvantages are the biological processes, especially if they can be successful in situ. Presently, laborato:y work has shown potential.

\section{PCBs in Groundwater}

Currently, the most reliable method for removing PCBs from groundwater involves carbon beds. This method can generate unwanted volumes of solid wastes, perhaps even mixed waste at the K-25 Site. This approach could show more potential if the bedis could be regenerated or burned "on site." An interesting idea that has been recen tly proposed is chemical dechlorination with iron (or a few other metal) particles. Although there is not much known about this technology, the initial results should be explored. UV-peroxide oxidation is believed to be effective for PCBs as well as chlorinated VOCs. However, the great toxicity of some intermediate oxidation products is likely to make "backup" carbon beds desirable when oxidation methods; are used with PCBs.

For long-term use, biological degradation could operate with less cost, especially in situ, and sliould be adequately explored.

\section{Hydrocarbons in Soils}

Effective hydrocarkion removal methods are available, but significant improvements can still be made. The best ways to improve hydrocarbon removal methods is to improve the reliability and predictability of in situ methods. For more volatile fractions, improvements in soil venting would be helpful, but in situ biodegradation methois could handle heavy and light hydrocarbons. Improvements in the reliability of these methods will often require better ways to characterize underground water and air flow in the vadose zone and the aquifers. This is important to removal methods like soil venting and to biodegradation methods. This should be a priority for short-term and long-term use. 


\section{Hydrocarbons in Groundwater}

Hydrocarbons can be removed from groundwater effectively with current technologies, but this problem is so common that savings can result from even small improvements. Reducing costs can start by removing hydrocarbons from soils and eliminating the source of the problem. Again, in situ methods are likely to be less expensive, and attempts should be made to reduce the number of wells required for treating contaminated plumes.

\section{Metals in Soils}

There is little potential for removing most metals from soils using in situ methods. Extensive development of removal methods is recommended to replace solidification. Reduction in the volume of solid wastes and, to a lesser extent, reduction in the volume of unusable soil by treatments such as grouting are significant goals. Removal methods are likely to involve some form of leaching. Within this group of processes, the preference should be for improved selectivity and minimal effects on the soil. Both of these goals would need milder, but more specific leaching reagents. In some cases, it may be possible to achieve these goals by incorporating chelating agents into mild leach liquors, especially selective chelating agents. It should be assumed that the effective chelating agents will be safe to use. These needs apply to short-term and the long-term priorities.

\section{Metals in Groundwater}

Adsorption and ion exchange are the most common and the best solution for metals in groundwater for short- and long-term use. Priorities should be directed toward improved selectivities of adsorbents and ion exchange materials for the toxic metals of interest. This, along with suitable regeneration methods, produces more concentrated forms of the reduced metals, lowering waste disposal costs and, possibly in a few cases, providing better potential for recovering some materials.

\section{Technetium in Soils}

Attention should be focused on removing $\mathrm{Tc}$, and less effort should be devoted to solidification of Tc containing soils. More specific leach solutions are needed, especially those that remove few other components from the soil. The general goals should be similar to those discussed above for toxic metals for short and long term. There is a possible balance of toxicities between the Tc and the processing agents. An important difference between Tc, uranium, and other toxic metals is the chemical forms of Tc in soils (and in groundwater). The low valence form, Tc(IV), has a very low solubility, but the higher valence forms, Tc(VII), has a much higher solubility and is difficult to retain in common cement grouts.

\section{Technetium in Groundwater}

Developments in $\mathrm{Tc}$ adsorption on iron particles have lead to an interesting short term approach. The initial results raise many concerns and the mechanism of the removal has not been established. Thus, the effects of several important 
parameters are still unklown. Further research should explore the potential use of iron, and (1) if the iron should be stored, (2) if the iron should be disposed of underground, (3) if the iron should be stored in containers, (4) if Tc should be removed from the iron for disposal and storage, and (5) if the iron can be used in the ground to hold Tc and treat Tc plumes. Other metals should be considered to see if significant improvements are possible in the long term. Improvements can involve removal capacity, removal rates, better regeneration, or operability over a greater range of conditions.

\section{Asbestos in Soils}

The most serious need for asbestos treatment involves determining the risk of leaving (or placing) asbestos in materials stored underground. Other improvements can be made in worker protection during the dismantlement of materials that may have to be removed from current underground burial. The treatment methods may differ from methods user to handle equipment in D\&D that contain asbestos.

\section{Dense Nonaqueous Phase Liquids}

Since the presence of DNAPL at K-25 has not been confirmed, it is difficult to place development of IINAPL treatment among the highest priorities for the K-25 Site, but it certainly would be among the highest priorities for other DOE sites. For instance, the $\mathrm{Y}-12$ site and the Paducah site are ont included in this wiring diagram or in the proposed wiring diagrams, but his certainly would be a high priority for those sites. If DNAPLs are confirmed to be present at $\mathrm{K}-25$, the priority for treatment mithods will rise greatly.

In the meantime, there is a major need for better ways to detect the presence of DNAPLs and then lociate their presence. It would even be helpful to know the regions that are not contaminated so treatment efforts can be confined to as small a region as possible. Kncwledge of the exact location of DNAPL "pools" may not be necessary. Since individual "pools" are likely to be very small, locating them may not be a practical option. After treatment, the ability to determine when a region has become free of DNAPLs becomes important. At present, decisions on continuation or termination of treatment are likely to be made on the basis of decline in recovered DNAPL, probably an adequate, but not exact basis for the decisions. 
DOE is currently developing technologies through the EM-30, EM-40, and EM50 program which have the potential for making effective contributions to solving environmental and waste recycling problems at the different DOE sites. Some of these projects may have relevant and beneficial elements with respect to the technologies identified in the K-25 Site TLD. A search of available information on programs funded in FY 1992 was performed to identify the possible matches between technologies in the K-25 TLD and TTPs (or ADSs). A listing of the DOE EM-50 Program Guide for FY 1992 and abstracts for funded EM-50 projects were the principal sources for determining matches and relevancy between TEDS and TTPs. Relevant ADS activities were identified through staff personal knowledge.

In Table 7.3, those projects described in TTP or ADS and determined to be potentially relevant and beneficial are listed by TTP (or ADS) number along with the corresponding relevant Technology Evaluation Data Sheet (TEDS) identifier. Along with the matched TEDS is a succinct statement of the technology approach or problem being addressed in both documents. 
Table 7.3. DOE funded development

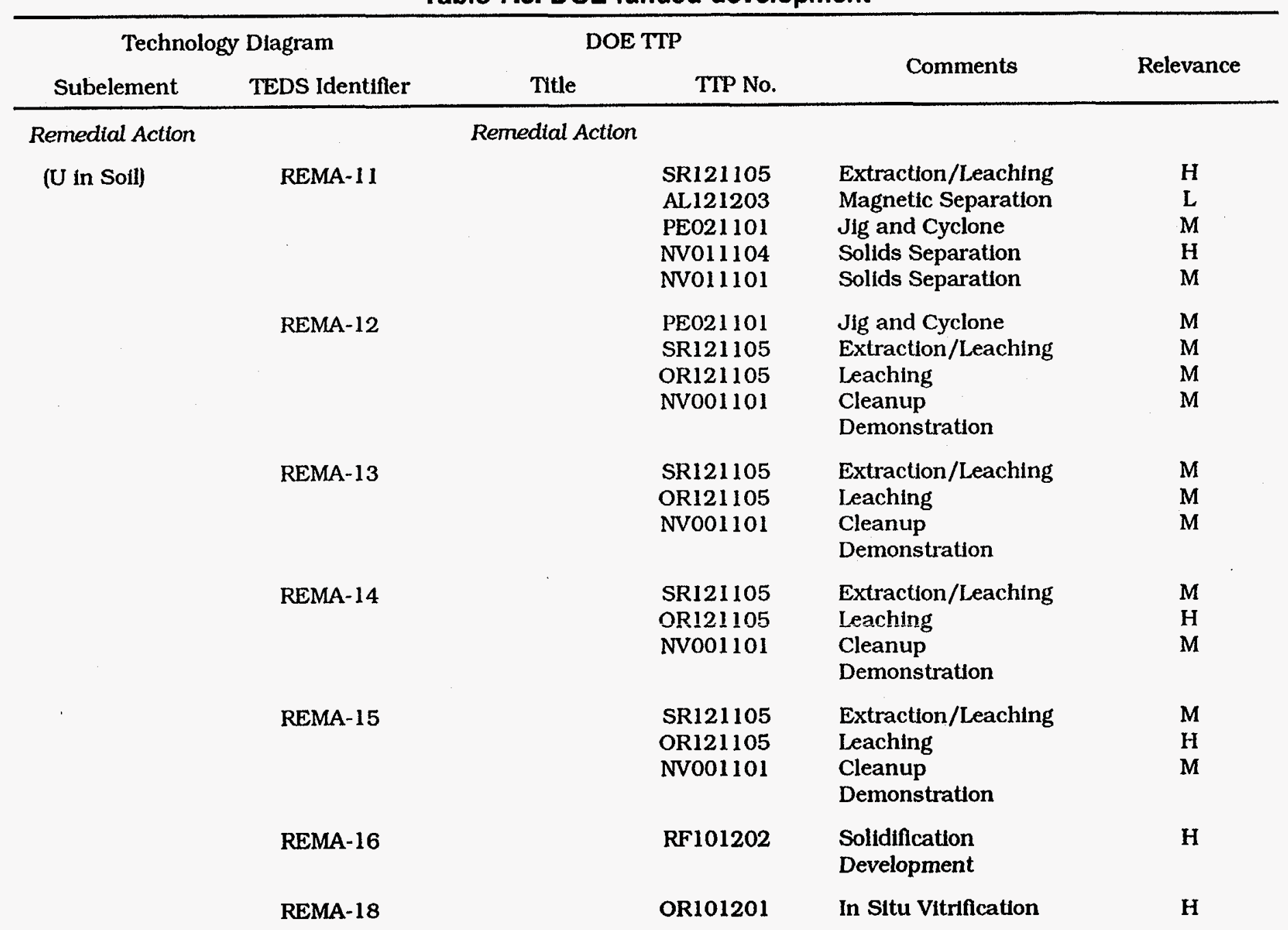


Table 7.3. (continued)

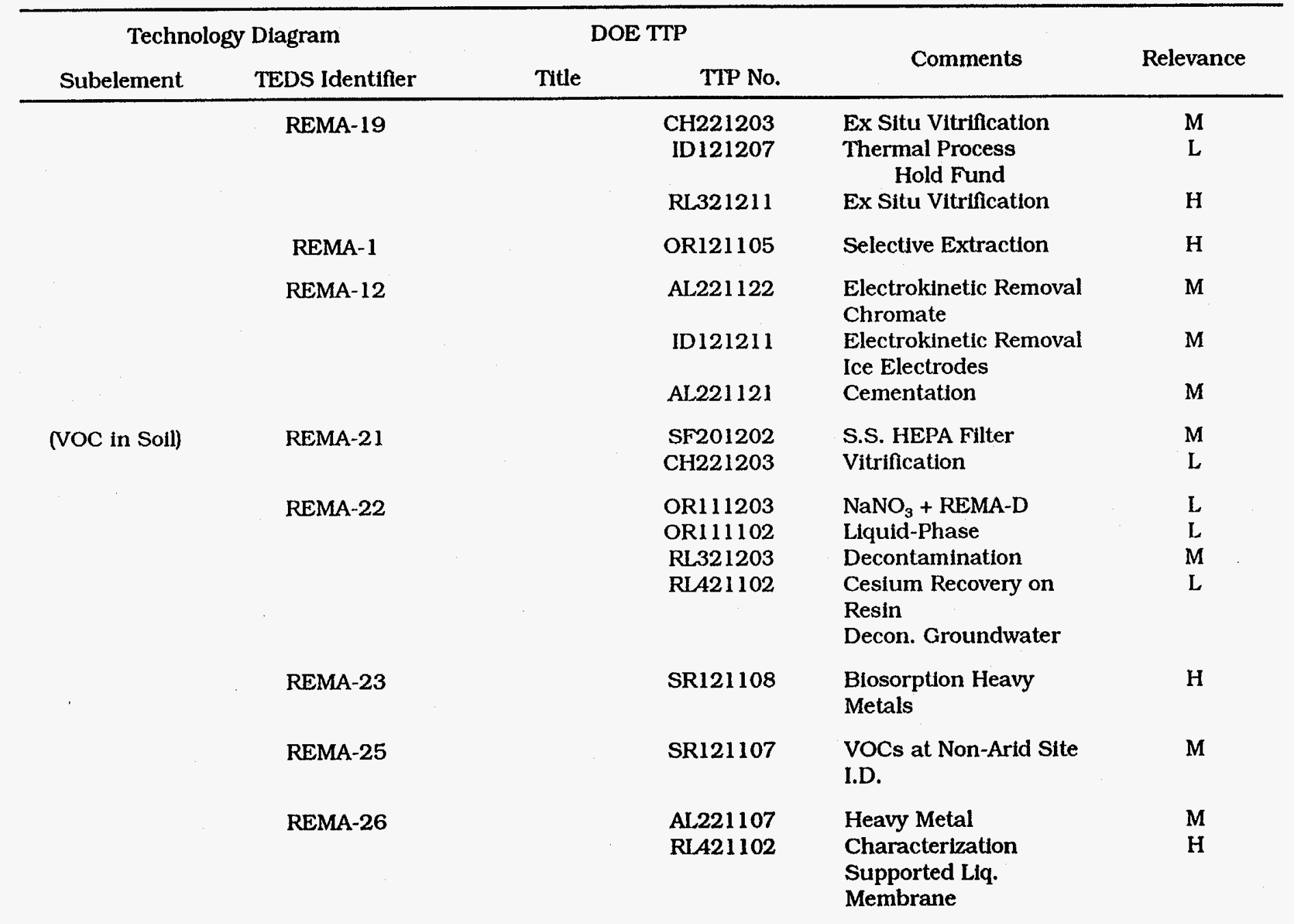


Table 7.3. (continued)

\begin{tabular}{|c|c|c|c|c|c|}
\hline \multicolumn{2}{|c|}{ Technology Diagram } & \multicolumn{2}{|c|}{ DOE TTP } & \multirow{2}{*}{ Comments } & \multirow{2}{*}{ Relevance } \\
\hline Subelement & TEDS Identifler & Title & TTP No. & & \\
\hline \multirow{11}{*}{\multicolumn{2}{|c|}{ REMA-31 }} & & CH221301 & Vacuum Extraction & $\mathbf{M}$ \\
\hline & & & RLA21101 & Vacuum Extraction & $\mathbf{M}$ \\
\hline & & & RLA21104 & Vacuum Extraction & $\mathbf{M}$ \\
\hline & & & SR121107 & Memb. Sep. & $\mathbf{M}$ \\
\hline & & & SR121106 & Vacuum Extraction & $\mathrm{L}$ \\
\hline & & & SFO11104 & Vaculum Extraction & $\mathbf{H}$ \\
\hline & & & ID121701 & RM Tasks & $\mathbf{M}$ \\
\hline & & & SR121104 & Vacuum Extraction & $\mathrm{H}$ \\
\hline & & & & Biofiltration & \\
\hline & & & & Integrated & \\
\hline & & & & Demonstration & \\
\hline \multirow{7}{*}{\multicolumn{2}{|c|}{ REMA-32 }} & & AL221121 & Steam Extraction & $\mathbf{M}$ \\
\hline & & & SF211104 & Steam Extraction & $\mathbf{M}$ \\
\hline & & & SR121104 & Steam Extraction & $\mathbf{L}$ \\
\hline & & & SR121106 & Remediation Tasks I.D. & L \\
\hline & & & SR121107 & Integrated & $\mathbf{M}$ \\
\hline & & & SR121104 & Demonstration & $\mathrm{H}$ \\
\hline & & & & $\begin{array}{l}\text { Integrated } \\
\text { Demonstration }\end{array}$ & \\
\hline \multirow{8}{*}{\multicolumn{2}{|c|}{ REMA-33 }} & & AL221121 & RF Heating & $\mathrm{H}$ \\
\hline & & & SF211104 & RF Heating & $\mathbf{H}$ \\
\hline & & & SR121106 & RF Heating & $\mathbf{M}$ \\
\hline & & & SR121107 & Integrated & $\mathbf{M}$ \\
\hline & & & ID121701 & Demonstration & $\mathbf{M}$ \\
\hline & & & SR121104 & Biofiltration & $\mathbf{H}$ \\
\hline & & & & Integrated & \\
\hline & & & & Demonstration & \\
\hline \multirow{3}{*}{\multicolumn{2}{|c|}{ REMA-34 }} & & ID121203 & Ground Freezing & $\mathbf{M}$ \\
\hline & & & SR121104 & Integrated & $\mathrm{H}$ \\
\hline & & & & Demonstration & \\
\hline
\end{tabular}


Table 7.3. (contInued)

\begin{tabular}{|c|c|c|c|c|c|}
\hline \multicolumn{2}{|c|}{ Technology Dlagram } & \multicolumn{2}{|c|}{ DOE TTP } & \multirow{2}{*}{ Comments } & \multirow{2}{*}{ Relevance } \\
\hline Subelement & TEDS Identiffer & Title & TTP No. & & \\
\hline & REMA-35 & & $\begin{array}{l}\text { OR123302 } \\
\text { OR111103 } \\
\text { SR121106 } \\
\text { OR111101 } \\
\text { SR121104 }\end{array}$ & $\begin{array}{l}\text { Bioremediation } \\
\text { Bioremediation } \\
\text { Bloremediation } \\
\text { Bloremediation } \\
\text { Integrated } \\
\text { Demonstration }\end{array}$ & $\begin{array}{l}\mathrm{H} \\
\mathrm{H} \\
\mathrm{H} \\
\mathrm{H} \\
\mathrm{H}\end{array}$ \\
\hline & REMA-36 & & $\begin{array}{l}\text { OR123302 } \\
\text { SR121104 }\end{array}$ & $\begin{array}{l}\text { Biodegradation } \\
\text { Integrated } \\
\text { Demonstration }\end{array}$ & $\begin{array}{l}\mathrm{H} \\
\mathrm{H}\end{array}$ \\
\hline & REMA-37 & & $\begin{array}{l}\text { OR101108 } \\
\text { OR111101 } \\
\text { SR121104 }\end{array}$ & $\begin{array}{l}\text { Ex Situ Bloremediation } \\
\text { Bioremediation } \\
\text { Integrated } \\
\text { Demonstration }\end{array}$ & $\begin{array}{l}\mathrm{L} \\
\mathrm{M} \\
\mathrm{H}\end{array}$ \\
\hline & REMA-38 & & $\begin{array}{l}\text { OR101108 } \\
\text { OR111101 } \\
\text { SR121104 }\end{array}$ & $\begin{array}{l}\text { Biodegradation } \\
\text { Bioremediation } \\
\text { Integrated } \\
\text { Demonstration }\end{array}$ & $\begin{array}{l}\mathrm{H} \\
\mathrm{H} \\
\mathbf{M}\end{array}$ \\
\hline \multirow[t]{2}{*}{$\begin{array}{l}\text { (VOC in } \\
\text { Groundwater) }\end{array}$} & REMA-41 & & $\begin{array}{l}\text { CH221301 } \\
\text { SF211104 } \\
\text { ID121701 } \\
\text { SR121104 }\end{array}$ & $\begin{array}{l}\text { VOC Decon. Water } \\
\text { Underground Stripping } \\
\text { Biofltration } \\
\text { Integrated } \\
\text { Demonstration }\end{array}$ & $\begin{array}{l}\mathrm{H} \\
\mathrm{M} \\
\mathrm{M} \\
\mathrm{H}\end{array}$ \\
\hline & REMA-42 & & $\begin{array}{l}\text { SR121107 } \\
\text { ID121701 } \\
\text { SR121104 }\end{array}$ & $\begin{array}{l}\text { Integrated } \\
\text { Demonstration } \\
\text { Blofiltration } \\
\text { Integrated } \\
\text { Demonstration }\end{array}$ & $\begin{array}{l}\mathbf{M} \\
\mathbf{M} \\
\mathbf{H}\end{array}$ \\
\hline
\end{tabular}


Table 7.3. (continued)

\begin{tabular}{|c|c|c|c|c|c|}
\hline \multicolumn{2}{|c|}{ Technology Diagram } & \multicolumn{2}{|c|}{ DOE TTP } & \multirow[b]{2}{*}{ Comments } & \multirow{2}{*}{ Relevance } \\
\hline Subelement & TEDS Identifler & Title & TTP No. & & \\
\hline & REMA-43 & & $\begin{array}{l}\text { SF211108 } \\
\text { SF221207 } \\
\text { SR121104 }\end{array}$ & $\begin{array}{l}\text { Ultraviolet Oxidation } \\
\text { Ultraviolet Oxidation } \\
\text { Integrated } \\
\text { Demonstration }\end{array}$ & $\begin{array}{l}\mathbf{H} \\
\mathbf{H} \\
\mathbf{H}\end{array}$ \\
\hline & REMA-44 & & $\begin{array}{l}\text { CH221301 } \\
\text { RIA21102 } \\
\text { SF201701 } \\
\text { SR121104 }\end{array}$ & $\begin{array}{l}\text { Membrane Separation } \\
\text { Membrane Separation } \\
\text { Membrane Separation } \\
\text { Integrated } \\
\text { Demonstration }\end{array}$ & $\begin{array}{l}\mathrm{M} \\
\mathrm{H} \\
\mathrm{H}\end{array}$ \\
\hline & REMA-46 & & $\begin{array}{l}\text { OR101202 } \\
\text { SR121104 }\end{array}$ & $\begin{array}{l}\text { Base-Catalyzed } \\
\quad \text { Destruction } \\
\text { Integrated } \\
\text { Demonstration }\end{array}$ & $\begin{array}{l}\mathrm{H} \\
\mathrm{H}\end{array}$ \\
\hline & REMA-47 & & $\begin{array}{l}\text { ID121701 } \\
\text { OR123302 } \\
\text { OR111101 } \\
\text { OR101104 } \\
\text { OR101108 } \\
\text { RL.321106 } \\
\text { SR121104 }\end{array}$ & $\begin{array}{l}\text { Bioremediation } \\
\text { Bioremediation } \\
\text { Bioremediation } \\
\text { Bioremediation } \\
\text { Bioremediation } \\
\text { Bioremediation } \\
\text { Integrated } \\
\text { Demonstration }\end{array}$ & $\begin{array}{l}\mathrm{H} \\
\mathrm{H} \\
\mathrm{H} \\
\mathrm{H} \\
\mathrm{H} \\
\mathrm{M} \\
\mathrm{H}\end{array}$ \\
\hline & REMA-48 & & $\begin{array}{l}\text { SF221207 } \\
\text { SR121104 }\end{array}$ & $\begin{array}{l}\text { Electrochemical } \\
\text { Oxidation } \\
\text { Integrated } \\
\text { Demonstration }\end{array}$ & $\begin{array}{l}\mathbf{M} \\
\mathbf{H}\end{array}$ \\
\hline (PCBs in Soil) & REMA-51 & & RL321211 & Arc Plasma & $\mathbf{L}$ \\
\hline & REMA-52 & & $\begin{array}{l}\text { OR121110 } \\
\text { AL121213 } \\
\text { OR111101 }\end{array}$ & $\begin{array}{l}\text { Bloremediation } \\
\text { Bloremediation } \\
\text { Bloremediation }\end{array}$ & $\begin{array}{l}\mathbf{H} \\
\mathbf{H} \\
\mathbf{H}\end{array}$ \\
\hline
\end{tabular}




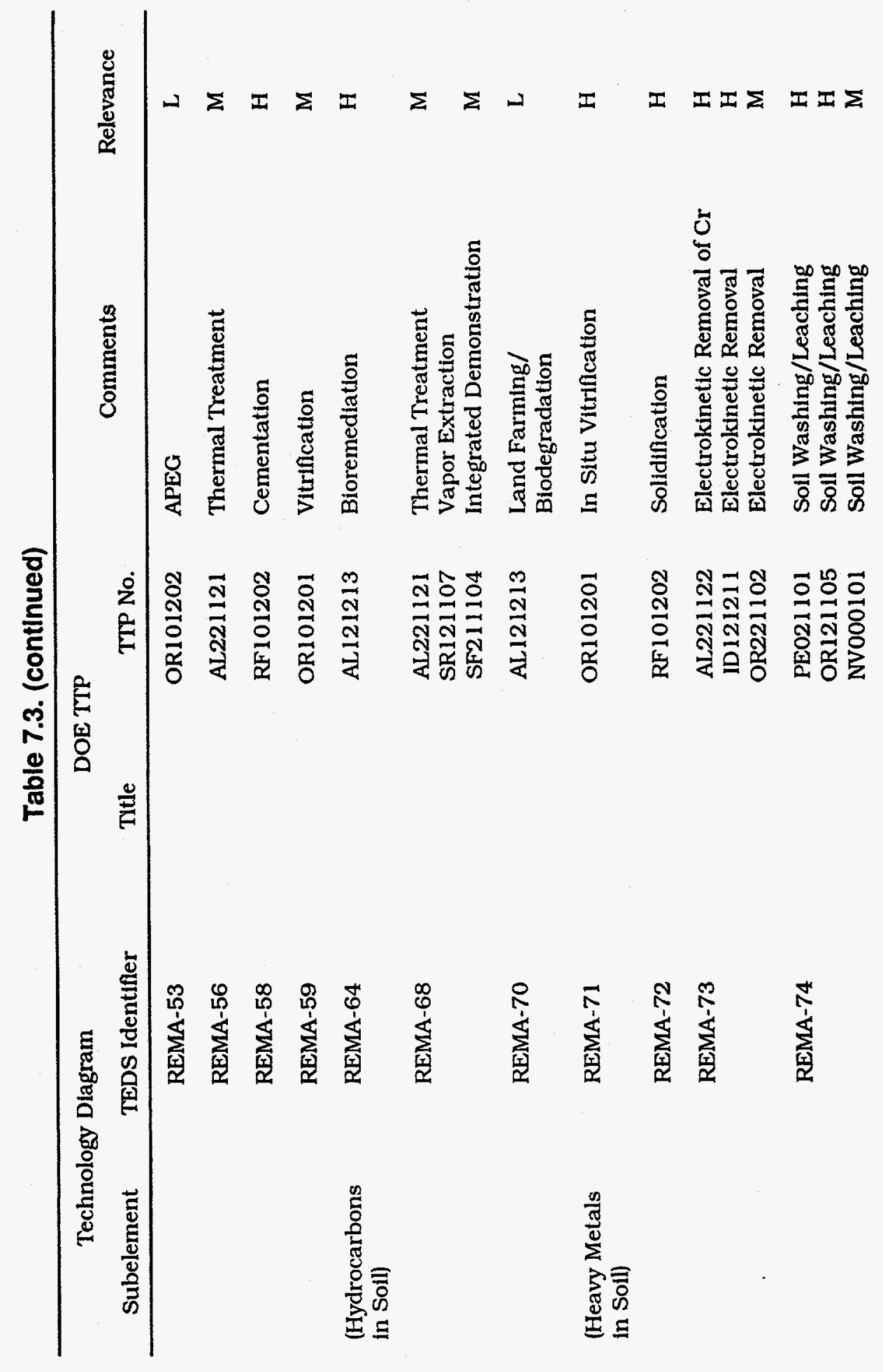




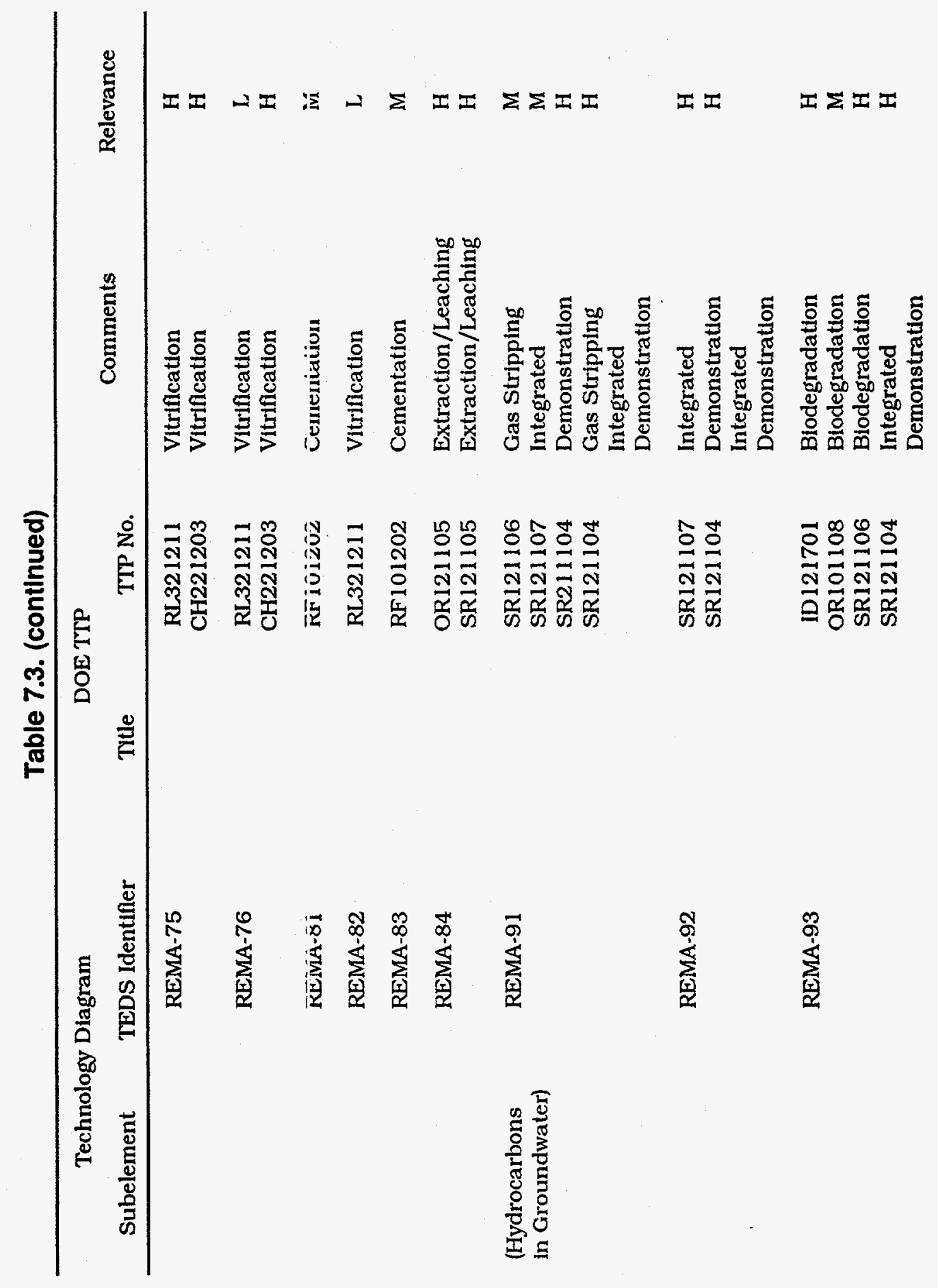


Table 7.3. (continued)

\begin{tabular}{|c|c|c|c|c|c|}
\hline \multicolumn{2}{|c|}{ Technology Diagram } & \multicolumn{2}{|c|}{ DOE TTP } & \multirow{2}{*}{ Comments } & \multirow{2}{*}{ Relevance } \\
\hline Subelement & TEDS Identifier & Title & TTP No. & & \\
\hline & REMA-94 & & $\begin{array}{l}\text { SF211108 } \\
\text { SF221207 } \\
\text { SR121104 }\end{array}$ & $\begin{array}{l}\text { Solar Detoxification } \\
\text { Electrochemical } \\
\text { Oxidation } \\
\text { Integrated } \\
\text { Demonstration }\end{array}$ & $\begin{array}{l}\mathrm{H} \\
\mathrm{H} \\
\mathbf{H}\end{array}$ \\
\hline \multirow{2}{*}{$\begin{array}{l}\text { (PCBs in } \\
\text { Groundwater) }\end{array}$} & REMA-102 & & OR101104 & Bioremediation & $\mathbf{M}$ \\
\hline & REMA-103 & & $\begin{array}{l}\text { SF211108 } \\
\text { SF221207 }\end{array}$ & $\begin{array}{l}\text { Solar Detoxification } \\
\text { Electrochemical } \\
\text { Oxidation }\end{array}$ & $\begin{array}{l}\mathrm{H} \\
\mathrm{H}\end{array}$ \\
\hline
\end{tabular}


8. Waste Management 


\section{WASTE MANAGEMENT}

\subsection{INTRODUCTION}

The WM section of the TLD focuses on addressing the technologies for processing the waste streams likely to be generated as a result of the D\&D, RA, and current waste management operations at the K-25 Site. The objectives of the WM TLDs are to enumerate and evaluate the WM options and to rank these options in three broad categories ranging from most effective to least effective in managing the wastes. The WM TLDs were developed to address the following EM problem areas as they relate to the K-25 Site D\&D and RA activities:

- Waste Stabilization

- Waste Retrieval

- Waste Processing

- Waste Minimization

- Waste Packaging, Handling, and Transportation (WPH\&T), and

- Waste Disposal

The development of the WM TLDs followed these methods to address the EM problem areas:

- For waste stabilization and waste processing, the approach was to identify and enumerate the plausible alternate processing routes for treating the solid, liquid, and gaseous wastes likely to be generated by the D\&D, RA, and related WM operations at the K-25 Site. These options were reviewed and ranked according to this criteria in terms of their effectiveness in treating the particular waste stream. It was assumed that RA and D\&D operations would precede, providing the waste streams for WM to treat for release to the environment in compliance with all applicable environmental regulations and DOE Orders.

- Because no unusual waste retrieval problems are likely to be encountered at the K-25 Site, the Waste Retrieval TLD essentially consists of commercially-available technologies whose applicability may need to be demonstrated at the K-25 Site.

- Because waste minimization is more an operating philosophy than a technology, the Waste Minimization TLD was developed to reflect the philosophical approach. Waste minimization can be applied at any step in the process, preferably at the start of the operation(s).

- For Waste Packaging, Handling, and Transportation (WPH\&T), the approach was to examine the pertinent issues involved with packaging, handling, and transporting wastes both on- and off-site. 
- For waste disposal, the approach was to examine plausible disposal options for the final disposal of the residues from WM operations. These residues are defined as the wastes (predominantly solids) that result following cost-effective, environmentally-compliant treatment of the wastes, focusing on waste minimization objectives. These residues are likely to be haz:ardous and/or LLW that should be sequestered from the environment for a long period of time (in some cases, hundreds or even thousands of years). Because the subject of repositories or land disposal facilities, where these residues can be buried, is still being debated nationally, the current (circa 1992) thinking on potential repositories for these wastes was used to develop the Waste Disposal TLD. The projected residues from the K-25 Site and their burial sites are given in the Waste Disposal TLD. 


\subsection{TECHNOLOGY OPTIONS}

\subsubsection{Introduction}

The purpose of the K-25 Site Waste Management Technology Logic Diagram (WMTLD) is to provide DOE and its operating contractors with a technical framework that relates the ER/WM problems at the K-25 Site to the potential technological solutions for waste management. The WMTLD is intended to serve as resource information for the technology component of short- and long-range strategic planning. The WMTLD emphasizes the identification of technology options and provides a preliminary technology implementation assessment of relevance to the projected waste management needs and opportunities for the K-25 Site. Technology implementation assessment considers the status of technology within the context of technology life-cycle from the conceptual to the operational phase.

The primary objective of this section is to scope the problem and the technical solutions for WM. A conceptual framework based on a systems approach is presented. This framework supports the development of the information presented in Vol. 3 also.

\subsubsection{Conceptual Framework for Waste Management Planning}

A systems approach is used as a conceptual framework to support the development of the WMTLD for the K-25 Site. This conceptual framework is illustrated in Fig. 8.1. The development of the WMTLD considers two categories of waste generation activities, primary and secondary. The primary waste generation activities (Fig. 8.1) include: (1) D\&D activities, (2) RA activities, and (3) mission support activities (excluding waste operations activities). Mission support activities include research, development, production, fabrication, maintenance, analytical, and facility upgrades.

Waste operations activities are considered a secondary waste generator. Waste operations include treatment, storage, disposal, and recycling. Relevant waste inventories for the WMTLD are those wastes accumulated because there is no identified existing capability (i.e., technology and capacity) for their treatment or disposal. Inventory accumulation includes untreated waste (i.e., incinerable waste destined for the TSCA Incinerator) and waste treatment residuals (i.e., TSCA Incinerator ash). For the purposes of the WMTLD, waste inventories generated from mission and support activities are considered part of waste operations activities.

Four combinations of end-product streams and their destinations for waste management are shown in Fig. 8.1. These combination are as follows:

End Product Stream - Quality Controlled Recyclable Material

End Product Stream Destination - Recycled Material Application

End Product Stream - Permitted Air Emission

End Product Stream Destination - Ambient Air 

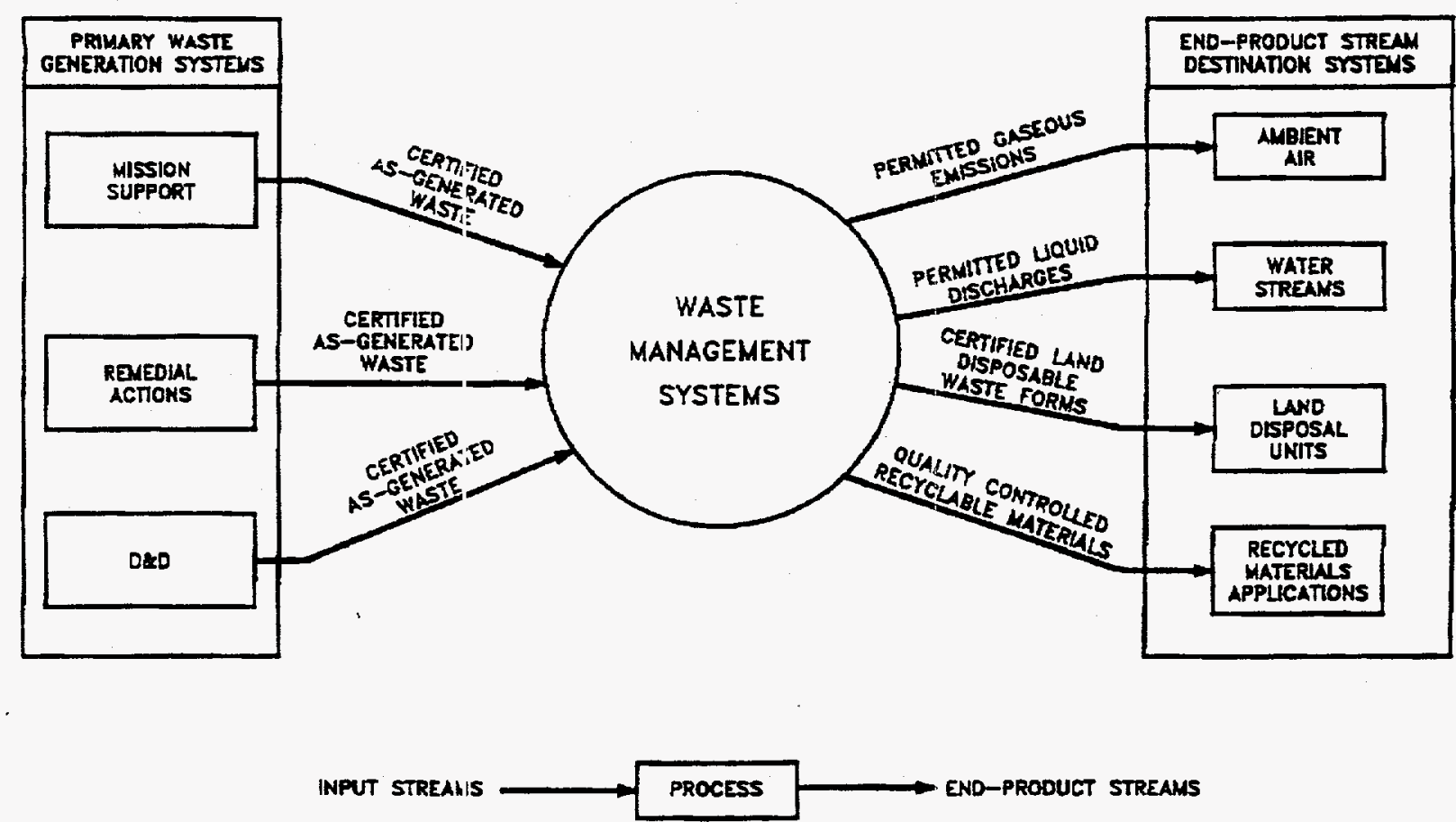

Fig. 8.1. Conceptual framework for waste management and technology planning.

End Product Stream - Permitted Water Discharge

End Product Stream Ilestination - Water Stream

End Product Stream - Certified Land Disposable Waste Form

End Product Stream Ilestination - Land Disposal Unit

WM systems are designed, evaluated, and prioritized by combining technologies into treatment processes so that the waste characteristics of the asgenerated waste one transformed into one or more of the end-product streams. An illustrative example for a combination of technologies for the management of a solid waste stream is shown in Fig. 8.2. As an element of waste management planning, technology planning is typically preceded by a needs assessment that include: (1) projected wiaste generation and inventory accumulation (waste quantities and characteristics), (2) projected waste management requirements, opportunities, and strategies, (3) projected waste management capability needs, (4) existing and planned waste management capabilities, and (5) additional projected waste management capability needs. Categories of waste management needs for technology applications are shown in Table 8.1.

For the purposes of the WMTLD, WM capability is equivalent to the combination of a technology base and a capacity. The technology base is determined mainly by the characteristics of the waste as it is generated and the characteristics of the end-product streams. The characteristics of the end-product streams are specified by the end-product stream destination acceptance criteria. 

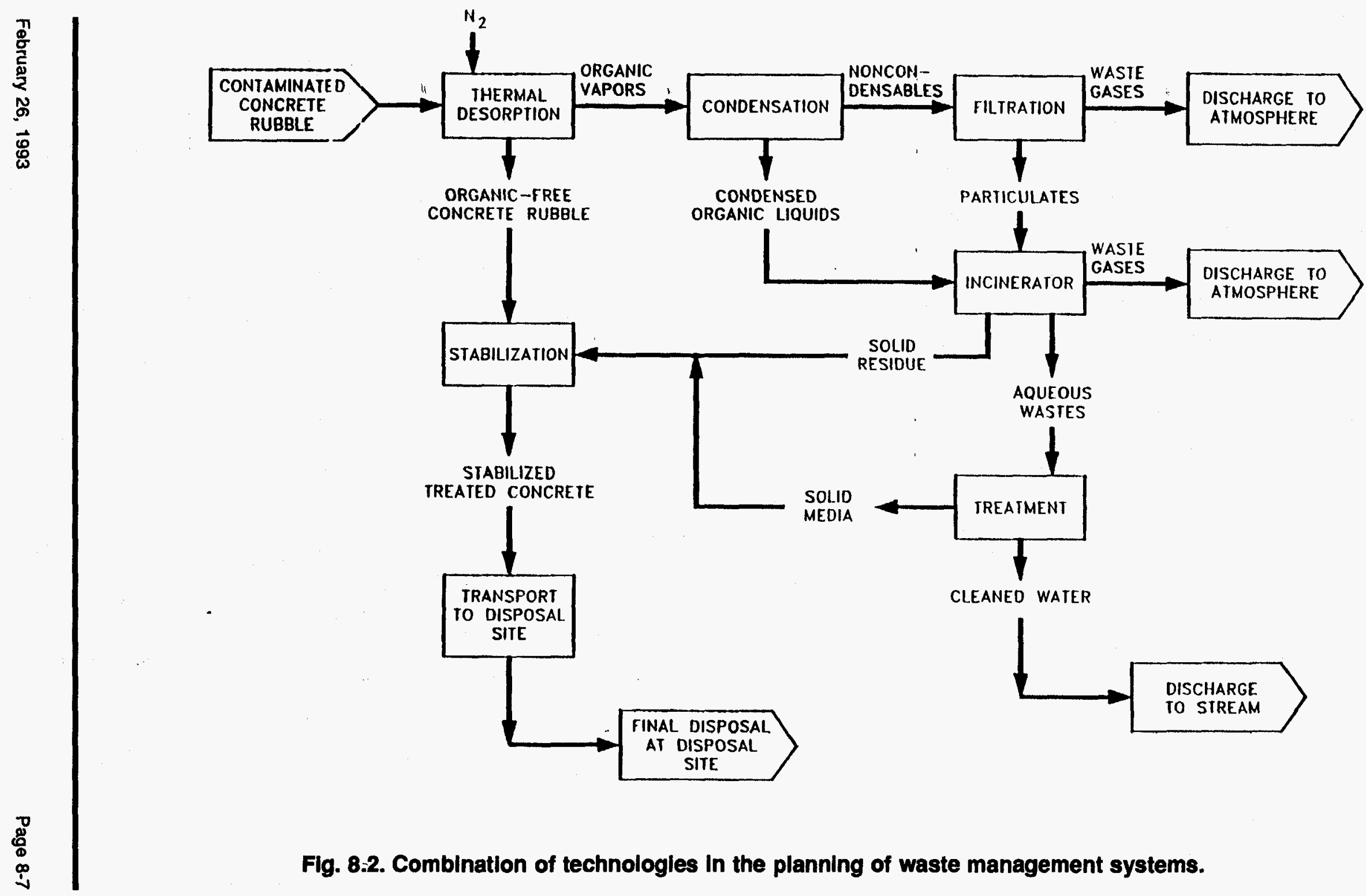

Fig. 8.2. Combination of technologies in the planning of waste management systems. 
Table 8.1. Categories of waste management needs for technology applications

\begin{tabular}{|c|c|c|}
\hline $\begin{array}{l}\text { Waste Management } \\
\text { Capability Needs } \\
\text { Category }\end{array}$ & $\begin{array}{l}\text { Waste Management } \\
\text { Capability Needs }\end{array}$ & $\begin{array}{c}\text { Sample } \\
\text { Technologies }\end{array}$ \\
\hline$A$ & $\begin{array}{l}\text { Reduction of waste volume or } \\
\text { size }\end{array}$ & $\begin{array}{l}\text { Compaction } \\
\text { Supercompaction } \\
\text { Shredding }\end{array}$ \\
\hline B & $\begin{array}{l}\text { Separation of phases or waste } \\
\text { components }\end{array}$ & $\begin{array}{c}\text { Filtration } \\
\text { Evaporation } \\
\text { Centrifugation }\end{array}$ \\
\hline C & $\begin{array}{l}\text { Reduction of the hazardousness } \\
\text { or toxicity of the waste or waste } \\
\text { components by chemical } \\
\text { transformation (i.e., changing the } \\
\text { chemical forms via } \\
\text { detoxification, deactivation, } \\
\text { destruction, oxidation, or } \\
\text { reduction) }\end{array}$ & $\begin{array}{l}\text { Incineration } \\
\text { Neutralization } \\
\text { Dechlorination } \\
\text { Ozonation } \\
\text { Biooxidation }\end{array}$ \\
\hline D & $\begin{array}{l}\text { Reduction of the release of } \\
\text { hazardous components during } \\
\text { disposal }\end{array}$ & $\begin{array}{l}\text { Stabilization } \\
\text { Technologies }\end{array}$ \\
\hline $\mathbf{E}$ & $\begin{array}{l}\text { Reduction of the release of } \\
\text { hazardous components and } \\
\text { health, safety, and environmental } \\
\text { impacts during waste handling, } \\
\text { storage, and transfer }\end{array}$ & $\begin{array}{l}\text { Packaging } \\
\text { Transportation }\end{array}$ \\
\hline
\end{tabular}

WM systems are similar to production systems and are engineered around the optimum combination of product-based technologies and process-based technologies. Product-based technology identification is aimed at engineering and control the desirable characteristics for the end-product streams and the intermediate materials. It is also aimed at engineering a process consisting of one or more technologies to produce and control the quality of the end-product streams. End-product stream quality control can be obtained by monitoring critical characteristics of the product or the process.

Regulatory requirements for WM tend to specify the characteristics of the endproduct stream (i.e., concentration limits) or the technology to process the waste (e.g., incineration). Product-based technology options assume that the characteristics of the encl-product stream are variables to be established. In most cases, however, the characteristics of the end-product streams are specified by regulatory drivers (i.e., water discharge limits, gaseous emission limits, and disposable waste form linits).

Opportunities for proluct-based technology options can be found in engineered waste forms. The incentive behind engineering final waste forms is obtaining performance credits for cisposal (i.e., higher allowable concentration limits for the 
disposal of engineered waste forms). Two additional criteria for engineering waste forms are the lack of on-site/off-site disposal capacity and economics.

Evaluation of technology options for selection and implementation at the K-25 Site consider the following: (1) the desired characteristics of the end-product strearns, (2) the technical and operational adequacy of the technical alternatives, (3) economics, and (4) regulatory compliance criteria and schedules. Other criteria for evaluation include locations (on-site vs off-site), risks, public acceptance, type of facilities (i.e., fixed vs mobile facilities), and facility ownership (i.e., DOE vs private). A qualitative evaluation or ranking of technology options are presented in Sect. 8.5.

For the purposes of the WMTLD, identified technologies are evaluated on the basis of anticipated technical performance or the ability of the combination of technology options to produce an end-product stream with the desirable characteristics. Those technologies that satisfy the performance expectations are considered technology options.

\subsubsection{Description of Functional Areas Included in the WMTLD}

Six areas of waste management for potential application of technology are considered in the WMTLD. These areas are: (1) waste minimization, (2) waste retrieval, (3) waste processing, (4) waste stabilization, (5) waste packaging, handling, and transportation, and (6) waste disposal. Waste characterization is an area of critical importance for waste management. However, this area has been addressed as a separate subelement of the K-25 Site TLD. Information on the waste characterization subelement can be found in Sect. 3.2.

\section{Waste Minimization}

Waste minimization is the first element of a comprehensive pollution prevention strategy. Waste minimization can be characterized with the four R's (i.e., reduce, reuse, recycle, and replace). Reduction focuses at reducing the total amount of media or contaminant. Recycle and reuse refer to utilizing materials so that they do not become wastes. Replace refers to substitution of, for example, hazardous with nonhazardous materials (e.g., solvents), which perform the same service. Waste segregation (i.e., radioactive from nonradioactive, hazardous from nonhazardous, radioactive from hazardous) is another area of opportunity for waste minimization. Although waste minimization is considered in all waste operations, it is an issue of main concern to primary waste generators (i.e., mission support, D\&D, and remedial actions).

\section{Waste Retrieval}

Waste retrieval is relevant in remediating underground storage tanks containing a toxic residual waste inventory and removing waste packages from low-level waste burial grounds. At the $\mathrm{K}-25$ Site for example, waste retrieval is relevant in removing pond sediments. Retrieval of waste materials from process equipment before dismantlement is another area of concern. These situations have been addressed by other subelements of the K-25 Site TLD (Dismantlement and Robotics/Automation). 
For the purposes of the WMTLD, there is concern for waste retrieval during the handling of waste inventories that have been in storage for long periods of time, specifically the transfer of waste materials from the storage container to processing or stabilization treatmerit. Retrieval can be significant to the WMTLD if waste retrievability becomes a waste disposal criteria.

\section{Waste Processing}

Waste processing includes all waste treatment before atmospheric release, water discharge, and land disposal. Waste processing can be implemented for removal, separation, destruction, detoxification, or volume reduction. Technological options carı be grouped as physical, chemical, thermal, or biological. A list of processing options for solids, liquids, and gaseous waste streams projected for the $\mathrm{K}-25$ Site are shown in Tables 8.2 through 8.6.

\section{Waste Stabilization}

Stabilization is used to designate a technology employing material additives (binders) to reduce the mobility of contaminants including toxic organics such as PCBs, metals, and radionuclides. This makes the waste acceptable for land disposal. Stabilization treatment is tailored to improve waste handling and physical characteristics, to decrease surface area across which pollutants can transfer or leach, to limut solubility of hazardous constituents, or to detoxify hazardous constituents. Solidification is another term used in stabilization treatment and implies that these treatment results are obtained primarily by the production of a monolith block of treated waste with high structural integrity. The physical characteristics of the waste may or may not be improved or changed after stabilization. Surface encapsulation (or simply encapsulation) is another stabilization technique to isolate the waste by placing a barrier (jacket) such as a membrane of impermealsle material between the waste and the environment. Microencapsulation is used for encapsulation of individual waste particles. Macroencapsulation is used for encapsulation of an agglomeration of waste particles or microencapsulated materials.

Solidification/stabilization technology can be characterized by the binder, by the binding or waste containment mechanism, or by the stabilization treatment operation type. Binders are developed from commonly known and proprietary materials. The binder car! be inorganic (i.e, hydraulic cements, pozzolan, gypsum, silicates, or glass), organic (i.e., asphalt, polyester, epoxy) or a combination of both (i.e., diatomaceous earth with cement and polystyrene). A binder formulation is designed by taking into consideration the characteristics of the untreated waste and the performance objectives for the stabilization product (treated waste). Proprietary formulationsi of binder materials are developed to increase the functionality of the binder during stabilization treatment. For example, binder materials can be formulcited to provide chemical destruction or detoxification of organics and chemical fixation of metals. A list of stabilization technology options is shown in Table 8.7.

Contaminant mechanisms include chemical bonding, precipitation, and physical trapment. Exaraple processes for physical trapment include pozzolan reactions, pozzolan-portliand cement reactions, thermoplastic encapsulation, and macroencapsulation. 
Table 8.2. Treatment processes for solld wastes

\begin{tabular}{|c|c|c|c|c|c|c|c|c|c|c|c|c|c|}
\hline \multirow[b]{2}{*}{ Technologies } & \multicolumn{13}{|c|}{ K-25 Site waste streams } \\
\hline & $1^{b}$ & 2 & 3 & 4 & 5 & 6 & 7 & 8 & 9 & 10 & 11 & 12 & 13 \\
\hline \multicolumn{14}{|l|}{ Chemical Treatment } \\
\hline - Solvent extraction & $\mathbf{X}$ & $\mathrm{x}$ & $\mathbf{x}$ & $\mathrm{x}$ & & $\mathbf{X}$ & $\mathbf{x}$ & & $\mathbf{X}$ & $\mathbf{X}$ & & $\mathbf{X}$ & $\mathbf{x}$ \\
\hline - Gamma radiolysis & $\mathrm{X}$ & $\mathrm{x}$ & $\mathbf{X}$ & $\mathrm{x}$ & & $\mathrm{x}$ & & & & & & & $\mathbf{x}$ \\
\hline - Leaching/Stripping & $\mathbf{x}$ & & & $\mathrm{x}$ & $\mathbf{X}$ & $\mathbf{X}$ & $\mathbf{X}$ & & & $\mathbf{X}$ & $\mathbf{X}$ & $\mathbf{x}$ & $\mathrm{x}$ \\
\hline $\begin{array}{l}\text { Electropolishing/ } \\
\text { osmosis/migration }\end{array}$ & $\mathbf{x}$ & $\mathrm{x}$ & $\mathbf{x}$ & $\mathbf{x}$ & & & & & & & & & \\
\hline - Gas phase $\left(\mathrm{C}_{1} \mathrm{~F}_{3}\right)$ & & & & & $\mathrm{X}$ & $\mathbf{X}$ & & & & & & & \\
\hline - Chemical precipitation & & & & & & & & & & $\mathbf{X}$ & & & \\
\hline - Bucky ball chemistry & & & & & & & & & & $\mathbf{x}$ & & & \\
\hline - Conversion to $\mathrm{U}_{3} \mathrm{O}_{8}$ & & & & & & & & & & & & & \\
\hline $\begin{array}{l}\text { Supercritical water } \\
\text { oxidation }\end{array}$ & & & & & & & & & & & $\mathbf{x}$ & & \\
\hline - Elution & & & & & & & & & & & $\mathbf{X}$ & & \\
\hline - Transmutation & & & & & & & & & & & & & $\mathbf{X}$ \\
\hline $\begin{array}{l}\text { - NAC (Nitrate- } \\
\text { Ammonia Ceramic) } \\
\text { process }\end{array}$ & & & & & & $\mathbf{x}$ & & & & & & & \\
\hline \multicolumn{14}{|l|}{ Thermal Treatment } \\
\hline . Thermal desorption & $\mathbf{x}$ & & & & & & & & & & & & \\
\hline - Plasma arc furnace & $\mathbf{X}$ & $\mathbf{x}$ & $\mathbf{X}$ & $\mathbf{x}$ & & & & & & & & & \\
\hline - Calcination/roasting & & $\mathbf{x}$ & $\mathbf{x}$ & $\mathbf{x}$ & $\mathbf{X}$ & $\mathbf{x}$ & & & & $\mathbf{X}$ & $\mathbf{X}$ & $\mathbf{X}$ & $\mathbf{X}$ \\
\hline Incineration & & $\mathrm{x}$ & $\mathbf{x}$ & $\mathrm{x}$ & & $\mathbf{x}$ & & $\mathbf{x}$ & $\mathbf{X}$ & & $\mathbf{x}$ & $\mathrm{x}$ & $\mathbf{x}$ \\
\hline - Catalytic destruction & & $\mathbf{x}$ & $\mathbf{X}$ & & $\mathbf{X}$ & $\mathbf{x}$ & & & & & $\mathbf{x}$ & $\mathbf{x}$ & \\
\hline - Pyrolysis & & & & $\mathrm{x}$ & & & & & & & & & \\
\hline - Smelting & & & & $\mathbf{x}$ & $\mathbf{X}$ & $\mathbf{x}$ & $\mathbf{x}$ & & & & & & \\
\hline - Mond process & & & & & $\mathrm{x}$ & & & & & & & & \\
\hline Molten salt oxidation & & & & & & & & $\mathbf{x}$ & $\mathbf{x}$ & & $\mathbf{x}$ & & $\mathbf{X}$ \\
\hline - Steam stripping & & & & & & & & & $\mathbf{X}$ & & & & \\
\hline Wet air oxidation & & & & & & & & & & & & $\mathbf{x}$ & $\mathrm{X}$ \\
\hline - Chem Char process & $\mathbf{x}$ & $\mathbf{x}$ & $\mathbf{X}$ & $\mathbf{x}$ & & & & $\mathbf{x}$ & $\mathbf{X}$ & & $\mathbf{x}$ & $\mathrm{x}$ & $\mathbf{X}$ \\
\hline Microwave heating & & & & & & & & & & & & $\mathbf{x}$ & $\mathbf{x}$ \\
\hline - Molten glass combustor & & & & & & & & & & $\mathbf{x}$ & $\mathbf{X}$ & $\mathbf{X}$ & $\mathbf{x}$ \\
\hline \multicolumn{14}{|l|}{ Biological Treatment } \\
\hline - Biodegradation & & & & & & & & & & & & $\mathbf{x}$ & \\
\hline
\end{tabular}

b $1=$ Contaminated concrete rubble; $2=S$ crap transite; $3=S$ crap asbestos pipe and insulation; $4=0$ ther scrap building materials (e.g., wood, tile, roofing, fixtures, gaskets); 5=Scrap porous nickel; 6=Scrap aluminum, copper, and other nonferrous metals (except nickel); $7=$ Scrap ferrous metal (iron and steel); $8=$ Scrap plastics, paper, and cloth [except personal protective clothing (PPC) and rags]; 9=Contaminated PPC and rags; $10=W$ aste $\mathrm{UO}_{2} \mathrm{~F}_{2} ; 11=$ Spent ion-exchange media; $12=$ Waste processing sludges; $13=$ Waste processing solid residuals

Blanks indicate that the treatment process is not applicable to the waste. 
Table 8.3. Physlcal treatment processes for liquid wastes

\begin{tabular}{|c|c|c|c|c|c|c|c|c|c|c|c|c|c|c|c|c|c|}
\hline \multirow[b]{2}{*}{ Technologies } & \multicolumn{17}{|c|}{ K-25 Site wastes } \\
\hline & $\mathbf{1}^{2}$ & 2 & 3 & 4 & 5 & 6 & 7 & 8 & 9 & 10 & 11 & 12 & 13 & 14 & 15 & 16 & 17 \\
\hline \multicolumn{18}{|l|}{ Physical Treatment } \\
\hline - Air sparging & & & & & $\mathrm{X}$ & & & & & & & & & & & & \\
\hline - Filtration & & & & & & & $\mathbf{x}$ & $\mathbf{x}$ & $\mathbf{X}$ & & & $\mathbf{x}$ & $\mathbf{X}$ & $\mathbf{X}$ & $\mathbf{x}$ & & $\mathbf{X}$ \\
\hline · Foaming & & & & $\mathbf{X}$ & & $\mathrm{X}$ & & $\mathbf{X}$ & $\mathbf{X}$ & & & & $\mathbf{X}$ & $\mathbf{X}$ & $\mathbf{X}$ & & \\
\hline - Decuaniation & & & & & & $\mathbf{X}$ & & & $\mathbf{X}$ & & $\mathbf{X}$ & $\mathbf{X}$ & & & $\mathbf{X}$ & & \\
\hline - Centrifugation & & & & & & & & $\mathbf{x}$ & $\mathbf{x}$ & & $\mathrm{X}$ & $\mathbf{x}$ & $\mathbf{X}$ & $\mathbf{X}$ & & & \\
\hline - Gravity separation & & & & & & & & & & & $\mathbf{X}$ & $\mathbf{x}$ & & & & $\mathbf{x}$ & $\mathbf{X}$ \\
\hline - Sedimentation & & & & $\mathrm{X}$ & & $\mathbf{X}$ & $\mathbf{X}$ & & & & & & & & & & \\
\hline - Adsorption & $\mathbf{X}$ & $\mathbf{X}$ & $\mathbf{X}$ & $\mathbf{X}$ & $\mathbf{X}$ & $\mathbf{X}$ & $\mathbf{X}$ & $\mathbf{X}$ & $\mathbf{X}$ & $\mathbf{X}$ & $\mathrm{X}$ & & $\mathbf{X}$ & $\mathbf{X}$ & $\mathbf{x}$ & & $\mathbf{X}$ \\
\hline - High gradient mag. sep. & & $\mathbf{X}$ & $\mathbf{X}$ & & & & & $\mathbf{X}$ & $\mathbf{X}$ & & & & $\mathbf{X}$ & $\mathbf{X}$ & & & \\
\hline - Electrolysis & $\mathbf{X}$ & & $\mathbf{X}$ & & & & $\mathbf{X}$ & & $\mathbf{X}$ & & & & $\mathbf{X}$ & $\mathrm{X}$ & & & \\
\hline \multicolumn{18}{|l|}{ - Membranes } \\
\hline - Reverse osmosis & $\mathbf{X}$ & $\mathbf{X}$ & $\mathbf{X}$ & & & $\mathbf{X}$ & & & & & & & & & & & \\
\hline - Electrodialysis & & $\mathbf{X}$ & & & & & & & & & & & & & & & \\
\hline - Ultrafiltration & $\mathbf{X}$ & $\mathbf{X}$ & $\mathbf{X}$ & & & $\mathbf{X}$ & & & $\mathbf{X}$ & & & & $\mathbf{X}$ & $\mathrm{X}$ & & & \\
\hline - Inorganic microporous filters & $\mathbf{X}$ & $\mathbf{X}$ & $\mathbf{X}$ & $\mathbf{X}$ & & & $\mathbf{X}$ & $\mathbf{X}$ & $\mathbf{X}$ & & & & $\mathbf{X}$ & $\mathbf{X}$ & & & $\mathbf{X}$ \\
\hline \multicolumn{18}{|c|}{$\begin{array}{l}1=\text { Radioactivity }(\mathrm{RAD}) \text { in water, } 2=\text { Technetium in water, } 3=\text { Heavy metals in water, } 4=\text { polychlorinated biphenyls (PCBs) in water, } 5=\text { Volatile organic compounds in } \\
\text { water; } 6=\text { Semivolatile organics in water, } 7=\text { Mercury in water, } 8=R A D \text { and technetium in oil; } 9=\text { Heavy metals in oil; } 10=P C B s \text { in oil; } 11=\text { Nonhalogenated organics in oil; } \\
12=\text { Mercury in oil; } 13=\mathrm{RAD} \text { in solvents; } 14=\text { Heavy metals in solvents; } 15=\mathrm{PCB} \text { in solvents; } 16=\mathrm{RAD} \text { (including technetium) in mercury; } 17=\text { Contaminated specialty } \\
\text { freons }\end{array}$} \\
\hline
\end{tabular}


Table 8.4. Chemical treatment processes for Ilquid wastes

\begin{tabular}{|c|c|c|c|c|c|c|c|c|c|c|c|c|c|c|c|c|c|}
\hline \multirow[b]{2}{*}{ Technologies } & \multicolumn{17}{|c|}{ K-25 Site wastes } \\
\hline & $1^{2}$ & 2 & 3 & 4 & 5 & 6 & 7 & 8 & 9 & 10 & 11 & 12 & 13 & 14 & 15 & 16 & 17 \\
\hline \multicolumn{18}{|l|}{ Chemical Treatment } \\
\hline - Chemical fixation & $\mathbf{x}$ & $\mathbf{x}$ & $\mathbf{x}$ & & & & $\mathbf{X}$ & & & & & $\mathbf{x}$ & $\mathbf{X}$ & $\mathbf{X}$ & & & \\
\hline - Chemical reduction/dechlorination & $\mathrm{X}$ & & $\mathbf{x}$ & $\mathbf{x}$ & & & & & & $\mathrm{x}$ & & & & & $\mathrm{X}$ & & \\
\hline Chemical precipitation & $\mathrm{x}$ & $\mathrm{x}$ & $\mathbf{x}$ & & & & & $\mathbf{x}$ & $\mathbf{x}$ & & & & $\mathbf{X}$ & $\mathbf{X}$ & & $\mathbf{X}$ & \\
\hline - Solvent extraction & $\mathbf{x}$ & $\mathrm{x}$ & $\mathrm{x}$ & $\mathbf{x}$ & $\mathbf{x}$ & $\mathbf{x}$ & & $\mathbf{x}$ & $\mathbf{x}$ & $\mathbf{x}$ & $\mathbf{x}$ & & $\mathbf{x}$ & & $\mathbf{X}$ & & $\mathrm{X}$ \\
\hline - Leaching/stripping & & & & & $\mathbf{X}$ & & & $\mathbf{x}$ & $\mathbf{x}$ & $\mathbf{X}$ & $\mathbf{x}$ & & $\mathrm{X}$ & $\mathbf{X}$ & $\mathrm{X}$ & $\mathbf{X}$ & \\
\hline - Ozonation-photolysis & & & & & $\mathrm{x}$ & $\mathbf{x}$ & & & & & & & & & & & \\
\hline - Gamma radiolysis & & & & $\mathbf{x}$ & & $\mathbf{x}$ & & & & $\mathbf{X}$ & $\mathbf{X}$ & & & & $\mathbf{X}$ & & \\
\hline - Bucky ball chemistry & & & & & & & & $\mathbf{x}$ & $\mathbf{x}$ & & & & $\mathbf{X}$ & $\mathbf{X}$ & & & \\
\hline Wet air oxidation & & & & $\mathbf{x}$ & $\mathbf{x}$ & $\mathbf{x}$ & & & & & & & & & & & \\
\hline - Supercritical water oxidation & & & & & & & & & & $\mathbf{X}$ & $\mathbf{x}$ & & & & $\mathrm{X}$ & & \\
\hline Ion exchange & $\mathbf{X}$ & $\mathbf{x}$ & $\mathbf{x}$ & & & & $\mathbf{X}$ & & & & & & & $\mathbf{x}$ & & & \\
\hline . Transmutation & & $\mathrm{x}$ & & & & & & & & & & & & & & & \\
\hline
\end{tabular}

$1=$ Radioactivity (RAD) in water, $2=$ Technetium in water, $3=$ Heavy metals in water, $4=P C B s$ in water, $5=$ Volatile organic compounds in water, $6=S$ emivolatile organic in water, 7=Mercury in water, 8=RAD and technetium in oil; 9=Heavy metals in oil; 10=Polychlorinated biphenyls (PCBs) in oil; 11=Nonhalogenated organics in oil; $12=$ Mercury in oil; 13=RAD in solvents; 14=Heavy metals in solvents; 15=PCBs in solvents; 16=RAD (including technetium) in mercury; 17=Contaminated specialty freons 
Table 8.5. Thermal and blological treatment processes for llquild wastes

\begin{tabular}{|c|c|c|c|c|c|c|c|c|c|c|c|c|c|c|c|c|c|}
\hline \multirow[b]{2}{*}{ Technologies } & \multicolumn{17}{|c|}{ K-25 Site wastes } \\
\hline & $1^{2}$ & 2 & 3 & 4 & 5 & 6 & 7 & 8 & 9 & 10 & 11 & 12 & 13 & 14 & 15 & 16 & 17 \\
\hline \multicolumn{18}{|l|}{ Thermal Treatment } \\
\hline Incineration & & & & $\mathbf{x}$ & $\mathbf{X}$ & $\mathbf{x}$ & & $\mathbf{x}$ & $\mathrm{X}$ & $\mathrm{x}$ & $\mathrm{X}$ & & $\mathrm{X}$ & $\mathbf{X}$ & $\mathrm{X}$ & & \\
\hline - Thermal desorption & & & & & $\mathbf{X}$ & & & & & & & $\mathrm{X}$ & & & & & \\
\hline - Molten salt oxidation & & & & & $\mathbf{X}$ & $\mathrm{X}$ & & $\mathrm{X}$ & $\mathrm{X}$ & $\mathrm{X}$ & $\mathrm{X}$ & $\mathbf{X}$ & $\mathrm{X}$ & $\mathbf{X}$ & $\mathbf{x}$ & & \\
\hline - Chem Char nrocess & & & & & $\mathbf{x}$ & $\underline{\mathbf{x}}$ & & $\underline{\mathbf{x}}$ & $\underline{\mathbf{x}}$ & $\underline{x}$ & $\underline{\mathbf{X}}$ & & $\mathbf{x}$ & $\underline{\mathbf{x}}$ & $\underline{\mathbf{x}}$ & & $\underline{\mathbf{x}}$ \\
\hline - Low temperature separation & & & & & & & & & & & $\mathrm{X}$ & & & & & & \\
\hline - Steam stripping & & & & & $\mathbf{x}$ & $\mathbf{x}$ & & & & & & & & & & & \\
\hline - Distillation & $\mathbf{x}$ & & & $\mathbf{x}$ & $\mathbf{x}$ & & & & & $\mathbf{x}$ & $\mathrm{X}$ & & $\mathbf{x}$ & & $\mathbf{x}$ & $\mathbf{x}$ & $\mathrm{x}$ \\
\hline - Evaporation & $\mathbf{x}$ & & $\mathbf{x}$ & & $\mathbf{x}$ & & & & & & & & & & & & $\mathbf{x}$ \\
\hline - Catalytic destruction & & & & $\mathbf{x}$ & $\mathbf{X}$ & $\mathbf{x}$ & & & & & & & & & & & \\
\hline \multicolumn{18}{|l|}{ Biological Treatment } \\
\hline Aerobic digestion & & & & $\mathbf{x}$ & $\mathbf{x}$ & & & & & $\mathrm{X}$ & & & & & & & \\
\hline Anaerobic digestion & & & & $\mathrm{x}$ & & & & & & & $\mathbf{x}$ & & & & & & \\
\hline - Biosorption & $\mathrm{x}$ & & & & & & & $\mathbf{x}$ & $\mathbf{x}$ & & & & & $\mathrm{X}$ & & & \\
\hline - Microbial dechlorination & & & & $\mathbf{X}$ & & & & & & $\mathrm{X}$ & & & & & $\mathbf{X}$ & & \\
\hline
\end{tabular}

"1=Radioactivity (RAD) in water, 2=Technetium in water, 3=Heavy metals in water, 4=PCBs in water, 5=Volatile organic compounds in water, 6=Semivolatile organics in water, $7=$ Mercury in water, $8=R A D$ and technetium in oil; $9=$ Heavy metals in oil; $10=$ Polychlorinated biphenyls (PCBs) in oil; $11=$ Nonhalogenated organics in oil; $12=$ Mercury in oil; $13=\mathrm{RAD}$ in solvents; 14=Heavy metals in solvents; 15=PCBs in solvents; 16=RAD (including technetium) in mercury; 17=Contaminated specialty freons 
Table 8.6. Treatment processes for gaseous wastes

\begin{tabular}{|c|c|c|c|c|c|c|}
\hline \multirow[b]{2}{*}{ Technologies } & \multicolumn{6}{|c|}{ K-25 Site wastes } \\
\hline & $\mathbf{1}^{2}$ & 2 & 3 & 4 & 5 & 6 \\
\hline \multicolumn{7}{|l|}{ Physical Treatment } \\
\hline Low temperature separation & $\mathbf{x}$ & $\mathbf{X}$ & & & & \\
\hline - Inorganic membrane separation & $\mathbf{X}$ & $\mathbf{X}$ & $\mathbf{X}$ & $\mathbf{X}$ & & \\
\hline - Membrane separation & $\mathbf{x}$ & $\mathbf{X}$ & $\mathrm{X}$ & $\mathbf{X}$ & & \\
\hline - Adsorption & $\mathbf{x}$ & & $\mathrm{X}$ & $\mathrm{X}$ & $\mathrm{X}$ & \\
\hline - Scrubbers & $x$ & $\mathbf{x}$ & $\mathrm{X}$ & $\mathrm{X}$ & $\mathrm{x}$ & \\
\hline - $\begin{array}{l}\text { Filtration (incl. bag, ESP", } \\
\text { HEPA }^{\circ} \text { ) }\end{array}$ & & $\mathbf{X}$ & $\mathrm{X}$ & $\mathrm{X}$ & $\mathrm{X}$ & \\
\hline Cyclone separation & & & $\mathbf{x}$ & $\mathbf{x}$ & & \\
\hline - HGMS $^{d}$ & & & $\mathrm{X}$ & $\mathbf{X}$ & & \\
\hline Recharacterize and repackage & & & & & & $\mathrm{X}$ \\
\hline \multicolumn{7}{|l|}{ Chemical Treatment } \\
\hline . Solvent scrubbing & $\mathbf{x}$ & $\mathbf{X}$ & $\mathrm{X}$ & $\mathrm{X}$ & $\mathrm{x}$ & $\mathbf{x}$ \\
\hline Ion-exchange & & & & & $\mathbf{x}$ & \\
\hline Bucky ball chemistry & & & & & $\mathbf{x}$ & \\
\hline \multicolumn{7}{|l|}{ Thermal Treatment } \\
\hline - Incineration & $\mathbf{x}$ & $\mathbf{X}$ & & & & \\
\hline Catalytic destruction & $\mathbf{x}$ & $\mathbf{X}$ & & & & \\
\hline . Electron beam destruction & $\mathbf{x}$ & $\mathbf{x}$ & & & & \\
\hline Molten salt oxidation & $\mathbf{x}$ & $\mathbf{x}$ & $\mathrm{X}$ & & & \\
\hline Steam stripping & $\mathbf{x}$ & $\mathbf{X}$ & & & & \\
\hline Flameless thermal oxidizer & $\mathbf{x}$ & $\mathbf{X}$ & & & & \\
\hline
\end{tabular}

$-1=$ Volatile organic compounds (VOCs) in gases; $2=$ Nonvolatile organics in gases; $3=$ Particulates in gases; $4=$ Inorganics in gases; $5=R A D$ in gases; $6=$ Orphan gas cylinders with no information on cylinder contents

electrostatic precipitation

'High-efficiency particulate air

'High gradient magnetic separation

Pozzolan reactions use a fine, noncrystalline silica in fly ash and the calcium in lime to produce low-strength cementation. Physical trapping of the contaminant in the cured pozzolan-concrete matrix is the primary containment mechanism. Pozzolan-portland cement reactions combine portland cement, fly ash, or other pozzolan to produce a relatively high-strength waste-and-concrete matrix. Soluble silicates may be added to aid processing and to assist in containment of metals through the formation of silicate gels. Thermoplastic encapsulation blends waste particulates with melted asphalt or similar materials. Physical entrapment is the primary containment mechanism. Macroencapsulation isolates a large volume of waste by jacketing with any acceptable material. A container, such as a 55-gal drum is a good example of macroencapsulation.

Stabilization treatment operation types include in-drum processing, in-plant processing, mobile-plant processing, and in-situ processing. 
Table 8.7. Gentric waste stabilization technologies

\begin{tabular}{l} 
- Cementitious solidification/stabilization \\
- $\quad$ Polymer impregnaled concrete \\
- Thermoplastic encipsulation \\
- High temperature crystalline materials encapsulation \\
- High temperature ron-crystalline materials encapsulation \\
\hline
\end{tabular}

Regulatory factors are expected to play a major role in the development and use of stabilization treatment technologies. It is expected that regulatory requirements will emphasize contaminant confinement by means of chemical immobilization and less reliance on physical confinement. With the exception of contaminant leaching measured by waste extract from the Toxicity Characteristic Leaching Procedure (TCI.P) as required by the RCRA, there are no set regulatory performance criteria which stabilization treatment products must meet. Therefore, stabilization technology effectiveness is limited to the results of the TCLP test. There is a need to understand and predict the long-term durability and performance characterisics of waste forms developed by stabilization treatment. Currently, the stabilization treatment design for a given waste is more trial and error. There is need for a scientifically-based design approach to waste stabilization. This knowledge is also needed to support the regulatory guidance in the application of this technology for waste treatment. Whether or not stabilization technology becomes an irnportant technology for the treatment of mixed waste will depend upon regulatory requirements and the ability of the technology to meet these requirements.

Currently, stabilization treatment of hazardous waste can be implemented in accordance with the standards specified in Subpart D of 40 CFR 268. These treatment standards are concentration-based and are expressed as a constituent concentration in waste ( 4.0 CFR 268.43, Table CCW) or constituent concentration in waste extract ( 40 CFR 268.41, Table CCWE). Stabilization treatment is used to meet the standards of Ta.ble CCWE.

\section{Waste Packaging, Hanclling, and Transportation}

The WPH\&T component of the K-25 WMTLD emphasizes the operator safety and environmental protection during the transfer of waste from the generator to treatment, storage, disposal, and recycle. Packaging includes the waste container(s), any absorbent materials used for the control or release of contaminant during the handling of waste, and any shielding to reduce radiation exposure to personnel. Transportation includes the identification of the transfer option (i.e., truck, ship, or plane) as well as the optimum route. 


\section{Waste Disposal}

Land disposal is the final destination for solid waste. Shallow-land burial (i.e., landfill) is the baseline technology for disposal of solid waste. Sanitary/industrial, low-level radioactive, and hazardous waste are currently disposed by landfill technology. However, the designs for low-level radioactive and hazardous waste have additional requirements for leachate collection and treatment. Other alternatives for shallow-land burial include earth-covered tumuli, above grade concrete structures, deep trenches, augured shafts, below-grade concrete structures, abandoned mines, and rock cavities. These alternative technologies provide greater confinement of waste contaminants than shallow-land burial. 


\subsection{SCIENCE AND TECHNOLOGY NEEDS}

\subsubsection{Introduction}

Because of the wide scope of activities covered under WM, the S/T needs for the WM processes and operations are summarized below according to the EM problem categories. The preponderance of the $S / T$ needs are in waste processing and waste stabilization because these two categories have the bulk of the innovative WM technologies being developed to efficiently treat the wastes expected from D\&D, RA, and current waste operations at the K-25 Site. WPH\&T and waste minimization have some $\mathrm{S} / \mathrm{T}$ needs. Waste retrieval $\mathrm{S} / \mathrm{T}$ needs for the $\mathrm{K}-25$ Site are discussed more fully under Dismantlement (Sect. 5.3) and Robotics/ Automation (Sect. 6.3). Waste disposal has not identified S/T needs, however, it has policy requirements that are discussed under WM implementation needs in the next chapter. When these policy requirements are addressed, some future S/T needs may result.

\subsubsection{Summary of Science and Technology Needs}

\section{Waste processing and stabilization}

The WM processes have the potential to be effective because of their innovative nature and level of development. The S/T requirements for these WM processes are as follows:

- Processes that list status as conceptual or evolving technology, such as Bucky ball chemistry, transmutation, and gamma radiolysis, the $\mathrm{S} / \mathrm{T}$ needs consist of developing the fundamentals of the technology to permit development of a viable WM process to treat the waste.

- Processes that list status as predemonstration, such as the NAC process, electropolishing/migration/osmosis, E-beam destruction, and inorganic microporous filters, the S/T needs consist of developing the technical data base on the process to advance its development from the laboratory scale to the pilot plant scale. ?his could consist of developing the chemical engineering aspects of the process, such as reaction kinetics, materials of construction, and process economics.

- Processes that list status as demonstration, such as ion exchange, highgradient magnetic separation, the Mond process, and supercritical water oxidation, the S/T needs consist of demonstrating that the technology can be efficiently used to treat the K-25 Site waste stream. This could consist of conducting an industrial-scale (e.g., tons per hour of waste processed) demonstration of the process while treating the K-25 Site stream.

- Processes that list status as accepted, such as precipitation, activated carbon or molecular sieve adssorption, and rotary kiln incineration, the S/T needs may 
be minimal because these are proven technologies that can be purchased from commercial vendors. The $\mathrm{S} / \mathrm{T}$ needs consist of designing and engineering the process to meet the K-25 Site waste treatment requirements.

Other S/T needs for specific waste processes are as follows:

- Incineration needs consist of understanding the thermochemistry of the incineration operations and the partitioning of the radionuclides and the toxic metals to the three media-air, water, and residue-during incineration. The $\mathrm{S} / \mathrm{T}$ needs should also include developing conditions and/or fluxes that will optimize the partitioning of the radionuclides and toxic metals to the incinerator residue stream.

- Reverse osmosis needs consist of developing membranes that are more effective for removing the radionuclides and hazardous metals from aqueous waste streams.

- Biotreatment process needs consist of developing the microorganisms and conditions for effectively degrading hazardous organics and the removal of metals.

- Stabilization process needs consist of developing models that will simulate the long-term, environmentally acceptable release of radionuclides and hazardous metals into the environment. All waste forms will eventually degrade and release the encapsulated species into the environment. It is important to understand the chemistry and the material science aspects of the waste forms.

\section{Waste packaging, handling, and transportation}

The WPH\&T S/T needs consist of developing multiuse, standardized, Type A packaging designs for shipping radioactive materials.

\section{Waste minimization}

Waste minimization S/T needs consist of developing and testing the Waste Minimization Evaluation System computer simulation model.

\section{Waste retrieval}

Unique waste retrieval operations were not identified for the K-25 Site. The waste retrieval S/T needs, if any, are discussed in depth in the Dismantlement and Robotics/Automation sections.

\section{Waste disposal}

Waste disposal S/T needs were not identified for handling the anticipated K-25 Site wastes. However, resolution of the concerns for the waste disposal policy may result in significant $S / T$ needs. 


\subsection{IMPLEMENTATION NEEDS}

An examination of WM technologies and processes indicates that one of the overwhelming needs is adequate funding to accomplish WM objectives. This includes establishment of waste generation projections, defensible disposal criteria, and technical objectives for waste treatment. Based on the guidelines for developing the implementation needs (Sect. 2.2) some other implementation needs in WM are as follows:

- For waste disposal, nizeds consist of developing a policy for the disposal of final residues from $R A, D \& D$, and waste treatment operations. An accepted national policy is required, which defines the characteristics of solid residues that can be disposed in, for example, national waste repositories. Given the present level of environmental activism, this is a long-term effort that will require national debate for developing a consensus on the waste characteristics that will result in optimizing waste disposal while reducing long-term environmental risk and impact to an acceptable level. This acceptable level cannot be zero because of the nature of the residues. The final residues will either contain hazardous species, long half-life radionuclides, or both. All of these have some environmental risk and impact. The risks can be reduced to varying degrees by appropriate WM operations and strategies. However, the potential environmental risk cannot be reduced to zero. Therefore, a major implementation need in this area is the development of acceptable disposal options and characteristics for the final waste forms.

- Waste minimization needs consist of developing and validating the Waste Minimization Evaluation System computer simulation model. Depending upon the emphasis placed on its development (and the related funding level), this could be accomplished within one year of initiation or stretched out over several years.

- Certain waste procesising options identified for the K-25 Site operations, such as the NAC process, development of inorganic membranes and filters, Bucky ball chemistry, enhanced storage of $\mathrm{UF}_{6}$ in cylinders, and the plasma arc furnace could have high paybacks. These options could become prime candidates for research, development, and demonstration (RD\&D) funding. The implementation need for these types of processes would be to perform the obligatory process and cost engineering assessments. These assessments would help to accurately define their payback potential thus helping to determine their RD\&D funding and status. 


\subsection{TECHNOLOGY RANKINGS FOR THE K-25 SITE}

\subsubsection{Introduction}

This section reviews the qualitative ranking of the usefulness of applicable WM technologies in managing the waste streams generated because of D\&D, RA, and WM operations. The rankings indicate the relative merit of the candidate processes for treating the wastes and provide guidance for potential funding for development to deployment. These rankings were performed based on the best available information on the wastes likely to be generated by $D \& D, R A$, and WM operations, the desired treatment objectives for the wastes, and the time frame for conducting the D\&D activities at the K-25 Site. The details of the ranking procedure and the rankings are given in the following subsections.

\subsubsection{Prioritized Rankings of Technologies}

Prioritized rankings were limited to the Waste Processing technologies. The other WM subelements [Waste Retrieval, Waste Minimization, Waste Stabilization, Waste Packaging, Handling, and Transportation (WPH\&T), and Waste Disposal] were not ranked because of the following reasons:

- Waste Retrieval operations at the K-25 Site are expected to be fairly routine. The potential waste retrieval options are discussed in depth and are ranked in Dismantlement (Sect. 5.5) and Robotics/Automation (Sect. 6.5).

- Waste Minimization is an operating philosophy that should be recognized and practiced at every stage of the WM operations. It consists of a set of guidelines which need to be followed whenever a unit operation is conducted. These guidelines are given on the Waste Minimization sheet in Vol. 2 of this document. The guidelines exist as a set and there are no options.

- The generically specified waste descriptions are not sufficiently detailed to allow ranking of the stabilization technologies. These waste stabilization methods could be ranked at a later date when the specifics of the waste residues to be stabilized, the type and the concentrations of the contaminants in the residues that require immobilization, and the waste acceptance criteria (WAC) of the disposal are determined. Resolving the final wasteform issues to meet the disposal site WAC will be paramount.

- Each waste type has identified acceptable packaging, handling, and transportation (PH\&T) criteria. All PH\&T options will be utilized.

- The waste disposal technologies (sites) have or will have specific waste acceptance criteria. All available listed options are likely to be utilized. 


\subsubsection{Ranking System}

The ranking system in this exercise consists of ranking the processes and/or technologies identified for each waste stream based on the criteria described in Sect. 8.5.4. This ranking; system consists of using the following letter grades:

- $\quad H=$ High-the criteria is favorable for the use of the technology for the waste WM.

- $\quad \mathbf{M}=$ Medium- the criteria is favorable for the use of the technology but less favorable than "H."

- $\quad \mathrm{L}=\mathrm{L}$-w-the criteria is favorable for the use of the technology but less favorable than "M."

\subsubsection{Ranking Criteria}

To facilitate the ranking operation, the time horizon for the deployment of the technology for D\&D WM operations was assumed to be 10 years hence in the year 2002. The time horizoin is an important factor because it influences the consideration and evaluation of developmental technologies since it determines whether certain technolcgies will be available for use within the time horizon. A 10-year horizon was seleited because most technologies require at least 10 years, to progress from early testing to initial deployment. Also, 10 years is about the length of time that future environmental regulations can be projected with any level of confidence. The elavironmental regulations impact the selection of the WM operations.

The criteria used for ranking the WM processes are as follows:

- Process Performance or efficiency. This factor evaluates the effectiveness of the process in removing the contaminants from the waste stream. If a process is highly efficient in removing the contaminants, it is given an $\mathrm{H}$ rating; if not, an appropriate lower rating is given.

- Process Cost. This factor captures both the capital and the operating cost for the process. If the process cost is high then the process is given an $L$ rating. If the cost is expected to be low, an $\mathrm{H}$ rating is given.

- Technical Maturity. This factor evaluates the development status of the process. If the process is expected to be ready for deployment within the time horizon, then it is given an $\mathrm{H}$ rating; if not, an appropriate lower rating is given.

- Reliability. This factor evaluates the reliability of the process to remove the contaminants from the waste stream. If the process appears to be able to consistently remove the contaminants to a high degree and is likely to operate with minimal down lime, then the process is given an $\mathrm{H}$ rating; if not, an appropriate lower rating is given. 
- ES\&H Impact. This factor assesses the ES\&H impact of the process. If the process uses hazardous/toxic reactants or produces hazardous/toxic products, then the process is given an L rating; if not, an appropriate higher rating is given.

- RD\&D Costs. This factor evaluates the RD\&D costs likely to be incurred in developing the process to the deployable state. If these costs are high, the process is given an $L$ rating; if not, an appropriate higher rating is given.

- Versatility. This factor measures the robustness of the technology. If the process can effectively treat wastes with a wide range of characteristics (e.g., the number and varying concentrations of the contaminants, varying physical conditions of the waste streams, etc.), then the process is given an $\mathrm{H}$ rating. If, however, the process requires that the wastes processed be within specific narrow characteristics, an appropriately lower rating is given.

- Process Complexity. This factor evaluates the complexity of the process. If the process is complex, involving for example, many stages or complex reaction conditions, then the process is given an L rating; if not, an appropriate higher rating is given.

- Waste Minimization Potential. This factor evaluates the ability of the process to minimize the production of secondary wastes. If the process produces fewer or lower volume or less hazardous wastes than the original waste being treated, the process is given an $\mathrm{H}$ rating; if not, an appropriate lower rating is given.

- Payback Potential. This factor examines the ability of the process (e.g., a developmental process) to save money in the future as compared to its present RD\&D costs. The future savings could result from lower treatment and disposal costs by using the technology for treating the waste stream. If the payback potential is high, then the process is given an $\mathrm{H}$ rating; if not, an appropriate lower rating is given. It should be noted that the payback potential for developed technologies will be high because of minimal RD\&D costs.

Each of these criteria have equal weight towards developing the overall ranking for the WM process to treat the waste stream.

\subsubsection{Ranking Procedure}

The WM technologies were ranked by a team of knowledgeable and experienced Energy Systems professionals. The team members first individually ranked the WM technologies for treating the particular waste stream. Then, these individual rankings were discussed in group sessions to develop the consensus rankings reported in this section. The results of this exercise are given in Tables 8.8 through 8.12. 
Table 8.8. Rankings for treatment processes for solid wastes

\begin{tabular}{|c|c|c|c|c|c|c|c|c|c|c|c|c|c|}
\hline \multirow[b]{2}{*}{ Technologies } & \multicolumn{13}{|c|}{ K-25 Site waste streams } \\
\hline & $\mathbf{1}^{2}$ & 2 & 3 & 4 & 5 & 6 & 7 & 8 & 9 & 10 & 11 & 12 & 13 \\
\hline \multicolumn{14}{|l|}{ Chemical Treatment } \\
\hline - Solvent extraction & $\mathrm{L}$ & L & $\mathbf{L}$ & $\mathrm{L}$ & & L & $\mathrm{L}$ & & $\mathbf{M}$ & $\mathbf{H}$ & & $\mathbf{M}$ & $\mathbf{M}$ \\
\hline - Gamma radiolysis & $\mathbf{M}$ & $\mathbf{M}$ & $\mathbf{M}$ & $\mathbf{M}$ & & $\mathbf{M}$ & & & & & & & \\
\hline - Leaching/stripping & $\mathbf{M}$ & & & $\mathbf{M}$ & $\mathbf{M}$ & $\mathbf{M}$ & $\mathbf{M}$ & & & $\mathbf{M}$ & $\mathbf{M}$ & $\mathbf{M}$ & $\mathbf{M}$ \\
\hline $\begin{array}{l}\text { Electropolishing/ } \\
\text { osmosis/migration }\end{array}$ & $\mathbf{M}$ & $\mathbf{M}$ & $\mathbf{M}$ & $\mathbf{M}$ & & & & & & & & & \\
\hline - Gas phase $\left(\mathrm{C}_{\text {treatment }}\right)$ & & & & & $\mathbf{M}$ & $\mathbf{M}$ & & & & & & & \\
\hline Chemical precipitation & & & & & & & & & & $\mathbf{M}$ & & & \\
\hline - Bucky ball chemistry & & & & & & & & & & $\mathbf{L}$ & & & \\
\hline \multicolumn{14}{|l|}{ - Conversion to $\mathrm{U}_{3} \mathrm{O}_{8}$} \\
\hline $\begin{array}{l}\text { Supercritical water } \\
\text { oxidation }\end{array}$ & & & & & & & & & & & $\mathbf{M}$ & & \\
\hline Elution & & & & & & & & & & & $\mathbf{M}$ & & \\
\hline Transmutation & & & & & & & & & & & & & $\mathbf{L}$ \\
\hline $\begin{array}{l}\text { NAC (Nitrate-Ammonia } \\
\text { Ceramic) process }\end{array}$ & & & & & & $\mathbf{M}$ & & & & & & & \\
\hline \multicolumn{14}{|l|}{ Thermal Treatment } \\
\hline . Thermal desorption & $\mathbf{M}$ & & & & & & & & & & & & \\
\hline Plasma arc furnace & $\mathbf{M}$ & $\mathbf{H}$ & $\mathbf{H}$ & $\mathbf{M}$ & & & & & & & & & \\
\hline . Calcination/roasting & & $\mathbf{M}$ & $\mathbf{M}$ & $\mathbf{M}$ & $\mathbf{M}$ & $\mathbf{M}$ & & & & $\mathbf{M}$ & $\mathbf{M}$ & $\mathbf{M}$ & $\mathbf{H}$ \\
\hline Incineration & & $\mathbf{M}$ & $\mathbf{M}$ & $\mathrm{H}$ & & $\mathbf{M}$ & & $\mathrm{H}$ & $\mathbf{H}$ & & $\mathbf{M}$ & $\mathbf{M}$ & $\mathbf{H}$ \\
\hline Catalytic destruction & & $\mathbf{M}$ & $\mathbf{M}$ & & $\mathbf{M}$ & $\mathrm{L}$ & & & & & $\mathbf{M}$ & $\mathbf{M}$ & \\
\hline - Pyrolysis & & & & $\mathbf{M}$ & & & & & & & & & \\
\hline . Smelting & & & & $\mathbf{M}$ & $\mathbf{M}$ & $\mathrm{H}$ & $\mathrm{H}$ & & & & & & \\
\hline Mond process & & & & & $\mathbf{H}$ & & & & & & & & \\
\hline Molten salt oxidation & & & & & & & & $\mathbf{H}$ & $\mathrm{H}$ & & $\mathbf{H}$ & & $\mathbf{M}$ \\
\hline Steam stripping & & & & & & & & & $\mathbf{M}$ & & & & \\
\hline Wet air oxidation & & & & & & & & & & & & $\mathbf{M}$ & $\mathbf{M}$ \\
\hline . Chem Char process & $\mathrm{L}$ & $\mathbf{L}$ & L & $\mathbf{L}$ & & & & $\mathrm{L}$ & L & & $\mathbf{M}$ & L & $\mathbf{L}$ \\
\hline Microwave heating & & & & & & & & & & & & $\mathbf{M}$ & $\mathbf{M}$ \\
\hline - Molten glass combustor & & & & & & & & & & $\mathbf{L}$ & L & $\mathrm{L}$ & $\mathbf{L}$ \\
\hline \multicolumn{14}{|l|}{ Biological Treatment } \\
\hline - Biodegradation & & & & & & & & & & & & $\mathbf{M}$ & \\
\hline
\end{tabular}

" $1=$ Contaminated concrete rubble; $2=$ icrap transite; $3=$ Scrap asbestos pipe and insulation; $4=0$ ther scrap building materials (e.g., wood, tile, roofing, fix tures, gaskets); $5=S$ crap porous nickel; $6=S c r a p$ aluminum, copper, and other nonferrous metals (except nickel); 7='icrap ferrous metal (iron and steel); $8=S c$ crap plastics, paper, and cloth (except personal protective clothing (PPC) and rags); $9=$ Contaminated $P P C$ and rags; $10=W$ aste $\mathrm{UO}_{2} \mathrm{~F}_{2} ; 11=$ Spent ion-exchange media; $12=$ Waste processing sludges; $13=$ Waste processing solid residuals

Blanks indicate that the treatment prosess is not applicable to the waste. 


\begin{tabular}{|c|c|c|c|c|c|c|c|c|c|c|c|c|c|c|c|c|c|}
\hline \multirow[b]{2}{*}{ Technologies } & \multicolumn{17}{|c|}{ K-25 Site wastes } \\
\hline & $1^{*}$ & 2 & $\mathbf{3}$ & 4 & 5 & 6 & 7 & 8 & 9 & 10 & 11 & 12 & 13 & 14 & 15 & 16 & 17 \\
\hline \multicolumn{18}{|l|}{ Physical Treatment } \\
\hline Air sparging & & & & & $\mathbf{H}$ & & & & & & & & & & & & \\
\hline Filtration & & & & & & & $\mathbf{M}$ & $\mathrm{H}$ & $\mathrm{H}$ & & & $\mathbf{M}$ & $\mathrm{H}$ & M & $\mathrm{H}$ & & $\mathrm{H}$ \\
\hline - Foaming & & & & $\mathbf{M}$ & & $\mathbf{M}$ & & $\mathbf{M}$ & M & & & & $\mathbf{M}$ & $\mathbf{M}$ & $\mathbf{M}$ & & \\
\hline Decantation & & & & & & $\mathbf{M}$ & & & $\mathbf{M}$ & & $\mathbf{M}$ & $\mathrm{H}$ & & & $\mathbf{M}$ & & \\
\hline - Centrifugation & & & & & & & & $\mathrm{H}$ & $\mathbf{M}$ & & $\mathbf{M}$ & $\mathbf{M}$ & $\mathbf{M}$ & $\mathbf{M}$ & & & \\
\hline Gravity separation & & & & & & & & & & & $\mathbf{M}$ & M & & & & L & $\mathbf{M}$ \\
\hline Sedimentation & & & & $\mathbf{M}$ & & $\mathbf{M}$ & H & & & & & & & & & & \\
\hline Adsorption & $\mathrm{H}$ & H & $\mathbf{H}$ & $\mathbf{H}$ & $\mathbf{H}$ & $\mathrm{H}$ & $\mathbf{H}$ & $\mathbf{M}$ & $\mathbf{M}$ & $\mathbf{M}$ & $\mathrm{H}$ & & $\mathbf{M}$ & $\mathrm{H}$ & $\mathbf{M}$ & & $\mathrm{H}$ \\
\hline High gradient mag. sep. & & L & $\mathbf{M}$ & & & & & $\mathbf{M}$ & $\mathbf{M}$ & & & & $\mathbf{M}$ & $\mathbf{M}$ & & & \\
\hline Electrolysis & $\mathbf{M}$ & & $\mathbf{M}$ & & & & $\mathbf{M}$ & & $\mathbf{M}$ & & & & $\mathbf{M}$ & $\mathbf{M}$ & & & \\
\hline \multicolumn{18}{|l|}{ Membranes } \\
\hline - Reverse osmosis & $\mathrm{H}$ & M & $\mathrm{H}$ & & & $\mathbf{M}$ & & & & & & & & & & & \\
\hline - Electrodialysis & & M & & & & & & & & & & & & & & & \\
\hline - Ultrafiltration & $\mathbf{M}$ & M & $\mathbf{M}$ & & & $\mathbf{M}$ & & & $\mathbf{M}$ & & & & $\mathbf{M}$ & $\mathbf{M}$ & & & \\
\hline - Inorganic microporous filters & $M$ & $\mathrm{~L}$ & M & $\mathrm{L}$ & & & $\mathbf{M}$ & $\mathbf{M}$ & $\mathbf{M}$ & & & & $\mathrm{L}$ & $\mathrm{L}$ & & & $\mathrm{L}$ \\
\hline
\end{tabular}

$" 1=R A D$ in water; $2=$ Technetium in water, $3=$ Heavy metals in water, $4=P C B s$ in water, $5=$ Volatile organic compounds in water, $6=$ Semivolatile organics in water,

$7=$ Mercury in water, $8=R A D$ and technetium in oil; $9=$ Heavy metals in oil; $10=P C B s$ in oil; $11=$ Nonhalogenated organics in oil; $12=$ Mercury in oil; $13=R A D$ in solvents; 14=Heavy metals in solvents; $15=\mathrm{PCBs}$ in solvents; $16=\mathrm{RAD}$ (including technetium) in mercury; $17=$ Contaminated specialty freons

Blanks indicate that the treatment process is not applicable to the waste. 


\begin{tabular}{|c|c|c|c|c|c|c|c|c|c|c|c|c|c|c|c|c|c|}
\hline \multirow[b]{2}{*}{ Technologies } & \multicolumn{17}{|c|}{ K-25 Site wastes } \\
\hline & $1^{\mathbf{a}}$ & 2 & 3 & 4 & 5 & 6 & 7 & 8 & 9 & 10 & 11 & 12 & 13 & 14 & 15 & 16 & 17 \\
\hline \multicolumn{18}{|l|}{ Chemical Treatment } \\
\hline - Chemical fixation & $\mathbf{M}$ & $\mathbf{M}$ & H & & & & M & & & & & $\mathbf{M}$ & L & $\mathbf{M}$ & & & \\
\hline - Chemical reduction/dechlorination & $\mathbf{M}$ & & M & $\mathbf{M}$ & & & & & & $\mathrm{H}$ & & & & & $\mathrm{H}$ & & \\
\hline - Chemical precipitation & $\mathrm{H}$ & $\mathrm{H}$ & $\mathrm{H}$ & & & & & $\mathrm{H}$ & $\mathbf{M}$ & & & & L & $\mathbf{M}$ & & $\mathbf{M}$ & \\
\hline - Solvent extraction & $\underline{M}$ & $\mathbf{M}$ & M & $M$ & M & $\underline{4}$ & & M & $M$ & $\mathbf{M}$ & $M$ & & $\mathbf{M}$ & & $M$ & & $M$ \\
\hline - Leaching/stripping & & & & & $\mathbf{M}$ & & & H & $\mathrm{H}$ & $\mathbf{M}$ & $\mathbf{M}$ & & $\mathbf{H}$ & $\mathbf{H}$ & $\mathbf{M}$ & $\mathbf{H}$ & \\
\hline - Ozonation-photolysis & & & & & $\mathbf{H}$ & $\mathbf{M}$ & & & & & & & & & & & \\
\hline - Gamma radiolysis & & & & $\mathbf{M}$ & & $\mathbf{M}$ & & & & $\mathbf{M}$ & $\mathbf{M}$ & & & & $\mathbf{M}$ & & \\
\hline - Bucky ball chemistry & & & & & & & & L & $\mathrm{L}$ & & & & $\mathbf{L}$ & $\mathrm{L}$ & & & \\
\hline Wet air oxidation & & & & $\mathbf{M}$ & $\mathbf{M}$ & $\mathbf{M}$ & & & & & & & & & & & \\
\hline - Supercritical water oxidation & & & & & & & & & & $\mathbf{M}$ & $\mathbf{M}$ & & & & $\mathbf{M}$ & & \\
\hline lon exchange & $\mathbf{M}$ & $\mathbf{H}$ & $\mathbf{H}$ & & & & $\mathrm{H}$ & & & & & & & $\mathbf{M}$ & & & \\
\hline - Transmutation & & $\mathbf{M}$ & & & & & & & & & & & & & & & \\
\hline
\end{tabular}

$1=R A D$ in water, $2=$ Technetium in water, $3=$ Heavy metals in water, $4=P C B s$ in water, $5=$ Volatile organic compounds in water, $6=$ Semivolatile organics in water,

$7=$ Mercury in water, $8=\mathrm{RAD}$ and technetium in oil; $9=$ Heavy metals in oil; $10=\mathrm{PCB}$ in oil; $11=$ Nonhalogenated organics in oil; $12=$ Mercury in oil; $13=\mathrm{RAD}$ in solvents: $14=$ Heavy metals in solvents; 15=PCBs in solvents; 16=RAD (including technetium) in mercury; 17=Contaminated specialty freons

Blanks indicate that the treatment process is not applicable to the waste. 
Table 8.11. Rankings for thermal and blological treatment processes for llquid wastes

\begin{tabular}{|c|c|c|c|c|c|c|c|c|c|c|c|c|c|c|c|c|c|}
\hline \multirow[b]{2}{*}{ Technologies } & \multicolumn{17}{|c|}{ K-25 Site wastes } \\
\hline & $1^{2}$ & 2 & 3 & 4 & 5 & 6 & 7 & 8 & 9 & 10 & 11 & 12 & 13 & 14 & 15 & 16 & 17 \\
\hline \multicolumn{18}{|l|}{ Thermal Treatment } \\
\hline Incineration & & & & H & H & $\mathbf{H}$ & & $\mathbf{M}$ & $\mathrm{H}$ & $\mathbf{H}$ & $\mathrm{H}$ & & $\mathbf{H}$ & $\mathbf{M}$ & $\mathbf{H}$ & & \\
\hline Thermal desorption & & & & & $\mathbf{H}$ & & & & & & & $\mathbf{M}$ & & & & & \\
\hline Molten salt oxidation & & & & & $\mathrm{H}$ & $\mathbf{H}$ & & $\mathbf{H}$ & $\mathbf{H}$ & $\mathbf{H}$ & $\mathbf{H}$ & $\mathbf{M}$ & $\mathrm{H}$ & $\mathbf{M}$ & $\mathbf{M}$ & & \\
\hline . Chem Char process & & & & & $\mathbf{M}$ & $\mathbf{M}$ & & $\mathbf{M}$ & $\mathrm{L}$ & $\mathbf{M}$ & $\mathrm{L}$ & & $\mathrm{L}$ & $\mathbf{L}$ & L & & $\mathrm{L}$ \\
\hline - Low temperature separation & & & & & & & & & & & $\mathbf{M}$ & & & & & & \\
\hline - Steam stripping & & & & & $\mathbf{H}$ & $\mathbf{M}$ & & & & & & & & & & & \\
\hline Distillation & $\mathbf{M}$ & & & $\mathbf{M}$ & $\mathbf{H}$ & & & & & $\mathbf{M}$ & $\mathbf{M}$ & & $\mathbf{M}$ & & $\mathbf{M}$ & $\mathbf{H}$ & $\mathrm{H}$ \\
\hline Evaporation & $\mathbf{M}$ & & $\mathbf{H}$ & & $\mathbf{H}$ & & & & & & & & & & & & $\mathbf{H}$ \\
\hline - Catalytic destruction & & & & $\mathbf{M}$ & $\mathbf{H}$ & $\mathbf{H}$ & & & & & & & & & & & \\
\hline \multicolumn{18}{|l|}{ Biological Treatment } \\
\hline - Aerobic digestion & & & & & L & & & & & L & & & & & & & \\
\hline Anaerobic digestion & & & & $\mathrm{L}$ & & & & & & & L & & & & & & \\
\hline - Biosorption & $\mathrm{L}$ & & & & & & & L & $\mathbf{L}$ & & & & & L & & & \\
\hline - Microbial dechlorination & & & & $\mathrm{L}$ & & & & & & $\mathrm{L}$ & & & & & L & & \\
\hline
\end{tabular}

$1=\mathrm{RAD}$ in water, $2=$ Technetium in water, $3=$ Heavy metals in water, $4=\mathrm{PCBs}$ in water, $5=$ Volatile organic compounds in water, $6=5$ emivolatile organics in water, 7=Mercury in water, 8=RAD and technetium in oil; 9=Heavy metals in oil; $10=$ PCBs in oil; 11=Nonhalogenated organics in oil; 12=Mercury in oil; 13=RAD in solvents; 14=Heavy metals in solvents; 15=PCBs in solvents; 16=RAD (including technetium) in mercury; 17=Contaminated specialty freons

Blanks indicate that the treatment process is not applicable to the waste. 
Table 8.12. Rankings for treatment processes for gaseous wastes

\begin{tabular}{|c|c|c|c|c|c|c|}
\hline \multirow[b]{2}{*}{ Technologies } & \multicolumn{6}{|c|}{ K-25 Site wastes } \\
\hline & 1 & 2 & 3 & 4 & 5 & 6 \\
\hline \multicolumn{7}{|l|}{ Physical Treatment } \\
\hline - Low temperature separation & $\mathbf{M}$ & $\mathbf{M}$ & & & & \\
\hline $\begin{array}{l}\text { Membrane separation } \\
\text { (including inorgani: } \\
\text { membranes) }\end{array}$ & $\mathbf{M}$ & $\mathbf{M}$ & M & $\mathbf{M}$ & & \\
\hline - Adsorption & $\mathbf{H}$ & & H & $\mathbf{M}$ & $\mathbf{H}$ & \\
\hline - Scrubbers & $\mathbf{M}$ & $\mathbf{M}$ & $\mathbf{H}$ & $\mathbf{M}$ & $\mathbf{M}$ & \\
\hline $\begin{array}{l}\text { Filtration (including bag, ESP, } \\
\text { inorganic membran!, stainless } \\
\text { steel, HEPA) }\end{array}$ & & $\mathbf{M}$ & H & H & $\mathbf{H}$ & \\
\hline Cyclone separation & & & $\mathrm{H}$ & $\mathbf{M}$ & & \\
\hline$\cdot$ HGMS & & & M & $\mathbf{M}$ & & \\
\hline - Recharacterize and repackage & & & & & & H \\
\hline \multicolumn{7}{|l|}{ Chemical Treatment } \\
\hline - Solvent scrubbing & $\mathbf{H}$ & $\mathrm{H}$ & $\mathbf{M}$ & $\mathbf{M}$ & $\mathbf{M}$ & $\mathbf{M}$ \\
\hline Ion-exchange & & & & & $\mathbf{M}$ & \\
\hline - Bucky ball chemisty & & & & & $\mathbf{L}$ & \\
\hline \multicolumn{7}{|l|}{ Thermal Treatment } \\
\hline . Incineration & $\mathbf{H}$ & $\mathrm{H}$ & & & & \\
\hline - Catalytic destruction & $\mathbf{H}$ & $\mathbf{M}$ & & & & \\
\hline - Electron beam destuction & $\mathbf{M}$ & $\mathbf{L}$ & & & & \\
\hline Molten salt oxidaticin & $\mathbf{H}$ & $\mathbf{H}$ & $\mathbf{M}$ & & & \\
\hline Steam stripping & $\mathbf{H}$ & $\mathbf{M}$ & & & & \\
\hline - Flameless thermal cxidation & $\mathbf{H}$ & $\mathbf{M}$ & & & & \\
\hline
\end{tabular}

$4=$ Volatile organic compounds in gases; $2=$ Semivolatile organics in gases; $3=$ Particulates in gases;

$4=$ Inorganics in gases; $5:=R A D$ in gases; $6=0$ rphan gas cylinders with no information on cylinder contents

Blanks indicate that the treatment process is not applicable to the waste.

\subsubsection{Conclusions trom Rankings}

As expected, the results given in Tables 8.8 through 8.12 indicate that under the ground rules of the ranking exercise, most of the potential WM technologies fall into the "M" rankings category. However, for each waste stream, there are processes that attain an " $\mathrm{H}$ " ranking. These technologies obviously stand out as prime candidates for support for further development to deployment. However, as cautioned in Sect. 4.5, this is not intended to detract from the viability of the other processes. Unfortunatelyr, the level of information that was the basis for this ranking exercise does riot permit more accurate discrimination between the processes. Given additiorial details, some of those processes having a " $\mathbf{M}$ " ranking may prove to be the process of choice for treating the particular waste stream and vice versa.

A firmer basis for the ranking can be established when definite plans and schedules are developed for the D\&D and ER of the K-25 Site. 


\subsection{TECHNOLOGIES UNDER DEVELOPMENT BY DOE}

DOE is currently developing technologies through the EM-30, EM-40, and EM50 program which have the potential for making effective contributions to solving environmental and waste recycling problems at the different DOE sites. Some of these projects may have relevant and beneficial elements with respect to the technologies identified in the K-25 Site TLD. A search of available information on programs funded in FY 1992 was performed to identify the possible matches between technologies in the K-25 TLD and TTPs (or ADSs). A listing of the DOE EM-50 Program Guide for FY 1992 and abstracts for funded EM-50 projects were the principal sources for determining matches and relevancy between TEDS and TTPs. Relevant ADS activities were identified through staff personal knowledge.

In Table 8.13, those projects described in TTP or ADS and determined to be potentially relevant and beneficial are listed by TTP (or ADS) number along with the corresponding relevant Technology Evaluation Data Sheet (TEDS) identifier. Along with the matched TEDS is a succinct statement of the technology approach or problem being addressed in both documents. 
Table 8.13. DOE funded development

\begin{tabular}{|c|c|c|c|c|c|}
\hline \multicolumn{2}{|c|}{ Technology Diagram } & \multicolumn{2}{|c|}{ DOE TTP } & \multirow{2}{*}{ Comments } & \multirow{2}{*}{ Relevance } \\
\hline Subelement & TEDS Identifier & Title & TTP No. & & \\
\hline \multirow[t]{14}{*}{ Waste Management } & & Mana & & & \\
\hline & WPRO-100 & & $\begin{array}{l}\text { ID101301 } \\
\text { SF211201 }\end{array}$ & $\begin{array}{l}\text { Gamma Radiolysis } \\
\text { Gamma Radiolysis }\end{array}$ & $\begin{array}{l}\mathrm{H} \\
\mathrm{H}\end{array}$ \\
\hline & WPRO-101 & & SF221103 & E-Beam Use & $\mathbf{L}$ \\
\hline & WPRO-105 & & OR111203 & $\begin{array}{l}\text { Radioactive } \mathrm{NaNO}_{3} \\
\text { Treatment }\end{array}$ & $\mathbf{H}$ \\
\hline & WPRO-106 & & RF121204 & Surface VOC Removal & $\mathbf{M}$ \\
\hline & WPRO-107 & & RL321211 & Plasma Arc Furnace & $\mathbf{H}$ \\
\hline & WPRO-108 & & RF101205 & $\begin{array}{l}\text { Incineration } \\
\text { Alternatives }\end{array}$ & $\mathbf{L}$ \\
\hline & WPRO-109 & & AL223310 & $\begin{array}{l}\text { Catalytic Destruction } \\
\text { (Pulsed) }\end{array}$ & $\mathbf{H}$ \\
\hline & WPRO-111 & & RL321211 & Smelting & L \\
\hline & WPRO-113 & & ID 121207 & Molten Salt OxIdation & $\mathbf{L}$ \\
\hline & WPRO-115 & & RF101201 & Microwave Fusing & $\mathrm{L}$ \\
\hline & WPRO-116 & & $\begin{array}{l}\text { ID121207 } \\
\text { RL321211 }\end{array}$ & $\begin{array}{l}\text { Molten Glass } \\
\text { Combustor } \\
\text { Glass Melter TSR }\end{array}$ & $\begin{array}{l}\text { H } \\
\text { L }\end{array}$ \\
\hline & WPRO-117 & & $\begin{array}{l}\text { OR123302 } \\
\text { RL321211 }\end{array}$ & $\begin{array}{l}\text { Blodegradation of } \\
\text { Waste Streams } \\
\text { Glass Melter TSR }\end{array}$ & $\mathbf{H}$ \\
\hline & WPRO-200 & & $\begin{array}{l}\text { SR121107 } \\
\text { SF211104 }\end{array}$ & $\begin{array}{l}\text { Air Sparging of VOC } \\
\text { Gasoline Removal from } \\
\text { Soil }\end{array}$ & $\begin{array}{l}\mathbf{M} \\
\mathbf{H}\end{array}$ \\
\hline
\end{tabular}


Table 8.13. (continued)

\begin{tabular}{|c|c|c|c|c|c|}
\hline \multicolumn{2}{|c|}{ Technology Dlagram } & \multicolumn{2}{|c|}{ DOE TTP } & \multirow[b]{2}{*}{ Comments } & \multirow[b]{2}{*}{ Relevance } \\
\hline Subelement & TEDS Identifler & Title & TTP No. & & \\
\hline & WPRO-201 & & NV011104 & $\begin{array}{l}\text { Filtration of Liquild and } \\
\text { Gas }\end{array}$ & $\mathbf{M}$ \\
\hline & WPRO-202 & & RL321203 & Adsorption & $\mathbf{H}$ \\
\hline & WPRO-203 & & SR121107 & $\begin{array}{l}\text { Charcoal or Molecular } \\
\text { Sieves }\end{array}$ & $\mathrm{L}$ \\
\hline & WPRO-204 & & AL121203 & Magnetic Separation & $\mathbf{M}$ \\
\hline & WPRO-205 & & ID121211 & Electrolysis & $\mathbf{M}$ \\
\hline & WPRO-206 & & $\begin{array}{l}\text { RLA211102 } \\
\text { AL221 } 107 \\
\text { RLA21101 }\end{array}$ & $\begin{array}{l}\text { Membrane Removal } \\
\text { Membrane Removal } \\
\text { Membrane Removal of } \\
\text { TCE \& PCE }\end{array}$ & $\begin{array}{l}\mathbf{M} \\
\mathbf{M} \\
\mathbf{H}\end{array}$ \\
\hline & & & RLA21104 & $\begin{array}{l}\text { Membrane Removal of } \\
\text { VOC }\end{array}$ & $\mathbf{H}$ \\
\hline & WPRO-207 & & $\begin{array}{l}\text { CH221301 } \\
\text { OR014102 } \\
\text { SF201310 }\end{array}$ & $\begin{array}{l}\text { Inorganic Microporous } \\
\text { Fulters } \\
\text { S.S. HEPA Filters } \\
\text { S.S. HEPA Fllters }\end{array}$ & $\begin{array}{l}\text { L } \\
\text { M } \\
\text { M }\end{array}$ \\
\hline & WPRO-209 & & OR101202 & $\begin{array}{l}\text { Chemical } \\
\text { Dechlorination }\end{array}$ & $\mathbf{H}$ \\
\hline & WPRO-211 & & OR121105 & $\begin{array}{l}\text { Solvent Extraction- } \\
\text { General }\end{array}$ & $\mathbf{L}$ \\
\hline & WPRO-212 & & OR121105 & $\begin{array}{l}\text { Solvent Extraction- } \\
\text { Leaching }\end{array}$ & $\mathbf{H}$ \\
\hline & WPRO-214 & & SF211108 & $\begin{array}{l}\text { UV } \\
\text { Photolysis/Oxidation }\end{array}$ & $\mathbf{L}$ \\
\hline
\end{tabular}




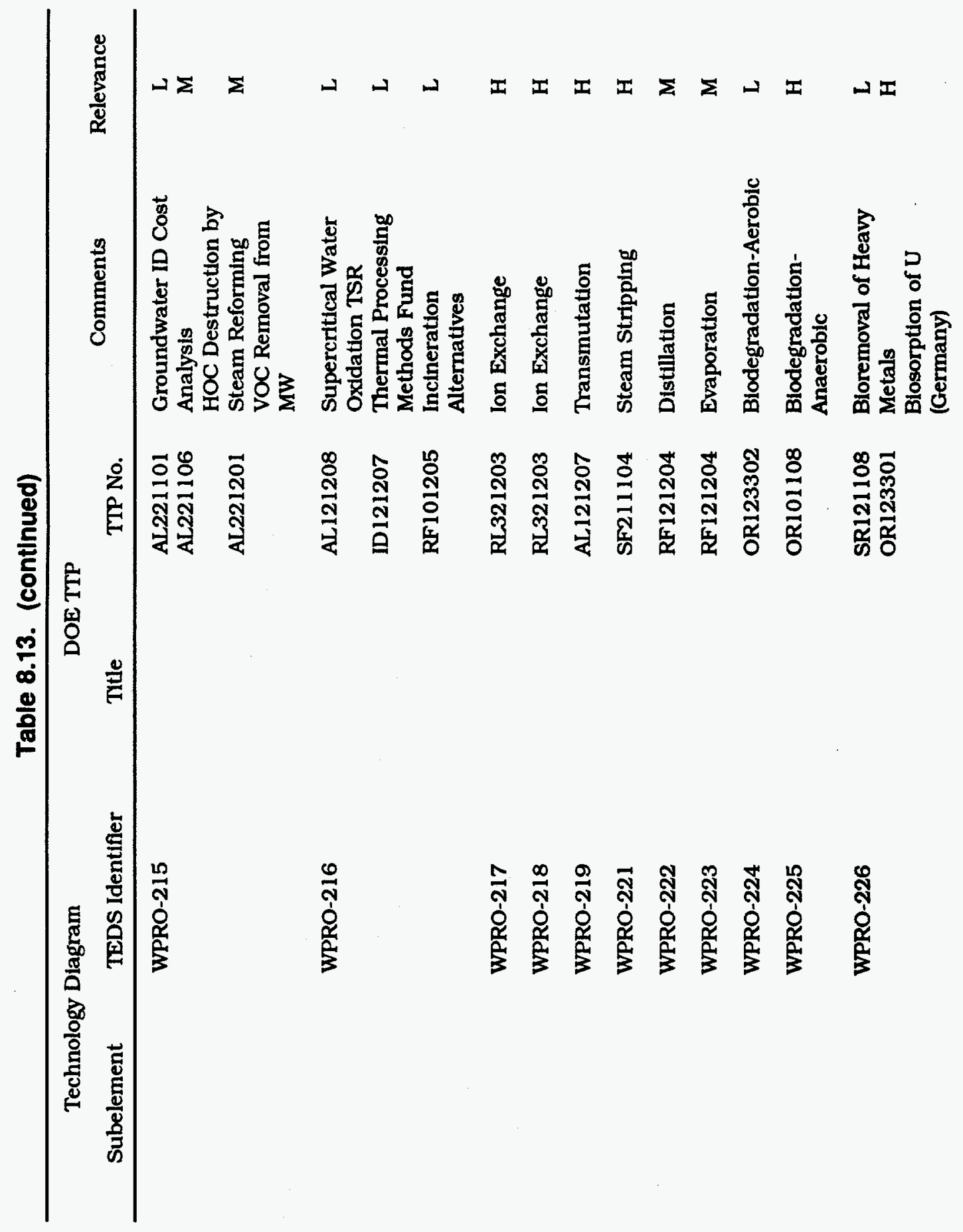


Table 8.13. (continued)

\begin{tabular}{|c|c|c|c|c|c|}
\hline \multicolumn{2}{|c|}{ Technology Diagram } & \multicolumn{2}{|c|}{ DOE TTP } & \multirow{2}{*}{ Comments } & \multirow{2}{*}{ Relevance } \\
\hline Subelement & TEDS Identifler & Tytle & TTP No. & & \\
\hline & WPRO-227 & & OR123302 & $\begin{array}{l}\text { Biodegradation } \\
\text { Dechlorination- } \\
\text { Anaerobic, } \\
\text { U.S./Germany }\end{array}$ & $\mathbf{L}$ \\
\hline & WPRO-300 & & OR121108 & $\begin{array}{l}\text { Inorganic Membranes } \\
\text { MW }\end{array}$ & $\mathbf{L}$ \\
\hline & WPRO-301 & & AL121215 & $\begin{array}{l}\text { Packed Bed Silent } \\
\text { Discharge }\end{array}$ & $\mathbf{H}$ \\
\hline & WPRO-302 & & $\begin{array}{l}\text { NV011104 } \\
\text { AL121203 } \\
\text { PE021101 }\end{array}$ & $\begin{array}{l}\text { Physical Methods of } \\
\text { Soll Sep. } \\
\text { Magnetic Separation } \\
\text { Jig and Cyclone } \\
\text { Separation }\end{array}$ & $\begin{array}{l}\mathbf{H} \\
\mathbf{H} \\
\mathbf{M}\end{array}$ \\
\hline & WPRO-304 & & SF221103 & $\begin{array}{l}\text { Electron Beam } \\
\text { Destruction }\end{array}$ & $\mathbf{H}$ \\
\hline & WPRO-305 & & RF101205 & $\begin{array}{l}\text { Oxidation on Hot } \\
\text { Ceramic Matrix }\end{array}$ & $\mathbf{L}$ \\
\hline & WSTA-100 & & RF101202 & $\begin{array}{l}\text { Cementitious } \\
\text { Solidiffcation/Stabiliza } \\
\text { tion }\end{array}$ & $\mathbf{H}$ \\
\hline & WSTA-102 & & RF111203 & $\begin{array}{l}\text { Thermoplastic } \\
\text { Encapsulation }\end{array}$ & $\mathbf{H}$ \\
\hline & WSTA-105 & & ID121207 & Conversion to Ceramic & $\mathbf{L}$ \\
\hline & WSTA-106 & & $\begin{array}{l}\text { ID121207 } \\
\text { CH221203 }\end{array}$ & $\begin{array}{l}\text { Vitrification } \\
\text { (Noncrystalline) } \\
\text { Vitrification } \\
\text { Development }\end{array}$ & $\begin{array}{l}\mathrm{L} \\
\mathrm{H}\end{array}$ \\
\hline
\end{tabular}




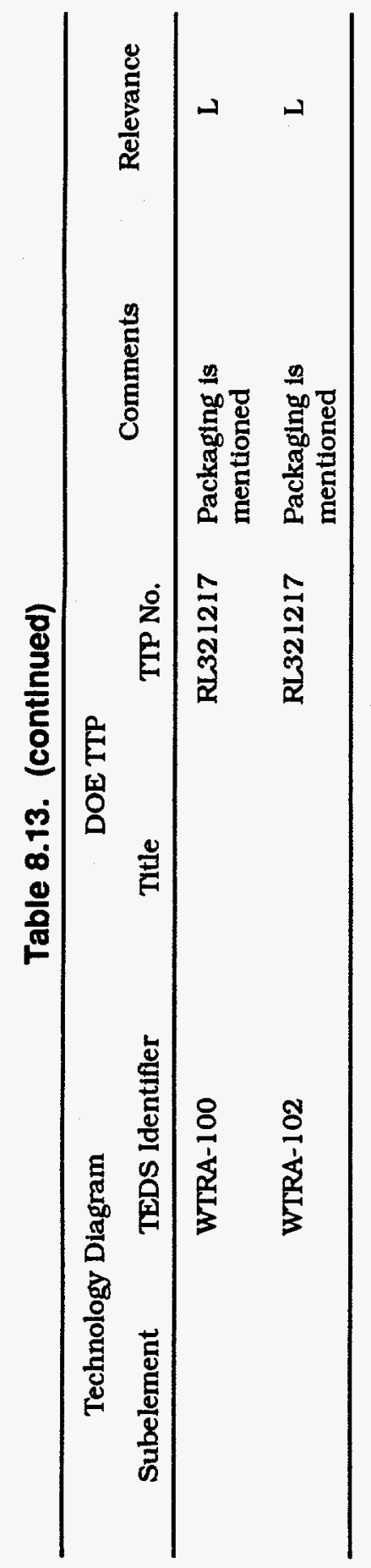

Page 8-34 


\section{Materials Disposition}




\section{MATERIALS DISPOSITION}

\subsection{INTRODUCTION}

\section{Definition and Scope}

The scope of materials disposition encompasses the characterization, handling, and any special treatment or conditioning required to recover economically valuable materials from waste streams generated from dismantlement, decontamination, RAs, and waste minimization activities. Here, recovery refers to separating valuable materials from waste streams into usable forms. Two general types of recovery may be distinguished: (1) recycling, which involves treating the material as an ore requiring a combination of beneficiation, reduction, refining, and fabrication, and (2) reuse, wherein objects (e.g., equipment items) are decontaminated and refurbished as necessary for similar uses.

The cleanup of inactive DOE facilities and sites is expected to generate very large quantities of waste materials, and the potential for economic benefits to the US taxpayer from optimizing recycling/reuse strategies in disposition of these materials may be correspondingly large. Material streams that need to be evaluated for recovery potentials include metals, concrete, sludges, various chemicals, and mixed wastes (containing both radioactive and hazardous materials). Hazardous components of these streams will be subject to special treatment requirements in accordance with existing RCRA regulations. One specific requirement of the RCRA 1984 Amendments is for states to consider recycling in comprehensive solid and hazardous waste management plans, acting in concert with the US Environmental Protection Agency (EPA).

Other considerations besides economics are clearly involved in material disposition. Under the Pollution Prevention Act of 1990 and its extension into Title III of the Superfund Amendments and Reauthorization Act (SARA), the U.S. Congress has mandated preventing or reducing of pollution at the source by potential generators. Emphasis is placed on prevention and waste minimization through recycling, with the environmentally safe treatment of necessary residuals. The Pollution Prevention Act states that disposal of or other releases of wastes into the environment should only be employed as a last resort. Similar laws have been enacted in many states.

Thus, the materials disposition activity selects and routes the appropriate treatments for the various material streams generated from ER activities. The general goal of materials disposition is to maximize feasible recycle/reuse and minimize the requirements for unproductive disposal into the environment. The nature of the selection processes requires that the activity be placed within a "systems" context (i.e., interrelations between all activities affected by a specific strategy for materials disposition need to be taken into account). The technologies involved in materials disposition fall primarily within the other task areas mentioned above, particularly the areas of decontamination and WM. Reference is made to these sections of the TLD for details of specific TDs and applications. 


\subsection{TECHNOLOGY OP'IIONS}

\subsubsection{Criteria for Selecting Materials Disposition}

\section{Regulatory Considerations}

A combination of technical and regulatory considerations need to be taken into account before developing appropriate strategies for materials disposition. An overview of the factors related to the recycle/reuse of components and materials from the decommissioning of nuclear facilities, taken from an international perspective, is given in a 1988 International Atomic Energy Agency (IAEA) publication. ${ }^{1}$ The largest potential source of recyclable materials, especially metals, from future ER activities is expected to be associated with D\&D programs. Examination of the technical and regulatory issues associated with metals recycling may be considered a general pattern for other materials as well.

This section will focus on some important regulatory considerations as seen from a U.S. perspective. ${ }^{2}$ A summary of existing U.S. regulatory requirements governing the treatment, storage, and disposition of materials contaminated with radioactivity and/or hazardous materials is given in Sect. 10. Various technologies can be identified, which may be applied to specific problems in metals decontamination. The technologies are discussed in detail in the decontamination sections of the TLD. How'ever, a critical issue, which has not been resolved from a U.S. regulatory standpoint, is the lack of standards governing the degree(s) of decontamination needed to permit the release of materials for recycle into the private sector of the ecoriomy.

DOE Order 5400.5, Chap. IV.5 establishes surface contamination guidelines for property that is to be: released to the public. These are identical to the U.S. Nuclear Regulatory Coinmission (NRC) guidelines contained in Regulatory Guide 1.86 (1974). In practical applications, (e.g., surface decontamination of metals for recycle/reusie), these guidelines are not considered technically enforceable standards. Consequently, the uncertainty and potential liability have often resulted in opting for burial rather than recycle.

For cases where surface decontamination is considered infeasible, other technologies of bulk treatment may be considered (e.g., metals smelting), which could result in the redistribution of a small residue of contaminants throughout the volume of material. Unlike surface treatments, however, the United States does not presently have guidelines or a de minimis standard for releasing materials that are bulk-contaminated with low levels of radioactivity. Clearly, this constraint has an important bearing on the feasibility of recycling these materials.

The NRC and the EPA are currently studying the release standards problems described above to develop a consensus for a solution among interested communities. However, prompt resolution of these fundamental issues is not anticipated. A possible interim strategy for initiating the recycle/reuse of materials generated from DOE site cleanup is that of restricted release for current or future uses in active sectors of the DOE Complex or the nuclear industry at large. An example of a potential future application in this category would be the use of bulkcontaminated stainless steel in the production of waste canisters. In restricted releases, the materials would remain under regulatory monitoring and controls, and special uses by DOE would need to be compatible with existing ES\&H regulations. 
A 'tiered' concept for establishing release standards for contamination is recommended in Ref. 2. Whether or not this proposal is ultimately adopted, certain details are of interest here to illustrate the various considerations involved in establishing a regulatory basis for metals recycle/reuse. Four usage tiers would be identified under this approach, defined as follows:

Tier 1 A 'below regulatory concern' level of contamination, below which materials could be released for recycle/reuse without radiological restrictions. There would be no need for tracking or record keeping after the verification survey measurements are completed and release is authorized.

Tier 2 A non-regulated, 'limited use' level of contamination which would allow the metals to be used in industrial or pre-established specific applications (example: use of various metals in heavy-duty industrial structural applications which go unattended for long periods.) The standard would be set by the critical exposure group, most likely the workers, to ensure their safety. However, certain worst-case scenarios assumed in Tier 1 would be eliminated through the limited use restrictions and allow a higher standard without increased public exposure.

Tier 3 A regulated but non-controlled 'nuclear industry use only' level, allowing direct recycle/reuse of the metals by either government or industry in nuclear applications, without restriction within the nuclear site boundary. An example would be the use of the materials in manufacture of new waste containers, which could be stored anywhere on site until loaded with radioactive wastes. Records would be maintained to document the on-site existence of the material, especially is sent off-site to a licensed facility, but detailed tracking records would not be required within the site boundary.

Tier 4 A regulated and controlled 'nuclear industry use only' level, which would allow the direct reuse of the metals by either government or industry in nuclear applications, with restriction as nuclear radioactive materials within controlled areas of the site. Metals used in these applications would require "cradle to grave" tracking and record keeping and be subject to routine surveillance and maintenance by health physicists.

According to Ref. 2, this tiered approach to standards setting would have the advantage of allowing generators and scrap metal facilities to obtain licenses for specific recycle operations that would permit metals recycling at any of the license approved tiers. 


\subsubsection{Economic and Other Usage Criteria}

Economic and enviro:nmental impact incentives, conditioned by technological performance capabilities, will interact with the preceding regulatory issues in determining strategies for materials disposition. A conceptual framework for graphically depicting somie of the tradeoffs, which are intrinsically involved in costrisk-benefit evaluations cf materials recycle/reuse options vs disposal is shown in Fig. 9.1. This is a hypothetical plot of the unit costs (e.g.,costs per ton) for materials decontamination, denoted by $C D$, vs the combined unit costs for packaging, transport, stcrage, and disposal of the material as wastes, denoted by $\mathrm{CW}$. The degree of decontamination (separation of primary contaminants from the bulk of the original material) increases with cost $C D$, along the vertical axis, and decreases as CW increases along the horizontal axis. Any particular point on the curve corresponds to a specific degree of decontamination and a strategy for WM and disposal, which will result in an acceptable level of risk. The total EM cost is considered here to be the sum of the decontamination and WM costs.

The horizontal and vertical scales in Fig. 9.1 should be interpreted as logarithmic scales. Conceptually, the cost curve should be interpreted as the envelope of economically optimized costs incurred to achieve the specified decontamination and wastes packaging/transport/storage and disposal conditions. That is, for any designated point the use of an optimized system or combination of technologies is implied. Otherwise, there would theoretically be a large number of possible combinations of technologies and associated costs which could achieve the specified cleanup conditions. The appropriate criteria for an optimized system would need to be defined for specific situations, but in this discussion it will be interpreted strictly in terms of cost minimization. In principle, each distinct material stream being evaluated would have an optimized cost envelope curve characteristic of that stream.

Also shown on this diagram are two hypothetical vertical dashed lines representing limiting conditions when fundamental changes may occur or be required in the strategy for materials disposition. The vertical line at the left represents an appropriale regulatory limit for low-level contamination permitted for a specific mode of recycle/reuse as an alternative to disposal as wastes. Similarly, the vertical line at the right represents a hypothetical limiting set of material contamination conditions wherein a different and more stringently controlled method of wastes disposal would be required (e.g., a shallow land burial mode of disposal would no longer be permissible, being replaced by deep repository burial or entombment).

In Fig. 9.1, it is assumed that the cost envelope curve will tend to be convex, (i.e., costs for achieving progressively higher degrees of decontamination will tend to rise at a progressively increasing rate). (This assumption is not vital to these cost trade-off arguments, but tends to simplify the discussion.) Under this assumption, there will be: a unique point along the cost curve, which will result in minimum total cost for clecontamination and wastes management and disposal. The unit costs associated with these specific conditions are denoted by the asterisk quantities $\mathrm{CD}^{*}$ and $\mathrm{CW}^{*}$ on the diagram. The sum of these quantities represents the hypothetical minimum environmental management cost that must be incurred for decontanination and disposition of the materials as wastes.

Based on this conceptual framework, the economic incentives for performing the additional decontamination processing required to meet the release limit for 


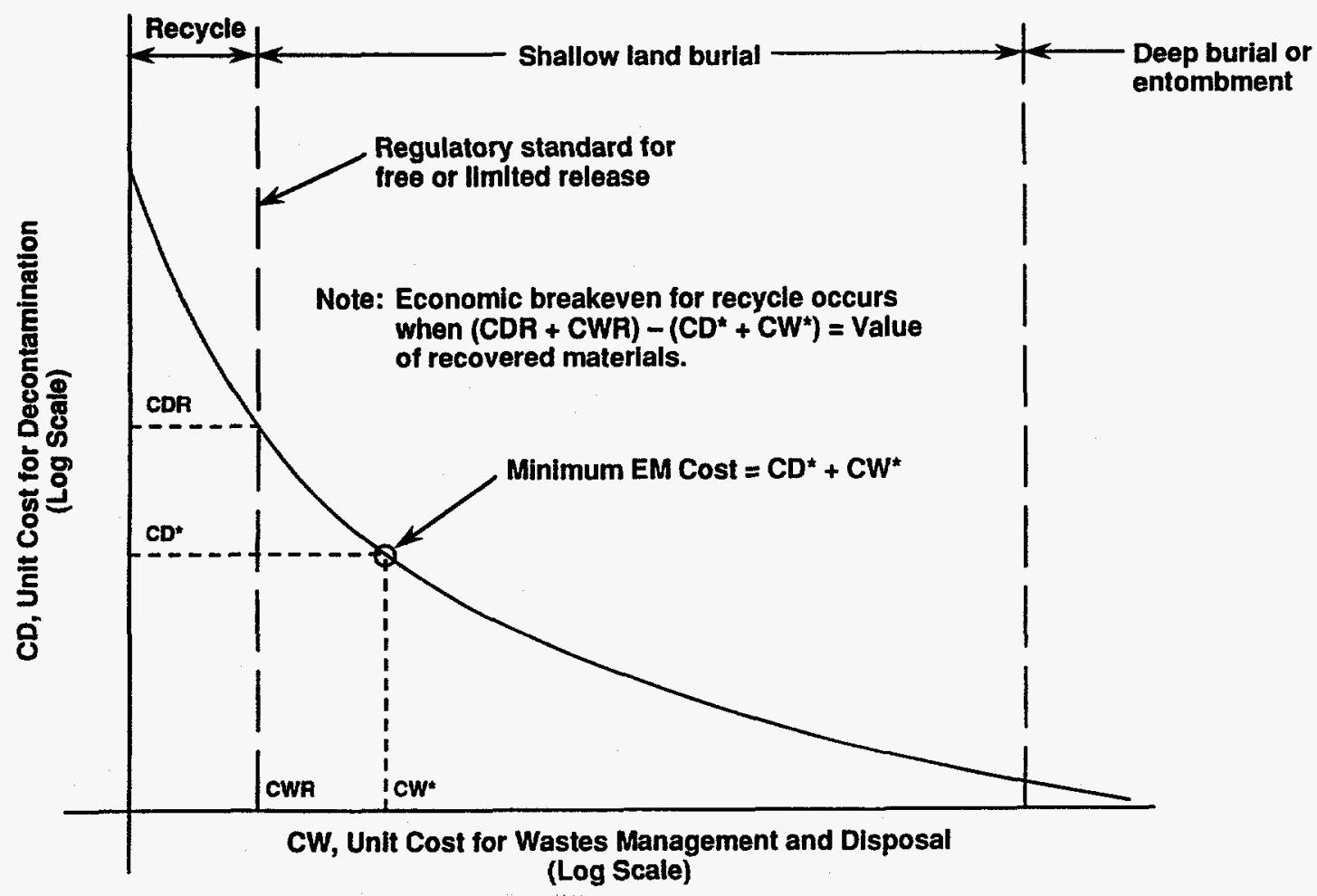

Fig. 9.1. Schematic showing relationship between costs for materials decontamination and wastes disposal.

recycle (left vertical line) can be estimated by comparing the sum of costs for decontamination and for disposal of the waste residuals with the minimum cost for EM defined above. The costs associated with the recycle limiting conditions are denoted by CDR and CWR in Fig. 9.1. Economic break-even conditions would occur when the difference between these sums equals the value of the recovered materials, or,

$(C D R+C W R)-\left(C D^{*}+\mathrm{CW}^{*}\right)=$ Minimum economic value of recovered materials.

Note that the magnitude of the residual waste disposal costs CWR is likely to be much smaller than $\mathrm{CW}^{*}$, since the residual masses and volumes would be minimized in conjunction with recovery of the valuable materials. Interpreted, this expression states that the value of recovered materials must be sufficient to pay the incremental costs of recovery relative to the minimum costs which would otherwise be incurred for environmentally safe disposition of the materials as wastes. In applying this criterion, the 'reference' economic value of the recovered materials would be determined by the costs for obtaining them from alternative sources (e.g., purchasing virgin materials).

An approximate version of the economic break-even analysis might also be considered, wherein the minimum value of recovered materials is equated to the decontamination costs, net of wastes disposal costs (CDR - CWR), thereby eliminating any reference to costs for the alternative mode of disposition as wastes. That is, the value of recovered materials must be sufficient to cover the incremental costs of decontamination, above the costs for disposing of the residual 
wastes (assumed to be incurred by the original waste generator). However, the above expression providies a more accurate representation of the real economic incentives for recovery, considered from a total systems or societal cost perspective. This critericn accounts for factors such as the cost avoidance and environmental preservalion advantages of not constructing expanded waste disposal facilities, and cost avoidance for long term storage of wastes and maintenance of disposal facilities. Depending on the minimum costs assessed for the alternative mode of disposition, use of the more appropriate break-even criterion could have the net effect of increasing the economic incentives for recycle.

It is important to note that risk, evaluated in terms of human health, safety, and environmental (eco ogical) effects, is an implicit parameter in the above analysis. In principle, the entire cost envelope curve illustrated in Fig. 9.1 corresponds to a specific set of criteria for "acceptable risks", governing (e.g., regulatory requirements for wastes disposal or limiting contamination conditions for materials recycle). Changes in these criteria may modify the incentives for choosing various options. Risk assessment is therefore implicated in the evaluation of material disiposition strategies, including all stages from generation, treatment, storage, transsportation, and recycle/disposal, particularly under the current situation wherein standards for releasing materials for recycle and disposing of LLW have not been firmly established.

Finally, in assessing the economic values of the recovered materials, the current market prices of these materials may not always be a reliable indicator of the intrinsic values for productive uses in the economy. Special factors could also play a role in establishing recycle incentives for some materials (e.g., conservation of valuable metals and the avoidance of negative health and environmental effects of extraction/replacement from other sources).

\subsubsection{Technology Developments and Initiatives}

The DOE Office of ElRWM has recently entered into Interagency Agreements with the EPA and other organizations for jointly developed projects aimed at scrap metal recycling technology (Ref. 2). These projects will involve cooperative efforts of the EM Offices of ER, WNM, and TD and will be executed as soon as practical. A two-phased recycling teclunology development project is envisioned, the first phase of which will include the following elements:

- Development of a summary of contaminated metal inventories at individual DOE sites.

- Development of a summary of the radionuclide contaminants and levels, and the types of contamination (surface, bulk).

- Projection of future quantities of radioactive scrap metals expected to be generated at DCE sites through the ER program.

- Identification of the technologies available for metals decontamination and recycling.

- Compilation of the total life cycle costs involved in scrap metal decontamination and recycling.

- Development of models for estimating radiological risk.

- Analysis of the zosts and benefits of metals recycling. 
The second phase will consist of the demonstration of selected, most promising technologies identified in Phase 1, concluding with a through analysis of results, identification of further R\&D needs, and an evaluation of the need for the DOE to develop in-house facilities for decontamination and recycling.

In support of these project goals, other agreements between the DOE and commercial/industrial firms can be anticipated in the future [e.g., in the form of cooperative research and development agreements (CRADAs) and Program Research and Development Announcements (PRDAs)], aimed at accomplishing specific technology demonstrations, pilot projects, and other tasks needed to develop a successful program for disposition of materials generated from ERWM activities. Also, from the perspective of international initiatives which could have important impact upon materials recycling, the Organization for Economic Cooperation and Development/Nuclear Energy Agency (OECD/NEA) has assembled a Task Group on Recycling and Reuse, chaired by the United States. This task group's conclusions and recommendations are expected to be presented to the IAEA in late 1993. If an agreement on common standards can be reached with the LAEA, these standards could be adopted in legally binding regulations among member states. ${ }^{2}$ All of the activities mentioned above could help to provide a route for the necessary regulatory development and successful implementation of the large-scale recycling of these materials.

\subsubsection{Description of the K-25 Site Situation}

The largest source of materials requiring disposition for the $\mathrm{K}-25$ Site should be associated with the D\&D Program. Phase I of this program, which is currently underway, is focused on removing hazardous materials to achieve environmental compliance for a permanent safe shutdown condition. Phase II, which will likely be a larger effort focused upon D\&D operations for the process equipment, auxiliary systems, and buildings, is in the early stages of planning. Innovative technology demonstrations may be associated with the Phase II program, aimed at achieving significant reductions in overall D\&D costs.

\section{Metals Disposition}

Of all materials generated from D\&D activities, metals are expected to have the greatest and most clear-cut potential for recycle / reuse. This discussion focuses upon a preliminary assessment of this potential. Depending on the technologies available for cleanup, most of the metals present in the diffusion plants may fall within this category. Metals present in large quantities include nickel, structural steel, copper, aluminum, stainless steel, monel (an alloy of nickel and copper), and various steel components such as ducts, pumps, piping, and valves.

A preliminary estimate of the quantities of metals which could be generated from D\&D of the gaseous diffusion plants (GDPs) was obtained from a 1991 study by Ebasco Services, Inc., performed for DOE. ${ }^{3}$ A summary of the metal streams having the clearest potential for recovery is given in Table 9.1. This table also includes information pertaining to GDP sites other than the K-25 Site since the scope of the Ebasco study encompassed the entire three-site GDP Complex. Presently, only the Oak Ridge plant has been permanently shut down. The remaining GDPs at Paducah, Ky., and Portsmouth, Ohio, are also expected to be shutdown soon after year 2000. Also, the Ebasco study assumed a specific "end- 
Table 9.1. Radioactive scrap metal streams arising from decommlssioning gaseous diffusion plants*

\begin{tabular}{|c|c|c|c|c|c|}
\hline Category & $\begin{array}{c}\text { K-25 Site } \\
\text { (KT) }\end{array}$ & $\begin{array}{c}\text { PGDP } \\
\text { (KT) }\end{array}$ & $\begin{array}{c}\text { PORTS } \\
\text { (KT) }\end{array}$ & $\begin{array}{c}\text { Totals } \\
\text { (KT) }\end{array}$ & $\begin{array}{l}\text { Est. Value } \\
\text { (\$M) }^{b}\end{array}$ \\
\hline Ferrous metals/steel ${ }^{c}$ & 103.7 & 74.0 & 91.4 & 269.1 & 24 \\
\hline Aluminum/copper & 8.5 & 6.1 & 7.6 & 22.2 & 27 \\
\hline Copper wire tubing, valve:s & 17.6 & 11.7 & 15.0 & 44.3 & 75 \\
\hline Monel pipe/valves & 1.7 & 1.2 & 1.5 & 4.4 & 19 \\
\hline Nickel & 22.1 & 15.9 & 19.8 & $\mathbf{5 7 . 8}$ & 350 \\
\hline $\begin{array}{l}\text { Miscellaneous } \\
\text { electrical/instrumentation } \\
\text { equipment and housings }\end{array}$ & 123.2 & 81.9 & 105.0 & 310.1 & $?$ \\
\hline
\end{tabular}

aStream quantitles derived from an analysis by Ebasco Services, Inc., 1991.

bestimated values as clean scrap, based upon 1992 average scrap metal prices for Iron/steel, aluminum, and copper, nickel valued at $\$ 3.00 \mathrm{per} \mathbf{l b}$.

Excludes some structural steel assumed left in place in decontaminated building structures.

point' scenario for the $\mathrm{D} \varepsilon \mathrm{D}$ operations, wherein the major process buildings were decontaminated to fre!-release standards but left standing for possible refurbishment after decontamination. Thus, the table excludes a significant amount of structural steel left in place. No final decisions have been made by the DOE concerning the enil points and schedules for completing D\&D activities; hence, the quantities of materials listed should be interpreted as potential rather than actual quantities.

The quantities of various metals listed in Table 9.1 are sums derived from specific materials estimates given on process flow diagrams given in the Ebasco study. A more detailed tabulation of these individual metal streams for the K-25 Site plant is given in Table 9.2. Certain streams were composites of more than one metal type and the precise composition was not specified in the Ebasco study. Also, the references made to 'clean' and 'contaminated' metal streams in this table relate to end-states reached after decontamination according to the processing concepts developed in the Ebasco study. Although most of the metal would be generated from dismantling the major process systems, components, and piping, there would also be a large number of auxiliary components classified in Table $\mathbf{9 . 2}$ as 'miscellaneous'. Many of these contain metals that could have market value and a significant portion should be relatively free of contaminants. The potentials for recycle/reuse would need to be evaluated.

In addition to the metals that could be generated from future D\&D of the GDPs, there is a large amount of radioactive scrap metal currently in storage at various sites throughout the DOE Complex. This is metal that has accumulated over the years from various site operations. Table 9.3 indicates approximate amounts stored at yards on the ORR (K-25 Sites, Y-12, and X-10 Sites), Paducah, Ky., Portsmouth, Ohio, and Fernald, Ohio (Feed Materials Production Center). This information was compiled and reported by DOE in Oak Ridge in context with the 
Ferrous metals/steel

Outside utilities \& tie lines, misc. steel

D\&D building, miscellaneous steel

Crane dismantling, equipment

C. st1., S.stl. pipe, valves

Small process equipment

Clean carbon steel

Contaminated carbon steel

Clean large pipe

Contaminated large pipe

Large valves

Steel enclosures/housings

16.3

HVAC equipment, ducting, vents, air intakes

16.2

Nonprocess equipment

Copper, aluminum, and nickel

Copper tubing/valves

0.21

Large copper wire

9.5

Small copper wire

7.9

Aluminum/copper from converters

8.5

Monel pipe/valves

Barrier tube and other nickel

Miscellaneous parts (compressor seals, etc.)

Miscellaneous

Electrical switchgear (outside utilities)

Transformer, circuit breaker, condenser

Nonprocess piping

0.36

Fire protection

15.0

Instrument air

0.79

Transformers (inside electrical/instruments)

18.8

Capacitors

Motors

Conduit and cable trays

Switchgear, instrument/control panel, switch housings

20.7

Source: "Environmental Restoration of the Gaseous Diffusion Plants," study by EBASCO Services, Inc., for U.S. DOE, October 1991. 
DOE Scrap Metal Recovery Program. ${ }^{4}$ Also, it was reported that the major portion of all existing DOE scrap metal was stored at the Nevada Test Site.

Indicators of the relative values of these metals are shown in Tables 9.4 and 9.5. Table 9.4 lists scrap metal prices as of June 1992, expressed as a range of values in some cases bec:ause the price is geographically dependent and are free on board the location of the scrap. As a matter of interest, the primary metal prices are shown in Table 9.5. These prices are those for the metals processed from the ore and in a form suitable for further processing into commercial alloys. For those metals that can be shown, in fact, to be uncontaminated the infrastructure will need to be developed to maximize the economic benefit to the government through sales in the open market.

The amount of copper in electrical components that is economically retrievable will need to be determinied. Processes may need to be developed to perform this retrieval for the contamilated and uncontaminated copper, stainless steel, and monel. It may be possible to sell some components directly in the open market. For example, many. of the electric motors were installed new in the cascades upgrade program during the late 1970 s, and there is a good chance that they will not be contaminated.

The 8.5 thousand tons of aluminum and copper obtained from dismantlement of converters and compressors at the $K-25$ Site would have a value of at least $\$ 5 \mathrm{M}$ (using aluminum scraj? values as a basis for estimation) if sufficient decontamination can be accomplished to qualify it as commercial scrap.

The contaminated nickel from the barrier tubes has the largest potential economic value. The 22 thousand tons estimated for the K-25 Site would have a decontaminated value between $\$ 110 \mathrm{M}$ and $\$ 150 \mathrm{M}$ provided that the level of bulk radioactive contamination could be reduced sufficiently to gain acceptance in the market place. As discussed in Sect. 9.2.2, acceptancy in the United States would require establishing of a de minimis regulatory standard.

There are presently no commercially available technologies and facilities with demonstrated capability of decontaminating the nickel to specified low levels of radioactivity. However, candidate technologies which appear capable of achieving very large decontamination factors include the well-established Mond process (INCO), leach/electrowinring (INCO), and the catalytic extraction process advanced by Molten Metals Technology, Inc. (See summary discussion under Sect. 4.5, Decontamination, in this volume and supporting information in remaining volumes of the TLD document.) These technologies are currently being evaluated for possible future application at the K-25 Site. Given a demonstration of the capability and cost-effectiveness of any of these technologies, together with the development of appropriate regulatory standards (discussed in Sect. 7.2.1), it appears likely that the nickel could be refined to a level required for recycle into the general economy.

Based on this summary perspective regarding the future disposition of metals from the K-25 Site, opportunities exist for applying innovative technological approaches to the recovery of ferrous and nonferrous metals. More detailed analyses of the various options, accounting for special economic constraints such as the scale-of-operations needed for production, transportation requirements, etc., could help facilitate: these developments. Considerable involvement of the commercial/industrial sector will be needed. The recent opening of the Scientific Ecology Group, Inc., (SEC) Metal Processing Facility near the K-25 Site, to be used in processing some of the DOE radioactive scrap metals, may prove to be a prototype for similar futiure operations at other DOE sites. Several commercial 


\begin{tabular}{|c|c|c|c|c|c|c|}
\hline Category & $\begin{array}{l}\text { Oak Ridge } \\
\text { (KT) }\end{array}$ & $\begin{array}{l}\text { Paducah } \\
\text { (KT) }\end{array}$ & $\begin{array}{l}\text { Ports } \\
\text { (KT) }\end{array}$ & $\begin{array}{l}\text { Fernald } \\
\text { (KT) }\end{array}$ & $\begin{array}{c}\text { Totals } \\
\text { (KT) }\end{array}$ & $\begin{array}{c}\text { Est. value } \\
\text { (\$, millions) }\end{array}$ \\
\hline $\begin{array}{l}\text { Ferrous } \\
\text { metal/steel }\end{array}$ & 43.1 & 14.6 & 21.7 & 11.1 & 90.5 & 7.1 \\
\hline Aluminum & 5.4 & 3.9 & 2.5 & & 11.8 & 5.0 \\
\hline $\begin{array}{l}\text { Nickel, monel } \\
\text { Nickel, ingots }\end{array}$ & $<.1$ & 10. & & & 10. & $>60$ \\
\hline $\begin{array}{l}\text { Copper, } \\
\text { ingots/wire }\end{array}$ & $<.1$ & & $<.25$ & 10.4 & 10.6 & 8.0 \\
\hline Other & $<.5$ & 2.5 & $<.4$ & 1.6 & 5.8 & \\
\hline
\end{tabular}

"Source: Material quantities dertved from Ref. 4. 
Table 9.4. Scrap metal prices

(Iron Age, June 1992)

\begin{tabular}{lc}
\hline \multicolumn{1}{c}{ Metal } & $\begin{array}{c}\text { Price } \\
(\$ / \mathrm{lb})\end{array}$ \\
\hline Carbon steel & $0.04-0.05$ \\
$18-3 \mathrm{SS}$ & $0.31-0.36$ \\
430 SS & $0.05-0.06$ \\
Copper wire & $0.80-0.90$ \\
Aluminum & 0.33 \\
Lead & 0.14 \\
Nicksel & $2.60-2.70$ \\
\hline
\end{tabular}

Table 9.5. Primary metal prices

(Iron Age, June 1992)

\begin{tabular}{lc}
\hline \multicolumn{1}{c}{ Metal } & $\begin{array}{c}\text { Price } \\
(\$ / \mathrm{lb})\end{array}$ \\
\hline Pig iron & 0.11 \\
Copper & 1.04 \\
Aluminum & 0.60 \\
Lead & 0.17 \\
Niclel & 3.37 \\
\hline
\end{tabular}

firms, including SEG, are anticipated to work cooperatively with the DOE in demonstrating metals recovery technologies and the manufacture of useful products (e.g., stainless steel rad-waste containers) using the recovered materials.

\section{Disposition of Other Materials}

Studies should assess the potentials for recycling other (nonmetal) bulkcontaminated materials generated during Phase II of the K-25 Site D\&D program. Such studies will be part of the overall planning efforts necessary to establish final technical requirements and approaches to be used for the program. Probably the largest material stream c|uantity in this category would be concrete (e.g., scabbled from floor and wall surfaces). If a sufficiently low-cost processing method could be demonstrated for removing the contaminants, this material might be suitable for use in road bullding or for incorporation into concrete for local DOE uses. Conventional economic considerations would indicate that transportation of 
aggregate for these uses is viable only for short distances. Pending more detailed assessments, it is likely that most of the material would need to be appropriately stabilized and disposed of in low-level radioactive land fills. 


\subsection{REFERENCES}

1. International Atomic: Energy Agency, "Factors Relevant to the Recycling or Reuse of Components Arising from the Decommissioning and Refurbishment of Nuclear Facilities," Technical Report Series No. 293, IAEA, Vienna, 1988.

2. W.E. Murphie, G. R. Bierman, and M. L. McKernan, "Environmental Restoration Opportunity - Recycle of DOE Contaminated Metal," paper presented at the National Meeting of the American Institute of Chemical Engineers, Minneapolis, Minnesota, August 9-12, 1992.

3. Ebasco Services, Inc., "Environmental Restoration of the Gaseous Diffusion Plants," Executive Summary, Technical Summary (2 Volumes), and Attachments, prepared under contract with U.S. Department of Energy Contract No. DE-AC15-910R21928, October, 1991.

4. Gant, R. E., et al, "Environmental Assessment of the Scrap Metal Program", Final Draft, U.S. Department of Energy, Oak Ridge Operations, Oak Ridge, TN, September, 1990. 


\section{Regulatory Compliance}




\section{REGULATORY COMPLIANCE}

\subsection{INTRODUCTION}

Many government-owned facilities that supported the early nuclear energy research and defense programs have no current use and have been retired. Some of these DOE facilities have residual radioactive or chemical contamination levels that require cleanup. The $D \& D$ Program is responsible for managing these surplus facilities to protect the public health and environment from radioactive contamination or hazardous materials that may be present. $D \& D$ is concerned with the safe caretaking of surplus nuclear facilities until their decontamination, entombment, dismantling and removal, or conversion to another nonnuclear reuse. D\&D tasks encompass: (1) surveillance and maintenance, (2) assessment and characterization, (3) environmental review, (4) engineering design, (5) D\&D operations, (6) waste disposal, and (7) closeout. The D\&D Program cost-effectively maintains surplus facilities awaiting decommissioning in a safe and secure state and ultimately completes decommissioning activities of the facilities.

Presently there is no law or regulation mandating decommissioning at DOE facilities, or setting de minimis or below-regulatory-concern (BRC) radioactivity levels to guide decommissioning activities at DOE facilities. The Nuclear Regulatory Commission (NRC) has the authority to issue licenses and promulgate rules regulating $\mathrm{NRC}$-licensed nuclear facilities and their decommissioning. $\mathrm{DOE}$, however, is exempt, under the Atomic Energy Act (AEA), from the NRC's authority and is not subject to their decommissioning regulations. The NRC has developed an Action Plan (57 FR 13389, April 16, 1992), which describes the approach it will follow to implement its Site Decommissioning Management Plan (SDMP) issued in 1990. The Action Plan lists specific steps and schedules NRC-licensed facilities must follow when undertaking decommissioning of a facility (e.g., site characterization report, site decommissioning plan). DOE has not promulgated parallel regulations outlining and defining the decommissioning process at $\mathrm{DOE}$ facilities. Under current regulations, hazardous waste components identified at D\&D sites could be subject to cleanup and permitting requirements under Resource Conservation and Recovery Act (RCRA) regulations. Further, these hazardous wastes would be subject to restrictive regulation prescribing treatment, storage, and disposal requirements that will significantly impact the search for innovative technology to deal with the clean up of hazardous wastes. Similarly, TSCA could drive cleanup (treatment, storage, and disposal) of any PCB or other TSCA wastes. More appropriately, the Comprehensive Environmental Response, Compensation, and Liability Act (CERCLA) should be the regulatory framework for driving, as well as controlling, such D\&D activities if there is any known potential for release of hazardous constituents to the environment (i.e., air, soil, surface water, or groundwater). The NRC and the EPA have failed, however, to promulgate de minimis or BRC levels acceptable to the public for the cleanup and release of residual radioactive materials that would guide $D \& D$ of the radioactive components at $D \& D$ sites. The absence of a regulatory driver for radioactive decontamination, as well as the lack of any clearly defined step-by-step process similar to NRC's Action Plan for decommissioning, is viewed as a deterrent to the orderly planning and implementation of $D \& D$ activities at DOE facilities. 
DOE has entered into a number of signed and pending agreements with state and federal parties, as well as appraisals and audits, however, which define committed milestones for ER and WM activities. Some of these major committed milestones impacting the K-25 Site D\&D activities include the FFA for the ORR, the Tennessee/DOE Monitoring and Oversight Agreement (TOA), the PCB Federal Facilities Compliance Agreement Between the U.S. DOE and the EPA, Washington, D.C. (TSCA-FFCA), and the Action Plan for the Management of K-1407-B and -C Ponds Waste at the Oak Ridge $K-25$ Site (K/PW-6).

The FFA among DOE, EPA Region IV, and TDEC focuses on resolving compliance issues associated with ER of the ORR. The agreement sets up a procedural framework and schedule for developing, implementing, and monitoring response actions conducted in compliance with RCRA, CERCLA, National Environmental Policy fict (NEPA), Tennessee laws/regulations, and other applicable and appropriate requirements.

The TOA details the obligations and agreements between DOE and TDEC with respect to the DOE provision for technical and financial support of state environmental activities. These activities include participation in the FFA, covering ER of the ORR, oversight, monitoring, access, and emergency response initiatives. Such activities are designed to ensure compliance with applicable federal, state, and local laws and reguliations concerning the ORR and its environs.

The TSCA-FFCA between DOE and EPA focuses on resolving compliance issues related to the regulation of PCBs under TSCA (40 CFR 761) at DOE uranium enrichment plants, such as the K-25 Site, and at their support facilities. The TSCA-FFCA was signed, effective Feb. 20, 1992.

The $\mathrm{K} / \mathrm{PW}-6$ is an Finergy Systems plan (approval pending) that proposes milestones to address issues originating from various audits and appraisals. The major issues identified in these reviews are addressed in other agreements or planning documents.

In addition, in June 1992, EPA and DOE signed another Federal Facilities Compliance Agreement for mixed waste subject to land disposal restriction for the Oak Ridge Reservation (LDR-FFCA/ORR) to bring mixed waste generation and storage facilities on the reservation into compliance with environmental law. Under the agreement, effective immediately, DOE-OR will submit plans that will include treatment and storage options for LDR mixed wastes to meet the requirements of RCRA. The plans, to bis prepared by DOE, will include proposals for waste minimization, treatment studies, technology development, facility construction, and schedules for future treatment. The LDR-FFCA/ORR allows DOE ORR facilities to continue to generate and store mixed wastes while addressing LDR mixed waste compliance issues. The mixed wastes covered under the LDR-FFCA/ORR include flammable and corrosive liquids, solvents, paint waste, waste oils and organics, and solid mixed wastes.

The Federal Facility Compliance Act of 1992 (FFCA of 1992) (Public Law 102-386, October 6, 199:2) amends $\$ 6001$ of the Solid Waste Disposal Act (SWDA) to waive immunity of the United States with respect to substantive and procedural requirements regarding control, abatement, or management of solid or hazardous waste. This waiver of imr.unity includes injunctive relief, administrative order, or civil or administrative penalties or fines, and subjects the federal government to the full range of available enforcement tools to penalize isolated, intermittent, or continuing violations. A delayed effective date of 3 years from enactment of the FFCA of 1992 is applied to the waiver of sovereign immunity for mixed waste 
regulated under SWDA $\$ 3004(\mathrm{j})$ so long as that waste is managed in accordance with other applicable requirements. Further, DOE is expressly exempt from the 3 year effective date for mixed waste in violation of SWDA of $\$ 3004(j)$ so long as DOE has in effect a plan that has been submitted and approved pursuant to SWDA $\$ 3021(\mathrm{~b})$, and an order requiring compliance with such plan has been issued pursuant to SWDA $\$ 3021$ (b).

This Act is not meant to alter, modify, or change any agreements, permits, or administrative orders that address compliance with SWDA $\$ 3004(j)$ mixed waste requirements that are in effect at the date of enactment of the Act, and to which a department, agency, or instrumentality of the executive branch of the Federal Government is a party.

Further sections of the Act regulate mixed waste inventory reports and plans required to be submitted by DOE within 180 days of the enactment of the FFCA of 1992. DOE has published its strategy for development of a national compliance plan for DOE mixed waste (57 FR 57170, December 3, 1992). DOE's National Compliance Plan will integrate environmental restoration and D\&D activities with the development of appropriate mixed waste treatment, storage and disposal capacity.

A second group of milestones, not considered commitments, are derived primarily from DOE's annual Five Year Plan, Current Year Work Plans, and Activity Data Sheets.

These milestones, both committed and uncommitted, serve as the regulatory drivers at this time for ER, WM, and D\&D activities. Examples of the types of milestones set under the above agreements and currently in effect are listed in Table 10.1. As D\&D commences or continues, the research and dismantling activities associated with it and the wastes produced will become subject to a number of major federal and state environmental laws as well as DOE Orders governing DOE facilities and activities. Regulatory drivers for these activities will be established through negotiated agreements, with associated compliance requirements and milestones defined therein. 
Table 10.1. Examples of major committed milestones under signed and pending agreements for the Oak Ridge Reservation

Date

Federal Facility Agreement for the ORR - Environmental Restoration (K-25 Site)

$\mathrm{K}-770$

K-901-A

$\mathrm{K}-1038$

Actd Pit

K-1070-A

Burial Ground

\section{$\mathrm{K}-1070-\mathrm{C} / \mathrm{D}$}

Burial Ground

K-1407-B

K-1407-C

K-1420
Phase I Site Characterization Summary (SCS) RCRA Facility Investigation (RFI) Report

RFI Plan

RFI Plan

Phase I SCS

RFI Report

Phase II SCS

Phase II RFI Report

Phase I SCS

RFI Report

Phase II SCS

Phase II RFI Report

Phase I SCS

Phase I RFI Report

Phase II SCS

Phase I SCS

Phase I RFI Report

Phase II

Phase I SCS

RFI Report
March 31, 1992

June 30, 1991

September 28, 1991

September 28, 1990

March 30, 1990

December 31, 1990

June 30, 1992

September 30,1992

March 30, 1990

December 31, 1990

June 30, 1992

September 30, 1992

December 31, 1990

September 30, 1991 June 30, 1992

September 28, 1990 June 28, 1991

June 30, 1992

June 30, 1992

September 30, 1992 
Environmental Monttoring Program and Report

Waste Minimization Plan

Source Reduction and Zero Discharges

Study

Waste and Residue Characterization

Accelerated Clean-up
Develop draft Environmental Monitoring Implementation Plans

TBD

Complete facllity-wide waste minimization plans and updates

Submit schedule for completing source reduction and zero discharges study report

Complete source reduction and zero discharges study report

Update and revise current DOE waste and residue characterization plan

Establish a target date for completion of a comprehenstve, facilitywide waste tracking system

Prepare an inventory of all ORR and standby status facilities in need of decontamination and decommissioning (D\&D)

Submit a schedule for near-term $D \& D$ activities and a summary of facility surveillance and maintenance programs

Include long-term schedules for $D \& D$ in the Headquarters Restoration and Waste Management Environmental Impact Statement

(EIS)

Submit a summary of FY-1991 D\&D activities
September 1991

August 1991

November 1992

TBD

October 1993

August 1991

September 1991

December 1991 
Specific Oversight Activities

Hazard Assessment

Emergency Notification and Information Management System
Submit East Fork Poplar Creek environmental restoration schedule and updates

Complete Applied Research, Development, Demonstration, Testing, and Evaluation Plans for Y-12 Bear Creek Burial Ground Uranium Chip Environmental Restoration

Submit ORR Waste Management EIS Schedule Complete RDDT\&E activities for Strontium 90 and Tritium releases into environs

Inventory and determine fate of radioactive and mixed waste shipments to and from ORR for reprocessing, treatment, storage and/or disposal

Complete ORR RCRA delisting activities including schedule for treatment, storage, and/or disposal

Complete Y-12 NPDES Effluent Toxdcity Corrective Action Plans, including RDDT\&E Activities

Complete integration of RCRA/FFA groundwater monitoring requirements, including Post Closure Permits, SWMUs, Waste Area Groupings, and Operable Units Complete ORR integration of NPDES/FFA area source pollution assessment and control requirements

Provide a detailed hazard assessment of all facilities on the ORR

Develop Emergency Notification Reporting and Emergency Information Management System
TBD

TBD

TBD

TBD

TBD

TBD

TBD

TBD

TBD

TBD 
Periodic Requirements "Quality assured" monitoring data on monitoring and analysis activities.

Progress reports to State on comprehensive waste tracking system. Updates of facility hazard assessment.

DOE Activity Data Sheets for ORR Site Specific Plan and Prioritization.

ORR response to TDEC review comments regarding DOE-ORR Site Specific Environmental Restoration and Waste Management Plan. DOE Environmental Restoration and Waste Management Plan Revised Draft.

DOE-ORR Site Specific Environmental Restoration and Waste Management Plan Revised Draft of Final Document.

DOE-ORR RDDT\&E Final Document.

TSCA-Federal Facilty Compliance Agreement (TSCA/FFCA) Envtronmental Restoration (K-25 Site)

Gaseous Diffusion Facilities

\section{Centrifuge Facilities}

Dispose of PCB-contaminated mineral oil

Complete disposition/storage of PCB electrical equipment

Complete PCB ventilation gasket removal from K-29, K-31, and $\mathrm{K}-$ 33

Complete disposal of all waste PCBs

None
Monthly

Quarterly

Annually

Annually

Annually

Annually

Annually Annually
March 31, 1992 September 30, 1994

August 1, 2001 December 31, 2015 or final Decommissioning Project Completion 


\begin{tabular}{|c|c|c|}
\hline Area/Program & Remedial Action/Activity & Date \\
\hline \multicolumn{3}{|c|}{$\begin{array}{c}\text { Plan for the Management of K-1407-B and -C Ponds } \\
\text { Waste at the Oak Ridge K-25 Site }\end{array}$} \\
\hline $\begin{array}{l}\text { K-1407-B and -C } \\
\text { Pond Waste Interim } \\
\text { Remediation (aiso } \\
\text { called K-1417 Drum } \\
\text { Storage Interim } \\
\text { Remediation) }\end{array}$ & $\begin{array}{l}\text { Part B Permit Application on } \mathrm{K}-1065 \text { Storage Facilities } \\
\text { Begin overpack and transfer of stabilized waste from } \mathrm{K}-1417 \\
\text { Part A Revision on } \overline{\mathrm{K}}-\overline{\mathrm{J}} \overline{\mathrm{K}} / \overline{\mathrm{K}}-\overline{3} \mathrm{~J} \text { storage sites } \\
\text { Part B Application on K-31/K-33 storage sites } \\
\text { Begin volume reduction on raw sludge } \\
\text { Complete transfer of stabilized waste } \\
\text { Complete volume reduction and transfer of material to compliant } \\
\text { storage }\end{array}$ & $\begin{array}{r}\text { February 2, } 1992 \\
\text { March 30, } 1992 \\
\text { Áprii 30ิ, 19ิ9̄ } \\
\text { May 30, } 1992 \\
\text { July 30, } 1992 \\
\text { October 30, } 1992 \\
\text { February 28, } 1993\end{array}$ \\
\hline
\end{tabular}




\subsection{OVERVIEW OF ENVIRONMENTAL LAWS AFFECTING DECONTAMINATION AND DECOMMISSIONING ACTIVITIES}

As DOE begins D\&D at some of its facilities on the ORR, special attention must be focused on the environmental laws that will impact these activities. These laws were promulgated to protect public health and the environment. The requirements of these environmental laws will dictate how the $\mathrm{D} \& \mathrm{D}$ activities are to be carried out. This section gives a general overview of the major environmental regulations that will affect $D O E D \& D$ activities.

The purpose of RCRA is to ensure the safe and environmentally acceptable management of hazardous and nonhazardous solid wastes. This law outlines the framework for national programs to achieve environmentally sound management of both hazardous and nonhazardous wastes. It is also concerned with the promotion of resource recovery techniques to reduce the volumes of waste. The Hazardous and Solid Waste Amendments of 1984 (HSWA) both expanded the scope of RCRA and increased the level of detail in many of its provisions.

CERCLA, as amended by SARA, was passed in response to a growing national concern about the release of hazardous substances into the environment. CERCLA "provides for liability, compensation, cleanup, and emergency response for hazardous substances released into the environment and the cleanup of inactive hazardous waste disposal sites." The intent of CERCLA is to provide for response to, and cleanup of, environmental problems that are not covered by the permit programs of the many other environmental laws.

CERCLA specifies that remedial actions for cleanup of hazardous substances must comply with requirements or standards under federal or more stringent state environmental laws that are applicable or relevant and appropriate to the hazardous substances or particular circumstances at a site. Inherent in the interpretation of applicable or relevant and appropriate requirements (ARARs) is the assumption that protection of human health and the environment is ensured. The National Oil and Hazardous Substances Pollution Contingency Plan (NCP) was amended to reflect changes made by SARA. In particular, Subpart E, Hazardous Substance Response, contains a detailed plan of authorized activities involved in abating and remedying releases or threats of releases of hazardous substances, including compliance with all ARARs.

The U.S. DOE ORR was proposed by the EPA for placement on the National Priorities List (NPL) under CERCLA on July 14, 1989 (54 FR 29820), with final NPL listing on Nov. 21, 1989, effective Dec. 21, 1989 (54 FR 48184). As a result of this listing, DOE, EPA, and TDEC, formerly the Tennessee Department of Health and Environment, have signed a FFA for the ER of the ORR (effective Jan. 1, 1992). This FFA is an LAG required by $\$ 120$ of CERCLA. FFA $\$ I V$ discusses the coordination between RCRA and CERCLA, and states that corrective actions previously established under DOE's current RCRA permit (HSWA TN 001) and the TDEC RCRA permit (TN1 890090 003) will be supplemented with response actions under CERCLA to ensure comprehensive remediation at the ORR. Because the ORR is on the NPL, most D\&D activities and technologies will be legally subject to CERCLA regulation, and the FFA will govern the scheduling and character of such activities. 
An effort is underway to incorporate into the FFA all inactive facilities which are known or suspected to contain significant quantities of residual hazardous materials. These facilities would be added to project lists under the FFA, and would subsequently undergo remediation pursuant to CERCLA. Facilities containing hazardous waste that remain listed as D\&D activities would undoubtedly be closed under RCRA. If D\&D activities proceed under RCRA, compliance with all legially applicable federal and state regulations must be assured; under CERCLA, compliance is also required with regulations that meet the definition of "relevant and appropriate" as defined in the NCP.

The assessment phasse of the Roadmap for the K-25 Site will address federal, state, and local codes, DOE Orders, Interagency Agreements and Federal Facility Compliance Agreements as they apply to waste management (See Sect. 1.6 for a description of the Roadmiap methodology). In addition, the Consolidated Storage Plan for K-25 addressed isignificant regulatory factors affecting storage capacities at K-25 (See Sect. 1.5.1). Therefore, the scope of this chapter will address regulatory drivers for $L \perp \& D$ activities proceeding under RCRA and CERCLA. Following is a summary of all federal laws and regulations that may be either legally applicable to cleanup of D\&D sites, or classify as ARARs for D\&D facilities that are grouped in the FFA under the umbrella of CERCLA.

The Clean Air Act of 1970 (CAA) is the major federal law regulating the air emissions of processes and facilities. The objectives of the CAA are to protect and enhance the quality of the nation's air resources and to protect public health and welfare, while fostering a beneficial productive capacity. This is accomplished through national ambient air quality standards (NAAQS), national emission standards for hazardous air pollutants (NESHAPs), air permits, and other standards and requirements set forth under the CAA. The CAA amendments of 1990 established a list of 189 hazardous air pollutants for which technology-based emission standards must be set. Depending on the type of activity or technology proposed, D\&D actions night be subject to any one or all of these CAA standards.

The Clean Water Act of 1972 (CWA) is the major water-related statute affecting D\&D activities. The objectives of the CWA include prohibition of toxic discharges, protection of fish and wildlife, and avallability of federal funds for public waste treatment works. All DOF facilities that discharge wastewaters to either a surface water body or a publicly owned treatment system must ensure compliance with the CWA.

The Safe Drinking Water Act of 1974 (SDWA) is an environmental statute that protects drinking water resources. Primary drinking water standards promulgated under the SDWA apply to drinking water "at the tap" as delivered by public water supply systems. As suci, the standards are directly applicable to those DOE facilities that meet the definition of a public water supply system. Of equal significance to $\mathrm{DOE}$ is the fact that these drinking water standards are used to determine groundwater protection regulations under a number of other statutes.

The Atomic Energy A.ct (AEA) of 1954 delegates authority to DOE, NRC, and EPA to control nuclear energy. NRC has the authority to issue licenses for use of radioactive materials at certain types of facilities and can promulgate rules regulating that use. DOE is exempted from NRC's authority under the AEA. Although NRC regulations are not legally applicable to DOE sites, DOE addresses the regulation of radioactive materials in its DOE Orders that are binding on all DOE sites. Standards outlined in the DOE Orders reiterate, for the most part, the standards promulgated under NRC regulations. 
TSCA is a comprehensive act governing toxic substances. TSCA protects human health and the environment by requiring that specific chemicals be tested and that regulations restricting their processing and uses be implemented. The objectives of TSCA include the development of adequate data to determine the health and environmental effects of chemicals and the control of any chemicals that present an unreasonable risk of injury. D\&D activities involving PCB and asbestos-contaminated materials, in particular, would be regulated under this act.

The Hazardous Materials Transportation Act of 1975, (HMTA) as amended, is the major transportation related statute affecting DOE. The objective of the HMTA is "...to improve the regulatory and enforcement authority of the Secretary of Transportation to protect the nation adequately against risks to life and property which are inherent in the transportation of hazardous materials in commerce." Any transportation of hazardous or radioactive materials off-site from a D\&D site would be regulated under HMTA.

The Occupational Safety and Health Act of 1970 (OSHA) is concerned with providing employees with a safe and healthy working environment. Under OSHA, rules have been promulgated to protect employees involved with cleanup operations at uncontrolled hazardous waste sites and to provide for worker protection during initial site characterization and analysis, monitoring activities, materials handling activities, training, and emergency response. All OSHA requirements apply to all $D O E D \& D$ activities.

The National Environmental Policy Act of 1969 (NEPA) establishes national policies and goals for protection of the environment. The purposes of NEPA include encouraging harmony between people and the environment, promoting efforts to prevent or eliminate damage to the environment and the biosphere, and encouraging the understanding of ecological systems and natural resources important to the country. NEPA ensures that federal agencies take into account the environmental impact of their actions.

The Endangered Species Act of 1973 (ESA) and the Fish and Wildlife Coordination Act of 1958 (FWCA) are major federal statutes designed to protect plant and animal resources from adverse effects of development projects. Both acts require consultation with wildlife authorities before committing resources to certain types of projects. ESA provides for the designation and protection of invertebrates, wildlife, fish, and plant species that are in danger of becoming extinct and conserves the ecosystems on which such species depend. The FWCA was passed because the goals of water-related projects may at times conflict with the goal of conserving fish and wildlife resources. Thus, this act ensures that fish and wildlife resources receive equal consideration with other factors during the planning of development projects that affect water resources.

The Federal Insecticide, Fungicide, and Rodenticide Act of 1947 (FIFRA) regulates pesticides. Its purpose is to control the use of pesticides by requiring that all pesticides be registered with the EPA. Under FIFRA, EPA conducts inspections to ensure compliance with FIFRA. For example, having pesticides labeled and stored properly. The act regulates the proper disposal of pesticides, which may impact D\&D activities involving pesticides or pesticide-contaminated materials.

It should be noted that all the major environmental laws also specify designated test methods and detailed sampling and analysis protocols that must be followed when testing materials or substances or verifying the applicability of a particular law to a given situation, substance, or material. 
DOE has issued orders addressing many of the activities regulated under the above-mentioned envirorumental statutes. These DOE Orders are binding between DOE and its contractors, in this case, Martin Marietta Energy Systems, Inc., which operates the facilities in Oak Ridge, Tennessee. Pertinent DOE Orders will be considered througholdt the chapter as they relate to $D \& D$ activities of $D O E$ facilities.

It is understood that DOE will comply with the requirements of NEPA as specified in DOE Order 5440.1D (National Environmental Policy Act Compliance Program). Further, DOE Order 5400.4 (Comprehensive Environmental Response, Compensation, and Liability Act Requirements) calls for integration of NEPA and CERCLA requirements for DOE RAs at CERCLA sites. This issue has been reaffirmed in the FFA $\S I(A)(3)$ and $\$ I I I(A)(2)$ and Secretary of Energy Notice (SEN) of Feb. 5, 1990 (SEN-15-90), which was issued to ensure that DOE's NEPA activities are carried out in a centralized and uniform manner. Therefore, the regulations found in $\mathrm{NE}$ 'PA $^{\mathrm{A}} \mathrm{\text {will }}$ not be addressed in this report.

Similarly, DOE adclresses occupational safety in DOE Orders 5480.11 (Radiation Protection for Dccupational Workers), 5480.4 (Enwironmental Protection, Safety, and Health Protection Standards), 5483.1A (Occupational Safety and Health Program for Contractors at GOCO Facilities), and 5480.9 (Construction Safety and Health Program), and it is understood that DOE will comply with these. The DOE Orders related to occupational safety are not addressed here unless they specifically apply to RAs

Environmental laws enacted by the state of Tennessee generally correlate to their federal counterparts. The differences that arise between the state and federal laws will be pointed out throughout the chapter.

Specific requirements and standards promulgated under each of the above laws are discussed in detial in the following sections. This regulatory summary has been modified from the Invironmental Restoration report Applicable or Relevant and Appropriate Requirements (ARARs) for Remedial Action at the Oak Ridge Reservation, A Compenclium of Major Environmental Laws, E. L. Etnier, E. P. McDonald, and L. M. Houlberg (ES/ER/TM-1/R1) (1992). Regulations are grouped into four major areas: (1) chemical-specific regulations-standards or limits based on the particular contsminant or pollutant present; (2) radiation protection standards-regulations governing radioactivity, promulgated to protect the public health and environment; (3) action-specific regulations-performance or design standards or restrictions; that set limits or controls based on the kind of activity planned at a site or designed into a particular technology; and (4) location-specific regulations-restrictions placed on pollutant concentrations or activities solely because they are in a particular location. 


\subsection{CHEMICAL-SPECIFIC REGULATIONS}

Chemical-specific regulations set health- or risk-based concentration limits or discharge limitations in various environmental media for specific hazardous substances, pollutants, or contaminants. These requirements generally set protective cleanup levels for the chemicals of concern in a designated media or indicate a safe level of discharge that may be incorporated when considering a specific remedial activity.

Although limited in number, chemical-specific standards have been established under several statutes, including RCRA, SDWA, CWA, TSCA, OSHA, CERCLA, and the CAA. Designated test methods and sampling/analysis protocols are delineated under each regulation for determining applicability of chemicalspecific standards. These methods and protocols must be followed exactly as outlined in the regulation.

\subsubsection{Groundwater and Surface Water}

Table 10.2 lists available chemical-specific standards that have been promulgated under federal law for groundwater, surface water, and air. The regulations for air are listed on the table and described in Sect. 10.3.2.

All groundwater at the ORR is scheduled to be cleaned up under CERCLA as part of the ER Program. As stated in the National Contingency Plan (NCP) (55 FR 8666, March 8, 1990), the goal of EPA's approach to cleanup of contaminated groundwater is to return usable groundwater to its beneficial use within a given time frame that is reasonable for the particular circumstances at a CERCLA site. Groundwater at the ORR has not been given an EPA classification. Although not legally applicable unless promulgated, EPA guidance on groundwater classification should be used to determine whether groundwater at ORR falls within Class I, II, or III. Classes I and IIA represent current sources of drinking water of varying value, Class IIB represents potential sources of drinking water, and Class III groundwater is not considered to be a potential source of drinking water and is of limited beneficial use. Restoration time periods vary, depending on the use classification of the groundwater, and may range from 1 year to several decades.

In the NCP, EPA states the preference for SDWA maximum contaminant levels (MCLs) and nonzero maximum contaminant level goals (MCLGs) or other healthbased standards, criteria, or guidance for cleanup of Class I and Class II groundwater at CERCLA sites (55 FR 8732). Alternate concentration limits (ACLs) may also be used when active restoration of the groundwater to MCLs or nonzero MCLGs is not practicable (55 FR 8754). For Class III groundwaters, EPA establishes remediation levels based on specific site conditions, the beneficial use of the groundwater, and environmental receptors (55 FR 8732). Final determination of applicable standards for site-specific cleanup of groundwater at the ORR will depend on the chosen groundwater classification.

The state of Tennessee has issued draft groundwater classification rules that classify groundwater as: (1) Class A-current or future sources of drinking water; (2) Class B-not a current or future source of drinking water but protected for other beneficial uses; (3) Class C-not protected for drinking water or for other beneficial uses; and (4) Surface Water Recharge-groundwater that recharges surface waters. 
Table 10.2. Chemical-speclfic federal regulations for protection of human health ${ }^{\alpha}$

\begin{tabular}{|c|c|c|c|c|}
\hline Chemical & $\begin{array}{c}\operatorname{RCRA}^{b} \text { MCLs }^{c} \\
(\mu g / L)\end{array}$ & $\begin{array}{c}\text { Safe Drinking } \\
\text { Water Act MCLs } \\
(\mu \mathrm{g} / \mathrm{L})\end{array}$ & $\begin{array}{c}\text { Safe Drinking Wa- } \\
\text { ter Act MCLGs } \\
(\mu \mathrm{g} / \mathrm{L})\end{array}$ & $\begin{array}{l}\text { Clean Air Act } \\
\text { NAAQS } \\
\left(\mu \mathrm{g} / \mathrm{m}^{3}\right)\end{array}$ \\
\hline Acrylamide $^{f}$ & & $\mathrm{TT}^{g}$ & 0 & \\
\hline Adipates [di(ethylhexyl)adipate] $^{h}$ & & 400 & 400 & \\
\hline Alachlor $f$ & & 2 & 0 & \\
\hline Aldicarb & & 3 & 1 & \\
\hline Aldicarb sulfone $e^{l}$ & & 2 & 1 & \\
\hline Aldicarts silfordde & & 1 & 1 & \\
\hline Antimony ${ }^{h}$ & & 6 & 6 & \\
\hline Arsenic & 50 & 50 & & \\
\hline Asbestos (fibers $>10 \mu \mathrm{m})^{f}$ & & $7^{k}$ & $7^{k}$ & \\
\hline Atrazine $f$ & & 3 & 3 & \\
\hline Barlum ${ }^{l}$ & 1,000 & 2,000 & 2,000 & \\
\hline Benzene $^{m}$ & & 5 & 0 & \\
\hline Benzo(a)pyrene ${ }^{h}$ & & 0.2 & $\mathbf{0}$ & \\
\hline Beryllium $^{h}$ & & 4 & 4 & \\
\hline Cadmium $^{n}$ & 10 & 5 & 5 & \\
\hline Carbofuran ${ }^{f}$ & & 40 & 40 & \\
\hline Carbon monoxdde & & & & $\begin{array}{l}40,000(1- \\
\text { hour }^{\circ} 10,000 \\
\text { (8-hour) }^{\circ}\end{array}$ \\
\hline Carbon tetrachloride $^{m}$ & & 5 & 0 & \\
\hline Chlordane & & 2 & 0 & \\
\hline Chromium (total) $^{n}$ & 50 & 100 & 100 & \\
\hline Copper & & $T^{p}$ & 1,300 & \\
\hline Cyanide $^{h}$ & & 200 & 200 & \\
\hline Dalapon ${ }^{h}$ & & 200 & 200 & \\
\hline 1,2-Dibromo-3-chloropropane $f$ & & 0.2 & 0 & \\
\hline o-Dichlorobenzene $f$ & & 600 & 600 & \\
\hline
\end{tabular}


Table 10.2. (contlnued)

\begin{tabular}{|c|c|c|c|c|}
\hline Chemical & $\begin{array}{c}\mathrm{RCRA}^{b} \mathrm{MCLs}^{c} \\
(\mu \mathrm{g} / \mathrm{L})\end{array}$ & $\begin{array}{c}\text { Safe Drinking } \\
\text { Water Act MCLs } \\
(\mu \mathrm{g} / \mathrm{L})\end{array}$ & $\begin{array}{c}\text { Safe Drinking Wa- } \\
\text { ter Act MCLGs } \\
(\mu \mathrm{g} / \mathrm{L})\end{array}$ & $\begin{array}{c}\text { Clean Air Act } \\
\text { NAAQS } \\
\left(\mu \mathrm{g} / \mathrm{m}^{3}\right)\end{array}$ \\
\hline$p$-Dichlorobenzene ${ }^{m}$ & & 75 & 75 & \\
\hline 1,2-Dichloroethane ${ }^{m}$ & & 5 & 0 & \\
\hline 1,1-Dichloroethylene $\mathrm{m}^{\mathrm{m}}$ & & 7 & 7 & \\
\hline cis-1,2-Dichloroethylene $f$ & & 70 & 70 & \\
\hline trans-1,2-Dichloroethylene ${ }^{f}$ & & 100 & 100 & \\
\hline $\begin{array}{l}\text { Dichloromethane (methylene chlo- } \\
\text { ride) }\end{array}$ & & 5 & 0 & \\
\hline $\begin{array}{l}\text { 2,4-Dichlorophenoxyacetic acid } \\
(2,4-D)^{n}\end{array}$ & 100 & 70 & 70 & \\
\hline 1,2-Dichloropropane $\mathrm{f}^{f}$ & & 5 & 0 & \\
\hline Dinoseb $^{h}$ & & 7 & 7 & \\
\hline Diquat $^{h}$ & & 20 & 20 & \\
\hline Endothall ${ }^{h}$ & & 100 & 100 & \\
\hline Endrin ${ }^{h}$ & 0.2 & 2 & 2 & \\
\hline Epichlorohydrin $f$ & & $\mathrm{TT}^{g}$ & 0 & \\
\hline Ethylbenzene $f$ & & 700 & 700 & \\
\hline Ethylene dibromide & & 0.05 & 0 & \\
\hline Fluoride $^{q}$ & & 4,000 & 4,000 & \\
\hline Glyphosate $^{h}$ & & 700 & 700 & \\
\hline Heptachlor ${ }^{f}$ & & 0.4 & 0 & \\
\hline Heptachlor epoxdde $f$ & & 0.2 & 0 & \\
\hline Hexachlorobenzene $^{h}$ & & 1 & 0 & \\
\hline Hexachlorocyclopentadiene ${ }^{h}$ & & 50 & 50 & \\
\hline Lead & 50 & $\operatorname{TT}^{p}$ & 0 & $1.5(90-\text { day })^{r}$ \\
\hline Lindane (gamma-HCCH) ${ }^{n}$ & 4 & 0.2 & 0.2 & \\
\hline Mercury $^{n}$ & 2 & 2 & 2 & \\
\hline Methoxychlor ${ }^{n}$ & 100 & 40 & 40 & \\
\hline
\end{tabular}


Table 10.2. (continued)

\begin{tabular}{|c|c|c|c|c|}
\hline Chemical & $\begin{array}{c}\mathrm{RCRA}^{b} \mathrm{MCLs}^{c} \\
(\mu \mathrm{g} / \mathrm{L})\end{array}$ & $\begin{array}{c}\text { Safe Drinking } \\
\text { Water Act MCLs } \\
\text { ( } \mu \mathrm{g} / \mathrm{L})\end{array}$ & $\begin{array}{c}\text { Safe Drinking Wa- } \\
\text { ter Act MCLGs } \\
(\mu \mathrm{g} / \mathrm{L})\end{array}$ & $\begin{array}{l}\text { Clean Air Act } \\
\text { NAAGS } \\
\left(\mu \mathrm{g} / \mathrm{m}^{3}\right)\end{array}$ \\
\hline Monochlorobenzene $^{f}$ & & 100 & 100 & \\
\hline Nickel $^{h}$ & & 100 & 100 & \\
\hline Nitrate (as N) ${ }^{n}$ & & 10,000 & 10,000 & \\
\hline Nitrite $(\text { as })^{f}$ & & 1,000 & 1,000 & \\
\hline Nitrate + Nitrite $(\text { as } N)^{f}$ & & 10,000 & 10,000 & \\
\hline Nitrogen dioxide & & & & $100(1-\text { year })^{\overline{-}}$ \\
\hline Ozone & & & & 235 (1-year) $^{0, t}$ \\
\hline Oxamyl (Vydate) ${ }^{h}$ & & 200 & 200 & \\
\hline Particulate matter & & & & $\begin{array}{l}260 \text { (24-hour) }^{o} \\
75 \text { (1-year) }^{u}\end{array}$ \\
\hline Pentachlorophenol ${ }^{l}$ & & 1 & 0 & \\
\hline $\begin{array}{l}\text { Phthalates [di(ethylhexyl)phthal- } \\
\text { ate] }^{h}\end{array}$ & & 6 & 0 & \\
\hline Picloram $^{h}$ & & 500 & 500 & \\
\hline Polychlorinated biphenyls $f$ & & 0.5 & 0 & \\
\hline Selenium ${ }^{n}$ & 10 & 50 & 50 & \\
\hline Silver" & 50 & & & \\
\hline Simazine $^{h}$ & & 4 & 4 & \\
\hline Styrene $^{f}$ & & 100 & 100 & \\
\hline Sulfate $^{w}$ & 400 & $0 / 500,000$ & $00 / 500,000$ & \\
\hline Sulfur oxides & & & & $\begin{array}{l}365 \text { (24-hour) }^{\circ} \\
80 \text { (1-year) }^{3}\end{array}$ \\
\hline Tetrachloroethylene ${ }^{f}$ & & 5 & 0 & \\
\hline Thallium $^{h}$ & & 2 & 0.5 & \\
\hline $\begin{array}{l}\text { 2,3,7,8-Tetrochlorodibenzo-p-dioxin } \\
\text { (Dloxin) }^{\mathrm{h}}\end{array}$ & & 0.00003 & 0 & \\
\hline Toluene $^{f}$ & & 1.000 & 1,000 & \\
\hline
\end{tabular}


Table 10.2. (continued)

\begin{tabular}{|c|c|c|c|c|}
\hline Chemical & $\begin{array}{c}\operatorname{RCRA}^{b} \mathrm{MCLs}^{c} \\
(\mu \mathrm{g} / \mathrm{L})\end{array}$ & $\begin{array}{c}\text { Safe Drinking } \\
\text { Water Act MCLs } \\
(\mu \mathrm{g} / \mathrm{L})\end{array}$ & $\begin{array}{l}\text { Safe Drinking Wa- } \\
\text { ter Act MCLGs }{ }^{d} \\
(\mu g / L)\end{array}$ & $\begin{array}{l}\text { Clean Air Act } \\
\text { NAAQS } \\
\left(\mu \mathrm{g} / \mathrm{m}^{3}\right)\end{array}$ \\
\hline Toxaphene $^{n}$ & 5 & 3 & 0 & \\
\hline 1,2,4-Trichlorobenzene ${ }^{h}$ & & 70 & 70 & \\
\hline 1,1,1-Trichloroethane $\mathrm{e}^{m}$ & & 200 & 200 & \\
\hline $1,1,2$-Trichloroethane ${ }^{h}$ & & 5 & 3 & \\
\hline Trichloroethylene $^{m}$ & & 5 & $\mathbf{0}$ & \\
\hline Trihalomethanes (total) ${ }^{j, x}$ & & 100 & & \\
\hline $\begin{array}{l}\text { 2,4,5-Trichlorophenoxy-propionic } \\
\text { acid }(2,4,5-T P)^{n}\end{array}$ & 10 & 50 & 50 & \\
\hline Vinyl chloride $^{m}$ & & 2 & 0 & \\
\hline Xylenes (total) $f$ & & 10,000 & 10.000 & \\
\hline
\end{tabular}

${ }^{a}$ Federally promulgated regulations under RCRA, the SDWA, and the CAA are included in this table. Clean Water Act regulations are listed in Tables 6.4 and 6.5. Tennessee state drinking water MCLs/MCLGs (Chapter 1200-5-1 of the Rules of the TDEC) are identical to the federal.

${ }^{b}$ RCRA = Resource Conservation and Recovery Act (40 CFR 264.94).

'MCL = maximum contaminant level; RCRA MCLs are properly termed "maximum concentration limits."

${ }^{d}$ MCLG = maximum contaminant level goal.

NAAQS = National Ambient Air Quality Standards (40 CFR 50.4, 50.6, 50.8 and 50.9-50.12).

$f_{56}$ FR 3526 (January 30, 1991). Effective July 30, 1992.

${ }^{9} \mathrm{TT}=$ treatment technology.

h57 FR 31776 (July 17, 1992). Effective January 17, 1994 except for the MCL/MCLG for Endrin which becomes effective August 17, 1992.

Effective date for aldicarb compounds, originally set for January 1,1993 , is postponed indefinitely pending further study (57 FR 22178 May 27, 1992).

$J_{40}$ FR 59570 (December 24, 1975).

MMillion fibers per liter.

'56 FR 30266 (July 1, 1991). Effective January 1, 1993.

$m_{52}$ FR 25690 (July 8, 1987). 


\begin{tabular}{|c|c|c|c|c|}
\hline Chemical & $\begin{array}{c}\operatorname{RCRA}^{b} \mathrm{MCLs}^{c} \\
(\mu \mathrm{g} / \mathrm{L})\end{array}$ & $\begin{array}{c}\text { Safe Drinking } \\
\text { Water Act MCLs } \\
(\mu g / L)\end{array}$ & $\begin{array}{c}\text { Safe Drinking Wa- } \\
\text { ter Act MCLGs }{ }^{d} \\
(\mu \mathrm{g} / \mathrm{L})\end{array}$ & $\begin{array}{l}\text { Clean Alr Act } \\
\text { NAAQS } \\
\left(\mu \mathrm{g} / \mathrm{m}^{3}\right)\end{array}$ \\
\hline
\end{tabular}

The final MCL/MCLG was set for this chemical (56 FR 3526, January 30, 1991) and supersedes the original interim SDWA MCL. Effective July 30, 1992; interim MCLs remain in effect until that time.

Maximum concentration not to be exceeded more than once per year.

PTT= treatment technology; 56 FR 26460 (June 7, 1991, effective December 7, 1992). When the "action level" of 15 or $1300 \mu \mathrm{g} / \mathrm{L}$, for lead or copper, respectively, measured in the 90th percentile at the consumer's tap, is exceeded for lead or copper, corrosion control studies and treatment requirements are triggered. However, an OSWER memorandum (dated June 21, 1990) recommends that a final

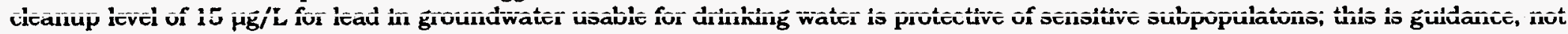
an ARAR.

9MCL - 51 FR 11396 (April 2, 1986); applies to community water systems only. MCLG - 50 FR 47141 (November 14, 1985).

"Three-month maximum arithmetic mean concentration.

sAnnual arithmetic mean concentration.

tHydrocarbon emissions are controlled as part of the ozone NAAgS strategy.

"Annual geometric mean.

"The interim SDWA MCL was revoked for this chemical (56 FR 3526, January 30, 1991) and a secondary MCL established instead (see Table 6.3). Effective July 30, 1992; interim MCL of $50 \mu \mathrm{g} / \mathrm{L}$ remains in effect until that time.

wThis is a proposed MCL/MCLG only (55 FR 30370, July 25, 1990). EPA has deferred setting a final MCL/MCLG for sulfate pending further study (57 FR 31776, July 17, 1992).

'Total trihalomethanes refers to the sum of the concentration of chloroform, bromodichloromethane, dibromochloromethane, and bromoform. 
Class A groundwaters are listed by aquifers; two are identified for east Tennessee-Cambrian-Ordovician Carbonate Aquifer and Crystalline Rock Aquifer. Final promulgation of this groundwater classification rule is projected for mid 1993 (Sinclair 1992).

\section{Resource Conservation and Recovery Act}

Subtitle C of RCRA lists maximum concentration levels for 14 chemicals; the concentration of these chemicals in groundwater at the plant boundary of a RCRApermitted treatment, storage, or disposal (TSD) facility may not exceed the stated maximum concentration level [Title 40, Code of Federal Regulations, Part 264, 894 (40 CFR 264.94)]. In addition, background concentrations or ACLs are established in 40 CFR 264.94 as groundwater protection standards. Table 10.2 lists RCRA maximum concentration levels; however, as mentioned above, EPA has specified SDWA MCLs and nonzero MCLGs for cleanup of Class I and Class II groundwater and site-specific remediation levels for Class III groundwaters. This approach is consistent with the substantive requirements of RCRA maximum concentration levels, ACLs, or background limits (53 FR 51433). The newly promulgated regulations for municipal landfills (56 FR 50978, October 9, 1991) establish all SDWA MCLs by reference, ACLs, or background concentrations as groundwater protection standards (40 CFR 258.55). Although not legally applicable to RAs found at the ORR, these may prove relevant and appropriate for cleanup of groundwater at some of the sites. ACLs may be calculated for chemicals without an MCL, using a risk-based approach (56 FR 51026).

Under the present RCRA Subtitle $C$ hazardous waste identification regulations, solid wastes ("solid wastes," as defined under RCRA, can be solid, liquid, semisolid, or contain gaseous material) generated during the D\&D process would be subject to RCRA regulation under the following conditions: (1) if they are identified as RCRA-listed or RCRA-characteristic hazardous wastes pursuant to 40 CFR Part 261; (2) if they are a "mixture" of solid waste and listed hazardous waste, "derived-from" a listed hazardous waste, or (3) if they have a listed hazardous waste "contained-in" the waste (40 CFR 261.3). Wastes are "characteristically hazardous" under RCRA if they (1) exhibit ignitability, corrosivity, reactivity, or toxicity, (2) meet certain toxicity criteria, or (3) contain certain toxic constituents (40 CFR 261.10-24). Currently, listed wastes remain hazardous unless they are "delisted" according to procedures set forth in 40 CFR 260.20 and 260.22 .

In an attempt to address instances where regulation of listed hazardous waste under the jurisdiction of RCRA Subtitle $C$ would cease without the need for a delisting petition, EPA proposed two alternative approaches for identifying a waste as a RCRA hazardous waste ("Hazardous Waste Identification Rule," 57 FR21450, May 20, 1992). However, this proposed rule was withdrawn due to a large number of policy and technical issues. Congress has charged EPA with promulgating rules to address the "derived from" and "mixture" issues by October 1994 (Houlberg et al. 1992).

\section{Safe Drinking Water Act}

EPA has promulgated primary and secondary drinking water regulations applicable to public water systems that have at least 15 service connections or 
serve an average of at lesıst 25 people daily at least 60 days of the year. National Primary Drinking Water Standards (NPDWS) are established in 40 CFR 141 and include MCLs and MCLCis. New drinking water standards promulgated for eight synthetic organic chemicals (52 FR 25690, July 8, 1987) added a new category of suppliers referred to as nioncommunity, nontransient systems that regularly serve at least 25 people for 6 months of the year. Table 10.2 lists SDWA MCLs and MCLGs.

MCLs are enforceable standards that take into consideration human health effects, available treatment technologies, and costs of treatment. MCLGs are strictly health-based staridards that disregard cost or treatment feasibility and are not legally enforceable. MCLs are legally applicable to water "at the tap" but are not applicable to cleanup of groundwater or surface water. However, they may be considered as relevant and appropriate in situations where groundwater or surface water may be used for drinking water. CERCLA \$121(d)(2)(A) specifically mentions that RAs must require a level or standard of control that at least attains MCLGs and federal ambient water quality criteria (WQC) where such goals or criteria are relevant and appropriate under the circumstances of the release. Although MCLGs and WGC are nonenforceable guidelines, Congress elevated them to a higher status by specifically mentioning them in CERCLA. Therefore, promulgated MCLGs are listed in Table 10.2. At present, EPA is planning to use the SDWA MCLs for RA compliance for carcinogems that have an MCLG of zero and any nonzero MCLG for systemic toxicants (55 Flर 8752).

EPA has revised its drinking water standards for lead and copper, eliminating the MCL and replacing it with a treatment technique requirement (56 FR 26460, June 7, 1991). If an "action level" of 15 or $1300 \mu \mathrm{g} / \mathrm{L}$, for lead or copper, respectively, is exceeded at the tap, a state is required to analyze source water samples and to decide what treatment levels are necessary to minimize lead or copper levels delivered to users from the affected distribution system. In the instance of contaminated groundwater, the action levels for lead and copper are neither legally applicable nor relevant and appropriate for cleanup; however, for copper, the MCLG of $1300 \mu \mathrm{g} / \mathrm{L}$ is relevant and appropriate. In addition, the EPA Office of Solid Waste and Emergency Response (OSWER) has recommended that a final cleanup level of $15 / \mu \mathrm{g} / \mathrm{L}$ for lead in groundwater usable for drinking water is protective of sensitive populations (OSWER memorandum dated June 21, 1990). This might be considered TBC guidance for remediation of lead-contaminated groundwater (footnoted in Table 10.2), and will serve as guidance to ensure the precision of analytical detection limits. TDEC has proposed a cleanup criteria of $15 \mathrm{\mu g} / \mathrm{L}$ for lead in groundwater (TDEC Rule 1200-1-13-.08, Table 8-2). When promulgated this criteria will be applicable to cleanup.

Chapter 1200-5-1 of the Rules of the TDEC, as amended effective Jan. 10 , 1991 , lists MCLs for public water systems, which are identical to the federal MCLs as of that date. These regulations will be revised to incorporate the recent revisions in federal MCLs, with yromulgation expected by June 1993 (Flexnor 1991). Therefore, the state regulations are not repeated here.

National Secondary Drinking Water Standards (NSDWS) regulate contaminants that affect the aesthetic qualities related to public acceptance of drinking water and are implemented in 40 CFR 143.3 as secondary maximum contaminant levels (SMCLs). (See Table: 10.3) These regulations are not federally enforceable but are intended to serve as guidelines for use by states in regulating water supplies. Tennessee has promulgated SMCLs in Chap. 1200-5-1.12 of the Rules of the 
Table 10.3. Federal and Tennessee secondary drinking water regulations

\begin{tabular}{|c|c|c|}
\hline Chemical & $\begin{array}{c}\text { Federal SMCL } \\
(\mathrm{mg} / \mathrm{L})\end{array}$ & $\begin{array}{c}\text { Tennessee SMCL } \\
\text { (mg/L) }\end{array}$ \\
\hline Aluminum & $0.05-0.2^{c, d}$ & \\
\hline Chloride & 250 & 250 \\
\hline Color & 15 (color units) & 15 (color units) \\
\hline Copper & 1 & 1 \\
\hline o-Dichlorobenzene $e^{e}$ & 0.01 & \\
\hline$p$-Dichlorobenzene $e^{e}$ & 0.005 & \\
\hline Ethylbenzene $^{e}$ & 0.03 & \\
\hline Fluoride & 2.0 & 2.0 \\
\hline $\begin{array}{l}\text { MBAS (methyl blue active } \\
\text { substance) }\end{array}$ & & 0.5 \\
\hline Hexachlorocyclopentadiene $e^{f}$ & 0.008 & \\
\hline Iron & 0.3 & 0.3 \\
\hline Manganese & 0.05 & 0.05 \\
\hline Odor & $\begin{array}{l}3 \text { (threshold odor } \\
\text { number) }\end{array}$ & $\begin{array}{l}3 \text { (threshold odor } \\
\text { number) }\end{array}$ \\
\hline Pentachlorophenol $^{e}$ & 0.03 & \\
\hline $\mathrm{pH}$ & $6.5-8.5$ & $6.5-8.5$ \\
\hline Silver & $0.1^{c}$ & \\
\hline Styrene $^{e}$ & 0.01 & \\
\hline Sulfate & 250 & 250 \\
\hline Toluene $^{e}$ & 0.04 & \\
\hline TDS (total dissolved solids) & 500 & 500 \\
\hline Xylene $^{e}$ & 0.02 & 0.02 \\
\hline Zinc & 5 & 5 \\
\hline
\end{tabular}

aFinal rule [44 FR 42198 (July 19, 1979)]. National Secondary Drinking Water Standards (NSDWS) are included in this table for completeness because they will be incorporated into the TDEC secondary drinking water regulations when they are revised.

${ }^{b}$ Chapter 1200-5-1.12 of the Rules of the TDEC.

'NSDWS final rule [56 FR 3526 (January 30, 1991)]. Effective date July 30, 1992.

Level recommended to prevent posttreatment precipitation in the distribution system.

Proposed NSDWS (54 FR 22062, May 22, 1989). EPA has deferred setting final standards for these chemicals pending further study ( $56 F R$ 3572, January 30, 1991).

fProposed NSDWS (55 FR 30370, July 25, 1990); EPA has deferred setting a final standard for this chemical pending further study (57 FR 31776, July 17, 1992). 
TDEC (See Table 10.3). These regulations are designed to provide water to the consumer, which is aesthetically pleasing, and they apply to all community water systems and to those noricommunity water systems "as may be deemed necessary" by TDEC. In that context, they would not be legally applicable to cleanup of groundwater or surface ivater, but may be considered as relevant and appropriate in instances where these media may provide private drinking water sources. EPA has proposed NSDWS for ten additional contaminants (54 FR 22062, May 22, 1989; 55 FR 30370 July 25, 1990); when these are promulgated, they will be incorporated into the TLIEC secondary drinking water regulations (Foster 1990). Therefore, they are included in Table 10.3 for completeness. A final NSDWS for aluminum and silver has appeared (56 FR 3526, January 30, 1991).

\section{Clean Water Act}

CERCLA §121(d)(2)(A) specifically states that RAs shall at least attain federal ambient WQC establishe:d under the CWA if they are relevant and appropriate. In determining whether any $\mathrm{WQC}$ are relevant and appropriate, one must consider the "designated or potential use of the surface or groundwater, the environmental media affected, the purposes for which the criteria were developed, and the latest information available" [CERCLA \$121(d)(2)(B)]. Federal WQC are derived for the protection of freshwater aquatic organisms and for the protection of human health from the consumption of contaminated drinking water and/or aquatic organisms.

Table 10.4 lists federal ambient WQC for the protection of human health. EPA has derived WQC for ingestion of drinking water and aquatic organisms and for the ingestion of aquatic: organisms alone. Since neither of these categories is relevant and appropriate for consideration of contaminated groundwater, WQC derived for the ingestion of drinking water alone are also included in Table 10.4. The EPA Region IV Water Quality Standards Unit has adjusted WQC for human health based on recent human toxicity information [reference doses (RFDs) and carcinogen slope factors [CSFs)] obtained from the EPA Integrated Risk Information System (IRIS). The values presented in Table 10.4 reflect the EPA Region IV revised WQC and are current als of October 1991 (EPA 1991a). They are intended to supersede all previous W/QC. Federal WQC are not promulgated standards. They are intended to serve as guidelines for individual states to use in promulgating state water quality standards. When a state adopts federal WQC and promulgates them in their state regulations, then they become legally enforceable under that state's law.

As part of the federal requirement for a triennial review of state water quality standards, the TDEC Division of Water Pollution Control has promulgated amendments to Chaps. 1200-4-3 and 1200-4-4 of the Rules of the TDEC. TDEC has revised its water quality standards and promulgated the federal SDWA MCLs as WGC for domestic water supplies (effective date Aug. 30, 1991). Included in this revision are criteria for pirotection of recreational uses. These criteria are human health criteria derived to protect the consumer from consumption of contaminated fish; these criteria are similar to the federal WQC for the protection of human health from consumption of fish alone. However, they are based on a risk of $10^{-5}$ rather than the $10^{-6}$ risk on which the federal WQC are based. Tennessee WQC for human health are listed in Table 10.5.

Chapter 1200-4-3 of the Rules of the TDEC lists seven use designation categories for Tennessee's surface waters and groundwaters. Specific water quality 
Table 10.4. Federal ambient water quality criterla (WQC) for the protectlon of human health $(\mu \mathrm{g} / \mathrm{L})$

\begin{tabular}{|c|c|c|c|}
\hline Chemical & $\begin{array}{c}\text { WQC for } \\
\text { aquatic } \\
\text { organisms and } \\
\text { drinking water }\end{array}$ & $\begin{array}{c}\text { WQC for } \\
\text { aquatic } \\
\text { organisms } \\
\text { alone }^{a} \\
\end{array}$ & $\begin{array}{c}\text { WQC for } \\
\text { drinking water } \\
\text { alone }^{b}\end{array}$ \\
\hline Acenaphthene & 20 (org) $^{c}$ & $\begin{array}{l}\text { NA } \\
780\end{array}$ & 2,100 \\
\hline $\begin{array}{l}\text { Acrolein } \\
\text { Acrvlonitrile }\end{array}$ & $\begin{array}{l}320 \\
0(0.059)\end{array}$ & $\begin{array}{l}780 \\
0(0.67)\end{array}$ & $0(0.065)$ \\
\hline $\begin{array}{l}\text { Acrylonitrile } \\
\text { Aldrin }\end{array}$ & $\begin{array}{l}0(0.059) \\
0(1.3 E-04)^{d}\end{array}$ & $\begin{array}{l}0(0.67) \\
0(1.4 \mathrm{E}-04)\end{array}$ & $\begin{array}{l}0(0.065) \\
0(2.1 \mathrm{E}-03)\end{array}$ \\
\hline $\begin{array}{l}\text { Aldrin } \\
\text { Anthracene }\end{array}$ & $\begin{array}{l}0(1.3 \mathrm{E}-04)^{d} \\
9,567.2\end{array}$ & $\begin{array}{l}0(1.4 \mathrm{E}-04) \\
107,692\end{array}$ & $\begin{array}{l}0(2.1 \mathrm{E}-03) \\
10.500\end{array}$ \\
\hline $\begin{array}{l}\text { Anthracene } \\
\text { Antimony }\end{array}$ & & 4,308 & $\begin{array}{l}10,500 \\
14\end{array}$ \\
\hline $\begin{array}{l}\text { Antimony } \\
\text { Arsenic }\end{array}$ & $\begin{array}{l}14 \\
0(0.018)\end{array}$ & $0(0.14)$ & $\begin{array}{l}14 \\
0(0.02)\end{array}$ \\
\hline $\begin{array}{l}\text { Arsenic } \\
\text { Asbestos }\end{array}$ & & & \\
\hline Asbestos & $\begin{array}{l}0(30,000 \mathrm{fi}- \\
\text { bers } / \mathrm{L})\end{array}$ & NA & \\
\hline Benzene & $0(1.18)$ & $0(71.28)$ & $O(1.2)$ \\
\hline Benzidine & $0(1.2 E-04)$ & $0(5.4 \mathrm{E}-04)$ & $0(1.5 \mathrm{E}-04)$ \\
\hline Benzo(a)anthracene & $0(2.8 \mathrm{E}-03)$ & $0(0.031)$ & \\
\hline Benzo(a)pyrene & $0(2.8 \mathrm{E}-03)$ & $0(0.031)$ & \\
\hline Benzo(k)fluoranthene & $0(2.8 \mathrm{E}-03)$ & $0(0.031)$ & \\
\hline 3.4-Benzofluoranthene & $0(2.8 \mathrm{E}-03)$ & $0(0.031)$ & \\
\hline Beryllium & $0(7.7 \mathrm{E}-03)$ & $0(0.13)$ & $0(8.1 \mathrm{E}-03)$ \\
\hline Bromoform & $0(4.38)$ & $0(363.5)$ & $0(4.4)$ \\
\hline Carbon tetrachloride & $0(0.254)$ & $0(4.42)$ & $\mathrm{O}(0.27)$ \\
\hline Chlordane & $0(5.8 \mathrm{E}-04)$ & $0(5.9 \mathrm{E}-04)$ & $0(0.03)$ \\
\hline \multicolumn{4}{|l|}{ Chlorinated benzenes } \\
\hline Monochlorobenzene & 20 (org) & NA & 700 \\
\hline 1,2-Dichlorobenzene & 2,667 & 17,432 & 3,150 \\
\hline 1,3-Dichlorobenzene & 400 & 2,600 & \\
\hline 1,4-Dichlorobenzene & 400 & 2,600 & \\
\hline $1,2,4,5$-Tetrachlorobenzene & 38 & 48 & \\
\hline Pentachlorobenzene & 74 & 85 & \\
\hline Hexachlorobenzene & $0(7.5 \mathrm{E}-04)$ & $0(7.7 \mathrm{E}-04)$ & \\
\hline \multicolumn{4}{|l|}{ Chlorinated ethanes } \\
\hline 1,2-Dichloroethane & $0(0.38)$ & $0(98.6)$ & $0(0.38)$ \\
\hline 1,1,1-Trichloroethane & 3,094 & 173,077 & 3,150 \\
\hline 1,1,2-Trichloroethane & $0(0.605)$ & $0(41.99)$ & $0(0.61)$ \\
\hline 1,1,2,2-Tetrachloroethane & $0(0.172)$ & $0(10.8)$ & $0(0.175)$ \\
\hline Hexachloroethane & $0(1.95)$ & $0(8.85)$ & $0(2.5)$ \\
\hline \multicolumn{4}{|l|}{ Chlorinated phenols } \\
\hline 2-Chlorophenol & 0.1 (org) $^{c}$ & NA & 175 \\
\hline 2,4-Dichlorophenol & 0.3 (org) $^{c}$ & NA & 105 \\
\hline 2,4,5-Trichlorophenol & 1.0 (org) $^{c}$ & NA & \\
\hline 2,4,6-Trichlorophenol & $0(2.1)$ & $0(6.5)$ & $0(3.2)$ \\
\hline Pentachlorophenol & $0(0.28)$ & $0(8.2)$ & $0(0.29)$ \\
\hline 3-Methyl-4-chlorophenol & 3,000 (org) $^{c}$ & NA & \\
\hline
\end{tabular}


Table 10.4. (continued)

\begin{tabular}{|c|c|c|c|}
\hline Chemical & $\begin{array}{c}\text { WQC for } \\
\text { aquatic } \\
\text { organisms and } \\
\text { drinking water }\end{array}$ & $\begin{array}{l}\text { WQC for } \\
\text { aquatic } \\
\text { organisms } \\
\text { alone }^{a}\end{array}$ & $\begin{array}{c}\text { WQC for } \\
\text { drinking water } \\
\text { alone }\end{array}$ \\
\hline \multicolumn{4}{|l|}{ Chloroalkyl ethers } \\
\hline bis-(Chloromethyl) ether & $0(1.6 \mathrm{E}-04)$ & $0(0.077)$ & $0(1.6 \mathrm{E}-04)$ \\
\hline bis-(2-Chloroethyl) ether & $0(0.031)$ & $0(1.42)$ & $0(0.032)$ \\
\hline $\begin{array}{l}\text { bis-(2-Chloroisopropyl) } \\
\text { ether }\end{array}$ & 1,389 & 174,400 & 1,400 \\
\hline Chlorodibromomethane & $0(0.412)$ & $0(34.2)$ & $0(0.417)$ \\
\hline Chloroform & $0(5.67)$ & $0(470.8)$ & $0(5.74)$ \\
\hline Chromium (III) & 33,300 & 673,077 & 35,000 \\
\hline Chrysene & $0(2.8 \mathrm{E}-03)$ & $0(0.031)$ & \\
\hline Copper & 1,000 (org) $^{c}$ & NA & \\
\hline DDD & $0(8.3 \mathrm{E}-04)$ & $\begin{array}{l}0 \\
(8.3 E-04)\end{array}$ & $0(0.15)$ \\
\hline DDE & $0(5.9 \mathrm{E}-04)$ & $\begin{array}{l}0 \\
(5.9 \mathrm{E}-04)\end{array}$ & $0(0.103)$ \\
\hline DDT & $0(5.9 \mathrm{E}-04)$ & $\begin{array}{l}0 \\
(5.9 E-04)\end{array}$ & $0(0.103)$ \\
\hline Dibenz(a,h)anthracene & $0(2.8 \mathrm{E}-03)$ & $0(0.031)$ & \\
\hline 3,3'-Dichlorobenzidine & $0(0.04)$ & $0(0.77)$ & $0(0.078)$ \\
\hline Dichlorobromomethane & $0(0.27)$ & $O(22.1)$ & $0(0.27)$ \\
\hline Dichlorodifluoromethant: & $0(5.67)$ & $0(470.8)$ & \\
\hline 1,1-Dichloroethylene & $0(0.06)$ & $0(3.2)$ & $O(0.058)$ \\
\hline \multicolumn{4}{|l|}{$\begin{array}{l}\text { Dichloropropanes/Dichl Jro } \\
\text { propenes }\end{array}$} \\
\hline cis-1,3-Dichloropropine & 10.4 & 1,691 & 10.5 \\
\hline trans-1,3-Dichloroprispene & 10.4 & 1,691 & 10.5 \\
\hline Dieldrin & $0(1.4 \mathrm{E}-04)$ & $\begin{array}{l}0 \\
(1.4 \mathrm{E}-04)\end{array}$ & $0(2.2 \mathrm{E}-03)$ \\
\hline 2,4-Dimethylphenol & 400 (org) $^{c}$ & NA & 200 \\
\hline 2,4-Dinitrotoluene & $0(0.11)$ & $0(9.1)$ & \\
\hline 1,2-Diphenylhydrazine & $0(0.041)$ & $0(0.54)$ & $0(0.044)$ \\
\hline Endosulfan $(a-, b-)$ & 0.932 & 1.99 & 1.8 \\
\hline Ethylbenzene & 3,120 & 28,718 & 3,500 \\
\hline Fluoranthene & 295.5 & 374.6 & 1,400 \\
\hline Fluorene & $1,275.6$ & $14,358.5$ & 1,400 \\
\hline Halomethanes & $0(5.67)$ & $0(470.8)$ & \\
\hline Heptachlor & $0(2.1 \mathrm{E}-04)$ & $\begin{array}{l}0 \\
(2.1 \mathrm{E}-04)\end{array}$ & $0(8.1 \mathrm{E}-03)$ \\
\hline Heptachlor epoxide & $0(1.0 \mathrm{E}-04)$ & $\begin{array}{l}0 \\
(1.0 \mathrm{E}-04)\end{array}$ & $0(3.8 \mathrm{E}-03)$ \\
\hline $\begin{array}{l}\text { Hexachlorobutadiene } \\
\text { Hexachlorocyclohexanes } \\
\text { (HC-CH) }\end{array}$ & $0(0.45)$ & $0(49.7)$ & $0(0.45)$ \\
\hline Alpha-HCCH & $0(0.004)$ & $0(0.013)$ & $0(5.5 \mathrm{E}-03)$ \\
\hline Beta-HCCH & $0(0.014)$ & $O(0.046)$ & $0(0.02)$ \\
\hline Gamma-HCCH & $0(0.019)$ & $0(0.063)$ & \\
\hline
\end{tabular}


Table 10.4. (continued)

\begin{tabular}{|c|c|c|c|}
\hline Chemical & $\begin{array}{l}\text { WQC for aquatic } \\
\text { organisms and } \\
\text { drinking water }\end{array}$ & $\begin{array}{c}\text { WQC for } \\
\text { aquatic } \\
\text { organisms alone }^{a} \\
\end{array}$ & $\begin{array}{c}\text { WQC for } \\
\text { drinking water } \\
\text { alone }^{b}\end{array}$ \\
\hline Hexachlorocyclopentadiene & 1 (org) $^{c}$ & NA & 245 \\
\hline Indeno( $(1,2,3-\mathrm{cd})$ pyrene & $0(2.8 \mathrm{E}-03)$ & $0(0.031)$ & \\
\hline Isophorone & $0(8.42)$ & 0 (599.7) & $0(8.5)$ \\
\hline Mercury & 0.151 & 0.153 & \\
\hline Methyl bromide & 48 & 4,020 & 49 \\
\hline Methyl chloride & $0(5.67)$ & $0(470.8)$ & \\
\hline Methylene chloride & $0(4.65)$ & $0(1,578)$ & $0(4.7)$ \\
\hline Nickel & 607 & 4,584 & 700 \\
\hline Nitrobenzene & 17.3 & 1,863 & 17.5 \\
\hline \multicolumn{4}{|l|}{ Nitrophenols } \\
\hline 2,4-Dinitrophenol & 69.7 & 14,264 & 70 \\
\hline 2,Methyl-4,6-dinitrophenol & 13.4 & 765 & \\
\hline \multicolumn{4}{|l|}{ Nitrosamines } \\
\hline n-Nitrosodimethylamine & $0(6.9 \mathrm{E}-04)$ & $0(8.12)$ & $0(6.8 \mathrm{E}-04)$ \\
\hline n-Nitrosodiphenylamine & $0(4.95)$ & $0(16.2)$ & $0(7.1)$ \\
\hline n-Nitrosopyrrolidine & $0(0.016)$ & $O(91.9)$ & \\
\hline Pentachlorobenzene & 74 & 85 & \\
\hline Phenol & 300 (org) $^{c}$ & $4,615,385$ & 21,000 \\
\hline \multicolumn{4}{|l|}{ Phthalate esters } \\
\hline Butylbenzyl phthalate & 2,984 & 5,202 & 7,000 \\
\hline Diethylphthalate & 22,631 & 118,019 & 10,500 \\
\hline Dimethylphthalate & 313,000 & $2,900,000$ & \\
\hline Di-n-butylphthalate & 2,715 & 12,100 & 3,500 \\
\hline Bis-2-ethylhexylphthalate & $0(1.8)$ & $0(5.9)$ & $0(2.5)$ \\
\hline $\begin{array}{l}\text { Polychlorinated biphenyls } \\
\quad(1016,1221,1242, \\
1254,1260)\end{array}$ & $0(4.4 \mathrm{E}-05)$ & $\begin{array}{l}0 \\
(4.5 \mathrm{E}-05)\end{array}$ & $0(4.5 E-03)$ \\
\hline $\begin{array}{l}\text { Polynuclear aromatic } \\
\text { hydrocarbons }\end{array}$ & $O(2.8 \mathrm{E}-03)$ & $\begin{array}{l}0 \\
(3.11 \mathrm{E}-02)\end{array}$ & \\
\hline Pyrene & 956.7 & $10,769.2$ & 1,500 \\
\hline $\begin{array}{l}\text { 2,3,7,8-Tetrachlorodibenzo- } \\
\text { p-dioxin }\end{array}$ & 0 (1.3E-08) & $\begin{array}{l}0 \\
(1.4 \mathrm{E}-08)\end{array}$ & $0(2.2 \mathrm{E}-07)$ \\
\hline $1,2,4,5$-Tetrachlorobenzene & 38 & 48 & \\
\hline Tetrachloroethylene & $0(0.8)$ & $0(8.9)$ & \\
\hline Thallium & 13 & 48 & \\
\hline Toluene & $6,764.8$ & 201,294 & 70,000 \\
\hline Toxaphene & $0(7.3 \mathrm{E}-04)$ & $\begin{array}{l}0 \\
(7.5 \mathrm{E}-04)\end{array}$ & $0(0.032)$ \\
\hline Trichloroethylene & $0(2.7)$ & $0(80.7)$ & \\
\hline Trichlorofluoromethane & $0(5.67)$ & $0(470.8)$ & \\
\hline Vinyl chloride & $0(2)$ & 0 (525) & \\
\hline Zinc & 5,000 (org) $^{c}$ & NA & \\
\hline
\end{tabular}

The criterion value of zero for all potential carcinogens is listed in the table. Concentrations in parentheses for potential carcinogens correspond to a risk of $10^{-6}$.

These adjusted criteria, for drinking water ingestion only, are estimated using a reference dose or carcinogen potency factor and a body weight of $70 \mathrm{~kg}$ and water ingestion rate of $2 \mathrm{~L} /$ day.

${ }^{c}$ Criteria designated as organoleptic are based on taste and odor effects, not human health effects. Healthbased WQC are not available for these chemicals.

Read as $1.3 \times 10^{-4}$.

NA $=$ not available.

Source: EPA 1991a. EPA Region IV Criteria Charts (October). 
Table 11.5. Tennessee water quality criterla for designated water uses $(\mu \mathrm{g} / \mathrm{L})^{2}$

\begin{tabular}{|c|c|c|c|c|}
\hline \multirow{2}{*}{ Chemical } & \multirow{2}{*}{$\begin{array}{c}\text { Domestic } \\
\text { Water Supply }\end{array}$} & \multirow[b]{2}{*}{ Recreation $^{b}$} & \multicolumn{2}{|c|}{ Fish and Aquatic Life } \\
\hline & & & $\mathrm{CMC}^{c}$ & $\operatorname{CCC}^{d}$ \\
\hline Acenaphthylene & NA & 0.3 & NA & NA \\
\hline Acrolein & NA & 780 & NA & NA \\
\hline Acrylonitrile & NA & 6.7 & NA & NA \\
\hline Aldrin & NA & 0.0014 & 3 & NA \\
\hline Anthracene & NA & 0.03 & NA & NA \\
\hline Antimony & NA & 4310 & NA & NA \\
\hline Arsenic (III) & NA & NA & 360 & 190 \\
\hline Arsenic (total) & 50 & NA & NA & NA \\
\hline Benzene & 5 & 710 & NA & NA \\
\hline Benzo(a)anthracene & NA & 0.3 & NA & NA \\
\hline Benzo(a)pyrene & NA & 0.3 & NA & NA \\
\hline 3,4-Benzofluoranthene & NA & 0.3 & NA & NA \\
\hline Benzo(k)fluoranthene & NA & 0.3 & NA & NA \\
\hline Beryllium & NA & 1.3 & NA & NA \\
\hline g-BHC (Lindane) & 4 & 0.63 & 2 & 0.08 \\
\hline Bis(2-chloroethyl)ether & NA & 14 & NA & NA \\
\hline $\begin{array}{l}\text { Bis(2- } \\
\text { ethylhexyl)phthalate }\end{array}$ & NA & 59 & NA & NA \\
\hline Boron & NA & NA & NA & NA \\
\hline \multicolumn{5}{|l|}{ Bromoform - } \\
\hline Cadmium & 10 & NA & $4^{e}$ & $1^{e}$ \\
\hline Carbon tetrachloride & 5 & 44 & NA & NA \\
\hline Chlordane & NA & 0.006 & 2.4 & 0.0043 \\
\hline \multicolumn{5}{|l|}{ Chloroform - } \\
\hline (Trichloromethane) & NA & 4700 & NA & NA \\
\hline Chromium (III) & NA & 670,000 & NA & NA \\
\hline Chromium (hexavalent) & NA & NA & 16 & 11 \\
\hline Chromium (total) & 50 & NA & NA & 100 \\
\hline Chrysene & NA & 0.03 & NA & NA \\
\hline Cobalt & NA & NA & NA & NA \\
\hline Copper & NA & NA & $18^{e}$ & $12^{e}$ \\
\hline Cyanide & NA & NA & 22 & 5.2 \\
\hline $4,4^{\prime}-\mathrm{DDT}$ & NA & 0.006 & 1.1 & 0.001 \\
\hline 4,4'-DDE & NA & 0.006 & NA & NA \\
\hline $4,4^{\prime}-\mathrm{DDD}$ & NA & 0.008 & NA & NA \\
\hline 1,2-Dichlorobenzene & NA & 17,000 & NA & NA \\
\hline 1,3-Dichlorobenzene & NA & 2600 & NA & NA \\
\hline $\begin{array}{l}\text { 1,4-Dichlorobenzene- } \\
\text { (para-Dichlorobenzene) }\end{array}$ & 75 & 2,600 & NA & NA \\
\hline Dichlorobromomethane & NA & 4700 & NA & NA \\
\hline
\end{tabular}


Table 10.5. (continued)

Chemical

Fish and Aquatic Life

\begin{tabular}{|c|c|c|c|c|}
\hline & $\begin{array}{c}\text { Domestic } \\
\text { Water Supply }\end{array}$ & Recreation $^{b}$ & $\mathrm{CMC}^{c}$ & $\operatorname{CCC}^{d}$ \\
\hline 1,2-Dichloroethane & 5 & 990 & NA & NA \\
\hline 1,1-Dichloroethylene & 7 & 32 & NA & NA \\
\hline 1,3-Dichloropropylene & NA & 1700 & NA & NA \\
\hline Dieldrin & NA & 0.0014 & 2.5 & 0.0019 \\
\hline Diethyl phthalate & NA & 20,000 & NA & NA \\
\hline Dimethyl phthalate & NA & 00,000 & NA & NA \\
\hline Di-n-butyl phthalate & NA & 12,000 & NA & NA \\
\hline 2,4-Dinitrophenol & NA & 14,000 & NA & NA \\
\hline 2,4-Dinitrotoluene & NA & 42 & NA & NA \\
\hline Dioxin & NA & 0.000001 & NA & NA \\
\hline$a$-Endosulfan & NA & 2.0 & 0.22 & 0.056 \\
\hline b-Endosulfan & NA & 2.0 & 0.22 & 0.056 \\
\hline Endrin & 0.2 & NA & 0.18 & 0.0023 \\
\hline Ethylbenzene & NA & 29,000 & NA & NA \\
\hline Fluoranthene & NA & 54 & NA & NA \\
\hline Fluorene & NA & 0.03 & NA & NA \\
\hline Heptachlor & NA & 0.002 & 0.52 & 0.0038 \\
\hline Heptachlor epoxide & NA & 0.001 & 0.52 & 0.0038 \\
\hline Hexachlorobenzene & NA & 0.007 & NA & NA \\
\hline Hexachlorobutadiene & NA & 500 & NA & NA \\
\hline $\begin{array}{l}\text { Hexachlorocyclo- } \\
\text { pentadiene }\end{array}$ & NA & NA & NA & NA \\
\hline Hexachloroethane & NA & 89 & NA & NA \\
\hline Lead & 50 & NA & $82^{e}$ & $\mathbf{3}^{e}$ \\
\hline Lindane ( $g-\mathrm{BHC})$ & 4 & 0.63 & 2 & 0.08 \\
\hline Lithium & NA & NA & NA & NA \\
\hline Manganese & $50^{f}$ & NA & NA & NA \\
\hline Mercury & 2 & 0.15 & 2.4 & 0.012 \\
\hline $\begin{array}{l}\text { Methyl chloride - } \\
\text { (Chloromethane) }\end{array}$ & NA & 4700 & NA & NA \\
\hline $\begin{array}{l}\text { 2-Methyl-4,6-dinitro-phe- } \\
\text { nol }\end{array}$ & & & & \\
\hline (4,6-Dinitro-o-cresol) & NA & 765 & NA & NA \\
\hline $\begin{array}{l}\text { Methylene chloride - } \\
\text { (Dichloromethane) }\end{array}$ & NA & 16,000 & NA & NA \\
\hline n-Butylbenzyl phthalate & NA & NA & NA & NA \\
\hline Nickel & NA & 4600 & 1400 & 160 \\
\hline Nitrobenzene & NA & 1900 & NA & NA \\
\hline Pentachlorophenol & NA & NA & $20^{g}$ & $13^{g}$ \\
\hline Phenanthrene & NA & 0.03 & NA & NA \\
\hline
\end{tabular}




\begin{tabular}{|c|c|c|c|c|}
\hline \multirow{2}{*}{ Chemical } & \multirow{2}{*}{$\begin{array}{c}\text { Domestic } \\
\text { Water Supply }\end{array}$} & \multirow[b]{2}{*}{ Recreation $^{b}$} & \multicolumn{2}{|c|}{ Fish and Aquatic Life } \\
\hline & & & $\mathrm{CMC}^{c}$ & $\mathrm{CCC}^{d}$ \\
\hline \multicolumn{5}{|l|}{$\begin{array}{l}\text { Polychlorinated } \\
\text { biphenyls }\end{array}$} \\
\hline PCB-1242 & NA & 0.0005 & NA & NA \\
\hline PCB-1254 & NA & 0.0005 & NA & NA \\
\hline PCB-1221 & NA & 0.0005 & NA & NA \\
\hline PCB-1232 & NA & 0.0005 & NA & NA \\
\hline PCB-1248 & NA & 0.0005 & NA & NA \\
\hline PCB-1260 & NA & 0.0005 & NA & NA \\
\hline PCB-1016 & NA & 0.0005 & NA & NA \\
\hline PCBs (total) & NA & 0.001 & NA & 0.001 \\
\hline Pyrene & NA & 0.03 & NA & NA \\
\hline Selenium & 10 & NA & 20 & 5 \\
\hline Silver & 50 & NA & $4^{e}$ & NA \\
\hline $\begin{array}{l}1,1,2,2- \\
\text { Tetrachloroethane }\end{array}$ & NA & 110 & NA & NA \\
\hline Tetrachloroethylene & NA & 88 & NA & NA \\
\hline Toluene & NA & 300,000 & NA & NA \\
\hline Toxaphene & 5 & 0.008 & 0.73 & 0.0002 \\
\hline 1,1,1-Trichloroethane & 200 & 170,000 & NA & NA \\
\hline 1,1,2-Trichloroethane & NA & 420 & NA & NA \\
\hline Trichloroethylene & 5 & 807 & NA & NA \\
\hline 2,4,6-Trichlorophenol & NA & 6.5 & NA & NA \\
\hline Vanadium & NA & NA & NA & NA \\
\hline Vinyl chloride & 2 & 5250 & NA & NA \\
\hline Zinc & $5000^{f}$ & NA & $117^{e}$ & $106^{e}$ \\
\hline
\end{tabular}

${ }^{a}$ Rules of the TDEC, Chapter 1200-4-3.

${ }^{b}$ Based on a $10^{-5}$ risk level "or carcinogens.

${ }^{\circ} \mathrm{CMC}=$ criterion maximur concentration.

${ }^{d} \mathrm{CCC}=$ criterion continuous concentration.

${ }^{e}$ Calculated for a water hardness of $100 \mathrm{mg} / \mathrm{L}$, the approximate average hardness of the Clinch River.

SSecondary MCL; Rules of the TDEC, Chapter 1200-5-1.12.

${ }^{g} \mathrm{At} \mathrm{pH}=7.8$. 
standards are promulgated for each use category. Under the Tennessee Water Quality Control Act, the Tennessee Water Quality Control Board has classified the Clinch River for domestic water supply, industrial water supply, fish and aquatic life, recreation, irrigation, and livestock watering and wildlife uses (Chap. 1200-4-4 of the Rules of the TDEC). The tributaries to the Clinch River have various use classifications, which need to be analyzed on a site-specific basis. The standards also state that "all other streams, named and unnamed, which have not been specifically noted shall be classified for fish and aquatic life, recreation, irrigation, and livestock watering and wildlife uses." TDEC has promulgated a change in the use classification that adds recreation as a category for all segments of rivers and streams that are not currently classified as such (effective August 1991).

Table 10.6 lists federal WQC for the protection of freshwater aquatic life. EPA Region IV has also revised these WQC based on current toxicity and bioaccumulation data for aquatic organisms, and these appear in Table 10.6 as well. When the designated use classification requires protection of aquatic life or when environmental factors are being considered at a D\&D site, a WQC for the protection of aquatic life that is more stringent than the SDWA MCL may be appropriate for cleanup. TDEC has promulgated WQC for the protection of aquatic organisms, effective Aug. 30, 1991; these are identical, for the most part, to the federal WQC and are listed in Table 10.5.

\subsubsection{Air}

Primary National Ambient Air Quality Standards (NAAQS) for six chemicals appear in 40 CFR 50; these standards are based on the direct health effects of those chemicals to sensitive groups, with no economic factors considered. The NAAQS take into consideration all sources of exposure to a given chemical and establish ceilings that are not to be exceeded in the United States. Only major new sources, or major modifications to existing sources, must attain NAAQS. Although the ORR is in a Tennessee state "attainment" area, it is unlikely that any emissions from D\&D cleanup will be considered a "major" source under present federal law. EPA has, however, listed "site remediation" as a major source category under Section 112(c) of the CAA (57 FR 31576, July 16, 1992). A regulatory schedule was issued in September 1992 for promulgating emission standards under Section 112(e) of the CAA for these newly-listed major source categories.

NAAQS are established as the criteria state and local governments must plan to achieve and, thus, are not directly enforceable. Under $\$ 110$ of the CAA, states are required to implement regulations to achieve the NAAQS. The ambient air quality standards established by the TDEC Division of Air Pollution Control appear in Chap. 1200-3-3 of the Rules of the TDEC and are identical to the federal primary NAAQS (see Table 10.2). The ambient standards of 1200-3-3 are translated into source-specific emission limitations (Rules of the TDEC, Chaps. 1200-3-4 to 1200-3-21) that must be considered legally applicable if they apply to any of the D\&D activities or technologies selected. Tennessee state air emission standards are considered "hybrid" regulations and will be summarized as actionspecific regulations in Sect. 10.5.3; they would have to be analyzed on a site- or technology-specific basis depending on the type of D\&D action planned for a site.

National Emission Standards for Hazardous Air Pollutants (NESHAPs) for various industrial sources that emit one of several pollutants are established in 40 CFR 61. Most of the NESHAPs are generally not legally applicable to cleanup 
Table 10.6. Federal ambient water quality criterla for the protection of freshwater organisms

\begin{tabular}{|c|c|c|}
\hline Chemical & $\begin{array}{l}\text { Maximum } \\
(\mu g / L)^{a}\end{array}$ & $\begin{array}{c}\text { 24-h } \\
(\mu g / L)^{b}\end{array}$ \\
\hline Aldrin & 3 & NA \\
\hline Aluminum & $750^{c}$ & $87^{c}$ \\
\hline Ammonia & \multicolumn{2}{|c|}{$\begin{array}{l}\text { Concentrations are temperature and } \\
\text { pH dependent }\end{array}$} \\
\hline Arsenic (III) & 360 & 190 \\
\hline Cadmium & $1.8^{d}$ & $0.66^{d}$ \\
\hline Chlordane & 2.4 & $4.3 \mathrm{E}-03^{e f}$ \\
\hline Chloride & 860,000 & 230,000 \\
\hline Chlorine & 19 & 11 \\
\hline Chlorpyrifos & 0.083 & 0.041 \\
\hline Chromium (VI) & 16 & 11 \\
\hline (III) & $984^{d}$ & $117^{d}$ \\
\hline Copper & $9.22^{d}$ & $6.54^{d}$ \\
\hline Cyanide & 22 & 5.2 \\
\hline dichlorodiphenyl-trichloroethane (DDT) & 1.1 & $1.0 \mathrm{E}-03^{g}$ \\
\hline Demeton & $\mathrm{NA}$ & 0.1 \\
\hline Dieldrin & 2.5 & $1.9 \mathrm{E}-03^{f}$ \\
\hline Endosulfan & 0.22 & 0.056 \\
\hline Endrin & 0.18 & $2.3 \mathrm{E}-03^{f}$ \\
\hline Guthion & NA & 0.01 \\
\hline Heptachlor & 0.52 & $3.8 \mathrm{E}-03^{f}$ \\
\hline Heptachlor epoxide & 0.52 & $3.8 \mathrm{E}-03^{f}$ \\
\hline $\begin{array}{l}\text { Hexachlorocyclohexaness (HCCH) } \\
\text { gamma-HCCH (Lindane) }\end{array}$ & 2 & 0.08 \\
\hline Hydrogen sulfide & NA & 2 \\
\hline Iron & NA & 1,000 \\
\hline Lead & $33.8^{d}$ & $1.32^{d}$ \\
\hline Malathion & NA & 0.1 \\
\hline Mercury & 2.4 & $0.012^{f}$ \\
\hline Methoxychlor & NA & 0.03 \\
\hline Mirex & NA & $1.0 \mathrm{E}-03$ \\
\hline Nickel & $789^{d}$ & $88^{d}$ \\
\hline Parathion & 0.065 & 0.013 \\
\hline Pentachlorophenol & $3.32^{h}$ & $2.1^{h}$ \\
\hline pH & NA & $6.5-9$ \\
\hline Polychlorinated bipheryls & NA & $0.014^{g}$ \\
\hline Selenium (inorganic selenite) & 20 & 5 \\
\hline Silver & $1.23^{d}$ & NA \\
\hline Sulfides & NA & 2 \\
\hline Zinc & $65^{d}$ & $59^{d}$ \\
\hline
\end{tabular}

${ }^{a}$ One-hour average conceniration not to be exceeded more than once every 3 years.

bour-day average concentration not to be exceeded more than once every 3 years.

pH 6.5-9.0.

Water hardness dependent criterla $\left(50 \mathrm{mg} / \mathrm{L}\right.$ as $\mathrm{CaCO}_{3}$ ).

Read as $4.3 \times 10^{-3}$.

$f_{\text {Based on marketability of fish. }}$

ginal residue value based on wildlife feeding study.

pH dependent criteria.

Source: EPA 1991a. Environmental Protection Agency Region IV Criteria Chart (October). 
at D\&D or CERCLA sites because they regulate particular types of sources that would not be expected to be found at these sites. However, the NESHAPs for asbestos and radionuclides should be considered as potential "hybrid" regulations on a site- or technology-specific basis depending on the D\&D actions planned at a site. The NESHAPs for radionuclides is discussed in Sect. 10.4.2.

The CAA Amendments of 1990 establish a list of 189 additional hazardous air pollutants for which technology-based standards must be promulgated. These will be applicable to categories of emission standards rather than to the substances emitted. No regulatory schedule is avallable yet for promulgation of these technology-based standards (Houlberg et al. 1992).

\subsubsection{Soil}

Very little legislation or guidance is avallable governing cleanup criteria for contaminated soils. RCRA has addressed land disposal of treated hazardous wastes in its land disposal restrictions (40 CFR 268) and these are addressed as action-specific regulations in Sect. 10.5.2. If a site is identified as a RCRA Sect. $3004(u)$ SWMU, or if RCRA-characteristic or RCRA-listed hazardous waste as defined in 40 CFR 261 is present at the site, it is subject to RCRA corrective action regulations. The proposed RCRA corrective action regulations address risk-based cleanup standards for soils (55 FR 30798); these are briefly discussed in Sect. 10.5.2. Treatment standards for contaminated soil and debris at CERCLA sites are discussed in Sect. 10.5.2.

The regulations found in the TSCA contain storage, disposal, and cleanup requirements for materials contaminated with PCBs. These regulations limit concentrations of PCBs disposed of in soil to $50 \mathrm{ppm}$ and require that any soils containing concentrations of PCBs greater than $50 \mathrm{ppm}$ ( 40 CFR 761.60) be incinerated (40 CFR 761.70) or stored in a chemical waste landfill (40 CFR 761.75). TSCA also specifies requirements that must be achieved for PCBs disposed of by incineration (40 CFR 761.70), in a chemical waste landfill (40 CFR 761.75), or by other disposal methods [40 CFR 761.60(a)(5)(iii)]. A further discussion of the TSCA requirements appears in Sect. 10.5.6.

\subsubsection{Nonregulatory Guidance}

EPA has suggested cleanup values for lead in soils based on studies of blood lead levels in exposed children. The EPA OSWER Directive 9355.4-02 (dated Sept. 7,1989 ) recommends a cleanup level for soils of 500-1000 ppm lead.

Although not a legal standard, EPA has published a TSCA PCB spill cleanup policy (52 FR 10688) that recommends cleanup standards for PCBs of 25-50 ppm for sites with restricted access; a $10-\mathrm{ppm}$ cleanup level is recommended for residential and unrestricted access rural areas. In this latter case, a 10-inch cap of clean soil must cover the site. In the EPA guidance report for RAs at Superfund sites containing PCBs, preliminary remediation goals are set at $1 \mathrm{ppm}$ for residential land use (a risk of $10^{-5}$ ) and between 10 and $25 \mathrm{ppm}$ for industrial and/or remote areas (a risk of $10^{-4}$ ) (EPA 1990). Alternatives should reduce concentrations to these levels or limit exposures. EPA also presents an approach to deriving cleanup levels of PCBs in sediments (EPA 1990). This approach results in "sediment quality criteria" as a function of organic carbon concentrations and is meant to protect wildlife consumers of freshwater benthic species. 
The TSCA-FFCA between the DOE and EPA focuses on resolving compliance issues related to the regulation of PCBs under TSCA (40 CFR 761) at DOE uranium enrichment plants, such as the K-25 Site, and at their support facilities. The TSCA-FFCA was signed, effective Feb. 20, 1992.

In the absence of federally or state-promulgated standards, or in the case where standards are not adequately protective, EPA states a preference for RfDs or reference concentrations (RFCs) for systemic toxicants, and CSFs for carcinogens or Office of Drinking Water (ODW) Health Advisories (HAs) (EPA 1988) for drinking water contarninants. The RfDs, RfCs, and CSFs are available through IRIS (EPA 1991b) and the EPA Health Effects Assessment Summary Tables (EPA 1992).

The EPA ODW has developed nonregulatory HAs for concentrations of noncarcinogenic contaminants in drinking water at which no adverse health effects would be expected to occur. E:PA uses the lifetime HA (for noncarcinogens only) to develop MCLs and MCLCis; HAs will most likely represent future MCL proposals. 


\subsection{RADIATION PROTECTION STANDARDS}

Very few standards are available that are legally applicable to the cleanup of radioactively contaminated media at ORR D\&D sites. The AEA and its amendments delegated authority for control of nuclear energy to DOE, NRC, and EPA. In addition, certain states have regulatory authority and programs for radioactive waste. EPA's regulations are derived from several other statutes as well, and cover many types of activities and all types of radioactive materials, including naturally occurring and accelerator-produced radioactive material (NARM). NRC licenses the possession and use of various types of radioactive materials at certain types of facilities. Tennessee is an NRC-agreement state and, as such, has its own authority and licensing regulations. In addition, Tennessee enforces NARM standards.

$D O E$ is authorized to control all types of nuclear materials at sites under its jurisdiction and is exempt from NRC licensing and regulatory requirements; therefore, NRC regulations are not considered to be legally applicable to D\&D activities at DOE facilities. DOE regulations for handling and cleanup of radioactive materials are outlined in a series of internal DOE Orders that are binding to DOE contractors.

Because a complete characterization of the identity and quantity of radioactive waste at ORR D\&D sites has not been completed, all of the available EPA regulations will be presented here, as well as the numerical NRC values. The proper definition of "mixed LLW and hazardous waste" has caused considerable debate with regard to dual jurisdiction by EPA and NRC. However, EPA has published a clarification of the problem ( 53 FR 37045, Sept. 23, 1988), as did DOE previously [52 FR 15937, May 1, 1987 and DOE Order 5400.3 (Hazardous and Radioactive Mixed Waste Program, dated Feb. 22, 1989)]. In effect, mixed wastes are those containing a RCRA hazardous waste as defined in 40 CFR 261 and a radioactive waste subject to the AEA. RCRA regulations apply to the hazardous component of the waste, and AEA regulations apply to the radioactive component. When the application of both standards is conflicting or inconsistent, RCRA yields to the AEA. Tennessee received final authorization to regulate radioactive mixed waste on July 3, 1986 (53 FR 37045, Sept. 23, 1988); however, the state has not implemented any regulations or guidance related to the handling of mixed waste (West 1991). On May 26, 1992, EPA published in the Federal Register (57 FR 22024) a notice, proposing to find that DOE has made all but one of the demonstrations required in its application, under RCRA rules in 40 CFR 268.5, for a one-year, case-by-case extension of the May 8, 1992, effective date of the LDRs applicable to certain mixed wastes generated or stored at 31 DOE facilities. Comments were due back to EPA by July 27, 1992, and no official final action has been taken on this proposal as yet. In June 1992, EPA and DOE signed the LDR-FFCA/ORR to bring mixed waste generation and storage facilities on the reservation into compliance with environmental law. Under the agreement, effective immediately, DOE-OR will submit plans that will include treatment and storage options for LDR mixed wastes to meet the requirements of RCRA. The plans, to be prepared by DOE, will include proposals for waste minimization, treatment studies, technology development, facility construction, and schedules for future treatment. The LDR-FFCA/ORR allows DOE ORR facilities to continue to generate and store mixed wastes while addressing LDR mixed waste compliance 
issues. The mixed wastes covered under the LDR-FFCA/ORR include flammable and corrosive liquids, solvents, paint waste, waste oils and organics, and solid mixed wastes.

\subsubsection{Generic Below-|Regulatory-Concern Levels for Radioactive Wastes}

The NRC has developed the concept of a risk threshold to distinguish those radioactive materials that do not warrant regulation to the same degree as other radioactive materials $t c$ ensure adequate protection of the public and the environment. The low levels of risk posed by these radioactive materials have been termed BRC. The NRC pıblished a policy statement (55 FR 27522, July 3, 1990) to guide its decisions on exemptions of BRC materials from the full scope of the NRC's regulatory prograin.

The BRC policy was established, in part, to ensure adequate and consistent decisions on acceptable risks posed by decontaminated and decommissioned nuclear facilities. The BFC concept is based on the premise that risk from doses to individuals for practices that are under consideration for exemption are comparable to the voluritary and involuntary risks commonly accepted by the general public from radiation exposures in their daily lives (i.e., natural background radiation, which results in risks corresponding to doses on the order of 5-10 mrem/year or an annual risk of about $10^{-6}$ ). This level of risk is within the risk-based guidelines of $10^{-4}$ to $10^{-7}$ established by the EPA.

Based on these considerations, the NRC policy states that the average dose to individuals in a critical group should be less than $10 \mathrm{mrem} / \mathrm{year}$ (a hypothetical incremental annual risk of $5 \times 10^{-6}$ ) for each exempted practice. In addition, for such practices that result in widespread distribution of radioactive materials (e.g., consumer products or recycled materials), the NRC recommends an interim dose criterion for individuals in the critical group of 1 mrem/year (a risk of $5 \times 10^{-7}$ ). These individual annual doses translate to a lifetime risk from continuing annual exposures in the order of $10^{-4}$ and $10^{-5}$, respectively.

The adoption of the 13RC policy generated widespread public concern over its implications and a general dissatisfaction with the process the NRC used to develop the BRC polic. $y$. Because of these concerns, the NRC declared a moratorium on implementation of the BRC policy and initiated a consensus process to provide advice to the NRC on the full range of issues related to the BRC policy (56 FR 36068, July 30, 1991).

EPA utilizes a similar policy in setting de minimis risk-based levels for exemption of hazardous chemicals from RCRA Subtitle C regulation (57 FR2 1450 , May 20, 1992). Health-bátsed exemption levels are proposed for systemic toxicants and carcinogens based o:n RfDs and Risk Specific Doses (RSDs), respectively. EPA has proposed a risk level. of $10^{-6}$ to establish exemption criteria for Groups A, B, and C carcinogens (see 51 FR 33992, September 24, 1986, for a discussion of EPA's carcinogen classiffcation scheme).

As of September 199:2, the NRC has been unable to reach consensus on a BRC policy acceptable to the general public and has no plans to pursue further action on this initiative, nor dors it plan to enforce the BRC policy issued in July 1990. Instead, it will focus on developing wastestream- and media-specific risk-based BRC levels, similar to E:PA's de minimis levels, through a series of individual rulemakings. Until these: individual rules are promulgated, the lack of a generic BRC policy for radioaclive wastes that would guide cleanup and release of 
radioactive components at $\mathrm{D} \& \mathrm{D}$ sites has hampered $\mathrm{D} \& \mathrm{D}$ activities at $\mathrm{DOE}$ facilities. At present, internal DOE Orders (see Sect. 10.4.5) provide the only guidance for such cleanup activities.

\subsubsection{EPA Regulations}

EPA has promulgated MCLs for radionuclides in community water systems (see Table 10.7). These MCLs appear in two forms-concentration limits for certain alpha-emitting radionuclides (40 CFR 141.15) and an annual dose limit for the ingestion of certain beta- and gamma-emitting radionuclides (40 CFR 141.16). MCLs and MCLGs were proposed for radon and uranium and reproposed for ${ }^{226} \mathrm{Ra}$ and ${ }^{228} \mathrm{Ra}$, beta emitters, and photon emitters on July 18,1991 , and are included in Table 10.7. Final promulgation of the concentration limits is not expected until April 1993. As with the chemical-specific MCLs, these concentration limits may be relevant and appropriate for cleanup of contaminated groundwater at the ORR.

Table 10.7. Radionuclide-specific standards under the SDWA for groundwater and surface water contamination at the Oak Ridge Reservation

\begin{tabular}{|c|c|c|}
\hline Radionuclide & $\begin{array}{l}\text { Current SDWA } \\
\text { MCLs }^{a}\end{array}$ & $\begin{array}{c}\text { Proposed SDWA } \\
\text { MCLs }^{b}\end{array}$ \\
\hline $\begin{array}{l}\text { Radium }^{c} \\
\text { Gross alpha }^{d} \\
\text { Gross beta } \\
\text { Natural uranium } \\
\text { Radon-222 }\end{array}$ & $\begin{array}{l}5 \mathrm{pCi} / \mathrm{L} \\
15 \mathrm{pCl} / \mathrm{L} \\
4 \mathrm{mrem} / \text { year }\end{array}$ & $\begin{array}{l}20 \mathrm{pCi} / \mathrm{L} \\
15 \mathrm{pCl} / \mathrm{L} \\
4 \mathrm{mrem} / \text { year } \\
20 \mu \mathrm{g} / \mathrm{L}^{e} \\
300 \mathrm{pCl} / \mathrm{L}\end{array}$ \\
\hline $\begin{array}{l}\text { Strontium-90 } \\
\text { Tritium }\end{array}$ & $\begin{array}{l}8 \mathrm{pCi} / \mathrm{L} \\
20.000 \mathrm{pCl} / \mathrm{L}\end{array}$ & $\begin{array}{l}8 \mathrm{pCi} / \mathrm{L} \\
20,000 \mathrm{pCi} / \mathrm{L}\end{array}$ \\
\hline $\begin{array}{l}\text { All other manmade } \\
\text { radionuclides }\end{array}$ & $4 \mathrm{mrem} /$ year $f$ & $4 \mathrm{mrem} /$ year $f$ \\
\hline
\end{tabular}

aSDWA MCL = Safe Drinking Water Act maximum contaminant level.

${ }^{b}$ Proposed rule, July 18, 1991 (56 FR 33050); final rule expected April 1993.

The present MCL applies to combined ${ }^{226} \mathrm{Ra}$ and ${ }^{228} \mathrm{Ra}$; the proposed MCL applies to each separately.

${ }^{d}$ The present MCL excludes radon and uranium but includes ${ }^{2{ }^{2}} \mathrm{Ra}$; the proposed MCL excludes all three radionuclides.

AApproximately equal to $30 \mathrm{pCi} / \mathrm{L}$.

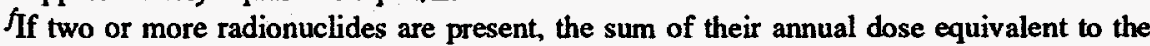
total body or to any organ shall not exceed $4 \mathrm{mrem} / \mathrm{year}$.

Table 10.8 lists EPA and DOE radiation protection standards that are described below. Subpart H of 40 CFR 61 addresses atmospheric radionuclide emissions from DOE facilities and may be applicable to airborne emissions during D\&D activities at ORR. EPA has issued a final NESHAP rule (54 FR 51654, Dec. $15,1989)$ that limits emissions of radionuclides to the ambient air from DOE facilities to amounts that would not cause any member of the public to receive an effective dose equivalent of $10 \mathrm{mrem} /$ year (40 CFR 61.92). 
Table 10.8. Radiation protection standards that may be appllcable to Oak Ridge Reservation D\&D actlvitles

\begin{tabular}{|c|c|c|c|}
\hline Regulation & Applicab llity & Exposure conditions & Standard \\
\hline 40 CFR 61 & $\begin{array}{l}\text { National Emission } \\
\text { Standards for Hazardous Air } \\
\text { Pollutants for DOE facillities }\end{array}$ & $\begin{array}{l}\text { Public exposure, } \\
\text { airborne emissions }\end{array}$ & $10 \mathrm{mrem} /$ year \\
\hline 40 CFR 141 & $\begin{array}{l}\text { Drinking water maximum } \\
\text { contaminznt levels }\end{array}$ & $\begin{array}{l}\text { Community water } \\
\text { systems, gross beta }\end{array}$ & $4 \mathrm{mrem} /$ year \\
\hline 40 CFR 191 & $\begin{array}{l}\text { Spent nuclear fuel, high- } \\
\text { level and transuranic wastes }\end{array}$ & $\begin{array}{l}\text { Public exposure, } \\
\text { all sources }\end{array}$ & $\begin{array}{l}25 \text { mrem/year } \\
\text { (total body) } \\
75 \text { mrem } \\
\text { (thyroid) }\end{array}$ \\
\hline \multirow[t]{3}{*}{$\begin{array}{l}\text { DOE Order } \\
5400.5^{\mathbf{a}}\end{array}$} & $\begin{array}{l}\text { Radiation Protection of the } \\
\text { Public ancl the Environment }\end{array}$ & $\begin{array}{l}\text { Public exposure, all } \\
\text { sources }\end{array}$ & $100 \mathrm{mrem} / \mathrm{year}$ \\
\hline & & $\begin{array}{l}\text { Temporary exemption, } \\
\text { maximum limit }\end{array}$ & $500 \mathrm{mrem} /$ year \\
\hline & & $\begin{array}{l}\text { Aquatic organism expo- } \\
\text { sure, absorbed dose }\end{array}$ & 1 Taja \\
\hline \multirow[t]{2}{*}{$\begin{array}{l}\text { DOE Order } \\
5820.2 \mathrm{~A}\end{array}$} & $\begin{array}{l}\text { Radioactive Waste } \\
\text { Management }\end{array}$ & $\begin{array}{l}\text { Public exposure, all } \\
\text { sources, excluding air }\end{array}$ & 25 mrem/year \\
\hline & & $\begin{array}{l}\text { Public exposure, atmo- } \\
\text { spheric releases }\end{array}$ & 10 mrem/year \\
\hline \multirow[t]{2}{*}{$\begin{array}{l}\text { DOE Order } \\
5480.11^{b}\end{array}$} & $\begin{array}{l}\text { Radiation Protection for } \\
\text { Occupational Workers }\end{array}$ & $\begin{array}{l}\text { Worker exposure limits, } \\
\text { continuous exposure }\end{array}$ & $\begin{array}{l}5 \mathrm{rem} / \text { year, } \\
\text { cancer effects } \\
50 \text { rem/year, } \\
\text { noncancer } \\
\text { effects, any } \\
\text { organ or tissue }\end{array}$ \\
\hline & & $\begin{array}{l}\text { Public exposures, con- } \\
\text { trolled areas, effective } \\
\text { dose equivalent }\end{array}$ & $100 \mathrm{mrem} /$ year \\
\hline
\end{tabular}

DOE plans to propose this order as 10 CFR 834 in May 1993.

bProposed as 10 CFR 835 (56 FR 64334, Dec. 9, 1991); final rule expected March 1993.

Environmental protection standards for the management, storage, and disposal of spent nuclear fuel, high-level wastes, and transuranic (TRU) wastes are found in 40 CFR 191. Management and storage must be conducted so as to provide a reasonable asisurance that no member of the public in the general environment will receive a combined annual dose equivalent or greater than $25 \mathrm{mrem}$ to the whole body and 75 mrem to any organ (40 CFR 191.03). The standards for disposal sy'stems, originally listed in Subpart B of 40 CFR 191, were vacated by a federal appeals court decision in 1987. These standards stated that disposal systems for the wastes defined above must be designed "to provide a reasonable expectation that, for 1000 years after disposal, undisturbed performance of the disp osal system shall not cause the annual dose equivalent from the disposal system to any member of the public in the accessible environment to exceed $2: 5$ mrem to the whole body and 75 mrem to any critical organ." All potential path ways must be considered ( 40 CFR 191.15). These vacated disposal standards thus could not be considered legally applicable to D\&D activities, but could provide some guidance. In 40 CFR 191.04, alternative standards are established for DOE facilities if EPA determines that such standards 
prevent any member of the public from receiving a continuous exposure of more than $100 \mathrm{mrem} /$ year effective dose equivalent or an infrequent exposure of more than $\mathbf{5 0 0} \mathrm{mrem} /$ year effective dose equivalent from all sources, excluding natural background, and medical exposures. However, EPA plans to revise its standards to create a new Subpart B and promulgate generally applicable environmental standards to establish limits for the release of radioactive materials to the environment [notice of proposed rulemaking (NPRM), February 1993; final rule, February 1994)]. Whether this proposed rule will contain the alternative standards clause is unknown. When promulgated, these standards will supersede those mentioned above as legally applicable standards.

EPA intends to develop environmental radiation protection standards for the disposal of LLW (possibly including NARM) under 40 CFR 193 and 764. The intent of these standards will be to protect the public health and general environment from potential adverse effects from LLW disposal. These proposed regulations may provide guidance for cleanup of the $D \& D$ sites when promulgated. The proposed rule is scheduled for September 1993, final rule September 1994 (Houlberg et al. 1992).

In addition, EPA intends to develop public health and environmental radiation protection criteria for cleanup of residual radioactive materials at decommissioned DOE, Department of Defense, and NRC-licensed sites, as well as others. These criteria may provide useful guidance for $\mathrm{D} \& \mathrm{D}$ activities at the ORR. However, there is no schedule for action for these criteria (Houlberg et al. 1992).

\subsubsection{Department of Transportation Regulations}

The Department of Transportation (DOT) Regulations for Hazardous Materials list general requirements for shipping and packaging at 49 CFR 172 and 173, and for requirements for carriage by public highway at 49 CFR 177. General requirements for shipping of hazardous materials are defined in 49 CFR 172, with specific marking, labeling, and placarding regulations for radioactive materials in 49 CFR 172.310, 172.403, and 172.556, respectively.

49 CFR 173, Subpart I, lists requirements for packaging and shipping radioactive materials. General package design requirements are given in 49 CFR 173.411, with specific design requirements for Type $A$ and $B$ packaging found in 49 CFR 173.412 and 173.413, respectively. Activity limits for normal form radioactive material (termed $A_{2}$ limits) are listed in 49 CFR 173.435 for various radionuclides. Type $A$ packaging is authorized for shipment if each package does not exceed the $A_{2}$ value ( 49 CFR 173.431). If package quantities exceed the $A_{2}$ value, Type $B$ packaging is required ( $49 \mathrm{CFR}$ 173.431). In addition, each package of radioactive materials must be designed and prepared for shipment such that under normal conditions, the radiation level does not exceed $200 \mathrm{mrem} / \mathrm{hour}$ at any external point on the package (49 CFR 173.441 ). Small quantities of solid radioactive materials are exempt from the packaging and shipping requirements of this part if the materials package limit is less than $10^{-3} \mathrm{~A}_{2}$ (49 CFR 173.4 and 173.423).

Standards for the packaging and shipment of NRC-licensed material are found in 10 CFR 71. These are not legally applicable to DOE activities. However, DOE Order 5480.3 (Safety Requirements for the Packaging and Transportation of Hazardous Materials, Hazardous Substances, and Hazardous Wastes) specifies the Type A packaging requirements, which are given in 49 CFR 173.411 and 412 . Type 
$B$ packages shall be in compliance with requirements found in 10 CFR 71 . Reference is made to 10 GFR 71.41 et seq. for general standards for all packages and special requirements; for Type B packages [DOE Order 5480.3(8)].

Regulations governing transportation of hazardous materials by public highway are found in $49 \mathrm{CFR}$ 177, and specific loading and unloading requirements for radioactive materials are in 49 CFR 177.842. The number of packages in any one motor vehicle must be limited so that the total transport index number does not exceed 50. The total transport index is described as the sum of the numbers expressing the maximum radiation level in mrem/hour at 1 meter ( $3.3 \mathrm{ft}$ ) from the external surface of each package (49 CFR 173.403bb).

\subsubsection{DOE Orders}

DOE Orders are not promulgated regulations and thus are not considered to be legally binding by EPA. They are, however, binding between DOE and Martin Marietta Energy Systems, Inc., because of contractual agreements. The radiation exposure limits for memtsers of the public from management and storage of TRU waste defined in DOE Order 5400.5 (Radiation Protection of the Public and the Environment, February 8, 1990) are: (1) an effective dose equivalent of 25 mrem/year to the whole body, or (2) $75 \mathrm{mrem} /$ year to a single organ [5400.5(II.1c)]. The basi: dose limit for routine DOE activities, including RA monitoring, cleanup, and control of residual radioactive material is 100 mrem/year. In addition, guidelines are given for levels of residual surface contamination that shall not be exceeded if a RA is to be considered completed and property released to the public without restrictions on use [5400.5(II.5a)]. These levels are listed fo: specific isotopes and beta-gamma emitters in general. In all instances, the overriding principle of the DOE Order is that all releases of radioactive material shall be ALARA. Chapter IV of the order lists guidelines for cleanup of radioactive real and personal property, management of the resulting wastes and residues, and release of property. Information on application of the guidelines and requirements presented in the order, including procedures for deriving specific propert $r$ guidelines for allowäble levels of residual radioactive material from basic dose: limits, is contained in DOE/CH 8901, "A Manual for Implementing Residual Radioactive Material Guidelines, A Supplement to the U.S. Department of Energy Guidelines for Residual Radioactive Material at FUSRAP and SFMP Sites," June 1989 [5400.5(IV.2)]. Table 10.9 summarizes the contents of DOE Order 5400.5 with respect to RAs. DOE will propose for codification as 10 CFR 834 the contents of DOE Order 5400.5 as radiation protection requirements for the public and the environment for DOE and DOE Contractor operations (NPRM May 1993).

DOE Order 5820.2A (Radioactive Waste Management, Sept. 9, 1988) states that the management of I,LW must ensure that external exposure to the waste and concentrations of radioactive material that may be released into surface water and soil does not exceed $25 \mathrm{n}$.rem/year to any member of the public. Releases to the atmosphere shall not exceed $10 \mathrm{mrem} / \mathrm{year}$ (Table 10.10). Reasonable effort should be made to mairtain releases to the environment to ALARA levels. The order pertains to the management of radioactive waste and contains closure and post-closure care requirements. Table 10.10 summarizes the substantive requirements of this DOls Order. 
Table 10.9. DOE Order 5400.5, "Radiation Protection of the Public and the Environment"

Action
Planning and performance of all
DOE activities
Routine DOE activities including

remedial action

Management and storage of spent nuclear fuel, high-level or

transuranic waste at a disposal

facility that is not regulated by the $\mathrm{NRC}^{b}$

Discharge of liquid waste containing radionuclides to surface water

\section{Requirement}

DOE will carry out all DOE activities to ensure that radiation doses to indtviduals will be as low as reasonably achievable (ALARA)

DOE must comply with all legally applicable requirements of 40 CFR 61 (NESHAPS $^{a}$ for DOE Facilities) and 40 CFR $191^{19}$ (Spent Nuclear Fuel, High-level, and Transuranic Wastes)

Exposures to members of the public from all radiation sources shall not cause an effective dose equivalent to be greater than $100 \mathrm{mrem}(1 \mathrm{mSv})$ per year

Exposures to members of the public from all radiation sources released into the atmosphere shall not cause an effective dose equtvalent to be greater than $10 \mathrm{mrem}(0.1 \mathrm{mSv})$ per year

Members of the public shall not receive an effective dose equivalent greater than $25 \mathrm{mrem}(0.25 \mathrm{mSv})$ to the whole body or $75 \mathrm{mrem}(0.75 \mathrm{mSv})$ to a single organ per year

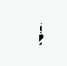

Radioactive materials released into public drinking water supplies shall not cause an effective dose equivalent to be greater than $4 \mathrm{mrem}(0.4 \mathrm{mSv})$ to an individual per year. Gross alpha activity shall not exceed $1.5 \times 10^{-8} \mu \mathrm{Ci} / \mathrm{ml}$

Liquid effluents shall not cause private or public drinking water systems downstream of the facility to exceed the MCL(s) of 40 CFR 141

Chapter

I.4

I

Implementation of best avallable technology (BAT) treatment required if discharge is at an annual average concentration greater than the derived concentration guide (DCG) level
II.1a 
Table 10.9. (continued)

\begin{tabular}{ll}
\hline \multicolumn{1}{c}{ Action } & \multicolumn{1}{c}{ Requirement } \\
\hline $\begin{array}{l}\text { Discharge of liquid waste containing } \\
\text { radionuclides to surface water } \\
\text { (continued) }\end{array}$ & $\begin{array}{l}\text { Discharge of liquid waste containing radionuclides to surface } \\
\text { water at an annual average concentration less than the DCG } \\
\text { level does not require the implementation of BAT treatment } \\
\text { The absorbed dose to native aquatic animal organisms shall } \\
\text { not exceed 1 rad/d from exposure to liquid wastes discharged } \\
\text { to natural waterways } \\
\text { Liquid wastes containing concentrations of radioactive } \\
\text { materlals greater than } 5 \text { times the DCG(s) may be discharged } \\
\text { to a federal sanitary sewerage system which provides liquid } \\
\text { waste treatment prior to discharge to surface water according } \\
\text { to II.3a(1). ALARA process considerations are required }\end{array}$
\end{tabular}

If a waste stream contains multiple radionuclides, then the DCG shall be the sum of the fractional DCG values

Management of low-level radioactive solid waste containing no RCRA constituents

Demonstration of compliance with the dose limits

Design, operational, and monitoring requirements are found in DOE Order 5820.2A (Radioactive Waste Management)

Chapter

\section{II. $3 a(2)$}

DOE shall make appropriate documentation containing information about compliance with dose limits for members of the public in the Immediate vicinity and within $80 \mathrm{~km}$ of the site

Conduct of radiological environmental protection programs

DCG(s) for water ingestion, air inhalation, and immersion in a gaseous cloud are provided as reference values. These DCG(s) are based on a committed effective dose equivalent of 100 mrem for the radionuclide taken into the body by ingestion or inhalation during one year

The DCG values apply to only one mode of exposure (1.e., elther ingestion -or- inhalation) 


\begin{tabular}{l} 
Action \\
\hline $\begin{array}{l}\text { Conduct of radiological } \\
\text { environmental protection program } \\
\text { (continued) }\end{array}$
\end{tabular}

Cleanup of residual radioactive material and management of resulting wastes or residues
For known mixtures of radionuclides the sum of the ratios of the observed concentration of each radionuclides to its corresponding DCG must not exceed 1.0

DOE facilities shall develop plans and protocols for the implementation of this guidance

These guidelines are for levels of residual radioactive material that is acceptable for public use of property without restrictions because of residual radioactive material

Generic guidelines are taken from existing radiation protection standards

Authorized limits are levels of residual radioactive material that shall not be exceeded if the remedial action is to be considered completed and the property is to be released without restrictions on use !

Monitoring, cleanup, and control of residual radioactive material are subject to the ALARA policy

The basic dose limits for exposure to residual radioactive material is 100 mrem ( $1 \mathrm{mSv}$ ) annually

Under unusual circumstances, the dose limit for exposure to residual radioactive material is increased from $100 \mathrm{mrem}$ (1 $\mathrm{mSv}$ ) to $\mathbf{5 0 0} \mathrm{mrem}(\mathbf{5} \mathrm{mSv}$ ) annually

Residual radioactive material in soil are those concentrations in excess of background concentrations averaged over an area of $100 \mathrm{~m}^{2}$. These derivations are obtained by means of environmental pathway analysis and basic dose limits
Chapter

III.2c

IV.1 \& 2

IV.2c

IV.2e 
Cleanup of residual radioactive materlal and management of resulting wastes or residues (continued)

Management of residual radioactivity above the guidelines specifted in IV.1-4
Residual concentrations of radionuclides in the air and water shall not exceed 100 mrem (1 mSv) per year

IV.4e

Limits for hot spots shall be developed in cases where the average concentration in any surface or below surface area equal to or less than $25 \mathrm{~m}^{2}$ exceeds the limit or guidelines by a factor of $(100 / \mathrm{A})^{0.5}$. Reasonable effort must be made to remove any radionuclide source that exceeds 30 times the limit

The generic guidelines for ${ }^{226} \mathrm{Ra},{ }^{228} \mathrm{Ra},{ }^{230} \mathrm{Th}$, and ${ }^{232} \mathrm{Th}$ are 5 $\mathrm{pCl} / \mathrm{g}$ averaged over the first $15 \mathrm{~cm}$ of soll or $15 \mathrm{pCl} / \mathrm{g}$ averaged over 15-cm-thick layers of soll below the first $15 \mathrm{~cm}$

Interim storage control and stabilization features shall be planned to have a minimum life of 25 years and, if reasonably achievable, an effective life of 50 years

Control features must be designed so that radionuclide concentration in the groundwater shall not exceed applicable federal and state standards

If residual radioactive material is in inaccessible locations and would be unreasonably costly to remove and when residual radioactive material exceeds guideline values, an interim management plan may be arranged to maintain the property

Administrative controls shall include (but are not limited to): - periodic monitoring as appropriate

- appropriate shielding

- physical barriers to prevent access

- appropriate radiological safety measures
IV.4a(1) 
Table 10.9. (continued)

Management of residual radioacttvity above the guidelines specified in IV.1-4 (continued)
Control and stabilization for uranium, thorlum, and their decay products must be designed to last at a minimum of 200 years and if reasonably achievable have an effective life of 1000 years

In accordance with legally applicable federal and state standards, DOE facllities shall protect groundwater

Use of and access to residual radioactive material shall be controlled through appropriate administrative and physical controls

Long-term management of other radionuclides shall be controlled by applicable requirements in Chapters II. III, and IV of DOE 5820.2A
IV.6d(1)(a)

$\operatorname{IV.6d(1)(d)}$

IV.6d(1)(e)

IV.6d(2)

${ }^{a}$ NESHAPS $=$ National Emission Standards for Hazardous Air Polluting Substances

bNR = Nuclear Regulatory Commission.

${ }^{c} \mathrm{RCRA}=$ Resource Conservation and Recovery Act. 


\begin{tabular}{|c|c|c|}
\hline Action & Requirement & Chapter \\
\hline \multirow[t]{6}{*}{$\begin{array}{l}\text { Management of low- } \\
\text { level radioactive waste }\end{array}$} & $\begin{array}{l}\text { Development of site-specific comprehensive closure plans shall address: } \\
\text { - Disposal sites' closure after the site has been flled for } 5 \text { years and } \\
\text { - National Environmental Policy Act (NEPA) requirements }\end{array}$ & III.3j(1) \\
\hline & $\begin{array}{l}\text { Residual radioactivity levels for surface soll will comply with DOE decommissioning } \\
\text { guldelines (DOE Order } 5400.5 \text { ) }\end{array}$ & III.3j(2) \\
\hline & $\begin{array}{l}\text { The Oak Ridge Reservation must correct problems that could jeopardize the attainment of } \\
\text { this order's performance objectives }\end{array}$ & III.3j(3) \\
\hline & $\begin{array}{l}\text { All disposal sites and units shall be maintained to conform with RCRA }{ }^{a}, \text { CERCLA }^{b} \text {, and } \\
\text { SARA }^{c} \text { standards }\end{array}$ & III.3j(4) \\
\hline & $\begin{array}{l}\text { An appropriate fleld organization shall revlew and approve any closure plans for new and } \\
\text { exdsting low-level waste disposal sites }\end{array}$ & III.3j(5) \\
\hline & $\begin{array}{l}\text { An analysis of site performance will be the basis for terminating the monitoring and } \\
\text { maintenance activity at closed facillities or sites at the end of the institutional control period }\end{array}$ & III.3j(6) \\
\hline \multirow[t]{3}{*}{$\begin{array}{l}\text { Management of burled } \\
\text { transuranic waste }\end{array}$} & $\begin{array}{l}\text { All disposal sites and units shall be maintained to conform with CERCLA and SARA } \\
\text { standards }\end{array}$ & II. 1 \\
\hline & $\begin{array}{l}\text { Transuranic waste shall be managed to protect the health and safety of the public and the } \\
\text { workers at the site }\end{array}$ & II. 2 \\
\hline & $\begin{array}{l}\text { Each DOE facility will develop a site closure plan which will include: } \\
\text { - NEPA requirements; } \\
\text { - Applicable federal, state, and local regulations; } \\
\text { - Permits required: } \\
\text { - Selected closure strategy and justification; and } \\
\text { - Postclosure monitoring and control }\end{array}$ & II. $31(4)$ \\
\hline
\end{tabular}

${ }^{\circ}$ RCRA = Resource Conservation and Recovery Act.

${ }^{b}$ CERCLA = Comprehensive Environmental Response, Compensation, and Liability Act.

'SARA = Superfund Amendments and Reauthorization Act. 
DOE Order 5480.11 (Radiation Protection for Occupational Workers) contains guidelines for worker protection, which are similar to those of 10 CFR 20 [i.e., 5 $\mathrm{rem} /$ year and $50 \mathrm{rem} /$ year annual effective dose equivalent for stochastic (cancer) and nonstochastic (systemic) effects, respectively, from both internal and external sources for continuous exposures]. Also included in the order are standards for the general public when entering a controlled area. Exposures to the public are limited to an effective dose equivalent of $100 \mathrm{mrem} /$ year (Table 10.8). As with the other DOE Orders, the ALARA principle prevails. Remediation of radionuclidecontaminated soils must ensure that exposures to on-site workers or public intruders will not exceed these standards. DOE has proposed for codification in 10 CFR 835 the primary standards for radiation protection of occupational workers from normal operation of DOE facilities (56 FR 64334, Dec. 9, 1991). A final rule is expected in March 1993. When promulgated, these standards will then be legally applicable for cleanup activities at D\&D sites. 
Performance, design, or other action-specific requirements set controls or restrictions on particuler kinds of activities related to the management of hazardous waste. Certain D\&D actions at a site may invoke the appropriate action-specific regulations that specify particular performance standards or technologies, as well as sipecific environmental levels for discharged or residual chemicals. Action-specific regulations are established under RCRA, CERCLA, CAA, CWA, SDWA, TSCA, FIFF', and OSHA.

\subsubsection{Comprehensive Environmental Response, Compensation, and Liability Act}

The intent of CERCLA as amended by SARA is to provide for the cleanup of inactive hazardous waste disposal sites and to provide for response to, and cleanup of, environmental problems that are not covered adequately by the permit programs of other environmental laws. D\&D activities that have been incorporated into the FFA would be subject to CERCLA regulations.

The administrative requirements of RCRA (e.g., permitting, reporting, and recordkeeping) or any other federal or state regulations are not required for on-site RA if a facility is being cleaned up under CERCLA ICERCLA \$121(e) and FFA §XXII(A)]. However, under CERCLA \$121(d)(3) and FFA §XXII(B), any removal or RA involving the off-isite transfer of hazardous substances, pollutants, or contaminants must involve a facility in compliance with all RCRA substantive and administrative requirements. CERCLA response actions will be coordinated with, and supplement, the corrective measures required and conducted by DOE under its current RCRA permit [FFA \&IV(A)].

\subsubsection{Resource Conservation and Recovery Act}

RCRA has nine distinct sections (subtitles) that regulate various aspects of hazardous waste. Three of these, Subtitle C "Hazardous Waste Management," Subtitle D "Solid Waste Management," and Subtitle I "Regulation of Underground Storage Tanks" (UST), provide the regulatory guidance for RCRA and will be considered for regulations for on-site D\&D activities and cleanup at the ORR.

Minimum national standards for acceptable management of hazardous waste appear in RCRA, although Tennessee has been authorized by EPA to administer and enforce its own stanilards in lieu of the federal RCRA regulations. Federally authorized state RCRA programs relate only to RCRA standards before HSWA.

Tennessee's promulgated RCRA requirements supersede federal regulations as legally applicable. However, Tennessee's substantive RCRA regulations are Identical for the most part to the federal RCRA regulations (Coutant and Heckman 1987). New regulations imposed in 1984 by HSWA are to be considered applicable under federal law in all sitates until each authorized state promulgates its own HSWA-related standards. Although the Tennessee Solid Waste Disposal Control Board has promulgated many of the HSWA regulations, EPA has not yet authorized the program (Hinch 1990). 


\section{RCRA Subtitle $C$ regulations}

RCRA Subtitle $\mathrm{C}$ regulates the generation, transportation, treatment, storage, and disposal of hazardous waste. Standards for the management of hazardous waste at RCRA-permitted TSD facilities were promulgated July 26, 1982, and appear as 40 CFR 264. Standards for interim TSD facilities are found in 40 CFR 265.

In general, this text will address the Part 264 rather than the Part 265 standards as they are the more stringent. Table 10.11 lists the pertinent subparts of the permitted and interim standards and the equivalent section of the TDEC hazardous waste management regulations.

As discussed in Sect. 10.2, D\&D activities which generate RCRA hazardous wastes but are not incorporated as CERCLA Sites into the FFA would be subject to regulation under RCRA. In contrast to CERCLA, D\&D activities subject to RCRA would be subject to the administrative as well as the substantive requirements of the law, including all the applicable permitting requirements.

The RCRA Subtitle C Part 264 regulations apply to particular waste management processes (e.g., capping or incineration) or to general procedures (e.g., treatment, disposal, or closure), and it may be necessary to combine the two types of categories to adequately address the action-specific regulations for a particular D\&D activity or technology.

\section{Land Disposal Restrictions}

If RCRA-listed or -characteristic waste is generated/identified during the D\&D process, these wastes would be subject to the RCRA land disposal restrictions. For each hazardous waste, EPA has established treatment standards that are protective of human health and the environment when the wastes are land disposed. Land disposal includes, but is not limited to placement in a landfill, surface impoundment, waste pile, and land treatment facility. In the final NCP, EPA reaffirms that movement of waste within a unit does not constitute "land disposal" for purposes of application of the RCRA land disposal restrictions; however, waste consolidation from different units at a CERCLA site are subject to the restrictions ( 55 FR 8759).

These LDR apply only to RCRA hazardous waste placed after the effective prohibition date. Wastes may be land disposed if they have been treated with the best demonstrated available technology (BDAT) set by EPA and meet the treatment standards. A final rule listing provisions for specific treatment standards and prohibiting land disposal of the following wastes has appeared. Table 10.12 lists the waste categories for which LDRs have been promulgated, the Federal Register citation, and the corresponding section in 40 CFR 268. Tennessee Rule 1200-1-11-.10 contains the state LDRs, which are similar to the RCRA LDRs.

EPA has determined that the RCRA treatment standards are generally inappropriate or infeasible when applied to contaminated soil or debris (55 FR 8760). Therefore, EPA is proposing separate rulemakings to establish treatment standards for disposal of such contaminated soil and debris. The advance notice of proposed rulemaking (ANPRM) for debris appeared in 56 FR 24444, May 30, 1991, and the NPRM on Jan. 9, 1992 (57 FR 958). The final rule was signed by EPA's administrator on June 30, 1992 (57 FR 37194; August 18, 1992). The rule requires contaminated debris to be treated before land 
Table 10.11. RCRA" Subtitle C-standards for the treatment, storage, and disposal of hazardous waste

\begin{tabular}{|c|c|c|}
\hline Federal & Tennessee & Category \\
\hline 40 CFR Part 264 & $1200-1-11-.06^{b}$ & \\
\hline Subpart I & Section 9 & Containers \\
\hline Subpart J & Section 10 & Tanks \\
\hline Subpart K & Section 11 & $\begin{array}{l}\text { Surface } \\
\text { impoundments }\end{array}$ \\
\hline Subpart L & Section 12 & Waste piles \\
\hline Subpart $\mathbf{M}$ & Section 13 & Land treatment \\
\hline Subpart N & Section 14 & Landfills \\
\hline Subpart $O$ & Section 15 & Incinerators \\
\hline Subpart X & Section 19 & $\begin{array}{l}\text { Miscellaneous } \\
\text { treatment units }\end{array}$ \\
\hline 40 CFR Part 265 & $1200-1-11-.05$ & \\
\hline Subparts 1-O & Sections 9-15 & As listed above \\
\hline Subpart P & Section 16 & Thermal treatment \\
\hline Subpart 9 & Section 17 & $\begin{array}{l}\text { Chemical, physical, } \\
\text { and biological } \\
\text { treatment }\end{array}$ \\
\hline
\end{tabular}

${ }^{\alpha}$ RCRA $=$ Resource Conservation and Recovery Act.

${ }^{b}$ Rule 1200 of the Tennessee Department of Environment and Conservation Hazardous Waste Manajyement Regulations.

Table 10.12. Federal RCRA ${ }^{2}$ land disposal regulations

\begin{tabular}{llc}
\hline \multicolumn{1}{c}{ Waste category } & \multicolumn{1}{c}{ Citation } & 40 CFR Part \\
\hline $\begin{array}{c}\text { Spent-solvent and dioxin- } \\
\text { containing wastes }\end{array}$ & $\begin{array}{l}51 \text { FR 40572 } \\
\text { (Nov. 7, 1986) }\end{array}$ & 268.30 \\
"California List" wastes & 52 FR 25760 & 268.31 \\
& $\begin{array}{l}\text { (July 8, 1987) } \\
\text { First Third wastes }\end{array}$ & 268.32 \\
& $\begin{array}{l}54 \text { FR 31138 } \\
\text { (Aug. 17, 1988) }\end{array}$ & 268.33 \\
Second Third wastes $^{b}$ & $\begin{array}{l}54 \text { FR 26594 } \\
\text { (June 23, 1989) }\end{array}$ & 268.34 \\
Final Third wastes $^{b}$ & 55 FR 22520 & \\
& (June 1, 1990) & 268.35 \\
\hline
\end{tabular}

$a_{\text {RCRA }}=$ Resource Conservation and Recovery Act.

${ }^{b}$ All listed hazardois wastes identified under 40 CFR 261. 
disposal using extraction, destruction, or immobilization technologies. Six different categories of debris and ten different categories of contaminants are specified in the rule. As with mixed waste, debris contaminated with both hazardous and radioactive waste must comply with the treatability standards for contaminated debris as well as those under the AEA. Disposal of treated debris and resultant wastes are discussed in the rule.

In the debris rule, EPA established a new treatment unit for treating contaminated debris; a "containment building" has been added to the definitions of 40 CFR 260.10 to provide for storage and treatment of contaminated debris that does not contain free liquids and is not amenable to treatment in tanks or containers (57 FR 979, January 9, 1992). Performance standards for the design and operation of such containment buildings are promulgated for a new Subpart DD to 40 CFR 264 and 265 for permitted facilities and interim status facilities, respectively. All containment buildings, permitted or unpermitted must comply with the same level of performance. These standards would be legally applicable to any $\mathrm{D \& D}$ activities involving dismantlement of structures and subsequent decontamination in a building. Physical extraction technologies such as abrasive blasting or spalling used to treat debris in place, but that is intended for discard (e.g., treatment of a contaminated building prior to demolition), are subject to the permit standards of 40 CFR 264, Subpart X for miscellaneous units or the interim status standards for chemical, physical, or biological treatment in 40 CFR 265, Subpart $\mathbf{Q}$ (preamble to the final debris rule).

The ANPRM for soil appeared Oct. 24, 1991 (56 FR 55160); the rulemaking schedule for the proposed soil rule is under negotiation (Houlberg et al. 1992). In the interim, EPA has developed guidance for obtaining and complying with a treatability variance for soil and debris that are contaminated with RCRA hazardous wastes for which treatment standards have already been set (OSWER Directive 9347.3-06FS, July 1989). Alternate treatment levels are presented for structural functional groups of organics and for ten inorganics based on actual treatment of soil and best management practices for debris. These should be considered as guidance when D\&D activities are scheduled that may contaminate or deal with contaminated soil. In addition,-EPA has granted an extension of the generic national capacity variance from the LDRs for certain solls and debris and radioactive mixed wastes until May 8, 1993 (57 FR 20766, May 15, 1992).

\section{Corrective action requirements}

Several sections of RCRA require promulgation of corrective action regulations; when finalized, these requirements will most likely be legally applicable to D\&D cleanup actions. Currently, only the 40 CFR 264 Subpart F regulations on groundwater protection at RCRA-regulated units are potentially applicable to D\&D actions within facility boundaries and these include groundwater protection standards (40 CFR 264.92 and 40 CFR 264.94) and groundwater monitoring requirements ( $40 \mathrm{CFR} 264.97$ ). The corrective action standards developed under RCRA §3004(u) will be applicable to any D\&D or CERCLA cleanup site that is also an active or a formerly active RCRA facility with an active SWMU; thus, the standards will also be applicable to a D\&D or CERCLA site where disposal is currently occurring. In addition, RCRA $\$ 3004(v)$ authorizes cleanup beyond facility boundaries. 
Requirements for corrective action for RCRA SWMUs have been proposed (55 FR 30798, July 27, 1990). A final rule is expected to appear February 1993. EPA proposes a risk-based approach to establish media cleanup standards for surface water, groundwater, soil, and air. These standards are to be established at concentrations that ensure protection of human health and the environment and are to be set for eack media of concern during the remedy selection process. RCRA corrective action levvels are not intended to be used as cleanup levels; they are intended only to "trigger" the corrective action process when exceeded. Target cleanup levels may initially be set at these RCRA action levels but must be modified as appropriate to reflect site-specific exposure assumptions (55 FR 30826). Appendix $A$ of the proposed rule lists proposed action levels for 165 compounds (55 FR 30865), and appendix $\mathrm{E}$ gives governing equations for calculating action levels (55 FR 30870).

\section{RCRA Subtitle I Regulations}

RCRA $\$ 9003$ requires promulgation of regulations pertaining to detection, prevention, and correction of releases from USTs; implementing regulations appear in 40 CFR 280.50 ("Release Reporting, Investigation, and Confirmation"), 280.60 ("Release Response and Corrective Action for UST Systems Containing Petroleum or Hazardous Substances"), and 280.70 ("Out-of-Service UST Systems and Closure") and should be considered as regulations for cleanup of any USTs located at D\&D sites or used in D\&D technologies. 40 CFR 280.66 specifies that corrective action plans designed to protect human health and the environment must be submitted to the "implementing agency" (TDEC UST Division) for approval. The state must be notifled of permanent closure plans not taken in response to corrective action (40 CFR 280.71); suggested cleaning and closure procedures are recommended in 40 CFR 280.71 and may be considered guidance for closure of any tanks at D\&D sites.

Tennessee Code Anncitated (TCA) \$68-53-101 et seq. authorized the UST Board to promulgate regulation is on July 1,1988 . The implementing regulations for release response and corrective action were promulgated April 15, 1990, and are found in TDEC Rules Chaps. 1200-1-15-.05 to 1200-1-15-.07. These regulations closely parallel the 40 CFR 280 regulations, although the state regulations only apply to USTs containing: petroleum products.

\section{RCRA Subtitle D regulations}

EPA has promulgated a final rule establishing a new 40 CFR Part 258, which sets forth revised minimum federal criteria for municipal solid waste landfills (56 FR 50978, Oct. 9, 19911. These criteria include closure and postclosure care requirements (40 CFR $25,8.60$ and 258.61 ).

In addition, the Tenriessee (Rules of the TDEC Chap. 1200-1-7) and federal RCRA regulations goverjing solid WM facilities may regulate $D \& D$ activities. Specifically, 40 CFR 257.3-3 prohibits nonpoint source contamination of surface waters from solid WM facilities. 40 CFR 257.3-3 also prohibits point source discharges of pollutantis into surface waters that are in violation of the requirements of the NPIJES. 40 CFR 257.3-.4 prohibits contamination of an underground drinking water source above SDWA MCLs. 


\subsubsection{Clean Air Act}

Chapter 25, "Air Pollution Control," of the TCA provides for the purity of the air resources of the state "consistent with the protection of normal health, general welfare and physical property of the people, maximum employment and the full industrial development of the state." Implementing these objectives are the Tennessee ambient air quality standards established by the TDEC Division of Air Pollution Control, which appear in Chap. 1200-3-3 of the Rules of the TDEC and are identical to the federal primary NAAGS (see Sect. 10.3.2 and Table 10.2). The ambient standards of Chap. 1200-3-3 are translated into source-specific emission limitations (Rules of the TDEC, Chaps. 1200-3-4 to 1200-3-21) that must be considered legally applicable if they apply to any of the D\&D sites or technologies. Table 10.13 lists sections of the Tennessee air emission standards that should be analyzed on a site-specific basis for each D\&D activity or each technology.

The CAA (\$111) requires EPA to promulgate standards for new sources of air emissions. This requirement has been implemented in 40 CFR 60 through the New Source Performance Standards (NSPS) that are based on the BDAT and set minimum federal emission limitations on classes of facilities. NESHAPs have been discussed as potential "hybrid" regulations (see Sects. 10.2 and 10.4.1), which should be considered as D\&D activities and technologies are selected.

Certain on-site construction and/or excavation activities may be necessary to prepare a site for D\&D or remediation. Airborne pollutants may result from these construction activities. The primary concern is elevation of particulate concentrations resulting from earth-moving and site-grading activities. The TDEC, Division of Air Pollution Control has promulgated regulations governing fugitive dust emissions (Rules of the TDEC, Chapter 1200-3-8-.010). An operator must take reasonable precautions to prevent particulate matter from becoming airborne. In addition, fugitive dust may not be emitted as visible emissions beyond property boundary lines for more than $5 \mathrm{~min} / \mathrm{hr}$ or $20 \mathrm{~min} /$ day.

\subsubsection{Clean Water Act}

The regulatory aspects of the CWA include site-specific pollutant limitations and performance standards designed to restore and maintain the chemical, physical, and biological integrity of the nation's surface waters. The NPDES permit program includes applicable effluent standards, monitoring requirements, and conditions for discharge. Tennessee has an EPA-authorized state program that is equivalent to the federal program. Various NPDES permits regulate discharges from the ORR to the Clinch River and its tributaries. The effluent limitations and monitoring requirements found in the NPDES permits should be analyzed on a site-specific basis for any cleanup at D\&D sites that would include discharge of pollutants to surface waters.

Direct discharge of dredge-and-fill material into navigable waters is regulated under CWA $\$ 404$ and implemented through 33 CFR 320-330 and 40 CFR 230. Actions that may be considered dredge-and-fill activities include dredging of sediments from contaminated water bodies, disposal of contaminated soll or materials in surface water, capping of a site, building berms and levees to contain wastes, excavation for the containment of effluent, and dewatering of a site to obtain adequate flow (EPA 1988). 
Tablı 10.13. Rules of the TDEC ${ }^{2}$ Bureau

of Environment Division of Air Pollution Control

\begin{tabular}{cl}
\hline \multicolumn{1}{c}{ Chapter } & \multicolumn{1}{c}{ Subject } \\
\hline $1200-3-1$ & General provisions \\
$1200-3-2$ & Definitions \\
$1200-3-4$ & Open burning \\
$1200-3-5$ & Visible emissions \\
$1200-3-6$ & Nonprocess emission standards \\
$1200-3-7$ & Process emission standards \\
$1200-3-8$ & Fugitive dust \\
$1200-3-11$ & Hazardous air contaminants \\
$1200-3-14$ & Control of sulfur dioxide emissions \\
$1200-3-16$ & New source performance standards \\
$1200-3-18$ & Volatile organic compounds \\
$1200-3-21$ & General alternate emission stan- \\
$1200-3-22$ & dards \\
$1200-3-23$ & Lead emission standards \\
$1200-3-24$ & Visibility protection \\
& Stack height regulations \\
\hline
\end{tabular}

${ }^{\alpha_{\text {TDEC }}}=$ Teunessee Department of Environment and

Conservation.

The U. S. Army Corris of Engineers (COE) issues dredge-and-fill permits for activities regulated under $\$ 10$ of the Rivers and Harbors Act and $\$ 404$ of the CWA; in addition, the Tennessiee Valley Authority Act \$26A approval application for streambed sediment removal may be necessary. The COE permits are not likely to be required for D\&D or ER activities at $\mathrm{K}-25$, as only the Clinch River and portions of Poplar Creek are designated as "navigable waters" by the COE. However, all of the CWA $\$ 404$ requirements for-protection of wetlands from fill operations are potentially applicable to activities at K-25 that would impact wetland communities (Se:e Sect. 10.6.3 and Table 10.14 for a further discussion of these issues). CERCLA. $\$ 121$ (e) stipulates that permits are not required for onsite CERCLA cleanup; however, the applicability of these regulations for on or offsite $D \& D$ activities should be addressed on a site-specific basis.

Storm water discharges from activities at industrial sites involving construction operations that result in the disturbance of five acres total land have been included in the final rule for NPDES permits for storm water discharges (40 CFR 122). Consultation with TDEC is required to ensure compliance with the substantive requirements of the NPDES permitting process for stormwater discharges during construction activities for CERCLA sites (Chapter 1200-4-10-.05 of the Rules of the TDE:C). For D\&D activities not operating under CERCLA, compliance with the full sitormwater permitting process is required. In either case, implementation of good site planning and best management practices to control storm water discharges is required. 


\subsubsection{Safe Drinking Water Act}

Part C of Title XIV of the SDWA authorizes the establishment of an underground injection control (UIC) permit program designed to prevent contamination of underground sources of drinking water. Any D\&D activities involving discharge by way of underground injection wells would be subject to these regulations. An underground drinking water source is defined in the UIC regulations (40 CFR 146.3) as an aquifer or its portion that supplies drinking water for human consumption, contains a sufficient supply of groundwater to supply a public water system, and contains fewer than 10,000 mg total dissolved solids per liter of water. Tennessee has a UIC program (Chap. 1200-4-6 of the Rules of the Water Control Board) that classifies all groundwater as useful for domestic water supply unless certain exemption criteria apply. Aquifers are exempted for various reasons, including economic or technical impracticality (1) in recovery because of depth or location or (2) in successful treatment of contaminated water for drinking water purposes.

\subsubsection{Toxic Substances Control Act}

Specific TSCA standards exist for incineration or alternate disposal of liquid and nonliquid waste and for articles and soils containing PCBs. For mixed waste containing radionuclides and $\mathrm{PCBs}$, the $\mathrm{K}-25 \mathrm{~K}-1435 \mathrm{TSCA}$-approved incinerator is the technology of choice. TSCA storage requirements for PCBs ( 40 CFR 761.65) specify that PCBs and PCB-containing items at concentrations of greater than $50 \mathrm{ppm}$ must be disposed of within 1 year after being placed in storage for disposal. Because of the limited disposal options for mixed waste contaminated with PCBs, the K-25 TSCA incinerator must store mixed waste for a time period exceeding 1 year. Therefore, the TSCA-FFCA has been signed between DOE and EPA, which allows for longer storage times (see Sect. 10.3.4). This agreement contains a compliance-attainment date after which a storage time of 1 year will again be in effect.

There are also structural requirements for facilities and containers used for storage of PCBs. These requirements, too detailed to be listed here, are delineated in 40 CFR 761.65(b) for facilities and 40 CFR 761.65(c) for containers.

\subsubsection{Federal Insecticide, Fungicide, and Rodenticide Act}

FIFRA delegates authority to EPA to regulate the disposal and storage of excess pesticides and pesticide containers. To that end, EPA has published nonregulatory procedures for disposal of pesticides in 40 CFR 165, Subpart C. These recommendations might provide guidance for cleanup of pesticides and pesticide containers at D\&D sites and should be analyzed on a site-specific basis. EPA is currently updating these guidelines to make them consistent with current regulations and technologies. Regulatory initiatives for 40 CFR 165 will be published in three phases. An NPRM for Phase I, concerning suspended and canceled pesticides, will be published in March 1993. The NPRM for Phase II, concerning container design, residue removal storage, containment, and excess, is due in June 1993, and the Phase III NPRM is due in 1994 (Houlberg et al. 1992). 


\subsubsection{Occupational Saffety and Health Administration}

Title I, \$126(b) of CE:RCLA mandated that OSHA promulgate standards for regulation of employee health and safety during hazardous waste operations at RCRA or CERCLA sites and during emergency response to hazardous substance releases. The final regulations for Hazardous Waste Operations and Emergency Response (29 CFR 1910) have appeared in 54 FR 9294 (Final Rule, March 6, 1989; effective date, March 19!30). These regulations are designed to protect workers involved in cleanup operations at uncontrolled hazardous waste sites and to provide for worker protection during initial site characterization and analysis, monitoring activities, materials handling activities, training, and emergency response. These regulations do not apply to those workers who would not be exposed. Federal construction activities involving no potential for hazardous substance exposure are covered by the OSHA standards in 29 CFR 1926, Federal Service Contracts.

Standards for the protection of workers involved in construction, demolition, alteration, or repair activities involving asbestos-containing materials are listed in 29 CFR 1926.58 and would be applicable to D\&D activities.

CERCLA provides in $\$ 126$ (b) that the OSHA regulations address certain worker protection provisions; however, employers would have to continue to comply with other pertinent OSHA standards found in 29 CFR 1910 (General Industry) as well. Air contaminant Permissible Exposure Limits (PELs) for general industry for 212 substances were revised and updated on Jan. 19, 1989 (54 FR 2332), effective March 1, 1989, and are listed in Tables Z-1, Z-2, and Z-3 of the final rule. On July 7, 1992, a U.S. Circuit Court of Appeals vacated and remanded this final rule; however, OSHA is appealing this decision. In the case of conflict or overlap of worker protection staindards and general industry standards, the more restrictive provisions apply.

\subsubsection{Federal and State Regulations}

Table 10.14 gives a. preliminary list of federal and state action-specific regulations established under RCRA and various other statutes discussed above. Action alternatives are listed alphabetically, followed by a summary of the requirements found in the particular statute cited. The prerequisites for applicability are also given; however, the regulations must be related to D\&D sitespecific or technology-specific conditions to determine whether the regulation cited is legally applicable. This table does not represent a complete listing of actionspecific regulations; analysis of the regulations on a site-specific or technologyspecific basis would be riecessary to ensure a comprehensive summary. 


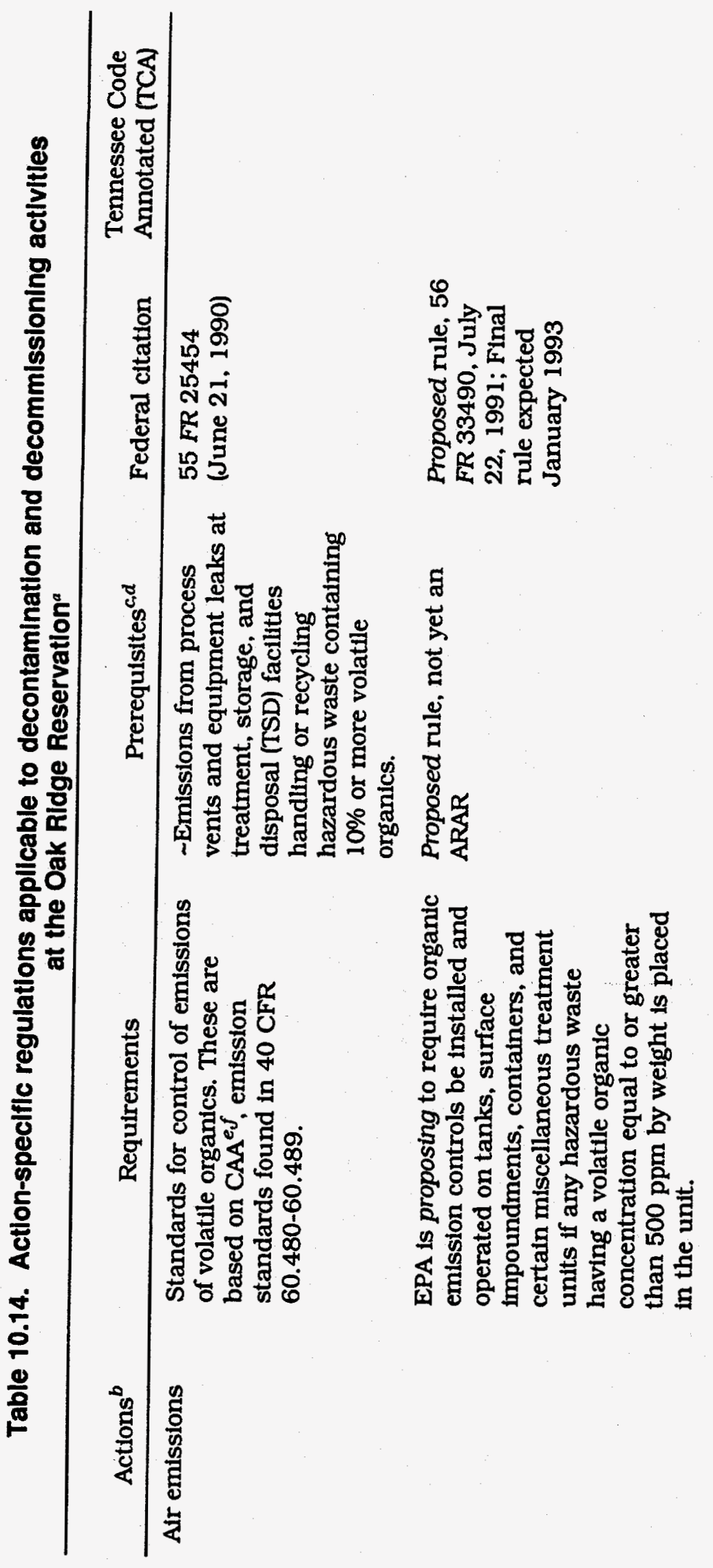


Table 10.14. (continued)

\begin{tabular}{|c|c|c|c|c|}
\hline Actions $^{b}$ & Requirements & Prerequisites $^{c, d}$ & Federal citation & $\begin{array}{l}\text { Tennessee Code } \\
\text { Annotated (TCA) }\end{array}$ \\
\hline Capping & $\begin{array}{l}\text { Placement of a cap over waste (e.g., } \\
\text { closing a landfill, or closing a } \\
\text { surface impoundment or waste pile } \\
\text { as a landfill, or similar action) } \\
\text { requires a cover designed and } \\
\text { constructed to: } \\
\text { - Provide long-term minimization of } \\
\text { migration of liquids through the } \\
\text { capped area; } \\
\text { - Function with minimum } \\
\text { maintenance; } \\
\text { - Promote drainage and minimize } \\
\text { erosion or abrasion of the cover; } \\
\text { - Accommodate settling and } \\
\text { subsidence so that the covers } \\
\text { integrity is maintained; and } \\
\text { - Have a permeability less than or } \\
\text { equal to the permeability of any } \\
\text { bottom liner system or natural } \\
\text { subsolls present. }\end{array}$ & $\begin{array}{l}\text { RCRA }^{g, h} \text { hazardous waste } \\
\text { placed at site after Nov. } 19, \\
1980, \text { or placement of } \\
\text { hazardous waste into another } \\
\text { unit will make requirements } \\
\text { applicable when the waste is } \\
\text { being covered with a cap for } \\
\text { the purpose of leaving it } \\
\text { behind after the remedy is } \\
\text { completed. Capping without } \\
\text { such placement will not } \\
\text { make requirements } \\
\text { applicable, but technical } \\
\text { requirements are likely to be } \\
\text { relevant and appropriate. }\end{array}$ & $\begin{array}{l}40 \text { CFR } \\
264.228(a) \\
\text { (Surface } \\
\text { Impoundments) } \\
40 \text { CFR } \\
264.258(b) \\
\text { (Waste plles) } \\
40 \text { CFR } \\
264.310(a) \\
\text { (Landfills) }\end{array}$ & $\begin{array}{l}1200-1-11- \\
.06(11)(\mathrm{t}) \\
1200-1-11- \\
.06(12)(\mathrm{i}) \\
1200-1-11- \\
.06(14)(\mathrm{k})\end{array}$ \\
\hline $\begin{array}{l}\text { Capping } \\
\text { (continued) }\end{array}$ & $\begin{array}{l}\text { Restrict postclosure use of property } \\
\text { as necessary to prevent damage to } \\
\text { the cover. }\end{array}$ & $\begin{array}{l}\text { Final closure of a RCRA } \\
\text { hazardous waste facility with } \\
\text { some hazardous materials or } \\
\text { residues left in place }\end{array}$ & $\begin{array}{l}40 \mathrm{CFR} \\
264.117(\mathrm{c})\end{array}$ & $\begin{array}{l}1200-1-11- \\
.06(7)(\mathrm{h})\end{array}$ \\
\hline
\end{tabular}




\begin{tabular}{|c|c|c|c|c|}
\hline Actions $^{b}$ & Requirements & Prerequisites $^{c, d}$ & Federal citation & $\begin{array}{l}\text { Tennessee Code } \\
\text { Annotated (TCA) }\end{array}$ \\
\hline & $\begin{array}{l}\text { Prevent run-on and run-off from } \\
\text { damaging the final cover. } \\
\text { Protect and maintain surveyed } \\
\text { benchmarks used to locate waste } \\
\text { cells (landfills, waste piles). }\end{array}$ & $\begin{array}{l}\text { Postclosure care } \\
\text { Postclosure care }\end{array}$ & $\begin{array}{l}40 \text { CFR } 264.228 \\
\text { (b) } \\
40 \mathrm{CFR} \\
264.310(\mathrm{~b}) \\
40 \mathrm{CFR} 264.310 \\
\text { (b) }\end{array}$ & $\begin{array}{l}1200-1-11- \\
.06(11)(1) \\
1200-1-11- \\
.06(14)(\mathrm{k}) \\
1200-1-11- \\
.06(14)(\mathrm{k})\end{array}$ \\
\hline $\begin{array}{l}\text { Clean closure } \\
\text { (e.g., closure with } \\
\text { no postclosure } \\
\text { care) }\end{array}$ & $\begin{array}{l}\text { Closure and postclosure standards } \\
\text { General performance standard } \\
\text { requires elimination of need for } \\
\text { further maintenance and control; } \\
\text { elimination of postclosure escape } \\
\text { of hazardous waste, hazardous } \\
\text { constituents, leachate, con- } \\
\text { taminated runoff, or hazardous } \\
\text { waste decomposition products to } \\
\text { groundwater, surface water, or the } \\
\text { environment. }\end{array}$ & $\begin{array}{l}\text { Applicable to land-based unit } \\
\text { containing hazardous waste }{ }^{d} \text {. } \\
\text { Applicable to RCRA } \\
\text { hazardous waste (listed or } \\
\text { charactertstic) placed at site } \\
\text { after Nov. } 19,1980, \text { or } \\
\text { placement of hazardous } \\
\text { waste into another unit. Not } \\
\text { applicable to material } \\
\text { undisturbed since Nov. 19, } \\
\text { 1980, or if treated in situ, or } \\
\text { consolidated within area of } \\
\text { contamination. Designed for } \\
\text { cleanup that will not require } \\
\text { long-term management; de- } \\
\text { signed for cleanup to health- } \\
\text { based standards. }\end{array}$ & $\begin{array}{l}40 \text { CFR 264.110- } \\
120 \\
\text { (Subpart G) } \\
40 \text { CFR 264.111 }\end{array}$ & $\begin{array}{l}1200-1-11- \\
.06(7)(\mathrm{a})-(\mathrm{k}) \\
1200-1-11- \\
.06(7)(\mathrm{b})\end{array}$ \\
\hline
\end{tabular}




\begin{tabular}{|c|c|c|c|c|}
\hline Actions $^{b}$ & Requirements & Prerequisites $^{c, d}$ & Federal citation & $\begin{array}{l}\text { Tennessee Code } \\
\text { Annotated (TCA) }\end{array}$ \\
\hline $\begin{array}{l}\text { Clean closure } \\
\text { (e.g., closure with } \\
\text { no postclosure } \\
\text { care) (continued) }\end{array}$ & $\begin{array}{l}\text { Removal or decontamination of } \\
\text { waste residues, contaminated } \\
\text { containment system components } \\
\text { (e.g., liners and dikes), } \\
\text { contaminated subsolls, and } \\
\text { structures and equipment con- } \\
\text { taminated with waste and leachate, } \\
\text { and management of them as } \\
\text { hazardous waste. }\end{array}$ & & $\begin{array}{l}\text { 40 CFR 264. } 114 \\
\text { 40 CFR 264.178 } \\
\text { 40 CFR 264.197 } \\
\text { 40 CFR 264.228 } \\
\text { 40 CFR 264.258 }\end{array}$ & $\begin{array}{l}1200-1-11- \\
.06(9)(\mathrm{c}) \\
1200-1-11- \\
.06(11)(1) \\
1200-1-11- \\
.06(12)(\mathrm{c}) \\
1200-1-11- \\
.06(13)(1) \\
1200-1-11- \\
.06(14)(1)\end{array}$ \\
\hline & $\begin{array}{l}\text { Must protect human health and } \\
\text { the environment. }\end{array}$ & & $\begin{array}{l}40 \mathrm{CFR} \\
264.111(\mathrm{~b})\end{array}$ & $\begin{array}{l}1200-1-11- \\
.06(7)(\mathrm{b})\end{array}$ \\
\hline $\begin{array}{l}\text { Closure with } \\
\text { waste in place } \\
\text { (capping) }\end{array}$ & $\begin{array}{l}\text { Eliminate free liquids by removal } \\
\text { or solidification. } \\
\text { Stabilization of remaining waste } \\
\text { and waste residues to support } \\
\text { cover. }\end{array}$ & $\begin{array}{l}\text { Applicable to land-based unit } \\
\text { containing RCRA hazardous } \\
\text { waste }^{d} \text {. }\end{array}$ & $\begin{array}{l}40 \text { CFR } \\
264.228(\mathrm{a})(2) \\
\text { (Surface } \\
\text { impoundments) } \\
40 \mathrm{CFR} \\
264.258(\mathrm{~b}) \\
\text { (Waste piles) } \\
40 \mathrm{CFR} \\
264.310 \text { (a) } \\
\text { (Landfills) }\end{array}$ & $\begin{array}{l}1200-1-11- \\
.06(12)(\mathrm{i}) \\
1200-1-11- \\
.06(16)(\mathrm{k})\end{array}$ \\
\hline $\begin{array}{l}\text { Closure with } \\
\text { waste in place } \\
\text { (capping) } \\
\text { (continued) }\end{array}$ & $\begin{array}{l}\text { Installation of final cover to provide } \\
\text { long-term minimization of } \\
\text { infiltration (see "capping" for } \\
\text { further restrictions). } \\
\text { Postclosure care and groundwater } \\
\text { monitoring." }\end{array}$ & & $\begin{array}{l}40 \text { CFR } 264.310 \\
40 \text { CFR } 264.310\end{array}$ & $\begin{array}{l}1200-1-11- \\
.06(14)(\mathrm{k}) \\
1200-1-11- \\
.06(14)(\mathrm{k})\end{array}$ \\
\hline
\end{tabular}




\begin{tabular}{|c|c|c|c|c|}
\hline Actions $^{b}$ & Requirements & Prerequisites ${ }^{c, d}$ & Federal citation & $\begin{array}{l}\text { Tennessee Code } \\
\text { Annotated (TCA) }\end{array}$ \\
\hline \multirow{2}{*}{$\begin{array}{l}\text { Closure with } \\
\text { waste in place } \\
\text { (hybrid closure) }\end{array}$} & $\begin{array}{l}\text { Removal of majority of } \\
\text { contaminated materials. }\end{array}$ & Proposed rule; not yet ARAR. & $\begin{array}{l}52 \text { FR } 8712 \\
\text { (March 19, 1987) }\end{array}$ & \\
\hline & $\begin{array}{l}\text { Application of cover and post- } \\
\text { closure monitoring based on } \\
\text { exposure pathways of concern. }\end{array}$ & Proposed rule; not yet ARAR. & $\begin{array}{l}52 \text { FR } 8712 \\
\text { (March 19, 1987) }\end{array}$ & \\
\hline $\begin{array}{l}\text { Consolidation } \\
\text { between units }\end{array}$ & $\begin{array}{l}\text { Placement on or in land outside } \\
\text { unit boundary or area of } \\
\text { contamination will trigger land } \\
\text { disposal requirements and } \\
\text { restrictions. }\end{array}$ & $\begin{array}{l}\text { Placement of RCRA } \\
\text { hazardous wastes subject to } \\
\text { land disposal restrictions. } \\
\text { Movement of hazardous } \\
\text { waste (listed or } \\
\text { characteristic) from one unit } \\
\text { or area of contamination into } \\
\text { another. Consolidation } \\
\text { within a unit or area of con- } \\
\text { tamination does not trigger } \\
\text { applicability. }{ }^{d d}\end{array}$ & $\begin{array}{l}40 \text { CFR } 268 \\
\text { (Subpart D) }\end{array}$ & $1200-1-11-.10(3)$ \\
\hline
\end{tabular}




\begin{tabular}{|c|c|c|c|c|}
\hline Actions $^{b}$ & Requirements & Prerequisites $^{c d}$ & Federal citation & $\begin{array}{l}\text { Tennessee Code } \\
\text { Annotated (TCA) }\end{array}$ \\
\hline $\begin{array}{l}\text { Container storage } \\
\text { (on site) }\end{array}$ & $\begin{array}{l}\text { Containers of hazardous waste } \\
\text { must be: } \\
\text { - Maintained in good condition; } \\
\text {. Compatible with hazardous waste } \\
\text { to be stored; and } \\
\text {. Closed during storage (except to } \\
\text { add or remove waste). } \\
\text { Inspect container storage areas } \\
\text { weekly for deterioration. }\end{array}$ & $\begin{array}{l}\text { Storage of RCRA hazardous } \\
\text { waste (listed or } \\
\text { characteristic) not meeting } \\
\text { small quantity generator } \\
\text { criteria held for a temporary } \\
\text { period before treatment, } \\
\text { disposal, or storage } \\
\text { elsewhere, in a container } \\
\text { (1.e., any portable device in } \\
\text { which a material is stored, } \\
\text { transported, disposed of, or } \\
\text { handled). A generator who } \\
\text { accumulates or stores } \\
\text { hazardous waste on site for } \\
90 \text { days or less in compliance } \\
\text { with } 40 \text { CFR } 262.34 \text { (a)(1-4) } \\
\text { is not subject to full RCRA } \\
\text { storage requirements. }\end{array}$ & $\begin{array}{l}40 \text { CFR } 264 \\
\text { (Subpart I) } \\
40 \text { CFR 264.171 } \\
40 \text { CFR } 264.172 \\
40 \text { CFR 264.173 } \\
40 \text { CFR 264.174 } \\
40 \text { CFR 264.175 }\end{array}$ & $\begin{array}{l}1200-1-11- \\
.06(9)(\mathrm{b}) \\
1200-1-11- \\
.06(9)(\mathrm{c}) \\
1200-1-11- \\
.06(9)(\mathrm{d}) \\
1200-1-11- \\
.06(9)(\mathrm{e}) \\
1200-1-11- \\
.06(9)(\mathrm{f})\end{array}$ \\
\hline & $\begin{array}{l}\text { Place containers on a sloped, } \\
\text { crackfree base, and protect from } \\
\text { contact with accumulated liquid. } \\
\text { Provide containment system with a } \\
\text { capacity of } 10 \% \text { of the volume of } \\
\text { containers. Remove spilled or } \\
\text { leaked waste in a timely manner to } \\
\text { prevent overflow to the } \\
\text { containment system. }\end{array}$ & & & \\
\hline
\end{tabular}




\begin{tabular}{ll}
\hline \multicolumn{1}{c}{ Actions $^{b}$} & \multicolumn{1}{c}{ Requirements } \\
\hline $\begin{array}{l}\text { Container storage } \\
\text { (on site) } \\
\text { (continued) }\end{array}$ & $\begin{array}{l}\text { Keep containers of ignitable or } \\
\text { reactive waste at least } 50 \mathrm{ft} \text { from } \\
\text { the facility's property line. }\end{array}$ \\
& $\begin{array}{l}\text { Keep incompatible materials } \\
\text { separate. Separate incompatible } \\
\text { materials stored near each other by } \\
\text { a dike or other barrier. }\end{array}$ \\
& $\begin{array}{l}\text { At closure, remove all hazardous } \\
\text { waste and residues from the } \\
\text { containment system, and } \\
\text { decontaminate or remove all } \\
\text { containers, liners. }\end{array}$ \\
& $\begin{array}{l}\text { Storage of banned wastes must be } \\
\text { in accordance with } 40 \text { CFR } 268 . \\
\text { When such storage occurs beyond } \\
\text { one year, the owner/operator bears } \\
\text { the burden of proving that such } \\
\text { storage is solely for the purpose of } \\
\text { accumulating sufficient quantities } \\
\text { to allow for proper recovery, } \\
\text { treatment, and disposal. }\end{array}$
\end{tabular}

Construction of new landfill on stte

(See Closure with waste in place and Clean closure)

\section{Mintmum Technology Requirements}

Install 2 liners or more: a top liner that prevents waste migration into the liner and a bottom liner that prevents waste migration through the liner. ${ }^{k}$
RCRA hazardous waste (listed or characteristic) currently being disposed of at a new, replacement, or expanded landfill.
Tennessee Code

Federal citation Annotated (TCA)

1200-1-11$.06(9)(g)$

40 CFR 264.177

1200-1-11$.06(9)(\mathrm{h})$

40 CFR 264.178 1200-1-11$.06(9)(1)$

40 CFR $268.50 \quad 1200-1-11-$ $.10(1)(e)$

\section{CFR 264.301 1200-1-11-} $.06(14)(b)$ 


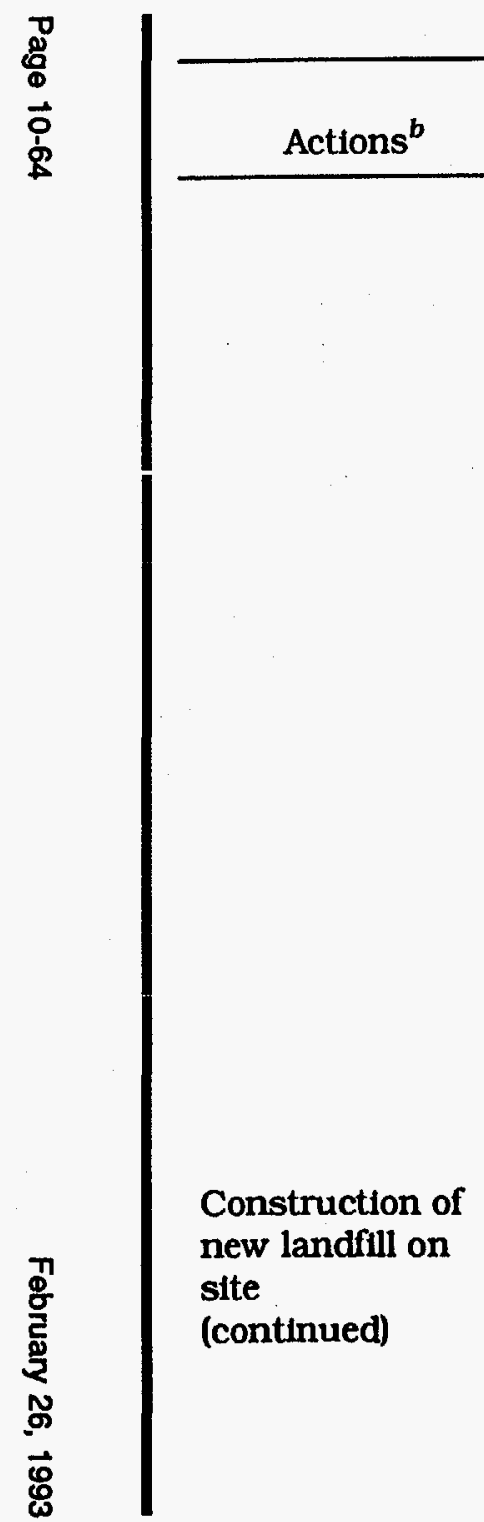

Table 10.14. (continued)

Install leachate collection systems above and between the liners.

Construct run-on and run-off control systems capable of handling the peak discharge of a 25-year storm.

Control wind dispersal of particulates.

Inspect liners and covers during and after installation.

Inspect facility weekly and after storms to detect malfunction of control systems or the presence of liquids in the leachate collection and leak detection systems.

Maintain records of the exact location, dimensions, and contents of waste cells.
Tennessee Code Annotated (TCA)

1200-1-11$.06(14)(\mathrm{b})$

40 CFR 264.301

1200-1-11$.06(14)(b)$

40 CFR 264.301

1200-1-11$.06(14)(\mathrm{b})$

40 CFR 264.303 1200-1-11$.06(14)(d)$

40 CFR 264.303

1200-1-11$.06(14)(d)$

40 CFR 264.304

1200-1-11$.06(14)(\mathrm{e})$ 


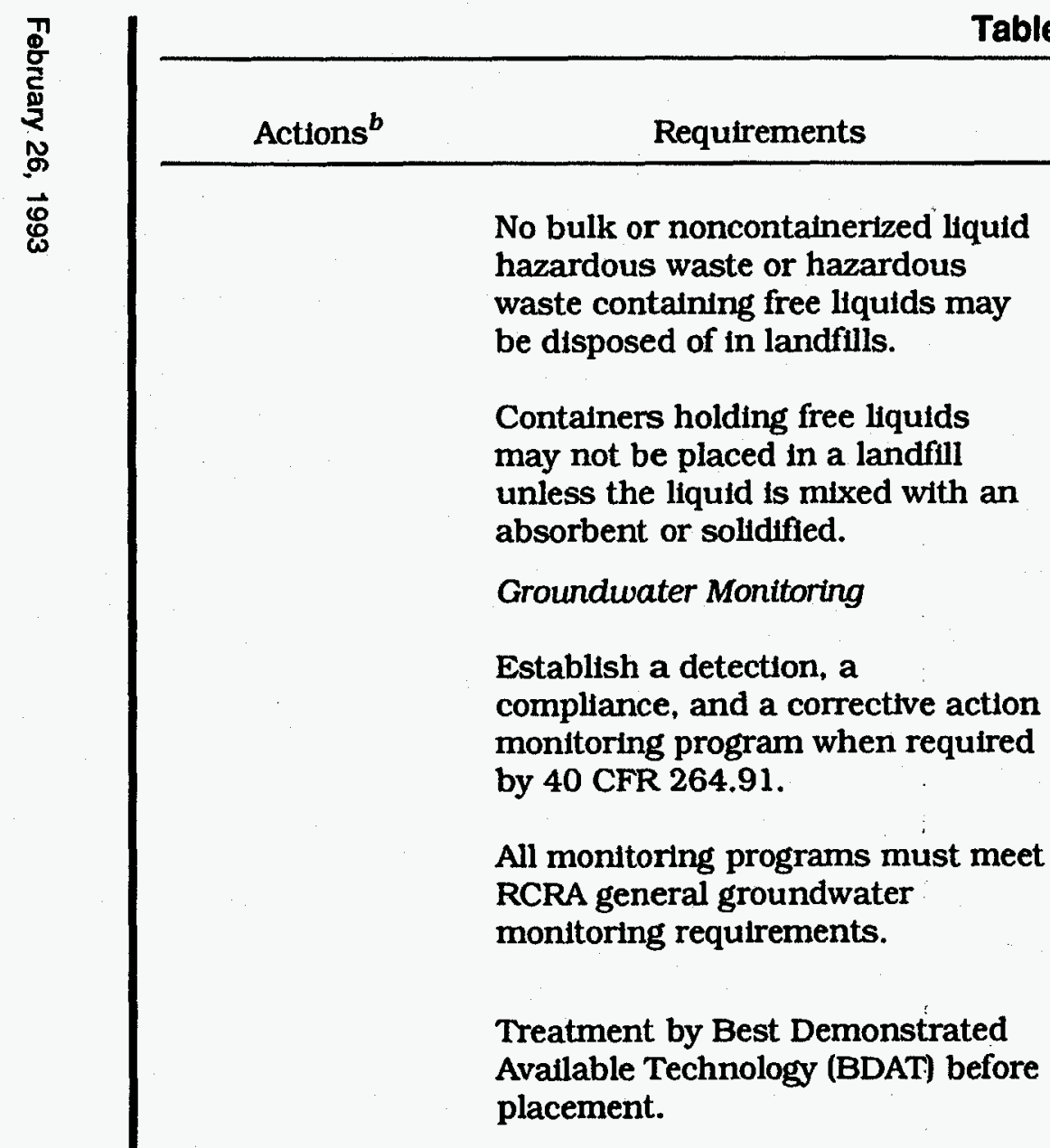

Placement of RCRA

hazardous waste subject to land disposal restrictions.

Creation of a new landfill to treat, store, or dispose of RCRA hazardous wastes as part of a remedial action.
Tennessee Code Federal citation

40 CFR 264.314

200-1-11 $.06(14)(0)$

40 CFR 264.314

1200-1-11$.06(14)(0)$

40 CFR 268

(Subpart D)

$1200-1-11-.10(3)$

40 CFR 264.91-

$$
100
$$

1200-1-11$.06(6)(b)-(k)$

40 CFR 264.97

1200-1-11$.06(6)(\mathrm{h})$ 
Table 10.14. (continued)

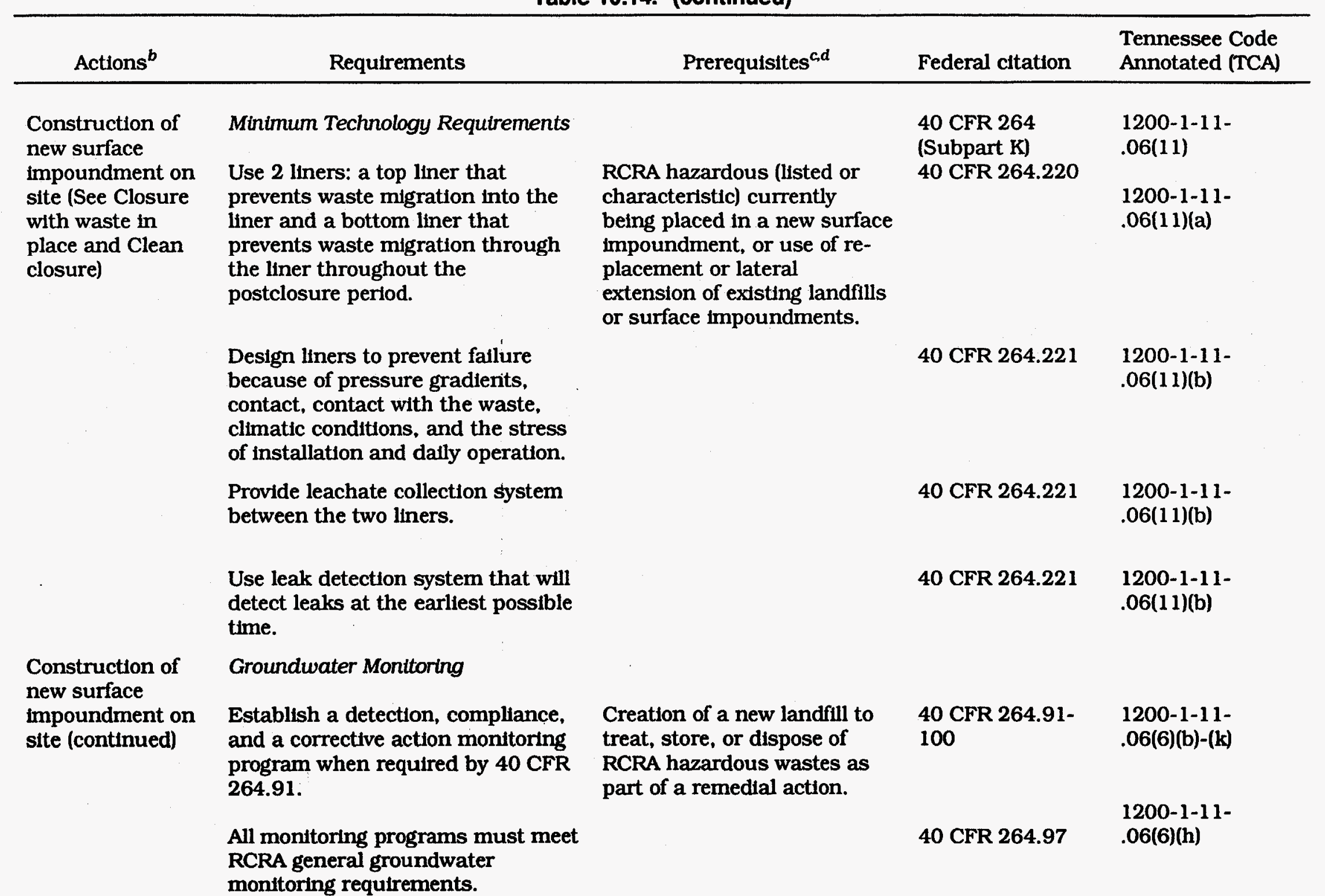




\begin{tabular}{|c|c|c|c|c|}
\hline Actions $^{b}$ & Requirements & Prerequisites $^{c, d}$ & Federal citation & $\begin{array}{l}\text { Tennessee Code } \\
\text { Annotated (TCA) }\end{array}$ \\
\hline \multirow[t]{3}{*}{ Dike construction } & $\begin{array}{l}\text { Design and operate facility to } \\
\text { prevent overtopping from } \\
\text { overfilling; wind and wave action; } \\
\text { rainfall; run-on; malfunctions of } \\
\text { level controllers, alarms, and other } \\
\text { equipment; and human error. }\end{array}$ & $\begin{array}{l}\text { Existing surface } \\
\text { impoundment containing } \\
\text { hazardous waste, or creation } \\
\text { of new surface } \\
\text { impoundment. }\end{array}$ & 40 CFR 264.221 & $\begin{array}{l}1200-1-11- \\
.06(11)(b)\end{array}$ \\
\hline & $\begin{array}{l}\text { Construct dikes with sufficient } \\
\text { structural integrity to prevent } \\
\text { massive failure. }\end{array}$ & & 40 CFR 264.221 & $\begin{array}{l}1200-1-11- \\
.06(11)(b)\end{array}$ \\
\hline & $\begin{array}{l}\text { Ensure that the dike, including } \\
\text { that portion which provides } \\
\text { freeboard, has structural integrity } \\
\text { that will withstand stress of } \\
\text { pressures from added wastes and } \\
\text { will not fall due to scouring or } \\
\text { piping. }\end{array}$ & $\begin{array}{l}\text { Following a pertod of stx } \\
\text { months or greater when an } \\
\text { impoundment has been out } \\
\text { of service }\end{array}$ & $\begin{array}{l}40 \mathrm{CFR} \\
264.226(\mathrm{c})\end{array}$ & $\begin{array}{l}1200-1-11- \\
.06(13)(g) 3\end{array}$ \\
\hline \multirow[t]{3}{*}{$\begin{array}{l}\text { Dike construction } \\
\text { (continued) }\end{array}$} & $\begin{array}{l}\text { Inspect weekly for proper operation } \\
\text { and integrity of the containment } \\
\text { devices. }\end{array}$ & & 40 CFR 264.226 & $\begin{array}{l}1200-1-11- \\
.06(11)(\mathrm{g})\end{array}$ \\
\hline & $\begin{array}{l}\text { Remove surface impoundment } \\
\text { from operation if the dike leaks or } \\
\text { there is a sudden drop in liquid } \\
\text { level. }\end{array}$ & & 40 CFR 264.227 & $\begin{array}{l}1200-1-11- \\
.06(11)(\mathrm{h})\end{array}$ \\
\hline & $\begin{array}{l}\text { U.S. Army Corps of Engineer } \\
\text { permit approval may be required. }\end{array}$ & $\begin{array}{l}\text { Structures or work in, or } \\
\text { affecting, navigable waters of } \\
\text { the U.S. }\end{array}$ & $\begin{array}{l}\$ \$ 9 \text { and } 10, \\
\text { Rivers and } \\
\text { Harbors Act. }\end{array}$ & \\
\hline
\end{tabular}


Table 10.14. (continued)

\begin{tabular}{|c|c|c|c|c|}
\hline Actions $^{b}$ & Requirements & Prerequilsites $^{c, d}$ & Federal citation & $\begin{array}{l}\text { Tennessee Code } \\
\text { Annotated (TCA) }\end{array}$ \\
\hline \multirow[t]{2}{*}{$\begin{array}{l}\text { Direct discharge } \\
\text { of treatment } \\
\text { system effluent }\end{array}$} & $\begin{array}{l}\text { National Pollutant Discharge } \\
\text { Elimination System (NPDES) } \\
\text { Permitting Program }\end{array}$ & & $\begin{array}{l}40 \text { CFR } 122 \\
\text { (Clean Water } \\
\text { Act) })^{n}\end{array}$ & $1200-4-5$ \\
\hline & $\begin{array}{l}\text { Use of best available technology } \\
\text { economically achievable is required } \\
\text { to control toxic and } \\
\text { nonconventional pollutants. Use of } \\
\text { best conventional pollutant control } \\
\text { technology is required to control } \\
\text { conventional pollutants. } \\
\text { Technology-based limitations may } \\
\text { be determined on a case-by-case } \\
\text { basis. }\end{array}$ & $\begin{array}{l}\text { Point source discharge to } \\
\text { waters of the United } \\
\text { States }^{L m} \text {. }\end{array}$ & 40 CFR 122.44(a) & \\
\hline \multirow[t]{3}{*}{$\begin{array}{l}\text { Direct discharge } \\
\text { of treatment } \\
\text { system effluent } \\
\text { (continued) }\end{array}$} & $\begin{array}{l}\text { The discharge must comply with } \\
\text { applicable federal water quality } \\
\text { requirements and more stringent } \\
\text { state requirements under the } \\
\text { Clean Water Act (CWA) }{ }^{\circ} \text {. }\end{array}$ & & $\begin{array}{l}40 \text { CFR 122.44(d) } \\
\text { and state } \\
\text { regulations ap- } \\
\text { proved under } \\
40 \text { CFR } 131\end{array}$ & $1200-4-3-.03$ \\
\hline & $\begin{array}{l}\text { The discharge must be consistent } \\
\text { with the requirements of a Water } \\
\text { Quality Management plan } \\
\text { approved by EPA under CWA } \\
\text { \$208(b). }\end{array}$ & & 40 CFR 122.44(d) & \\
\hline & $\begin{array}{l}\text { Discharge limitations must be } \\
\text { established for all toxic pollutants } \\
\text { that are or may be discharged at } \\
\text { levels greater than that which can } \\
\text { be achleved by technology-based } \\
\text { standards. }\end{array}$ & & 40 CFR 122.44(e) & \\
\hline
\end{tabular}




\begin{tabular}{|c|c|c|c|c|}
\hline Actions $^{b}$ & Requirements & Prerequisites ${ }^{c, d}$ & Federal citation & $\begin{array}{l}\text { Tennessee Code } \\
\text { Annotated (TCA) }\end{array}$ \\
\hline & $\begin{array}{l}\text { Develop and implement a best } \\
\text { management practice (BMP) } \\
\text { program and incorporate in the } \\
\text { NPDES permit to prevent the } \\
\text { release of toxic constituents to } \\
\text { surface waters. }\end{array}$ & & 40 CFR 125.100 & \\
\hline \multirow{9}{*}{$\begin{array}{l}\text { Direct discharge } \\
\text { of treatment } \\
\text { system effluent } \\
\text { (continued) }\end{array}$} & Criteria and standards for NPDES & & 40 CFR 125 & $1200-4-5$ \\
\hline & The BMP program must: & Discharge to waters of the & 40 CFR 125.104 & \\
\hline & $\begin{array}{l}\text { Establish spectfic procedures for } \\
\text { the control of toxdc and } \\
\text { hazardous pollutant spills; }\end{array}$ & & & \\
\hline & $\begin{array}{l}\text { Include a prediction of direction, } \\
\text { rate of flow, and total quantity of } \\
\text { toxic pollutants where experience } \\
\text { indicates a reasonable potential } \\
\text { for equipment fallure; }\end{array}$ & & & \\
\hline & $\begin{array}{l}\text { Ensure proper management of } \\
\text { solid and hazardous waste in } \\
\text { accordance with regulations } \\
\text { promulgated under RCRA. }\end{array}$ & & & \\
\hline & $\begin{array}{l}\text { To ensure compliance, discharge } \\
\text { must be monitored for: }\end{array}$ & & 40 CFR $122.44(1)$ & \\
\hline & - The mass of each pollutant; & & & \\
\hline & The volume of effluent; & & & \\
\hline & $\begin{array}{l}\text { Frequency of discharge and other } \\
\text { measurements as approprlate. }\end{array}$ & & & \\
\hline
\end{tabular}




\begin{tabular}{|c|c|}
\hline Actions $^{b}$ & Requirements \\
\hline \multirow[t]{4}{*}{$\begin{array}{l}\text { Direct discharge } \\
\text { of treatment } \\
\text { system effluent } \\
\text { (continued) }\end{array}$} & $\begin{array}{l}\text { Approved test methods must be } \\
\text { followed for monitored waste } \\
\text { constituents. Detalled require- } \\
\text { ments for analytical procedures } \\
\text { and quality control are providec }\end{array}$ \\
\hline & 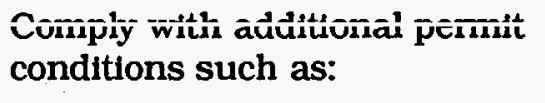 \\
\hline & $\begin{array}{l}\text { Duty to mitigate any adverse } \\
\text { effects of any discharge; and }\end{array}$ \\
\hline & $\begin{array}{l}\text { Proper operation and } \\
\text { maintenance of treatment } \\
\text { systems. }\end{array}$ \\
\hline
\end{tabular}

Discharge to Publicly owned treatment works (POTW)
Pollutants that pass through the POTW without treatment, interfere with POTW without operation, or contaminate POTW sludge are prohibited.

The discharge of pollutants of POTWs is prohibited if they:

- Create a fire or explosion hazard in the POTW;

- Are corrostve (pH < 5.0);

- Obstruct flow, resulting in interference;

Tennessee Code

Federal citation Annotated (TCA)

Off-site discharge ${ }^{p}$. The same regulations apply regardless of whether the waste is discharged into a sewer or trucked to a POTW.
40 CFR 136.1-

$136.3(\mathrm{e})$

Ori-sitte dischiañğes.

$40 \mathrm{CFR}$

122.41(d,e)

\section{CFR 403.5}

(Clean Water Act)

40 CFR 403.5(b) 


\begin{tabular}{|c|c|}
\hline Actions $^{b}$ & Requirements \\
\hline $\begin{array}{l}\text { Discharge to } \\
\text { POTw (continued) }\end{array}$ & $\begin{array}{l}\text { Are discharged at a flow rate } \\
\text { and/or concentration that will } \\
\text { result in interference; and }\end{array}$ \\
\hline & $\begin{array}{l}\text { Increase the temperature of } \\
\text { wastewater entering the } \\
\text { treatment plant which would } \\
\text { result in interference, but in no } \\
\text { case raise the POTW } \\
\text { temperature above } 104^{\circ} \mathrm{F} \\
\left(40^{\circ} \mathrm{C}\right) \text {. }\end{array}$ \\
\hline
\end{tabular}

Discharge must comply with local POTW pretreatment program.

RCRA permit-by-rule requirements may be complied with for discharges of RCRA hazardous wastes to POTWs by truck, rall, or dedicated pipe.

Discharge of dredge and fill material to navigable waters
The four conditions that must be satisfied before dredge and fill is an allowable alternattve are:

\section{- There must be no practicable} alternative.
40 CFR 403.5(d)

40 CFR 270.60(c) 1200-1-11$.07(1)(\mathrm{c})$
40 CFR 230.10

(Marine

Protection,

Research, and Sanctuaries Act) 


\begin{tabular}{|c|c|}
\hline Actions $^{b}$ & Requirements \\
\hline \multirow[t]{6}{*}{$\begin{array}{l}\text { Discharge of } \\
\text { dredge and fill } \\
\text { materlal to } \\
\text { navigable waters } \\
\text { (continued) }\end{array}$} & $\begin{array}{l}\text { Discharge of dredge or fill } \\
\text { material must not cause a } \\
\text { violation of state water quality } \\
\text { standards, violate any } \\
\text { applicable toxdc effluent } \\
\text { standards, jeopardize an } \\
\text { endangered species, or injure } \\
\text { marine sanctuary. }\end{array}$ \\
\hline & $\begin{array}{l}\text { No discharge shall be permitte } \\
\text { that will cause or contribute } t \\
\text { significant degradation of the } \\
\text { water. }\end{array}$ \\
\hline & $\begin{array}{l}\text { Appropriate steps to minimize } \\
\text { adverse effects must be taken. }\end{array}$ \\
\hline & $\begin{array}{l}\text { Determine long- and short-term } \\
\text { effects on physical, chemical, a } \\
\text { blological components of the } \\
\text { aquatic ecosystems. }\end{array}$ \\
\hline & $\begin{array}{l}\text { Comply with additional substan } \\
\text { conditions such as: }\end{array}$ \\
\hline & $\begin{array}{l}\text { Duty to mitigate any adverse } \\
\text { effects of any discharge; and }\end{array}$ \\
\hline $\begin{array}{l}\text { Discharge of } \\
\text { dredge and fill } \\
\text { material to }\end{array}$ & $\begin{array}{l}\text { Proper operation and } \\
\text { maintenance of treatment } \\
\text { systems. }\end{array}$ \\
\hline
\end{tabular}

navigable waters systems. 


\begin{tabular}{ll}
\hline Actions $^{b}$ & \multicolumn{1}{c}{ Requirements } \\
\hline & $\begin{array}{l}\text { Monitor and report results as } \\
\text { required by permit (minimum of at } \\
\text { least annually). } \\
\text { Dredging }\end{array}$ \\
& \\
& Removal of all contaminated soil. \\
& $\begin{array}{l}\text { Prohibits construction of any } \\
\text { structures, or work in or affecting } \\
\text { navigable waters, without approval } \\
\text { of the U.S. Corps of Engineers. }\end{array}$
\end{tabular}

Excavation

Excavation (continued)
Site excavations must be shored or sloped to prevent accidental collapse in accordance with Subpart P of 29 CFR 1926.

Movement of excavated materials to new location and placement in or on land will trigger land disposal restrictions for the excavated waste or closure requirements for the unit in which the waste is placed.

Total suspended particulates (TSP) must be maintained below National Ambient Air Quality Standards
Off-site discharges.

Federal citation

Tennessee Code

Annotated (TCA)

RCRA hazardous waste placed at site after Nov. 19 1980 , or movement of hazardous waste from one unit, area of contamination or location into another unit or area of concentration.

Work performed in navigable waters of U.S.

Occupational Safety and Health Act (OSHA) regulations for workers at hazardous waste sites.

Materials containing RCRA hazardous wastes subject to land disposal restrictions are placed in another unit.

Nonpoint source contribution to fugitive dust emissions
40 CFR 122.44(i)

40 CFR 264.228

(surface

1200-1-11$.06(11)(1)$

impoundments)

40 CFR 264.258

(waste plles)

1200-1-11$.06(11)(1)$

$\$ \S 9$ and 10 ,

Rivers and

Harbors Act.

29 CFR 1926, 54

FR 45894

(Nov. 31, 1989)

40 CFR 268

(Subpart D)

$1200-1-11-.10(3)$

40 CFR 50.6

1200-3-3-.03 


\begin{tabular}{|c|c|c|c|c|}
\hline Actions $^{b}$ & Requirements & Prerequisites ${ }^{c, d}$ & Federal citation & $\begin{array}{l}\text { Tennessee Code } \\
\text { Annotated (TCA) }\end{array}$ \\
\hline
\end{tabular}

Gas collection diversion

Incineration

(on site)
Control of fugitive dust emissions

may be required under state air quality regulations.

Standards for control of emissions of volatile organics. These are bascd on CAA emisston standuards found in 40 CFR 60.480-60.489.

Excavation of soll for construction of slurry wall may trigger closure or land disposal restrictions.

Site excavations must be shored or sloped to prevent accidental collapse in accordance with Subpart P of 29 CFR 1926.

Analyze the waste feed.

Dispose of all hazardous waste and residues, including ash, scrubber water, and scrubber sludge.
Emissions from process vents and equipment leaks at TSD factlttics handlinis o: recycling hazardous waste containing $10 \%$ or more volatile organics.

Materials containing RCRA hazardous waste subject to land disposal restrictions if moved to another unit.

OSHA regulations for workers at waste sites.

RCRA hazardous waste.
54 FR 9294

(March 3. 1989)

55 FR 25454

(June 21, 1990)

40 CFR 268

(Subpart D)

$1200-1-11-.10(3)$

40 CFR 264.341

1200-1-11$.06(15)(b)$ 


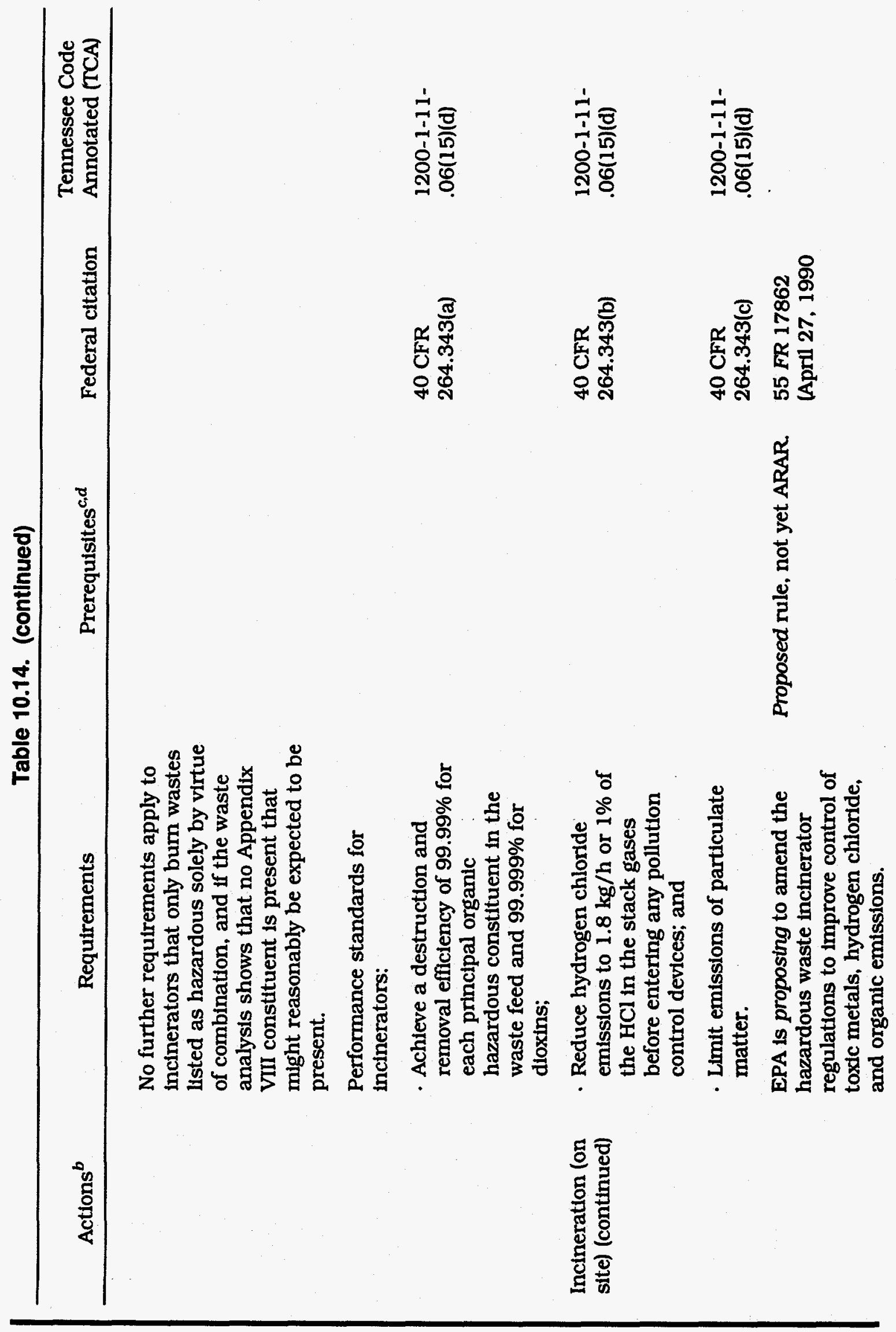

February 26, 1993

Page 10-75 


\begin{tabular}{|c|c|c|c|c|}
\hline Actions $^{b}$ & Requirements & Prerequisites $^{c, d}$ & Federal citation & $\begin{array}{l}\text { Tennessee Code } \\
\text { Annotated (TCA) }\end{array}$ \\
\hline & $\begin{array}{l}\text { Monitoring of various parameters } \\
\text { during operation of the incinerator } \\
\text { is required. These parameters } \\
\text { include: }\end{array}$ & & 40 CFR 264.347 & $\begin{array}{l}1200-1-11- \\
.06(15)(g)\end{array}$ \\
\hline & - Combustion temperature; & & & \\
\hline & Waste feed rate; & & & \\
\hline & $\begin{array}{l}\text { An indicator of combustion gas } \\
\text { velocity; and }\end{array}$ & & & \\
\hline & - Carbon monoxide & & & \\
\hline & $\begin{array}{l}\text { Control fugittve emissions either } \\
\text { by: }\end{array}$ & & $\begin{array}{l}40 \mathrm{CFR} \\
264.345 \text { (d) }\end{array}$ & $\begin{array}{l}1200-1-11- \\
.06(15)(f)\end{array}$ \\
\hline \multirow[t]{5}{*}{$\begin{array}{l}\text { Incineration (on } \\
\text { site) (continued) }\end{array}$} & $\begin{array}{l}\text { Keeping combustion zone } \\
\text { sealed; or }\end{array}$ & & & \\
\hline & $\begin{array}{l}\text { Maintaining combustion zone } \\
\text { pressure lower than } \\
\text { atmospheric pressure. }\end{array}$ & & & \\
\hline & $\begin{array}{l}\text { Utilize automatic cutoff system to } \\
\text { stop waste feed when operating } \\
\text { conditions deviate. }\end{array}$ & & $\begin{array}{l}40 \mathrm{CFR} \\
264.345(\mathrm{e})\end{array}$ & $\begin{array}{l}1200-1-11- \\
.06(15)(f)\end{array}$ \\
\hline & $\begin{array}{l}\text { Special performance standards for } \\
\text { incineration of polychlorinated } \\
\text { blphenyls }\end{array}$ & & $\begin{array}{l}40 \text { CFR } 761.70(b) \\
\text { (Total Substances }^{\text {Control Act) }}\end{array}$ & \\
\hline & $\begin{array}{l}\text { New source performance standards } \\
\text { for incinerators. }\end{array}$ & $\begin{array}{l}\text { Incinerators with a charge } \\
\text { rate greater than } 45 \text { metric } \\
\text { tons/d. }\end{array}$ & $\begin{array}{l}40 \text { CFR 60.50- } \\
60.54 \\
\text { (Clean Air Act) }\end{array}$ & \\
\hline
\end{tabular}




\begin{tabular}{|c|c|c|c|}
\hline Requirements & Prerequisites ${ }^{c, d}$ & Federal citation & $\begin{array}{l}\text { Tennessee Code } \\
\text { Annotated (TCA) }\end{array}$ \\
\hline $\begin{array}{l}\text { Ensure hazardous constituents are } \\
\text { degraded, transformed, or } \\
\text { Immobilized within the treatment } \\
\text { zone. }\end{array}$ & $\begin{array}{l}\text { RCRA hazardous waste being } \\
\text { treated or placed into } \\
\text { another unit. }\end{array}$ & $\begin{array}{l}40 \mathrm{CFR} \\
264.271(\mathrm{a})\end{array}$ & $\begin{array}{l}1200-1-11- \\
.06(13)(b)\end{array}$ \\
\hline $\begin{array}{l}\text { Maximum depth of treatment zone } \\
\text { must be no more than } 1.5 \text { meters } \\
\text { ( } 5 \mathrm{ft} \text { ) from the initial soil surface; } \\
\text { and more than } 1 \text { meter ( } 3 \mathrm{ft}) \text { above } \\
\text { the seasonal high-water table. }\end{array}$ & & $\begin{array}{l}40 \mathrm{CFR} \\
264.271(\mathrm{c})\end{array}$ & $\begin{array}{l}1200-1-11- \\
.06(13)(b)\end{array}$ \\
\hline $\begin{array}{l}\text { Minimize run-off of hazardous } \\
\text { constituents. }\end{array}$ & & $\begin{array}{l}40 \mathrm{CFR} \\
264.273(\mathrm{~b})\end{array}$ & $\begin{array}{l}1200-1-11- \\
.06(13)(d)\end{array}$ \\
\hline $\begin{array}{l}\text { Maintain run-on/run-off control } \\
\text { and management system. }\end{array}$ & & $\begin{array}{l}40 \mathrm{CFR} \\
264.273(\mathrm{c})\end{array}$ & $\begin{array}{l}1200-1-11- \\
.06(13)(d)\end{array}$ \\
\hline $\begin{array}{l}\text { Special application conditions if } \\
\text { food-chain crops grown in or on } \\
\text { treatment zone. }\end{array}$ & & 40 CFR 264.276 & $\begin{array}{l}1200-1-11- \\
.06(13)(g)\end{array}$ \\
\hline $\begin{array}{l}\text { Unsaturated zone monitoring } \\
\text { program required. }\end{array}$ & & 40 CFR 264.278 & $\begin{array}{l}1200-1-11- \\
.06(13)(i)\end{array}$ \\
\hline $\begin{array}{l}\text { Special requirements for ignitable } \\
\text { or reactive waste. }\end{array}$ & & 40 CFR 264.281 & $\begin{array}{l}1200-1-11- \\
.06(13)(1)\end{array}$ \\
\hline $\begin{array}{l}\text { Special requirements for } \\
\text { incompatible waste. }\end{array}$ & & 40 CFR 264.282 & $\begin{array}{l}1200-1-11- \\
.06(13)(\mathrm{m})\end{array}$ \\
\hline $\begin{array}{l}\text { Special requirements for RCRA } \\
\text { hazardous wastes. }\end{array}$ & $\begin{array}{l}\text { RCRA waste FO20, FO21, } \\
\text { FO22, FO23, FO26, FO27, }\end{array}$ & 40 CFR 264.283 & $\begin{array}{l}1200-1-11- \\
.06(13)(n)\end{array}$ \\
\hline
\end{tabular}




\begin{tabular}{|c|c|c|c|c|}
\hline Actions $^{b}$ & Requirements & Prerequisites ${ }^{c . d}$ & Federal citation & $\begin{array}{l}\text { Tennessee Code } \\
\text { Annotated (TCA) }\end{array}$ \\
\hline & $\begin{array}{l}\text { Prior to land disposal, waste must } \\
\text { be treated to BDAT levels or meet a } \\
\text { "no migration" standard. }\end{array}$ & $\begin{array}{l}\text { RCRA hazardous waste being } \\
\text { disposed of in another unit. }\end{array}$ & $\begin{array}{l}40 \text { CFR } 268 \\
\text { (Part D) }\end{array}$ & $1200-1-11-.10(3)$ \\
\hline & $\begin{array}{l}\text { Treatment standards and land } \\
\text { disposal restrictions apply to: } \\
\text { spcint solicint wastes, dfusini- } \\
\text { containing wastes, California-list } \\
\text { wastes, and all RCRA hazardous } \\
\text { waste (see Treatment). }\end{array}$ & & $\begin{array}{l}52 \text { FR } 25760 \\
\text { (July 8, 1987) } \\
\text { RCRA 30OAf(u) }\end{array}$ & \\
\hline $\begin{array}{l}\text { Operation and } \\
\text { maintenance }\end{array}$ & $\begin{array}{l}\text { 30-year postclosure care to ensure } \\
\text { that site is maintained and } \\
\text { monitored. }\end{array}$ & $\begin{array}{l}\text { Closure of hazardous waste } \\
\text { management units. }\end{array}$ & 40 CFR 264.117 & $\begin{array}{l}1200-1-11- \\
.06(7)(\mathrm{h})\end{array}$ \\
\hline \multirow[t]{2}{*}{$\begin{array}{l}\text { Placement of } \\
\text { liquild waste in } \\
\text { landfill }\end{array}$} & $\begin{array}{l}\text { No bulk or noncontainerized liquid } \\
\text { hazardous waste or hazardous } \\
\text { waste containing free liquids may } \\
\text { be disposed of in landfills. }\end{array}$ & $\begin{array}{l}\text { Placement of a bulk or } \\
\text { noncontainerized RCRA } \\
\text { waste in a landfill }\end{array}$ & $\begin{array}{l}40 \mathrm{CFR} \\
264.314(\mathrm{~b})\end{array}$ & $\begin{array}{l}1200-1-11- \\
.06(14)(0)\end{array}$ \\
\hline & $\begin{array}{l}\text { Containers holding free liquid may } \\
\text { not be placed in a landfill unless } \\
\text { the liquid is mixed with an } \\
\text { absorbent or solidified. }\end{array}$ & & & \\
\hline $\begin{array}{l}\text { Placement of } \\
\text { waste in land } \\
\text { disposal unit }\end{array}$ & $\begin{array}{l}\text { Attain land disposal treatment } \\
\text { standards to comply with "land } \\
\text { ban" restrictions (see Treatment) }\end{array}$ & $\begin{array}{l}\text { Placement of RCRA } \\
\text { hazardous waste in a landfill, } \\
\text { surface impoundment, waste } \\
\text { pile, injection well, land } \\
\text { treatment facility, salt dome } \\
\text { formation, salt bed } \\
\text { formation, or underground } \\
\text { cave or mine. }\end{array}$ & $\begin{array}{l}40 \text { CFR } 268 \\
\text { (Subpart D) }\end{array}$ & $1200-1-11-.10(3)$ \\
\hline
\end{tabular}




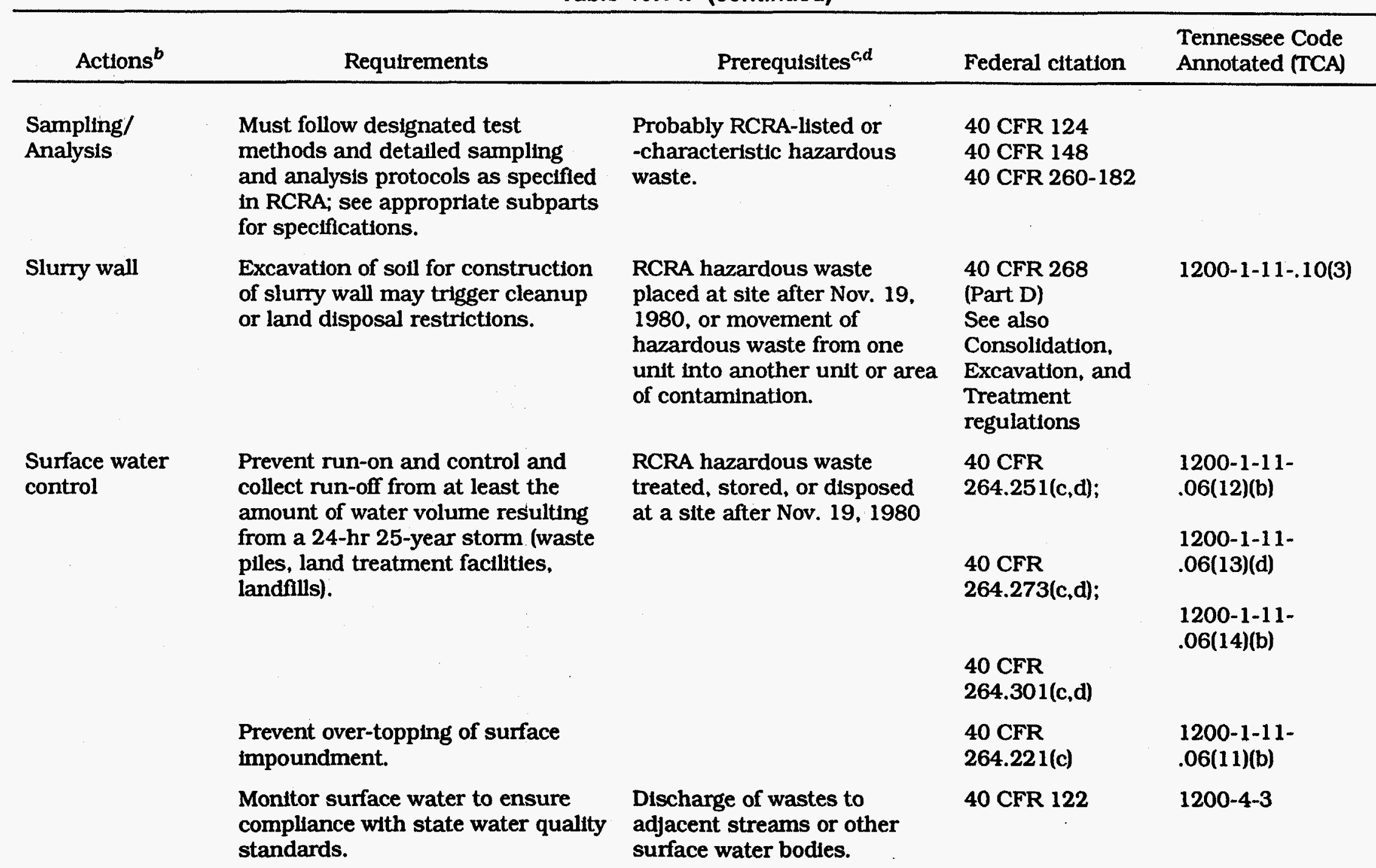




\begin{tabular}{|c|c|c|}
\hline Actions $^{b}$ & Requirements & Prerequisites $^{c, d}$ \\
\hline $\begin{array}{l}\text { Tank storage (on } \\
\text { site) }\end{array}$ & $\begin{array}{l}\text { Existing and new tanks must have } \\
\text { sufficient structural strength, } \\
\text { compatible with the waste, and } \\
\text { corrosion protection to ensure that } \\
\text { they do not collapse or rupture. }\end{array}$ & $\begin{array}{l}\text { Storage of RCRA hazardous } \\
\text { waste (listed or } \\
\text { characteristic) not meeting } \\
\text { small quantity generator } \\
\text { criteria held for a temporary } \\
\text { period greater than } 90 \text { days } \\
\text { before treatment, disposal, or } \\
\text { storage elsewhere, in a tank } \\
\text { (i.e., any portable device in } \\
\text { which a material is stored, } \\
\text { transported, disposed of, or } \\
\text { handled). A generator who } \\
\text { accumulates or stores } \\
\text { hazardous waste on site for } \\
90 \text { days or less in compliance } \\
\text { with } 40 \text { CFR } 262.34 \text { (a)(1-4) } \\
\text { is not subject to full RCRA } \\
\text { storage requirements. }\end{array}$ \\
\hline
\end{tabular}

Waste must not be incompatible with the tank material unless the tank is protected by a liner or by other means.

Tanks must be provided with secondary containment and controls to prevent overfilling, and sufficient freeboard maintained in open tanks to prevent overtopping by wave action or precipitation. Annotated (TCA)

\section{CFR 264.191- 1200-1-11-}

192

$.06(10)(b)-(c)$
40 CFR 264.193- 1200-1-11194 $.06(10)(d)-(e)$
1200-1-11$.06(10)(b)$ 


\begin{tabular}{|c|c|c|c|c|}
\hline Actions $^{b}$ & Requirements & Prerequisites ${ }^{c, d}$ & Federal citation & $\begin{array}{l}\text { Tennessee Code } \\
\text { Annotated (TCA) }\end{array}$ \\
\hline \multirow[t]{6}{*}{$\begin{array}{l}\text { Tank storage (on } \\
\text { site) (continued) }\end{array}$} & $\begin{array}{l}\text { Prevent the migration of spills or } \\
\text { leaks to solls or surface water. } \\
\text { Remove and dispose of any visible } \\
\text { containment of solls or surface } \\
\text { water. }\end{array}$ & $\begin{array}{l}\text { Leaks or spills from tanks or } \\
\text { secondary containment } \\
\text { systems containing RCRA } \\
\text { hazardous waste. }\end{array}$ & $\begin{array}{l}40 \mathrm{CFR} \\
264.196(\mathrm{c})\end{array}$ & $\begin{array}{l}1200-1-11- \\
.06(12)(d) 3\end{array}$ \\
\hline & $\begin{array}{l}\text { Remove tank from service; remove } \\
\text { waste from tank or secondary } \\
\text { containment system. }\end{array}$ & & $\begin{array}{l}40 \text { CFR } \\
264.196(a, b)\end{array}$ & $\begin{array}{l}1200-1-11- \\
.06(12)(d) 3\end{array}$ \\
\hline & $\begin{array}{l}\text { Repair any corrosion, crack, or } \\
\text { leak. }\end{array}$ & & $\begin{array}{l}40 \mathrm{CFR} \\
264.196(\mathrm{c})\end{array}$ & $\begin{array}{l}1200-1-11- \\
.06(12)(d) 3\end{array}$ \\
\hline & $\begin{array}{l}\text { Notify pursuant to } 40 \text { CFR } 302 \text { if } \\
\text { spill or leak is above a reportable } \\
\text { quantity }\end{array}$ & & $\begin{array}{l}40 \text { CFR } \\
264.196(d)\end{array}$ & $\begin{array}{l}1200-1-11- \\
.06(12)(d) 3\end{array}$ \\
\hline & $\begin{array}{l}\text { Inspect the following: overfilling } \\
\text { control; control equipment, } \\
\text { monitoring data, waste level (for } \\
\text { uncovered tanks), tank condition, } \\
\text { above-ground portions of tanks (to } \\
\text { assess their structural integrity), } \\
\text { and the area surrounding the tank } \\
\text { (to identify signs of leakage). }\end{array}$ & & 40 CFR 264. 195 & $\begin{array}{l}1200-1-11- \\
.06(10)(f)\end{array}$ \\
\hline & $\begin{array}{l}\text { At closure, remove all hazardous } \\
\text { waste and hazardous waste } \\
\text { residues from tanks, discharge } \\
\text { control equipment, and discharge } \\
\text { confinement structures. }\end{array}$ & & 40 CFR 264. 197 & $\begin{array}{l}1200-1-11- \\
.06(10)(\mathrm{h})\end{array}$ \\
\hline
\end{tabular}




\begin{tabular}{|c|c|c|c|c|}
\hline Actions $^{b}$ & Requirements & Prerequisites $^{c d}$ & Federal citation & $\begin{array}{l}\text { Tennessee Code } \\
\text { Annotated (TCA) }\end{array}$ \\
\hline \multirow[t]{2}{*}{$\begin{array}{l}\text { Tank storage (on } \\
\text { site) (continued) }\end{array}$} & $\begin{array}{l}\text { Store ignitable and reactive waste } \\
\text { so as to prevent the waste from } \\
\text { Igniting or reacting. Ignitable or } \\
\text { reactive wastes in covered tanks } \\
\text { must comply with buffer zone } \\
\text { requirements in "Flammable and } \\
\text { Combustible Liquids Code," Tables } \\
2-1 \text { through } 2-6 \text { (National Fire } \\
\text { Protection Association } 1976,1981 \text { ). }\end{array}$ & & 40 CFR 264. 198 & $\begin{array}{l}1200-1-11- \\
.06(10)(1)\end{array}$ \\
\hline & $\begin{array}{l}\text { Storage of banned wastes must be } \\
\text { in accordance with } 40 \text { CFR } 268 \text {. } \\
\text { When such storage exceeds one } \\
\text { year, the owner/operator bears the } \\
\text { burden of proving that the storage } \\
\text { is solely for the purpose of } \\
\text { accumulating sufficient quantities } \\
\text { to allow for proper recovery. } \\
\text { treatment, and disposal. }\end{array}$ & & 40 CFR 268.50 & $\begin{array}{l}1200-1-11- \\
.10(4)(a)\end{array}$ \\
\hline \multirow[t]{2}{*}{ Transportation } & $\begin{array}{l}\text { Compliance with the RCRA } \\
\text { manifest and pretransportation } \\
\text { regulations must be achieved. }\end{array}$ & $\begin{array}{l}\text { Transportation of RCRA } \\
\text { waste to an off-site } \\
\text { treatment, storage, or } \\
\text { disposal facility }\end{array}$ & 40 CFR 262 & $1200-1-11-.03$ \\
\hline & $\begin{array}{l}\text { Compliance with Department of } \\
\text { Transportation (DOT) packaging, } \\
\text { labeling, markdng, and placarding } \\
\text { requirements must be achieved ( } 49 \\
\text { CFR 172-179) }\end{array}$ & , & 40 CFR 262 & $1200-1-11-.03$ \\
\hline
\end{tabular}




\begin{tabular}{|c|c|c|c|c|}
\hline Actions $^{b}$ & Requirements & Prerequisites ${ }^{c, d}$ & Federal citation & $\begin{array}{l}\text { Tennessee Code } \\
\text { Annotated (TCA) }\end{array}$ \\
\hline \multirow[t]{5}{*}{$\begin{array}{l}\text { Treatment (in a } \\
\text { unit) }\end{array}$} & $\begin{array}{l}\text { Design and operating standards for } \\
\text { units in which hazardous waste is } \\
\text { treated must ensure protection of } \\
\text { human health and the environ- } \\
\text { ment. }\end{array}$ & $\begin{array}{l}\text { Treatment of RCRA } \\
\text { hazardous waste in a unit. }\end{array}$ & $\begin{array}{l}40 \text { CFR 264.601 } \\
\text { (Miscellaneous } \\
\text { treatment units) }\end{array}$ & $\begin{array}{l}1200-1-11- \\
.06(19)(\mathrm{b})\end{array}$ \\
\hline & $\begin{array}{l}\text { Prevention of any releases that } \\
\text { may have adverse effects on } \\
\text { human health or the environment } \\
\text { due to migration of waste } \\
\text { constituents }\end{array}$ & & & \\
\hline & $\begin{array}{l}\text { Specific considerations must be } \\
\text { made to prevent adverse effects in: }\end{array}$ & & $\begin{array}{l}40 \mathrm{CFR} \\
264.601(\mathrm{a})\end{array}$ & $\begin{array}{l}1200-1-11- \\
.06(19)(b)\end{array}$ \\
\hline & $\begin{array}{l}\text { the groundwater or subsurface } \\
\text { environment. }\end{array}$ & & & \\
\hline & $\begin{array}{l}\text { surface water, or wetlands, or } \\
\text { the soll surface. }\end{array}$ & & & \\
\hline
\end{tabular}




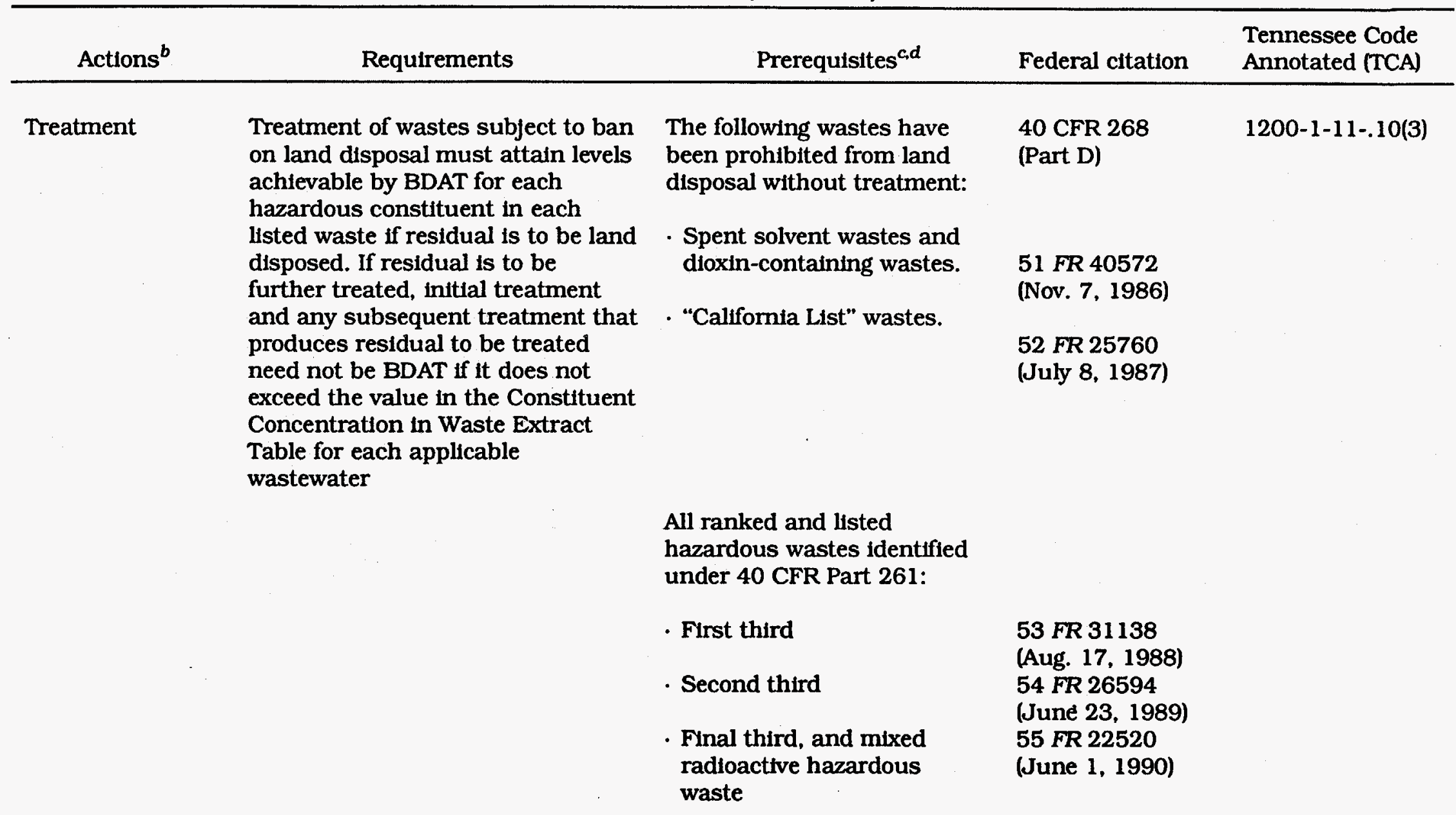




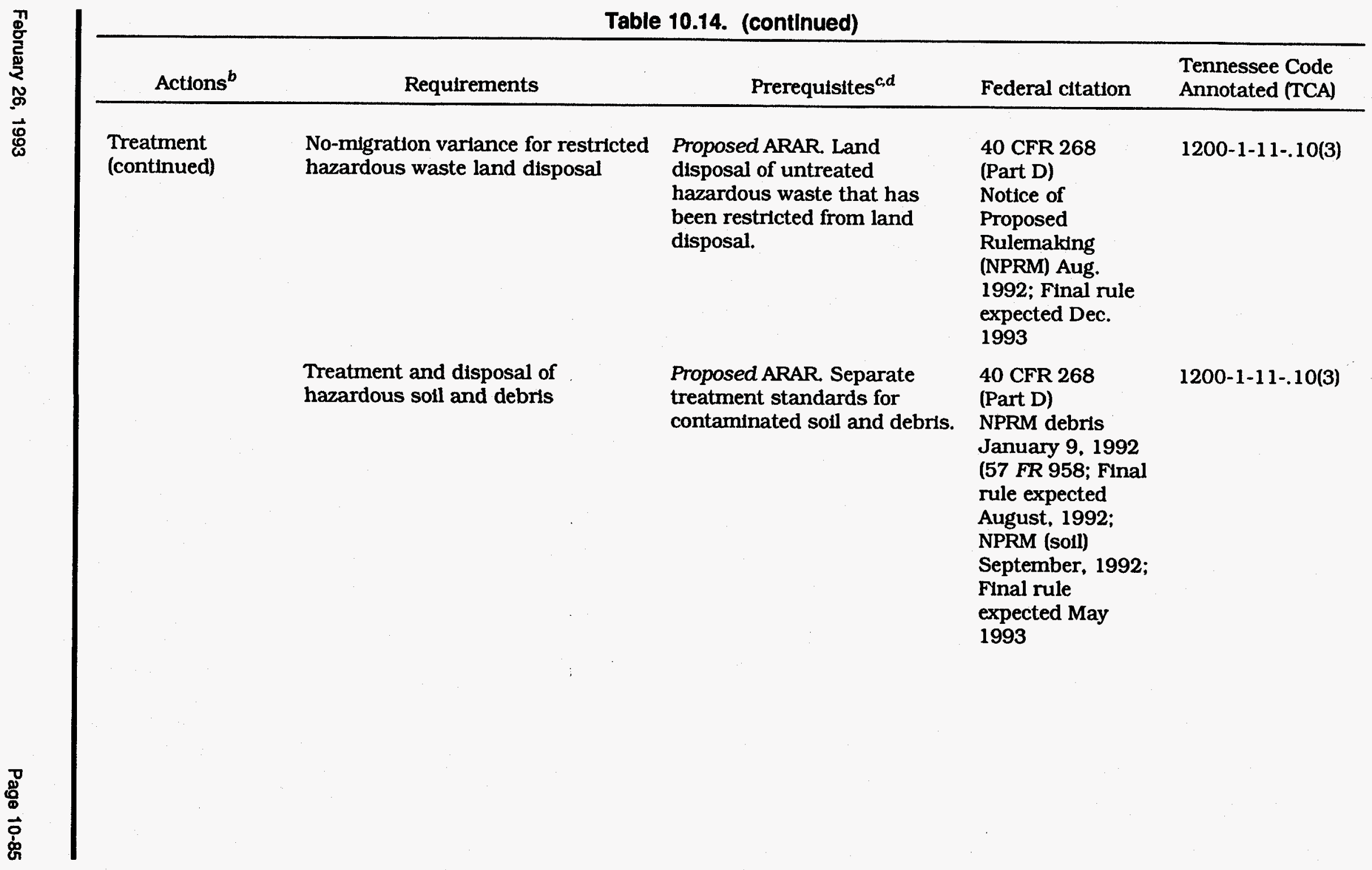


Table 10.14. (continued)

\begin{tabular}{|c|c|c|}
\hline Actions $^{b}$ & Requirements & Prerequisites $^{c d d}$ \\
\hline $\begin{array}{l}\text { Treatment } \\
\text { (continued) }\end{array}$ & & $\begin{array}{l}\text { Effective Nov. } 8,1990, \\
\text { disposal of contaminated soll } \\
\text { or debris resulting from } \\
\text { CERCLA' response actions or } \\
\text { RCRA corrective actions is } \\
\text { subject to land disposal } \\
\text { prohibitions and/or treat- } \\
\text { ment standards established } \\
\text { for spent solvent wastes, } \\
\text { dioxin-containing wastes, } \\
\text { and "California List" wastes. }\end{array}$ \\
\hline & & $\begin{array}{l}\text { Disposal of soil and debris } \\
\text { contaminated with RCRA } \\
\text { hazardous waste for which } \\
\text { the treatment standard is } \\
\text { incineration is not subject to } \\
\text { the land disposal restrictions } \\
\text { until Aug. 1990. July } 1991 \text {, } \\
\text { and Nov. 1991, for the three } \\
\text { thirds, respectively. Mixed } \\
\text { radioactive waste is included } \\
\text { in the final third capacity } \\
\text { national capacity varlance } \\
\text { schedule. }\end{array}$ \\
\hline
\end{tabular}

Underground injection of wastes and treated groundwater
Underground Injection Control (UIC) program prohibits:
40 CFR 144 (Safe Drinking Water Act) ${ }^{s}$ 
Table 10.14. (continued)

\begin{tabular}{ll}
\hline \multicolumn{1}{c}{ Actions $^{b}$} & \multicolumn{1}{c}{ Requirements } \\
\hline $\begin{array}{l}\text { Underground } \\
\text { Injection of } \\
\text { wastes and } \\
\text { treated } \\
\text { groundwater } \\
\text { (continued) }\end{array}$ & $\begin{array}{l}\text { Injection activities that allow } \\
\text { movement of contaminants into } \\
\text { underground sources of drinking } \\
\text { water (USDW) and results in } \\
\text { violation of MCLs or adversely } \\
\text { affects healtht }\end{array}$ \\
& $\begin{array}{l}\text { Construction of new Class IV } \\
\text { wells, and operation and } \\
\text { maintenance of existing wells. }\end{array}$
\end{tabular}

Subsurface emplacement of waste fluids into groundwater in area of regional rock deformation of the magnitude that occurs in east Tennessee

Excludes Class IV wells used to reinject contaminated groundwater that has been treated if part of a CERCLA or RCRA remedial action.

Class I wells
Tennessee Code

Federal citation Annotated (TCA)

40 CFR 144.12

1200-4-6-.04

40 CFR 144. 13

$1200-4-6-.13$

$1200-4-6-.10(1)(c)$

40 CFR 144.14

All hazardous waste injection wells must also comply with the RCRA Part 264 permitting requirements. 


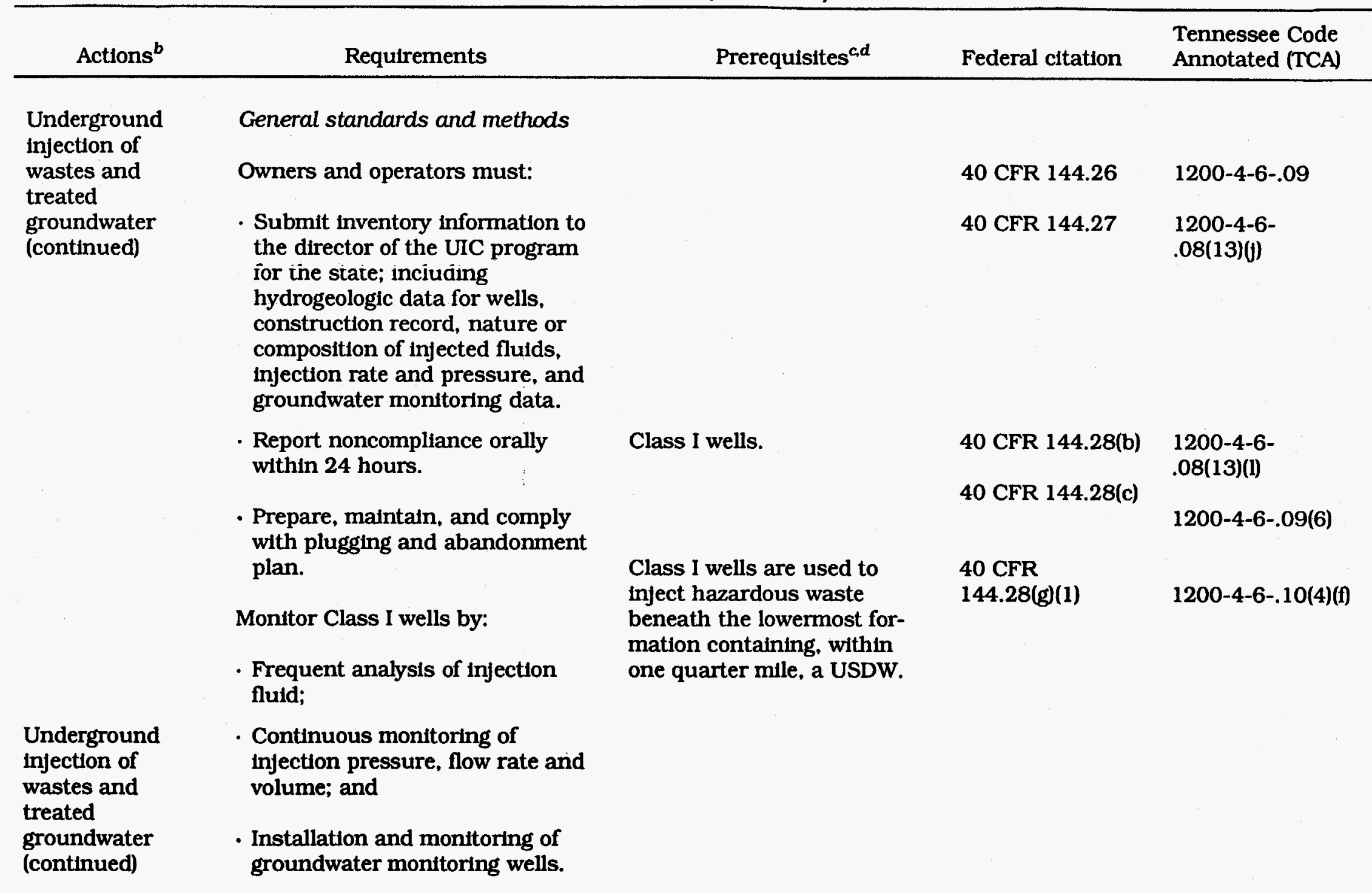




\begin{tabular}{|c|c|c|c|c|}
\hline Actions $^{b}$ & Requirements & Prerequisites ${ }^{c, d}$ & Federal citation & $\begin{array}{l}\text { Tennessee Code } \\
\text { Annotated (TCA) }\end{array}$ \\
\hline & \multicolumn{4}{|l|}{$\begin{array}{l}\text { Applicants for Class I permits } \\
\text { must: }\end{array}$} \\
\hline & $\begin{array}{l}\text { Identify all injection wells within } \\
\text { the area of review; }\end{array}$ & & 40 CFR 144.55 & $\begin{array}{l}1200-4-6- \\
.10(3)(b)\end{array}$ \\
\hline & $\begin{array}{l}\text { Take action as necessary to } \\
\text { ensure that such wells are } \\
\text { properly sealed, completed, or } \\
\text { abandoned to prevent } \\
\text { contamination of USDW. }\end{array}$ & & 40 CFR 146.4 & $1200-4-6-.10(5)$ \\
\hline & $\begin{array}{l}\text { Case and cement all Class I wells } \\
\text { to prevent movement of fluids into } \\
\text { USDW, taking into consideration } \\
\text { well depth, injection pressure, hole } \\
\text { size, composition of injected waste, } \\
\text { and other factors. }\end{array}$ & & $\begin{array}{l}40 \mathrm{CFR} \\
146.12(\mathrm{a})(\mathrm{b})\end{array}$ & $\begin{array}{l}1200-4-6- \\
.10(3)(d)(2) \\
1200-4-6-.10(3)(f)\end{array}$ \\
\hline & $\begin{array}{l}\text { Appropriate logs shall be recorded } \\
\text { and other tests conducted during } \\
\text { construction and a descriptive } \\
\text { report prepared and submitted to } \\
\text { the UIC program director. }\end{array}$ & & 40 CFR $146.12(d)$ & $1200-4-6-.10(1)$ \\
\hline $\begin{array}{l}\text { Underground } \\
\text { injection of } \\
\text { wastes and } \\
\text { treated } \\
\text { groundwater } \\
\text { (continued) }\end{array}$ & $\begin{array}{l}\text { Injection pressure may not exceed } \\
\text { a maximum level designed to } \\
\text { ensure that injection does not } \\
\text { initiate new fractures or propagate } \\
\text { existing ones and cause the } \\
\text { movement of fluids into a USDW. }\end{array}$ & & 40 CFR 146.13(b) & $\begin{array}{l}1200-4-6- \\
.10(4)(\mathrm{b})(1) \\
1200-4-6- \\
.10(4)(\mathrm{b})(2)\end{array}$ \\
\hline
\end{tabular}




\begin{tabular}{|c|c|c|c|c|}
\hline Actions $^{b}$ & Requirements & Prerequisites $^{c, d}$ & Federal citation & $\begin{array}{l}\text { Tennessee Code } \\
\text { Annotated (TCA) }\end{array}$ \\
\hline & $\begin{array}{l}\text { Continuous monitoring of injection } \\
\text { pressure, flow rate and volume, } \\
\text { and annual pressure, if required. }\end{array}$ & & 40 CFR 146.13(a) & $\begin{array}{l}1200-4-6-.10(4)(\mathrm{e}) \\
1200-4-6-.10(4)(\mathrm{f}) \\
1200-4-6-.10(4)(\mathrm{g})\end{array}$ \\
\hline & $\begin{array}{l}\text { Demonstration of mechanical } \\
\text { integrity is required every } 3 \text { years. }\end{array}$ & & $\begin{array}{l}40 \mathrm{CFR} \\
146.12(\mathrm{a})(\mathrm{b})\end{array}$ & $\begin{array}{l}1200-4-6- \\
.10(4)(\mathrm{e})(6)\end{array}$ \\
\hline & $\begin{array}{l}\text { Criteria for determining whether an } \\
\text { aquifer may be an exempted } \\
\text { aquifer include current and future } \\
\text { use, yield, and water quality } \\
\text { characteristics. }\end{array}$ & & & \\
\hline & $\begin{array}{l}\text { Groundwater monitoring may also } \\
\text { be required. }\end{array}$ & & 40 CFR $146.13(b)$ & $\begin{array}{l}1200-4-6-.10(4)(\mathrm{e}) \\
1200-4-6-.10(4)(f)\end{array}$ \\
\hline & $\begin{array}{l}\text { Prohibits underground injection of } \\
\text { hazardous wastes (solvents and } \\
\text { dioxins) in Class I wells; } \\
\text { amendments to existing UIC } \\
\text { regulations. }\end{array}$ & Class I injection wells & $\begin{array}{l}53 \text { FR } 28118 \\
\text { (July } 26,1988 \text { ) }\end{array}$ & $1200-4-6-.10(1)$ \\
\hline $\begin{array}{l}\text { Underground } \\
\text { storage tanks } \\
\text { (UST) temporary } \\
\text { closure }\end{array}$ & $\begin{array}{l}\text { Continuous monitoring for leaks; } \\
\text { leave vent lines open and } \\
\text { functioning; cap and secure all } \\
\text { other lines, pumps, manways and } \\
\text { ancillary equipment; notify } \\
\text { implementing agency of return to } \\
\text { service or permanent closure. }\end{array}$ & $\begin{array}{l}\text { Pertains to releases of } \\
\text { CERCLA hazardous } \\
\text { substances from any one or a } \\
\text { combination of tanks the } \\
\text { volume of which is } 10 \% \text { or } \\
\text { more beneath the surface of } \\
\text { the ground (including pipes). } \\
\text { Tanks that have been out of } \\
\text { service for 3-24 months. }\end{array}$ & $\begin{array}{l}53 \text { FR } 37082 \\
\text { (Sept. 23, 1988) } \\
40 \text { CFR Part } \\
280.80(a)(b)\end{array}$ & \\
\hline
\end{tabular}




\begin{tabular}{|c|c|c|c|c|}
\hline Actions $^{b}$ & Requirements & Prerequisites $^{c, d}$ & Federal citation & $\begin{array}{l}\text { Tennessee C } \\
\text { Annotated } ?\end{array}$ \\
\hline \multirow[t]{2}{*}{$\begin{array}{l}\text { Underground } \\
\text { storage tanks } \\
\text { (UST) } \\
\text { permanent } \\
\text { closure }\end{array}$} & $\begin{array}{l}\text { Removal requires removing all } \\
\text { flammable liquids from the UST, } \\
\text { removing all pipes from the UST, } \\
\text { and purging the UST of all hazard- } \\
\text { ous vapors before removal and } \\
\text { disposal. }\end{array}$ & $\begin{array}{l}\text { Pertains to releases of } \\
\text { CERCLA hazardous } \\
\text { substances from any one or a } \\
\text { combination of tanks the } \\
\text { volume of which is } 10 \% \text { or } \\
\text { more beneath the surface of } \\
\text { the ground (including pipes). } \\
\text { Tanks that have been out of } \\
\text { service for } 3-24 \text { months. }\end{array}$ & $\begin{array}{l}53 \text { FR } 37082 \\
\text { (Sept. 23, 1988) } \\
40 \text { CFR Part } \\
280.80(c-f)\end{array}$ & \\
\hline & $\begin{array}{l}\text { Closure requires removal of all } \\
\text { flammable liquids from the UST, } \\
\text { disconnect or cap all pipes, fill } \\
\text { tank system with an inert solid } \\
\text { material }\end{array}$ & & $\begin{array}{l}52 \text { FR } 12662 \\
\text { (April 17, } 19870\end{array}$ & \\
\hline \multirow[t]{4}{*}{ Waste pile } & $\begin{array}{l}\text { Use liner and leachate collection } \\
\text { and removal system. }\end{array}$ & $\begin{array}{l}\text { RCRA hazardous waste, } \\
\text { noncontainerized } \\
\text { accumulation of solid, } \\
\text { nonflammable hazardous } \\
\text { waste that is used for } \\
\text { treatment or storage in piles. }\end{array}$ & 40 CFR 264.25(a) & \\
\hline & $\begin{array}{l}\text { Proposed double liner } \\
\text { requirements. }\end{array}$ & Proposed rule; not yet ARAR. & $\begin{array}{l}52 F R 20218 \\
\text { (May 29, 1987) }\end{array}$ & \\
\hline & $\begin{array}{l}\text { Proposed amendments to waste } \\
\text { plle closure regulations. }\end{array}$ & $\begin{array}{l}\text { Proposed standards; not yet } \\
\text { ARAR }\end{array}$ & $\begin{array}{l}52 \text { FR } 8712 \\
\text { (March 19, 1987) }\end{array}$ & \\
\hline & $\begin{array}{l}\text { Operate and maintain run-on and } \\
\text { run-off control systems for at least }\end{array}$ & & $\begin{array}{l}40 \text { CFR } 264.251 \\
\text { (c)(d) }\end{array}$ & $\begin{array}{l}1200-1-11- \\
.06(12)(b)\end{array}$ \\
\hline
\end{tabular}




\begin{tabular}{|c|c|c|c|c|}
\hline Actions $^{b}$ & Requirements & Prerequisites ${ }^{c d}$ & Federal citation & $\begin{array}{l}\text { Tennessee Code } \\
\text { Annotated (TCA) }\end{array}$ \\
\hline & $\begin{array}{l}\text { Pile must be managed to control } \\
\text { wind erosion. }\end{array}$ & & $\begin{array}{l}40 \mathrm{CFR} \\
264.251(\mathrm{f})\end{array}$ & $\begin{array}{l}1200-1-11- \\
.06(12)(b)\end{array}$ \\
\hline & $\begin{array}{l}\text { Pile must be monitored and } \\
\text { inspected. }\end{array}$ & & 40 CFR 264.254 & $\begin{array}{l}1200-1-11- \\
.06(12)(\mathrm{e})\end{array}$ \\
\hline & $\begin{array}{l}\text { Closure and postclosure care } \\
\text { required. }\end{array}$ & & 40 CFR 264.258 & $\begin{array}{l}1200-1-11- \\
.06(12)(1)\end{array}$ \\
\hline
\end{tabular}

${ }^{a}$ Adapted from EPA (1989). Currently only RCRA, CWA, and Safe Drinking Water Act requirements are included. Additional action-specific requirements will be added as additional statutes are analyzed.

bAction alternatives from the Record of Decision keyword Index, FY 1986 Record of Decision Annual Report. January 1987, Hazardous Site Control Division, EPA.

'Requirements have been proposed but not promulgated for various remedial actions. When these regulations are promulgated, they will be included in the matrix.

¿Some action-specific requirements listed may be relevant and appropriate even if RCRA definitions of storage, disposal, or hazardous waste are not met (40 CFR 260.10), or if the waste at the site is similar to but not identiflable as a RCRA hazardous waste.

CAA = Clean Air Act.

Fitle I of the CAA covers Air Pollution Prevention and Control, and Implementing regulations are found in 40 CFR Parts 50-99.

RCRA = Resource Conservation and Recovery Act.

'Subtitle C of RCRA governs hazardous waste management (\$3001-3020), Implementing regulations appear in 40 CFR Parts 260-268, 270, 271, 280 , and 124.

Regional administrator may revise length of postclosure care period (40 CFR 264.117).

In many cases there are no defined "units" at a CERCLA site. Instead, there are areas of contamination with differing concentration levels (including hot spots) of hazardous substances, pollutants, or contaminants. When RCRA hazardous wastes are moved into or out of an area of contamination, RCRA disposal requirements are applicable to the waste being managed and certain treatment, storage, or disposal requirements (such as for closure) are applicable to the area where the waste is received.

k andfill units meeting the requirements of 40 CFR 264.301(i) are not subject to RCRA minimum technology requirements.

The term "Waters of the U.S." is defined broadly in 40 CFR 122.2 and includes essentlally any water body and wetland.

msection 121 of the Superfund Amendments and Reauthorization Act of 1986 (SARA) exempts on-site CERCLA activities from obtaining permits. However, the substantive requirements of a law or regulation must be met. In particular, on-site discharges to surface waters are exempt from procedural NPDES permit requirements. Off-site dischargers would be required to apply for and obtain an NPDES permit. 


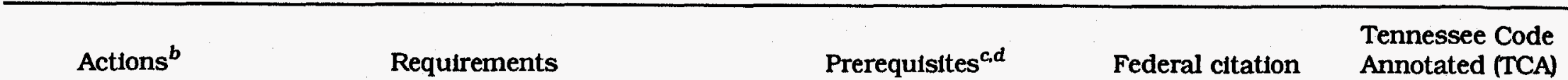

mitles III and IV of the CWA cover Standards and Enforcement, and Permits and Licenses, respectively. Implementing regulations appear in 40 CFR Parts 110,112,116, 117, 122, 124, 125, 131, and 136. 40 CFR Subchapter $N$ sets forth effluent guidelines for various point source categories.

Federal Water Quality Criteria (WQC) may be relevant and approprlate depending on the designated or potential use of the water, the media affected, the purposes of the criteria, and current information [SARA \$121(d)(2)(B)(i)]. Federal WQC for the protection of aquatic life will be relevant and appropriate when environmental factors (e.g., protection of aquatic organisms) are being considered (55 FR 8755, March 8, 1990).

Discharge to POTWs is considered an off-site activity. Off-site actions must comply with all legally applicable requirements, both substantive and administrative. The concept of "relevant and appropriate" is not avallable for off-site actions.

Implementing regulations for the Toxic Substance Control Act of importance to cleanup at CERCLA sites are 40 CFR Parts 717 and 761 .

'CERCLA = Comprehensive Environmental Response, Compensation, and Liability Act

Title IV of the Safe Drinking Water Act covers Safety of Public Water Systems. Implementing regulations are found in 40 CFR Parts 124 and 141-147.

A USDW is a nonexempted aquifer or its portion which: (1) supplies any public water system, or (2) contains sufficient quantity of groundwater to supply a public water system and currently supplies drinking water for human consumption or contains fewer than $10,000 \mathrm{mg} / \mathrm{L}$ total
} dissolved solids (40 CFR 144.3). 
Location-specific requirements set restrictions upon the concentration of hazardous substances or the conduct of activities solely because they are in special locations. In determining the use of location-specific regulations for actions at $D \& D$ sites, one must investigate the jurisdictional prerequisites of each of the regulations. Basic definitions and exemptions should be analyzed on a site-specific basis to confirm the correct application of the requirements. Table 10.15 lists the major federal and state location-specific regulations that might be pertinent to D\&D actions at the ORR.

\subsubsection{Caves, Salt-Dome Formations, Salt-Bed Formations, and Underground Mines}

The ORR, located in the Valley and Ridge Physiographic Province of eastern Tennessee, is characterired by gently to moderately sloping ridges and valleys (Rogers et al. 1989). A variety of geologic formations of sedimentary origin underlie the ORR. The most important formations are the Rome Formation and the Conasauga, Knox, and Chicamauga Groups. Both the Y-12 and K-25 sites have areas underlain by the Knox Group limestones, which are subject to cave formation, sinkhole development, and trends of groundwater movement that could cause problems for site modifications (Lee 1991). There are no indications of saltdome formations, salt-bed formations, or underground mines on or near the ORNL, K-25, or Y-12 sites (Lee 1991). However, there is evidence of sinkholes above the ridge near the $\mathrm{K}-25 \mathrm{~K}-1070-\mathrm{A}$ contaminated burial ground (Lee 1991). If any caves are located in. areas where remedial activities or D\&D activities might occur, the regulations found in RCRA [40 CFR 264.18(c)], which prohibit the placement of noncontainerized or bulk liquid hazardous waste in caves, might be applicable (Table 10.15).

\subsubsection{Faults}

The White Oak Mouritain and Copper Creek thrust faults transect the ORR (Ketelle 1991). The faults on the ORR are ancient (pre-Holocene) and are stable (Ketelle 1991). The possibility of fault movement is considered extremely unlikely (Chance 1986).

The DOE ORR is exempted from compliance with the RCRA seismic requirements of 40 CFR 264.18 because 40 CFR 264.18(a) stipulates that all facilities located within political jurisdictions other than those listed in Appendix VI of $\mathbf{4 0}$ CFR 264.18 are assumed to be in compliance for location of new treatment, storage, or disposal facilities. Tennessee is not listed in the appendix. However, EPA intends to propose additional seismic restrictions for location of TSD facilities (NPRM, February 1994), and these restrictions will be incorporated into the TDEC Hazardous Waste Management regulations (Hinch 1989). At that time, the TDEC seismic regulations may be applicable to $D \& D$ actions at the ORR. 
Table 10.15. Location-specific regulations applicable to decontamination and decommissloning activitles at the Oak Ridge Reservation

\begin{tabular}{lllll}
\hline Location characteristic(s) & Operating condition(s) & Requirement(s) & Citation(s) \\
\hline
\end{tabular}

Faults

With displacement in Holocene time

Salt-dome formations, salt-bed formations, underground mines or caves

\section{Wetlands}

Presence of wetlands as defined in Executtve Order 11990 \$7(c) and 40 CFR 6, Appendix A §4(j)
New treatment, storage or disposal facility

RCRA ${ }^{a}$-defined listed or characteristic hazardous waste (40 CFR 261) -or- RCRApermitted facility

RCRA-defined listed or characteristic hazardous waste (40 CFR 261) -or- RCRA- permitted facility

Agency action which involves: - acquiring, managing, and disposing of

lands and facilities

- providing federally undertaken. financed, or assisted construction and

improvements

- conducting federal activities and programs affecting land use
Portions of new facilities must not be within 61

meters (200 ft) of such fault

Placement of

noncontainerized or bulk

liquid hazardous waste in

these locations is prohibited

Whenever possible, actions must avoid or minimize adverse impacts on wetlands and act to preserve and enhance their natural and beneficial values. New construction in wetlands areas should be particularly avoided unless there are no practicable alternatives Wetlands protection considerations shall be Incorporated into planning. regulating, and decisionmaking processes
40 CFR 264.18(a)

40 CFR 264.18(c)

Executtve Order 11990 40 CFR 6.302(a) 40 CFR 6. Appendix A 10 CFR 1022 
Table 10.15. (continued)

\begin{tabular}{lll}
\hline \multicolumn{1}{c}{ Location characteristic(s) } & \multicolumn{1}{c}{ Operating condition(s) } & \multicolumn{1}{c}{ Requirement(s) } \\
\hline $\begin{array}{l}\text { Presence of wetlands as defined in } \\
\text { 40 CFR 230.3(t) and 33 CFR }\end{array}$ & $\begin{array}{l}\text { Action involving discharge of } \\
\text { dredge or fill material into } \\
\text { wetlands }\end{array}$ & $\begin{array}{l}\text { Action to avoid degradation } \\
\text { or destruction of wetlands } \\
\text { must be taken to the extent } \\
\text { possible. Discharges for } \\
\text { which there is a practicable }\end{array}$ \\
& $\begin{array}{l}\text { alternative with less adverse } \\
\text { impacts or those which }\end{array}$ \\
& $\begin{array}{l}\text { would cause or contribute to } \\
\text { significant degradation are } \\
\text { prohibited }\end{array}$ \\
& $\begin{array}{l}\text { If adverse impacts are } \\
\text { unavoidable, action must be } \\
\text { taken to enhance, restore, or } \\
\text { create alternative wetlands }\end{array}$
\end{tabular}

\section{Floodplains}

Within 100-year floodplain
Treatment, storage, or disposal facility

RCRA-defined listed or

characteristic hazardous waste

(40 CFR 261) -or- RCRA- permitted facility
Facility must be designed. constructed, operated, and maintained to prevent washout of any hazardous waste by 100-year flood
Clean Water Act $\$ 404$

40 CFR 230

33 CFR 320-330 possible. Discharges for prohibited create alternative wetlands

40 CFR 264.18(b) 
Table 10.15. (continued)

\begin{tabular}{|c|c|c|}
\hline Location characteristic(s) & Operating condition(s) & Requirement(s) \\
\hline $\begin{array}{l}\text { Within "lowland and relatively flat } \\
\text { areas adjoining inland and coastal } \\
\text { waters and other floodprone areas } \\
\text { such as offshore islands, } \\
\text { including at a minimum, that } \\
\text { area subject to a one percent or } \\
\text { greater chance of flooding in any } \\
\text { given year." [Executive Order } \\
11988 \text { \$6(c) and } 40 \text { CFR 6, } \\
\text { Appendix A } \$ 4(d)]\end{array}$ & $\begin{array}{l}\text { Action which involves: } \\
\text { - acquiring, managing, and } \\
\text { disposing } \\
\text { of lands and facilities } \\
\text { - providing federally undertaken, } \\
\text { financed, or assisted } \\
\text { construction } \\
\text { and improvernents } \\
\text { - conducting federal activities and } \\
\text { programs affecting land use }\end{array}$ & $\begin{array}{l}\text { Action shall be taken to } \\
\text { reduce the risk of flood loss, } \\
\text { minimize the impact of floods } \\
\text { on human safety, health and } \\
\text { welfare, and restore and } \\
\text { preserve the natural and } \\
\text { benefictal values of flood- } \\
\text { plains } \\
\text { The potential effects of } \\
\text { actions in floodplains shall } \\
\text { be evaluated and } \\
\text { consideration of flood } \\
\text { hazards and floodplain } \\
\text { management ensured } \\
\text { If action is taken in } \\
\text { floodplains, alternatives that } \\
\text { avoid adverse effects and } \\
\text { incompatible development } \\
\text { and minimize potential } \\
\text { harms shall be considered }\end{array}$ \\
\hline
\end{tabular}

Wilderness areas, Wildife

resources, Wildlife refuges, Scenic rivers

Within area encompassing or affecting waters of the state of Tennessee as defined in TCA ${ }^{b} 69$ 3-103(32) and the presence of wildlife or aquatic life

Action involving the discharge of any pollutants into the waters of the state [see TCA 69-3-103(18) and (21) for noninclusive list]
Discharge of "substances" which "will result or will likely result in harm. potential harm or detriment to the health of animals, birds, fish, or aquatic life" is prohibited
Executtve Order (EO)

11988

40 CFR 6.302(b)

40 CFR 6 (Appendix A)

10 CFR 1022

Tennessee Water Ruality Control Act of 1977 (TCA 69-3-101 et seq.)

Stream Use Classifications (TDEC ${ }^{c}$ Rules - Chap. 1200-4-4) 
Table 10.15. (continued)

$\begin{array}{llll}\text { Location characteristic(s) } & \text { Operating condition(s) } & \text { Requirement(s) } & \text { Citation(s) }\end{array}$

Within area affecting stream or river -and-presence of fish or wildlife resources

Location encompassing aquatic ecosystem with dependent fish. wildilife, other aquatic life, or habitat

Location encornpassing a statedesignated natural area
Action which results in the control or structural modification of a natural stream or body of water

Action involving the discharge of dredge or fill material into aquatic ecosystem
The effects of water-related projects on fish and wildlife resources must be

considered

Action must be taken to

prevent, mitigate, or

compensate for project-

related damages or losses to

fish and wildlife resources

Off-site actions that alter a

resource require consultation

with the FWS ${ }^{d}$, NMFS ${ }^{e}$.

and/or appropriate state

agency

Consultation is also strongly

recommended for on-site

actions

Degradation or destruction of aquatic ecosystems must be avolded to the extent possible. Discharges which cause or contribute to significant degradation of the water of such ecosystem are prohibited

The scientific, scenic, recreational, and educational values of these areas must be preserved and steps taken to prevent Impairment

thereof
Fish and Wildlife

Coordination Act (16 USC

661 et seq.)

40 CFR 6.302(g)
Clean Water Act $\$ 404$

40 CFR 230

33 CFR 320-330 
Table 10.15. (contlnued)

\begin{tabular}{lllll}
\hline Location characteristic(s) & Operating condition(s) & Requirement(s) & Citation(s) \\
\hline
\end{tabular}

Endangered, Threatened, or Rare Species

Presence of endangered or threatened specles -or-critical habitat of such

species as designated in 50 CFR 17, 50 CFR 226, or 50 CFR 227

Presence of endangered or threatened species or critical habitat (see above citation) of same within an aquatic ecosystem as defined in 40 CFR 230.3(c)
Action which is likely to jeopardize species or destroy or adversely modify critical habitat

Action involving discharge of dredge or fill material into aquatic ecosystem
Actions that jeopardize species/habitat must be avoided or appropriate mitigation measures taken Off-site actions that affect species/habitat require consultation with DOI. FWS, NMFS, and/or state agencies, as appropriate, to ensure that proposed actions do not jeopardize the continued existence of the species or adversely modify or destroy critical habitat Consultation is also strongly recommended for on-site actions

Dredge or fill material shall not be discharged into an aquatic ecosystem if it would Jeopardize such species or would likely result in the destruction or adverse modification of a critical habitat of the species
Endangered Species Act of 1973 (16 USC 1531 et seq.) 50 CFR 402

40 CFR 6.302(h)

Fish and Wildlife

Coordination Act (16 USC

661 et seq.)

Clean Water Act $\$ 404$

40 CFR 230.10(b) 


\begin{tabular}{|c|c|c|}
\hline Location characteristic(s) & Operating condition(s) & Requirement(s) \\
\hline $\begin{array}{l}\text { Presence of Tennessee state-listed } \\
\text { endangered or threatened animal } \\
\text { species as created and amended } \\
\text { pursuant to TCA 70-8-105 }\end{array}$ & & $\begin{array}{l}\text { Protected species may not be } \\
\text { taken, possessed. } \\
\text { transported, exported, pro- } \\
\text { cessed, sold, offered for sale, } \\
\text { or shipped. Certain } \\
\text { exceptions may be allowed } \\
\text { such as for educational, } \\
\text { scientific, etc., reasons or } \\
\text { where necessary to alleviate } \\
\text { property damage or protect } \\
\text { human health or safety. } \\
\text { These exceptions require a } \\
\text { permit if the remedial action } \\
\text { or its attendant effects are off } \\
\text { site }\end{array}$ \\
\hline
\end{tabular}

Archaeologic and Historic

\section{Resources}

Presence of archaeological resources on public land

Presence of archaeologic or historic resources
Action which would impact resource

Action involving dam construction or other alteration of terrain which might cause irreparable loss or destruction of significant scientific, prehistoric, historic, or archaeologic data
Steps must be taken to protect archaeological resources and sites

The Secretary of Interior must be advised of the presence of the data A survey of affected areas for resources and data must be conducted and steps taken to recover, protect, and preserve data therefrom or request that $\mathrm{DOI}$ do so
Tennessee Nongame and Endangered or Threatened Wildlife Species

Conservation Act of 1974

(TCA 70-8-101 et seq.)
Archaeological Resources Recovery Act of 1979 (16

USC 470aa-11) 43 CFR 7

Archaeological and Historic Preservation Act (16 USC 469a-c)

40 CFR 6.301 
Table 10.15. (contInued)

\begin{tabular}{|c|c|c|c|}
\hline Location characteristic(s) & Operating condition(s) & Requirement(s) & Citation(s) \\
\hline $\begin{array}{l}\text { Presence of federally owned, } \\
\text { administered, or controlled } \\
\text { prehistoric or historic resources - } \\
\text { or- the likelihood of undiscovered } \\
\text { resources }\end{array}$ & & $\begin{array}{l}\text { Cultural resources included } \\
\text { on or eligible for inclusion on } \\
\text { the National Register of } \\
\text { Historic Places ( } 36 \text { CFR 60) } \\
\text { or National Historic } \\
\text { Landmark Program ( } 36 \text { CFR } \\
65 \text { ) must be identified } \\
\text { Action(s) that will affect such } \\
\text { resources must be identified } \\
\text { and alternatives to the } \\
\text { action(s) examined and } \\
\text { considered } \\
\text { When alteration or } \\
\text { destruction of the resource is } \\
\text { unavoidable, steps must be } \\
\text { taken to minimize or mittgate } \\
\text { the impacts and to preserve } \\
\text { records and data of the } \\
\text { resource } \\
\text { When all or part of a } \\
\text { remedial action is off site, } \\
\text { the consultation require- } \\
\text { ments of } 16 \text { USC } 470 \text { must } \\
\text { be completed } \\
\text { Consultation is also strongly } \\
\text { recommended for on-site } \\
\text { actions }\end{array}$ & $\begin{array}{l}\text { National Historic } \\
\text { Preservation Act ( } 16 \text { USC } \\
470 a-w) \\
\text { Executtie Order } 11593 \\
40 \text { CFR } 6.301 \\
\text { 36 CFR } 800\end{array}$ \\
\hline $\begin{array}{l}\text { Cemetery located on property } \\
\text { within Tennessee }\end{array}$ & & $\begin{array}{l}\text { Destruction or degradation of } \\
\text { property in a graveyard or } \\
\text { cemetery is prohibited }\end{array}$ & $\begin{array}{l}\text { Tennessee General } \\
\text { Cemetery Act of } 1968 \text { (TCA } \\
46-1-101 \text { et seq.) }\end{array}$ \\
\hline
\end{tabular}

aRCRA = Resource Conservation and Recovery Act; definitions appear at 40 CFR 260.10.

TCA $=$ Tennessee Code Annotated.

TDEC $=$ Tennessee Department of Environment and Conservation.

${ }^{d}$ FWS $=$ Fish and Wildlife Service.

NMFS = National Marine Fisheries Service.

DOOI $=$ Department of Interlor. 


\subsubsection{Wetlands and Floodplains}

The ORR is located within the Clinch River drainage basin and is bounded on the south and west by the Clinch River. Each of the three DOE facilities is located in a different sub-basin cf the Clinch River. As might be expected in an area with abundant water resources and aquatic habitats, portions of ORNL, the K-25 Site, and Y-12 are located within 100- and 500-year floodplains (UCC 1984).

There are a number of wetlands located in and around all three facilities. A draft report of a recent wetlands survey was released in March 1991 (Cunningham and Pounds 1991). Before any D\&D action is taken, this report should be consulted and a survey conducted of the particular site to determine whether there are wetlands present that could be impacted by D\&D activities. If any $D \& D$ activities are selected which would impact floodplains, the requirements found in Executive Orde: 1 1988, 40 CFR 264.18(b), 40 CFR 6.302(b), 40 CFR 6 (Appendix A), and 10 CFR 1022 would provide applicable or relevant and appropriate requirement; for ORR. If wetlands are affected, consideration should be given to Executive Oriter 11990, 40 CFR 6.302(a), 40 CFR 6 (Appendix A), 10 CFR 1022, CWA $\$ 404,41$ CFR 230, and 33 CFR 320-330 for applicable requirements. In addition, EPA intends to propose additional floodplain restrictions for location of TSD facilities (NPRM 1994), and these restrictions will be incorporated into the TDEC Hazardous Waste Management regulations (Hinch 1989). At that time, the TDEC floodplain regulations may be applicable to D\&D actions at the ORR.

\subsubsection{Wilderness Are:ıs, Wildlife Refuges, Wildlife Resources, and Scenic Rivers}

There are no known designated wilderness areas, wildlife refuges, or scenic rivers on the ORR or within range of the reservation such that D\&D actions would likely impact these resources. However, if any $D \& D$ actions result in the control or structural modification of a natural stream or water body, the provisions found in the FWCA [16 United States Code (USC) 661 et seq.] and 40 CFR 6.302(g) may be applicable. If any acticin involves the discharge of dredge or fill material into an aquatic system, the CWA $\$ 404,40$ CFR 230, and 33 CFR 320-330 may also be implicated.

The Clinch River, Poplar Creek with its various tributaries and forks, and White Oak Creek have all been classified by TDEC for a variety of uses, including fish and aquatic life and wildlife. It is therefore possible that the provisions of the Tennessee Water Guality Control Act (TCA 69-3-101 et seq.) would be legally applicable should any DikD actions at the ORR cause, or be likely to cause, harm to wildlife or aquatic life in these waters.

Slightly over 5000 acres of the ORR have been designated as a DOE National Environmental Research Park (NERP), which also includes Research Areas (RSAs) located both within and without the NERP itself (Parr and Pounds 1987). Portions of the NERP come to within at least $2-3 \mathrm{~km}$ of the $\mathbb{K}-25$ Site, ORNL, and Y-12. There are also RSAs in blose vicinity to all three facilities. RSA No. 51, K-1700 stream monitoring, is less than $0.5 \mathrm{~km}$ from the $\mathrm{K}-25$ Site (Parr and Pounds 1987). 
In addition to the NERP and its associated RSAs, DOE has also designated areas on the ORR as DOE-NERP Reference Areas (RAs) and DOE-NERP Natural Areas (NAs). The RAs and NAs are located in various sites on the ORR, with several in close proximity to the reservation facilities. Specifically, RA17-McKinney Ridge Hemlocks, RA18-Blackoak Ridge white pines, and RA23-Poplar Creek rookery are within $\sim 1 \mathrm{~km}$ of the K-25 Site (Parr and Pounds 1987). NA1-Campbell Bend bluffs and forest, is located approximately 1-2 kilometers west of $\mathrm{K}-25$, adjacent to the Clinch River (Parr and Pounds 1987). Eight of the RAs and NAs have also been registered by Tennessee as State Natural Areas (SNAs). Three of these-No. 1, Campbell Bend river bluff, and Nos. 2 and 3, Poplar Creek hemlock bluffs-are located within a few kilometers of K-25 (Parr and Pounds 1987).

Because of the unique purposes and goals in establishing the NERP, the uses and restrictions that apply to these resources should be considered nonregulatory guidance if D\&D activities appear likely to impact the designated areas. Guidance regarding the permitted uses and restrictions of the various locations can be obtained from the NERP Project Manager at ORNL. For a general overview, please refer to Volume 23 of The Resource Management Plan for the Oak Ridge Reservation (Parr and Pounds 1987). Such impacts should be avoided. In addition, should areas which are also designated SNAs by the state of Tennessee be affected, the provisions of the Tennessee Natural Areas Preservation Act of 1971 (TCA 11-14-101 et seq.) may be applicable.

\subsubsection{Rare, Threatened, or Endangered Species}

In 1991 a draft report was issued, which compiled the results of various surveys done at different sites on the ORR for rare plants (Parr 1992). Although it does not purport to be exhaustive, the report detailed 14 plant species that occur on the ORR and are listed as endangered, threatened, or of special concern by the state of Tennessee (Parr 1992). There have been additional rare plants identified since that draft report, but the update is not available at this time (Parr 1992).

In addition to the plants, there are a number of federal- and state-listed endangered or threatened or "in need of management" animal and avian species known to occur in east Tennessee (Kroodsma 1987; 50 CFR 17). An in-depth discussion of these species appears in Vol. No. 24 of The Resource Management Plan of the Oak Ridge Reservation (Kroodsma 1987). The list of rare and endangered species for the ORR, provided by the state of Tennessee, also includes two state-listed and federally listed endangered clams (DES 1991), which are not mentioned in the various data for the reservation. Therefore they have not been documented during surveys, or there is no information available.

Should any D\&D actions at the ORR impact any federally listed endangered or threatened species, the provisions found in the Endangered Species Act of 1973 (16 USC 1531 et seq.), 50 CFR 492, 40 CFR 6.302(h), and the FWCA (16 USC 661 et seq.) may be legally applicable. Additionally, if the RAs involve the discharge of dredge or fill material, CWA $\$ 404$ and 40 CFR $230.10(\mathrm{~b})$ may be applicable. If any proposed actions impact state-listed endangered or threatened animal species the Tennessee Non-Game and Endangered or Threatened Wildlife Species Conservation Act of 1974 (TCA 70-8-101 et seq.) may be applicable. The prohibitions of the Tennessee Rare Plant Protection and Conservation Act of 1985 (TCA 11-26-201 et seq.) do not apply to a landowner, lessee, or other person 
entitled to possession of the land on which the species is located (TCA 11-26-209). This also includes managers in the case of publicly owned land and those with written permission of the landowner or manager (TCA 11-26-209). These exclusions would apparently apply to the ORR. However, the purpose of the statute to protect and preserve rare plants should be considered guidance for any D\&D RAs on the reservation.

\subsubsection{Historic Sites and Archaeological Findings}

The ORR, as well as the surrounding region, is rich in both archaeological and historic resources (Sanders 1984). Although there have not been complete and exhaustive archaeological or historical surveys of the reservation, there have been a number of studies over the years, all indicating the presence of abundant resources on and around the reservation. These surveys were summarized in Volume 3 of the Resource Management Plan for the U. S. Department of Energy Oak Ridge Reservation (Sanders 1984), which also includes a list and descriptions of most of the documented sites. However, none of the surveys are recent, nor have they covered all of the specific sites where $D \& D$ actions may be planned or contemplated. Several laws require that such information be obtained and documented if there is ample reason to suspect the presence of these resources [Archaeological and Historic Preservation Act (16 USC 469a-c); Archaeological Resources Recovery Act of 1979 (16 USC 470aa-11)].

The National Register of Historic Places lists a number of sites in the fivecounty area surrounding the ORR (DOI 1991). Only two, the Graphite Reactor located at ORNL, and the Freels Cabin located near the Scarboro Facility, lie within the boundary of the ORR (DOI 1991). The Freels Cabin was just placed on the National Register on May 6, 1992. In 1977, an historic sites reconnaissance of much of the ORR was completed (Fielder et al. 1977). There were a total of 414 sites recorded during this reconnaissance, although 215 of these did not actually have any physical remains present (Sanders 1984).

In 1974 an archaeological survey of the ORR was conducted by the Department of Anthropclogy of the University of Tennessee, Knoxville (Fielder 1975). Sites of aboriginal occupation, which might be affected by future activities on the reservation were located and evaluated. According to the study, 45 sites of prehistoric aboriginal occupations and several historic Euro-American homestead sites were examined. The: sites were distributed along the drainage system of the Clinch River, with the majority on the main river (Fielder 1975). Ten archaeological sites were located in the immediate K-25 Site area, four of which were recommended for excavalion if potentially impacted by any construction activities.

If any D\&D activity is; undertaken which would cause irreparable harm, loss, or destruction to any historic or archaeological site, the provisions of the Archaeological Resources Recovery Act (16 USC 470aa-11), 43 CFR 7, the Archaeological and Historic Preservation Act (16 USC 469a-c) and 40 CFR 6.301 may be legally applicable. In addition, identification of cultural resources eligible for the National Register of Historic Places (36 CFR 60) or the National Historic Landmark Program (36 CFR 65) is mandated by the National Historic Preservation Act (16 USC 470a-w). The provisions of this latter statute would also apply to the Graphite Reactor and the Freels Cabin along with Executive Order 11593, 40 CFR 6.301 and 36 CFR 800 et seq. Lastly, there are a number of cemeteries 
located on the ORR which predate the acquisition of the property by the government. Any D\&D actions that affect these cemeteries would be subject to the provisions of the Tennessee Cemetery Protection Act (TCA 46-1-101 et seq.), which prohibits their destruction or degradation. 


\subsection{REFERENCES}

Chance, W. W. 1986. Resource Management Plan for the Oak Ridge Reservation: Resource Information and Site Analysis (V. 22), ORNL/ESH-1/V22, Martin Marietta Energy Systems, Inc., Oak Ridge National Laboratory, Oak Ridge, Tennessee.

Coutant, C.C. and C.L. Heckman. 1987. A Review of State Regulations that Exceed Those of the Federal Resource Conservation and Recovery Act (RCRA), DOE/HWP40, Oak Ridge National Laboratory, Oak Ridge, Tennessee.

Cunningham, M. and L. Pounds. 1991. Resource Management Plan for the Oak Ridge Reservation: Wetlands on the Oak Ridge Reservation (V.28), ORNL/NERP5/V28, Martin Marietta Energy Systems, Inc., Oak Ridge National Laboratory, Oak Ridge, Tennessee.

Division of Ecological Senrices. July 30, 1991. List of Rare and Endangered Species for Oak Ridge National Laboratory, Division of Ecological Services, Tennessee Department of Environment and Conservation, Nashville, Tennessee.

Department of the Interior, National Park Service. 1991. The National Register of Historic Places, U.S. Government Printing Office, Washington, D.C.

U.S. Environmental Protection Agency. 1988. CERCLA Compliance with Other Laws Manual, Draft Guidance. Vol. I, Office of Solid Waste and Emergency Response Directive 9254.1-01, Environmental Protection Agency Office of Emergency and Remedial Response, Washington, D.C.

U.S. Environmental Protection Agency. August 1990. Guidance on Remedial Actions for Superfund Sites with PCB Contamination, EPA/540/G-90/007, Environmental Protection Agency Office of Emergency and Remedial Response, Washington, D.C.

U.S. Environmental Protection Agency. 1991a. Region IV Criteria Charts (October).

U.S. Environmental Protection Agency. 1991b. Integrated Risk Information System (IRIS), EPA/600/8-86/032a, Environmental Protection Agency Office of Health and Environmental Assessment, Cincinnati, Ohio.

U.S. Environmental Protection Agency. 1992. Health Effects Assessment Summary Tables. FY 1992, OERR 9200.6-303-(92), Environmental Protection Agency Office of Emergency and Remedial Response, Washington, D.C.

Fielder, G. F., Jr. 1975. Archaeological Survey with Emphasis on Historic Sites of the Oak Ridge Reservation, Oak Ridge, TN, ORNL/TM-4694, Martin Marietta Energy Systems, Inc., Oak Ridge National Laboratory, Oak Ridge, Tennessee. 
Etnier, E. L., E. P. McDonald and L. M. Houlberg. April 1992. Applicable or Relevant and Appropriate Requirements (ARARs) for Remedial Action at the Oak Ridge Reservation, A Compendium Major Environmental Laws, ES/ER/TM-1R1, Martin Marietta Energy Systems, Inc., Oak Ridge National Laboratory, Oak Ridge, Tennessee

Fielder, G. F. Jr., et al. April 1977. Historic Sites Reconnaissance of the Oak Ridge Reservation, Oak Ridge, TN, ORNL/TM-5811, Martin Marietta Energy Systems, Inc., Oak Ridge National Laboratory, Oak Ridge, Tennessee.

Flexnor, M. August 30, 1991. Biologist, Water Quality Standards Coordinator, Tennessee Department of Environment and Conservation, personal communication to E. L. Etnier.

Foster, R. L. February 28, 1990. Deputy Director, Tennessee Department of Environment and Conservation, Division of Drinking Water, personal communication to E. L. Etnier.

Hinch, T. December 4, 1989. Tennessee Department of Environment and Conservation. Solid Waste Management Division, personal communication to E. L. Etnier.

Hinch, T. May 15, 1990. Tennessee Department of Environment and Conservation, Solid Waste Management Division, personal communication to E. L. Etnier.

Houlberg, L. M., G. T. Hawkins, and M. S. Salk. 1992. Environmental Regulatory Update Table, November/December, ORNL/M-1929/R5, Martin Marietta Energy Systems, Inc., Oak Ridge National Laboratory, Oak Ridge, Tennessee.

Ketelle, R. August 20, 1991. Oak Ridge National Laboratory, Energy Division, personal communication to E. P. McDonald.

Kroodsma, R. L. January 1987. Resource Management Plan for the Oak Ridge Reservation, Volume 24: Threatened and Endangered Animal Species, ORNL/ESH 1/24, Martin Marietta Energy Systems, Inc., Oak Ridge National Laboratory, Oak Ridge, Tennessee.

Lee, R. R. August 16, 1991. Oak Ridge National Laboratory, Environmental Sciences Division, personal communication to E. P. McDonald.

Parr, P. March 19, 1992. Environmental Sciences Division, Oak Ridge National Laboratory, Oak Ridge, Tennessee, personal communication to E. P. McDonald.

Parr, P. D. and L. R. Pounds. May 1987. Resource Management Plan for the Oak Ridge Reservation, Volume 23: Oak Ridge National Environmental Research Park, Research Sites, and State Natural Areas, ORNL/ESH-1/V23, Martin Marietta Energy Systems, Inc., Oak Ridge National Laboratory, Oak Ridge, Tennessee. 
Rogers, J. G., K. L. Dartiels, S. T. Goodpasture, C. W. Kimbrough, and N. L. Prince. May 1989. Oak Ridge Reservation Enwironmental Report for 1988, Volume 1: Narrative, Summary, and Conclusions, ES/ESH-8/V1, Martin Marietta Energy Systems, Inc., Oak Ridge, Tennessee.

Sanders, M. 1984. Resource Management Plan for the U.S. Department of Energy Oak Ridge Reservation, Volume 3, Appendix B: Archeological Considerations, ORNL-6026/V4, July.

Sinclair, R. July 24, 1992. Tennessee Department of Environment and Conservation, Division of Superfund, personal communication to L. M. Houlberg.

Tennessee Department of Environment and Conservation. 1991. "Draft Uniform Soil and Water Cleanup Standards." Tennessee Department of Environment and Conservation Uniform Standards Committee letter to Carter Witt, President, Tennessee Association of Business, October 21.

Union Carbide Corporaticn. March 1984. Oak Ridge Gaseous Diffusion Plant Flood Map. Oak Ridge Gaseouls Diffusion Plant Site Development Plan, Oak Ridge, Tennessee.

West, C. December 1, 1991. Tennessee Department of Environment and Conservation, Office of lRadiation Programs, personal communication to E. L. Etnier. 


\begin{tabular}{|c|c|}
\hline ACLs & alternate concentration limits \\
\hline AEA & Atomic Energy Act \\
\hline ALARA & as low as reasonably achievable \\
\hline ANPRM & advance notice of proposed rulemaking \\
\hline ARARs & applicable or relevant and appropriate requirements \\
\hline BAT & Best Available Technology \\
\hline BDAT & Best Demonstrated Available Technology \\
\hline BMP & Best Management Practice \\
\hline BRC & below-regulatory-concern \\
\hline CAA & Clean Air Act of 1970 \\
\hline CERCLA & Comprehensive Environmental Response, Compensation, and Liability Act \\
\hline COE & U. S. Army Corps of Engineers \\
\hline CSFs & carcinogen slope factors \\
\hline CWA & Clean Water Act of 1972 \\
\hline $\mathrm{D} \& \mathrm{D}$ & decontamination and decommissioning \\
\hline DCG & derived concentration guide \\
\hline DES & Division of Ecological Services \\
\hline DOI & Department of the Interior \\
\hline DOT & Department of Transportation \\
\hline EIS & Environmental Impact Statement \\
\hline EO & Executive Order \\
\hline EPA & U.S. Environmental Protection Agency \\
\hline ER & Environmental Restoration \\
\hline ESA & Endangered Species Act of 1973 \\
\hline FFAs & Federal Facility Agreement \\
\hline FFCA of 1992 & Federal Facility Compliance Act of 1992 \\
\hline FIFRA & $\begin{array}{l}\text { Federal Insecticide, Fungicide, and } \\
\text { Rodenticide Act of } 1947\end{array}$ \\
\hline FWCA & Fish and Wildlife Coordination Act of 1958 \\
\hline HAS & Health Advisories \\
\hline HMTA & Hazardous Materials Transportation Act of 1975 \\
\hline HSWA & Hazardous and Solid Waste Amendments of 1984 \\
\hline IRIS & Integrated Risk Information System \\
\hline LDR-FFCA/ORR & $\begin{array}{l}\text { Federal Facilities Compliance Agreement for mixed waste } \\
\text { subject to land disposal restriction for the } \\
\text { Oak Ridge Reservation }\end{array}$ \\
\hline MCLGs & maximum contaminant level goals \\
\hline MCLS & maximum contaminant levels \\
\hline NAAQS & National Ambient Air Quality Standards \\
\hline NARM & $\begin{array}{l}\text { naturally occurring and accelerator-produced } \\
\text { radioactive material }\end{array}$ \\
\hline NAs & Natural Areas \\
\hline NCP & $\begin{array}{l}\text { National Oil and Hazardous Substance Pollution } \\
\text { Contingency Plan }\end{array}$ \\
\hline NEPA & National Environmental Policy Act of 1969 \\
\hline NERP & DOE National Environmental Research Park \\
\hline NESHAPS & National Emission Standards for Hazardous Air Pollutants \\
\hline NPDES & National Pollutant Discharge Elimination System \\
\hline NPDWS & National Primary Drinking Water Standards \\
\hline NPL & National Priorities List \\
\hline NPRM & Notice of Proposed Rulemaking \\
\hline NRC & Nuclear Regulatory Commission \\
\hline
\end{tabular}




\begin{tabular}{|c|c|}
\hline NSDWS & National Secondary Drinking Water Standards \\
\hline NSPS & New Source Performance Standards \\
\hline ODW & Office of Drinking Water \\
\hline OSHA & Occupational Safety and Health Act \\
\hline OSWER & Office of Solid Waste and Emergency Response \\
\hline PELS & Permissible Exposure Limits \\
\hline POTW & publicly owned treatment works \\
\hline RAs & Reference Areas \\
\hline RCRA & Resource Conservation and Recovery Act \\
\hline RFCs & reference concentrations \\
\hline RFDs & reference doses \\
\hline RFI & RCRA F'acility Investigation \\
\hline RSAs & Research Areas \\
\hline SARA & Superfind Amendments and Reauthorization Act of 1986 \\
\hline SCS & Site Characterization Summary \\
\hline SDMP & Site Delommissioning Management Plan \\
\hline SDWA & Safe Drinking Water Act of 1974 \\
\hline SEN & Secretary of Energy Notice \\
\hline SMCLs & second:iry maximum contaminant levels \\
\hline SNAS & State Natural Areas \\
\hline SWDA & Solid Waste Disposal Act \\
\hline TCA & Tennesisee Code Annotated \\
\hline TDEC & Tennessiee Department of Environment and Conservation \\
\hline TOA & Tennessiee/DOE Monitoring and Oversight Agreement \\
\hline TRU & transuranic \\
\hline TSCA-FFCA & $\begin{array}{l}\text { PCB Fe deral Facilities Compliance Agreement } \\
\text { Between the U.S. DOE and the EPA. }\end{array}$ \\
\hline & Washington, D.C. for the Uranium Enrichment Facilities \\
\hline TSD & treatment, storage, or disposal \\
\hline TSP & total suspended particulates \\
\hline UCC & Union Carbide Corporation \\
\hline UIC & Underg!:ound injection control \\
\hline USC & United States Code \\
\hline USDW & underground source of drinking water \\
\hline UST & underground storage-tanks \\
\hline WQC & water quality criteria \\
\hline
\end{tabular}

